\title{
DEMONSTRATION OF A FULL-SCALE RETROFIT OF THE ADVANCED HYBRID PARTICULATE COLLECTOR TECHNOLOGY
}

\author{
Final Report \\ October 2002 - December 2004 \\ Addendum Section added for Period \\ January 2005 - December 2005 \\ Prepared by: \\ Tom Hrdlicka \\ Otter Tail Power Company \\ Plant Engineer \\ William Swanson \\ Otter Tail Power Company \\ Principal Engineer \\ Prepared for: \\ United States Department of Energy \\ National Energy Technology Laboratory \\ DOE Award No. DE-FC26-02NT41420
}

Submitting Organization:

Otter Tail Power Company

Big Stone Plant

PO Box 218

Big Stone City, SD 57216-0218 


\section{DISCLAIMER}

This report was prepared as an account of work sponsored by an agency of the United States Government. Neither the United States Government nor any agency thereof, nor any of their employees, makes any warranty, express or implied, or assumes any legal liability or responsibility for the accuracy, completeness, or usefulness of any information, apparatus, product, or process disclosed, or represents that its use would not infringe privately owned rights. Reference herein to any specific commercial product, process, or service by trade name, trademark, manufacturer, or otherwise does not necessarily constitute or imply its endorsement, recommendation, or favoring by the United States Government or any agency thereof. The views and opinions of authors expressed herein do not necessarily state or reflect those of the United States Government or any agency thereof. 


\begin{abstract}
The Advanced Hybrid Particulate Collector (AHPC), developed in cooperation between W.L. Gore \& Associates and the Energy \& Environmental Research Center (EERC), is an innovative approach to removing particulates from power plant flue gas. The AHPC combines the elements of a traditional baghouse and electrostatic precipitator (ESP) into one device to achieve increased particulate collection efficiency. As part of the Power Plant Improvement Initiative (PPII), this project was demonstrated under joint sponsorship from the U.S. Department of Energy and Otter Tail Power Company. The EERC is the patent holder for the technology, and W.L. Gore \& Associates was the exclusive licensee for this project.
\end{abstract}

The project objective was to demonstrate the improved particulate collection efficiency obtained by a full-scale retrofit of the AHPC to an existing electrostatic precipitator. The full-scale retrofit was installed on an electric power plant burning Powder River Basin (PRB) coal, Otter Tail Power Company's Big Stone Plant, in Big Stone City, South Dakota. The \$13.4 million project was installed in October 2002. Project related testing concluded in December 2005.

The following Final Technical Report has been prepared for the project entitled "Demonstration of a Full-Scale Retrofit of the Advanced Hybrid Particulate Collector Technology" as described in DOE Award No. DE-FC26-02NT41420. The report presents the operation and performance results of the system. 


\title{
POINT OF CONTACT
}

For further information on the "Demonstration of a Full-Scale Retrofit of the Advanced Hybrid Particulate Collector Technology", please contact:

\author{
William Swanson \\ Otter Tail Power Company \\ Big Stone Plant \\ PO Box 218 \\ Big Stone City, SD 57216-0218
}




\section{TABLE OF CONTENTS}

SECTION

PAGE

TABLE OF CONTENTS .............................................................................

LIST OF ACRONYMS ............................................................................................. VII

EXECUTIVE SUMMARY ............................................................................ 1

PROJECT NOMENCLATURE DISCUSSION ...................................................... 3

1.0 INTRODUCTION ........................................................................................ 4

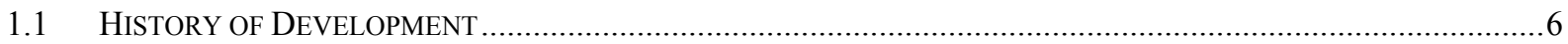

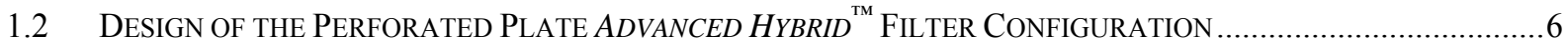

1.3 PRESSURE DROP THEORY AND PERFORMANCE EVALUATION CRITERIA..................................................... 10

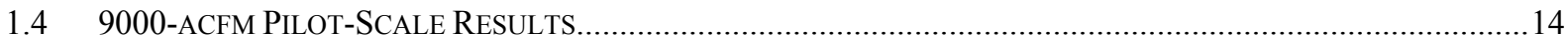

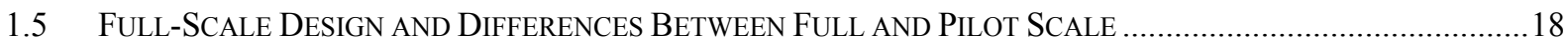

2.0 EXPERIMENTAL ........................................................................... 21

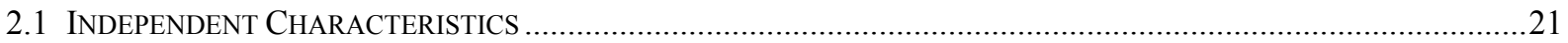

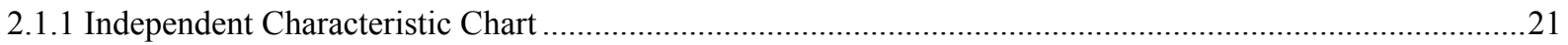

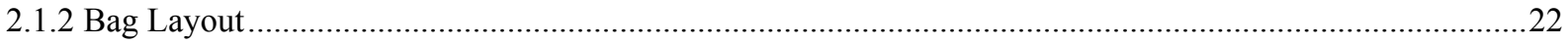

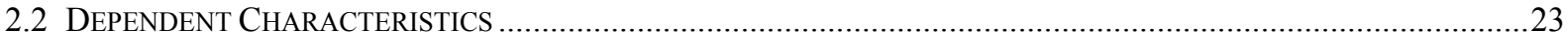

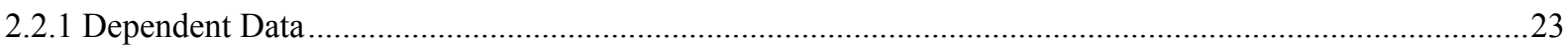

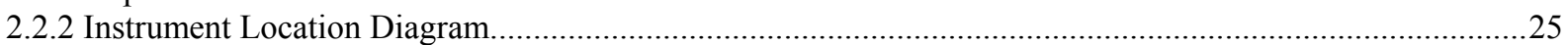

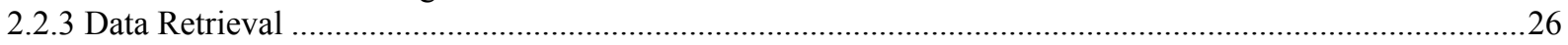

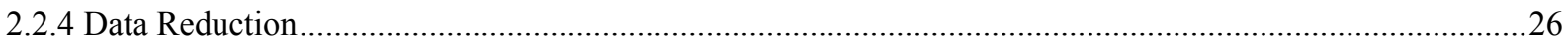

3.0 RESULTS AND DISCUSSION............................................................... 27

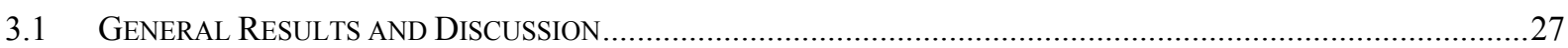

GENERAL DISCUSSION (FIRST QUARTER 10/2002 - 12/2002) ….......................................................................29

GENERAL DISCUSSION (SECOND QUARTER 1/2003 - 3/2003) ........................................................................

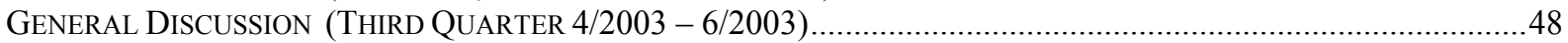

GENERAL DISCUSSION (FOURTH QUARTER 7/2003 - 9/2003)…................................................................5

GENERAL DISCUSSION (FIFTH QUARTER 10/2003 - 12/2003).....................................................................5

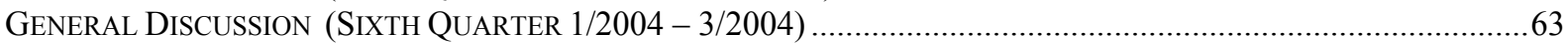

GENERAL DISCUSSION (SEVENTH QUARTER 4/2004 - 6/2004) …...................................................................69

GENERAL DISCUSSION (EIGHTH QUARTER 7/2004 - 9/2004)..................................................................................

GENERAL DISCUSSION (NINTH QUARTER 10/2004 - 12/2004) .....................................................................76

ADDENDA: GENERAL DISCUSSION (MAJOR ACTIVITIES 1/2005 - 12/2005) ....................................................77

4.0 CONCLUSIONS .......................................................................... 79

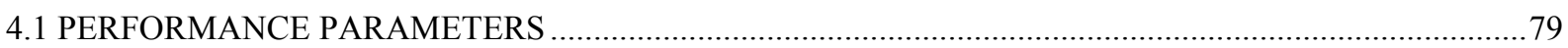

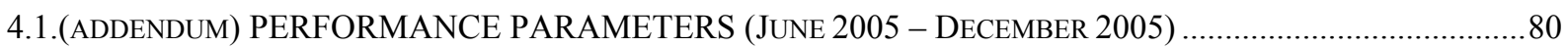

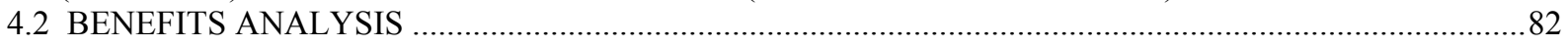

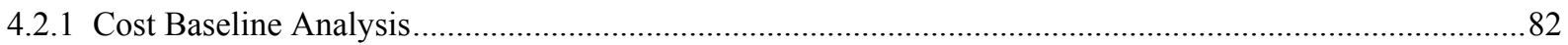

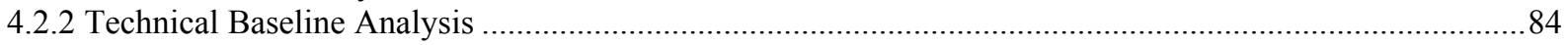

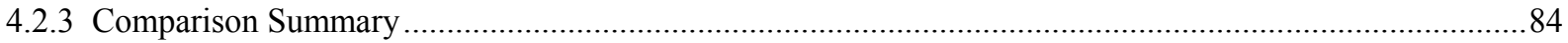

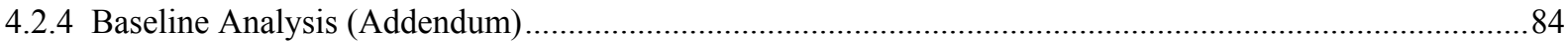

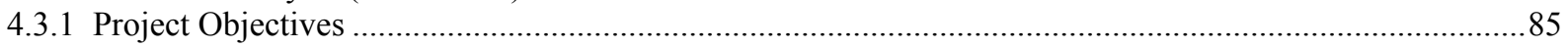




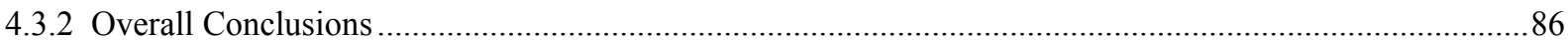

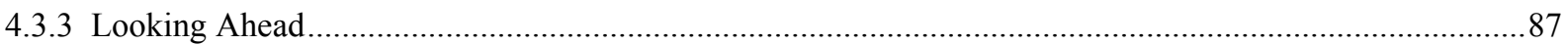

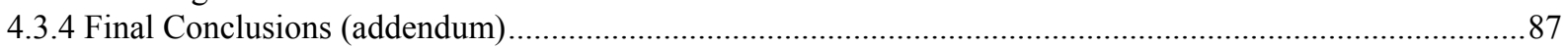

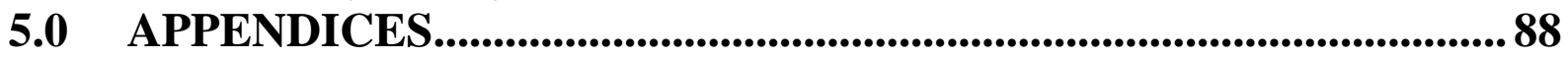

APPENDIX A - COMMENTS ON ANOMALIES OF GRAPHICAL DATA

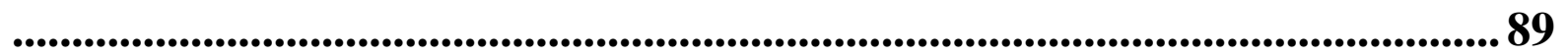

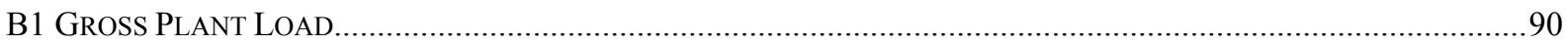

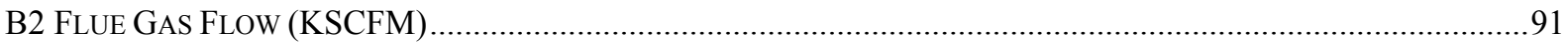

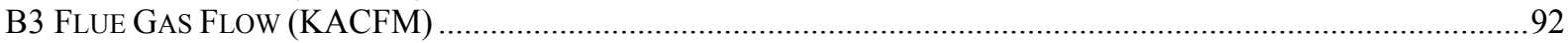

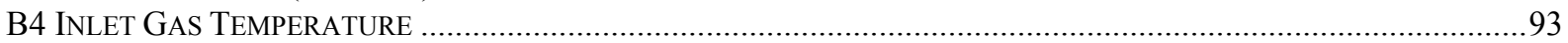

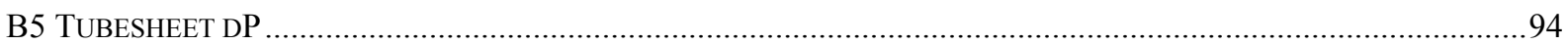

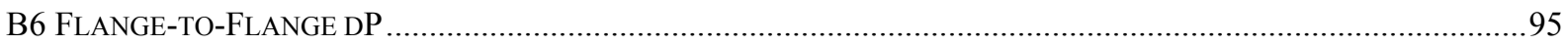

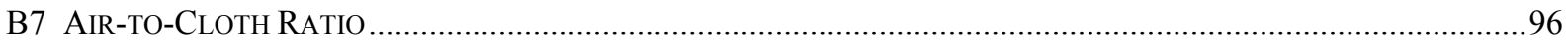

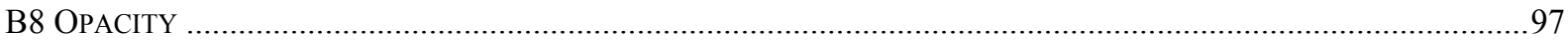

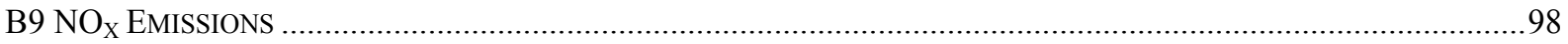

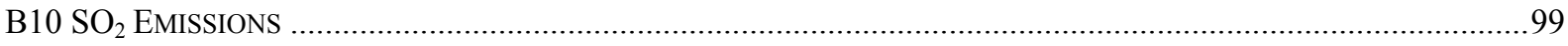

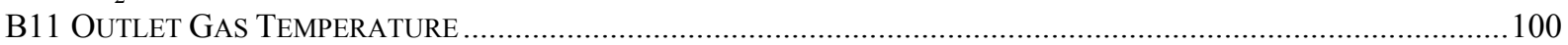

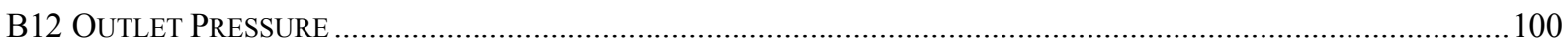

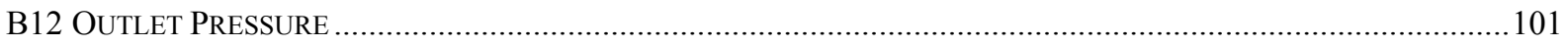

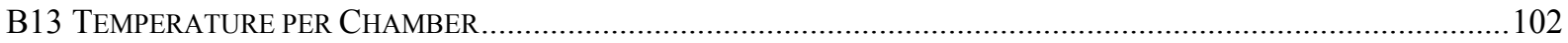

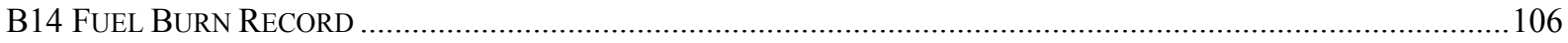

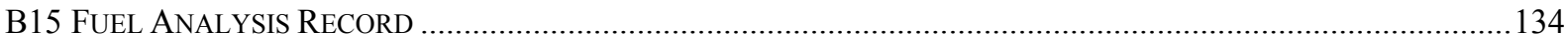

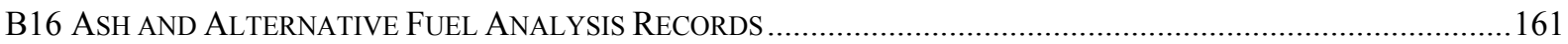

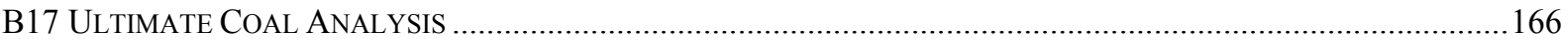

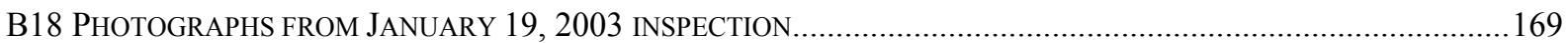

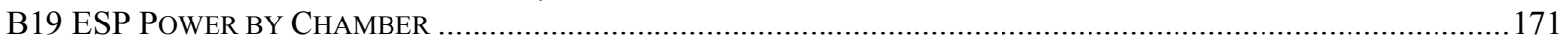

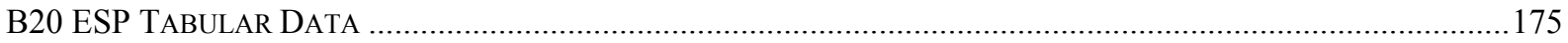

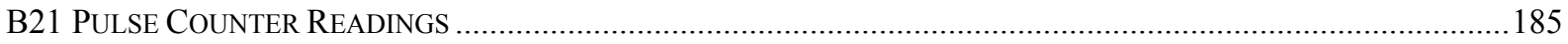

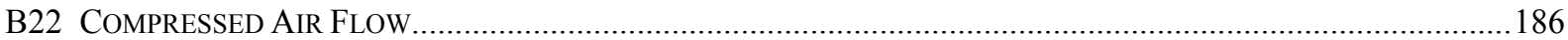

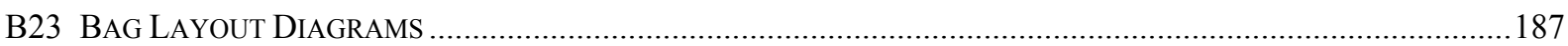

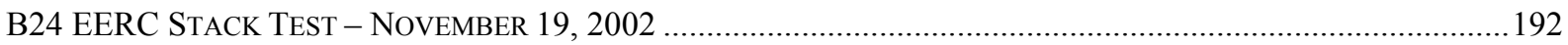

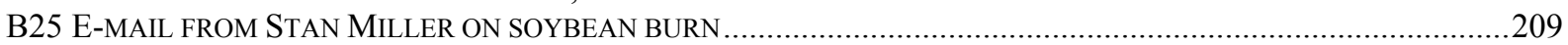

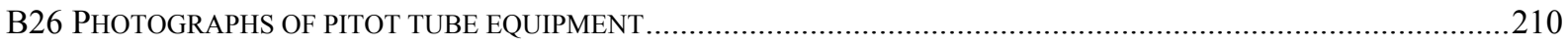

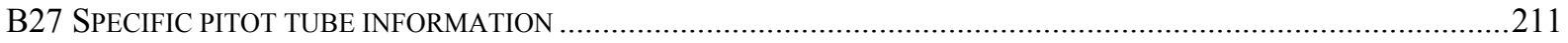

B28 Specific Pitot Tube Placement on Bag Layout Diagram ..............................................................215

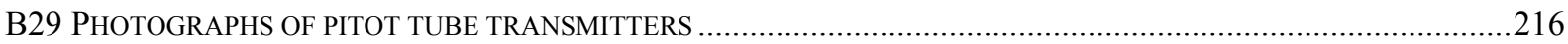

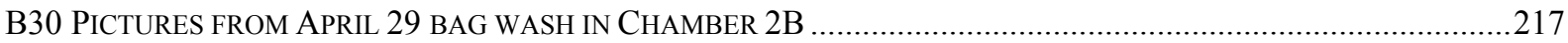

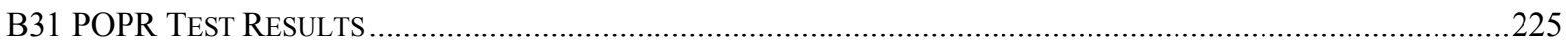

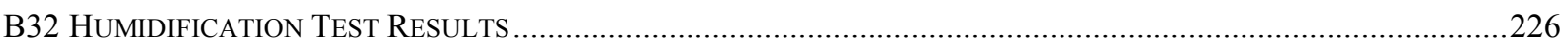

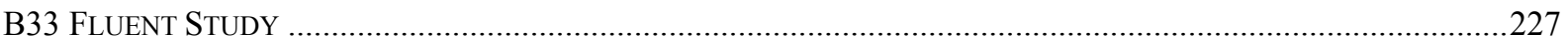

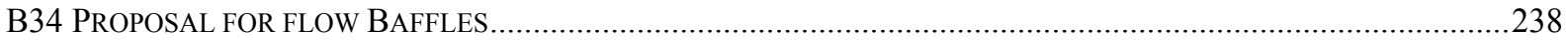

B35 PHOTOGRAPH OF BAG WASH OF ORIGINAL BAGS IN BIG STONE TURBINE BAY ……....................................240

B36 PHOTOGRAPH OF BAG ROW BAFFLES PRIOR TO INSTALLATION ON ADVANCED HYBRID WALKWAY................241

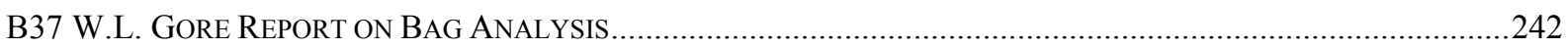

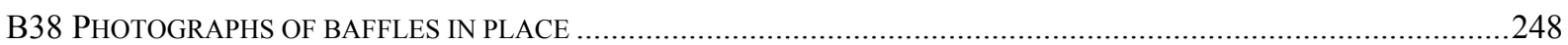

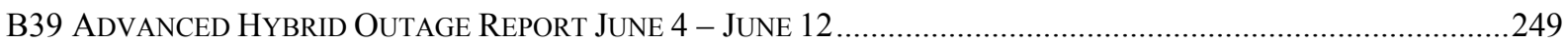

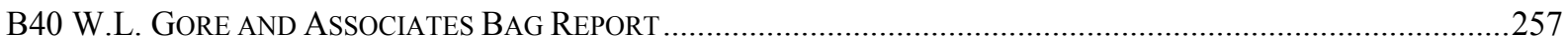

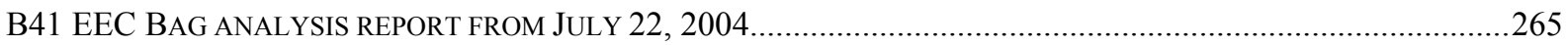

B42 EEC BAG ANALYSIS REPORT FROM DECEMBER 3, 2004 …..................................................................25

B43 ADDENDUM - STARTUP REPORT AFTER THE REPLACEMENT OF THE INLET FIELD. ......................................22

B44 ADDENDUM - BAG LAYOUT MAP AFTER INSTALLATION OF AH COMPONENTS IN THE INLET FIELD................285

B45 ADDENDUM - PERFORMANCE GRAPHS FROM 10/2002 THROUGH 12/2005 …................................................28 


\section{LIST OF ACRONYMS}

$\begin{array}{ll}\text { A/C } & \text { air-to-cloth ratio } \\ \text { AG } & \text { (Swiss, translation roughly is Incorporation or consolidation) } \\ \text { AHPC } & \text { advanced hybrid particulate collector } \\ \text { APS } & \text { aerodynamic particle sizer } \\ \text { COHPAC } & \text { compact hybrid particulate collector } \\ \text { CPC } & \text { condensation particle counter } \\ \text { DOE } & \text { U.S. Department of Energy } \\ \text { EERC } & \text { Energy \& Environmental Research Center } \\ \text { EPA } & \text { U.S. Environmental Protection Agency } \\ \text { ePTFE } & \text { expanded polytetrafluoroethylene } \\ \text { ESP } & \text { electrostatic precipitator } \\ \text { FF } & \text { fabric filter } \\ \text { HEPA } & \text { high-efficiency particulate air } \\ \text { HiPPS } & \text { high-performance power system } \\ \text { MWh } & \text { megawatt hours } \\ \text { Hm } & \text { micrometer } \\ \text { NSPS } & \text { New Source Performance Standards } \\ \text { O\&M } & \text { operating and maintenance } \\ \text { OEMs } & \text { original equipment manufacturers } \\ \text { OTP } & \text { Otter Tail Power Company } \\ \text { P\&ID } & \text { Piping and Intrumentation Diagram } \\ \text { PID } & \text { Proportional-Integral-Derivative } \\ \text { PJBH } & \text { pulse-jet baghouse } \\ \text { PM } & \text { particulate matter } \\ \text { PPS } & \text { polyphenylene sulfide } \\ \text { PRB } & \text { Powder River Basin } \\ \text { PJFF } & \text { pulse-jet fabric filter } \\ \text { P-84 } & \text { aromatic polyimide fiber } \\ \text { QAPP } & \text { quality assurance project plan } \\ \text { RGFF } & \text { reverse-gas fabric filter } \\ \text { SCA } & \text { specific collection area } \\ \text { SMPS } & \text { scanning mobility particle sizer } \\ \text { TR } & \text { transformer-rectifier } \\ \text { UND } & \text { University of North Dakota } \\ \text { W.C. } & \text { water column } \\ & \end{array}$




\section{EXECUTIVE SUMMARY}

This document summarizes the operational results of a project titled "Demonstration of a Full-Scale Retrofit of the Advanced Hybrid Particulate Collector Technology". The Department of Energy's National Energy Technology Laboratory awarded under a program entitled the Power Plant Improvement Initiative Program.

The advanced hybrid particulate collector (AHPC) was developed with funding from the U.S. Department of Energy (DOE). The AHPC combines the best features of electrostatic precipitators (ESPs) and baghouses in novel manner. The AHPC combines fabric filtration and electrostatic precipitation in the same housing, providing major synergism between the two methods, both in particulate collection and in transfer of dust to the hopper. The AHPC provides ultrahigh collection efficiency, overcoming the problem of excessive fine-particle emissions with conventional ESPs, and solves the problem of reentrainment and recollection of dust in conventional baghouses.

Big Stone Power Plant operated a 2.5 MWe slipstream AHPC (9000 scfm) for $1 \frac{1 / 2}{2}$ years. The AHPC demonstrated ultrahigh particulate collection efficiency for submicron particles and total particulate mass. Collection efficiency was proven to exceed $99.9 \%$ by one to two orders of magnitude over the entire range of particles from 0.01 to $50 \mu \mathrm{m}$. This level of control is well below any current particulate emission standards. These results were achieved while operating at significantly higher air-to-cloth ratios (up to 12 $\mathrm{ft} /$ min compared to $4 \mathrm{ft} / \mathrm{min}$ ) than standard pulse-jet baghouses. To achieve $99.99 \%$ control of total particulate and meet possible stricter fine-particle standards, the AHPC is being demonstrated as the possible economic choice over either ESPs or baghouses.

Otter Tail Power Company and its partners, Montana-Dakota Utilities and NorthWestern Energy, installed the AHPC technology into an existing ESP structure at the Big Stone Power Plant. The overall goal of the project is to demonstrate the AHPC concept in a full-scale application. Specific objectives are to demonstrate $99.99 \%$ collection of all particles in the 0.01 to $50 \mu \mathrm{m}$ size range, low pressure drop, overall reliability of the technology and long-term bag life.

This is the project final report. It is meant to summarize the operational experience over the last three plus years (October 2002 - December 2005). 
Addenda Note:

The final report is now being submitted after the initial draft of this final report was completed. This further information is intended to cover the material changes and information that occurred to the Advanced Hybrid ${ }^{\mathrm{TM}}$ system through 2005. The sections described, as "Addendum" will describe the events and conclusions during this period. 


\section{PROJECT NOMENCLATURE DISCUSSION}

When this technology was originally developed, the device was referred to as the "Advanced Hybrid Particulate Collector". Since the original development, from concept to an attempt at a commercial demonstration, the name of the technology has changed to "Advanced Hybrid" ${ }^{\mathrm{TM}}$ ". This name was trademarked by W.L. Gore and Associates, Inc. to aid in the commercialization effort and tries to maintain the continuity of the successful history to date. Either "Advanced Hybrid Particulate Collector"

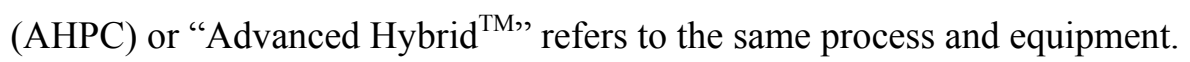




\subsection{INTRODUCTION}

The Advanced Hybrid ${ }^{\mathrm{TM}}$ filter combines the best features of ESPs and baghouses in a unique approach to develop a compact but highly efficient system. Filtration and electrostatics are employed in the same housing, providing major synergism between the two collection methods, both in the particulate collection step and in the transfer of dust to the hopper. The Advanced Hybrid ${ }^{\mathrm{TM}}$ filter provides ultrahigh collection efficiency, overcoming the problem of excessive fine-particle emissions with conventional ESPs, and solves the problem of reentrainment and re-collection of dust in conventional baghouses.

The goals for the Advanced Hybrid ${ }^{\mathrm{TM}}$ filter are as follows: $>99.99 \%$ particulate collection efficiency for particle sizes ranging from 0.01 to $50 \mu \mathrm{m}$, applicable for use with all U.S. coals, and cost savings compared to existing technologies.

The electrostatic and filtration zones are oriented to maximize fine-particle collection and minimize pressure drop. Ultrahigh fine-particle collection is achieved by removing over $90 \%$ of the dust before it reaches the fabric and using a GORE-TEX ${ }^{\circledR}$ membrane fabric to collect the particles that reach the filtration surface. Charge on the particles also enhances collection and minimizes pressure drop, since charged particles tend to form a more porous dust cake. The goal is to employ only enough ESP plate area to precollect approximately $90 \%$ of the dust. ESP models predict that $90 \%-95 \%$ collection efficiency can be achieved with full-scale precipitators with a specific collection area (SCA) of less than $100 \mathrm{ft}^{2} / \mathrm{kacfm}$ $(1,2)$. FF models predict that face velocities greater than $12 \mathrm{ft} / \mathrm{min}$ are possible if some of the dust is precollected and the bags can be adequately cleaned. The challenge is to operate at high $\mathrm{A} / \mathrm{C}$ ratios (8$14 \mathrm{ft} / \mathrm{min}$ ) for economic benefits while achieving ultrahigh collection efficiency and controlling pressure drop. The combination of GORE-TEX ${ }^{\circledR}$ membrane filter media (or similar membrane filters from other manufacturers), small SCA, high A/C ratio, and unique geometry meets this challenge.

Studies have shown that FF collection efficiency is likely to deteriorate significantly when the face velocity is increased $(3,4)$. For high collection efficiency, the pores in the filter media must be effectively bridged (assuming they are larger than the average particle size). With conventional fabrics at low A/C ratios, the residual dust cake serves as part of the collection media, but at high $\mathrm{A} / \mathrm{C}$ ratios, only a very light residual dust cake is acceptable, so the cake cannot be relied on to achieve high collection efficiency. The solution is to employ a sophisticated fabric that can ensure ultrahigh collection efficiency and endure frequent high-energy cleaning. In addition, the fabric should be reliable under the most severe chemical environment likely to be encountered (such as high $\mathrm{SO}_{3}$ ). 
Assuming that low particulate emissions can be maintained through the use of advanced filter materials and that $90 \%$ of the dust is precollected, operation at face velocities in the range of $8-14 \mathrm{ft} / \mathrm{min}$ should be possible, as long as the dust can be effectively removed from the bags and transferred to the hopper without significant redispersion and re-collection. With pulse-jet cleaning, heavy residual dust cakes are not typically a problem because of the fairly high cleaning energy that can be employed. However, the high cleaning energy can lead to significant redispersion of the dust and subsequent re-collection on the bags. The combination of a very high-energy pulse and a very light dust cake tends to make the problem of redispersion much worse. The barrier that limits operation at high $\mathrm{A} / \mathrm{C}$ ratios is not so much the dislodging of dust from the bags as it is the transferring of the dislodged dust to the hopper. The Advanced Hybrid $^{\mathrm{TM}}$ filter achieves enhanced bag cleaning by employing electrostatic effects to precollect a significant portion of the dust and by trapping in the electrostatic zone the redispersed dust that comes off the bags following pulsing. 


\subsection{History of Development}

The Advanced Hybrid ${ }^{\mathrm{TM}}$ filter concept was first proposed to DOE in September 1994 in response to a major solicitation addressing air toxics. DOE has been the primary funder of the Advanced Hybrid ${ }^{\mathrm{TM}}$ filter development since that time, along with significant cost-sharing from industrial cosponsors. Details of all of the results have been reported in DOE quarterly technical reports, final technical reports for completed phases, and numerous conference papers. A chronology of the significant development steps for the Advanced Hybrid ${ }^{\mathrm{TM}}$ filter is shown below.

- September 1994 - Advanced Hybrid ${ }^{\mathrm{TM}}$ filter concept proposed to DOE

- October 1995 - September 1997 - Phase I - Advanced Hybrid ${ }^{\mathrm{TM}}$ filter successfully demonstrated at 0.06-MW (200-acfm) scale

- March 1998 - February 2000 - Phase II - Advanced Hybrid ${ }^{\mathrm{TM}}$ filter successfully demonstrated at 2.5-MW (9000-acfm) scale at Big Stone Plant

- September 1999 - August 2001 - Phase III - Advanced Hybrid ${ }^{\mathrm{TM}}$ filter commercial components tested and proven at 2.5-MW scale at Big Stone Plant

- Summer 2000 - Minor electrical damage on bags first observed

- January-June 2001 - To prevent electrical damage, the Advanced Hybrid ${ }^{\mathrm{TM}}$ filter perforated plate configuration was developed, tested, and proven to be superior to the original design

- July 2001 - December 2004 - Mercury Control with the Advanced Hybrid ${ }^{\mathrm{TM}}$ Filter - Extensive additional testing of the perforated plate concept was conducted with the 2.5-MW pilot unit

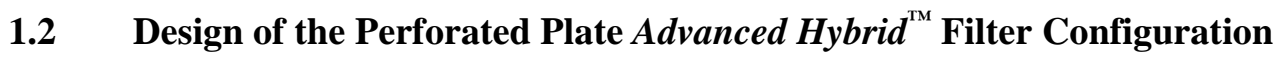

After bag damage was observed in summer 2000, extensive experiments were carried out at an Energy \& Environmental Research Center (EERC) laboratory to investigate the interactions between electrostatics and bags under different operating conditions. The 200-acfm Advanced Hybrid ${ }^{\mathrm{TM}}$ filter was first operated without fly ash under cold-flow conditions with air. The effects of electrode type, bag type, plate-to-plate spacing, the relative distance from the electrodes to plates compared to the distance from the electrodes to the bags (spacing ratio), and various grounded grids placed between the electrodes and bags were all evaluated. Several of the conditions from the cold-flow tests were selected and further evaluated in hotflow coal combustion tests. While all of these tests resulted in very low current to the bags, there appeared to be a compromise in overall Advanced Hybrid ${ }^{\mathrm{TM}}$ filter performance for some configurations.

A configuration that appeared to have promise was a perforated plate design in which a grounded perforated plate was installed between the discharge electrodes and the bags to protect the bags. On the 
opposite side of the electrodes, another perforated plate was installed to simulate the geometric arrangement where each row of bags would have perforated plates on both sides, and no solid plates were used. The discharge electrodes were then centered between perforated plates located directly in front of the bags. With this arrangement, the perforated plates function both as the primary collection surface and as a protective grid for the bags. With the 200 -acfm Advanced Hybrid ${ }^{\mathrm{TM}}$ filter, the perforated plate configuration produced results far better than in any previous Advanced Hybrid ${ }^{\mathrm{TM}}$ filter tests and provided adequate protection of the bags.

Based on the 200-acfm results, a perforated plate configuration was designed and installed on the 9000acfm slipstream pilot unit at the Big Stone Power Plant. The differences between the new perforated plate design and the previous Advanced Hybrid ${ }^{\mathrm{TM}}$ filter can be seen by comparing Figure 1 with Figure 2. Figure 1 is a simplified top view of the $9000-\mathrm{acfm}$ Advanced Hybrid ${ }^{\mathrm{TM}}$ filter configuration at the start of Phase III, which had a plate-to-plate spacing of 23.6 in. For the perforated plate configuration (Figure 2), the bag spacing was not changed, allowing use of the same tube sheet as in the previous configuration (Figure 1). However, the distance from the discharge electrodes to the perforated plates as well as the distance from the bags to the perforated plates can be reduced without compromising performance. Therefore, one of the obvious advantages of the perforated plate configuration is the potential to make the Advanced Hybrid ${ }^{\mathrm{TM}}$ filter significantly more compact than the earlier design.

Another difference is that directional electrodes are not required with the perforated plate design. With the previous design, directional electrodes (toward the plate) were needed to prevent possible sparking to the bags. This means that conventional electrodes can be used with the Advanced Hybrid ${ }^{\mathrm{TM}}$ filter. Electrode alignment is also less critical because an out-of-alignment electrode would simply result in potential sparking to the nearest grounded perforated plate, whereas with the old design, an out-of-alignment electrode could result in sparking to a bag and possible bag damage.

While the perforated plate configuration did not change the overall Advanced Hybrid $^{\mathrm{TM}}$ filter concept (precollection of $>90 \%$ of the dust and enhanced bag cleaning), the purpose of the plates did change. The perforated plates serve two very important functions: as the primary collection surface and as a protective grid for the bags. With approximately $45 \%$ open area, there is adequate collection area on the plates to collect the precipitated dust while not restricting the flow of flue gas toward the bags during normal filtration. During pulse cleaning of the bags, most of the reentrained dust from the bags is forced back through the perforated plates into the ESP zone. The 9000 -acfm results as well as the 200 -acfm results showed better ESP collection than the previous design while maintaining good bag cleanability. The better ESP collection efficiency is likely the result of forcing all of the flue gas through the perforated 
plate holes before reaching the bags. This ensures that all of the charged dust particles pass within a maximum of one-half of the hole diameter distance of a grounded surface. In the presence of the electric field, the particles then have a greater chance of being collected. In the old Advanced Hybrid ${ }^{\mathrm{TM}}$ filter design, once the gas reached the area between the electrodes and bags, it would be driven toward the bags rather than the plates, and a larger fraction of the dust was likely to bypass the ESP zone. 


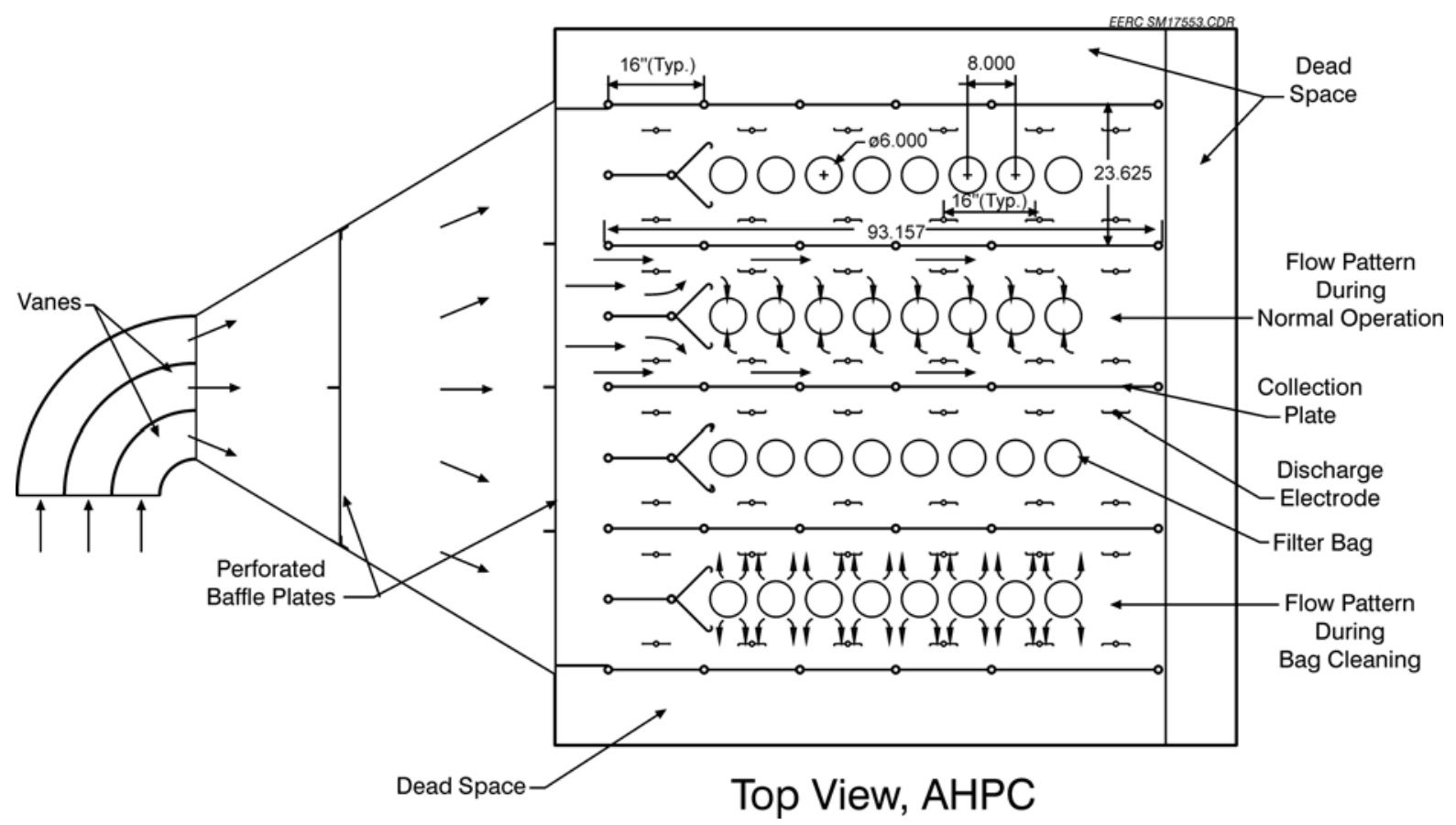

Figure 1. Top view of the old configuration for the 9000-acfm Advanced Hybrid ${ }^{\mathrm{TM}}$ filter at Big Stone.

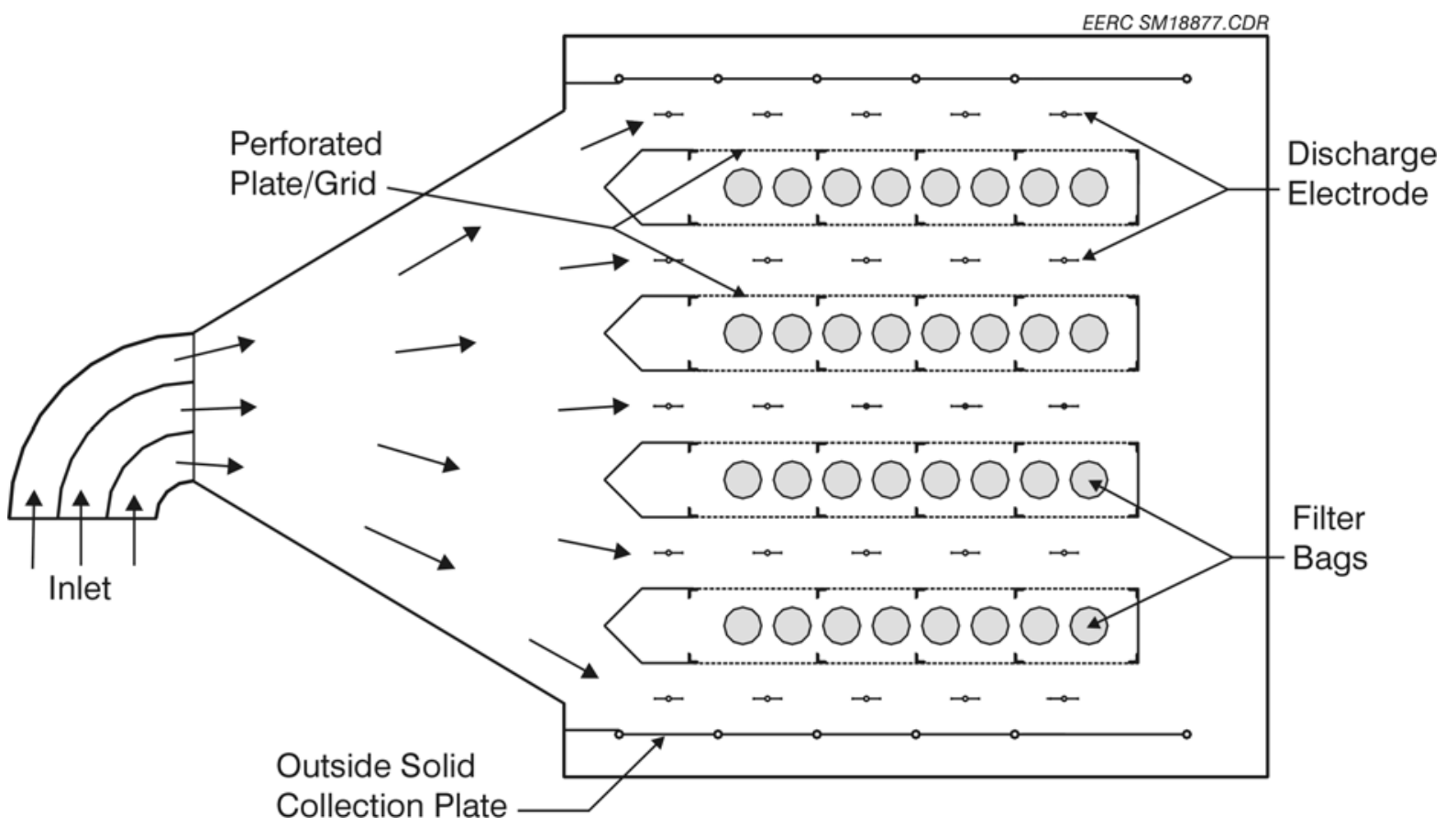

Figure 2. Top view of the perforated plate configuration for the 9000-acfm Advanced Hybrid ${ }^{\mathrm{TM}}$ filter. 


\subsection{Pressure Drop Theory and Performance Evaluation Criteria}

Pressure drop across the bags is one of the main operational parameters that defines overall performance. It must be within capacity limits of the boiler fans at the maximum system flow rate. Since acceptable pressure drop is so critical to successful operation, a detailed discussion of the theory and factors that control pressure drop follows.

For viscous flow, pressure drop across a FF is dependent on three components:

$$
\mathrm{dP}=\mathrm{K}_{\mathrm{f}} \mathrm{V}+\mathrm{K}_{2} \mathrm{~W}_{\mathrm{R}} \mathrm{V}+\frac{\mathrm{K}_{2} \mathrm{C}_{\mathrm{i}} \mathrm{V}^{2} \mathrm{t}}{7000}
$$

where:

$\mathrm{dP}=$ differential pressure across baghouse tube sheet (in. W.C.)

$\mathrm{K}_{\mathrm{f}}=$ fabric resistance coefficient (in. W.C.-min/ft)

$\mathrm{V}=$ face velocity or $\mathrm{A} / \mathrm{C}$ ratio $(\mathrm{ft} / \mathrm{min})$

$\mathrm{K}_{2}=$ specific dust cake resistance coefficient (in. W.C.-ft-min/lb)

$\mathrm{WR}=$ residual dust cake weight $\left(\mathrm{lb} / \mathrm{ft}^{2}\right)$

$\mathrm{C}_{\mathrm{i}}=$ inlet dust loading (grains/acf)

$\mathrm{t}=$ filtration time between bag cleaning $(\mathrm{min})$

The first term in Eq. 1 accounts for the pressure drop across the fabric. For conventional fabrics, the pore size is quite large, and the corresponding fabric permeability is high, so the pressure drop across the fabric alone is negligible. To achieve better collection efficiency, the pore size can be significantly reduced, without making fabric resistance a significant contributor to pressure drop. The GORE-TEX ${ }^{\circledR}$ membrane $^{\circ}$ filter media allows for this optimization by providing a microfine pore structure while maintaining sufficient fabric permeability to permit operation at high $\mathrm{A} / \mathrm{C}$ ratios. A measure of the new fabric permeability is the Frazier number which is the volume of gas that will pass through a square foot of fabric sample at a pressure drop of 0.5 in. W.C. The Frazier number for new GORE-TEX ${ }^{\circledR}$ bags is in the range from 4 to $8 \mathrm{ft} / \mathrm{min}$. Through the filter, viscous (laminar) flow conditions exist, so the pressure drop varies directly with flow velocity. Assuming a new fabric Frazier number of $6 \mathrm{ft} / \mathrm{min}$, the pressure drop across the fabric alone would be $1.0 \mathrm{in}$. W.C. at an $\mathrm{A} / \mathrm{C}$ ratio (filtration velocity) of $12 \mathrm{ft} / \mathrm{min}$.

The second term in Eq. 1 accounts for the pressure drop contribution from the permanent residual dust cake that exists on the surface of the fabric. For operation at high $\mathrm{A} / \mathrm{C}$ ratios, the bag cleaning must be sufficient to maintain a very light residual dust cake and ensure that the pressure drop contribution from this term is reasonable. The contribution to pressure drop from this term is one of the most important indicators of longer-term bag cleanability. 
The third term in Eq. 1 accounts for the pressure drop contribution from the dust accumulated on the bags since the last bag cleaning. $\mathrm{K}_{2}$ is determined primarily by the fly ash particle-size distribution and the porosity of the dust cake. Typical $\mathrm{K}_{2}$ values for a full dust loading of pulverized coal (pc)-fired fly ash range from about 4 to $20 \mathrm{in.} \mathrm{W.C.-ft-min/lb} \mathrm{but} \mathrm{may,} \mathrm{in} \mathrm{extreme} \mathrm{cases,} \mathrm{cover} \mathrm{a} \mathrm{wider} \mathrm{range.} \mathrm{Within} \mathrm{this}$ term, the bag-cleaning interval, $t$, is the key performance indicator. The goal is to operate with as long of a bag-cleaning interval as possible, since more frequent bag pulsing can lead to premature bag failure and require more energy consumption from compressed air usage. An earlier goal for the pilot-scale tests was to operate with a pulse interval of at least 10 min while operating at an $\mathrm{A} / \mathrm{C}$ ratio of $12 \mathrm{ft} / \mathrm{min}$. While this goal was exceeded in the pilot-scale tests, a pulse interval of only $10 \mathrm{~min}$ is now considered too short to demonstrate good Advanced Hybrid ${ }^{\mathrm{TM}}$ filter performance over a longer period. With a shorter pulse interval, the Advanced Hybrid ${ }^{\mathrm{TM}}$ filter does not appear to make the best use of the electric field, because of the reentrainment that occurs just after pulsing. Current thought is that a pulse interval of at least $60 \mathrm{~min}$ is needed to demonstrate the best long-term performance.

Total tube sheet pressure drop is another key indicator of overall performance of the Advanced Hybrid ${ }^{\mathrm{TM}}$ filter. Here, the goal was to operate with a tube sheet pressure drop of 8 in. W.C. at an A/C ratio of 12 $\mathrm{ft} / \mathrm{min}$. Note that the average pressure drop is not the same as the pulse-cleaning trigger point. For many of the previous and current tests, the pulse trigger point was set at 8 in. W.C., but the average pressure drop was significantly lower.

To help analyze filter performance, the terms in Eq. 1 can be normalized to the more general case by dividing by velocity. The $\mathrm{dP} / \mathrm{V}$ term is commonly referred to as drag or total tube sheet drag, $\mathrm{D}_{\mathrm{T}}$ :

$$
\frac{\mathrm{dP}}{\mathrm{V}}=\mathrm{D}_{\mathrm{T}}=\mathrm{K}_{\mathrm{f}}+\mathrm{K}_{2} \mathrm{~W}_{\mathrm{R}}+\frac{\mathrm{K}_{2} \mathrm{C}_{\mathrm{i}} \mathrm{Vt}}{7000}
$$

The new fabric drag and the residual dust cake drag are typically combined into a single term called residual drag, $\mathrm{D}_{\mathrm{R}}$ :

$$
\mathrm{D}_{\mathrm{T}}=\mathrm{D}_{\mathrm{R}}+\frac{\mathrm{K}_{2} \mathrm{C}_{\mathrm{i}} \mathrm{Vt}}{7000}
$$

The residual drag term then is the key indicator of how well the bags are cleaning over a range of $\mathrm{A} / \mathrm{C}$ ratios, but may still be somewhat dependent on $\mathrm{A} / \mathrm{C}$ ratio. For example, it may be more difficult to overcome a dP of 10 in. W.C. to clean the bags than cleaning at a dP of 5 in. W.C. For most baghouses, the residual drag typically climbs somewhat over time and must be monitored carefully to evaluate the longer-term performance. Current thought is that excellent Advanced Hybrid ${ }^{\mathrm{TM}}$ filter performance can be 
demonstrated with a residual drag value of 0.6 or lower.

Between bag cleanings, from the second term in Eq. 3, the drag increases linearly with $\mathrm{K}_{2}$ (dust cake resistance coefficient), $\mathrm{C}_{\mathrm{i}}$ (inlet dust concentration), $\mathrm{V}$ (filtration velocity), and $\mathrm{t}$ (filtration time). For conventional baghouses, the $\mathrm{C}_{\mathrm{i}}$ term is easily determined from an inlet dust loading measurement, and approximate $\mathrm{K}_{2}$ values can be determined from the literature or by direct measurement. However, for the Advanced Hybrid ${ }^{\mathrm{TM}}$ filter, the concentration of the dust that reaches the bags is generally not known and would be very difficult to measure experimentally. From the Phase I laboratory tests, results indicated approximately $90 \%$ of the dust was precollected and did not reach the fabric. However, this amount is likely to fluctuate significantly with changes to the electrical field and with the dust resistivity. Since $C_{i}$ is not known, for evaluation of Advanced Hybrid ${ }^{\mathrm{TM}}$ filter performance, the $\mathrm{K}_{2}$ and $\mathrm{C}_{\mathrm{i}}$ can be considered together:

$$
\mathrm{K}_{2} \mathrm{C}_{\mathrm{i}}=\frac{\left(\mathrm{D}_{\mathrm{T}}-\mathrm{D}_{\mathrm{R}}\right) 7000}{\mathrm{Vt}}
$$

Evaluation of $\mathrm{K}_{2} \mathrm{C}_{\mathrm{i}}$ can help in assessing how well the ESP portion of the Advanced Hybrid ${ }^{\mathrm{TM}}$ filter is functioning, especially by comparing with the $\mathrm{K}_{2} \mathrm{C}_{\mathrm{i}}$ during short test periods in which the ESP power was shut off. For the Big Stone ash, the $\mathrm{K}_{2} \mathrm{C}_{\mathrm{i}}$ value has typically been about 20 without the ESP field. For the 9000-acfm pilot Advanced Hybrid ${ }^{\mathrm{TM}}$ filter, longer-term $\mathrm{K}_{2} \mathrm{C}_{\mathrm{i}}$ values of 1.0 have been demonstrated with the ESP field on, which is equivalent to $95 \%$ precollection of the dust by the ESP. Again, the goal is to achieve as low of a $\mathrm{K}_{2} \mathrm{C}_{\mathrm{i}}$ value as possible; however, good Advanced Hybrid ${ }^{\mathrm{TM}}$ filter performance can be demonstrated with $\mathrm{K}_{2} \mathrm{C}_{\mathrm{i}}$ values up to 4 , but this is interdependent on the residual drag and filtration velocity.

Eq. 4 can be solved for the bag-cleaning interval, t, as shown in Eq. 5. The bag-cleaning interval is inversely proportional to the face velocity, $\mathrm{V}$, and the $\mathrm{K}_{2} \mathrm{C}_{\mathrm{i}}$ term and directly proportional to the change in drag before and after cleaning (delta drag). The delta drag term is dependent on the cleaning set point or maximum pressure drop as well as the residual drag. The face velocity, delta drag, and $\mathrm{K}_{2} \mathrm{C}_{\mathrm{i}}$ terms are relatively independent of each other and should all be considered when the bag-cleaning interval is evaluated. However, as mentioned above, the drag may be somewhat dependent on velocity if the dust does not clean off the bags as well at high velocity as at low velocity. Similarly, the $\mathrm{K}_{2} \mathrm{C}_{\mathrm{i}}$ is somewhat dependent on velocity for a constant plate collection area. At the greater flow rates, the SCA of the precipitator is reduced, which will result in a greater dust concentration, $\mathrm{C}_{\mathrm{i}}$, reaching the bags. 


$$
\mathrm{t}=\frac{\left(\mathrm{D}_{\mathrm{T}}-\mathrm{D}_{\mathrm{R}}\right) 7000}{\mathrm{VK}_{2} \mathrm{C}_{\mathrm{i}}}
$$

By evaluating these performance indicators, the range in possible $\mathrm{A} / \mathrm{C}$ ratios can be calculated by using Eq. 1. For example, using the acceptable performance values of a 60-min pulse interval and a residual drag of 0.6 , Eq. 1 predicts that a $\mathrm{K}_{2} \mathrm{C}_{\mathrm{i}}$ value of 2.33 would be needed when operating at an $\mathrm{A} / \mathrm{C}$ ratio of 10 $\mathrm{ft} / \mathrm{min}$ and a pulse trigger of $8 \mathrm{in}$. W.C. Obviously, deterioration in the performance of one indicator can be offset by improvement in another. Results to date show that performance is highly sensitive to the A/C ratio and that excellent Advanced Hybrid ${ }^{\mathrm{TM}}$ filter performance can be achieved as long as a critical $\mathrm{A} / \mathrm{C}$ ratio is not exceeded. If the $\mathrm{A} / \mathrm{C}$ ratio is pushed too high, system response is to more rapidly pulse the bags. However, too rapid of pulsing tends to make the residual drag increase faster and causes the $\mathrm{K}_{2} \mathrm{C}_{\mathrm{i}}$ to also increase, both of which lead to poorer performance. The design challenge is to operate the Advanced Hybrid $^{\mathrm{TM}}$ filter at the appropriate $\mathrm{A} / \mathrm{C}$ ratio for a given set of conditions. 


\section{$1.4 \quad$ 9000-acfm Pilot-Scale Results}

During the summer of 2002 the 9000-acfm Advanced Hybrid ${ }^{\mathrm{TM}}$ filter was operated from June 28 through early September with minimal changes to the operating parameters. This is the longest time the pilot unit was operated without interruption and is the best example of the excellent performance demonstrated with the 9000-acfm Advanced Hybrid ${ }^{\mathrm{TM}}$ filter. One of the main objectives of the summer 2002 tests was to assess the effect of carbon injection for mercury control on longer-term Advanced Hybrid ${ }^{\mathrm{TM}}$ filter performance. In order to achieve steady-state Advanced Hybrid ${ }^{\mathrm{TM}}$ filter operation prior to starting carbon injection, the Advanced Hybrid ${ }^{\mathrm{TM}}$ filter was started with new bags on June 28 and operated continuously until the start of the carbon injection for mercury control in August. Operational parameters are given in Table 1, and the bag-cleaning interval, pressure drop, and $\mathrm{K}_{2} \mathrm{C}_{\mathrm{i}}$ data from June 28 to September 3 are shown in Figures 3-5. The daily average pressure drop data increased slightly with time as would be expected after starting with new bags. When the carbon was started on August 7, there was no perceptible change in pressure drop. The bag-cleaning interval was somewhat variable as a result of temperature and load swings, but, again there was no increase when the carbon feed was started. The $\mathrm{K}_{2} \mathrm{C}_{\mathrm{i}}$ values are an indication of the amount of dust that reaches the bags and subsequently relate to how well the ESP portion of the Advanced Hybrid ${ }^{\mathrm{TM}}$ filter is working. Again, there was no perceptible change when the carbon was started. These data show that the Advanced Hybrid ${ }^{\mathrm{TM}}$ filter can be expected to provide good mercury removal with upstream injection of carbon without any adverse effect on performance.

From August 21 to August 26, the Advanced Hybrid ${ }^{\mathrm{TM}}$ filter current was deliberately reduced to $25 \mathrm{~mA}$ compared to the normal $55 \mathrm{~mA}$ setting (see Figures 3-5) to see if good mercury removal could be maintained. The bag-cleaning interval dropped to about one-half, and the $\mathrm{K}_{2} \mathrm{C}_{\mathrm{i}}$ value approximately doubled, which would be expected. Both of these indicate that about twice as much dust reached the bags at $25 \mathrm{~mA}$ compared to $55 \mathrm{~mA}$. However, almost no effect on pressure drop was seen. This implies that it should be possible to optimize Advanced $\mathrm{Hybrid}^{\mathrm{TM}}$ filter operational parameters to get the best overall mercury removal while maintaining good Advanced Hybrid ${ }^{\mathrm{TM}}$ filter performance. 
Table 1. 2.5-MW Advanced Hybrid ${ }^{\mathrm{TM}}$ Filter Test Parameters and Operational Summary, June 28 - September 2, 2002

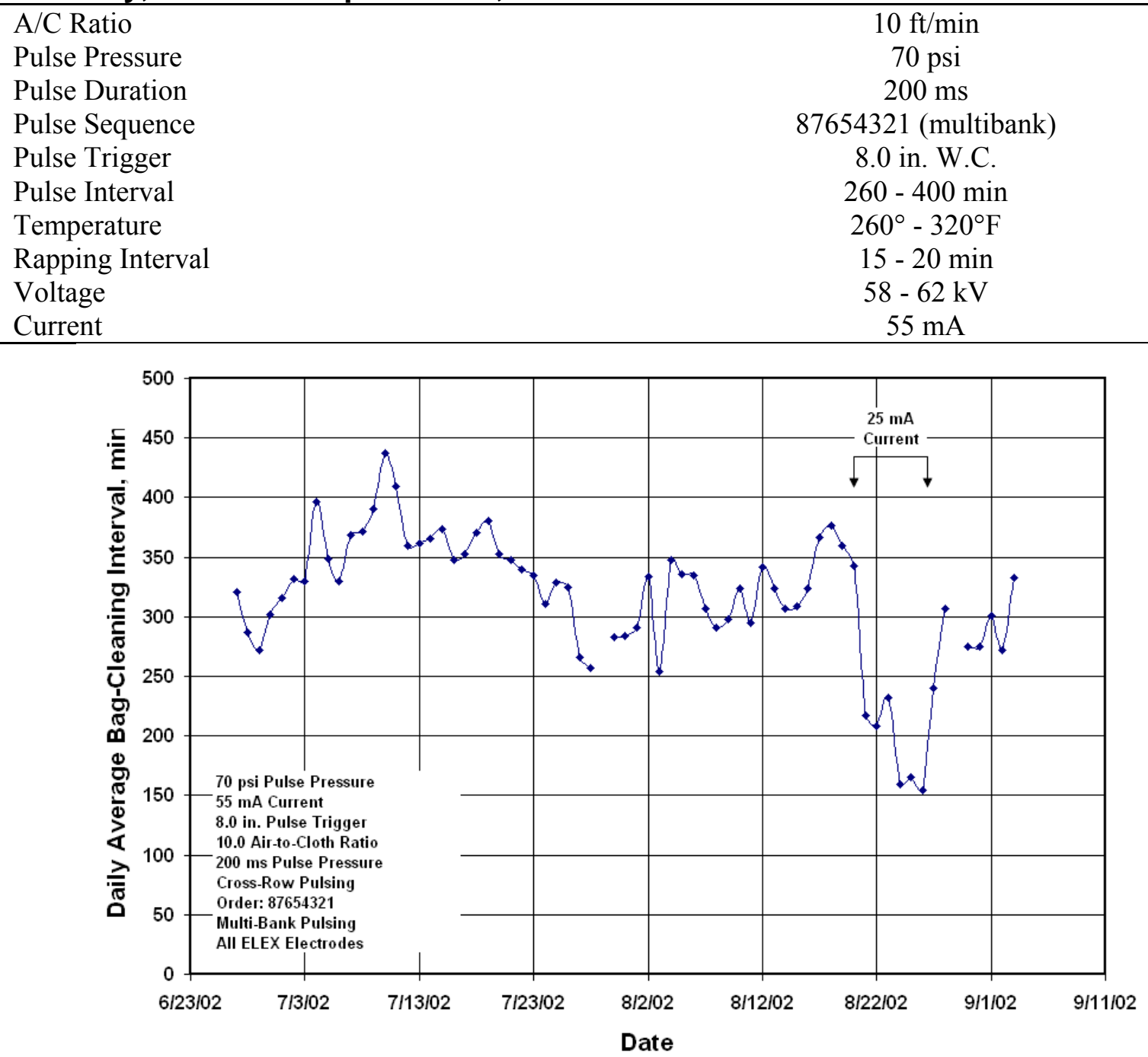

Figure 3. Daily average bag-cleaning interval for summer 2002 tests with the 9000 -acfm Advanced Hybrid ${ }^{\mathrm{TM}}$ filter. 


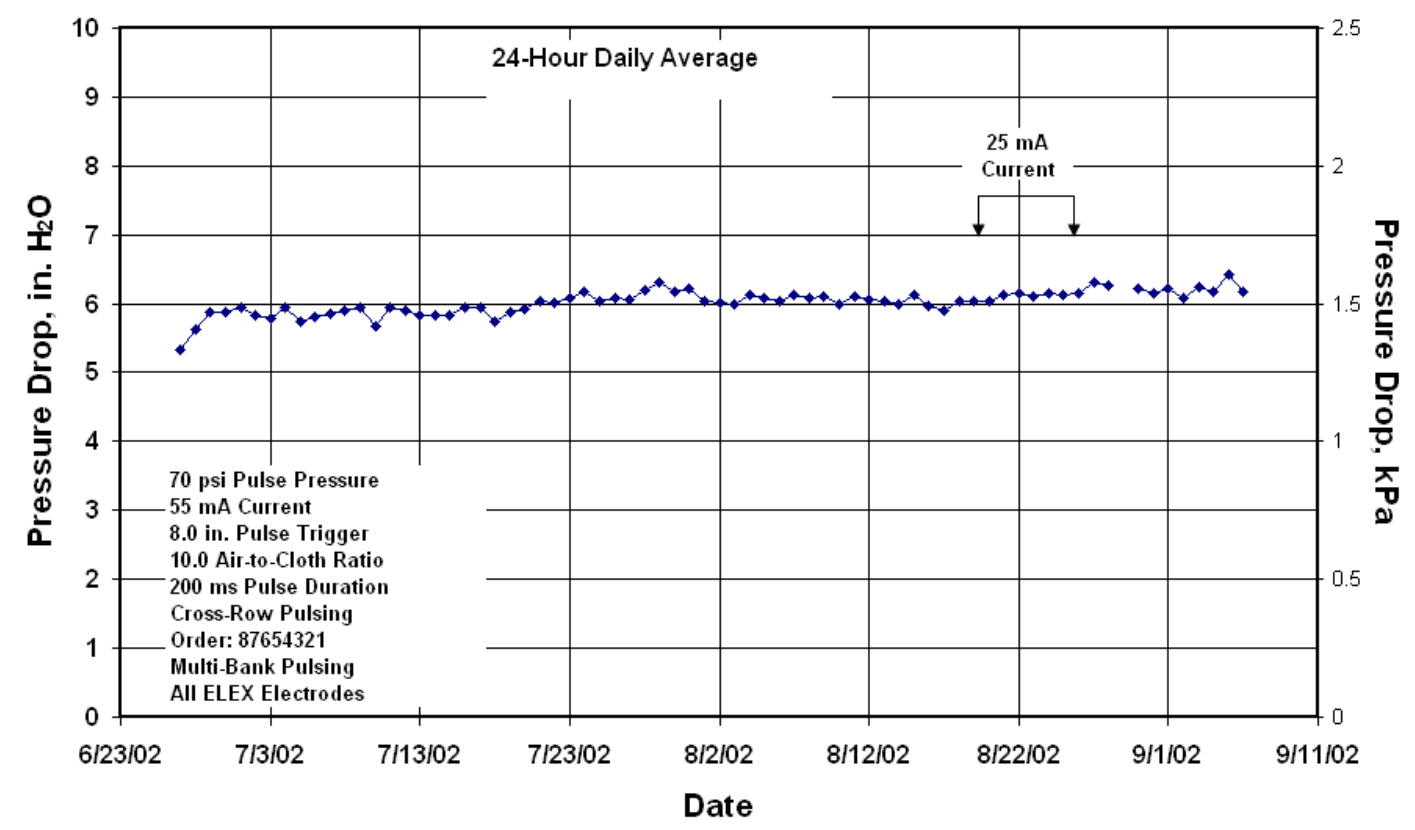

Figure 4. Daily average pressure drop for summer 2002 tests with the 9000-acfm Advanced Hybrid $^{\mathrm{TM}}$ filter. 


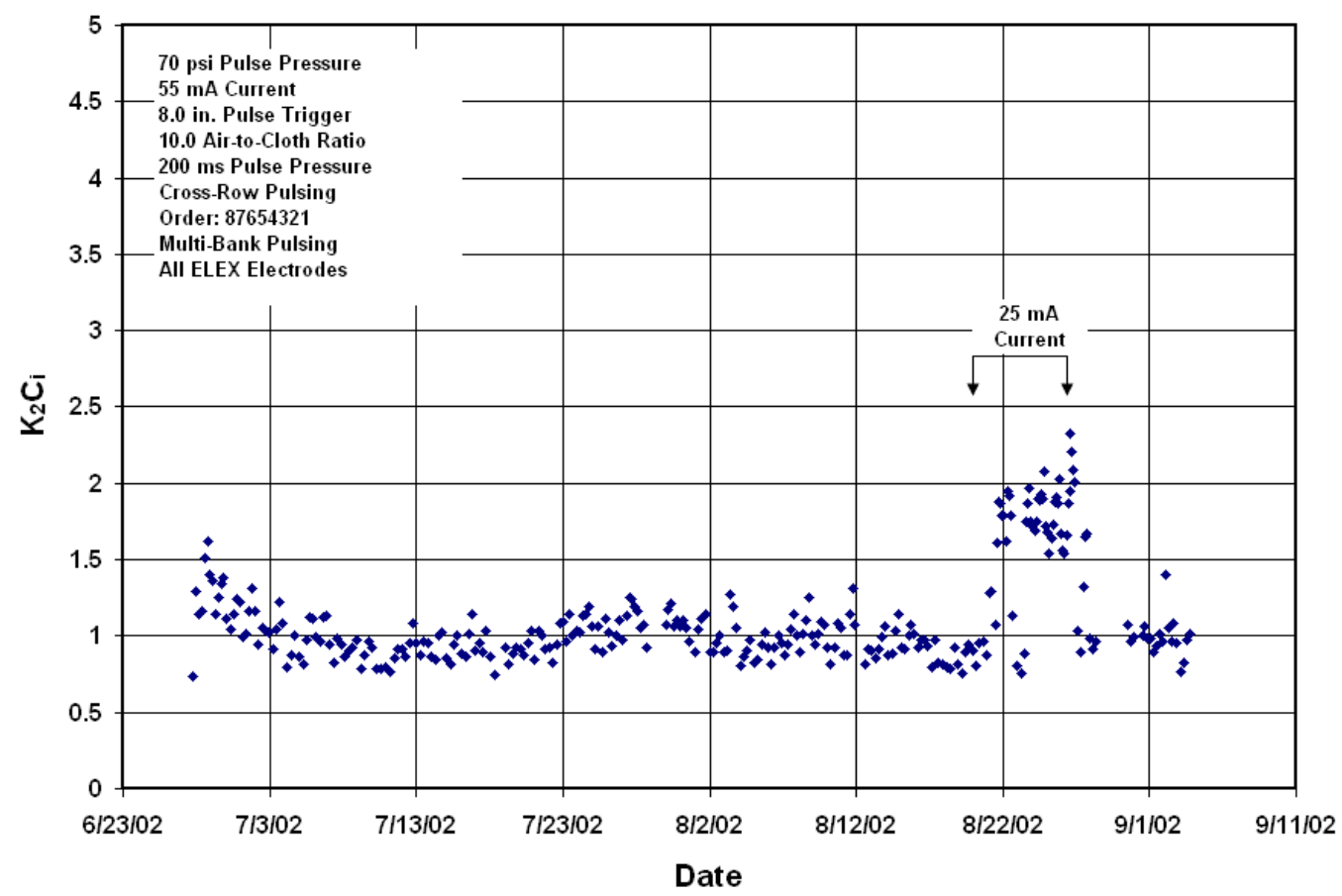

Figure 5. $\mathrm{K}_{2} \mathrm{C}_{\mathrm{i}}$ for summer 2002 tests with the 9000-acfm Advanced Hybrid ${ }^{\mathrm{TM}}$ filter.

A summary of the results in Table 2 shows the excellent operational performance achieved with the 9000acfm at an $\mathrm{A} / \mathrm{C}$ ratio of $10 \mathrm{ft} / \mathrm{min}$.

Table 2. Summary of 9000 -acfm PilotScale Results from Summer 2002

\begin{tabular}{lc}
\hline $\mathrm{A} / \mathrm{C}$ Ratio & $10 \mathrm{ft} / \mathrm{min}$ \\
Average dP & $\sim 6 \mathrm{in} . \mathrm{W} . \mathrm{C}$. \\
Bag-Cleaning Interval & $2-5 \mathrm{hr}$ \\
Residual Drag & $0.4-0.5$ \\
$\mathrm{~K}_{2} \mathrm{C}_{\mathrm{i}}$ & $0.9-1.5$ \\
\hline
\end{tabular}

The 9000-acfm pilot Advanced Hybrid ${ }^{\mathrm{TM}}$ filter was also used to vary the operational parameters to assess the most critical effects. One of the most important findings was the observed significant effect of the pulse interval on the $\mathrm{K}_{2} \mathrm{C}_{\mathrm{i}}$ value, as shown in Figure 6. The large increase in $\mathrm{K}_{2} \mathrm{C}_{\mathrm{i}}$ at the lowest pulse intervals indicates that the benefit of the electric field is diminished at lower pulse intervals. This indicates that for good Advanced Hybrid ${ }^{\mathrm{TM}}$ filter performance, a minimum allowable pulse interval should be established. Based on Figure 6, a 60 min pulse interval would be a good minimum performance goal. 


\section{$\mathrm{K}_{2} \mathrm{C}_{\mathrm{i}}$ Versus Bag-Cleaning Cycle Time for the 2.5-MW (9000-acfm)}

Advanced Hybrid ${ }^{\mathrm{TM}}$ Filter

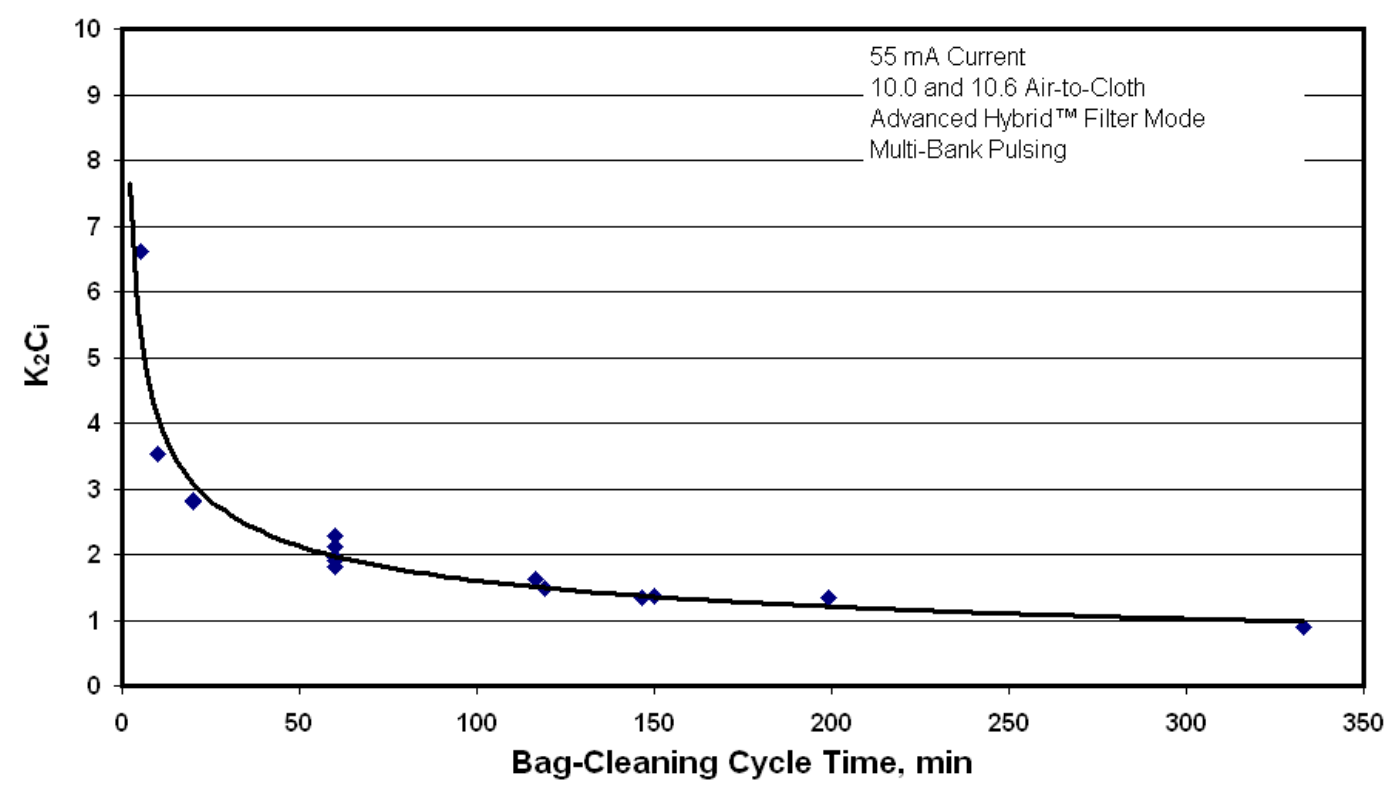

Figure 6. Effect of pulse interval on $\mathrm{K}_{2} \mathrm{C}_{\mathrm{i}}$ for 9000 -acfm pilot Advanced Hybrid ${ }^{\mathrm{TM}}$ filter.

\subsection{Full-Scale Design and Differences Between Full and Pilot Scale}

The original ESP at Big Stone consisted of a Lurgi-Wheelabrator design with four main chambers and four collecting fields in series within each chamber. Only the last three fields in each chamber were converted into an Advanced Hybrid ${ }^{\mathrm{TM}}$ filter while the first field was unchanged (Figure 7). Since the ESP plates are $40 \mathrm{ft}$ high, but the Advanced Hybrid ${ }^{\mathrm{TM}}$ filter bags are only $23 \mathrm{ft}$ long, there is a large open space between the bottom of the bags and the hoppers (Figure 8). The outer six compartments (Figure 7) are arranged with 20 rows and 21 bags per row, while the six inner compartments have 19 rows with 21 bags per row. The total number of planned bags for the 12 compartments was 4914 . However, because of a spacing limitation from the electrode rapping mechanism, a total of 81 bags had to be removed, so the total number of bags in service is 4834 .

The main differences between the 2.5-MW pilot Advanced Hybrid ${ }^{\mathrm{TM}}$ filter and the full-scale Big Stone Advanced Hybrid ${ }^{\mathrm{TM}}$ filter are as follows:

- The pilot unit has a small precollection zone consisting of one discharge electrode, while the fullscale unit has no precollection zone (without the first field on). The effect would be better ESP collection (lower $\mathrm{K}_{2} \mathrm{C}_{\mathrm{i}}$ ) in the pilot unit. The pilot unit has shorter bags, $15 \mathrm{ft}$ versus $23 \mathrm{ft}$ for the 
full-scale Advanced Hybrid ${ }^{\mathrm{TM}}$ filter. The expected result would be better bag cleaning with the pilot unit (lower residual drag).

- The full-scale Advanced Hybrid ${ }^{\mathrm{TM}}$ filter has an ESP plate spacing of 12 in. compared to $13.5 \mathrm{in}$. for the pilot-scale unit. The expected result is somewhat better ESP collection efficiency.

- The entrance velocity of the flue gas is $4-8 \mathrm{ft} / \mathrm{s}$ for the full-scale unit versus $2 \mathrm{ft} / \mathrm{s}$ in the pilotscale unit. The expected effect is better ESP collection efficiency with the pilot unit.

- The pilot unit has very uniform side inlet flow distribution while the full-scale Advanced Hybrid ${ }^{\mathrm{TM}}$ filter has flow from the side for the first Advanced Hybrid ${ }^{\mathrm{TM}}$ filter compartment and from the bottom in the back 2 compartments.

In the pilot unit all of the flow is uniformly distributed from the side and none of the flow comes from the bottom. In the full-scale Advanced Hybrid ${ }^{\mathrm{TM}}$ filter, flow entering the first Advanced Hybrid ${ }^{\mathrm{TM}}$ filter chamber comes from the side (similar to the pilot unit). The flow to the back two compartments must first travel below the first Advanced Hybrid ${ }^{\mathrm{TM}}$ filter compartment and then either directly up from the bottom into the compartment or up from the bottom into the areas between compartments and then horizontally into the compartments (Figure 8). 


\section{Big Stone Layout}

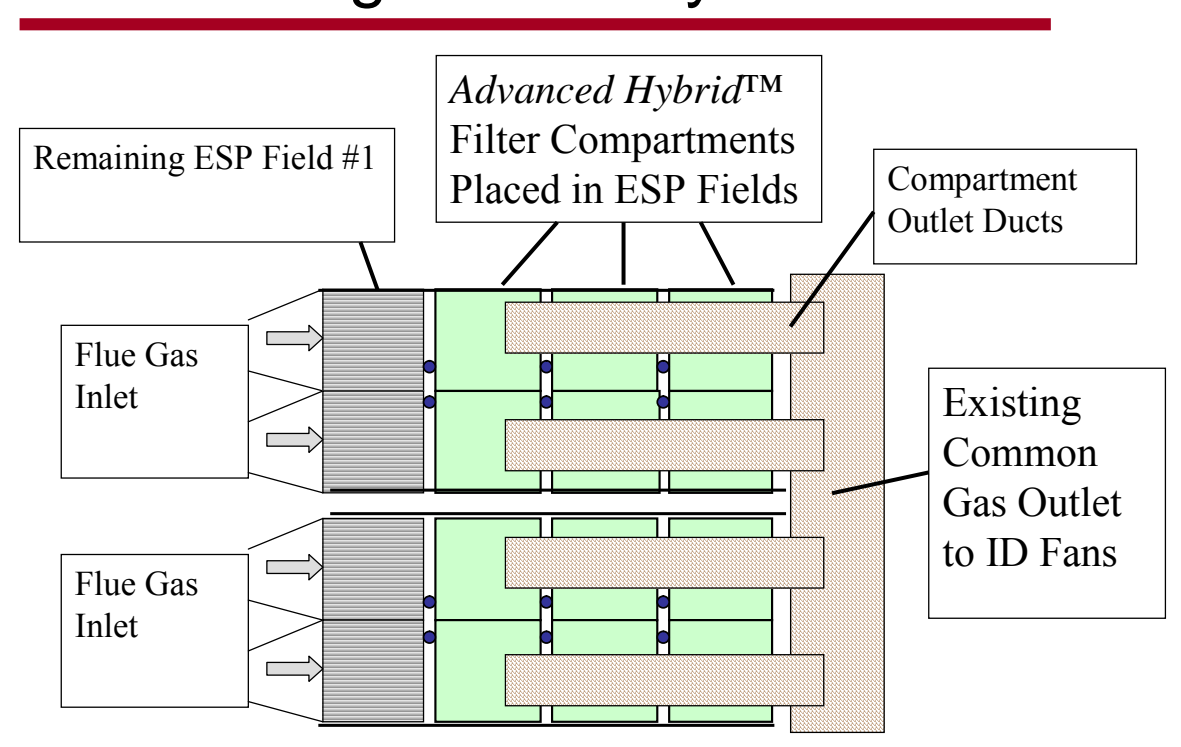

Figure 7. Top view of the Advanced Hybrid ${ }^{\mathrm{TM}}$ filter full-scale retrofit configuration at Big Stone.

Advanced Hybrid ${ }^{\mathrm{TM}}$ Filter Retrofit

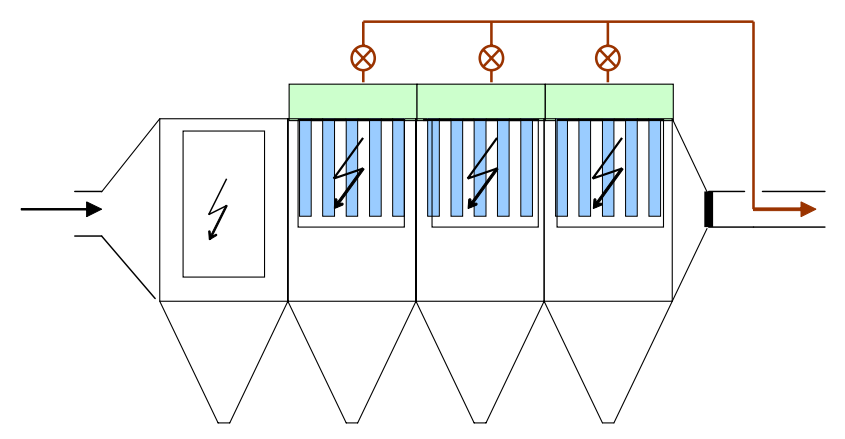

Figure 8. Side view of the Advanced Hybrid ${ }^{\mathrm{TM}}$ filter full-scale retrofit configuration at Big Stone. 


\subsection{EXPERIMENTAL}

\subsection{Independent Characteristics}

\subsubsection{Independent Characteristic Chart}

The following chart lists the specific independent characteristics of the Advanced Hybrid System. If changes are made to the independent data, they will be described in the section listed under the "Notes" column.

Table 3.

\begin{tabular}{|c|c|c|}
\hline Data & Status & Notes \\
\hline ESP Collecting Surface & $170,500 \mathrm{ft}^{2}$ & Unchanged \\
\hline \# of Discharge Electrodes & 2,706 & Unchanged \\
\hline \# of Filter Bags & 4833 & Unchanged \\
\hline Filter Bag Dimensions & 7 Meters Long, 6 Inches Diameter & Unchanged \\
\hline Filter Bag Surface Area & $36.07 \mathrm{ft}^{2}$ & Unchanged \\
\hline Filter Bag Material & See 2.1.2 & Unchanged \\
\hline Pulse Pressure & $80 \mathrm{psi}$ & Unchanged \\
\hline Cleaning Mode & Threshhold Cleaning & Unchanged \\
\hline TR Rating of AH Field & $1500 \mathrm{ma}, 55 \mathrm{kV}$ & Unchanged \\
\hline TR Rating of Inlet ESP Field & $2000 \mathrm{ma}, 55 \mathrm{kV}$ & Unchanged \\
\hline \multicolumn{3}{|l|}{ Inlet ESP Field Data } \\
\hline Inlet Field Dimensions $^{1}$ & 45 gas passages, 40 feet high, 14 feet deep/chamber & Unchanged \\
\hline Inlet Field Plate Area $^{1}$ & $50,400 \mathrm{ft}^{2}$ & Unchanged \\
\hline Inlet Field Electrodes $^{1}$ & Wheelabrator bed frame "Star" Electrodes & Unchanged \\
\hline
\end{tabular}

${ }^{1}$ The inlet ESP field was left in place. The design is the original configuration as installed in 1975. It is not the intention to operate the inlet field, however it was left in place as an added benefit of the system. 


\subsubsection{Bag Layout}

For specific bag layout and description over the life of the project, refer to Appendix B23. 


\subsection{Dependent Characteristics}

\subsubsection{Dependent Data}

The dependent data is largely presented in graphical format in the Appendix. The specific data points that are instrumented and presented are as follows;

Plant Gross Load: Continuously monitored TDC-3000 calculated value based on the generator output voltage and current. When the plant trips offline or shuts down for maintenance, the plant gross load will be zero.

Total Flue Gas Flow: Continuously monitored using United Science Inc.'s Ultra Flow 100 ultrasonic flow monitor. The flow monitor is located at the stack midlevel (see position \#6 on the figure in 2.2.2). The readout of the flow monitor is in kscfm using $68^{\circ} \mathrm{F}$ and 29.92 in $\mathrm{HG}$ as standard conditions. The flow is converted to kacfm using the following equation:

Gas Flow $(\mathrm{kacfm})=\frac{\left(\text { Gas Flow }(\mathrm{kscfm}) *\left(460+\text { Inlet Gas Temp }{ }^{\circ} \mathrm{F}\right)\right.}{\left(460+68^{\circ} \mathrm{F}\right)}{ }^{*} \frac{29.92 \text { in HG }}{(28.56 \text { in HG + AHPC outlet Pressure })}$

Inlet Flue Gas Temperature: Continuously monitored using a grid of Type E thermocouples. The thermocouples are located at the AHPC inlet (see position \#1 on the figure in 2.2.2). There are eight thermocouples at the inlet of each of the four AHPC chambers for a total of 32 thermocouples.

Tubesheet Differential Pressure: Continuously monitored on two of the twelve compartments. Pressure taps above and below the tubesheet (see positions \#3 and \#4 on the figure in 2.2.2) are equipped with Honeywell 3000 Smart DP Transmitters.

Flange-Flange Differential Pressure: Continuously monitored using two Honeywell 3000 Smart DP Transmitters at the AHPC inlet (see position \# 2 in the figure in 2.2.2) and two Honeywell 3000 Smart DP Transmitters at the AHPC outlet (see position \#5 on Diagram 1). Continuously calculated by the TDC- 3000 by taking the difference between the flue gas pressure at the AHPC inlet and outlet.

Air-to-Cloth Ratio: Calculated by dividing the Gas Flow (acfm) by the total surface area of the bags. 
Opacity: Continuously measured by the plant opacity monitor, Monitor Labs Model \#LS541. Opacity is measured in the Plant Stack, position 6 on the figure in 2.2.2. Position 6 is approximately at the $300 \mathrm{ft}$. level from grade.

Flue Gas Outlet Pressure: Continuously monitored using two Honeywell 3000 Smart DP Transmitters at the AHPC outlet (see position \#5 in the figure in 2.2.2). The inlet pressure can be determined by the difference between the outlet pressure, and the flangeto-flange pressure drop.

Temperature per Chamber: See Inlet Temperature above.

ESP Power Consumption: Continuously monitored with a watt-hour meter to each chamber.

Compressed Air Flow: Continuously monitored using a Diamond II Annubar flow sensor equipped with a Honeywell 3000 Smart DP Transmitter. This ANNUBAR instrument is in the compressed air supply line after the compressors but before the desiccant dryer.

The non-instrumented data that can be found in the appendix is as follows

- Coal Analysis

- Flyash Analysis

- Coal and Alternative fuel Burned 


\subsubsection{Instrument Location Diagram}

1 \& 2: Advanced Hybrid Inlet

3 \& 4: Above and Below Tubesheet

5: $\quad$ Advanced Hybrid Outlet

6: $\quad$ Plant Stack

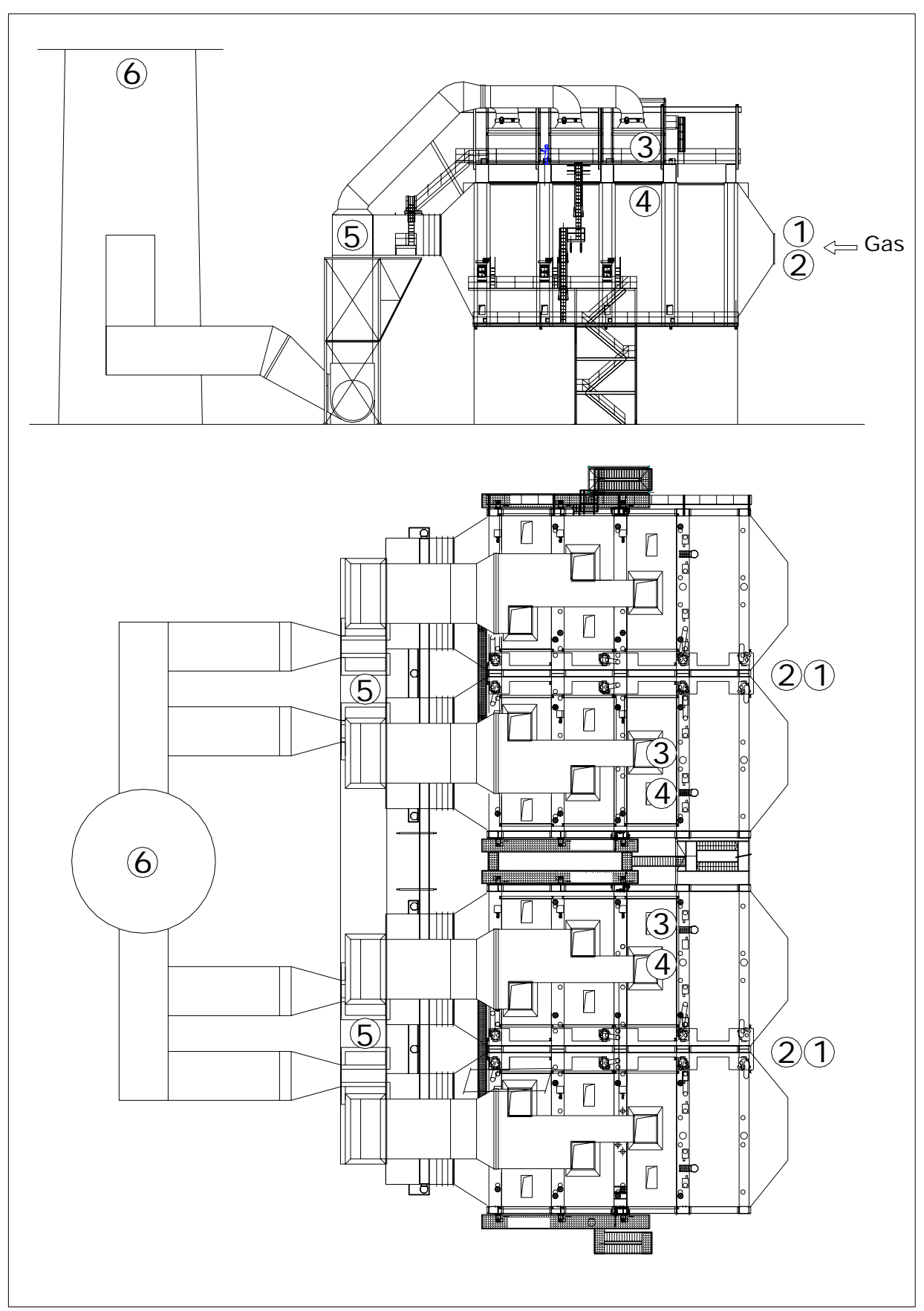




\subsubsection{Data Retrieval}

Big Stone Plant's Honeywell TDC-3000 process control system monitors and controls a large number of actuators, sensors, and processes using PID controllers, programmable logic controllers, and specialpurpose programs. Data gathered by the TDC-3000 is retrieved using an existing plant historian database. The dependent characteristic data presented in this report is calculated using 60-minute averages of the TDC-3000 readings, which are recorded every minute.

\subsubsection{Data Reduction}

Reported $\mathrm{NO}_{\mathrm{X}}$ and $\mathrm{SO}_{2}$ emissions have had 5\% of data removed due to erroneous spikes occurring during daily calibration of CEMS instrumentation. No other assumptions or restrictions were used to transform the raw measured data into a form usable for interpretation. 


\subsection{Results AND Discussion}

\subsection{General Results and Discussion}

3.1.1 Chronological History of Significant Accomplishments

Quarter 1 (October 2002 - December 2002)

System Startup

October 2002

Rapper Problems Realized

November 2002

Pulse Valve Problems Realized

November 2002

EERC Testing (99.99\% particulate capture goal met)

Inlet Field Energized

November 2002

December 2002

Quarter 2 (January 2003 - March 2003)

Soybeans burned at Big Stone as Alternative Fuels

Derates due to high $\mathrm{dP}$ across the $\mathrm{AH}$ system begin

Comparative Testing of Pilot unit to full-scale unit

Plant shut down to wash boiler

January 2003

January 2003

February 2003

February 2003

Quarter 3 (April 2003 - June 2003)

Meeting to discuss improvement options

April 2003

Bags washed in two chambers

Pitot data used for evaluation and decision

Decision to replace filter bags

Complete bag changeout

Inlet field evaluated

Plant restored to full load

April/May 2003

May 2003

May 2003

June 2003

June 2003

June 2003

Quarter 4 (July 2003 - September 2003)

Big Stone limited to $440-445 \mathrm{MW}$ not due to $\mathrm{AH}$

July/Sept 2003

Performance Tests

Fluent Analysis Plan

July/Sept 2003

Preliminary baffle design submitted

Sept 2003

Sept 2003

Quarter 5 (October 2003 - December 2003)

Opacity rise attributed to initiation of bag failures

Competitive bidding of replacement bags

October 2003

Fluent modeling results for flow baffles

Test flow baffles installed

Four compartments of bags replaced

November 2003

November 2003

December 2003

December 2003

Quarter 6 (January 2004 - March 2004)

Stable system operation

Jan/March 2004

Fluent modeling work continues

February 2004

Technology goals reviewed

Next phase of project reviewed \& proposed by OTP

February 2004

March 2004 
Quarter 7 (April 2004 - June 2004)

PPS Bags Failing and Opacity Rising

Inlet Field AH Proposal

All PPS Bags replaced with P-84 Bags

Chamber 2B baffles installed

One compartment of blowpipes modified

Opacity returned to low levels

Bag analysis performed

Additional 8 bags removed for testing

Quarter 8 (July 2004 - September 2004)

Independent Lab Analysis of Bags Completed

Evidence of NOMEX Bag failure

Future project reviewed

Failed P-84 bags discovered

April/June 2004

June 2004

May 2004

June 2004

June 2004

June 2004

June 2004

June 2004

July 2004

August 2004

July/Sept 2004

September 2004

Quarter 9 (October 2004 - December 2004)

NOMEX Bags replaced with fiberglass

$1 / 2$ compartment of $\mathrm{P}-84$ bags replaced

High $\mathrm{dP}$ through the end of the year

Independent Lab Analysis of P-84 Bags

Quarter 10 (January 2005 - March 2005)

Design for inlet field modifications finalized

Fabrication of inlet field equipment

Construction plans finalized

2005

February 2005

March 2005

Quarter 11 (April 2005 - June 2005)

Modification of Inlet field

Startup of lower A:C Ratio Advanced Hybrid

Shakeout of new installation

April/May 2005

June 2005

July 2005

Quarter 12 (July 2005 - September 2005)

Investigation of performance issues

Corrected known ESP clearance problems

Investigated TR Set issues

July 2005

September 2005

Quarter 13 (October 2005 - December 2005)

Replaced failed pulse header joints

December 2005

Corrected additional ESP clearance problems

December 2005

Final determination of technology (OTP)

December 2005 


\subsubsection{Discussion of Results of Significant Accomplishments}

\section{General Discussion (First Quarter 10/2002 - 12/2002)}

\section{$\underline{\text { Initial Startup Problems }}$}

The Plant was put on-line (after the scheduled maintenance outage) on October 25 at 17:37, which is the official beginning of commercial operation of the Advanced Hybrid system. Startup and checkout of the system went fairly smoothly. There were few significant issues that came up during system startup, as described below.

First, there appeared to be a problem with damper operability as the dampers were commanded to open and close to check functionability. The indication for opened and closed did not come in to the plant control room. This was a simple limit switch setting in the controller. Specific training needed to take place between the ELEX startup engineers and Big Stone Plant personnel, as setting the limit switches required knowledge of procedures that, if not followed correctly, would result in the unintended dismantling of the controller body. The manual wheel on the actuator would unscrew from the controller body allowing the oil to leak out, thus rendering the actuator inoperable. This occurred 3 or 4 times before startup personnel familiarized themselves and from that point it proceeded well.

Second, ice had formed in the pressure sensing lines after the advanced hybrid system (just prior to the ID fans). At startup, the pulse controller used the flange-to-flange pressure drop as the input for pulse frequency. If a high enough differential had been realized, the system would not have started pulsing because there would have been no pressure measurement. This could have delayed startup. The sensing lines were about 70 feet long and run 50 feet overhead. However, the ice buildup was not significant and was cleared using torches and poke rods.

Third, pre-coating the bags was a new experience and the procedure was not well developed. The bag manufacturer deemed pre-coating the bags necessary. A supplier delivered crushed limestone via truck and had to wait until the system was ready to be pre-coated. Pre-coating was a manual operation, as Big Stone Plant operators moved a four inch flexible line from duct to duct to inject the crushed limestone into the appropriate chambers. This process directly added to the critical path of the outage, and therefore the time that it takes to pre-coat the bags is directly related to delays in starting up the unit. If this must continue in the future, it would be necessary to install a silo and automatic feed system so the process could be completed in minutes rather than hours. This was an oversight in the project design and plans 
should be taken into account for future installations if bag pre-coating is necessary.

Fourth, the pulse system was not tested with compressed air until the system was started up. The system worked to pulse the bags, however it required the ELEX startup engineers several days to work the bugs out of the pulsing program to consider it functional for normal operation.

Overall system startup went well and fairly trouble free. The operational issues listed above are only the points of interest, and in general, the system components fit and worked together.

\section{Operational Experience}

The operational experience was mixed during the initial phases of operation. W.L. Gore and Associates produced the graph in Figure 9. The graph shows that the drag on the system was running between 0.9 and $1.0 \mathrm{INH} 2 \mathrm{O} / \mathrm{ft} / \mathrm{min}$ during the first few days of startup. However, the whole story includes the bag pulse

Big Stone Advanced Hybrid(TM) Data

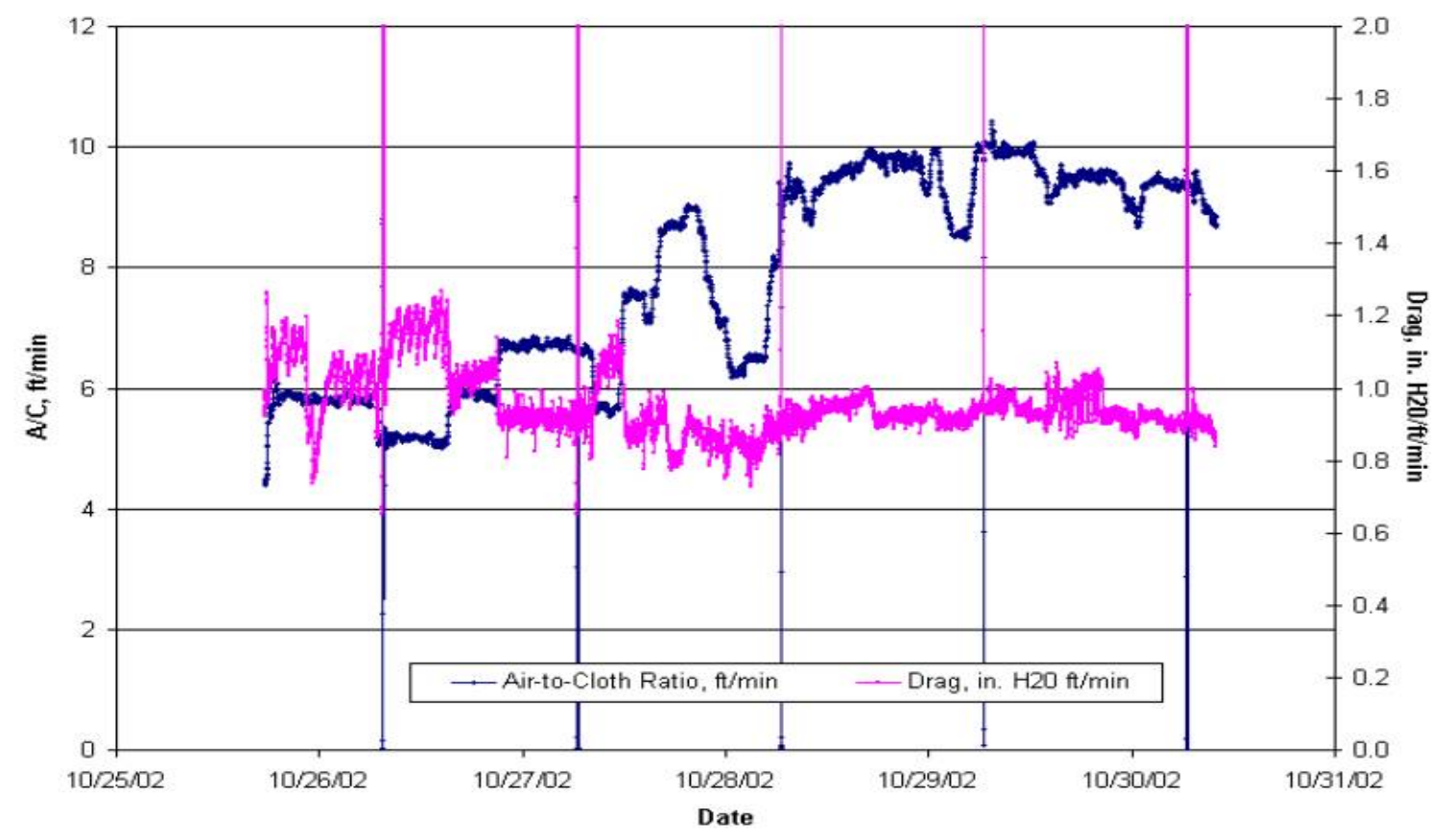

Figure 9 - A/C Ratio and drag during the first week of operation 
frequency. The system is attempting to run at a flange-to-flange pressure drop at $9.0 \mathrm{INH} 2 \mathrm{O}$. It is accomplishing this by changing the rate at which the 504 pulse valves are firing. That rate is not currently being recorded so there is no history. In Figure 1, we do not know if the pulse valves are running continuously (about 1.2 seconds between pulses), or one tenth of that (about 12 seconds between pulses), or any amount between. As a result, it is very difficult to put a meaningful analysis together on how the system was operating. The system was pulsing very quickly (about $1.2-2.4$ seconds between pulses), within days of initial operation. During the first month of operation, it was deemed necessary to get some type of pulse signal into history. Eventually (around December 5, 2002) a system was installed to measure and record the pulse frequency. By that time the system was in constant pulsing while at full load, and the recorded history was not very useful.

One of the first mechanical issues seen after startup was sticking solenoid valves. On October 28 , the Monday after startup, it was noticed that a fair number of solenoid valves were not operational. This was traced to the compressed air supply lines that were not blown clear prior to being connected. The cutting oil and debris in the lines contaminated the solenoid valves. The Big Stone Plant technicians disassembled and cleaned a portion of the solenoid valves to alleviate this problem. After the initial rash of sticking valves, the problem disappeared.

One of the first tests run was the off -line bag cleaning function of the Hesch pulse valve controller. This function intended to enable one compartment (1/12 of the total) to be isolated from gas flow, and pulsed without gas going through the bags. This should have resulted in improved cleaning and a lower differential pressure. This feature was tested on October 29, but did not work as the pulse valves did not activate when the damper was closed to the compartment. This was a software problem and a software update was shipped from Hesch and installed on November 12. The software fix did allow the functionality of off-line cleaning, but through intermittent tests, it was not clearly defined as a benefit to the normal cleaning modes and was not implemented as the normal mode. The differential was too high with 12 compartments in service, and taking one of the compartments out of service raised the overall differential pressure to intolerable levels.

On October 31, forced cleaning mode was also tested. This mode continuously pulsed the cleaning 
valves. This also did not work correctly, but the software fix mentioned in the paragraph above resolved this issue.

During the first week of operation, two filter bags were found in the ash hoppers below the Advanced Hybrid system. This was a strong concern at the time, as we were not sure if all of the bags were prone to being dislodged from the cage and tubesheet fit. It appears there were only a few ill-fitting or misinstalled bags which came loose and fell. Two bags represents $0.04 \%$ of the total bags installed.

The Big Stone Plant was derated on November 9 to replace these two bags, and inspect that portion of the AHPC. One bag was removed for examination by W.L. Gore personnel. During startup and limited first data, from the first two weeks, the bags were in good shape and there were no adverse effects from startup or short-term operation.

Alternative fuels burned at Big Stone were started back up on November 1. The specific amounts can be seen in Appendix B14.

On November 18, the Energy and Environmental Research Center (EERC) performed the first stack test to evaluate the particulate capture of the system. The full report can be found in the Appendix, but the summary chart in Figure 10 shows that the particulate capture of the system was very high as expected.

Table 6. Advanced Hybrid ${ }^{\mathrm{TM}}$ Particulate Collection Efficiency (From Appendix)

\begin{tabular}{|c|c|c|c|c|c|c|}
\hline Date & $\begin{array}{l}\text { Sample } \\
\text { Method }\end{array}$ & $\begin{array}{l}\text { Advanced } \\
\text { Hybrid } \\
\text { Inlet } \\
\text { Dust } \\
\text { Loading, } \\
\text { grains/scf }\end{array}$ & $\begin{array}{c}\text { Advanced } \\
\text { Hybrid }^{\mathrm{TM}} \\
\text { Inlet }^{1} \\
\text { Dust } \\
\text { Loading, } \\
\mathrm{lb} / 10^{6} \mathrm{Btu}\end{array}$ & $\begin{array}{c}\text { Stack } \\
\text { Dust } \\
\text { Loading, } \\
\text { grains/scf }\end{array}$ & $\begin{array}{c}\text { Stack }^{1} \\
\text { Dust } \\
\text { Loading, } \\
\text { lb/10 } 10^{6} \mathrm{Btu}\end{array}$ & $\begin{array}{c}\text { Particulate } \\
\text { Collection } \\
\text { Efficiency, } \\
\%\end{array}$ \\
\hline $11 / 18 / 2002$ & EPA Method 17 & & & 0.00002 & 0.00003 & 99.998 \\
\hline $11 / 19 / 2002$ & $\begin{array}{l}\text { EPA Method } 29 \\
\text { Multicyclones }\end{array}$ & $\begin{array}{l}1.02092 \\
0.64099\end{array}$ & $\begin{array}{l}1.38378 \\
0.86882\end{array}$ & & & \\
\hline $11 / 20 / 2002$ & $\begin{array}{l}\text { EPA Method } 17 \\
\text { EPA Method } 29 \\
\text { EPA Method } 29\end{array}$ & $\begin{array}{l}0.85856 \\
0.92151\end{array}$ & $\begin{array}{l}1.16372 \\
1.24904\end{array}$ & 0.00006 & 0.00008 & 99.994 \\
\hline $11 / 21 / 2002$ & $\begin{array}{l}\text { EPA Method } 17 \\
\text { Multicyclones } \\
\text { Multicyclones }\end{array}$ & $\begin{array}{l}0.66113 \\
0.70044\end{array}$ & $\begin{array}{l}0.89611 \\
0.94940\end{array}$ & 0.00003 & 0.00004 & 99.997 \\
\hline
\end{tabular}

\footnotetext{
${ }^{1}$ Values were calculated based on the Fd factors shown in Table 3 for $100 \%$ PRB.
}

Figure 10 - Results of Stack Testing by the EERC 
During the month of November, two more bags were found in the hoppers. On November 23, three fourths of the system was removed from service to complete an inspection of the system. Two more bags that had fallen from the tubesheet were located and replaced. There was significant ash buildup on the perforated plates and the rapping schedule was adjusted for a higher frequency of rapping.

The Big Stone Plant electricians completed routine external inspections of the plate rapper system by manual operation of the rapper system and observation from the exterior. During one of these inspections in later November, it was found that one of the rappers in Chamber 2B was not turning. Electricians disconnected the motor and verified that rapper shaft was jammed internal to the system. On the $17^{\text {th }}$ of December, the system was removed from service and inspected. At the time, the rapper shaft was found to need repairs; there was a broken hammer, bent rollers, and hammer to anvil alignment problems. The collar that grips the rapper shaft appeared loose. There were two fundamental issues with the reliability of the plate rappers. First, the rapper shafts were the wrong diameter. The collars that grip these shafts to keep them from floating laterally could not effectively maintain the shaft alignment. Second, the internal walkways were mounted fixed at the opposite wall as the fixed point of the rapper shafts. As the system heats up when flue gas is put through it, the walkways and the rapper shafts expand in opposite directions and misalignment between the rapper hammers and the anvils occurs. The system was also taken down on December 31, with misalignment of the rapper shaft to the walkway components the cause of another frozen rapper.

The Goyen pulse valves appeared to have an operational problem during the month of November as observed by listening to the valves operating. Occasionally a valve would not pulse with as much energy as the adjacent valve. This indication was a loud squeak or a muffled noise as opposed to a strong pulse. A Goyen representative was dispatched to the site on December 18 to review the operation of the valves. He recommended removal of the silencers on each valve to reduce the noise. It is possible that these silencers might have been plugged during startup or normal operation. All 504 silencers were removed from the pulse valves and it seemed to take care of the problem. No significant improvement in overall differential pressure was realized, so it is doubtful if more than $5-10 \%$ of the valves had problems with these silencers.

As the differential pressure had risen in the first couple of months of operation, it was decided to energize the unmodified inlet ESP fields to reduce the ash loading to the Advanced Hybrid system. This was planned as an only-in-an-emergency contingency, but was implemented so a performance and improvement plan could be evaluated. There is one inlet field of original Wheelabrator ESP in each 
chamber. These fields were energized on December 12 and have remained in service.

There appears to be a discrepancy in the gas flow and sizing of the system. It is our understanding that the system was sized on a stoichiometric flow value based on fuel flow into the boiler, the measured oxygen level after the economizer and the air heater leakage as has been measured at the plant. The flow value was $1,824,000 \mathrm{acfm}$. However, the stack flow monitor is reading $5-15 \%$ more flow than is predicted by the stoichiometric balance. Using the 1,824,000 acfm value and dividing by the installed cloth surface area would result in an air-to-cloth ratio of $10.5 \mathrm{fpm}$. The goal of the technology was demonstration of acceptable performance at an air-to-cloth ratio of $12 \mathrm{fpm}$ so that it would be the clear economic choice when compared to other retrofit technologies. The gas flow through the system presented in Appendices B2, B3, \& B7 are based on the stack flow monitor, which reads $5-15 \%$ more than the stoichiometric balance predicts. 


\section{General Discussion (Second Quarter 1/2003 - 3/2003)}

The system to date has experienced significant operational problems. The focus is the high differential pressure across the bags. Some of the mechanical issues have been resolved, but the primary performance concerns appear to be design and/or process related. Very significant derates of power plant output have occurred as a result of ID fan limitations, caused by the high differential pressure across the bags of the Advanced Hybrid system. The factors that appear to be contributing to this are described below.

The first regular full-load plant derate due to the high differential pressure across the Advanced Hybrid system occurred on January 8, 2003. Since that date, the plant has experienced derates as high as 55 MW. This is a significant detriment to the plant and the company's portfolio of available energy. As a result, an aggressive stance to improve AHPC performance has been taken. The performance of the system still boils down to two factors, mechanical reliability and process performance.

\section{Mechanical Issues}

Two issues remain with the mechanical operation of the system, plate rapper alignment and compressed air supply pressure to the headers of the pulse valves.

Two of the plate rappers remain a problem with regards to internal clearances and binding of the rapper shafts while in operation. A derate was taken on January $19^{\text {th }}$ to inspect the system, evaluate the cause, and develop possible solutions. The problem with the rapper shafts binding due to internal obstructions as the system heats up is related to two problems. First, the rapper shafts being too small for the retaining collars at the wall. The second issue is, the opposite expansion of the rapper shafts and walkways due to opposite fixed points. This problem is described in the first quarterly report from the period of October 2002 - December 2002. Several pictures can be found in Appendix B18. The most likely fix is the replacement of the section of the rapper shafts extending through the fixed bearing so the retaining equipment can prevent the shaft from sliding laterally. This would most likely occur during the outage in June, 2003.

The other likely fix is to modify the existing equipment binding due to thermal expansion differences. There are five collars per rapper shaft that have clearance issues. The collar bolting is the problem. The collars, bolts, and visual evidence of the damage that occurs are shown in the pictures in Appendix B18 titled "Missing Roller" and "Damaged Bolt \& Nut". Modifications to this system will take place during the scheduled wash outage in June. Other damage that occurred can be seen in the pictures titled "Anvil Front View" and "Anvil - Angle View". Since there is poor hot alignment, a portion of the hammers are 
not striking the anvils squarely, damaging the anvils.

The other mechanical concern is the flow limitation from the pressure regulators in the compressed air system. As the system was installed, there were six regulators installed as described in the following table (location diagram of chambers and fields is included in multiple areas in the appendix). The AHPC system is capable of faster, more aggressive pulsing, but the regulators are limiting how much

\begin{tabular}{|l|l|l|}
\hline Regulator \# & Size & Compartment Supply \\
\hline 1 & $1.5^{\prime}$ & Chamber 1A, Fields 2, 3, \& 4 \\
\hline 2 & $1.5^{\prime}$ & Chamber 1B, Fields 3 \& 4 \\
\hline 3 & $1.5^{\prime}$ & Chamber 2A, Fields 3 \& 4 \\
\hline 4 & $1.5^{\prime}$ & Chamber 2B, Fields 2, 3, \& 4 \\
\hline 5 & $1.0 ”$ & Chamber 1B, Field 2 \\
\hline 6 & $1.0 ”$ & Chamber 2A, Field 2 \\
\hline
\end{tabular}

compressed air flow they allow through. During periods of off-line cleaning, we need to be able to pulse through all of the valves as quickly as possible to bring the off-line compartment back on-line. The following description of the efforts to resolve this issue can best be broken down by describing the "Compressed Air Flow" graph in Appendix B22.

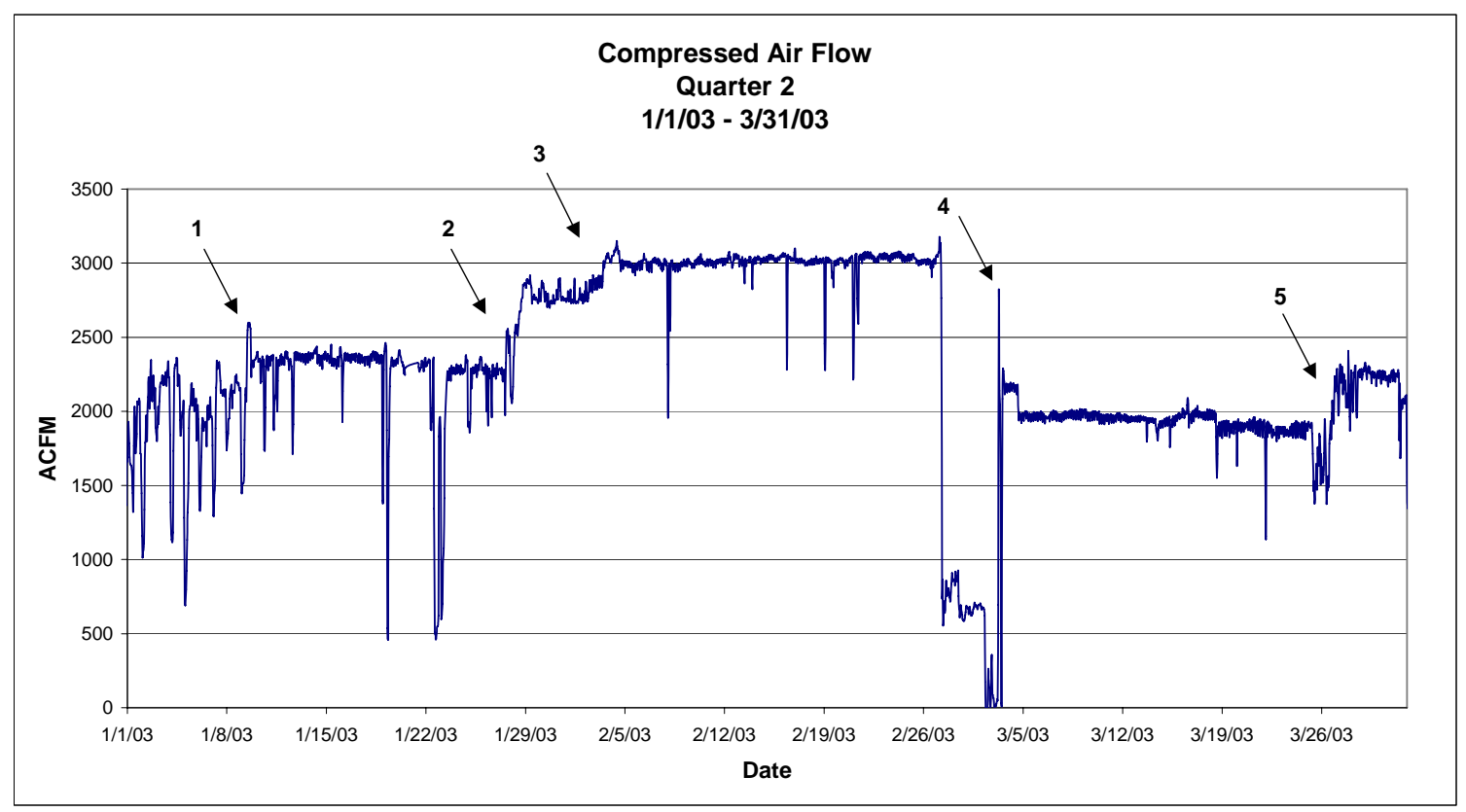

Period 1. During this period, we removed regulators 2 and 3 from service and allowed full plant air system pressure to reach the headers, approximately $100 \mathrm{psig}$. Just prior to this date, the plant began 
derating due to high differential across the bags. A slight increase in compressed air usage is seen on the graph. This made only slight improvements to lower the differential pressure (Appendix B5).

Period 2. We changed regulators 1 and 4 to 2 " regulators and set the pulse cleaning cycle pause time to 0.1 seconds. We have been limited to 0.4 seconds of pause time between pulses due to the time required to refill the headers. A noticeable step change from $2250 \mathrm{acfm}$ to $2800 \mathrm{acfm}$ is seen on the trend. We were greatly exceeding the desiccant dryer capacity at this time, as this is rated for approximately 2000 acfm.

Period 3. We removed regulators 1 and 4 from service. This is the highest period of compressed air usage and we had great difficulty maintaining the compressed air system pressure in the plant.

Period 4. The plant was off-line to wash the steam heat transfer surfaces of the boiler. During this outage, we noticed the bags experiencing the highest pulse pressures were forming small concentric wear areas approximately 1 inch in diameter at the very bottom of the bags. This was likely due to the aggressive pulse energy and a poor bag-to-cage fit causing the bag to flex and rebound into the bottom of the cage. At that time we were exceeding the rating of the dessicant dryer. The plant compressed air system was not capable of supplying that continuous volume of compressed air. We put all regulators back in service and increased the pause time to 0.4 seconds.

Period 5. Twelve individual regulators were installed (one per compartment) and the cycle pause time was decreased from 0.4 seconds to 0.3 seconds. This has been the normal state since that time. Graphical data indicates constant pulsing with the pause time at 0.4 seconds results in compressed air usage of approximately $1900 \mathrm{acfm}$, and a pause time of 0.3 seconds results in a compressed air usage of approximately $2250 \mathrm{acfm}$.

With all twelve compartments having a dedicated pressure regulator, we have resolved the problem of not maintaining the pressure in the header during pulsing. After regulator installation, the headers have been maintaining a pulse pressure of approximately 80 psig.

\section{$\underline{\text { System Performance }}$}

A great deal of effort has been put forth to both establish where we are at with the existing performance, and what can be done to improve performance. The very high differential pressure is significantly different than the previously reported results of the Pilot Unit operation. The first step in evaluating the 
performance was to attempt baseline testing with the pilot unit in place. The pilot unit was started up on

February 3, and testing took place on February 8. There were two parameters, $\mathrm{K} 2 \mathrm{Ci}$ and Residual Drag, which needed to be evaluated to compare performance of the two units. A short explanation of these terms and how they are calculated follows.

\section{$\underline{\mathrm{K} 2 \mathrm{Ci}}$}

$\mathrm{K} 2 \mathrm{Ci}$ a measure of the loading rate of dust to the filter bags. The measurement was completed by stopping the bag pulsing and measuring the rate of the rise in differential pressure. A slower rate of differential pressure rise would mean that the ESP portion of the Advanced Hybrid was taking out more dust prior to it reaching the bags. A faster differential pressure rise would mean that the ESP portion is not removing as much dust prior to it reaching the filter bags. Various tests were completed the night of February 8. A trend of the differential pressure of both the full-scale unit and the pilot unit is included below. A description of the individual tests follows.

\section{$\underline{\text { Residual Drag }}$}

Residual Drag is the minimum resistance possible after pulse cleaning, or the resistance of the system with just the bags and whatever dust cake cannot be removed from the bags from pulsing. It is calculated by taking the differential pressure immediately after cleaning and dividing by the air-to-cloth ratio. The units for this measurement are $\mathrm{INH} 2 \mathrm{O} / \mathrm{ft} / \mathrm{min}$. Although the test was not set up to measure the residual drag of the pilot plant, previously reported results are in the $0.5-0.6$ range.

\section{ESP Efficiency}

For our test, ESP efficiency was calculated by a rule of thumb method. The loading rate with no ESP section in service was taken as the $0 \%$ ESP efficiency state. A $100 \%$ efficient ESP would have a 0 loading rate. Therefore, if the $\mathrm{K} 2 \mathrm{Ci}$ value was found to be $5.0 \mathrm{IN} \mathrm{H} 2 \mathrm{O} / \mathrm{HR}$, and the no ESP loading rate was found to be 19.0, the efficiency value was calculated by the following equation;

$$
\text { ESP Efficiency }=(19.0-5.0) / 19.0 * 100=73.7 \%
$$

This is an unconventional method of calculating ESP efficiency but works well for our comparison testing.

Test \#1. The TRs to only the Advanced Hybrid fields were energized. Both the full-scale system and the pilot unit were operating at $10.4 \mathrm{fpm}$ according to flow instrumentation. The pulsing of the full-scale 
system was halted until the differential pressure reached unacceptable levels. Then the pulse system was started, but the rate of differential pressure increase was measured, and the differential pressure after one

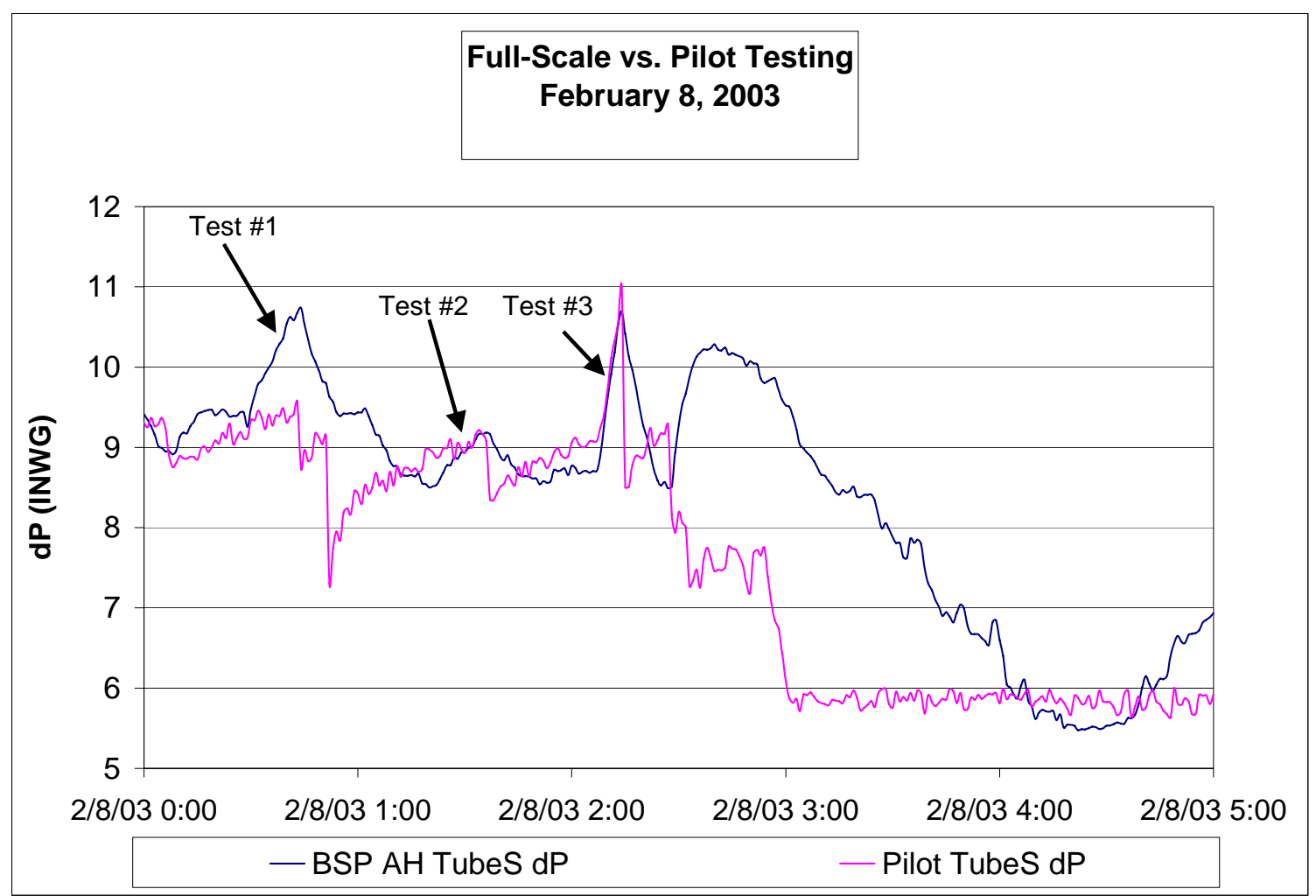

cycle of cleaning was measured.

Test \#2. The first test was repeated with all of the TRs, including the full-scale inlet field, energized.

Test\#3. The same test was repeated with all of the TRs for both the pilot unit and the full-scale unit shut off. This test should be a good comparison of the overall ash loading rate to the bags without any electrostatic cleaning of the flue gas.

The following table is the summary of the test results.

\begin{tabular}{|c|c|c|c|c|c|c|}
\hline & $\begin{array}{c}\text { Air-to-cloth } \\
\text { Ratio }\end{array}$ & \multicolumn{2}{|c|}{ K2Ci } & \multicolumn{2}{c|}{ ESP Efficiency } & $\begin{array}{c}\text { Residual } \\
\text { Drag }\end{array}$ \\
\hline & & Full-Scale & Pilot & Full-Scale & Pilot & Full-Scale \\
\hline Test \#1 & 10.4 & 5.17 & 0.91 & $72.5 \%$ & $95.4 \%$ & 0.91 \\
\hline Test \#2 & 10.4 & 3.02 & 1.5 & $83.9 \%$ & $92.5 \%$ & 0.83 \\
\hline
\end{tabular}




\begin{tabular}{|c|c|c|c|c|c|c|}
\hline Test \#3 & 10.4 & 19.94 & 18.77 & $0 \%$ & $0 \%$ & NA \\
\hline
\end{tabular}

Very significant conclusions can be made by analyzing the results of this testing. The loading rate of ash to the bags is $3-5$ times higher in the full-scale unit when compared to the pilot unit. This means that the amount of dust that is being removed by the ESP portion of the systems is significantly different.

The residual drag is significantly higher in the full-scale unit as noticed during the first few days of startup (see Quarter 1 report).

Running the inlet field of the full-scale system reduces the ash loading to the bags by about 40\% ((5.17$3.02) / 5.17 * 100)$. Improving the ESP portion of the system also has a significant effect by reducing the residual drag. By doing nothing more than improving the overall collection of the ESP sections (inlet field and Advanced Hybrid fields) from $72.5 \%$ to $83.9 \%$, the residual drag has been reduced from 9.1 to 8.3 , approximately $9 \%$

The comparison results from Test 3 show a very good correlation to the full-scale unit and the pilot unit. This tells us that the inlet dust loading to both systems is about equal. 


\section{$\underline{\text { Possible Reasons for Performance Differences }}$}

Trying to formulate a plan for improving the performance of the system involves putting together several hypothesis as to why the performance may be different than expected, how it can be verified, and what can realistically be done to improve the system.

Possible explanations for the ESP efficiency difference have been a flow distribution difference as the pilot unit is a side entry system and the full-scale unit is more of a combination of $1 / 3$ side entry and $2 / 3$ bottom entry. Some flue gas may also be bypassing the ESP section if there is a significant portion of the flue gas that is coming up from the area below the bags.

A better description of the flow differences can be found in the following diagrams. The diagrams represent the flow as modeled by ELEX AG at the beginning of the project. Some of the flow is vertical as represented by the red arrows. However, the pilot unit flow is more represented by the flow only in the first field. After entering this field in the pilot, the gas flow is upwards and into the clean gas plenum. There are no "back fields" of Advanced Hybrid components in the Pilot unit.

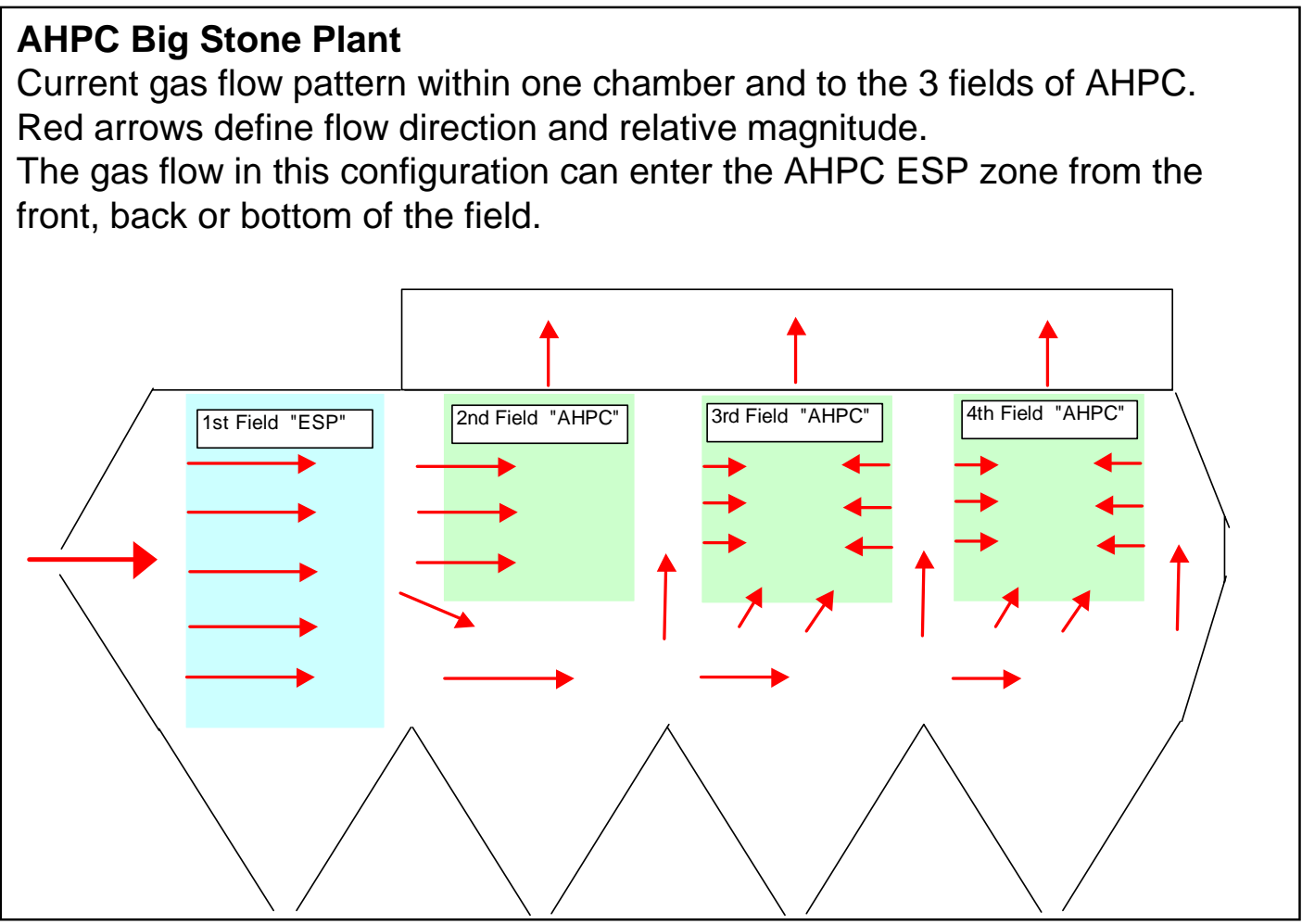




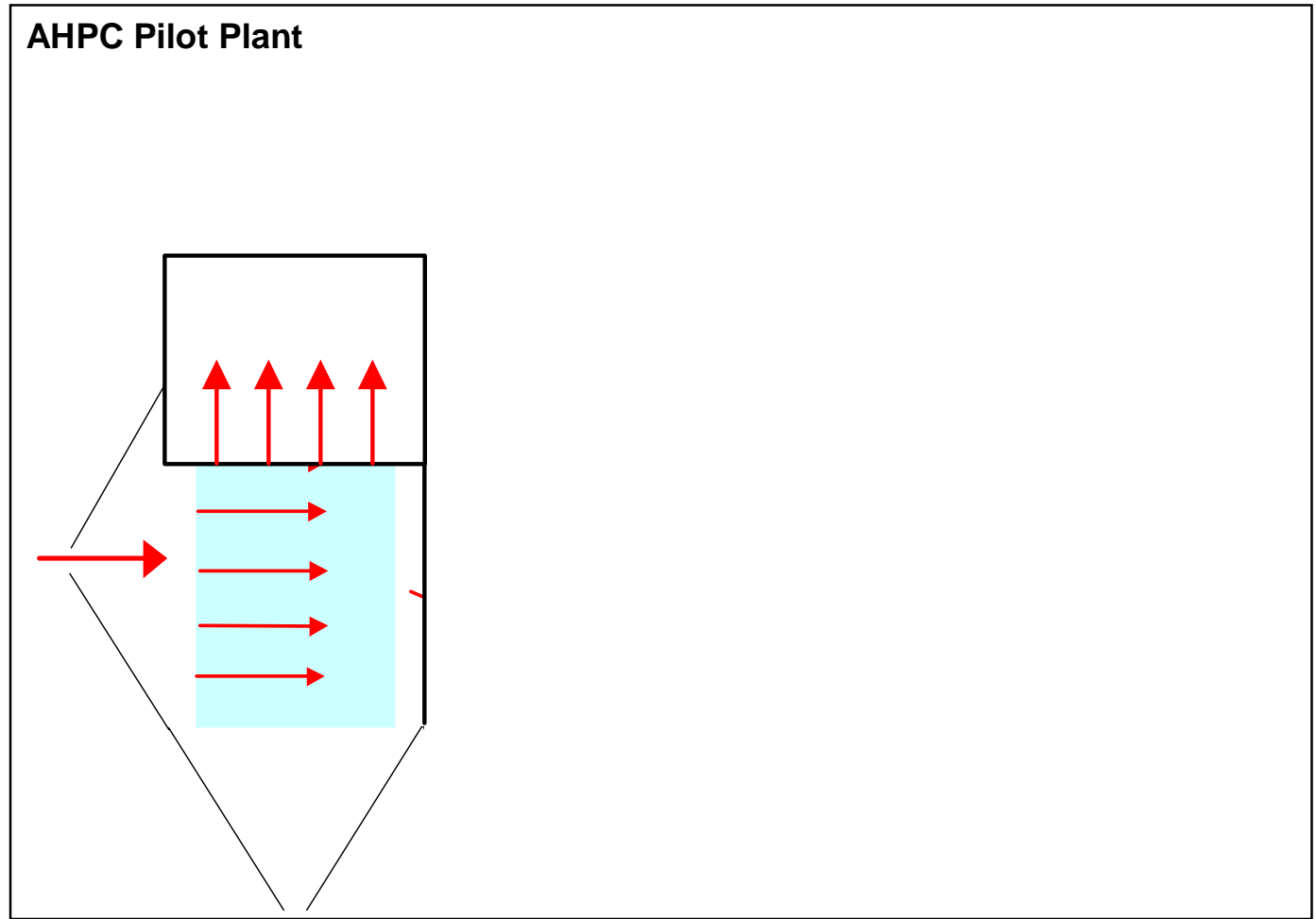

At this time, no reasonable improvements to the Advanced Hybrid ESP portion could be ascertained. The only suggested improvements are power off rapping or the potential for flow baffles that would require significant funding and mechanical changes to the system.

Possible explanations to the residual drag issue are more resistance due to bag material or manufacture, cleaning system deficiencies, or ash characteristics limiting removal during pulsing.

We investigated the effect of the burning of soybeans in the Big Stone Plant as an alternative fuel. During the first two months of the year, approximately 15,000 tons of soybeans ( $5 \%$ of the total fuel) were burned, with the obvious effect of fouling the steam tube surfaces inside the boiler furnace. This might have had some effect on increasing the residual drag of the system by depositing ash on the bags that cannot be easily removed. The EERC analyzed the residual ash cake taken from a bag in service and found a high percentage of potassium. An analysis of soybeans and corn (which is also an alternative fuel fired at the Big Stone Plant) is included in Appendix B16. We should have documented the residual drag of the system at the end of December and the residual drag of the system after the soybeans were burned. This would have given us more information as to how much of the residual drag difference between the pilot unit and the full-scale unit was due to combustion of higher potassium fuels. The EERC determined 
it is likely the flyash from the soybeans was a factor in the increase of the residual drag. The e-mail from Stan Miller from the EERC is included in Appendix B25.

\section{Performance Improvement Plan}

A great deal of effort was put into assembling a performance improvement plan. There were two tactics taken as a part of this effort; a short-term plan designed to help the plant get back to full-load capability, and a long-term plan to bring the Advanced Hybrid system performance up to expected levels.

\section{Short-term Improvement Plan}

- Testing the off-line cleaning system

- Testing power off rapping

- Improvements to the ESP Inlet Field

- Washing the filter bags

- Pitot tube data gathering

\section{Off-line Cleaning}

The intention of the off-line cleaning system was to close the outlet damper of one of the twelve compartments of the system and pulse that chamber while no gas flow is passing through the bags. In theory, this would allow a better cleaning of the bags, reducing the residual drag and the differential pressure of the system. Once the issues with the compressed air regulators were resolved, this technique was attempted several times. Although there were times when there appeared to be a slight improvement in differential pressure, the results were miniscule at best and this path was not further pursued. The existing cleaning system was removing the ash at the same rate in either cleaning mode. Another difficulty in this arrangement is that simply closing the outlet damper to a single compartment raised the dP by $1.0-1.5 \mathrm{INH} 2 \mathrm{O}$ and this could cause the existing condition of limited fan capability to worsen and result in an ID fan stall.

\section{Power Off Rapping}

Power off rapping was also tried to improve the overall field strength of the ESP system. In almost all cases the field strength was increased, but the overall effect on differential pressure was minimal or nonexistent. The existing system did not have a true power off rapping system installed, so the test of the system was done manually by shutting off the power to the TR to a certain field, and manually commanding the plate and electrode rappers to run. Since little to no benefit was seen with regards to power off rapping it was not adopted as a performance improvement strategy. 


\section{Improvements to the ESP Inlet Field}

The performance of the inlet ESP field seemed to vary considerably from chamber to chamber. Since the original ESP equipment was over 25 years old and difficult to maintain improvements to plate spacing or rapping could be made to bring the ash removal abilities of the inlet field to the maximum. Although improving this section of the system does not improve the Advanced Hybrid system, it was determined that the field would be analyzed by technicians from ELEX AG and modifications made to try to improve the overall performance.

\section{Washing the Filter Bags}

W.L. Gore personnel recommended washing the existing bags to remove the residual dust cake that could not be removed by pulsing. This seemed like an attractive option as the concern over the potassium rich flyash from the soybeans burned in the Big Stone Boiler could be eliminated. However, there was an even larger concern that water would be in direct contact with the flyash in the Advanced Hybrid box. This material is much like concrete dust and if some of the dust were to get wet and not be removed, this could cause major problems inside the system. More investigation was needed to make this decision.

\section{Pitot Tube Data Gathering}

One of the corner stones to decision making was the effort by W.L. Gore and Associates to install a substantial number of pitot tubes directly over an individual bag. This should allow better specific information with regards to potential improvement options. The effort to complete this task was significant, and the decisions that were made with regards to bag washing and bag replacement were in large part based on this tool. A brief description of this effort is needed to understand the measurement history.

\section{Pitot Tube Measurements}

Pitot tube measurements were used successfully on the Pilot unit and reported to the NETL by the EERC. The best description of the Pitot tube effort is the pictures included in Appendix B26. These are photographs depicting the installation of the pitot tubes as they were clamped on to the pulse pipes and extended into the bags. Also included in Appendix B27 is a document from Rich Gebert of W.L. Gore and Associates with more specific design and details of the pitot tubes. The placement of the Pitot tubes can be found on a specific bag layout chart in Appendix B28. These pitots were installed during the boiler wash outage from February 26 through March 2. Low pressure transmitters (Appendix B29) were set up near these compartment locations to record the velocity and static pressure data. There were a 
limited number of transmitters available for velocity pressure readings, so the connection lines to the transmitters have to be moved frequently to show multiple compartment data.

\section{Data from Pitot Tube Measurements}

By the end of the quarter, only limited data was available for analysis. The following graphs are some examples of the data that was retrieved and reported by W.L. Gore and Associates personnel. There are three different types of information that could be garnered from the data; velocity pressure, air-to-cloth ratio, and filter bag drag. (These are represented in the first three graphs below). The fourth graph represents an example of the actual data as it is read from the PLC recording the data from the instruments. No substantial conclusions could be made as to the overall performance of the system by the end of the quarter. The limited data seemed to indicate there were fairly significant flow differences between compartments and between bag locations within compartments. However, the team did feel this was going to be a valuable tool and would aid in the evaluation of the following two aspects in the next quarter;

- Flow differences before and after a bag wash

- Flow differences between bag materials

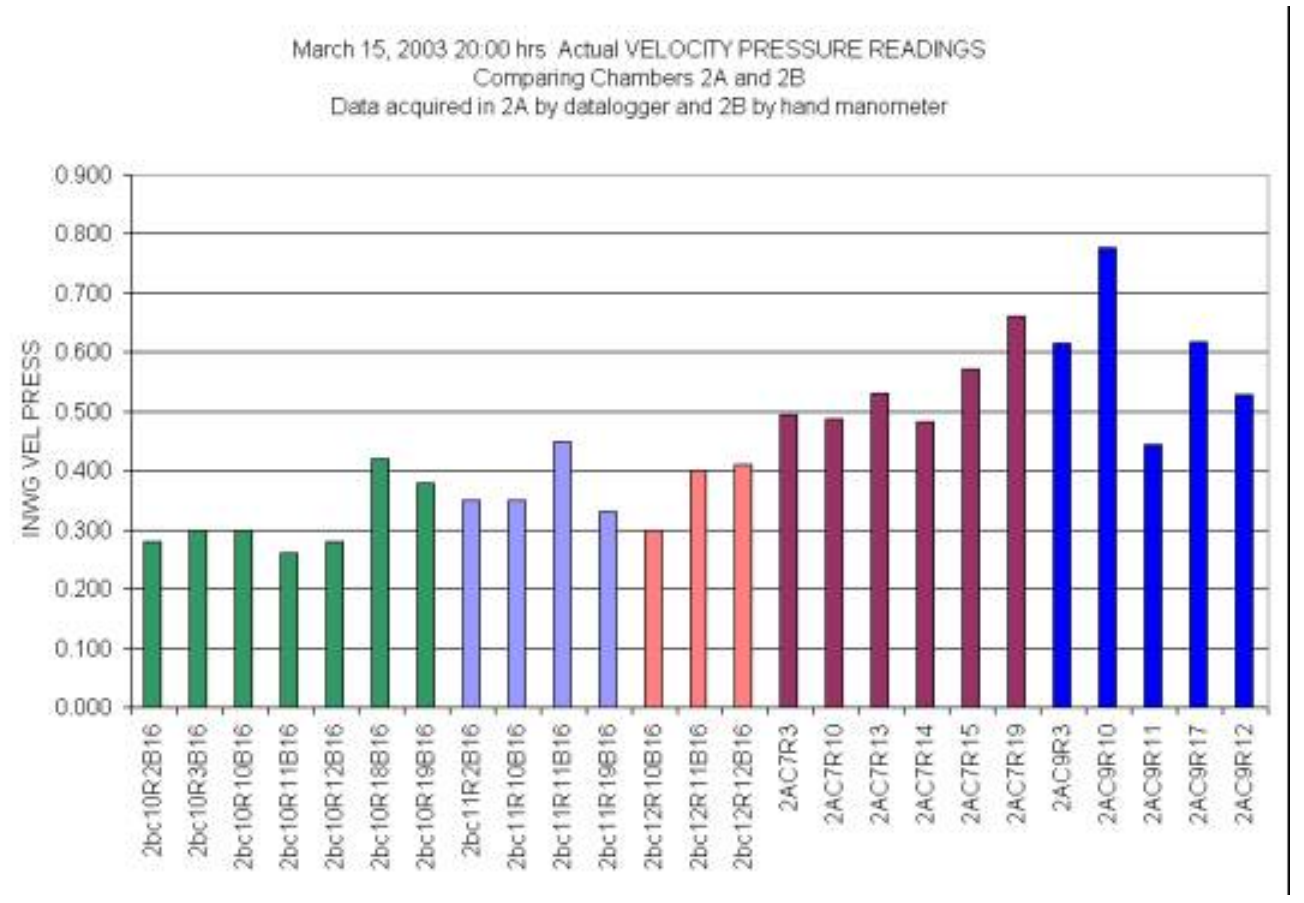




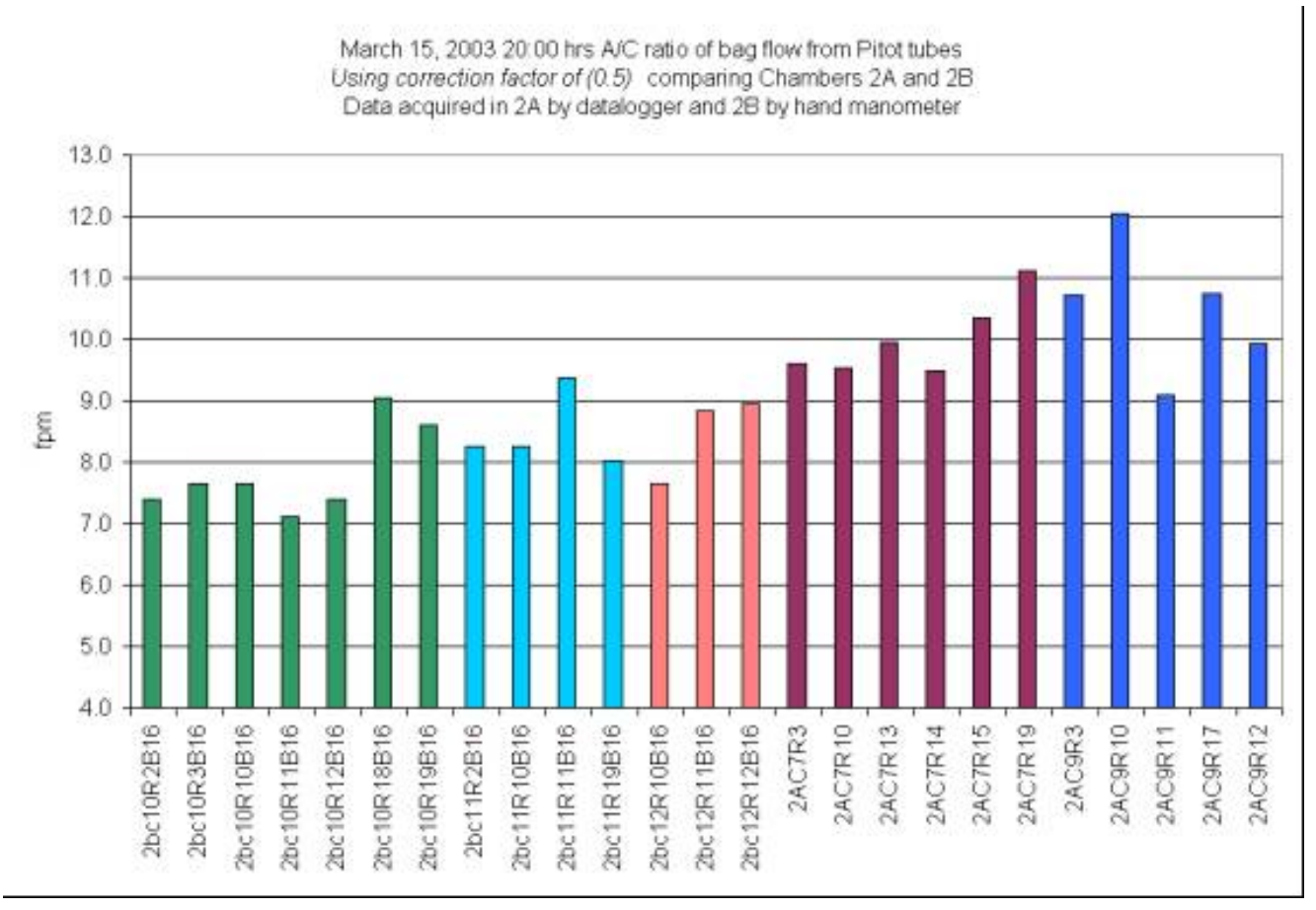



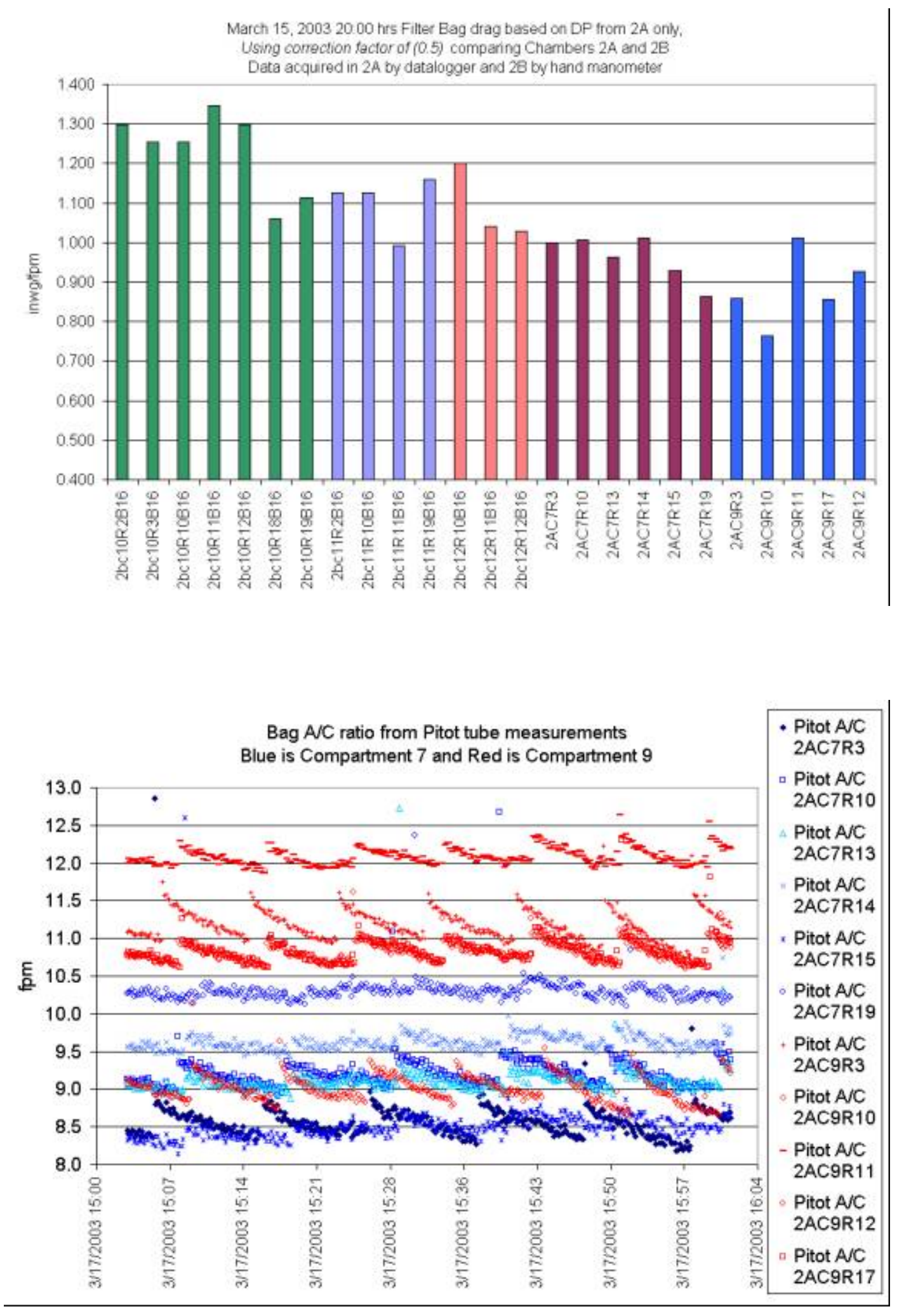


\section{General Discussion (Third Quarter 4/2003 - 6/2003)}

Significant amounts of work, testing, evaluation, and many accomplishments have taken place during the third quarter of operation of the Advanced Hybrid system. Most of the efforts have taken the project in a new direction than was ever planned or possibly anticipated. In keeping with the format of previous quarterly reports, a quick description of the mechanical issues will precede a much longer description of system performance issues.

\section{$\underline{\text { Mechanical Issues }}$}

The primary mechanical issue yet to be resolved was the functioning capability of the existing plate rapper system. As has been discussed in previous reports, there were two problems found with the plate rapper system. The first was a sizing problem with the first section of rapper shaft as it penetrates the wall of the Advanced Hybrid system. This was solved during a scheduled boiler wash outage in the first week of June by replacing all of the first section of rapper shafts with the proper diameter shaft. The second issue was the misalignment of the rapping components and the internal walkway that had fixed points at opposite ends. These systems were better aligned and adjusted so there would be no interference while in the hot condition. It appears that these fixes will resolve the remaining startup mechanical issues.

\section{$\underline{\text { Performance Issues }}$}

The primary idea from the previous quarter was to instrument and study potential modifications to the system to improve the performance (specifically the high differential pressure) so the restricted ability of the power plant to produce electricity is removed.

The Advanced Hybrid team members met on April 8-9 to review the current status and set a course to improve the existing performance. We agreed to evaluate the following;

- Filter bag washing to reduce residual drag

- Pulse cleaning system modifications

- Flue gas conditioning

- Reduction of gas volume in-leakage

- Install pressure relief valves

- Removal of ID Fan outlet dampers

- Investigate other bag types 


\section{Filter Bag Washing}

The first item considered was an in-place filter bag wash to remove the residual dust cake that could not be removed from the bags by pulsing. This was met with some hesitance on the part of the Big Stone Plant staff as the results of mixing water and flyash have been disastrous. Flyash will set up like cement in the right type of atmospheric conditions.

The power plant was derated to enter the Advanced Hybrid system for a couple of tasks. First, the inlet field was inspected by ELEX personnel to try to evaluate if the inlet field performance could be improved through normal maintenance during the scheduled June wash outage. The following issues were found during the inspection;

- Chamber 1B Field 1: No problems found

- Chamber 2B Field 1:

o Four discharge electrode support insulators are cracked

o One discharge electrode rapper is not functioning correctly

o One discharge electrode support frame is out of alignment

This did not appear to be a great deal of work or potential improvement, but if even one section of the ESP portion is significantly out of alignment, it could affect the entire field. It was determined to be worth the effort to go into the system and make these repairs during the June wash outage.

The second effort during the outage was to remove one of the filter bags from service and attempt a wash of the bag while it was not in the system. The bag wash appeared effective as the visual dust cake was removed and the black finish of the original bag was clearly seen. The decision was made to try some type of mass bag washing.

\section{Bag Comparison Test}

Approximately ten days later, the boiler experienced another outage due to an unrelated equipment failure. At that time, several different bag options were installed and instrumented with pitot tubes to aid in the data gathering and decision making process for potential solutions. These bags were;

- A new original style all-ptfe bag

- An original all-ptfe bag was removed from the system, washed outside of the system, and then replaced

- A new conductive PPS bag with ptfe membrane 
The location of these bags seemed to be of importance because a difference in flow and the corresponding bag position within a compartment seemed to vary if the bags were not in close proximity to each other. This effect was noted and the bags were placed to minimize this effect. The earliest graph of significance in this regard is included below. This graph shows a distinct difference in $\mathrm{A} / \mathrm{C}$ ratio between the new PPS

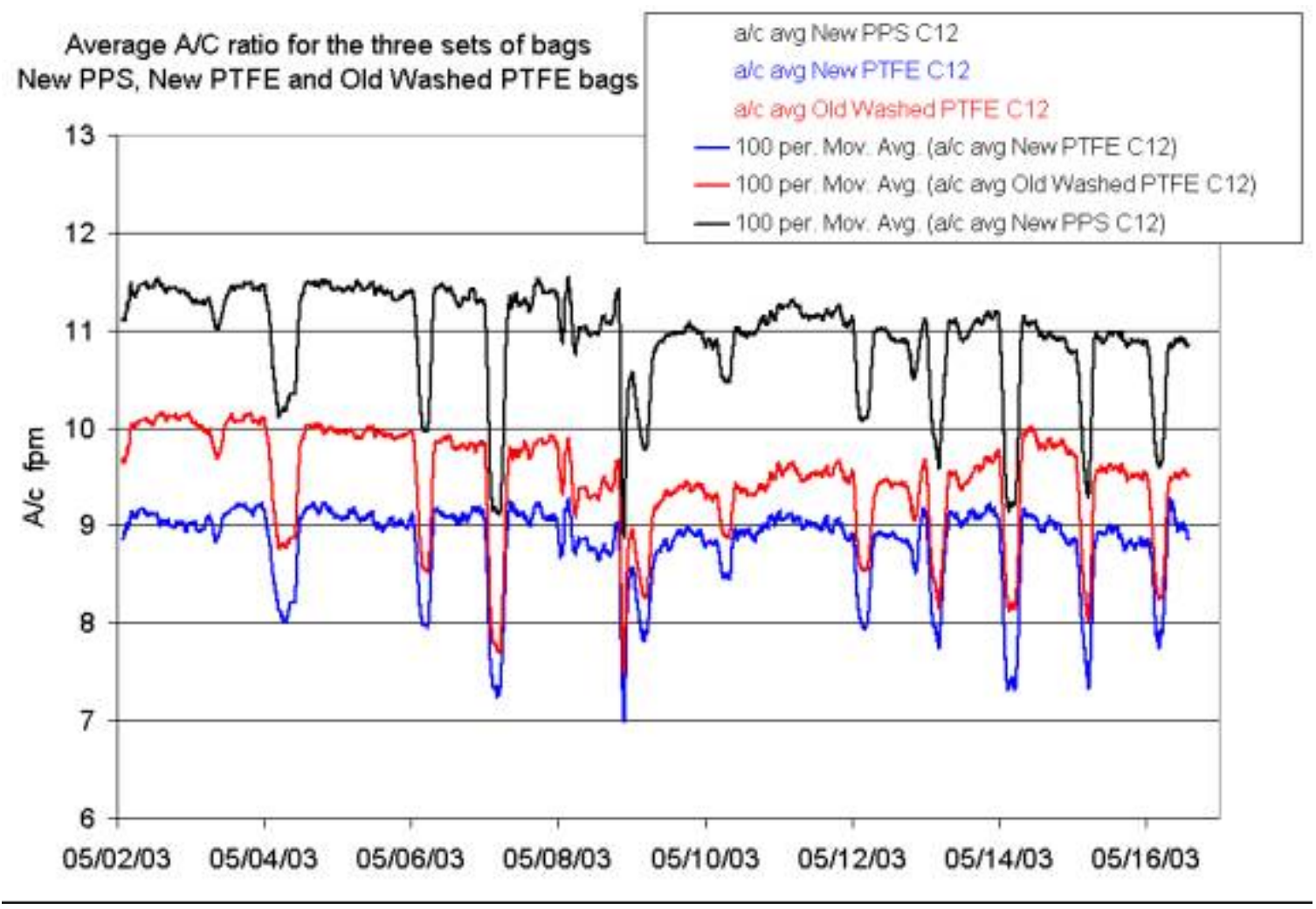

bags and the ptfe bags. The A/C ratio of the PPS bags is nearly $15-20 \%$ higher than the ptfe bags.

This result was very significant since it was the first evidence that a different bag type could result in a dramatic reduction in differential pressure or increased flow capabilities at the existing pressure drop.

\section{Bag Washing}

During the month of April, we developed plans to wash the Advanced Hybrid filter bags while they were in place. Many problems had to be resolved such as; how to handle the wet ash slurry as it flowed down through the hoppers, how to get the water on to the bags in an even and consistent manner, how to assure that the ash washed down the bags with no patches of ash remaining that could damage or restrict the bags, and the logistics of getting the work done in as safe and timely a manner as possible.

Working with W.L. Gore and Associates personnel, a bag wash boom was developed and built at the plant by Big Stone Plant personnel. The picture below shows the boom during testing in the plant maintenance 
shop. This boom was designed to completely wash one row of bags during a single lift and decent cycle. This would ensure the bags were washed fairly well on the way up, and then rinsed on the way down to lessen the risk of leaving material on the bags. Three booms were built allowing all three compartments in the same chamber to be washed at the same time, reducing the overall duration of the plant derate.
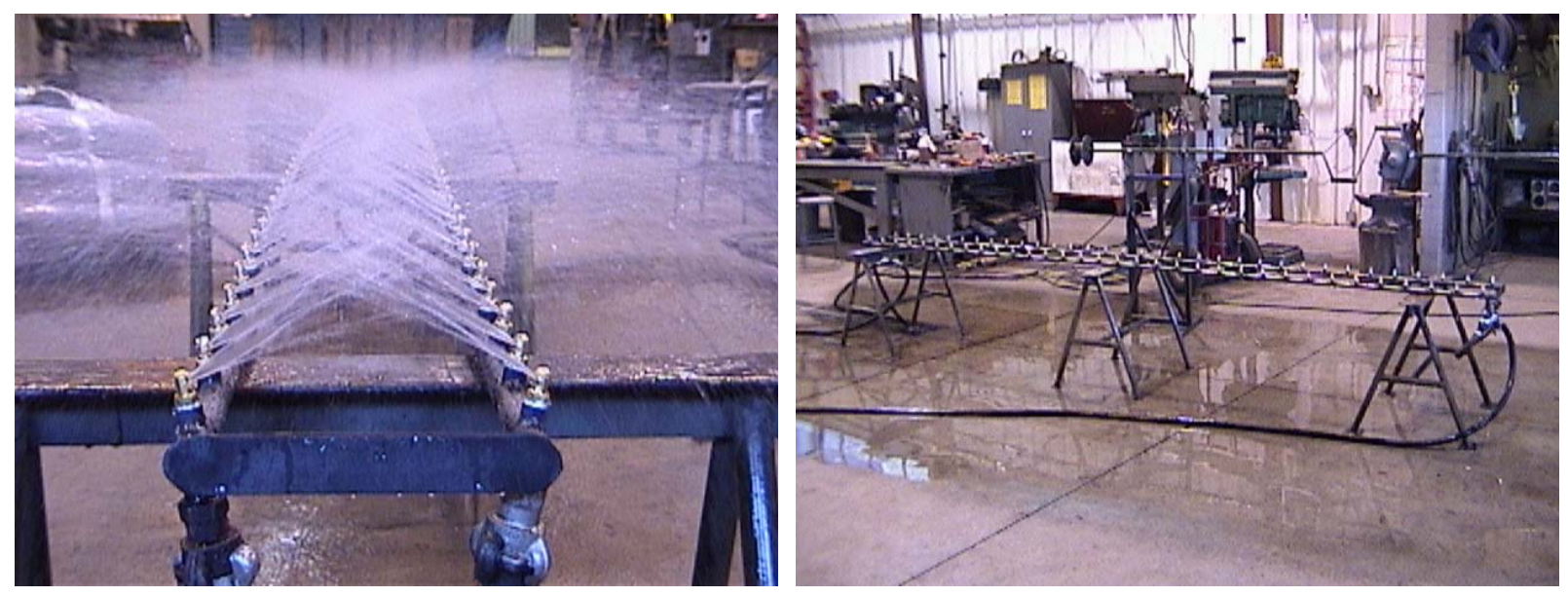

The first bag wash occurred on April 29. It required nearly all of the available plant personnel to complete in approximately 24 hours. Employees washed all of the bags in chamber 2B. A presentation was prepared with pictures of the wash and these are included in Appendix B30. This was an extremely difficult task to accomplish and a lot of credit goes to the Big Stone Plant employees for accomplishing this task under difficult circumstances.

\section{$\underline{\text { Bag Wash Results }}$}

After the $100 \mathrm{MW}$ derate for approximately 24 hours, the plant was able to regain approximately $10 \mathrm{MW}$ of load. This was dependant on the temperature of flue gas into the Advanced Hybrid.

A second bag wash in chamber $1 \mathrm{~A}$ was completed on May 8. This was similar to the previous bag wash although the total time required to complete the task was reduced to approximately 16 hours. The results were about the same, with the plant able to increase the load carrying capability by another $10 \mathrm{MW}$.

\section{Conclusions from Bag Wash}

Bag washing at the plant appeared to be beneficial to the system. Washing the bags for half of the system reduced the restriction of the bags by about $20 \mathrm{MW}$ total. If the remainder of the bags were washed, the plant might have been able to recover approximately $40 \mathrm{MW}$ of load, at least for the short-term.

However, the ambient temperatures were going to increase significantly during the summer months and as long as there was no operating margin at the time, load was going to continue to be restricted. This would 
cause a significant problem at the plant as the high cost of power through the summer months would make the situation worse. More improvements needed to be found to improve the system through the summer months.

\section{Bag Type Evaluation}

W.L. Gore and Associates began evaluating several different bag types at the end of April. The results of these bag studies continued to show a reduced flow resistance when compared to the original all PTFE design. One option considered was a complete or partial bag replacement with PPS or some other style bag. The bags considered for replacement included;

- Original all PTFE design

- PTFE membrane with Conductive PPS backing (rastek scrim)

- PTFE membrane non-conductive PPS backing (PPS scrim)

This decision was not an easy one. We decided that every effort to bring the plant back to full load must be undertaken, and the bags would be completely replaced. This involved some risk, as non-conductive bags had not been tested in the pilot unit for a period of time. PPS bags had not been exposed to the flue gas conditions at Big Stone and their reliability to withstand these conditions was a relative unknown. A decision needed to be made in the first week of May so that the bags could be fabricated and delivered to the site in the first week of June

\section{$\underline{\text { June Outage Activities }}$}

The Big Stone Plant had a scheduled wash outage and the following list of tasks was completed in the AHPC;

- All bags replaced

- Inlet fields inspected and repairs made

- Rapper shafts replaced

- Rappers aligned

- Pressure relief dampers installed

All of the existing bags were replaced during the boiler wash outage in June. Due to the very short time frame to get the bags to the site, W.L. Gore and Associates had to supply some of each of the bag styles to make the delivery date. All bags replaced had a PTFE membrane, the differences occurred in the backing and scrim material, and bag conductivity. Please refer to Appendix B23 for a more informative description of the location, type, and number of bags installed. 
The inlet field was inspected and there was not a significant amount of work accomplished. This work mostly centered on replacement of some of the insulator crocks that support the electrodes. Some electrode frames were re-aligned and plate rapper hammers were repaired.

The Advanced Hybrid rappers were repaired as described in an earlier section.

The last significant accomplishment was the installation of pressure relief dampers that could possibly pass approximately $5-10 \%$ of the flue gas after ESP cleaning only. This would be used as a last resort in case the system improvements were not sufficient to lower the differential pressure.

\section{$\underline{\text { Results After Startup }}$}

The Big Stone Plant was put back on-line on June 11. Early results were extremely positive, as the differential pressure was controllable.

Some tests with the inlet field on and off were conducted but these tests went on through the summer and will be covered in the next quarterly report.

The pressure relief dampers were tested for operation on June 17, and opacity was not acceptable during this short test (approximately 20 minutes). As a result, these dampers were never used to control the differential pressure and remained closed. 


\section{General Discussion (Fourth Quarter 7/2003 - 9/2003) \\ General Comments}

In general the Advanced Hybrid system has performed significantly better this quarter than in previous quarters. The system is still not performing as is required to demonstrate it commercially. The excellent performance seen immediately after the outage in June has not been maintained, as the differential pressure has risen from 7 to $8.5 \mathrm{INH} 2 \mathrm{O}$ at the highest $\mathrm{A} / \mathrm{C}$ ratios seen so far. The inlet ESP field remains charged to reduce the ash loading to the Advanced Hybrid system.

The focus of this quarter is to maintain stable operation of the power plant and delve further into the available data and instrumentation tools to understand the root causes of the performance differences between the pilot unit and the full-scale unit demonstrations.

\section{Performance Testing}

A series of performance tests were conducted to measure current performance. These tests are:

- $\mathrm{A} / \mathrm{C}$ ratio range testing with the inlet field not energized

- $\quad$ Power Off /Plate Rapper Testing (POPR)

- Humidification Testing

- Further pitot testing as a basis for Computational Fluid Dynamic Modeling

The $\mathrm{A} / \mathrm{C}$ ratio range testing is documentation of existing performance with the inlet field on and off to determine performance over an $\mathrm{A} / \mathrm{C}$ ratio range. These results are summarized in the following two tables; 


\begin{tabular}{|c|c|c|c|c|c|}
\hline Date & A/C & Inlet Ten甲 & K2Ci & Drag & Pulse Interval \\
\hline & $\mathbf{f t / m i n}$ & deg F & & Residual & min \\
\hline $8 / 5 / 03$ & 9.67 & 294.29 & 4.22 & 0.61 & 36.81 \\
\hline $8 / 3 / 03$ & 9.66 & 288.21 & 3.66 & 0.59 & 47.17 \\
\hline $7 / 15 / 03$ & 9.49 & 287.83 & 4.01 & 0.53 & 56.87 \\
\hline $7 / 19 / 03$ & 9.48 & 306.32 & 3.80 & 0.61 & 45.77 \\
\hline $8 / 24 / 03$ & 9.15 & 309.42 & 3.99 & 0.67 & 38.55 \\
\hline $7 / 14 / 03$ & 8.79 & 289.11 & 3.25 & 0.52 & 94.75 \\
\hline $7 / 13 / 03$ & 8.66 & 279.42 & 2.45 & 0.50 & 140.64 \\
\hline $8 / 2 / 03$ & 8.36 & 270.88 & 2.64 & 0.56 & 124.63 \\
\hline $9 / 17 / 03$ & 8.05 & 286.92 & 3.06 & 0.63 & 103.27 \\
\hline $9 / 2 / 03$ & 8.00 & 269.94 & 2.44 & 0.61 & 138.64 \\
\hline $9 / 1 / 03$ & 7.98 & 268.47 & 2.74 & 0.60 & 127.58 \\
\hline
\end{tabular}

Table 2 - Advanced Hybrid

Performance with inlet field OFF

\begin{tabular}{|c|c|c|c|c|c|}
\hline Date & A/C & Inlet Temp & $\mathrm{K} 2 \mathrm{Ci}$ & Drag & Pulse Interval \\
\hline & $\mathrm{ft} / \mathrm{min}$ & $\mathrm{deg} \mathrm{F}$ & & Residual & $\mathrm{min}$ \\
\hline $8 / 6 / 03$ & 10.17 & 296.20 & 1.81 & 0.61 & 68.76 \\
\hline $9 / 28 / 03$ & 10.15 & 289.03 & 1.91 & 0.63 & 57.00 \\
\hline $10 / 22 / 03$ & 9.77 & 295.33 & 2.06 & 0.62 & 69.23 \\
\hline $8 / 7 / 03$ & 9.60 & 287.57 & 0.82 & 0.57 & 234.36 \\
\hline $8 / 12 / 03$ & 9.49 & 288.73 & 0.76 & 0.58 & 252.96 \\
\hline $9 / 12 / 03$ & 8.84 & 282.05 & 1.11 & 0.61 & 211.54 \\
\hline $9 / 10 / 03$ & 8.69 & 290.25 & 0.66 & 0.66 & 322.00 \\
\hline $10 / 5 / 03$ & 8.57 & 274.37 & 0.82 & 0.64 & 288.75 \\
\hline $9 / 16 / 03$ & 8.17 & 280.08 & 0.35 & 0.64 & 839.79 \\
\hline $9 / 4 / 03$ & 7.71 & 270.58 & 0.38 & 0.67 & 869.04 \\
\hline
\end{tabular}

Table 3 - Advanced Hybrid performance with inlet field $\mathrm{ON}$ 
The test periods were limited to times of reduced plant load in the evenings. During these periods either the inlet field was de-energized (Table 2) or the conditions were noted if the inlet field was left on ( Table 3). The results are similar to those obtained in the second quarter of the demonstration period. When referring to the results from Table 2, there is a considerable difference in the $\mathrm{K} 2 \mathrm{Ci}$ values of the system when compared to the pilot unit. It is estimated that the $\mathrm{K} 2 \mathrm{Ci}$ valued for the pilot unit would be less than 1 at an $\mathrm{A} / \mathrm{C}$ ratio of $9.0 \mathrm{fpm}$. The full-scale unit $\mathrm{K} 2 \mathrm{Ci}$ at $9.0 \mathrm{fpm}$ appears to be about 4.0. This is an ash loading rate to the bags of four times the rate when compared to the pilot unit. These results lead us to focus on performance improvement effort in the Advanced Hybrid ESP section. Contrarily, the residual drag portion of the system is now comparable with the results of the pilot unit at approximately $0.5-0.6$ $\mathrm{INH} 2 \mathrm{O} / \mathrm{ft} / \mathrm{min}$.

The Power Off Plate Rap tests were performed by turning off the power to the individual compartments and rapping the ESP components to try to improve the ash collection of the ESP section. A graph of these results is included in Appendix B32. In this specific test, as in almost all the power off rapping tests, the ESP power increased slightly, but had no significant effect in the $\mathrm{K} 2 \mathrm{Ci}$, Residual Drag, or differential pressure. This may indicate there is a portion of flue gas bypassing the ESP zones or another problem with flow distribution.

The humidification test was another short-term improvement test to determine if the existing plant flue gas conditioning system could be used to improve ESP performance. The humidification system was used to inject a minimum amount of water and proprietary chemical to determine if an improvement could be made. As can be seen in the graph in Appendix B25, very little improvement was seen during this test.

The last significant testing was the analysis of the existing pitot tube data. As was described by W.L. Gore and Associates, there appears to be a fairly significant K2Ci performance difference between the first, second, and third section of some individual compartments. Pitot testing indicated the K2Ci value of the bags in the middle section of Chamber 2A Field 3 was about 2.0, while the back section of Chamber 2A Field 3 was abut 5.0. In another interesting comparison, the front section of Chamber $2 \mathrm{~A}$ Field 4 was about 4.5, while the middle section of Chamber 2A Field 4 was about 1.5. This is described by the graph in Appendix B26. All of these test results point towards a gas flow distribution issue that may help explain the difference in loading rate between the pilot and full-scale unit.

\section{Performance Improvement Effort}


Now that the Big Stone Plant has returned to full load capability, an effort towards a long-term improvement is being made. This effort is focused on the gas flow dynamics of the system and how an understanding of these dynamics may aid us in improving the system. Fluent Inc. was brought on board to evaluate the system through Computational Fluid Dynamic (CFD) modeling of the existing system. A description of the effort by Fluent Inc. is included in Appendix B33. The most reasonable approach to improvement of the ESP portion of the system is the addition of baffles below the bag rows in each section. A proposal in the form of a presentation is included in Appendix B34 with further details on the principal theory of the baffles.

The results of the Fluent Inc. modeling should be completed in the next quarter of demonstration. 


\section{General Discussion (Fifth Quarter 10/2003 - 12/2003)}

General Discussion

Problems have again developed with the Advanced Hybrid system. Significant bag failures have occurred in the PPS bags with the PPS scrim since installation three months prior. Indications and likely reasons for bag failure are included below. As a result, a competitive bidding effort has taken place with several different suppliers of various bag materials. This should allow us a greater flexibility of bag options, but also increase the amount of unknowns.

Other than the bag failures, performance has been maintained and even slightly improved as cooler gas temperatures into the Advanced Hybrid are realized. The cooler temperatures are due to lower ambient temperatures heading into the winter.

Some modeling results from Fluent Inc. are available and will be reviewed.

\section{Bag Failures}

In early October, it became apparent there were opacity spikes occurring during periods of pulsing. The graph below shows a two-hour time duration and the observed indications. During periods of pulsing (red), opacity (green) is increasing from around $8 \%$ to about $10-11 \%$. These spikes contribute to an overall opacity rise, seen in Appendix B8.

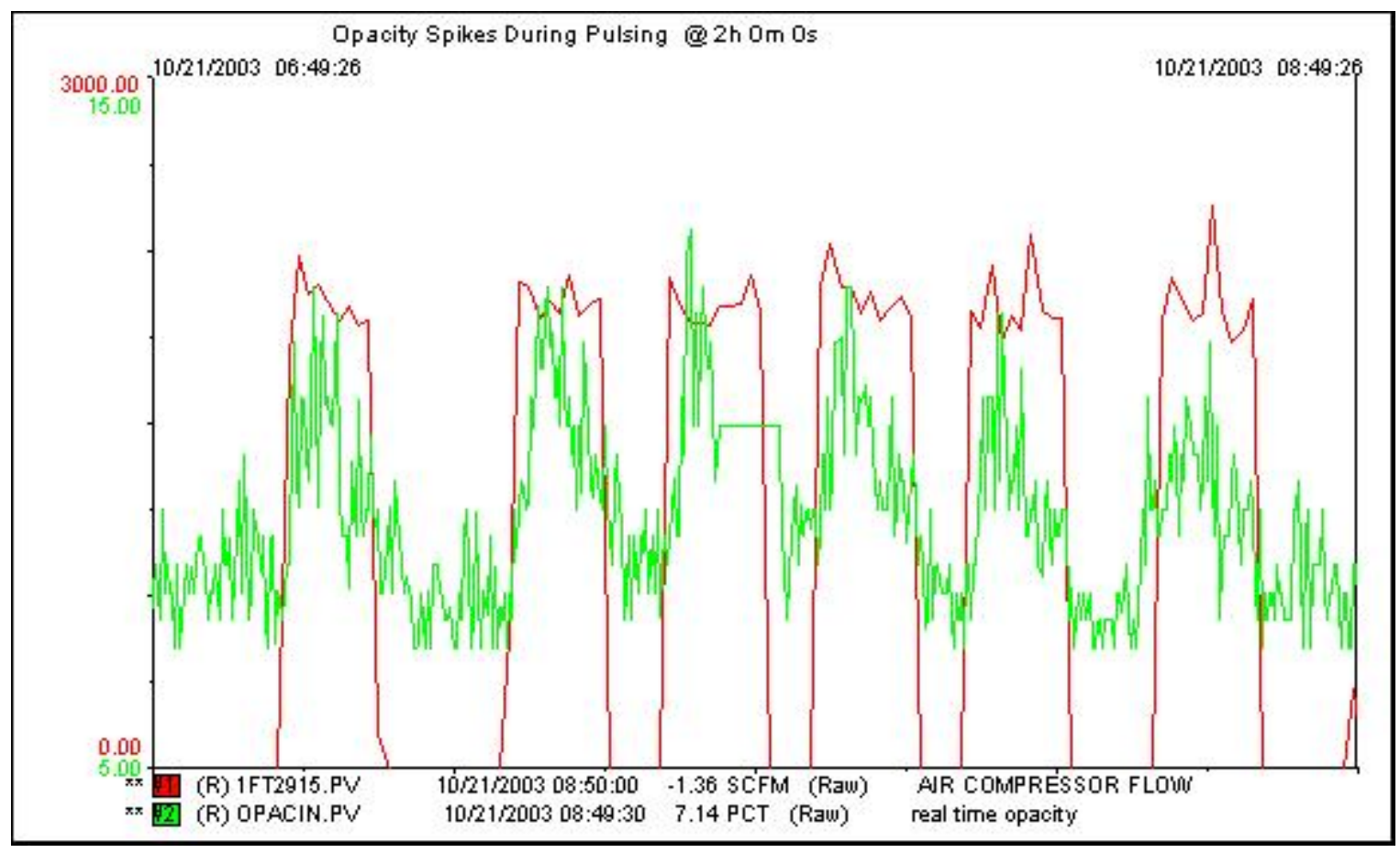




\section{$\underline{\text { Specific Bag Failures }}$}

An exact number of failed bags is not known. The failing bags were the PPS bags with the PPS scrim. The reasons for failures appear to be the weakening of the strength of the fibers and cleaning pulsing. The temperature is likely the primary factor in weakening the bag material. The compartments of PPS bags with the most failures to the least failures are ranked in this order

1. Chamber 1B Field 3 (most failures)

2. Chamber 1B Field 4

3. Chamber 2B Field 4

4. Chamber 2A Field 4

The PPS bags in Chamber 1A appear to have few, if any, failures. The all-ptfe bags had no failures, and the PPS bags with the rastek scrim show only a few failures occurring in chamber $2 \mathrm{~B}$. There is an operating temperature difference between the chambers due to the regenerative style air preheater used to transfer heat from the flue gas to incoming air. As a result, $1 \mathrm{~B} \& 2 \mathrm{~B}$ chambers operate approximately 20 degrees higher average temperature than $1 \mathrm{~A} \& 2 \mathrm{~A}$. This would logically explain why the compartments in chambers $1 \mathrm{~B}$ and $2 \mathrm{~B}$ have the most failures of PPS bags. However, the failures that occurred in Chamber 2A don't seem to follow this same pattern. A likely contributing factor to these failures was a high temperature event experienced in July 2003. During a plant trip, a failure of the air heater system caused a short-term temperature excursion. The temperatures into Chambers $2 \mathrm{~A} \& 2 \mathrm{~B}$ exceeded the 375 degrees rating of the

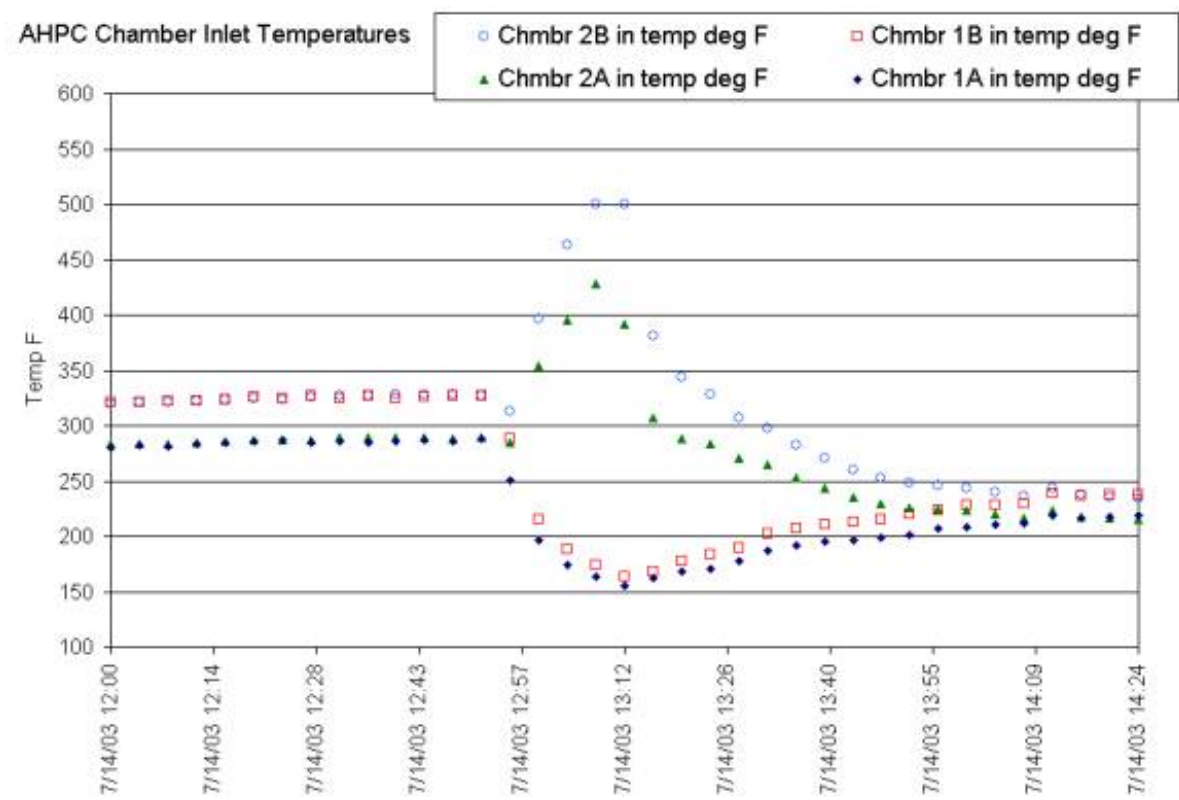


PPS bags for about fifteen minutes.

$\underline{\text { Bag Replacement Decisions }}$

Some bag replacement was necessary during the scheduled boiler wash outage in December. A significant operational performance improvement was made with the decision to replace the original allPTFE bags with PPS bags in June 2003. The original style bags would not likely be considered for replacement due to high differential pressure concerns. Only PTFE membrane bags were considered allowing the fundamental goal of $99.99 \%$ particulate removal to be maintained. We considered bags of the following materials for use in the Advanced Hybrid system:

- All PTFE (new)

- All PTFE (original bag washed outside the Advanced Hybrid system)

- $\mathrm{P}-84$

- Nomex

- PPS with the rastek scrim

- Fiberglass

- Superflex $^{\mathrm{TM}}$

The only bags with operational history were the all-PTFE bags and the PPS bags with the rastek scrim. Both of these options seemed questionable because of either high differential pressure issues (all-PTFE), or questionable reliability strength issues (PPS). We decided to install one compartment of P-84 bags into Chamber 2B field 4, one compartment of NOMEX bags into Chamber 1B field 4, and one compartment of original all-PTFE washed bags in Chamber 2A field 3. Approximately 1000 bags were washed in the Big Stone Plant turbine bay prior to the outage. Fortunately this was accomplished, because an unexpected outage extension of 7 days occurred (unrelated to the Advanced Hybrid system). The bags in a fourth compartment Chamber 2A field 4 were also replaced with original washed all-PTFE bags. Bags in four of the twelve compartments were replaced during the December boiler wash outage. For more description of the specific type and styles, see section 2.1.2 or Appendix B23.

\section{Fluent Modeling Effort}

During the previous quarter, an effort was undertaken by Fluent Inc. to model the gas flow dynamics of the system. This was attempted to gain a better understanding of where gas flow dynamics may be adversely affecting performance, and what could be done to improve performance. The most likely improvement was the installation of flow baffles to direct gas flow from the bottom more directly into the ESP zones of the Advanced Hybrid components. Preliminary results indicated approximately $15 \%$ of the flue gas flow could be entering the area directly 
beneath the bag rows and bypassing the ESP zone. The significance of this is fairly strong. If the flue gas passing through the ESP portion of the Advanced Hybrid system is being cleaned at a rate of $90 \%$, and if $15 \%$ of the flue gas is bypassing this ESP zone with $100 \%$ of the ash loading, this would result in an overall ESP efficiency of only $76.5 \%$. This may be better understood by taking the example of a loading rate of 1 grain/acf, and working through the potential ESP efficiency calculations. First, assume a true 90\% ESP efficiency rate;

Ash loading to bags $=1 \mathrm{gr} . / \mathrm{acf} *(100 \%-90 \%)=0.1 \mathrm{gr} . / \mathrm{acf}$

However, if the actual case is a $15 \%$ gas bypass of untreated flue gas, the result is;

Ash loading to bags $=85 \% *(1 \mathrm{gr} / \mathrm{acf} *(100 \%-90 \%))+15 \% *((1 \mathrm{gr} / \mathrm{acf} *(100 \%))=0.235 \mathrm{gr} / \mathrm{acf}$

This would mean a loading rate to the bags nearly 2.4 times the estimated rate of an ESP efficiency of $90 \%$. This level of change would be needed to approach the loading rate demonstrated in the pilot unit. The full-scale unit loading rate is nearly four times the loading rate of the pilot unit.

Unfortunately, final modeling results were not available at the time baffles needed to be ordered for installation during the December boiler wash outage. Otter Tail Power Company personnel decided to purchase and install 3 sets of these baffles to allow an operational evaluation. The only reliable information in this limited format would be issues associated with installation and with operation (specifically whether or not the baffles plugged with ash during operation).

Three sets of baffles were designed by and purchased from Southern Environmental Inc. Installation was accomplished with Big Stone plant personnel. Some difficulties during installation were noted and modifications will be made if more baffles are ordered. A picture of the baffles is included in the Appendix.

A section of pitot tubes was installed across the bags with these baffles, but limited data and analysis is expected due to such a small number of baffles.

\section{Blowpipe Modifications}

Big Stone plant personnel modified one of the existing blowpipes so a single pulse valve pulsed 19 bags instead of 10. This was accomplished in a forward-looking manner, as there may be reasons in the future 
to modify the system to remove the stacked blowpipe arrangement. This arrangement has caused a definite increase in bag replacement costs when compared to a standard baghouse arrangement with no stacked blowpipes. If successful, this would lower the cost of the existing system by reducing the required headers, pulse valves, control system and pulse pipes by half. There may also be an improvement in performance, as all the valves could be cycled through in half the time. Assuming an equal cleaning efficiency per pulse, this could result in a lower residual drag. Lastly, there is evidence that we are still over-cleaning the bags, indicated by an increased rate of bag failure on the short blow tubes as compared to the long blow tubes. A picture of this blow tube is included in the Appendix B39. The Big Stone Plant pitot instrumentation will be placed on the bags on this tube and some analysis may be possible. 


\section{General Discussion (Sixth Quarter 1/2004 - 3/2004) \\ General Discussion}

Operation of the Advanced Hybrid system has been stable since startup after the December boiler wash outage. The bags are still being aggressively cleaned. There have been no significant plant limitations due to the Advanced Hybrid system since prior to the June 2003 boiler wash outage. There have been four primary efforts this quarter. These are;

- Performance improvement investigation - Fluent/baffle effort

- Evaluation of changes made - baffles, blowpipe, bags

- Review of technology results and goals - Technology team

- Proposal and review of second phase of project

\section{Performance Improvement Investigation}

The CFD modeling with Fluent continued through this quarter of demonstration. Some very informative and good modeling data has been generated. The figure below is taken from a presentation of the CFD results from Fluent. The first is a description of the assumptions and a three dimensional view of the
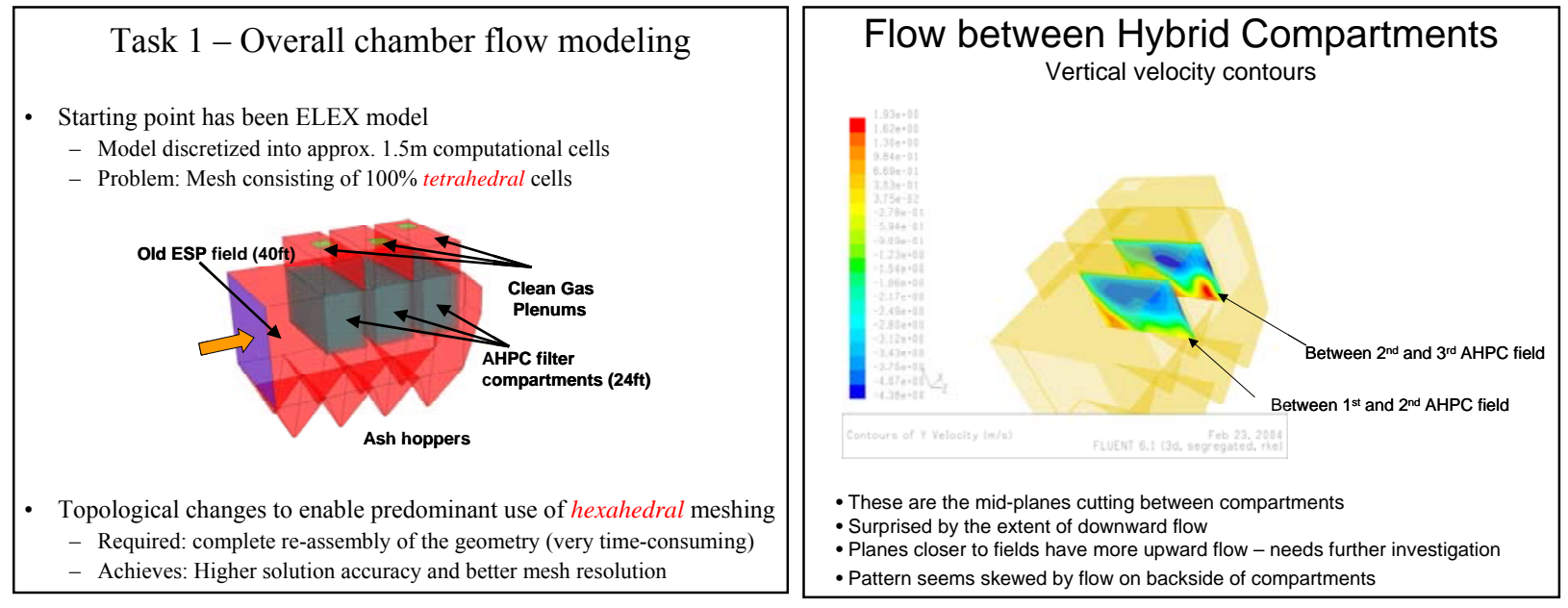

model. The second is a graphical display of the vertical gas flow components between the individual compartments in one chamber. This work aided the team to better understand the gas dynamics of the system, suggesting areas of improvement through baffling. Since mid-February this work has been on hold as the team has evaluated the overall goals and methods of improvement.

\section{Evaluation of Changes Made}

Several changes have been made to the system. These are 
- Three rows of baffles installed

- A single blow tube installed

- P-84 and NOMEX bags installed

Three sets of baffles were installed in Chamber 2B field 3 during the boiler wash outage in December. These were installed to evaluate the ease of installation and to find any areas of concern during operation. A short pitot tube analysis was also completed, but as anticipated, the results have minimal reliability because so few baffles were installed. In general, the baffles may be reducing the ash loading by about $10 \%$ to the bags. During a short load drop on February 28, the baffles were inspected and found to be in satisfactory condition. There was no ash plugging and only a slight buildup on the baffles. An effort is underway to fund and install one complete chamber of baffles during the scheduled boiler wash in June of 2004.

Another change made was the modification of one blowpipe. Currently, one blowpipe charged by one three-inch pulse valve, is assigned to clean 10 bags. There are 20 bags in a cleaning row, meaning that two valves per cleaning row are necessary. The blowpipes for the system must be stacked so the compressed air to the second ten bags in any row is supplied through a solid line that travels over the blowpipe for the first ten bags. This current arrangement has advantages and drawbacks.

\section{$\underline{\text { Advantages }}$}

- Better/more aggressive cleaning of bags

$\underline{\text { Drawbacks }}$

- Significantly more expensive system

- Difficult to change bags/more expensive bag replacement

- Stacked blowpipe creates hazardous walking conditions inside plenum

- Aggressive cleaning may contribute to premature bag failure

- Longer time needed to complete one pulse cycle

One blowpipe was changed and instrumented with pitot tubes to try to determine if 20 bags could be pulsed effectively by one three inch pulse valve. The graph below depicts some of the pitot data as recorded by the Power Plant data historian. 


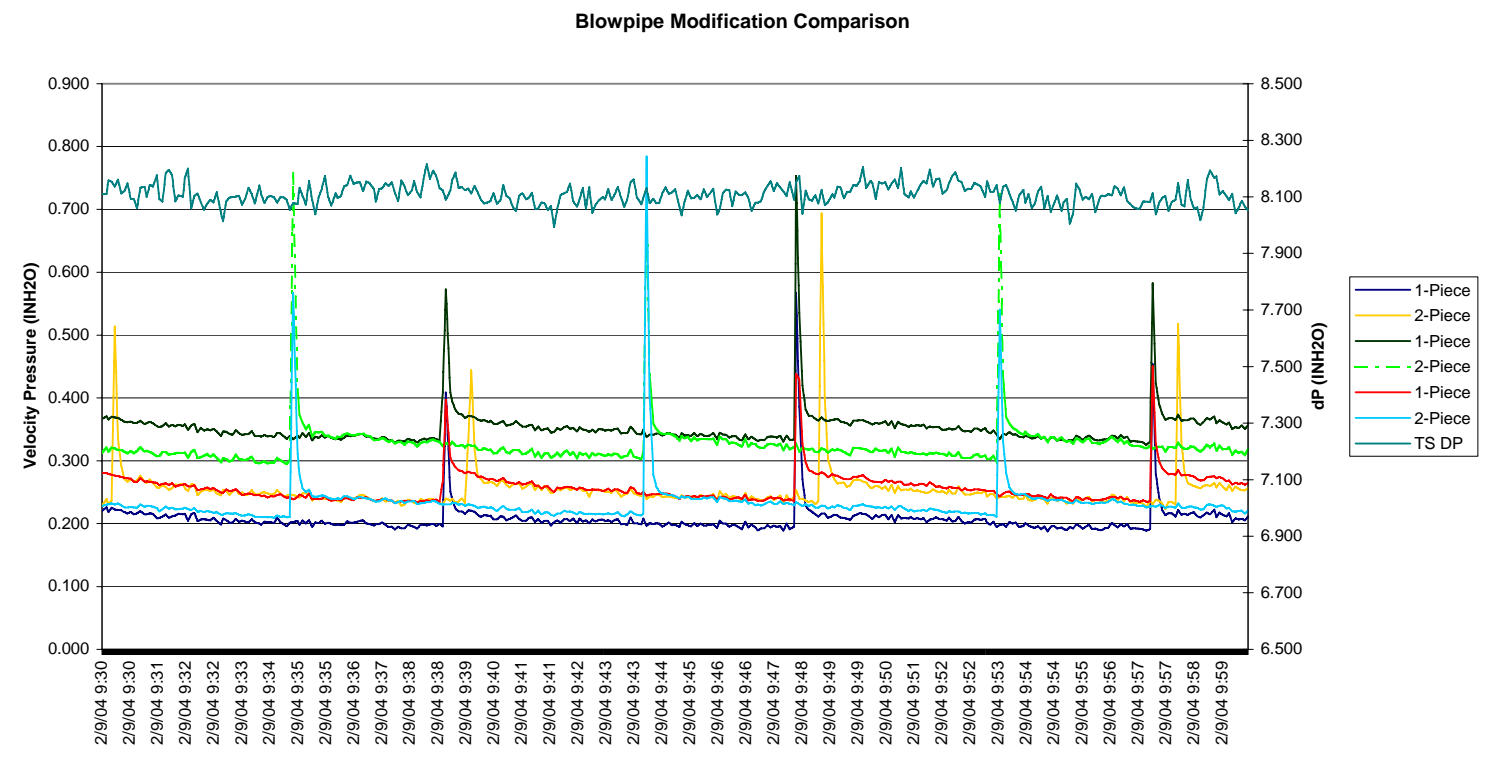

The above graph shows the changes in velocity pressure as the bags are pulsed using either a 1-piece or 2piece blowpipe. The chart below summarizes these changes $\left(\mathrm{VP}_{\mathrm{i}}=\right.$ Initial Velocity Pressure, $\mathrm{VP}_{\mathrm{f}}=$ Final velocity pressure):

\begin{tabular}{|l|lcccccccc|}
\hline & Blowpipe & $\begin{array}{c}\text { Load } \\
\text { GMWH }\end{array}$ & $\begin{array}{c}\text { Inlet Temp } \\
{ }^{0} \mathrm{~F}\end{array}$ & $\begin{array}{c}\mathrm{A} / \mathrm{C} \\
\mathrm{ft} / \mathrm{min}\end{array}$ & $\begin{array}{c}\text { Presure } \\
\mathrm{psig}\end{array}$ & $\begin{array}{c}\text { Duration } \\
\mathrm{ms}\end{array}$ & $\begin{array}{c}\mathrm{VP}_{\mathrm{i}} \\
\text { inwg }\end{array}$ & $\begin{array}{c}\mathrm{VP}_{\mathrm{f}} \\
\text { inwg }\end{array}$ & $\begin{array}{c}\text { Delta } \\
\%\end{array}$ \\
\hline Pitot \#1 & 1-Piece & 468 & 283 & 11.2 & 80 & 200 & & & \\
Pitot \#2 & 2-Piece & & & & & & 0.196 & 0.517 & 164 \\
Pitot \#3 & 1-Piece & & & & & & 0.236 & 0.550 & 133 \\
Pitot \#4 & 2-Piece & & & & & & 0.333 & 0.654 & 96 \\
Pitot \#5 & 1-Piece & & & & & & 0.304 & 0.659 & 117 \\
Pitot \#6 & 2-Piece & & & & & & 0.236 & 0.566 & 140 \\
\hline
\end{tabular}

Further testing has been performed using various pulse pressures and pulse durations at different $\mathrm{A} / \mathrm{C}$ ratios. All the data indicates that there is no significant change in pulse efficiency when comparing the 1piece modified blowpipe to the 2-piece blowpipe.

The last significant change was the installation of a compartment of P-84 bags and a compartment of NOMEX bags. The P-84 bags in Chamber 2B field 4 were inspected during the February 28 derate and no holes were seen at that time. At the end of this quarter, no specific information is known on the NOMEX bags as no other inspections have taken place.

\section{$\underline{\text { Review of Technology Results and Goals }}$}

A group effort was undertaken in February to try to review the current status, goals and path forward for the technology. The real impetus behind this effort is a scheduled major outage of the Big Stone Plant in 
April and May of 2005. If major changes to the system need to occur this would be the only reasonable chance until a projected outage some time in 2010. OTP facilitated a review in an attempt to reach a consensus. The current active stakeholders in the project and the technology include;

- Otter Tail Power Company (responded)

- National Energy Technology Laboratory

- Energy and Environmental Research Center (responded)

- W.L. Gore and Associates (responded)

- $\quad$ ELEX AG (responded)

- Southern Environmental Inc.

Four of the stakeholders listed above responded to questions to determine project status and goals. The main questions that need to be answered are;

- What defines successful operation of the Advanced Hybrid system?

- What $\mathrm{A} / \mathrm{C}$ ratio can we currently claim would meet successful operation?

- What $\mathrm{A} / \mathrm{C}$ ratio is needed for the technology to compete commercially?

- Is there a reasonable chance, through improving the existing system while maintaining the current $\mathrm{A} / \mathrm{C}$ ratio, to demonstrate successful operation?

A summary of responses is listed below.

What defines successful operation of the Advanced Hybrid system?

Certainly particulate control and bag life are important factors to consider for successful operation. At the heart of the question is operation on a routine, minute-to-minute basis. In general, the best and simplest way to define successful minute-to-minute operation is the pulse interval. This is the time required to clean the bags completely through one cleaning until the differential pressure rises high enough to initiate the next cleaning. Approximately 30 to 60 minutes was the range discussed. OTP is of the strong opinion the pulse interval should be no less than 60 minutes. After some general discussion, this was agreed upon.

What $\mathrm{A} / \mathrm{C}$ ratio can we currently claim would meet successful operation?

The approximate value is $8.0 \mathrm{fpm}$. This depends on the acceptable pulse interval from the previous question. At 60 minutes, the best approximation at this time is $8.0 \mathrm{fpm}$ with the inlet ESP field off (true Advanced Hybrid). 
What $\mathrm{A} / \mathrm{C}$ ratio is needed for the technology to compete commercially?

The current commercialization partner feels strongly that an $\mathrm{A} / \mathrm{C}$ ratio of at least $10 \mathrm{fpm}$ is needed to compete commercially. Using the data from Appendix B7, the $\mathrm{A} / \mathrm{C}$ ratio at full load has been 10.5 to 11.5 fpm since startup. This means that the system is in a competitive commercial range, but could be sized larger to reduce the $\mathrm{A} / \mathrm{C}$ ratio by a range of $5-15 \%$.

Is there a reasonable chance, though improving the existing system while maintaining the current $\mathrm{A} / \mathrm{C}$ ratio, to demonstrate successful operation?

It is generally felt it would be difficult to demonstrate acceptable minute-to-minute performance at the current $\mathrm{A} / \mathrm{C}$ ratios.

Several broad conclusions can be drawn from the opinions of the group. First, there is a significant difference between the current successful $\mathrm{A} / \mathrm{C}$ ratio $(8 \mathrm{fpm})$, and the actual $\mathrm{A} / \mathrm{C}$ ratio $(11.5 \mathrm{fpm})$. Second, the system can be resized by about $15 \%$ and still remain competitive commercially. Third, it would be difficult, if not impossible, to maintain the same $\mathrm{A} / \mathrm{C}$ ratio and demonstrate successful minute-to-minute operation through improvements to the system.

Taking this thought process forward, Otter Tail Power Company personnel are proposing to re-size the existing system.

\section{Proposal and Review of Second Phase of Project}

Otter Tail Power Company has proposed that a new phase of this project be entered into to advance the needs of the power plant and improve the chances of bringing the technology to the commercial marketplace.

The proposed next phase of this project would be the replacement of the existing inlet ESP field with improved Advanced Hybrid components and some small changes to the existing system to improve overall performance. Primarily, this effort would reduce the A/C ratio of the system from approximately $11.5 \mathrm{fpm}$, to $70 \%$ of the current level or $8.05 \mathrm{fpm}$. This would accomplish two primary objectives. First, it would drop the $\mathrm{A} / \mathrm{C}$ ratio to a range that has been demonstrated as acceptable during short term testing. Second, several design improvements could be implemented that may improve performance to meet a new goal of $10 \mathrm{fpm}$. Third, by sizing the system conservatively large, we will have the flexibility to increase the $\mathrm{A} / \mathrm{C}$ ratio if changes made to the system are very successful. Conversely, we will not need to 
maintain minimum commercially acceptable $\mathrm{A} / \mathrm{C}$ ratios to meet the full load needs of the power plant.

Improvement ideas being currently discussed are;

- Installation of bag row baffles

- Further baffling to improve gas flow distribution

- Closer plate-bag spacing

- $20 \%$ more cloth surface in the same footprint

- $\quad$ Enhanced ESP zones

- Blow tube modifications 


\section{General Discussion (Seventh Quarter 4/2004 - 6/2004)}

\section{$\underline{\text { General Discussion }}$}

Operation of the Advanced Hybrid has been fairly stable. There have been no significant derates of the power plant due to Advanced Hybrid system. The remaining PPS bags have begun to fail at an unacceptable rate, and it was a good decision to plan on replacing all of the PPS bags during the scheduled June shut down. The major activities of this quarter were;

- Work related to the boiler wash outage including;

o Replacement of 1928 PPS filter bags with P-84/BHATex filter bags.

o One complete chamber of Baffles installed

o One compartment of blowpipes modified

o 10 filter bags pulled and sent to independent laboratory for analysis

- Review of proposed design for installation of $\mathrm{AH}$ components in the inlet field

- $\quad$ Bag testing data reviewed

\section{June Boiler Wash Outage}

The plant was shut down from June $5^{\text {th }}$ to June $12^{\text {th }}$ for the scheduled boiler wash. During this period, Southern Environmental Inc. was contracted to come in and perform the tasks listed above. A complete report of these activities can be found in Appendix 24.

Overall, the work that was completed was done well and on-time. It appears that our choice of using the P-84 bag from BHA was a good one and will hopefully get us through the warm summer temperatures without premature bag failures.

\section{Proposed Project for Installation of Advanced Hybrid components in inlet field}

A meeting between OTP, EERC, and SEI was held at the Big Stone Plant on Friday, March 5, 2004. The purpose of the meeting was to discuss the bid requirements and design optimization for the following items:

1. Manufacture and install 1 Chamber of bag row baffles in June 2004

2.Modify one compartment of blowpipes in June 2004

3. Convert 4 inlet ESP fields into Advanced Hybrid compartments in April 2005

4. Include with item 3, installing ESP field below new AH compartments

5.Design and construct new AH chamber for construction in April 2005 
An engineering review meeting was held at SEI headquarters on April 13-14. The bag row baffle design and blowpipe modifications for the June 2004 outage were finalized. SEI also presented their progress on the items 3-5 above. Main items of discussion were:

1. Changing the plate-to-plate spacing from $12 \mathrm{in.}$ to $10 \mathrm{in}$.

- This closer spacing allows for more rows of bags thus lowering the A:C

- This will not degrade the ESP performance

2. Determining the maximum number of bags per compartment

- Four additional rows of bags will be added in each compartment

- Total of 1974 additional bags representing a $41 \%$ increase in filtration surface area

3. Extending the length and increasing the number of the electrodes and plates

- Rigid electrodes and collecting plates will be lengthened from 25 feet to 37 feet creating an ESP collecting zone below the fabric filter components

- Below the level of the bag row baffles, the collecting plates will be solid instead of perforated.

- There will be no discharge electrodes in the gas passages below the filter bags

- The area below the pulse headers will be filled from the hot roof to the top of the hoppers with new discharge electrodes and solid collecting plates

4. Rapping systems

- Electromagnetic rappers will be used instead of tumbling hammers for the discharge electrodes

- The drive from the existing collecting plate tumbling hammer rapper system will be relocated and reused.

5. Duct work tie in

- Outlet ductwork from new inlet compartment will tie straight into the outlet duct from field two

6. Electrical \& controls

- Discussed cable splicing options and Hesch pulse controller capabilities to handle additional compartments

7. New compartments include bag row baffles and modified blowpipe design

A brief discussion was held concerning the design and construction of a new AH chamber. Few details were discussed as converting the inlet fields to Advanced Hybrid was agreed upon as the most economical performance improvement option. 
Following this meeting, a purchase order was issued to SEI for bag row baffles in one chamber and modification of the blowpipes in one compartment. Both of which took place during the June 2004 outage. SEI has also submitted a firm bid to convert the inlet ESP fields into the Advanced Hybrid as discussed above. The quote for $\$ 3,625,000$, would not include, filter bags, taxes, baffles or blowpipe modifications for the remaining compartments, or any additional costs as a result of NETL participation (EERC testing and reporting). They have requested a letter of intent and partial purchase order from OTP to begin engineering no later than August 1, 2004 to ensure construction readiness in April 2005.

\section{Bag Testing Data}

A significant amount of bag testing data was reviewed this quarter. The entire report by W.L. Gore and Associates is included in the appendix. The summary table from that report is included below.

\begin{tabular}{|c|c|c|c|c|c|c|c|c|c|c|c|}
\hline \multicolumn{12}{|c|}{\begin{tabular}{|l|} 
Otter Tail Power Company \\
Big Stone Power Plant Improvement Initiative Demonstration Site \\
Filter Bag analysis summary chart - All Frazier \#゙S are reported as cfm/tt2@0.5 in.w.g. driving force
\end{tabular}} \\
\hline Location & $\begin{array}{l}\text { Service } \\
\text { Time }\end{array}$ & $\begin{array}{l}\text { Max. } \\
\text { exposed } \\
\text { temp (F) }\end{array}$ & Backing & $\begin{array}{l}\text { As rec'd } \\
\text { (F-n) }\end{array}$ & $\begin{array}{l}\text { Mullen } \\
\text { Burst } \\
\text { (psi) }\end{array}$ & \begin{tabular}{|l|} 
Mullen \\
Burst \% \\
Strength \\
Retention
\end{tabular} & \begin{tabular}{|l|} 
Tensile \\
strength - \\
cross \\
machine \\
direction \\
(psi)
\end{tabular} & $\begin{array}{l}\% \text { Tensile } \\
\text { strength } \\
\text { retention } \\
\text { cmd }\end{array}$ & $\begin{array}{l}\text { Tensile } \\
\text { strength } \\
\text { machine } \\
\text { direction } \\
\text { (psi) }\end{array}$ & $\begin{array}{l}\% \\
\text { Tensile } \\
\text { strength } \\
\text { retention } \\
\text { - md }\end{array}$ & Comments \\
\hline 1BF3 R1B1 & $\begin{array}{c}6 / 10 / 03 \text { to } \\
9 / 17 / 03\end{array}$ & 365 & all PPS & 2.9 & 249 & 72 & 113 & 39 & 83 & 61 & membrane $O K, \tan$ felt color \\
\hline 1BF3 R1B3 & $"$ & 365 & all PPS & 3.6 & 226 & 66 & & & & & $\begin{array}{l}\text { membrane cracking along some of the } \\
\text { vertical cage wires }\end{array}$ \\
\hline 1BF3R1B4 & $"$ & 365 & all PPS & 4 & 223 & 65 & & & & & $\begin{array}{l}\text { membrane cracking at vertical/horizontal } \\
\text { cage wire junctures }\end{array}$ \\
\hline 1BF3 R1B6 & $"$ & 365 & all PPS & 3.8 & 182 & 53 & & & 51 & 37 & membrane delaminated during $\mathrm{HEC}$ cleaning \\
\hline 1BF3R1B7 & $"$ & 365 & all PPS & 2.7 & 236 & 69 & 114 & 39 & 61 & 45 & membrane cracking, tan felt color \\
\hline 2BF2 R3B5 & $"$ & 500 & all GT & 1.9 & 717 & 100 & & & & & membrane OK \\
\hline 2BF2 R3B8 & $"$ & 500 & all GT & 1.5 & 735 & 100 & & & & & membrane OK \\
\hline 2BF3 R19B6 & $"$ & 500 & cond PPS & 2.3 & 481 & 96 & 181 & 54 & 243 & 100 & membrane OK, chocalat brown felt color \\
\hline 2BF3 R19B7 & " & 500 & cond PPS & 2.2 & 473 & 94 & 180 & 54 & 200 & 83 & bag turned inside out during removal \\
\hline 2BF4 R20B7 & $"$ & 500 & all PPS & 2.8 & 208 & 60 & 90 & 31 & 73 & 53 & $\begin{array}{l}\text { membrane scraped during removal, dark tan } \\
\text { felt color }\end{array}$ \\
\hline 1A.F4 R11B11 & $\begin{array}{c}6 / 10 / 03 \text { to } \\
9 / 27 / 03\end{array}$ & 322 & all PPS & 3.9 & 234 & 68 & 123 & 43 & 90 & 66 & $\begin{array}{l}\text { membrane cracking along vertical and } \\
\text { horizontal cage wires }\end{array}$ \\
\hline 1AF4 R1B20 & $\begin{array}{c}6 / 10 / 03 \text { to } \\
10 / 24 / 03\end{array}$ & 322 & all PPS & 3.6 & 368 & 78 & 104 & 36 & 42 & 31 & $\begin{array}{l}\text { membrane cracking in vertical direction } \\
\text { between vertical cage wires }\end{array}$ \\
\hline 1AF4 R1B12 & $"$ & 322 & all PPS & 4 & 229 & 67 & 73 & 25 & 24 & 17 & $\begin{array}{l}\text { membrane cracking at vertical/horizontal } \\
\text { cage wire junctures, tan felt color }\end{array}$ \\
\hline 1BF3 R21B5 & $"$ & 365 & all PPS & 6.9 & 203 & 59 & 48 & 16 & 10 & 8 & $\begin{array}{l}\text { holes formed through felt backer, choc. } \\
\text { brown felt }\end{array}$ \\
\hline 1BF3 R21B6 & " & 365 & all PPS & 5 & 210 & 61 & 33 & 11 & 2 & 2 & membrane delamination, holes in felt \\
\hline 2AF4 R21B14 & " & 450 & cond PPS & 2 & 463 & 92 & 115 & 34 & 197 & 82 & tan discoloration, hole in felt \\
\hline 1AF2 R15B11 & $\begin{array}{c}6 / 10 / 103 \text { to } \\
2 / 28 / 04\end{array}$ & 322 & cond PPS & 2.6 & 449 & 89 & 224 & 67 & 205 & 85 & membrane OK \\
\hline 1AF3 R11B15 & $"$ & 322 & all PPS & 3 & 214 & 59 & 125 & 43 & 78 & 57 & $\begin{array}{l}\text { holes formed at vertical/horizontal cage wire } \\
\text { junctures }\end{array}$ \\
\hline 2AF4 R13B10 & $\begin{array}{l}12 / 3 / 03 \text { to } \\
2 / 28 / 04\end{array}$ & 350 & SUPERFLEX & 3.5 & 870 & 100 & 483 & 100 & 405 & 100 & membrane OK \\
\hline 2AF4 R13B9 & $"$ & 350 & Fiberglass & 3.1 & 920 & 100 & 729 & 100 & 461 & 100 & $\begin{array}{l}\text { membrane OK, small areas scraped during } \\
\text { removal }\end{array}$ \\
\hline 2BF4 R11B6 & $"$ & 365 & P-84 & 5.1 & 337 & & 185 & & 97 & & $\begin{array}{l}\text { membrane delamination throughout entire } \\
\text { length of bag }\end{array}$ \\
\hline & new & 80 & NOMEX & 5.4 & 513 & & 408 & & 160 & & brand new \\
\hline & & & new all PPS & & 366 & & 289 & & 137 & & \\
\hline & & & cond PPS & & 503 & & 337 & & 241 & & \\
\hline & & & all GT & & 650 & & & & & & \\
\hline
\end{tabular}


The overall conclusions in the report from W.L. Gore and Associates are as follows:

Conclusions:

- GORE-NO STAT ${ }^{\circledR}$ filter bags continue to maintain excellent membrane integrity and physical strength.

- Laboratory analysis of the filter bags revealed no membrane damage caused by electrostatic discharge or sparking.

- After 10 weeks of service SUPERFLEX ${ }^{\circledR}$ and fiberglass backed filter bags exhibited no loss in physical strength and membrane integrity.

- The all PPS backed and conductive PPS backed GORE-TEX ${ }^{\circledR}$ membrane filter bags have shown they are sensitive to temperature upsets.

- Future physical strength analysis should include Tensile strength testing, preferably using the Instron instrument.

${ }^{\circledR}$ GORE-TEX and GORE-NO STAT are registered trademarks of W. L. Gore \& Associates, Inc.

As the power plant operator, we consider the information in this light, 'What bag should be installed in the system to give a balance of low resistance to gas flow and strength retention in service for prolonged mechanical life?'. With the operation results of the all PPS bags unacceptable with regards to mechanical bag life, it seems that our options looking ahead for filter bag backing are as follows (each of these bags would likely include a PTFE membrane);

- PTFE

- Superflex

- Fiberglass

- $\mathrm{P}-84$

- NOMEX

At this time, it has not been determined which bag is the most likely candidate to give a good balance of performance. Additional testing and operation time is needed. Factors such as the Frazier number, as well as percentage strength retention need to be taken into account. 


\section{General Discussion (Eighth Quarter 7/2004 - 9/2004)}

\section{General Discussion}

Operation of the Advanced Hybrid system has been stable during the last quarter. There has been very little change in operation or significant operational accomplishments. The plant was loaded a little bit lighter this summer due to an unseasonably cool temperatures. However, we still saw some derates and uncontrollable pressure drop during the warmest period of the summer.

Some of the significant points of discussion are:

- Independent bag analysis from Environmental Consulting Company (ECC)

- Full chamber baffle installation and blowpipe modification

- Bag life concerns with NOMEX

- Decision to move ahead with the inlet field modification

- P-84 Failures discovered

\section{Independent bag analysis from ECC}

An independent bag analysis company was contracted to perform testing and analysis on a variety of bags in the Advanced Hybrid system. The report is included in Appendix B41. The major conclusions are included below:

- NOMEX has undergone sulfur trioxide degradation and under the 6 month exposure has suffered high deterioration. NOMEX Aramid is not recommended for service in this application.

- The life projections for the following candidates based on limited testing data is as follows
o Fiberglass
4-5 years
o $\quad \mathrm{P}-84$
5-6 years
o PTFE felt
8-9 years

- Other conclusions can be found in the Appendix

It was apparent to us that the NOMEX bags were beginning to fail unacceptably during the bag inspection last June. The analysis from ECC backed up those conclusions. However, of some concern is the estimate of 5-6 years of bag life remaining for the P-84 bags when some bag failures were seen during an impromptu inspection during a boiler tube leak outage in the last days of September. This is discussed in the last bullet item of this section. 
Full chamber baffle installation and blowpipe modification

During the scheduled boiler wash outage in June, a full chamber of flow baffles was installed. This represents $1 / 4$ of the entire Advanced Hybrid system. There has not been a clear measurable advantage with the flow baffles in the system. Undoubtedly, the baffles are working to divert some of the formerly untreated flue gas into the ESP zone, but this is very difficult to measure.

Likewise, two blowpipe sections were combined into one long blowpipe to determine if this could be done to improve the overall usability of the system and reduce the system costs. Further research and testing will need to be done to evaluate if this is an acceptable option.

\section{$\underline{\text { Bag life concerns with NOMEX }}$}

As mentioned earlier, our independent lab analysis of the NOMEX bags revealed that the strength of these bags was deteriorating at an unacceptable rate. It will be necessary to change these bags out during the scheduled boiler wash outage in October. It was determined that the most logical choice for replacement was fiberglass bags. Two options exist currently, a straight fiberglass bag or a fiberglass/PTFE composite (both membrane bags). A couple of these bags have been in service since December 2003, and have not failed, but a large scale (full compartment) needs to be tested in a warmer chamber. A purchase order was issued to Midwesco Inc. for a full compartment of fiberglass bags.

\section{Decision to move ahead with the inlet field modification}

A letter of intent and purchase order were issued to Southern Environmental from Otter Tail Power Company to install additional Advanced Hybrid components. This was done to lower the air:cloth ratio of the existing system to levels that have been demonstrated as successful. Currently the system operates at up to $12 \mathrm{fpm}$. The planned installation of 4 more compartments will reduce this to approximately $75 \%$ of current levels, or $9 \mathrm{fpm}$. A separate project is being considered for this work and it will not be covered under the existing reporting or project arrangement. It is uncertain at this time whether or not additional NETL participation will occur.

\section{$\underline{\text { P-84 Failures discovered }}$}

The last item of interest was the discovery of a significant number of failed P- 84 bags in the last compartment of Chamber 2B. These were discovered by chance during an unscheduled bag inspection that occurred during a boiler tube leak on September $29^{\text {th }}$. Other than the NOMEX compartment, which had a very significant percentage of failed bags, the compartment with P-84 bags that were installed in December 2003 was the only other compartment to have visual evidence of a significant number of failed bags. An estimated 40 bags have holes in them and about $50 \%$ occurred in the $9^{\text {th }}$ and $10^{\text {th }}$ position of the 
short blowpipe in that compartment. Also, $100 \%$ of the failed bags were under the short blowpipe in other positions. This is a significant concern as the P-84 bags were considered the best, reasonable cost bag option until this time. The fact that the ECC bag analysis predicted 5-6 years of life and significant failures occurred in approximately 9 months needs further evaluation. The fact that these bags were all on the short blowpipe would also lead us to believe that there is an imbalance in the blow pipe design, and further refinement in the design is needed. Further testing and explanation of the failed P- 84 bags with ECC will be completed. 


\section{General Discussion (Ninth Quarter 10/2004 - 12/2004)}

Although not intended to cover an additional two months of reporting on the operations of the Advanced Hybrid system, Otter Tail Power Company is including data from the last months of the year in this final report.

The final demonstration period for the Advanced Hybrid system has been fairly stable. The most significant accomplishments were;

- Replacement of 1 compartment of NOMEX bags with fiberglass bags (with membrane)

- Replacement of $1 / 2$ compartment of P-84 Bags with Superflex ${ }^{\mathrm{TM}}$ bags

- Independent analysis of the failed P-84 bags

- Continued work towards installing Advanced Hybrid components in the inlet field

\section{Replacement of 1 compartment of NOMEX bags with fiberglass bags (with membrane)}

The last compartment of Chamber 1B (Field 4, compartment \#6) was replaced with membrane-style fiberglass bags from Midwesco. The installation went well, and only time will tell how these fiberglass bags will hold up during operation.

\section{Replacement of $1 / 2$ compartment of P-84 Bags with Superflex ${ }^{\mathrm{TM}}$ bags}

One half of the bags in the last compartment of Chamber 2B (Field 4, compartment \#12), was replaced with Superflex ${ }^{\mathrm{TM}}$ bags from W.L. Gore and Associates. All of these bags were under the short blow-pipe section. Again, only time and operational experience will tell if this type of bag will stand up to actual operational conditions.

\section{Independent analysis of the failed P-84 bags}

EEC was again contracted to perform and analysis on the P-84 bags which failed since the last outage. The report focused on the failure of the P-84 bags in service. It appears that the primary factor for failure was acid attack on the bags from moisture in the pulse air system. The report can be found in Appendix B42. 


\section{Addenda: General Discussion (Major Activities 1/2005 - 12/2005)}

During 2005, the major focus has been the design, fabrication, construction and operation of additional Advanced Hybrid Components in the existing inlet field. The existing inlet field of the original system was left as designed in 1975 as a standard ESP section. The main goals of this modification were the following;

- Lower the $\mathrm{A} / \mathrm{C}$ ratios to levels where acceptable performance has been demonstrated

- Improved ESP design and performance

- Improved pulse cleaning design

- Optimize bag placement and space consideration

- Return the Big Stone Power Plant to full load and stable operation

\section{Lower A/C Ratios}

The fundamental change to the system is the addition of 4 more AHPC compartments to bring the total number of compartments of the Advanced Hybrid system from 12 compartments to 16 compartments. In general, the operating air:cloth ratios have been reduced from $12 \mathrm{fpm}$ to $8 \mathrm{fpm}$. This has been the air:cloth ratio that had been demonstrated from the performance of the initial system to be acceptable (see Tables $2 \& 3$ from "General Discussions Fourth Quarter). Also, see the performance graphs included as B45 Addendum - Performance Graphs from 10/2002 through 12/2005

\section{Improved ESP design and performance}

After the initial design, a likely improvement option from the opinion of most working on the project included improving the ESP design. These design changes included extending the plates and electrodes longer than the original design. In the original design, the plates were only extended to cover the length of the installed bags. In the new design, approximately 10 feet of additional collecting surface was extended downward. This should have improved the pre-collection effect, as approximately $75 \%$ of the total gas stream will pass below the inlet field to the back three compartments of each chamber. Also, the area of open space beneath the current header design will be filled with ESP components. This should have improved the pre-collection of the flue gas that would normally bypass around the ESP components laterally with the old design.

\section{Improved Pulse Cleaning Design}

With the original design, the blowpipes were arranged in a two-piece system. The first half blowpipe 
would pulse the first half of the bags closest to the pulse header and the second half blowpipe would pulse the second half farthest from the header. This design proved to be aggressive to the point of accelerating bag failures and very difficult from a maintenance perspective to replace bags. During extensive testing and a demonstration of the improved single blowpipe design in one of the original compartments, it was determined that a single blowpipe design was superior for long-term bag life and maintainability, without poorly effecting performance. As a result, both the four new inlet compartments and the existing twelve compartments were retrofitted for a single blowpipe design.

\section{Optimize Bag Placement and Space Consideration}

In order to maximize the new cloth surface of the system, the new design was implemented with 10" plate spacing rather than 12 " plate spacing. This design will allow for three more rows of bags (21 bags per row) per compartment. Also, successful demonstration of this concept would shrink the footprint of the system by over $10 \%$.

\section{$\underline{\text { Return the Big Stone Power Plant to full load and stable operation }}$}

Although the effort at replacing the inlet field with Advanced Hybrid design took advantage of lessons learned during the initial effort, the primary reason was to return the Big Stone Power Plant to full load stable operation. The performance of the Big Stone Plant primary particulate collection device needed to improve. In particular, the differential pressure across the system needs to be brought below 8 INH2O to allow the existing plant ID fans to function normally at full load. Any improvement efforts of the Advanced Hybrid system that did not lend themselves to this concept were not considered. Failure of the effort to improve system performance enough to bring Big Stone back to full load would result in abandoning the technology from Otter Tail Power Company's opinion.

\section{General Discussion in Conclusion}

During a six-week outage at Big Stone in the spring of 2005, the inlet field of ESP components was replaced with improved Advanced Hybrid Design described in general above. The results of this effort are described in the next sections, but in general, the project failed to meet the primary goal of overall improved performance. 


\subsection{Conclusions}

\subsection{PERFORMANCE PARAMETERS}

The four fundamental performance parameters of the Advanced Hybrid system are;

- Opacity (Appendix B8)

- $\quad$ Air-to-cloth ratio (Appendix B7)

- $\quad$ Tubesheet dP (Appendix B5)

- Compressed air flow (Appendix B22)

Particulate control is ultimate goal of the Advanced Hybrid system. Only one stack test was performed by the EERC during the demonstration, although the stack opacity readings were recorded during the entire demonstration and this graph can be found in Appendix B8. The results of that stack test met the ultimate goal of $99.99 \%$. However, as the various bag types were tried in an effort to reduce the differential pressure across the system, significant bag failures resulted in particulate control that falls short of the goal. It is generally accepted that to reach the $99.99 \%$ collection efficiency goal, an generally low opacity reading would be measured. After the initial set of bags was removed, the opacity would rise above minimum values and we are quite confident that the system would not reach the $99.99 \%$ goal. Significant improvements in the existing system must be realized so that overall performance will be acceptable, and bag integrity maintained so that the $99.99 \%$ particulate capture goal is met in the short term.

The A/C ratio during the demonstration has been between 10.5 and $12 \mathrm{fpm}$ during full load operation. Significant plant reductions in load $(5-50 \mathrm{MW})$ have been taken at times as the plant ID Fans have begun to stall during operation. Although this range of $\mathrm{A} / \mathrm{C}$ was the goal of the system, what was determined as acceptable performance was not reached for the vast majority of this $\mathrm{A} / \mathrm{C}$ ratio range. In addition to this, there is a discrepancy with regards to the overall flue gas flow volume of about $10 \%$. In other words, the flue gas volume that was predicted by the stoichiometric equations and the volume measured by the stack flow probe is different by about $10 \%$. If the expected stoichiometric flow was used instead of the stack flow monitor, it would result in an $\mathrm{A} / \mathrm{C}$ ratio of about $9.5-10.8$.

The tubesheet $\mathrm{dP}$ goal for the demonstration was $8.0 \mathrm{INH} 2 \mathrm{O}$. At full load conditions during the two-year demonstration, the differential pressure exceeded this value up to maximum of $10.5 \mathrm{IN} \mathrm{H} 2 \mathrm{O}$ at full load 
operation.

The compressed air usage for the system is a good representation of performance if the differential pressure is being maintained below $8 \mathrm{IN} \mathrm{H} 2 \mathrm{O}$. If the differential pressure is above $8 \mathrm{IN} \mathrm{H} 2 \mathrm{O}$, it can be assumed that the pulse system is working at maximum and the compressed air flow would be represented at around $2200 \mathrm{acfm}$. However, at times when the differential pressure is below $8 \mathrm{IN} \mathrm{H2O}$, the pulse system will automatically pull back to reduce the compressed air usage while maintaining the differential pressure at $8 \mathrm{IN} \mathrm{H2O}$. It can be seen in Appendix B22 that the compressed air flow was at $2000 \mathrm{acfm}$ or greater at the beginning of the demonstration and at the end. While testing the various bag types, the compressed air flow varied greatly from as low as $500 \mathrm{acfm}$, to the level consistent with constant pulsing.

\section{1.(addendum) PERFORMANCE PARAMETERS (June 2005 - December 2005)}

The four fundamental performance parameters of the Advanced Hybrid system are;

- Opacity (Addendum Appendix B45)

- Air-to-cloth ratio (Addendum Appendix B45)

- Tubesheet dP (Addendum Appendix B45)

- Compressed air flow (Addendum Appendix B45)

Opacity during this period remains a challenge. Although after modification of the inlet fields, the opacity of the system was in the 5\% range, in four to five months, the opacity had risen again to $10-12 \%$. The failed bags were replaced in December 2005. The primary bag type that had failed was the BHA fiberglass bags.

The $\mathrm{A} / \mathrm{C}$ ratio after the installation of the Advanced Hybrid components dropped to 7-8 fpm as compared to the $10-12 \mathrm{fpm}$ with the original design.

The tubesheet $\mathrm{dP}$ for the system has not decreased as anticipated. One clarification needs to be made with regards to the performance graph at the end of the report. The mode of control for the entire plant changed after the spring 2005 outage. Rather than being a base loaded plant, due to energy market fluctuations as part of the MISO market system, the unit has been cycling to lower loads during certain times. This has resulted in wider load swings than the system has seen in the past. This accounts for the 
greater variaation in the graphical data presentation in both the Tubesheet $\mathrm{dP}$ and Flange-to-flange $\mathrm{dP}$ in the addendum section.

The compressed air usage after the new inlet field system was installed shows an increase from 2000 acfm to approximately $2400-2750 \mathrm{acfm}$. This is consistent with the installation of additional bags and pulse valves associated with the inlet field upgrade. One other note is that the increase above $3000 \mathrm{acfm}$ at the end of the graph was due to a modification in piping at the plant and not related to an increased demand to the Advanced Hybrid system. 


\subsection{BENEFITS ANALYSIS}

\subsubsection{Cost Baseline Analysis}

The cost baseline analysis before and after installation of the system is based on three primary factors, electrical energy usage, ongoing maintenance costs, and bag replacement costs. The electrical energy comparison information is presented in the following table.

Table 3 Electrical Energy Comparison

\begin{tabular}{|c|c|c|c|c|}
\hline & & ESP Only & Advanced Hybrid $^{\text {TM }}$ \\
\hline Precipitator 1A & KW & 188.8 & 110.1 \\
\hline Precipitator 1B & KW & 190.4 & 93.4 \\
\hline Precipitator 2A & KW & 172.3 & 130.4 \\
\hline Precipitator 2B & KW & 133.0 & 98.3 \\
\hline Total ESP Usage & KW & $\mathbf{6 8 4 . 5}$ & $\mathbf{4 3 2 . 2}$ \\
\hline ID Fan A & & & $1,888.5$ \\
\hline ID Fan B & KW & $1,552.0$ & $1,835.7$ \\
\hline ID Fan C & KW & $1,567.6$ & $1,835.0$ \\
\hline ID Fan D & KW & $1,541.7$ & $1,851.1$ \\
\hline Total ID Fan Power & KW & $1,573.9$ & $\mathbf{7 , 4 1 0 . 4}$ \\
\hline Air Compressor D & KW & $\mathbf{6 , 2 3 5 . 2}$ & 173.6 \\
\hline Air Compressor E & KW & 87.2 & 181.5 \\
\hline Air Compressor F & KW & 127.9 & $\mathbf{8 , 3 7 2 . 5}$ \\
\hline Total & KW & $\mathbf{3 2 0 . 6}$ & $\mathbf{1 , 1 3 2 . 2}$ \\
\hline Dotal Electrical Energy & KW & $\mathbf{7 , 2 4 0 . 3}$ & $\mathbf{5 2 9 . 9}$ \\
\hline
\end{tabular}


Table 4 Cost Comparison

\begin{tabular}{|c|c|c|c|}
\hline & & ESP Only & Advanced Hybrid $^{\mathrm{TM}}$ \\
\hline Labor \& Materials & \$/month & $\$ 5,741$ & $\$ 35,670$ \\
\hline Humidification Chemical & \$/month & $\$ 7,022$ & $\mathrm{NA}$ \\
\hline Bag Replacement Cost & \$/month & NA & $\$ 174,028$ \\
\hline Average & \$/Month & $\$ 12,762$ & $\$ 209,698$ \\
\hline Sum of Monthly Average & \$/Year & $\$ 153,144$ & $\$ 2,516,376$ \\
\hline Difference & \$/Year & & $+\$ 2,363,232$ \\
\hline
\end{tabular}

Notes on the table above:

The Advanced Hybrid ${ }^{\mathrm{TM}}$ costs are derived from the spreadsheet AHPC Work Plan. The labor and materials are are taken from the operators and other union personnel time. The material cost is derived from the OTP costs with the bags removed.

Table 5 MWH - Derate Comparison

\begin{tabular}{|c|c|c|c|c|c|}
\hline & $\begin{array}{c}\text { ESP Opacity } \\
\text { Derates }\end{array}$ & $\begin{array}{c}\text { ESP Repair } \\
\text { Derates }\end{array}$ & $\begin{array}{c}\text { Advanced Hybrid }^{\mathrm{TM}} \\
\text { Opacity Derates }\end{array}$ & $\begin{array}{c}\text { Advanced Hybrid } \\
\text { Repair \& Operational } \\
\text { Derates }\end{array}$ \\
\hline 1999 & 7,786 & 16,004 & & & \\
\hline $\begin{array}{c}\text { Average } \\
\text { MWH/Year }\end{array}$ & $\mathbf{7 , 3 2 3}$ & $\mathbf{1 6 , 3 4 0}$ & & & \\
\hline 2000 & & & & & 99,324 \\
\hline 2004 & & & & $\mathbf{7 0 6}$ & 29,108 \\
\hline $\begin{array}{c}\text { Average } \\
\text { MWH/Year }\end{array}$ & & & & $\mathbf{3 5 3}$ & $\mathbf{6 4 , 2 1 6}$ \\
\hline $\begin{array}{c}\text { Difference } \\
\text { by Category }\end{array}$ & & & & $\mathbf{- 6 , 9 7 0}$ & $\mathbf{+ 4 7 , 8 7 6}$ \\
\hline $\begin{array}{c}\text { Total Derate } \\
\text { Difference }\end{array}$ & & & & & $\mathbf{+ 4 0 , 9 0 6}$ \\
\hline
\end{tabular}




\subsubsection{Technical Baseline Analysis}

The technical baseline information is a comparison of the last particulate loading test that was performed at Big Stone and the Stack test that was performed by the EERC in November 2002 after the installation of the Advanced Hybrid ${ }^{\mathrm{TM}}$ system.

Table 6 - Collection Efficiency Comparison

\begin{tabular}{|c|c|c|c|}
\hline & & ESP & Advanced Hybrid $^{\text {TM }}$ \\
\hline Particulate Matter $^{1}$ & gr/scf & .0068 & .00004 \\
\hline Collection Efficiency $^{2}$ & Gr/acf & $99.29 \%$ & $99.996 \%$ \\
\hline
\end{tabular}

1 acf converted to scf by measured value during demonstration

2 Inlet loading during previous stack test assumed to be the same as the inlet loading during the EERC stack test.

\subsubsection{Comparison Summary}

Table 7 Comparison Summary Table

\begin{tabular}{|c|c|c|c|}
\hline & & ESP Only & Advanced Hybrid $^{\text {TM }}$ \\
\hline Collection Efficiency & Gr/acf & $\mathbf{9 9 . 2 9 \%}$ & $\mathbf{9 9 . 9 9 6 \%}$ \\
\hline Cost Difference & \$/Year & & $+\$ 2,363,232$ \\
\hline $\begin{array}{c}\text { Electrical Energy Usage } \\
\text { Difference }\end{array}$ & KW & & $+1,132.2$ \\
\hline \begin{tabular}{c} 
Opacity Derate Difference \\
\hline
\end{tabular} & MWH/year & & $\mathbf{- 6 , 9 7 0}$ \\
\hline $\begin{array}{c}\text { Operational \& Repair } \\
\text { Derate Difference }\end{array}$ & MWH/year & & $+47,876$ \\
\hline
\end{tabular}

\subsubsection{Baseline Analysis (Addendum)}

There were no significant changes to the performance after the inlet field upgrade. So no additional comparison was made. However, as a point of note, the cost for the inlet field upgrade was approximately, $\$ 7,907,374$. 


\subsection{Final Project Conclusions}

\subsubsection{Project Objectives}

Demonstrate that the AHPC technology can be retrofitted into an existing ESP at the full-scale level This objective was met. The overall installation of the Advanced Hybrid ${ }^{\mathrm{TM}}$ system into the existing Wheelabrator-Frye electrostatic precipitator box was a significant success. The installation of the equipment was accomplished during a 5.5-week outage in October 2002. There was no difficulty in making this installation timeline.

Demonstrate the ability of a retrofitted AHPC to meet performance specifications without derating the plant because of high opacity

This objective was not met, as the plant had to derate output in October of 2004 as the bags began failing.

Demonstrate the ability of the AHPC to provide $>99.99 \%$ particulate collection efficiency for all particle sizes greater than $0.01 \mu \mathrm{m}$.

This objective was met as the results of the stack test performed in November 2002 showed. Although, in general, it may have been better to state this objective as meeting the particulate collection efficiency goal after a certain period of time that would be considered acceptable. A likely better objective would have been $99.99 \%$ collection efficiency after 3-5 years of operation. The Advanced Hybrid ${ }^{\mathrm{TM}}$ system would $^{-}$ not have met the objective in this case due to the failure of the filter bags.

Demonstrate the reliability of the AHPC as defined by acceptable maintenance requirements that are the same or less than standard ESP's or Baghouses.

This is somewhat speculative to answer, although I would say that the spirit of this objective was met. Obviously, when comparing the benefits and cost comparisons in the previous section, the Advanced Hybrid system is significantly more expensive to maintain than the previous ESP system. However, there are two underlying components that need to be considered. First, there was some difficulty after startup with the plate rapping systems, and working the bugs out of the system. This occurred for about six months or until the next week-long outage. After this outage, these issues were resolved and the rapping system worked fairly well. The other, considerably larger, factor is the significant work with the bag changes. If we would remove these two factors, it is our opinion that this objective would have been met. Other than the ongoing bag concerns, the maintenance for operation is at acceptable levels.

Demonstrate the ability of the AHPC to achieve low-pressure (guaranteed) pressure drop at an air-cloth 
ratio of $12 \mathrm{ft} / \mathrm{min}$

This objective was not met. Although the system was operated at $10.5-12 \mathrm{fpm}$ (using the stack flow meter), the tubesheet differential pressure ranged from 8 - $10 \mathrm{IN} \mathrm{H} 2 \mathrm{O}$. Because of this, significant limitations of the plant output were realized. This is the primary objective that drives the view of success of this project, as well as the primary consideration looking ahead.

Demonstrate the long-term operability of the AHPC

This objective was not met, since the previous objective was not met.

Demonstrate the economic viability of the AHPC

This objective was not met. This judgment is based on the previous two objectives not being met, as well as the high cost of the replacement bags to date.

\subsubsection{Overall Conclusions}

When reviewing the project objectives, three of the seven objectives were met. Overall however, the system is not where the project team estimated it would be at the conclusion of this demonstration. This can be attributed to two primary factors, differential pressure and air:cloth ratio.

If the differential pressure had met the $8.0 \mathrm{IN} \mathrm{H} 2 \mathrm{O}$ goal, there would not have been any plant output restrictions. The original filtration bags installed in October 2002 would still be in the system, and the significant cost and problems associated with attempting the use of various bag materials would not have occurred. The reason the differential pressure goal was not met is likely a scale-up problem from the pilot unit to the full-scale unit.

The most significant test and information came from a one-time test in February 2003. The details of this test can be found in pages 36-39 of this report. After this test the performance levels of full-scale system when compared to the pilot system were known. With a residual drag nearly $30 \%$ greater than previously reported results, and 3-5 times the rate of ash loading to the bags, the full-scale system was simply too far outside the reasonable range of performance. The system as designed and built was simply not able to demonstrate acceptable performance. All attempts to improve performance failed over the long-term, and the decision to re-size the system to a lower air: cloth ratio was made. 


\subsubsection{Looking Ahead}

The current plans for the system involve the installation of improved Advanced Hybrid ${ }^{\mathrm{TM}}$ components in the existing inlet field at Big Stone. This will result in operation at an air:cloth ratio of approximately 8-9 fpm, or $75 \%$ of current levels. Using the table of demonstrated performance on page 54 , this should result in acceptable performance. However, as was seen in the first phase of this project, unforeseen difficulties may still arise and the system needs to be demonstrated prior to being considered a viable market technology.

There are also questions as to which bag material is appropriate for the system. This has not yet been resolved, and will take additional demonstration before it can be concluded.

\subsubsection{Final Conclusions (addendum)}

The inclusion of Advanced Hybrid components in the inlet field of the Big Stone ESP failed to significantly improve performance to satisfactory levels. In fact, as can be seen by the performance graphs in the addendum section at the end of this report, differential pressure across the system actually increased during periods of full load.

The goal of installing the Advanced Hybrid system in the inlet field was improved performance demonstrated at lower $\mathrm{A} / \mathrm{C}$ ratios during the operation of the Advanced Hybrid system and reported on Tables 2 and 3 in the Fourth Quarter General Discussion section of this report. It is the professional opinion of the authors of this paper that the reasons for this lack of performance improvement are due to the inability of the AHPC to precollect any flyash on the perforated collecting plates prior to the fabric filters. Main reasons for the lack of ESP collection are (1) high gas velocities, (2) high ash restivity, and (3) inability to maintain design clearances between the plates and electrodes. With out the benefit of ESP precollection on the perforated collecting plates, the AHPC operates just as a conventional PJFF does. In essence, we replaced a working inlet field ESP with a PJFF compartment operating at an A/C of 8:1.

As a result of the lack of performance improvement, Otter Tail Power Company has made the decision to abandon the Advanced Hybrid technology, and is looking at full-scale replacement of the primary particulate device. 
5.0 APPENDICES 


\section{APPENDIX A - COMMENTS ON ANOMALIES OF GRAPHICAL DATA}

Appendix B5 \& B6. The initial dP data was not historized correctly, so the first couple of days of dP history do not exist in the Plant Historian.

Appendix B19. Significant increases in Chamber Power typically indicate periods where the initial inlet field was energized, although spikes also occur during periods of reduced loading on the unit.

Appendix B17. Right hand column of units is incorrect. The $\mathrm{ug} / \mathrm{g}$ unit is correct, but this is not a direct percent.

Appendix B8. Opacity Graph shows two spikes in the opacity reading that were not real $(1 / 15 / 2003 \&$ 3/1/2003). These spikes were instrumentation failures and/or calibrations.

Appendix B8. Opacity graph shows spikes around 6/10/2003. These are instrument difficulties, and not representative of actual opacity.

Appendix B15. bam, ebm, etc. are Powder River Basin mine codes

Appendix B14 \& 15. The "adjustment" refers to an end of the month correction based on a comparison between visual levels and bookkeeping levels.

Appendix B21. Pulse counter graph seems to indicate no pulsing after the June 12, 2003 startup until the end of June. However, the scale is so large and the pulse cycle frequency was so insignificant, that it cannot be seen as a clear increase until the next quarter. The number of pulse cycles by June 30,2003 was 284.

Appendix B2, B3 \& B7. Low stack flow readings around 7/21/2003 are instrument problems and not real readings. As can be seen in B1, the plant was on-line and operating during the indicated period of no flow.

Appendix B8. Opacity spikes around 7/21/2003 and 9/23/2003 are instrument problems and not representative of actual high opacity.

Appendix B8. During the plant outage, (the period represented approximately 12/4/2003 - 12/9/2003 on the graph), the opacity is out of scale because it was removed from the plant stack and a "clear stack" calibration was performed in a clean environment. So the data from that period is not valid.

Appendix B6. There is no clear reason for the high differential pressure reading around 3/3/2003.

Appendix B8. The Opacity spike around 3/25/2004 was due to a calibration, and not a real opacity event. The step change in opacity can be attributed to a calibration issue and not a real opacity event.

Appendix B6. Beginning around 9/23/2004, there was a plugged sensing line for the Flange-to-Flange dP and this reading is in error. 
APPENDIX B - Graphical \& Tabular Performance Data

B1 Gross Plant Load
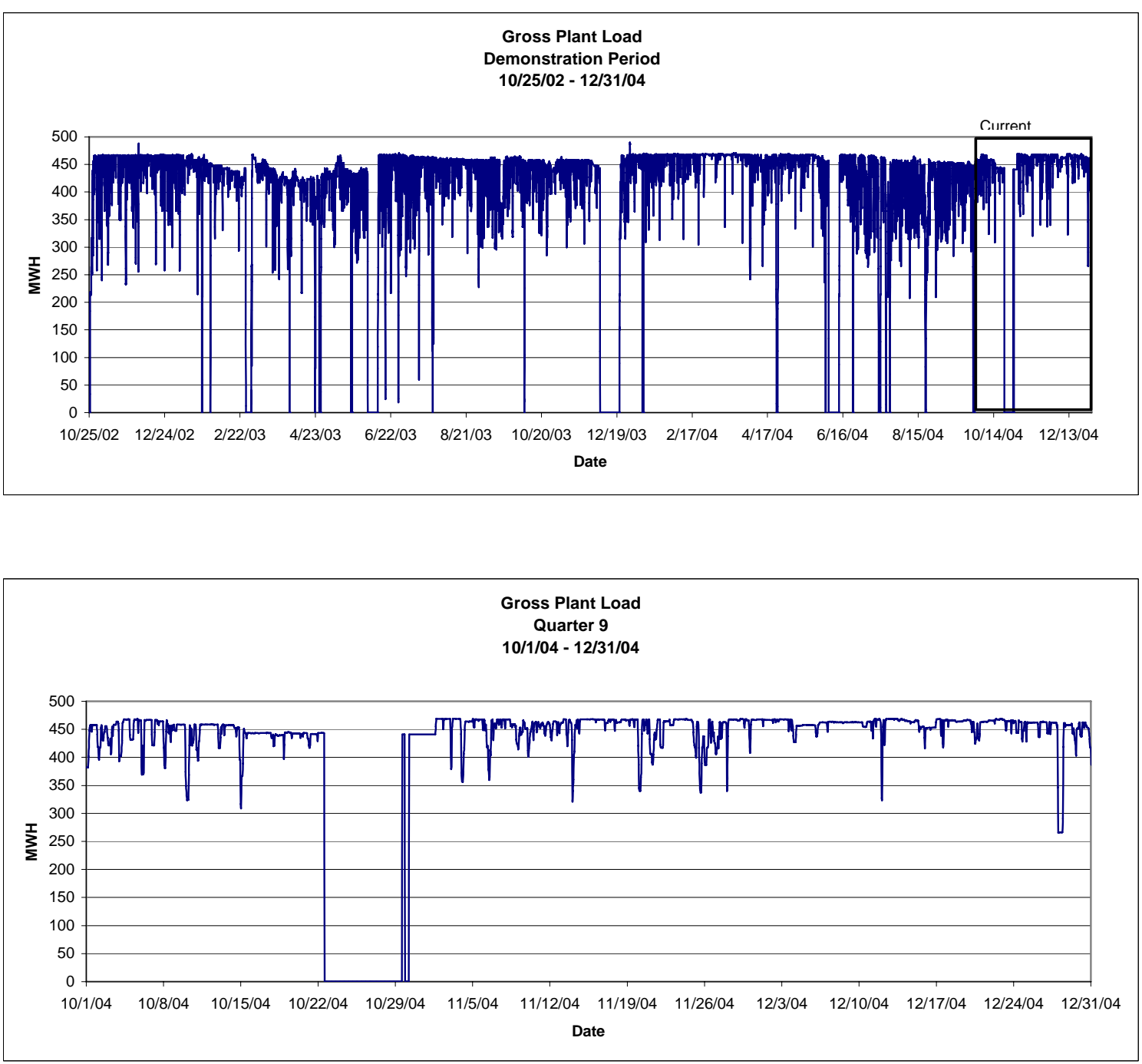


\section{B2 Flue Gas Flow (KSCFM)}
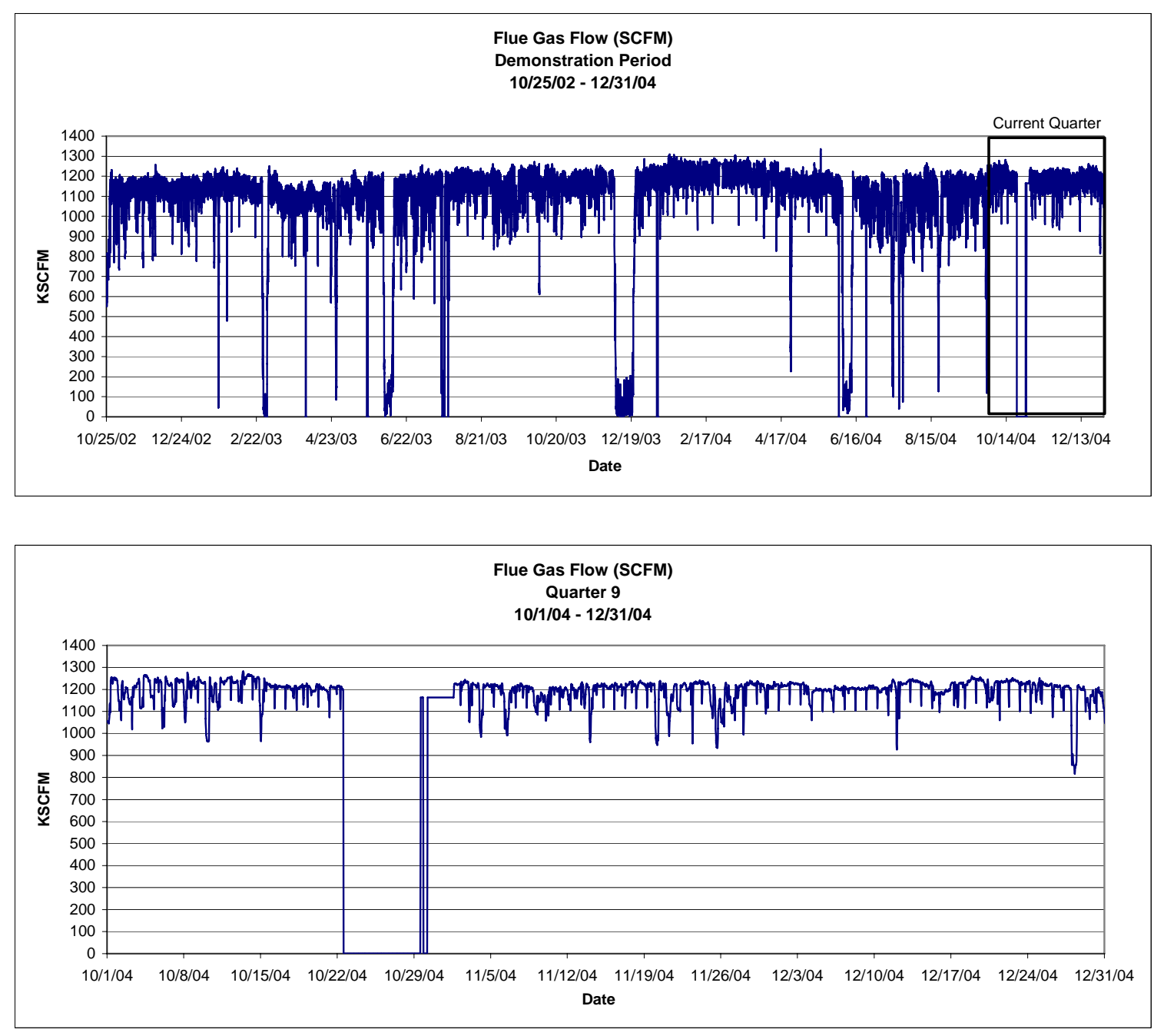
B3 Flue Gas Flow (KACFM)
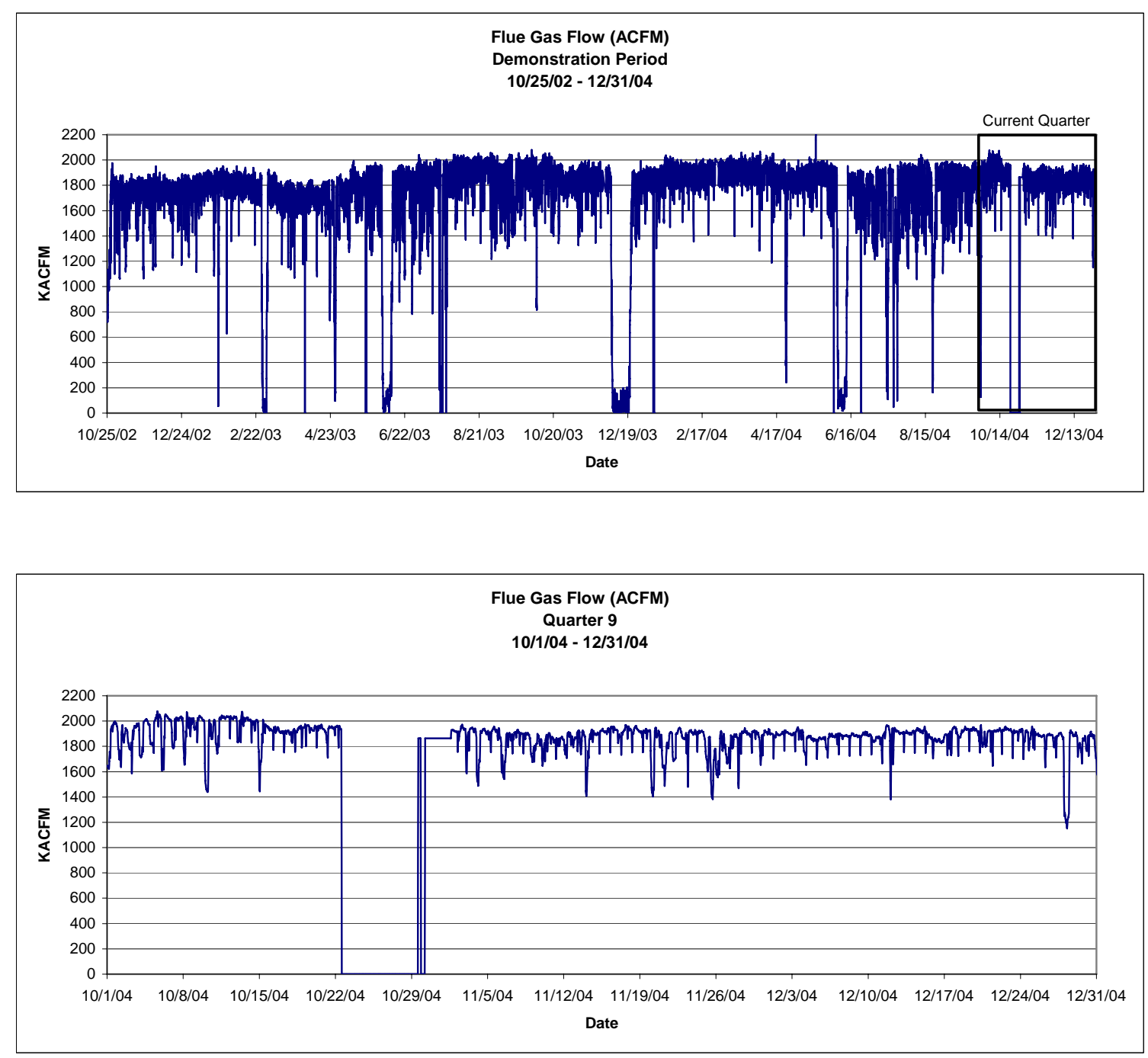
B4 Inlet Gas Temperature
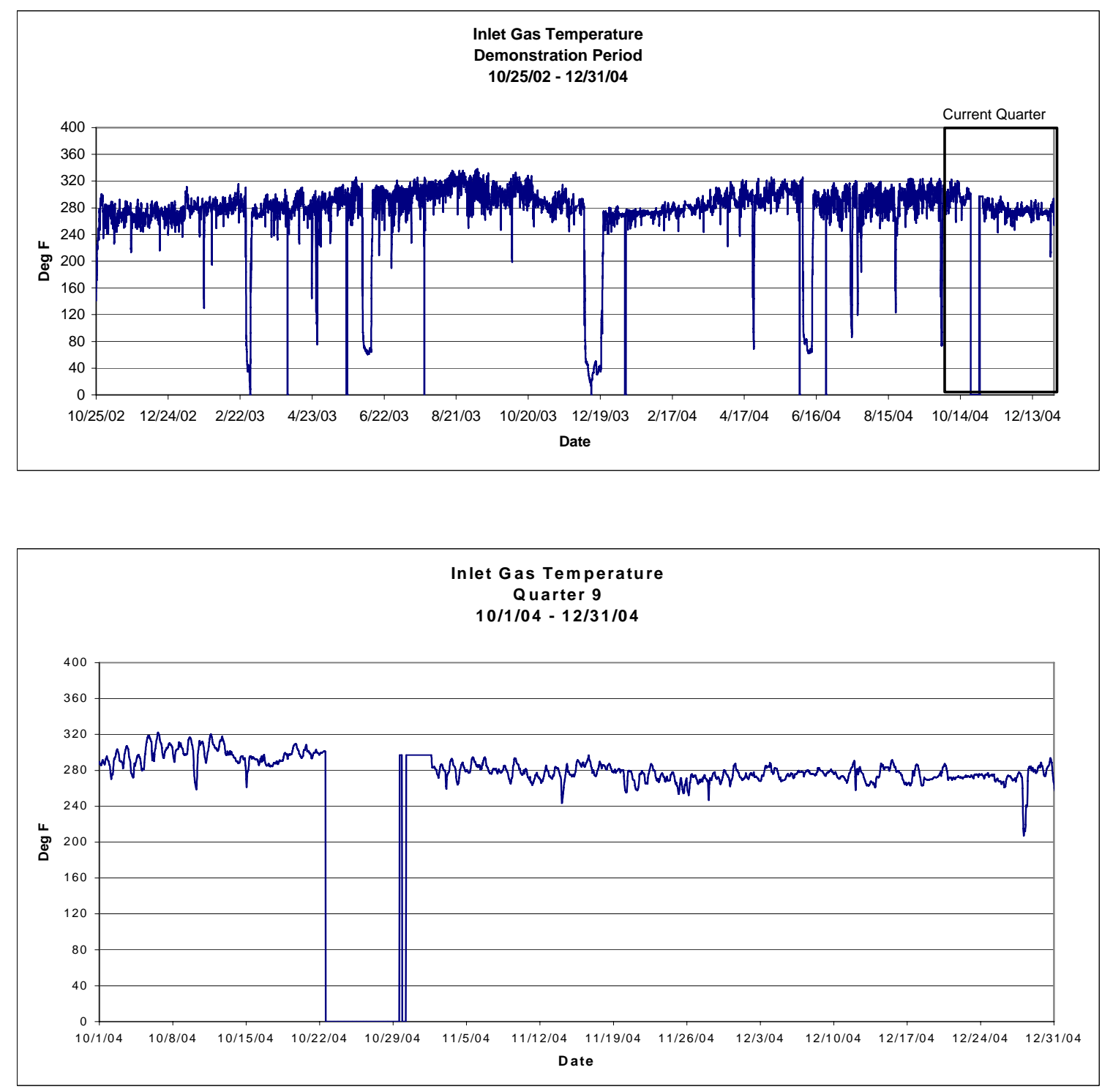


\section{B5 Tubesheet dP}
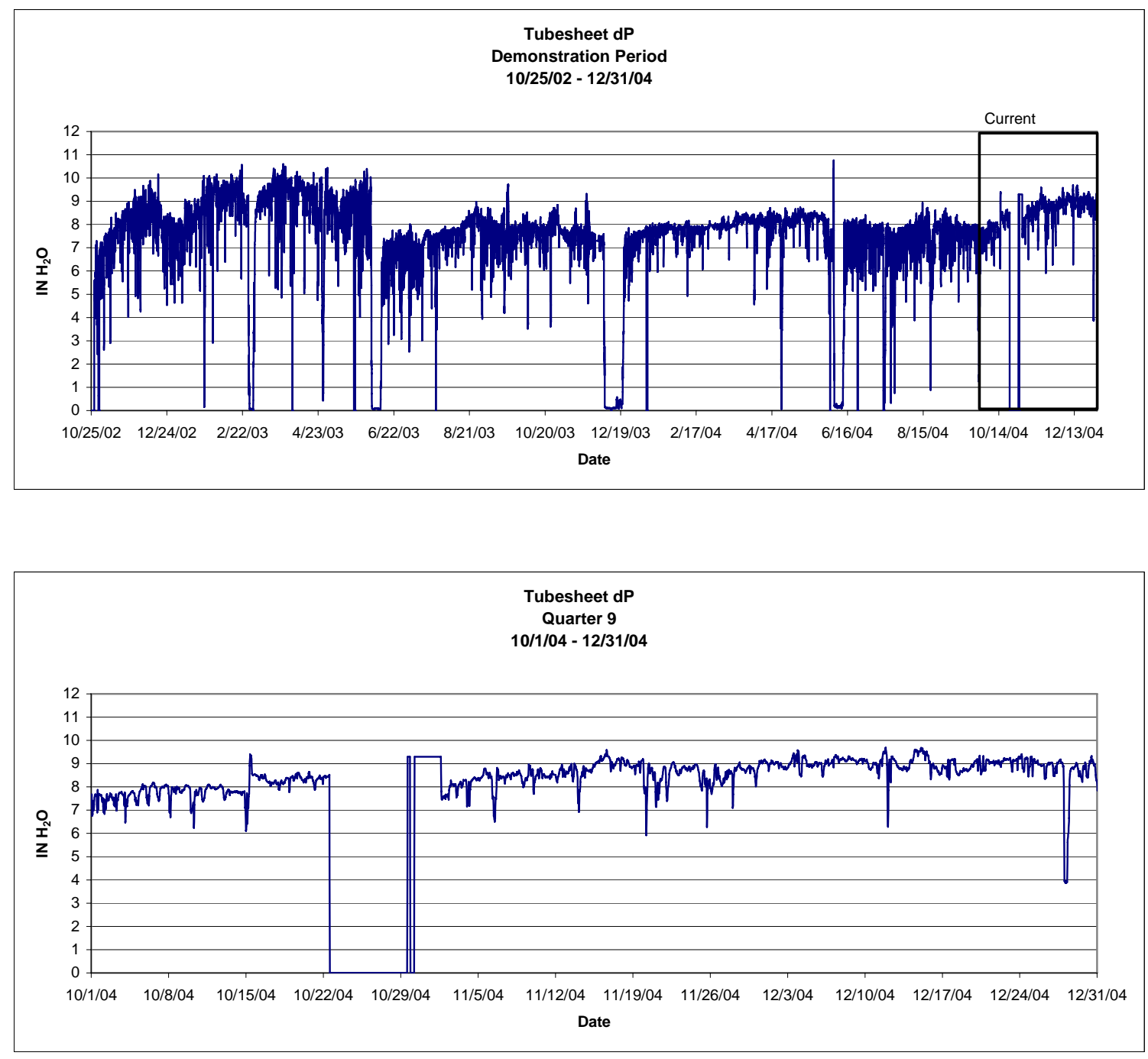
B6 Flange-to-Flange dP
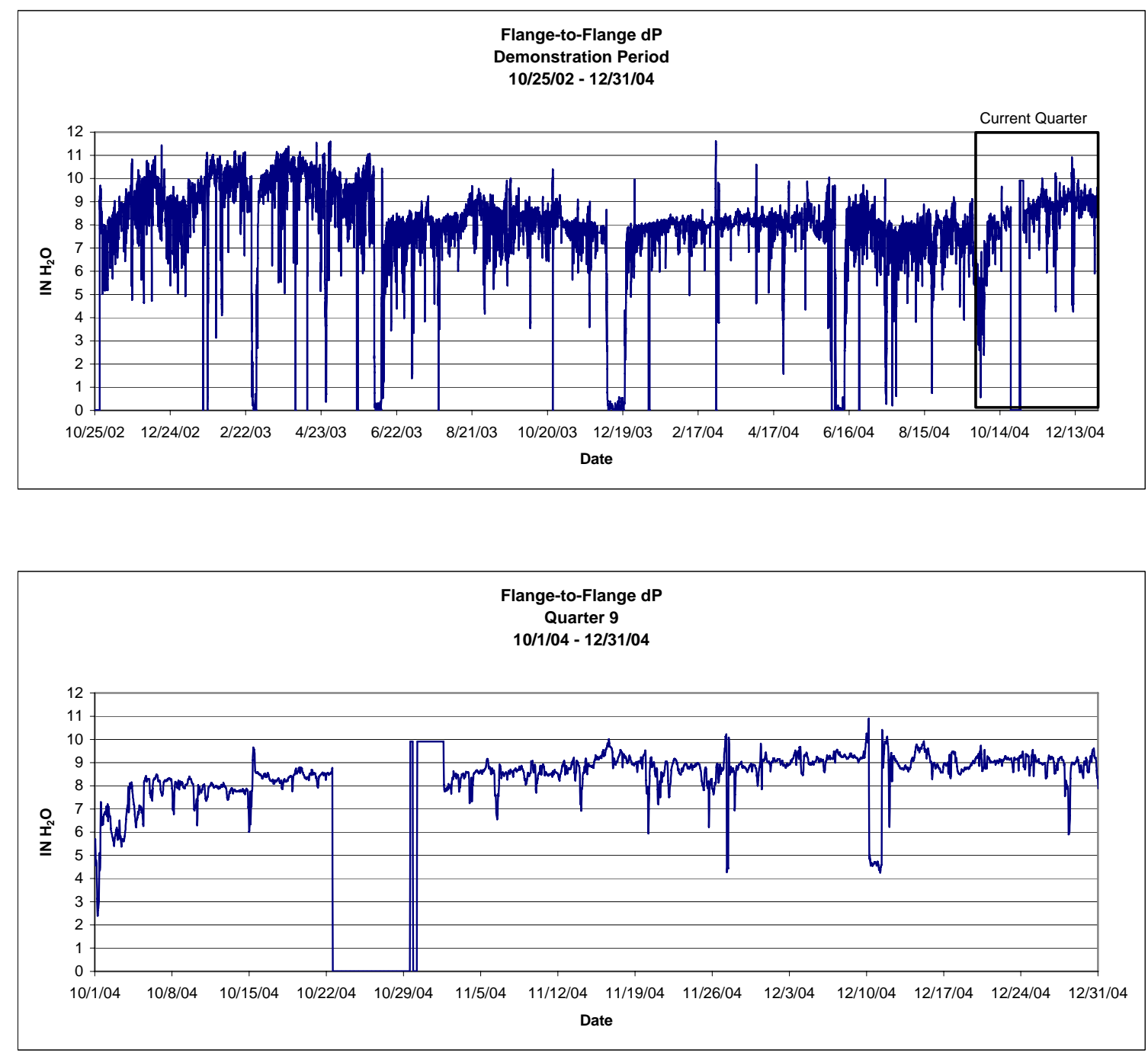


\section{B7 Air-to-Cloth Ratio}
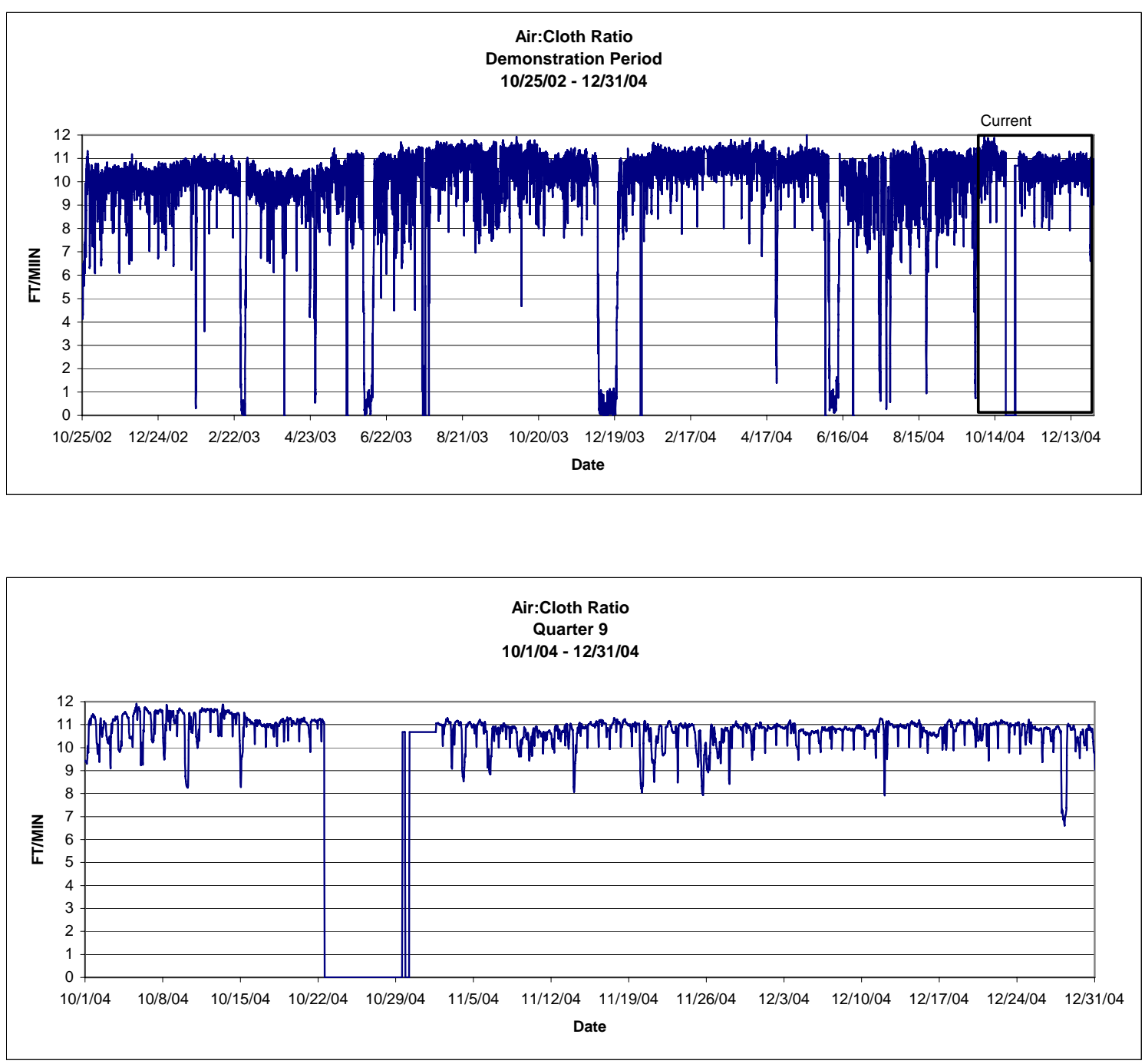


\section{B8 Opacity}
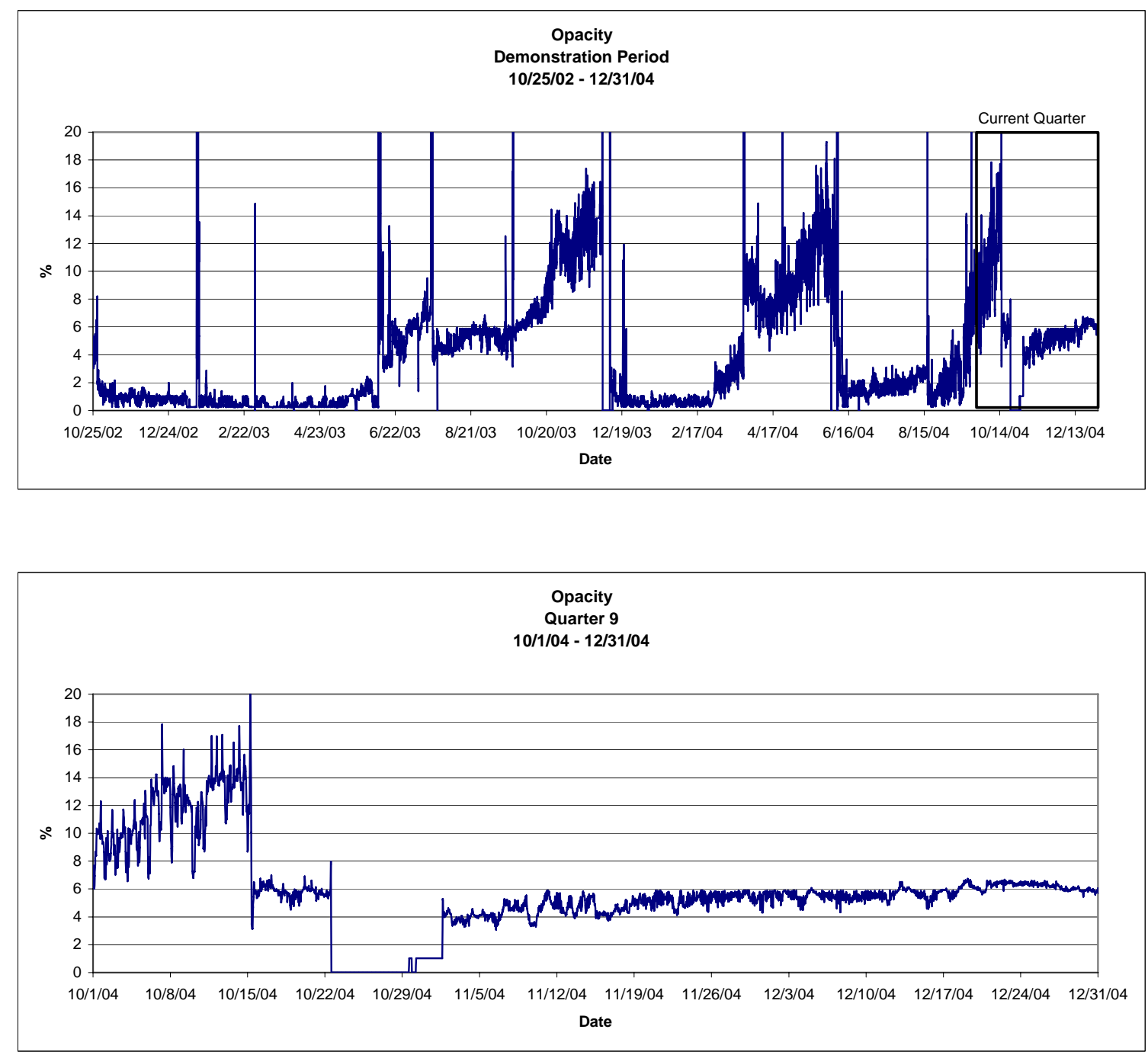


\section{B9 $\mathrm{NO}_{\mathrm{X}}$ Emissions}
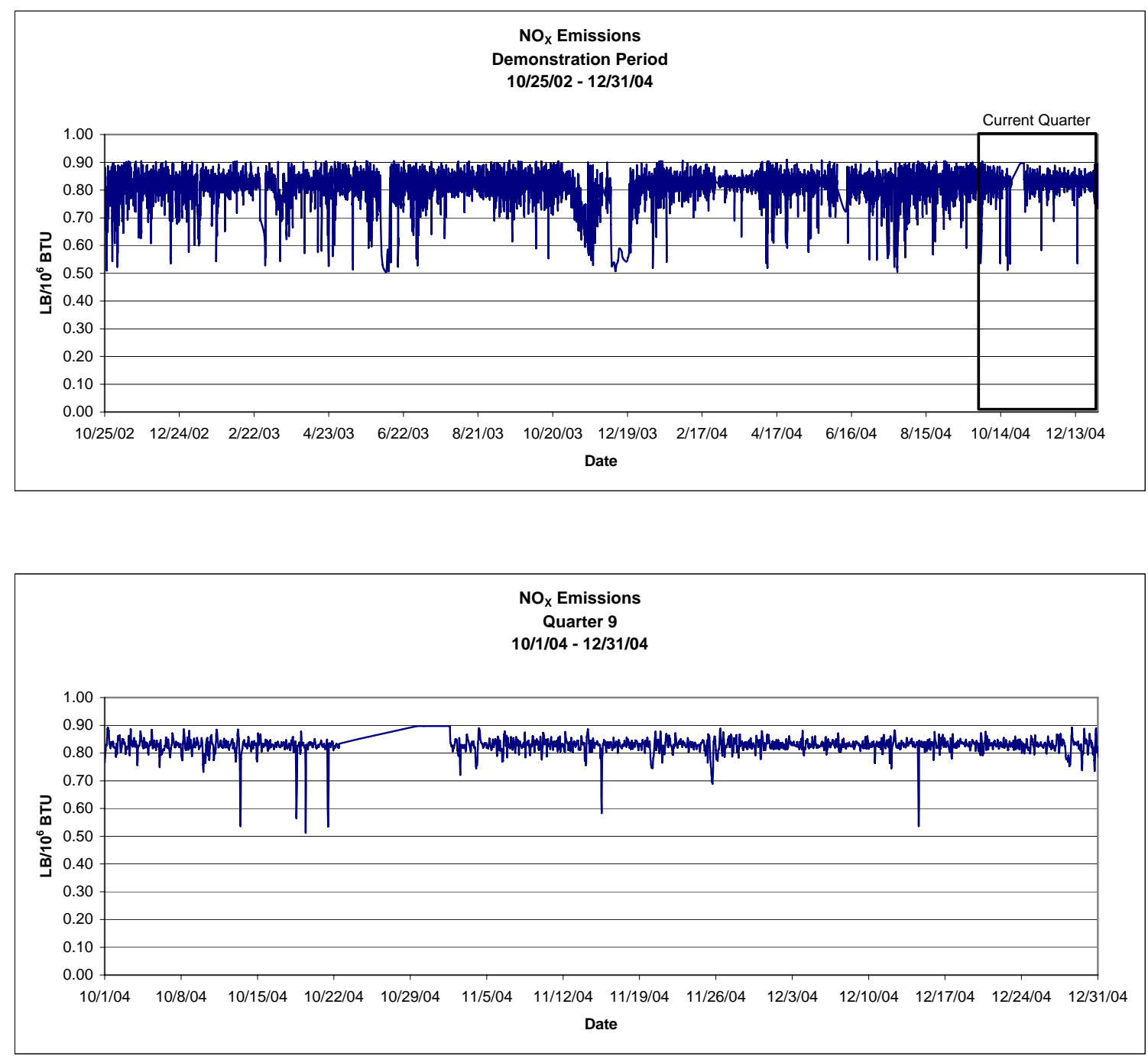


\section{$\mathrm{B10} \mathrm{SO}_{2}$ Emissions}
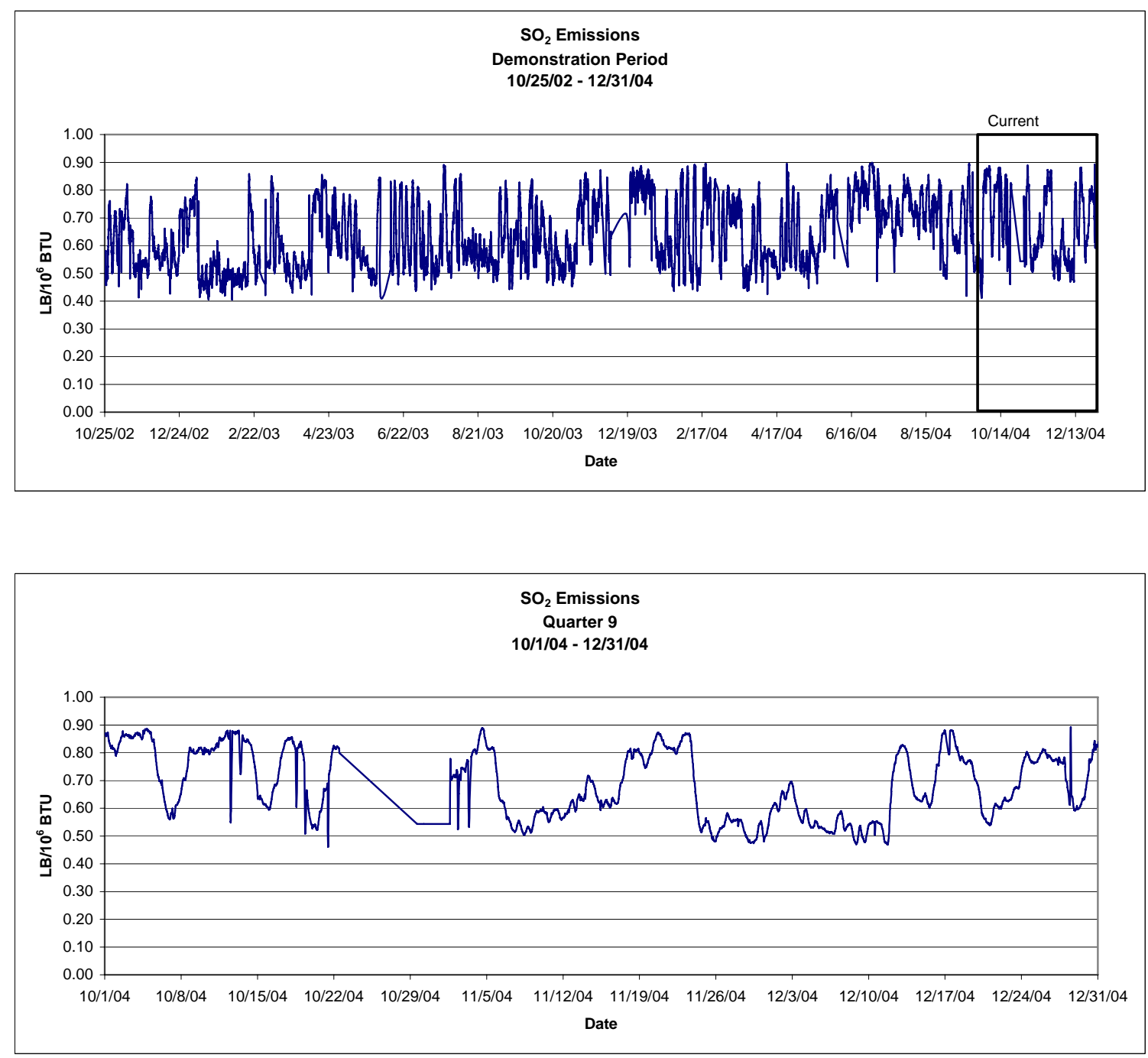


\section{B11 Outlet Gas Temperature}
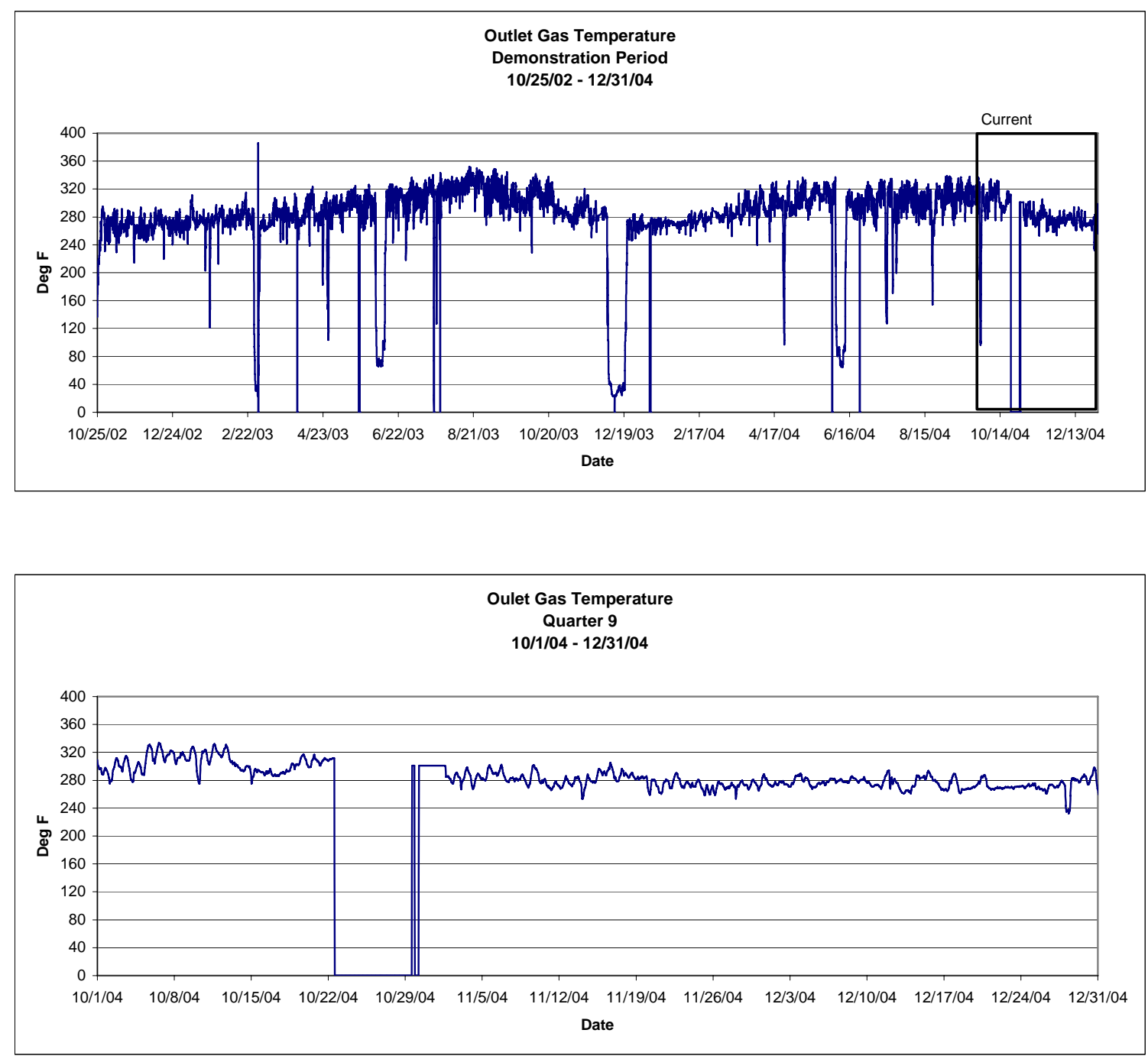


\section{B12 Outlet Pressure}
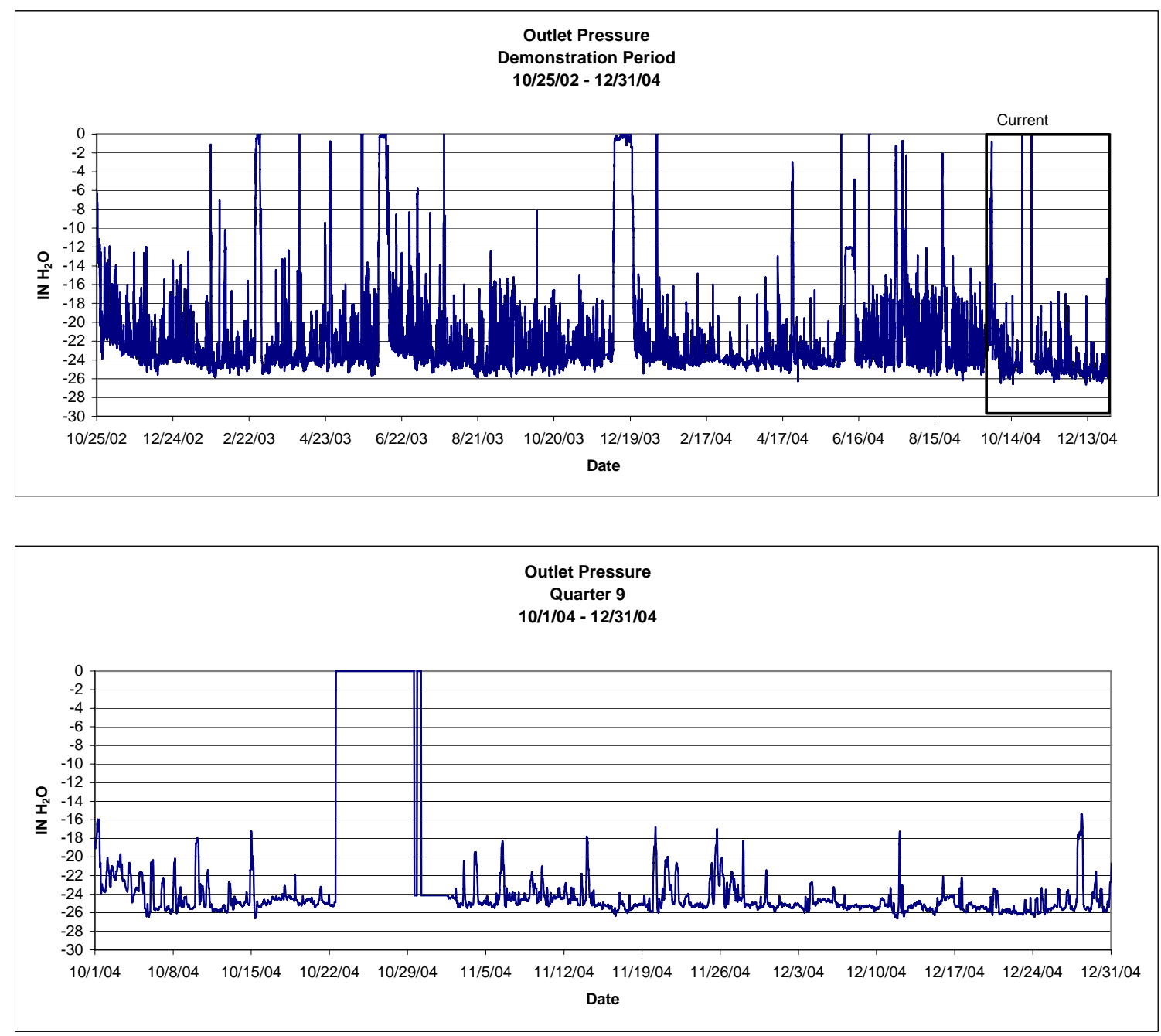


\section{B13 Temperature per Chamber}
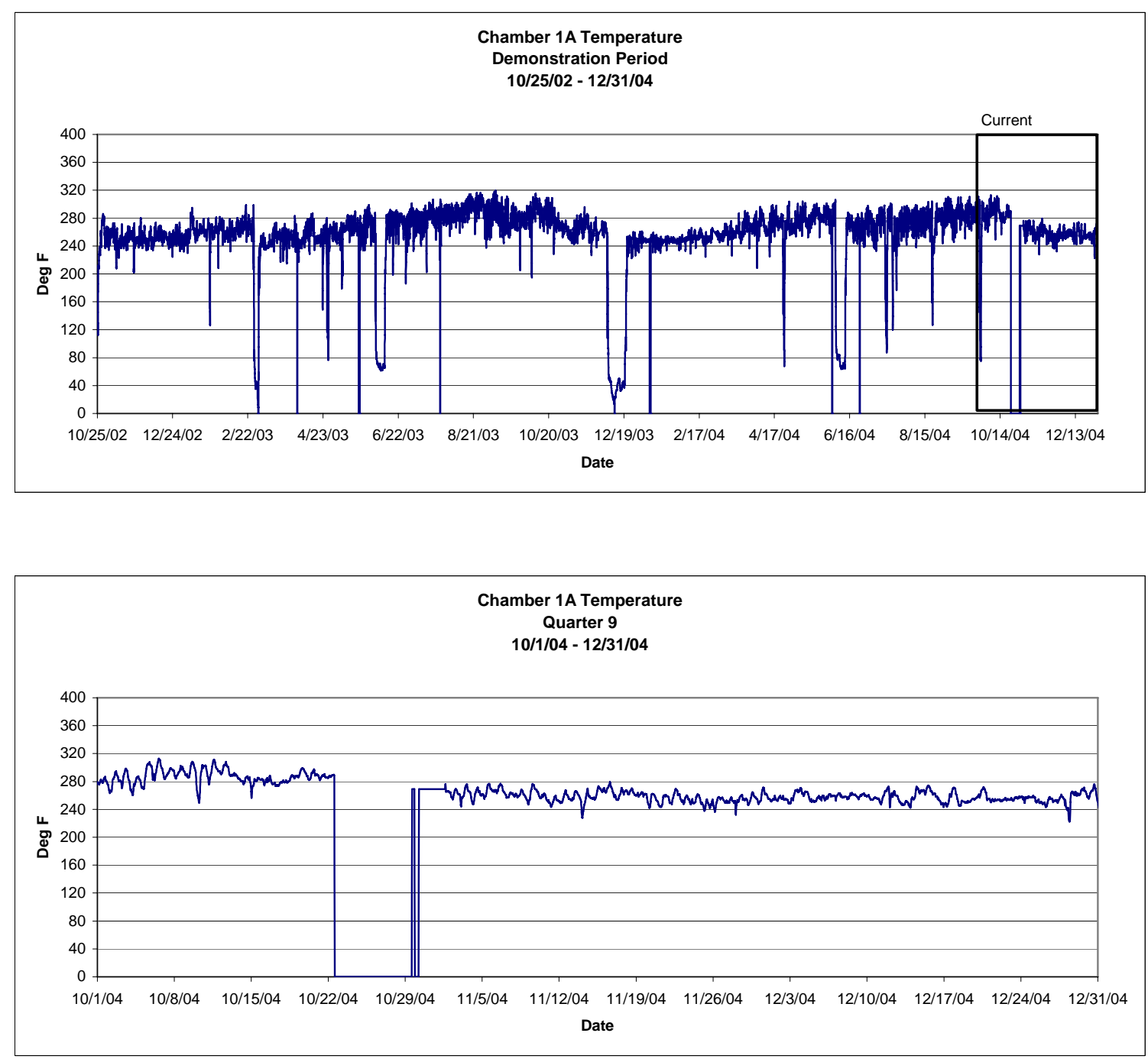

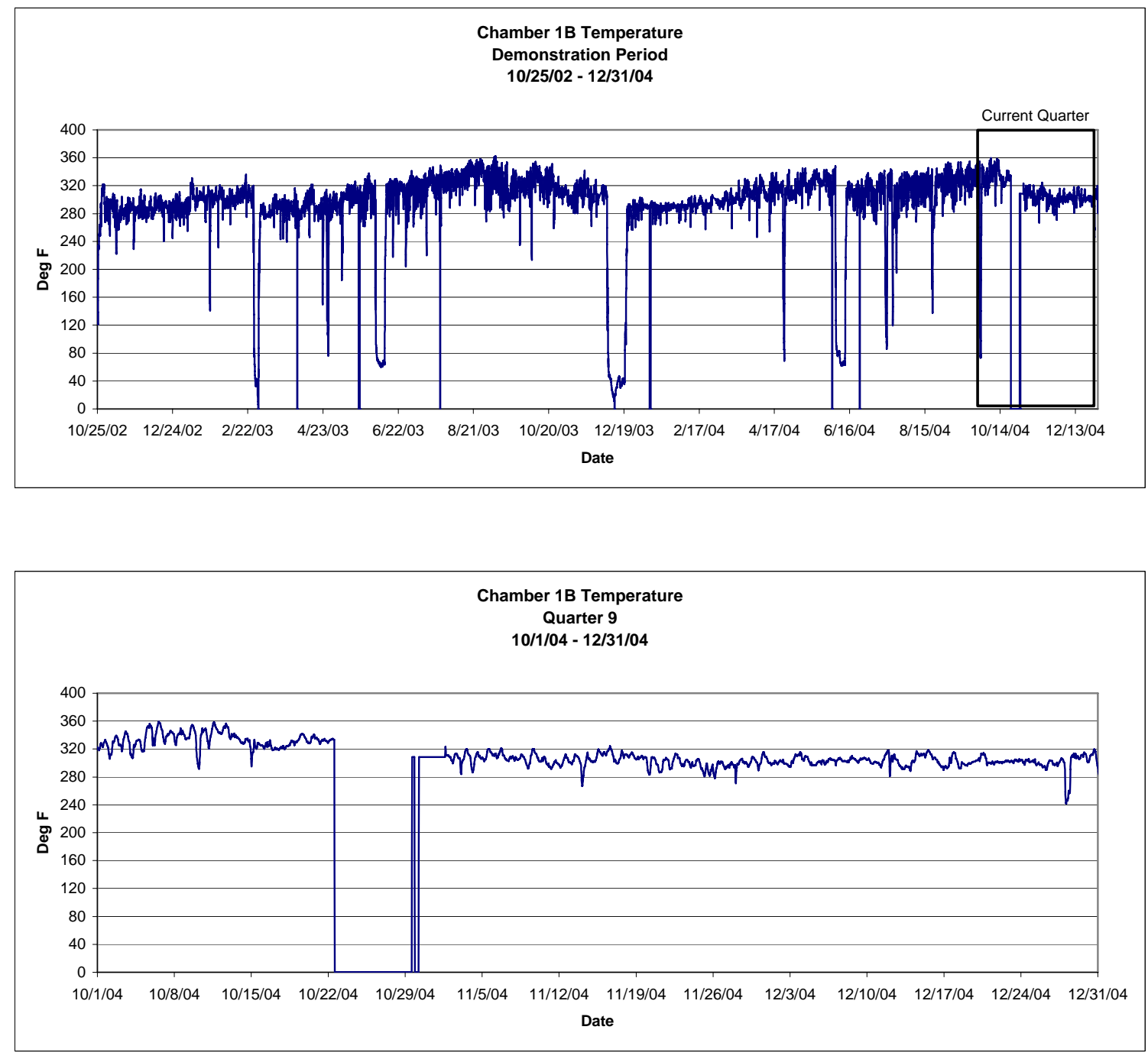

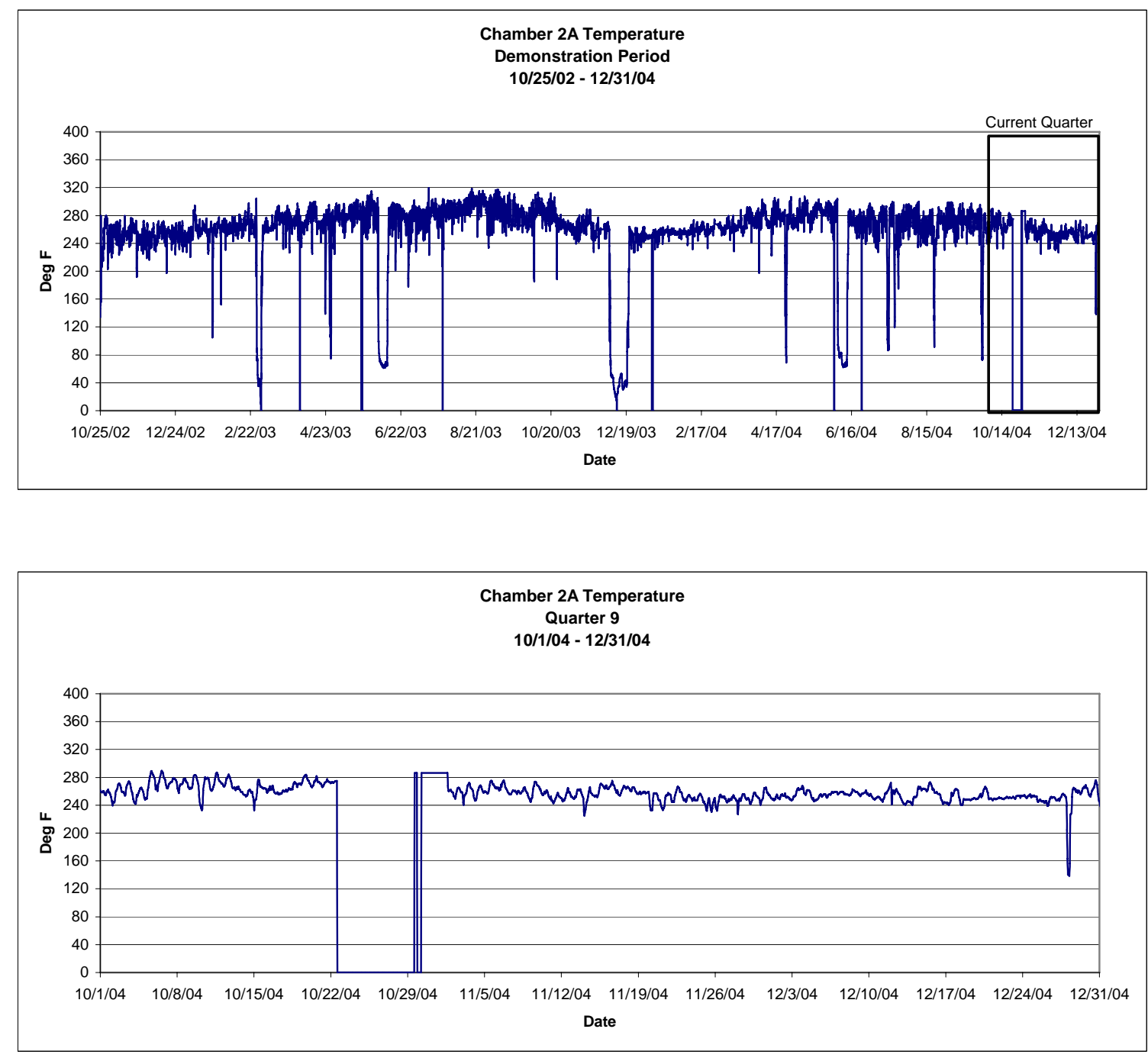

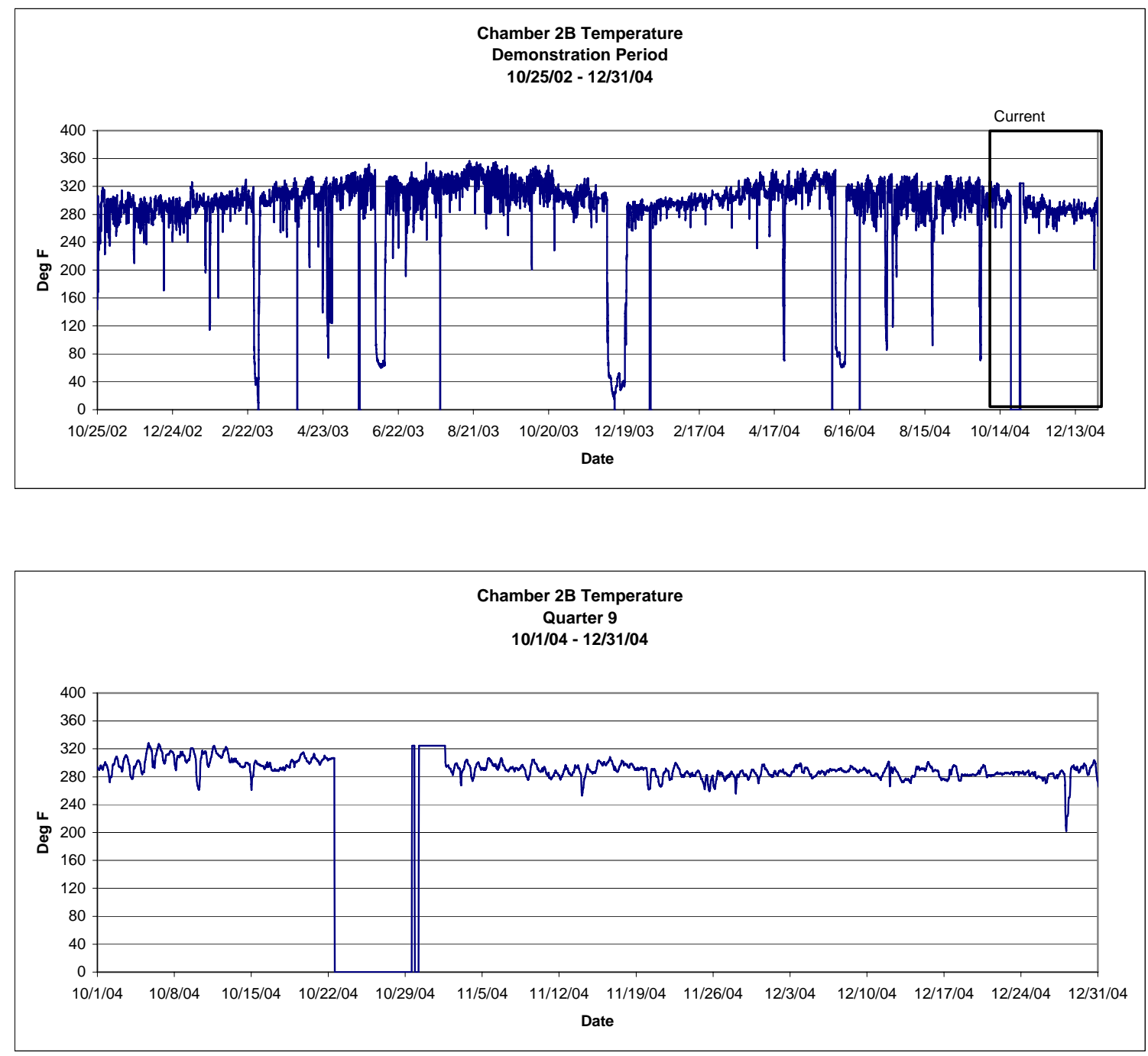
B14 Fuel Burn Record

\begin{tabular}{|c|c|c|c|c|c|c|c|c|}
\hline \multirow[b]{2}{*}{ DATE } & \multirow[b]{2}{*}{ Coal } & \multicolumn{5}{|c|}{$\begin{array}{c}\text { BIG STONE PLANT } \\
\text { FUEL BURN RECORD - page } 1 \\
\text { Oct-02 }\end{array}$} & \multirow[b]{2}{*}{$\begin{array}{l}\text { Canvas } \\
\text { Belting }\end{array}$} & \multirow[b]{2}{*}{$\begin{array}{l}\text { Plastic } \\
\text { Chips }\end{array}$} \\
\hline & & P. Coke & TDF & $\begin{array}{l}\text { Waste } \\
\text { Seeds }\end{array}$ & Toner & $\begin{array}{l}\text { Gran. } \\
\text { Insul. }\end{array}$ & & \\
\hline & (Tons) & (Tons) & (Tons) & (Tons) & (Tons) & (Tons) & (Tons) & (Tons) \\
\hline 1-Oct-02 & 0.00 & 0.00 & 0.00 & 0.00 & 0.00 & 0.00 & 0.00 & 0.00 \\
\hline 2-Oct-02 & 0.00 & 0.00 & 0.00 & 0.00 & 0.00 & 0.00 & 0.00 & 0.00 \\
\hline 3-Oct-02 & 0.00 & 0.00 & 0.00 & 0.00 & 0.00 & 0.00 & 0.00 & 0.00 \\
\hline 4-Oct-02 & 0.00 & 0.00 & 0.00 & 0.00 & 0.00 & 0.00 & 0.00 & 0.00 \\
\hline 5-Oct-02 & 0.00 & 0.00 & 0.00 & 0.00 & 0.00 & 0.00 & 0.00 & 0.00 \\
\hline 6-Oct-02 & 0.00 & 0.00 & 0.00 & 0.00 & 0.00 & 0.00 & 0.00 & 0.00 \\
\hline 7-Oct-02 & 0.00 & 0.00 & 0.00 & 0.00 & 0.00 & 0.00 & 0.00 & 0.00 \\
\hline 8-Oct-02 & 0.00 & 0.00 & 0.00 & 0.00 & 0.00 & 0.00 & 0.00 & 0.00 \\
\hline 9-Oct-02 & 0.00 & 0.00 & 0.00 & 0.00 & 0.00 & 0.00 & 0.00 & 0.00 \\
\hline $10-$ Oct-02 & 0.00 & 0.00 & 0.00 & 0.00 & 0.00 & 0.00 & 0.00 & 0.00 \\
\hline 11 -Oct-02 & 0.00 & 0.00 & 0.00 & 0.00 & 0.00 & 0.00 & 0.00 & 0.00 \\
\hline $12-$-Oct-02 & 0.00 & 0.00 & 0.00 & 0.00 & 0.00 & 0.00 & 0.00 & 0.00 \\
\hline 13 -Oct-02 & 0.00 & 0.00 & 0.00 & 0.00 & 0.00 & 0.00 & 0.00 & 0.00 \\
\hline $14-O c t-02$ & 0.00 & 0.00 & 0.00 & 0.00 & 0.00 & 0.00 & 0.00 & 0.00 \\
\hline 15 -Oct-02 & 0.00 & 0.00 & 0.00 & 0.00 & 0.00 & 0.00 & 0.00 & 0.00 \\
\hline 16 -Oct-02 & 0.00 & 0.00 & 0.00 & 0.00 & 0.00 & 0.00 & 0.00 & 0.00 \\
\hline 17 -Oct-02 & 0.00 & 0.00 & 0.00 & 0.00 & 0.00 & 0.00 & 0.00 & 0.00 \\
\hline 18 -Oct-02 & 0.00 & 0.00 & 0.00 & 0.00 & 0.00 & 0.00 & 0.00 & 0.00 \\
\hline 19-Oct-02 & 0.00 & 0.00 & 0.00 & 0.00 & 0.00 & 0.00 & 0.00 & 0.00 \\
\hline 20 -Oct-02 & 0.00 & 0.00 & 0.00 & 0.00 & 0.00 & 0.00 & 0.00 & 0.00 \\
\hline 21-Oct-02 & 0.00 & 0.00 & 0.00 & 0.00 & 0.00 & 0.00 & 0.00 & 0.00 \\
\hline 22 -Oct-02 & 0.00 & 0.00 & 0.00 & 0.00 & 0.00 & 0.00 & 0.00 & 0.00 \\
\hline 23 -Oct-02 & 0.00 & 0.00 & 0.00 & 0.00 & 0.00 & 0.00 & 0.00 & 0.00 \\
\hline $24-$ Oct- 02 & 24.30 & 0.00 & 0.00 & 0.00 & 0.00 & 0.00 & 0.00 & 0.00 \\
\hline 25 -Oct- 02 & $1,245.30$ & 0.00 & 0.00 & 0.00 & 0.00 & 0.00 & 0.00 & 0.00 \\
\hline 26-Oct-02 & $3,534.20$ & 0.00 & 0.00 & 0.00 & 0.00 & 0.00 & 0.00 & 0.00 \\
\hline $27-$ Oct- 02 & $5,058.80$ & 0.00 & 0.00 & 0.00 & 0.00 & 0.00 & 0.00 & 0.00 \\
\hline 28-Oct-02 & $5,969.60$ & 0.00 & 0.00 & 0.00 & 0.00 & 0.00 & 0.00 & 0.00 \\
\hline $29-$-Oct- 02 & $6,442.60$ & 0.00 & 0.00 & 0.00 & 0.00 & 0.00 & 0.00 & 0.00 \\
\hline $30-$-Oct- 02 & $6,363.10$ & 0.00 & 0.00 & 0.00 & 0.00 & 0.00 & 0.00 & 0.00 \\
\hline 31-Oct-02 & $5,619.90$ & 0.00 & 0.00 & 0.00 & 0.00 & 0.00 & 0.00 & 0.00 \\
\hline Adjustment & 0.00 & & & & & & & \\
\hline Total Burned & $34,257.80$ & 0.00 & 0.00 & 0.00 & 0.00 & 0.00 & 0.00 & 0.00 \\
\hline Total Delivered & $56,477.36$ & 0.00 & 22.39 & 189.33 & 0.00 & 0.00 & 0.00 & 0.00 \\
\hline HHV & 8538 & 0 & 15000 & 7187 & 0 & 0 & 0 & 0 \\
\hline$\%$ Ash & $4.41 \%$ & $0.00 \%$ & $7.04 \%$ & $1.10 \%$ & $0.00 \%$ & $0.00 \%$ & $0.00 \%$ & $0.00 \%$ \\
\hline Tons Ash & $1,511.61$ & 0.00 & 51.48 & 12.52 & 0.00 & 0.00 & 0.00 & 0.00 \\
\hline
\end{tabular}




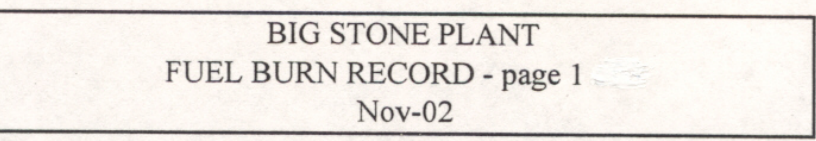

\begin{tabular}{|c|c|c|c|c|c|c|c|c|}
\hline DATE & Coal & P. Coke & TDF & $\begin{array}{l}\text { Waste } \\
\text { Seeds }\end{array}$ & Toner & $\begin{array}{l}\text { Gran. } \\
\text { Insul. }\end{array}$ & $\begin{array}{l}\text { Canvas } \\
\text { Belting } \\
\end{array}$ & $\begin{array}{r}\text { Plastic } \\
\text { Chips } \\
\end{array}$ \\
\hline & (Tons) & (Tons) & (Tons) & (Tons) & (Tons) & (Tons) & (Tons) & (Tons) \\
\hline $1-N o v-02$ & $5,987.98$ & 0.00 & 22.39 & 189.33 & 0.00 & 0.00 & 0.00 & 0.00 \\
\hline $2-\mathrm{Nov}-02$ & $6,001.00$ & 0.00 & 0.00 & 0.00 & 0.00 & 0.00 & 0.00 & 0.00 \\
\hline $3-N o v-02$ & $5,640.70$ & 0.00 & 0.00 & 0.00 & 0.00 & 0.00 & 0.00 & 0.00 \\
\hline 4-Nov-02 & $4,601.40$ & 0.00 & 90.01 & 979.79 & 0.00 & 0.00 & 0.00 & 0.00 \\
\hline $5-$ Nov- 02 & $5,871.32$ & 0.00 & 22.61 & 36.17 & 0.00 & 0.00 & 0.00 & 0.00 \\
\hline $6-N o v-02$ & $6,181.69$ & 0.00 & 45.36 & 47.65 & 0.00 & 0.00 & 0.00 & 0.00 \\
\hline $7-$ Nov- 02 & $6,062.10$ & 0.00 & 0.00 & 0.00 & 0.00 & 0.00 & 0.00 & 0.00 \\
\hline 8 -Nov-02 & $5,518.75$ & 0.00 & 249.68 & 98.17 & 0.00 & 0.00 & 0.00 & 0.00 \\
\hline $9-N o v-02$ & $5,418.00$ & 0.00 & 0.00 & 0.00 & 0.00 & 0.00 & 0.00 & 0.00 \\
\hline $10-$ Nov-02 & $6,080.30$ & 0.00 & 0.00 & 0.00 & 0.00 & 0.00 & 0.00 & 0.00 \\
\hline 11-Nov-02 & $6,315.50$ & 0.00 & 0.00 & 0.00 & 0.00 & 0.00 & 0.00 & 0.00 \\
\hline 12-Nov-02 & $6,169.84$ & 0.00 & 45.18 & 24.18 & 0.00 & 0.00 & 0.00 & 0.00 \\
\hline $13-$ Nov-02 & $6,139.55$ & 0.00 & 91.71 & 23.04 & 0.00 & 0.00 & 0.00 & 0.00 \\
\hline 14-Nov-02 & $6,305.74$ & 0.00 & 117.44 & 48.82 & 0.00 & 0.00 & 0.00 & 0.00 \\
\hline $15-$ Nov-02 & $6,202.35$ & 0.00 & 46.40 & 84.85 & 0.00 & 0.00 & 0.00 & 0.00 \\
\hline $16-$ Nov-02 & $6,510.70$ & 0.00 & 0.00 & 0.00 & 0.00 & 0.00 & 0.00 & 0.00 \\
\hline 17-Nov-02 & $6,185.30$ & 0.00 & 0.00 & 0.00 & 0.00 & 0.00 & 0.00 & 0.00 \\
\hline 18 -Nov-02 & $5,796.69$ & 0.00 & 43.73 & 160.38 & 0.00 & 0.00 & 0.00 & 0.00 \\
\hline 19-Nov-02 & $6,013.24$ & 0.00 & 22.87 & 194.89 & 0.00 & 0.00 & 0.00 & 0.00 \\
\hline 20-Nov-02 & $6,289.60$ & 0.00 & 0.00 & 0.00 & 0.00 & 0.00 & 0.00 & 0.00 \\
\hline $21-\mathrm{Nov}-02$ & $6,364.60$ & 0.00 & 0.00 & 0.00 & 0.00 & 0.00 & 0.00 & 0.00 \\
\hline 22-Nov-02 & $6,037.07$ & 0.00 & 139.47 & 179.66 & 0.00 & 0.00 & 0.00 & 0.00 \\
\hline $23-$ Nov-02 & $4,780.70$ & 0.00 & 0.00 & 0.00 & 0.00 & 0.00 & 0.00 & 0.00 \\
\hline 24-Nov-02 & $6,275.70$ & 0.00 & 0.00 & 0.00 & 0.00 & 0.00 & 0.00 & 0.00 \\
\hline 25-Nov-02 & $6,341.81$ & 0.00 & 22.79 & 0.00 & 26.60 & 0.00 & 0.00 & 0.00 \\
\hline 26-Nov-02 & $6,248.70$ & 0.00 & 0.00 & 0.00 & 0.00 & 0.00 & 0.00 & 0.00 \\
\hline 27-Nov-02 & $6,151.53$ & 0.00 & 0.00 & 78.47 & 0.00 & 0.00 & 0.00 & 0.00 \\
\hline 28-Nov-02 & $5,913.10$ & 0.00 & 0.00 & 0.00 & 0.00 & 0.00 & 0.00 & 0.00 \\
\hline 29-Nov-02 & $5,651.60$ & 0.00 & 45.50 & 0.00 & 0.00 & 0.00 & 0.00 & 0.00 \\
\hline $30-$ Nov-02 & $6,338.20$ & 0.00 & 0.00 & 0.00 & 0.00 & 0.00 & 0.00 & 0.00 \\
\hline Adjustment & $5,000.00$ & & & & & & & \\
\hline Total Burned & $184,394.76$ & 0.00 & $1,005.14$ & $2,145.40$ & 26.60 & 0.00 & 0.00 & 0.00 \\
\hline Total Delivered & $193,968.54$ & 0.00 & 982.75 & $1,956.07$ & 26.60 & 0.00 & 0.00 & 0.00 \\
\hline HHV & 8534 & 0 & 15000 & 7187 & 16932 & 0 & & \\
\hline$\%$ Ash & $4.73 \%$ & $0.00 \%$ & $7.04 \%$ & $1.10 \%$ & $0.00 \%$ & $0.00 \%$ & & \\
\hline Tons Ash & $8,715.21$ & 0.00 & 70.76 & 23.60 & 0.00 & 0.00 & 0.00 & 0.00 \\
\hline
\end{tabular}


BIG STONE PLANT

FUEL BURN RECORD - page 1

Dec-02

\begin{tabular}{|c|c|c|c|c|c|c|c|c|}
\hline DATE & Coal & P. Coke & TDF & $\begin{array}{l}\text { Waste } \\
\text { Seeds }\end{array}$ & Toner & $\begin{array}{l}\text { Gran. } \\
\text { Insul. }\end{array}$ & $\begin{array}{l}\text { Canvas } \\
\text { Belting }\end{array}$ & $\begin{array}{r}\text { Plastic } \\
\text { Chips } \\
\end{array}$ \\
\hline & (Tons) & (Tons) & (Tons) & (Tons) & (Tons) & (Tons) & (Tons) & (Tons) \\
\hline 1-Dec-02 & $5,707.30$ & 0.00 & 0.00 & 0.00 & 0.00 & 0.00 & 0.00 & 0.00 \\
\hline 2-Dec-02 & $6,179.46$ & 0.00 & 46.14 & 0.00 & 0.00 & 0.00 & 0.00 & 0.00 \\
\hline 3-Dec-02 & $5,916.85$ & 0.00 & 43.80 & 97.85 & 0.00 & 0.00 & 0.00 & 0.00 \\
\hline 4-Dec-02 & $6,348.34$ & 0.00 & 22.26 & 0.00 & 0.00 & 0.00 & 0.00 & 0.00 \\
\hline 5-Dec-02 & $6,340.69$ & 0.00 & 20.11 & 0.00 & 0.00 & 0.00 & 0.00 & 0.00 \\
\hline 6-Dec-02 & $6,484.34$ & 0.00 & 46.06 & 0.00 & 0.00 & 0.00 & 0.00 & 0.00 \\
\hline 7-Dec-02 & $6,378.70$ & 0.00 & 0.00 & 0.00 & 0.00 & 0.00 & 0.00 & 0.00 \\
\hline 8-Dec-02 & $6,530.40$ & 0.00 & 0.00 & 0.00 & 0.00 & 0.00 & 0.00 & 0.00 \\
\hline 9-Dec-02 & $6,317.27$ & 0.00 & 43.53 & 0.00 & 0.00 & 0.00 & 0.00 & 0.00 \\
\hline 10 -Dec-02 & $6,267.33$ & 0.00 & 45.67 & 26.00 & 0.00 & 0.00 & 0.00 & 0.00 \\
\hline 11 -Dec-02 & $6,394.00$ & 0.00 & 94.30 & 0.00 & 0.00 & 0.00 & 0.00 & 0.00 \\
\hline 12-Dec-02 & $6,523.60$ & 0.00 & 0.00 & 0.00 & 0.00 & 0.00 & 0.00 & 0.00 \\
\hline 13-Dec-02 & $6,257.51$ & 0.00 & 93.99 & 0.00 & 0.00 & 0.00 & 0.00 & 0.00 \\
\hline 14-Dec-02 & $6,373.00$ & 0.00 & 0.00 & 0.00 & 0.00 & 0.00 & 0.00 & 0.00 \\
\hline 15 -Dec-02 & $6,351.50$ & 0.00 & 0.00 & 0.00 & 0.00 & 0.00 & 0.00 & 0.00 \\
\hline 16 -Dec-02 & $6,274.49$ & 0.00 & 70.37 & 17.64 & 0.00 & 0.00 & 0.00 & 0.00 \\
\hline 17-Dec-02 & $5,785.53$ & 0.00 & 45.77 & 0.00 & 0.00 & 0.00 & 0.00 & 0.00 \\
\hline 18-Dec-02 & $6,368.68$ & 0.00 & 47.44 & 47.88 & 0.00 & 0.00 & 0.00 & 0.00 \\
\hline 19-Dec-02 & $6,374.26$ & 0.00 & 24.14 & 48.00 & 0.00 & 0.00 & 0.00 & 0.00 \\
\hline 20-Dec-02 & $6,453.80$ & 0.00 & 0.00 & 0.00 & 0.00 & 0.00 & 0.00 & 0.00 \\
\hline 21-Dec-02 & $6,289.90$ & 0.00 & 0.00 & 0.00 & 0.00 & 0.00 & 0.00 & 0.00 \\
\hline 22-Dec-02 & $6,072.40$ & 0.00 & 0.00 & 0.00 & 0.00 & 0.00 & 0.00 & 0.00 \\
\hline 23-Dec-02 & $6,171.47$ & 0.00 & 64.61 & 71.82 & 0.00 & 0.00 & 0.00 & 0.00 \\
\hline 24-Dec-02 & $6,183.60$ & 0.00 & 0.00 & 0.00 & 0.00 & 0.00 & 0.00 & 0.00 \\
\hline $25-$ Dec-02 & $6,604.60$ & 0.00 & 0.00 & 0.00 & 0.00 & 0.00 & 0.00 & 0.00 \\
\hline 26-Dec-02 & $6,236.90$ & 0.00 & 0.00 & 0.00 & 0.00 & 0.00 & 0.00 & 0.00 \\
\hline 27-Dec-02 & $6,056.94$ & 0.00 & 44.89 & 25.47 & 0.00 & 0.00 & 0.00 & 0.00 \\
\hline 28-Dec-02 & $6,240.40$ & 0.00 & 0.00 & 0.00 & 0.00 & 0.00 & 0.00 & 0.00 \\
\hline 29-Dec-02 & $6,168.90$ & 0.00 & 0.00 & 0.00 & 0.00 & 0.00 & 0.00 & 0.00 \\
\hline 30-Dec-02 & $5,950.50$ & 0.00 & 0.00 & 0.00 & 0.00 & 0.00 & 0.00 & 0.00 \\
\hline 31-Dec-02 & $5,951.26$ & 0.00 & 116.11 & 75.03 & 0.00 & 0.00 & 0.00 & 0.00 \\
\hline Adjustment & $3,000.00$ & & & & & & & \\
\hline Total Burned & $196,553.92$ & 0.00 & 869.19 & 409.69 & 0.00 & 0.00 & 0.00 & 0.00 \\
\hline Total Delivered & $195,368.84$ & & 869.19 & 409.69 & 0.00 & & & 0.00 \\
\hline HHV & 8533 & & 15000 & 7187 & 0 & 0 & & \\
\hline$\%$ Ash & $4.71 \%$ & & $7.04 \%$ & $1.10 \%$ & $0.00 \%$ & $0.00 \%$ & & \\
\hline Tons Ash & $9,254.39$ & 0.00 & 70.76 & 23.60 & 0.00 & 0.00 & 0.00 & 0.00 \\
\hline
\end{tabular}




\begin{tabular}{|c|c|c|c|c|c|c|c|c|}
\hline \multirow[b]{2}{*}{ DATE } & \multirow[b]{2}{*}{ Coal } & \multicolumn{5}{|c|}{$\begin{array}{c}\text { BIG STONE PLANT } \\
\text { FUEL BURN RECORD - page } 1 \\
\text { Jan-03 }\end{array}$} & \multirow[b]{2}{*}{$\begin{array}{l}\text { Canvas } \\
\text { Belting } \\
\end{array}$} & \multirow[b]{2}{*}{$\begin{array}{l}\text { Plastic } \\
\text { Chips }\end{array}$} \\
\hline & & P. Coke & TDF & $\begin{array}{l}\text { Waste } \\
\text { Seeds }\end{array}$ & Toner & $\begin{array}{l}\text { Gran. } \\
\text { Insul. }\end{array}$ & & \\
\hline & (Tons) & (Tons) & (Tons) & (Tons) & (Tons) & (Tons) & (Tons) & (Tons) \\
\hline 1-Jan-03 & $6,184.60$ & 0.00 & 0.00 & 0.00 & 0.00 & 0.00 & 0.00 & 0.00 \\
\hline 2-Jan-03 & $6,223.02$ & 0.00 & 22.37 & 62.31 & 0.00 & 0.00 & 0.00 & 0.00 \\
\hline 3-Jan-03 & $6,319.77$ & 0.00 & 45.77 & 148.16 & 0.00 & 0.00 & 0.00 & 0.00 \\
\hline 4-Jan-03 & $6,287.80$ & 0.00 & 0.00 & 0.00 & 0.00 & 0.00 & 0.00 & 0.00 \\
\hline 5-Jan-03 & $6,049.40$ & 0.00 & 0.00 & 0.00 & 0.00 & 0.00 & 0.00 & 0.00 \\
\hline 6-Jan-03 & $5,943.97$ & 0.00 & 47.26 & 431.57 & 0.00 & 0.00 & 0.00 & 0.00 \\
\hline 7-Jan-03 & $5,505.74$ & 0.00 & 48.59 & 707.47 & 0.00 & 0.00 & 0.00 & 0.00 \\
\hline 8-Jan-03 & $5,576.26$ & 0.00 & 0.00 & 685.74 & 0.00 & 0.00 & 0.00 & 0.00 \\
\hline 9-Jan-03 & $5,577.80$ & 0.00 & 0.00 & 600.00 & 0.00 & 0.00 & 0.00 & 0.00 \\
\hline 10-Jan-03 & $6,179.08$ & 0.00 & 113.66 & 123.16 & 0.00 & 0.00 & 0.00 & 0.00 \\
\hline 11-Jan-03 & $6,298.00$ & 0.00 & 0.00 & 0.00 & 0.00 & 0.00 & 0.00 & 0.00 \\
\hline 12-Jan-03 & $6,378.60$ & 0.00 & 0.00 & 0.00 & 0.00 & 0.00 & 0.00 & 0.00 \\
\hline 13-Jan-03 & $6,490.30$ & 0.00 & 0.00 & 0.00 & 0.00 & 0.00 & 0.00 & 0.00 \\
\hline 14-Jan-03 & $5,816.07$ & 0.00 & 85.58 & 649.45 & 0.00 & 0.00 & 0.00 & 0.00 \\
\hline 15-Jan-03 & $5,903.21$ & 0.00 & 22.25 & 501.34 & 0.00 & 0.00 & 0.00 & 0.00 \\
\hline 16-Jan-03 & $5,714.59$ & 0.00 & 22.39 & 607.02 & 0.00 & 0.00 & 0.00 & 0.00 \\
\hline 17-Jan-03 & $5,764.70$ & 0.00 & 21.32 & 650.88 & 0.00 & 0.00 & 0.00 & 0.00 \\
\hline 18-Jan-03 & $6,306.50$ & 0.00 & 0.00 & 0.00 & 0.00 & 0.00 & 0.00 & 0.00 \\
\hline 19-Jan-03 & $4,924.90$ & 0.00 & 0.00 & 0.00 & 0.00 & 0.00 & 0.00 & 0.00 \\
\hline 20-Jan-03 & $5,896.70$ & 0.00 & 89.30 & 430.20 & 0.00 & 0.00 & 0.00 & 0.00 \\
\hline 21-Jan-03 & $6,340.98$ & 0.00 & 0.00 & 76.42 & 0.00 & 0.00 & 0.00 & 0.00 \\
\hline 22-Jan-03 & $3,694.64$ & 0.00 & 85.16 & 0.00 & 0.00 & 0.00 & 0.00 & 0.00 \\
\hline 23-Jan-03 & $5,248.81$ & 0.00 & 0.00 & 267.79 & 0.00 & 0.00 & 0.00 & 0.00 \\
\hline 24-Jan-03 & $6,305.73$ & 0.00 & 22.79 & 258.18 & 0.00 & 0.00 & 0.00 & 0.00 \\
\hline 25-Jan-03 & $6,292.92$ & 0.00 & 0.00 & 258.18 & 0.00 & 0.00 & 0.00 & 0.00 \\
\hline 26-Jan-03 & $6,222.60$ & 0.00 & 0.00 & 258.20 & 0.00 & 0.00 & 0.00 & 0.00 \\
\hline 27-Jan-03 & $5,989.95$ & 0.00 & 0.00 & 269.15 & 0.00 & 0.00 & 0.00 & 0.00 \\
\hline 28-Jan-03 & $5,962.19$ & 0.00 & 66.12 & 211.39 & 0.00 & 0.00 & 0.00 & 0.00 \\
\hline 29-Jan-03 & $5,537.96$ & 0.00 & 45.82 & 293.22 & 0.00 & 0.00 & 0.00 & 0.00 \\
\hline 30-Jan-03 & $6,049.60$ & 0.00 & 60.00 & 200.00 & 0.00 & 0.00 & 0.00 & 0.00 \\
\hline 31-Jan-03 & $5,930.53$ & 0.00 & 77.47 & 220.00 & 0.00 & 0.00 & 0.00 & 0.00 \\
\hline Adjustment & $3,500.00$ & & & & & & & \\
\hline Total Burned & $186,416.92$ & 0.00 & 875.85 & $7,909.83$ & 0.00 & 0.00 & 0.00 & 0.00 \\
\hline Total Delivered & $177,149.11$ & 0.00 & 875.85 & $8,352.78$ & 0.00 & 0.00 & 0.00 & 0.00 \\
\hline $\mathrm{HHV}$ & 8595 & 0 & 15000 & 9000 & 0 & 0 & 0 & 0 \\
\hline$\%$ Ash & $4.49 \%$ & 0.00 & $7.04 \%$ & $4.00 \%$ & $0.00 \%$ & $0.00 \%$ & $0.00 \%$ & $0.00 \%$ \\
\hline Tons Ash & $8,377.48$ & 0.00 & 61.66 & 316.39 & 0.00 & 0.00 & 0.00 & 0.00 \\
\hline
\end{tabular}




\begin{tabular}{|c|c|c|c|c|c|c|c|c|}
\hline \multirow[b]{2}{*}{ DATE } & \multirow[b]{2}{*}{ Coal } & \multicolumn{5}{|c|}{$\begin{array}{c}\text { BIG STONE PLANT } \\
\text { FUEL BURN RECORD - page } 1 \\
\text { Feb-03 }\end{array}$} & \multirow[b]{2}{*}{$\begin{array}{l}\text { Canvas } \\
\text { Belting }\end{array}$} & \multirow[b]{2}{*}{$\begin{array}{l}\text { Plastic } \\
\text { Chips } \\
\end{array}$} \\
\hline & & P. Coke & TDF & $\begin{array}{l}\text { Waste } \\
\text { Seeds }\end{array}$ & Toner & $\begin{array}{l}\text { Gran. } \\
\text { Insul. }\end{array}$ & & \\
\hline & (Tons) & (Tons) & (Tons) & (Tons) & (Tons) & (Tons) & (Tons) & (Tons) \\
\hline $1-F e b-03$ & $5,984.90$ & 0.00 & 0.00 & 220.00 & 0.00 & 0.00 & 0.00 & 0.00 \\
\hline 2 -Feb- 03 & $5,587.95$ & 0.00 & 0.00 & 222.95 & 0.00 & 0.00 & 0.00 & 0.00 \\
\hline 3-Feb-03 & $6,017.17$ & 0.00 & 45.99 & 159.24 & 0.00 & 0.00 & 0.00 & 0.00 \\
\hline 4-Feb-03 & $5,920.68$ & 0.00 & 45.07 & 417.35 & 0.00 & 0.00 & 0.00 & 0.00 \\
\hline $5-\mathrm{Feb}-03$ & $6,006.06$ & 0.00 & 0.00 & 261.54 & 0.00 & 0.00 & 0.00 & 0.00 \\
\hline 6-Feb-03 & $6,188.40$ & 0.00 & 0.00 & 260.00 & 0.00 & 0.00 & 0.00 & 0.00 \\
\hline 7-Feb-03 & $6,038.76$ & 0.00 & 85.34 & 317.00 & 0.00 & 0.00 & 0.00 & 0.00 \\
\hline 8-Feb-03 & $5,878.50$ & 0.00 & 0.00 & 317.00 & 0.00 & 0.00 & 0.00 & 0.00 \\
\hline 9-Feb-03 & $6,067.20$ & 0.00 & 0.00 & 315.00 & 0.00 & 0.00 & 0.00 & 0.00 \\
\hline $10-F e b-03$ & $6,066.62$ & 0.00 & 21.19 & 288.99 & 0.00 & 0.00 & 0.00 & 0.00 \\
\hline $11-F e b-03$ & $6,050.17$ & 0.00 & 0.00 & 186.63 & 0.00 & 0.00 & 0.00 & 0.00 \\
\hline $12-F e b-03$ & $5,829.92$ & 0.00 & 43.13 & 377.75 & 0.00 & 0.00 & 0.00 & 0.00 \\
\hline $13-F e b-03$ & $5,933.10$ & 0.00 & 0.00 & 300.00 & 0.00 & 0.00 & 0.00 & 0.00 \\
\hline 14-Feb-03 & $5,666.96$ & 0.00 & 113.84 & 465.00 & 0.00 & 0.00 & 0.00 & 0.00 \\
\hline $15-$ Feb- 03 & $5,849.10$ & 0.00 & 0.00 & 465.00 & 0.00 & 0.00 & 0.00 & 0.00 \\
\hline $16-F e b-03$ & $5,875.29$ & 0.00 & 0.00 & 465.11 & 0.00 & 0.00 & 0.00 & 0.00 \\
\hline $17-F e b-03$ & $6,093.09$ & 0.00 & 0.00 & 235.81 & 0.00 & 0.00 & 0.00 & 0.00 \\
\hline 18 -Feb-03 & $5,753.45$ & 0.00 & 43.27 & 568.28 & 0.00 & 0.00 & 0.00 & 0.00 \\
\hline $19-$ Feb- 03 & $5,749.92$ & 0.00 & 90.18 & 450.00 & 0.00 & 0.00 & 0.00 & 0.00 \\
\hline $20-$ Feb- 03 & $5,925.30$ & 0.00 & 25.00 & 475.00 & 0.00 & 0.00 & 0.00 & 0.00 \\
\hline 21-Feb-03 & $5,237.62$ & 0.00 & 91.58 & 847.00 & 0.00 & 0.00 & 0.00 & 0.00 \\
\hline $22-$ Feb- 03 & $5,307.10$ & 0.00 & 0.00 & 847.00 & 0.00 & 0.00 & 0.00 & 0.00 \\
\hline 23 -Feb-03 & $5,211.31$ & 0.00 & 0.00 & 849.29 & 0.00 & 0.00 & 0.00 & 0.00 \\
\hline 24-Feb-03 & $6,015.68$ & 0.00 & 45.43 & 72.19 & 0.00 & 0.00 & 0.00 & 0.00 \\
\hline $25-F e b-03$ & $6,154.61$ & 0.00 & 86.29 & 1.60 & 0.00 & 0.00 & 0.00 & 0.00 \\
\hline $26-$ Feb-03 & $4,497.00$ & 0.00 & 0.00 & 0.00 & 0.00 & 0.00 & 0.00 & 0.00 \\
\hline $27-F e b-03$ & 0.00 & 0.00 & 0.00 & 0.00 & 0.00 & 0.00 & 0.00 & 0.00 \\
\hline $28-F e b-03$ & 0.00 & 0.00 & 0.00 & 0.00 & 0.00 & 0.00 & 0.00 & 0.00 \\
\hline Adjustment & $3,500.00$ & & & & & & & \\
\hline Total Burned & $154,405.86$ & 0.00 & 736.31 & $9,384.73$ & 0.00 & 0.00 & 0.00 & 0.00 \\
\hline Total Delivered & $158,173.51$ & 0.00 & 736.31 & $8,960.31$ & 0.00 & 0.00 & 0.00 & 0.00 \\
\hline HHV & 8551 & & 15000 & 7187 & 0 & 0 & 0 & 0 \\
\hline$\%$ Ash & $4.58 \%$ & & $7.05 \%$ & $1.10 \%$ & $0.00 \%$ & $0.00 \%$ & $0.00 \%$ & $0.00 \%$ \\
\hline Tons Ash & $7,074.24$ & 0.00 & 51.91 & 103.23 & 0.00 & 0.00 & 0.00 & 0.00 \\
\hline
\end{tabular}




BIG STONE PLANT
FUEL BURN RECORD - page 1
Mar-03

\begin{tabular}{|c|c|c|c|c|c|c|c|c|}
\hline DATE & Coal & P. Coke & TDF & $\begin{array}{l}\text { Waste } \\
\text { Seeds }\end{array}$ & Toner & $\begin{array}{l}\text { Gran. } \\
\text { Insul. }\end{array}$ & $\begin{array}{l}\text { Canvas } \\
\text { Belting }\end{array}$ & $\begin{array}{l}\text { Plastic } \\
\text { Chips } \\
\end{array}$ \\
\hline & (Tons) & (Tons) & (Tons) & (Tons) & (Tons) & (Tons) & (Tons) & (Tons) \\
\hline 1-Mar-03 & 0.00 & 0.00 & 0.00 & 0.00 & 0.00 & 0.00 & 0.00 & 0.00 \\
\hline 2-Mar-03 & 127.60 & 0.00 & 0.00 & 0.00 & 0.00 & 0.00 & 0.00 & 0.00 \\
\hline 3-Mar-03 & $3,960.94$ & 0.00 & 0.00 & 66.66 & 0.00 & 0.00 & 0.00 & 0.00 \\
\hline 4-Mar-03 & $6,652.70$ & 0.00 & 0.00 & 0.00 & 0.00 & 0.00 & 0.00 & 0.00 \\
\hline 5-Mar-03 & $6,493.70$ & 0.00 & 0.00 & 0.00 & 0.00 & 0.00 & 0.00 & 0.00 \\
\hline 6-Mar-03 & $6,344.91$ & 0.00 & 22.49 & 0.00 & 0.00 & 0.00 & 0.00 & 0.00 \\
\hline 7-Mar-03 & $6,362.77$ & 0.00 & 22.40 & 24.93 & 0.00 & 0.00 & 0.00 & 0.00 \\
\hline 8-Mar-03 & $6,451.40$ & 0.00 & 0.00 & 0.00 & 0.00 & 0.00 & 0.00 & 0.00 \\
\hline 9-Mar-03 & $6,504.70$ & 0.00 & 0.00 & 0.00 & 0.00 & 0.00 & 0.00 & 0.00 \\
\hline 10-Mar-03 & $6,307.69$ & 0.00 & 64.94 & 71.57 & 0.00 & 0.00 & 0.00 & 0.00 \\
\hline 11-Mar-03 & $6,365.86$ & 0.00 & 0.00 & 24.04 & 0.00 & 0.00 & 0.00 & 0.00 \\
\hline 12-Mar-03 & $6,457.50$ & 0.00 & 45.90 & 0.00 & 0.00 & 0.00 & 0.00 & 0.00 \\
\hline 13-Mar-03 & $6,327.30$ & 0.00 & 21.64 & 24.46 & 0.00 & 0.00 & 0.00 & 0.00 \\
\hline 14-Mar-03 & $6,138.03$ & 0.00 & 46.65 & 70.22 & 0.00 & 0.00 & 0.00 & 0.00 \\
\hline 15-Mar-03 & $5,959.30$ & 0.00 & 0.00 & 0.00 & 0.00 & 0.00 & 0.00 & 0.00 \\
\hline 16-Mar-03 & $6,199.70$ & 0.00 & 0.00 & 0.00 & 0.00 & 0.00 & 0.00 & 0.00 \\
\hline 17-Mar-03 & $6,167.22$ & 0.00 & 44.96 & 96.12 & 0.00 & 0.00 & 0.00 & 0.00 \\
\hline 18-Mar-03 & $5,862.80$ & 0.00 & 22.59 & 417.11 & 0.00 & 0.00 & 0.00 & 0.00 \\
\hline 19-Mar-03 & $6,370.60$ & 0.00 & 0.00 & 0.00 & 0.00 & 0.00 & 0.00 & 0.00 \\
\hline 20-Mar-03 & $5,727.87$ & 0.00 & 46.66 & 72.77 & 0.00 & 0.00 & 0.00 & 0.00 \\
\hline 21-Mar-03 & $6,160.10$ & 0.00 & 45.25 & 77.95 & 0.00 & 0.00 & 0.00 & 0.00 \\
\hline 22-Mar-03 & $5,656.60$ & 0.00 & 0.00 & 0.00 & 0.00 & 0.00 & 0.00 & 0.00 \\
\hline 23-Mar-03 & $5,468.60$ & 0.00 & 0.00 & 0.00 & 0.00 & 0.00 & 0.00 & 0.00 \\
\hline 24-Mar-03 & $5,771.78$ & 0.00 & 22.18 & 122.64 & 0.00 & 0.00 & 0.00 & 0.00 \\
\hline 25-Mar-03 & $5,276.36$ & 0.00 & 44.19 & 100.35 & 0.00 & 0.00 & 0.00 & 0.00 \\
\hline 26-Mar-03 & $5,672.84$ & 0.00 & 22.08 & 123.18 & 0.00 & 0.00 & 0.00 & 0.00 \\
\hline 27-Mar-03 & $5,965.90$ & 0.00 & 0.00 & 0.00 & 0.00 & 0.00 & 0.00 & 0.00 \\
\hline 28-Mar-03 & $5,931.49$ & 0.00 & 90.03 & 147.28 & 0.00 & 0.00 & 0.00 & 0.00 \\
\hline 29-Mar-03 & $6,182.80$ & 0.00 & 0.00 & 0.00 & 0.00 & 0.00 & 0.00 & 0.00 \\
\hline 30-Mar-03 & $6,139.50$ & 0.00 & 0.00 & 0.00 & 0.00 & 0.00 & 0.00 & 0.00 \\
\hline 31-Mar-03 & $5,827.97$ & 0.00 & 0.00 & 70.93 & 0.00 & 0.00 & 0.00 & 0.00 \\
\hline Adjustment & $2,800.00$ & & & & & & & \\
\hline Total Burned & $177,636.53$ & 0.00 & 561.96 & $1,510.21$ & 0.00 & 0.00 & 0.00 & 0.00 \\
\hline Total Delivered & $163,580.34$ & 0.00 & 561.96 & $1,565.08$ & 0.00 & 0.00 & 0.00 & 0.00 \\
\hline HHV & 8562 & 0 & 15000 & 7187 & 0 & 0 & 0 & 0 \\
\hline$\%$ Ash & $4.45 \%$ & $0.00 \%$ & $7.05 \%$ & $1.10 \%$ & $0.00 \%$ & $0.00 \%$ & $0.00 \%$ & $0.00 \%$ \\
\hline Tons Ash & $7,907.69$ & 0.00 & 39.62 & 16.61 & 0.00 & 0.00 & 0.00 & 0.00 \\
\hline
\end{tabular}




\begin{tabular}{|c|c|c|c|c|c|c|c|c|}
\hline \multirow[b]{2}{*}{ DATE } & \multirow[b]{2}{*}{ Coal } & \multicolumn{5}{|c|}{$\begin{array}{c}\text { BIG STONE PLANT } \\
\text { FUEL BURN RECORD - page } 1 \\
\text { Apr-03 }\end{array}$} & \multirow[b]{2}{*}{$\begin{array}{l}\text { Canvas } \\
\text { Belting }\end{array}$} & \multirow[b]{2}{*}{$\begin{array}{l}\text { Plastic } \\
\text { Chips }\end{array}$} \\
\hline & & P. Coke & TDF & $\begin{array}{l}\text { Waste } \\
\text { Seeds }\end{array}$ & Toner & $\begin{array}{l}\text { Gran. } \\
\text { Insul. }\end{array}$ & & \\
\hline & (Tons) & (Tons) & (Tons) & (Tons) & (Tons) & (Tons) & (Tons) & (Tons) \\
\hline 1-Apr-03 & $5,563.81$ & 0.00 & 22.09 & 73.40 & 0.00 & 0.00 & 0.00 & 0.00 \\
\hline 2-Apr-03 & $5,828.17$ & 0.00 & 22.34 & 69.09 & 0.00 & 0.00 & 0.00 & 0.00 \\
\hline 3-Apr-03 & $5,440.20$ & 0.00 & 0.00 & 0.00 & 0.00 & 0.00 & 0.00 & 0.00 \\
\hline 4-Apr-03 & $5,785.41$ & 0.00 & 22.24 & 171.15 & 0.00 & 0.00 & 0.00 & 0.00 \\
\hline 5-Apr-03 & $6,027.70$ & 0.00 & 0.00 & 0.00 & 0.00 & 0.00 & 0.00 & 0.00 \\
\hline 6-Apr-03 & $5,921.70$ & 0.00 & 0.00 & 0.00 & 0.00 & 0.00 & 0.00 & 0.00 \\
\hline 7-Apr-03 & $6,107.43$ & 0.00 & 19.79 & 96.28 & 0.00 & 0.00 & 0.00 & 0.00 \\
\hline 8-Apr-03 & $6,021.43$ & 0.00 & 22.25 & 72.12 & 0.00 & 0.00 & 0.00 & 0.00 \\
\hline 9-Apr-03 & $5,992.65$ & 0.00 & 0.00 & 23.05 & 0.00 & 0.00 & 0.00 & 0.00 \\
\hline $10-A p r-03$ & $6,040.10$ & 0.00 & 0.00 & 0.00 & 0.00 & 0.00 & 0.00 & 0.00 \\
\hline 11-Apr-03 & $5,759.20$ & 0.00 & 44.97 & 20.73 & 0.00 & 0.00 & 0.00 & 0.00 \\
\hline $12-A p r-03$ & $5,021.35$ & 0.00 & 0.00 & 0.00 & 21.35 & 0.00 & 0.00 & 0.00 \\
\hline 13-Apr-03 & $5,995.50$ & 0.00 & 0.00 & 0.00 & 0.00 & 0.00 & 0.00 & 0.00 \\
\hline $14-A p r-03$ & $5,846.61$ & 0.00 & 21.87 & 23.42 & 0.00 & 0.00 & 0.00 & 0.00 \\
\hline 15-Apr-03 & $6,072.20$ & 0.00 & 0.00 & 0.00 & 0.00 & 0.00 & 0.00 & 0.00 \\
\hline $16-A p r-03$ & $5,651.65$ & 0.00 & 44.32 & 46.13 & 0.00 & 0.00 & 0.00 & 0.00 \\
\hline 17-Apr-03 & $6,275.50$ & 0.00 & 0.00 & 0.00 & 0.00 & 0.00 & 0.00 & 0.00 \\
\hline $18-A p r-03$ & $6,208.24$ & 0.00 & 22.40 & 23.46 & 0.00 & 0.00 & 0.00 & 0.00 \\
\hline 19-Apr-03 & $5,907.50$ & 0.00 & 0.00 & 0.00 & 0.00 & 0.00 & 0.00 & 0.00 \\
\hline 20-Apr-03 & $6,086.50$ & 0.00 & 0.00 & 0.00 & 0.00 & 0.00 & 0.00 & 0.00 \\
\hline 21-Apr-03 & $5,906.60$ & 0.00 & 46.60 & 0.00 & 0.00 & 0.00 & 0.00 & 0.00 \\
\hline 22-Apr-03 & $3,986.91$ & 0.00 & 22.79 & 0.00 & 0.00 & 0.00 & 0.00 & 0.00 \\
\hline 23-Apr-03 & $5,485.18$ & 0.00 & 23.22 & 0.00 & 0.00 & 0.00 & 0.00 & 0.00 \\
\hline 24-Apr-03 & $5,787.10$ & 0.00 & 0.00 & 0.00 & 0.00 & 0.00 & 0.00 & 0.00 \\
\hline $25-A p r-03$ & $5,903.63$ & 0.00 & 68.87 & 22.40 & 0.00 & 0.00 & 0.00 & 0.00 \\
\hline 26-Apr-03 & 909.30 & 0.00 & 0.00 & 0.00 & 0.00 & 0.00 & 0.00 & 0.00 \\
\hline $27-A p r-03$ & $2,884.70$ & 0.00 & 0.00 & 0.00 & 0.00 & 0.00 & 0.00 & 0.00 \\
\hline 28-Apr-03 & $5,998.40$ & 0.00 & 0.00 & 0.00 & 0.00 & 0.00 & 0.00 & 0.00 \\
\hline 29-Apr-03 & $5,001.50$ & 0.00 & 0.00 & 0.00 & 0.00 & 0.00 & 0.00 & 0.00 \\
\hline 30-Apr-03 & $5,389.63$ & 0.00 & 90.93 & 24.24 & 0.00 & 0.00 & 0.00 & 0.00 \\
\hline Adjustment & 0.00 & & & & & & & \\
\hline Total Burned & $164,805.80$ & 0.00 & 494.68 & 665.47 & 21.35 & 0.00 & 0.00 & 0.00 \\
\hline Total Delivered & $182,856.19$ & 0.00 & 494.68 & 665.47 & 21.35 & 0.00 & 0.00 & 0.00 \\
\hline HHV & 8491 & 0 & 15000 & 7187 & 16932 & 0 & 0 & 0 \\
\hline$\%$ Ash & $4.65 \%$ & $0.00 \%$ & $7.05 \%$ & $1.10 \%$ & $0.00 \%$ & $0.00 \%$ & $0.00 \%$ & $0.00 \%$ \\
\hline Tons Ash & $7,657.92$ & 0.00 & 34.87 & 7.32 & 0.00 & 0.00 & 0.00 & 0.00 \\
\hline
\end{tabular}


FUEL BURN RECORD - page 1 May-03

\begin{tabular}{|c|c|c|c|c|c|c|c|c|}
\hline DATE & Coal & P. Coke & TDF & $\begin{array}{l}\text { Waste } \\
\text { Seeds }\end{array}$ & Toner & $\begin{array}{l}\text { Gran. } \\
\text { Insul. }\end{array}$ & $\begin{array}{l}\text { Canvas } \\
\text { Belting }\end{array}$ & $\begin{array}{l}\text { Plastic } \\
\text { Chips }\end{array}$ \\
\hline & (Tons) & (Tons) & (Tons) & (Tons) & (Tons) & (Tons) & (Tons) & (Tons) \\
\hline 1-May-03 & $6,018.26$ & 0.00 & 24.09 & 23.35 & 0.00 & 0.00 & 0.00 & 0.00 \\
\hline $2-$ May-03 & $5,927.28$ & 0.00 & 44.56 & 46.66 & 0.00 & 0.00 & 0.00 & 0.00 \\
\hline 3-May-03 & $6,080.60$ & 0.00 & 0.00 & 0.00 & 0.00 & 0.00 & 0.00 & 0.00 \\
\hline 4-May-03 & $5,982.70$ & 0.00 & 0.00 & 0.00 & 0.00 & 0.00 & 0.00 & 0.00 \\
\hline $5-$ May -03 & $6,266.11$ & 0.00 & 26.89 & 0.00 & 0.00 & 0.00 & 0.00 & 0.00 \\
\hline 6-May-03 & $5,945.43$ & 0.00 & 46.37 & 0.00 & 0.00 & 0.00 & 0.00 & 0.00 \\
\hline 7-May-03 & $5,759.10$ & 0.00 & 0.00 & 0.00 & 0.00 & 0.00 & 0.00 & 0.00 \\
\hline 8-May-03 & $4,741.50$ & 0.00 & 0.00 & 0.00 & 0.00 & 0.00 & 0.00 & 0.00 \\
\hline 9-May-03 & $6,216.94$ & 0.00 & 48.64 & 46.02 & 0.00 & 0.00 & 0.00 & 0.00 \\
\hline $10-$ May-03 & $6,429.90$ & 0.00 & 0.00 & 0.00 & 0.00 & 0.00 & 0.00 & 0.00 \\
\hline 11-May-03 & $6,585.20$ & 0.00 & 0.00 & 0.00 & 0.00 & 0.00 & 0.00 & 0.00 \\
\hline 12-May-03 & $6,301.40$ & 0.00 & 0.00 & 0.00 & 0.00 & 0.00 & 0.00 & 0.00 \\
\hline 13-May-03 & $6,073.81$ & 0.00 & 22.39 & 180.00 & 0.00 & 0.00 & 0.00 & 0.00 \\
\hline 14-May-03 & $6,003.37$ & 0.00 & 46.04 & 182.69 & 0.00 & 0.00 & 0.00 & 0.00 \\
\hline 15-May-03 & $6,222.40$ & 0.00 & 0.00 & 0.00 & 0.00 & 0.00 & 0.00 & 0.00 \\
\hline 16-May-03 & $5,882.91$ & 0.00 & 26.53 & 140.16 & 0.00 & 0.00 & 0.00 & 0.00 \\
\hline 17-May-03 & $6,158.00$ & 0.00 & 0.00 & 0.00 & 0.00 & 0.00 & 0.00 & 0.00 \\
\hline 18-May-03 & $6,133.60$ & 0.00 & 0.00 & 0.00 & 0.00 & 0.00 & 0.00 & 0.00 \\
\hline $19-$ May-03 & $6,011,02$ & 0.00 & 69.35 & 71.33 & 0.00 & 0.00 & 0.00 & 0.00 \\
\hline 20-May-03 & $6,156.23$ & 0.00 & 69.86 & 73.01 & 0.00 & 0.00 & 0.00 & 0.00 \\
\hline $21-$ May- 03 & $6,109.67$ & 0.00 & 0.00 & 93.83 & 0.00 & 0.00 & 0.00 & 0.00 \\
\hline 22-May-03 & $5,943.65$ & 0.00 & 22.29 & 47.96 & 0.00 & 0.00 & 0.00 & 0.00 \\
\hline 23-May-03 & $5,777.39$ & 0.00 & 45.17 & 24.04 & 0.00 & 0.00 & 0.00 & 0.00 \\
\hline 24-May-03 & $5,838.90$ & 0.00 & 0.00 & 0.00 & 0.00 & 0.00 & 0.00 & 0.00 \\
\hline 25-May-03 & $5,751.90$ & 0.00 & 0.00 & 0.00 & 0.00 & 0.00 & 0.00 & 0.00 \\
\hline 26-May-03 & $5,543.30$ & 0.00 & 0.00 & 0.00 & 0.00 & 0.00 & 0.00 & 0.00 \\
\hline 27-May-03 & $5,637.15$ & 0.00 & 22.39 & 24.06 & 0.00 & 0.00 & 0.00 & 0.00 \\
\hline 28-May-03 & $5,847.93$ & 0.00 & 45.07 & 0.00 & 0.00 & 0.00 & 0.00 & 0.00 \\
\hline 29-May-03 & $6,051.70$ & 0.00 & 0.00 & 0.00 & 0.00 & 0.00 & 0.00 & 0.00 \\
\hline 30-May-03 & $5,865.58$ & 0.00 & 67.36 & 116.26 & 0.00 & 0.00 & 0.00 & 0.00 \\
\hline 31-May-03 & $5,579.90$ & 0.00 & 0.00 & 0.00 & 0.00 & 0.00 & 0.00 & 0.00 \\
\hline Adjustment & 0.00 & & & & & & & \\
\hline Total Burned & $184,842.83$ & 0.00 & 627.00 & $1,069.37$ & 0.00 & 0.00 & 0.00 & 0.00 \\
\hline Total Delivered & $183,962.43$ & 0.00 & 627.00 & $1,069.37$ & 0.00 & 0.00 & 0.00 & 0.00 \\
\hline HHV & 8560 & 0 & 15000 & 7187 & 0 & 0 & 0 & 0 \\
\hline$\%$ Ash & $4.59 \%$ & $0.00 \%$ & $7.05 \%$ & $1.10 \%$ & $0.00 \%$ & $0.00 \%$ & $0.00 \%$ & $0.00 \%$ \\
\hline Tons Ash & $8,486.63$ & 0.00 & 44.20 & 11.76 & 0.00 & 0.00 & 0.00 & 0.00 \\
\hline
\end{tabular}




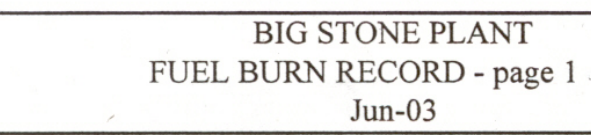

\begin{tabular}{|c|c|c|c|c|c|c|c|c|}
\hline DATE & Coal & P. Coke & TDF & $\begin{array}{l}\text { Waste } \\
\text { Seeds }\end{array}$ & Toner & $\begin{array}{l}\text { Gran. } \\
\text { Insul. }\end{array}$ & $\begin{array}{l}\text { Canvas } \\
\text { Belting } \\
\end{array}$ & $\begin{array}{l}\text { Plastic } \\
\text { Chips }\end{array}$ \\
\hline & (Tons) & (Tons) & (Tons) & (Tons) & (Tons) & (Tons) & (Tons) & (Tons) \\
\hline 1-Jun-03 & $5,439.10$ & 0.00 & 0.00 & 0.00 & 0.00 & 0.00 & 0.00 & 0.00 \\
\hline 2-Jun-03 & $5,564.42$ & 0.00 & 110.79 & 67.89 & 0.00 & 0.00 & 0.00 & 0.00 \\
\hline 3-Jun-03 & $4,109.30$ & 0.00 & 0.00 & 0.00 & 0.00 & 0.00 & 0.00 & 0.00 \\
\hline 4-Jun-03 & 0.00 & 0.00 & 0.00 & 0.00 & 0.00 & 0.00 & 0.00 & 0.00 \\
\hline 5-Jun-03 & 0.00 & 0.00 & 0.00 & 0.00 & 0.00 & 0.00 & 0.00 & 0.00 \\
\hline 6-Jun-03 & 0.00 & 0.00 & 0.00 & 0.00 & 0.00 & 0.00 & 0.00 & 0.00 \\
\hline 7-Jun-03 & 0.00 & 0.00 & 0.00 & 0.00 & 0.00 & 0.00 & 0.00 & 0.00 \\
\hline 8-Jun-03 & 0.00 & 0.00 & 0.00 & 0.00 & 0.00 & 0.00 & 0.00 & 0.00 \\
\hline 9-Jun-03 & 0.00 & 0.00 & 0.00 & 0.00 & 0.00 & 0.00 & 0.00 & 0.00 \\
\hline 10-Jun-03 & 0.00 & 0.00 & 0.00 & 0.00 & 0.00 & 0.00 & 0.00 & 0.00 \\
\hline 11-Jun-03 & $1,062.40$ & 0.00 & 0.00 & 0.00 & 0.00 & 0.00 & 0.00 & 0.00 \\
\hline 12-Jun-03 & $5,927.60$ & 0.00 & 0.00 & 0.00 & 0.00 & 0.00 & 0.00 & 0.00 \\
\hline 13-Jun-03 & $5,769.17$ & 0.00 & 22.39 & 264.44 & 0.00 & 0.00 & 0.00 & 0.00 \\
\hline 14-Jun-03 & $6,184.20$ & 0.00 & 0.00 & 0.00 & 0.00 & 0.00 & 0.00 & 0.00 \\
\hline 15-Jun-03 & $6,104.80$ & 0.00 & 0.00 & 0.00 & 0.00 & 0.00 & 0.00 & 0.00 \\
\hline 16-Jun-03 & $5,980.04$ & 0.00 & 166.09 & 23.97 & 0.00 & 0.00 & 0.00 & 0.00 \\
\hline 17-Jun-03 & $5,115.89$ & 0.00 & 67.18 & 120.33 & 0.00 & 0.00 & 0.00 & 0.00 \\
\hline 18-Jun-03 & $5,903.29$ & 0.00 & 65.80 & 174.41 & 0.00 & 0.00 & 0.00 & 0.00 \\
\hline 19-Jun-03 & $6,263.74$ & 0.00 & 22.79 & 195.97 & 0.00 & 0.00 & 0.00 & 0.00 \\
\hline 20-Jun-03 & $5,968.70$ & 0.00 & 73.28 & 319.12 & 0.00 & 0.00 & 0.00 & 0.00 \\
\hline 21-Jun-03 & $5,994.10$ & 0.00 & 0.00 & 0.00 & 0.00 & 0.00 & 0.00 & 0.00 \\
\hline 22-Jun-03 & $5,455.90$ & 0.00 & 0.00 & 0.00 & 0.00 & 0.00 & 0.00 & 0.00 \\
\hline 23-Jun-03 & $6,339.77$ & 0.00 & 25.69 & 167.34 & 0.00 & 0.00 & 0.00 & 0.00 \\
\hline 24-Jun-03 & $6,446.21$ & 0.00 & 46.45 & 176.04 & 0.00 & 0.00 & 0.00 & 0.00 \\
\hline 25-Jun-03 & $6,148.46$ & 0.00 & 72.23 & 445.61 & 0.00 & 0.00 & 0.00 & 0.00 \\
\hline 26-Jun-03 & $5,846.29$ & 0.00 & 45.47 & 388.54 & 0.00 & 0.00 & 0.00 & 0.00 \\
\hline 27-Jun-03 & $6,209.24$ & 0.00 & 46.04 & 158.02 & 0.00 & 0.00 & 0.00 & 0.00 \\
\hline 28-Jun-03 & $5,261.90$ & 0.00 & 0.00 & 0.00 & 0.00 & 0.00 & 0.00 & 0.00 \\
\hline 29-Jun-03 & $5,916.40$ & 0.00 & 0.00 & 0.00 & 0.00 & 0.00 & 0.00 & 0.00 \\
\hline 30-Jun-03 & $5,968.60$ & 0.00 & 0.00 & 0.00 & 0.00 & 0.00 & 0.00 & 0.00 \\
\hline Adjustment & $-1,000.00$ & & & & & & & \\
\hline Burned & $127,979.52$ & 0.00 & 764.20 & $2,501.68$ & 0.00 & 0.00 & 0.00 & 0.00 \\
\hline Delivered & $129,386.06$ & 0.00 & 810.36 & $2,674.20$ & 0.00 & 0.00 & 0.00 & 0.00 \\
\hline HHV & 8482 & 0 & 15000 & 7187 & 0 & 0 & 0 & 0 \\
\hline$\%$ Ash & $4.57 \%$ & $0.00 \%$ & $7.04 \%$ & $1.10 \%$ & $0.00 \%$ & $0.00 \%$ & $0.00 \%$ & $0.00 \%$ \\
\hline Tons Ash & $5,842.41$ & 0.00 & 53.80 & 27.52 & 0.00 & 0.00 & 0.00 & 0.00 \\
\hline
\end{tabular}




\begin{tabular}{|c|c|c|c|c|c|c|c|c|}
\hline & & \multicolumn{5}{|c|}{$\begin{array}{c}\text { BIG STONE PLANT } \\
\text { FUEL BURN RECORD - page } 1 \\
\text { Jul-03 }\end{array}$} & \multirow[b]{2}{*}{$\begin{array}{l}\text { Canvas } \\
\text { Belting }\end{array}$} & \multirow[b]{2}{*}{$\begin{array}{l}\text { Plastic } \\
\text { Chips }\end{array}$} \\
\hline DATE & Coal & P. Coke & TDF & $\begin{array}{l}\text { Waste } \\
\text { Seeds }\end{array}$ & Toner & $\begin{array}{l}\text { Gran. } \\
\text { Insul. }\end{array}$ & & \\
\hline & (Tons) & (Tons) & (Tons) & (Tons) & (Tons) & (Tons) & (Tons) & (Tons) \\
\hline 1-Jul-03 & $5,608.91$ & 0.00 & 92.25 & 380.44 & 0.00 & 0.00 & 0.00 & 0.00 \\
\hline 2-Jul-03 & $6,015.40$ & 0.00 & 27.52 & 474.68 & 0.00 & 0.00 & 0.00 & 0.00 \\
\hline 3-Jul-03 & $6,544.89$ & 0.00 & 73.64 & 23.87 & 0.00 & 0.00 & 0.00 & 0.00 \\
\hline 4-Jul-03 & $4,873.10$ & 0.00 & 0.00 & 0.00 & 0.00 & 0.00 & 0.00 & 0.00 \\
\hline 5-Jul-03 & $5,833.60$ & 0.00 & 0.00 & 0.00 & 0.00 & 0.00 & 0.00 & 0.00 \\
\hline 6-Jul-03 & $6,044.60$ & 0.00 & 0.00 & 0.00 & 0.00 & 0.00 & 0.00 & 0.00 \\
\hline 7-Jul-03 & $5,899.67$ & 0.00 & 71.91 & 71.12 & 0.00 & 0.00 & 0.00 & 0.00 \\
\hline 8-Jul-03 & $6,241.19$ & 0.00 & 25.32 & 94.59 & 0.00 & 0.00 & 0.00 & 0.00 \\
\hline 9-Jul-03 & $6,305.42$ & 0.00 & 96.76 & 91.92 & 0.00 & 0.00 & 0.00 & 0.00 \\
\hline 10-Jul-03 & $5,807.50$ & 0.00 & 100.00 & 75.00 & 0.00 & 0.00 & 0.00 & 0.00 \\
\hline 11-Jul-03 & $5,939.50$ & 0.00 & 0.00 & 0.00 & 0.00 & 0.00 & 0.00 & 0.00 \\
\hline 12-Jul-03 & $6,269.10$ & 0.00 & 0.00 & 0.00 & 0.00 & 0.00 & 0.00 & 0.00 \\
\hline 13-Jul-03 & $6,282.60$ & 0.00 & 0.00 & 0.00 & 0.00 & 0.00 & 0.00 & 0.00 \\
\hline 14-Jul-03 & $5,493.97$ & 0.00 & 70.85 & 39.18 & 0.00 & 0.00 & 0.00 & 0.00 \\
\hline 15-Jul-03 & $6,311.10$ & 0.00 & 24.00 & 117.93 & 26.47 & 0.00 & 0.00 & 0.00 \\
\hline 16-Jul-03 & $6,525.20$ & 0.00 & 0.00 & 0.00 & 0.00 & 0.00 & 0.00 & 0.00 \\
\hline 17-Jul-03 & $6,477.53$ & 0.00 & 74.24 & 113.33 & 0.00 & 0.00 & 0.00 & 0.00 \\
\hline 18-Jul-03 & $6,706.77$ & 0.00 & 22.62 & 48.41 & 0.00 & 0.00 & 0.00 & 0.00 \\
\hline 19-Jul-03 & $6,507.10$ & 0.00 & 0.00 & 0.00 & 0.00 & 0.00 & 0.00 & 0.00 \\
\hline 20-Jul-03 & $6,703.70$ & 0.00 & 0.00 & 0.00 & 0.00 & 0.00 & 0.00 & 0.00 \\
\hline 21-Jul-03 & $6,560.20$ & 0.00 & 0.00 & 0.00 & 0.00 & 0.00 & 0.00 & 0.00 \\
\hline 22-Jul-03 & $6,099.20$ & 0.00 & 0.00 & 0.00 & 0.00 & 0.00 & 0.00 & 0.00 \\
\hline 23-Jul-03 & $6,304.46$ & 0.00 & 162.95 & 95.89 & 0.00 & 0.00 & 0.00 & 0.00 \\
\hline 24-Jul-03 & $6,202.95$ & 0.00 & 72.30 & 141.55 & 0.00 & 0.00 & 0.00 & 0.00 \\
\hline 25-Jul-03 & $5,521.04$ & 0.00 & 46.39 & 92.57 & 0.00 & 0.00 & 0.00 & 0.00 \\
\hline 26-Jul-03 & $5,869.10$ & 0.00 & 0.00 & 0.00 & 0.00 & 0.00 & 0.00 & 0.00 \\
\hline 27-Jul-03 & $6,624.50$ & 0.00 & 0.00 & 0.00 & 0.00 & 0.00 & 0.00 & 0.00 \\
\hline 28-Jul-03 & $6,418.90$ & 0.00 & 93.00 & 72.50 & 0.00 & 0.00 & 0.00 & 0.00 \\
\hline 29-Jul-03 & $6,652.26$ & 0.00 & 24.17 & 48.67 & 0.00 & 0.00 & 0.00 & 0.00 \\
\hline 30-Jul-03 & $6,493.44$ & 0.00 & 70.91 & 94.55 & 0.00 & 0.00 & 0.00 & 0.00 \\
\hline 31-Jul-03 & $6,868.90$ & 0.00 & 0.00 & 0.00 & 0.00 & 0.00 & 0.00 & 0.00 \\
\hline Adjustment & 0.00 & & & & & & & \\
\hline Total Burned & $192,005.80$ & 0.00 & $1,148.83$ & $2,076.20$ & 26.47 & 0.00 & 0.00 & 0.00 \\
\hline Total Delivered & $154,635.98$ & 0.00 & $1,271.15$ & $1,974.87$ & 26.47 & 0.00 & 0.00 & 0.00 \\
\hline HHV & 8561 & 0 & 15000 & 7187 & 16932 & 0 & 0 & 0 \\
\hline$\%$ Ash & $4.61 \%$ & $0.00 \%$ & $7.04 \%$ & $1.10 \%$ & $0.00 \%$ & $0.00 \%$ & $0.00 \%$ & $0.00 \%$ \\
\hline Tons Ash & $8,860.09$ & 0.00 & 80.88 & 22.84 & 0.00 & 0.00 & 0.00 & 0.00 \\
\hline
\end{tabular}




\begin{tabular}{c}
\hline BIG STONE PLANT \\
FUEL BURN RECORD - page 1 \\
Aug-03 \\
\hline
\end{tabular}

\begin{tabular}{|c|c|c|c|c|c|c|c|c|}
\hline DATE & Coal & P. Coke & TDF & $\begin{array}{l}\text { Waste } \\
\text { Seeds }\end{array}$ & Toner & $\begin{array}{l}\text { Gran. } \\
\text { Insul. }\end{array}$ & $\begin{array}{l}\text { Canvas } \\
\text { Belting }\end{array}$ & $\begin{array}{c}\text { Plastic } \\
\text { Chips } \\
\end{array}$ \\
\hline & (Tons) & (Tons) & (Tons) & (Tons) & (Tons) & (Tons) & (Tons) & (Tons) \\
\hline 1-Aug-03 & $6,743.00$ & 0.00 & 133.00 & 50.00 & 0.00 & 0.00 & 0.00 & 0.00 \\
\hline 2-Aug-03 & $6,317.90$ & 0.00 & 133.00 & 46.00 & 0.00 & 0.00 & 0.00 & 0.00 \\
\hline 3-Aug-03 & $6,319.74$ & 0.00 & 131.88 & 45.98 & 0.00 & 0.00 & 0.00 & 0.00 \\
\hline 4-Aug-03 & $6,600.60$ & 0.00 & 0.00 & 0.00 & 0.00 & 0.00 & 0.00 & 0.00 \\
\hline 5-Aug-03 & $6,103.03$ & 0.00 & 237.82 & 229.15 & 0.00 & 0.00 & 0.00 & 0.00 \\
\hline 6-Aug-03 & $6,689.25$ & 0.00 & 70.01 & 61.74 & 0.00 & 0.00 & 0.00 & 0.00 \\
\hline 7-Aug-03 & $6,693.50$ & 0.00 & 50.00 & 50.00 & 0.00 & 0.00 & 0.00 & 0.00 \\
\hline 8-Aug-03 & $6,789.10$ & 0.00 & 0.00 & 0.00 & 0.00 & 0.00 & 0.00 & 0.00 \\
\hline 9-Aug-03 & $6,780.00$ & 0.00 & 0.00 & 0.00 & 0.00 & 0.00 & 0.00 & 0.00 \\
\hline 10 -Aug-03 & $6,640.30$ & 0.00 & 0.00 & 0.00 & 0.00 & 0.00 & 0.00 & 0.00 \\
\hline 11-Aug-03 & $6,610.40$ & 0.00 & 100.00 & 100.00 & 0.00 & 0.00 & 0.00 & 0.00 \\
\hline 12-Aug-03 & $6,517.90$ & 0.00 & 47.40 & 0.00 & 0.00 & 0.00 & 0.00 & 0.00 \\
\hline 13-Aug-03 & $6,741.74$ & 0.00 & 73.02 & 4.04 & 0.00 & 0.00 & 0.00 & 0.00 \\
\hline 14-Aug-03 & $6,556.76$ & 0.00 & 95.61 & 42.73 & 0.00 & 0.00 & 0.00 & 0.00 \\
\hline 15 -Aug-03 & $6,450.81$ & 0.00 & 141.44 & 146.75 & 0.00 & 0.00 & 0.00 & 0.00 \\
\hline 16-Aug-03 & $6,755.10$ & 0.00 & 0.00 & 0.00 & 0.00 & 0.00 & 0.00 & 0.00 \\
\hline 17-Aug-03 & $6,812.20$ & 0.00 & 0.00 & 0.00 & 0.00 & 0.00 & 0.00 & 0.00 \\
\hline 18 -Aug-03 & $6,816.46$ & 0.00 & 91.94 & 0.00 & 0.00 & 0.00 & 0.00 & 0.00 \\
\hline 19-Aug-03 & $6,597.90$ & 0.00 & 100.00 & 75.00 & 0.00 & 0.00 & 0.00 & 0.00 \\
\hline 20 -Aug-03 & $6,597.61$ & 0.00 & 69.93 & 81.46 & 0.00 & 0.00 & 0.00 & 0.00 \\
\hline 21-Aug-03 & $6,665.60$ & 0.00 & 50.00 & 50.00 & 0.00 & 0.00 & 0.00 & 0.00 \\
\hline 22-Aug-03 & $5,870.40$ & 0.00 & 119.63 & 440.07 & 0.00 & 0.00 & 0.00 & 0.00 \\
\hline 23-Aug-03 & $5,911.43$ & 0.00 & 0.00 & 440.07 & 0.00 & 0.00 & 0.00 & 0.00 \\
\hline 24-Aug-03 & $5,922.23$ & 0.00 & 0.00 & 440.07 & 0.00 & 0.00 & 0.00 & 0.00 \\
\hline 25 -Aug-03 & $5,927.41$ & 0.00 & 300.00 & 294.19 & 0.00 & 0.00 & 0.00 & 0.00 \\
\hline 26-Aug-03 & $6,611.26$ & 0.00 & 0.00 & 70.04 & 0.00 & 0.00 & 0.00 & 0.00 \\
\hline 27 -Aug-03 & $6,262.98$ & 0.00 & 0.00 & 241.62 & 0.00 & 0.00 & 0.00 & 0.00 \\
\hline 28 -Aug-03 & $6,548.60$ & 0.00 & 10.14 & 24.16 & 0.00 & 0.00 & 0.00 & 0.00 \\
\hline 29-Aug-03 & $6,496.20$ & 0.00 & 75.00 & 100.00 & 0.00 & 0.00 & 0.00 & 0.00 \\
\hline 30 -Aug-03 & $6,021.40$ & 0.00 & 50.00 & 100.00 & 0.00 & 0.00 & 0.00 & 0.00 \\
\hline 31-Aug-03 & $5,848.66$ & 0.00 & 68.17 & 54.77 & 0.00 & 0.00 & 0.00 & 0.00 \\
\hline Adjustment & 0.00 & & & & & & & \\
\hline Total Burned & $200,219.47$ & 0.00 & $2,147.99$ & $3,187.84$ & 0.00 & 0.00 & 0.00 & 0.00 \\
\hline Total Delivered & $184,120.00$ & 0.00 & $1,979.51$ & $3,116.65$ & 0.00 & 0.00 & 0.00 & 0.00 \\
\hline HHV & 8575 & 0 & 15000 & 7187 & 0 & 0 & 0 & 0 \\
\hline$\%$ Ash & $4.70 \%$ & $0.00 \%$ & $7.04 \%$ & $1.10 \%$ & $0.00 \%$ & $0.00 \%$ & $0.00 \%$ & $0.00 \%$ \\
\hline Tons Ash & $9,417.23$ & 0.00 & 151.22 & 35.07 & 0.00 & 0.00 & 0.00 & 0.00 \\
\hline
\end{tabular}




BIG STONE PLANT
FUEL BURN RECORD - page 1
Sep-03

\begin{tabular}{|c|c|c|c|c|c|c|c|c|}
\hline DATE & Coal & P. Coke & TDF & $\begin{array}{l}\text { Waste } \\
\text { Seeds }\end{array}$ & Toner & $\begin{array}{l}\text { Gran. } \\
\text { Insul. }\end{array}$ & $\begin{array}{l}\text { Canvas } \\
\text { Belting }\end{array}$ & $\begin{array}{l}\text { Plastic } \\
\text { Chips } \\
\end{array}$ \\
\hline & (Tons) & (Tons) & (Tons) & (Tons) & (Tons) & (Tons) & (Tons) & (Tons) \\
\hline 1-Sep-03 & $6,062.70$ & 0.00 & 0.00 & 0.00 & 0.00 & 0.00 & 0.00 & 0.00 \\
\hline 2 -Sep-03 & $6,086.80$ & 0.00 & 0.00 & 0.00 & 0.00 & 0.00 & 0.00 & 0.00 \\
\hline 3-Sep-03 & $5,671.17$ & 0.00 & 210.82 & 68.41 & 0.00 & 0.00 & 0.00 & 0.00 \\
\hline 4-Sep-03 & $5,901.99$ & 0.00 & 72.78 & 46.73 & 0.00 & 0.00 & 0.00 & 0.00 \\
\hline 5 -Sep- 03 & $6,225.60$ & 0.00 & 100.00 & 50.00 & 0.00 & 0.00 & 0.00 & 0.00 \\
\hline 6-Sep-03 & $6,367.08$ & 0.00 & 121.38 & 45.94 & 0.00 & 0.00 & 0.00 & 0.00 \\
\hline 7-Sep-03 & $6,247.40$ & 0.00 & 0.00 & 0.00 & 0.00 & 0.00 & 0.00 & 0.00 \\
\hline 8-Sep-03 & $6,102.54$ & 0.00 & 118.94 & 45.62 & 0.00 & 0.00 & 0.00 & 0.00 \\
\hline 9-Sep-03 & $6,146.21$ & 0.00 & 93.05 & 23.64 & 0.00 & 0.00 & 0.00 & 0.00 \\
\hline $10-$ Sep- 03 & $6,064.33$ & 0.00 & 73.44 & 22.13 & 0.00 & 0.00 & 0.00 & 0.00 \\
\hline $11-$ Sep-03 & $6,289.50$ & 0.00 & 50.00 & 25.00 & 0.00 & 0.00 & 0.00 & 0.00 \\
\hline $12-$ Sep- 03 & $6,321.90$ & 0.00 & 120.00 & 75.00 & 0.00 & 0.00 & 0.00 & 0.00 \\
\hline $13-$ Sep-03 & $6,091.00$ & 0.00 & 120.00 & 75.00 & 0.00 & 0.00 & 0.00 & 0.00 \\
\hline $14-$ Sep-03 & $5,974.33$ & 0.00 & 122.40 & 61.67 & 0.00 & 0.00 & 0.00 & 0.00 \\
\hline $15-\mathrm{Sep}-03$ & $6,299.81$ & 0.00 & 46.85 & 76.14 & 0.00 & 0.00 & 0.00 & 0.00 \\
\hline $16-\mathrm{Sep}-03$ & $5,977.12$ & 0.00 & 50.40 & 97.98 & 0.00 & 0.00 & 0.00 & 0.00 \\
\hline $17-$ Sep-03 & $5,232.80$ & 0.00 & 50.00 & 100.00 & 0.00 & 0.00 & 0.00 & 0.00 \\
\hline 18 -Sep-03 & $5,167.98$ & 0.00 & 72.67 & 23.15 & 0.00 & 0.00 & 0.00 & 0.00 \\
\hline 19-Sep-03 & $5,666.01$ & 0.00 & 42.13 & 57.86 & 0.00 & 0.00 & 0.00 & 0.00 \\
\hline $20-$ Sep-03 & $6,506.90$ & 0.00 & 0.00 & 0.00 & 0.00 & 0.00 & 0.00 & 0.00 \\
\hline 21-Sep-03 & $6,583.80$ & 0.00 & 0.00 & 0.00 & 0.00 & 0.00 & 0.00 & 0.00 \\
\hline $22-$ Sep-03 & $6,181.04$ & 0.00 & 94.33 & 274.73 & 0.00 & 0.00 & 0.00 & 0.00 \\
\hline $23-$ Sep-03 & $5,796.03$ & 0.00 & 72.63 & 25.94 & 0.00 & 0.00 & 0.00 & 0.00 \\
\hline 24-Sep-03 & $6,275.00$ & 0.00 & 25.47 & 13.83 & 0.00 & 0.00 & 0.00 & 0.00 \\
\hline $25-$ Sep-03 & $6,363.60$ & 0.00 & 25.00 & 25.00 & 0.00 & 0.00 & 0.00 & 0.00 \\
\hline 26-Sep-03 & $6,267.41$ & 0.00 & 66.80 & 107.39 & 0.00 & 0.00 & 0.00 & 0.00 \\
\hline 27-Sep-03 & $5,787.30$ & 0.00 & 0.00 & 100.00 & 0.00 & 0.00 & 0.00 & 0.00 \\
\hline 28-Sep-03 & $6,336.90$ & 0.00 & 0.00 & 100.00 & 0.00 & 0.00 & 0.00 & 0.00 \\
\hline $29-$ Sep-03 & $6,446.52$ & 0.00 & 95.13 & 46.25 & 0.00 & 0.00 & 0.00 & 0.00 \\
\hline $30-$ Sep- 03 & $6,170.55$ & 0.00 & 125.33 & 23.02 & 0.00 & 0.00 & 0.00 & 0.00 \\
\hline Adjustment & $3,000.00$ & & & & & & & \\
\hline Total Burned & $185,611.32$ & 0.00 & $1,969.55$ & $1,610.43$ & 0.00 & 0.00 & 0.00 & 0.00 \\
\hline Total Delivered & $194,770.48$ & 0.00 & $1,969.55$ & $1,610.43$ & 0.00 & 0.00 & 0.00 & 0.00 \\
\hline HHV & 8530 & 0 & 15000 & 7187 & 0 & 0 & 0 & 0 \\
\hline$\%$ Ash & $4.59 \%$ & 0.00 & $7.04 \%$ & $1.10 \%$ & $0.00 \%$ & $0.00 \%$ & $0.00 \%$ & $0.00 \%$ \\
\hline Tons Ash & $8,526.64$ & 0.00 & 51.48 & 12.52 & 0.00 & 0.00 & 0.00 & 0.00 \\
\hline
\end{tabular}




BIG STONE PLANT
FUEL BURN RECORD - page 1
Oct-03

\begin{tabular}{|c|c|c|c|c|c|c|c|c|}
\hline DATE & Coal & P. Coke & TDF & $\begin{array}{l}\text { Waste } \\
\text { Seeds }\end{array}$ & Toner & $\begin{array}{l}\text { Gran. } \\
\text { Insul. }\end{array}$ & $\begin{array}{l}\text { Canvas } \\
\text { Belting }\end{array}$ & $\begin{array}{c}\text { Plastic } \\
\text { Chips }\end{array}$ \\
\hline & (Tons) & (Tons) & (Tons) & (Tons) & (Tons) & (Tons) & (Tons) & (Tons) \\
\hline $1-O c t-03$ & $6,319.50$ & 0.00 & 0.00 & 0.00 & 0.00 & 0.00 & 0.00 & 0.00 \\
\hline 2 -Oct- 03 & $6,536.17$ & 0.00 & 45.23 & 0.00 & 0.00 & 0.00 & 0.00 & 0.00 \\
\hline $3-$-Oct- 03 & $6,161.23$ & 0.00 & 296.40 & 86.67 & 0.00 & 0.00 & 0.00 & 0.00 \\
\hline 4-Oct- 03 & $6,153.70$ & 0.00 & 0.00 & 0.00 & 0.00 & 0.00 & 0.00 & 0.00 \\
\hline 5-Oct-03 & $6,127.10$ & 0.00 & 0.00 & 0.00 & 0.00 & 0.00 & 0.00 & 0.00 \\
\hline $6-O c t-03$ & $4,974.05$ & 0.00 & 147.85 & 0.00 & 0.00 & 0.00 & 0.00 & 0.00 \\
\hline 7-Oct- 03 & $5,985.37$ & 0.00 & 119.23 & 0.00 & 0.00 & 0.00 & 0.00 & 0.00 \\
\hline 8-Oct-03 & $5,818.22$ & 0.00 & 122.59 & 23.79 & 0.00 & 0.00 & 0.00 & 0.00 \\
\hline 9-Oct-03 & $5,941.70$ & 0.00 & 100.00 & 25.00 & 0.00 & 0.00 & 0.00 & 0.00 \\
\hline $10-$ Oct-03 & $6,004.76$ & 0.00 & 95.84 & 125.00 & 0.00 & 0.00 & 0.00 & 0.00 \\
\hline 11-Oct-03 & $6,554.80$ & 0.00 & 0.00 & 125.00 & 0.00 & 0.00 & 0.00 & 0.00 \\
\hline 12-Oct-03 & $6,555.37$ & 0.00 & 0.00 & 103.33 & 0.00 & 0.00 & 0.00 & 0.00 \\
\hline 13-Oct-03 & $6,034.57$ & 0.00 & 96.92 & 68.61 & 0.00 & 0.00 & 0.00 & 0.00 \\
\hline 14-Oct-03 & $6,098.22$ & 0.00 & 92.88 & 0.00 & 0.00 & 0.00 & 0.00 & 0.00 \\
\hline $15-O c t-03$ & $5,814.86$ & 0.00 & 120.71 & 220.33 & 0.00 & 0.00 & 0.00 & 0.00 \\
\hline $16-$ Oct-03 & $6,119.60$ & 0.00 & 0.00 & 0.00 & 0.00 & 0.00 & 0.00 & 0.00 \\
\hline 17-Oct-03 & $6,173.77$ & 0.00 & 146.93 & 0.00 & 0.00 & 0.00 & 0.00 & 0.00 \\
\hline 18 -Oct-03 & $5,794.62$ & 0.00 & 144.46 & 98.92 & 0.00 & 0.00 & 0.00 & 0.00 \\
\hline $19-$ Oct-03 & $5,757.80$ & 0.00 & 0.00 & 0.00 & 0.00 & 0.00 & 0.00 & 0.00 \\
\hline $20-$ Oct-03 & $5,855.49$ & 0.00 & 120.98 & 41.93 & 0.00 & 0.00 & 0.00 & 0.00 \\
\hline 21-Oct-03 & $6,047.70$ & 0.00 & 69.50 & 16.10 & 0.00 & 0.00 & 0.00 & 0.00 \\
\hline 22 -Oct-03 & $6,050.10$ & 0.00 & 0.00 & 0.00 & 0.00 & 0.00 & 0.00 & 0.00 \\
\hline $23-O c t-03$ & $6,053.61$ & 0.00 & 73.99 & 0.00 & 0.00 & 0.00 & 0.00 & 0.00 \\
\hline 24-Oct-03 & $4,424.76$ & 0.00 & 151.22 & 149.32 & 0.00 & 0.00 & 0.00 & 0.00 \\
\hline $25-$ Oct- 03 & $6,050.20$ & 0.00 & 0.00 & 0.00 & 0.00 & 0.00 & 0.00 & 0.00 \\
\hline 26-Oct-03 & $6,437.20$ & 0.00 & 0.00 & 0.00 & 0.00 & 0.00 & 0.00 & 0.00 \\
\hline 27-Oct-03 & $5,984.16$ & 0.00 & 71.57 & 71.57 & 0.00 & 0.00 & 0.00 & 0.00 \\
\hline $28-O c t-03$ & $5,872.19$ & 0.00 & 95.15 & 49.26 & 0.00 & 0.00 & 0.00 & 0.00 \\
\hline 29-Oct-03 & $6,055.15$ & 0.00 & 95.25 & 22.40 & 0.00 & 0.00 & 0.00 & 0.00 \\
\hline $30-$ Oct- 03 & $5,880.57$ & 0.00 & 118.97 & 117.46 & 0.00 & 0.00 & 0.00 & 0.00 \\
\hline $31-$ Oct-03 & $5,939.92$ & 0.00 & 141.81 & 145.87 & 0.00 & 0.00 & 0.00 & 0.00 \\
\hline Adjustment & $6,000.00$ & & & & & & & \\
\hline Total Burned & $191,576.46$ & 0.00 & $2,467.48$ & $1,490.56$ & 0.00 & 0.00 & 0.00 & 0.00 \\
\hline Total Delivered & $209,506.85$ & 0.00 & $2,467.48$ & $1,490.56$ & 0.00 & 0.00 & 0.00 & 0.00 \\
\hline $\mathrm{HHV}$ & 8630 & 0 & 15000 & 7187 & 0 & 0 & 0 & 0 \\
\hline$\%$ Ash & $4.83 \%$ & $0.00 \%$ & $7.04 \%$ & $1.10 \%$ & $0.00 \%$ & $0.00 \%$ & $0.00 \%$ & $0.00 \%$ \\
\hline Tons Ash & $9,245.59$ & 0.00 & 51.48 & 12.52 & 0.00 & 0.00 & 0.00 & 0.00 \\
\hline
\end{tabular}




BIG STONE PLANT
FUEL BURN RECORD - page 1
Nov-03

\begin{tabular}{|c|c|c|c|c|c|c|c|c|}
\hline DATE & Coal & P. Coke & TDF & $\begin{array}{l}\text { Waste } \\
\text { Seeds }\end{array}$ & Toner & $\begin{array}{c}\text { Coyote } \\
\text { Lignite }\end{array}$ & $\begin{array}{l}\text { Canvas } \\
\text { Belting } \\
\end{array}$ & $\begin{array}{l}\text { Plastic } \\
\text { Chips }\end{array}$ \\
\hline & (Tons) & (Tons) & (Tons) & (Tons) & (Tons) & (Tons) & (Tons) & (Tons) \\
\hline $1-N o v-03$ & $6,484.30$ & 0.00 & 0.00 & 0.00 & 0.00 & 0.00 & 0.00 & 0.00 \\
\hline 2-Nov-03 & $6,474.40$ & 0.00 & 0.00 & 0.00 & 0.00 & 0.00 & 0.00 & 0.00 \\
\hline $3-\mathrm{Nov}-03$ & $6,412.21$ & 0.00 & 25.77 & 46.72 & 0.00 & 0.00 & 0.00 & 0.00 \\
\hline 4-Nov-03 & $6,243.01$ & 0.00 & 144.47 & 46.62 & 0.00 & 0.00 & 0.00 & 0.00 \\
\hline $5-\mathrm{Nov}-03$ & $6,174.34$ & 0.00 & 50.92 & 122.44 & 0.00 & 0.00 & 0.00 & 0.00 \\
\hline 6-Nov-03 & $6,346.40$ & 0.00 & 49.08 & 22.32 & 0.00 & 0.00 & 0.00 & 0.00 \\
\hline $7-\mathrm{Nov}-03$ & $6,248.46$ & 0.00 & 71.89 & 146.85 & 0.00 & 0.00 & 0.00 & 0.00 \\
\hline 8-Nov-03 & $6,498.10$ & 0.00 & 0.00 & 0.00 & 0.00 & 0.00 & 0.00 & 0.00 \\
\hline 9-Nov-03 & $6,083.10$ & 0.00 & 0.00 & 0.00 & 0.00 & 0.00 & 0.00 & 0.00 \\
\hline 10 -Nov-03 & $6,156.57$ & 0.00 & 116.35 & 99.78 & 0.00 & 0.00 & 0.00 & 0.00 \\
\hline $11-$ Nov-03 & $6,259.45$ & 0.00 & 47.69 & 21.96 & 0.00 & 0.00 & 0.00 & 0.00 \\
\hline $12-\mathrm{Nov}-03$ & $6,308.90$ & 0.00 & 0.00 & 0.00 & 0.00 & 0.00 & 0.00 & 0.00 \\
\hline $13-$ Nov-03 & $6,683.30$ & 0.00 & 0.00 & 0.00 & 0.00 & 0.00 & 0.00 & 0.00 \\
\hline $14-$ Nov-03 & $6,373.22$ & 0.00 & 45.69 & 209.89 & 0.00 & 0.00 & 0.00 & 0.00 \\
\hline 15 -Nov- 03 & $6,382.90$ & 0.00 & 0.00 & 0.00 & 0.00 & 0.00 & 0.00 & 0.00 \\
\hline $16-$ Nov-03 & $6,384.60$ & 0.00 & 0.00 & 0.00 & 0.00 & 0.00 & 0.00 & 0.00 \\
\hline $17-$ Nov- 03 & $6,274.89$ & 0.00 & 98.81 & 0.00 & 0.00 & 0.00 & 0.00 & 0.00 \\
\hline 18 -Nov-03 & $6,086.07$ & 0.00 & 166.07 & 26.16 & 0.00 & 71.00 & 0.00 & 0.00 \\
\hline 19-Nov-03 & $6,099.04$ & 0.00 & 123.90 & 69.86 & 0.00 & 0.00 & 0.00 & 0.00 \\
\hline 20 -Nov-03 & $6,122.30$ & 0.00 & 100.00 & 25.00 & 0.00 & 0.00 & 0.00 & 0.00 \\
\hline 21-Nov-03 & $6,488.06$ & 0.00 & 0.00 & 94.94 & 0.00 & 0.00 & 0.00 & 0.00 \\
\hline $22-$ Nov- 03 & $6,415.90$ & 0.00 & 0.00 & 0.00 & 0.00 & 0.00 & 0.00 & 0.00 \\
\hline $23-\mathrm{Nov}-03$ & $6,336.40$ & 0.00 & 0.00 & 0.00 & 0.00 & 0.00 & 0.00 & 0.00 \\
\hline $24-N o v-03$ & $6,750.64$ & 0.00 & 23.69 & 107.87 & 0.00 & 0.00 & 0.00 & 0.00 \\
\hline $25-\mathrm{Nov}-03$ & $6,614.30$ & 0.00 & 140.83 & 25.57 & 0.00 & 0.00 & 0.00 & 0.00 \\
\hline $26-$ Nov- 03 & $6,731.28$ & 0.00 & 49.32 & 25.80 & 0.00 & 0.00 & 0.00 & 0.00 \\
\hline $27-$ Nov- 03 & $6,078.70$ & 0.00 & 0.00 & 0.00 & 0.00 & 0.00 & 0.00 & 0.00 \\
\hline 28 -Nov- 03 & $6,769.58$ & 0.00 & 22.22 & 0.00 & 0.00 & 0.00 & 0.00 & 0.00 \\
\hline 29-Nov-03 & $6,704.20$ & 0.00 & 0.00 & 0.00 & 0.00 & 0.00 & 0.00 & 0.00 \\
\hline $30-$ Nov-03 & $6,171.30$ & 0.00 & 0.00 & 0.00 & 0.00 & 0.00 & 0.00 & 0.00 \\
\hline Adjustment & $3,000.00$ & & & & & & & \\
\hline Total Burned & $194,155.92$ & 0.00 & $1,276.70$ & $1,091.78$ & 0.00 & 71.00 & 0.00 & 0.00 \\
\hline Total Delivered & $181,630.49$ & 0.00 & $1,276.70$ & $1,091.78$ & 0.00 & 71.00 & 0.00 & 0.00 \\
\hline HHV & 8521 & 0 & 15000 & 7187 & 16932 & 6500 & & \\
\hline$\%$ Ash & $4.77 \%$ & $0.00 \%$ & $7.04 \%$ & $1.10 \%$ & $0.00 \%$ & $0.00 \%$ & & \\
\hline Tons Ash & $9,263.57$ & 0.00 & 89.88 & 12.01 & 0.00 & 0.00 & 0.00 & 0.00 \\
\hline
\end{tabular}




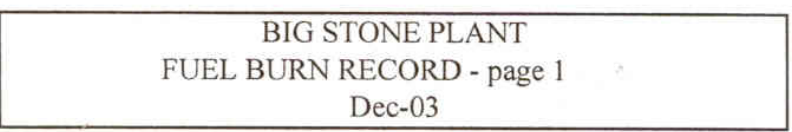

\begin{tabular}{|c|c|c|c|c|c|c|c|c|}
\hline DATE & Coal & P. Coke & TDF & $\begin{array}{l}\text { Waste } \\
\text { Seeds } \\
\end{array}$ & Toner & $\begin{array}{l}\text { Gran. } \\
\text { Insul. }\end{array}$ & $\begin{array}{l}\text { Canvas } \\
\text { Belting } \\
\end{array}$ & $\begin{array}{l}\text { Plastic } \\
\text { Chips }\end{array}$ \\
\hline & (Tons) & (Tons) & (Tons) & (Tons) & (Tons) & (Tons) & (Tons) & (Tons) \\
\hline 1-Dec-03 & $6,499.83$ & 0.00 & 97.26 & 26.21 & 0.00 & 0.00 & 0.00 & 0.00 \\
\hline 2-Dec-03 & $6,494.57$ & 0.00 & 22.17 & 24.39 & 27.17 & 0.00 & 0.00 & 0.00 \\
\hline 3-Dec-03 & $6,512.82$ & 0.00 & 22.21 & 22.57 & 0.00 & 0.00 & 0.00 & 0.00 \\
\hline 4-Dec-03 & $6,367.76$ & 0.00 & 0.00 & 99.74 & 0.00 & 0.00 & 0.00 & 0.00 \\
\hline $5-$ Dec- 03 & $4,476.77$ & 0.00 & 50.83 & 0.00 & 0.00 & 0.00 & 0.00 & 0.00 \\
\hline 6-Dec-03 & 0.00 & 0.00 & 0.00 & 0.00 & 0.00 & 0.00 & 0.00 & 0.00 \\
\hline 7-Dec-03 & 0.00 & 0.00 & 0.00 & 0.00 & 0.00 & 0.00 & 0.00 & 0.00 \\
\hline 8-Dec-03 & 0.00 & 0.00 & 0.00 & 0.00 & 0.00 & 0.00 & 0.00 & 0.00 \\
\hline 9-Dec-03 & 0.00 & 0.00 & 0.00 & 0.00 & 0.00 & 0.00 & 0.00 & 0.00 \\
\hline 10-Dec-03 & 0.00 & 0.00 & 0.00 & 0.00 & 0.00 & 0.00 & 0.00 & 0.00 \\
\hline 11-Dec-03 & 0.00 & 0.00 & 0.00 & 0.00 & 0.00 & 0.00 & 0.00 & 0.00 \\
\hline 12-Dec-03 & 0.00 & 0.00 & 0.00 & 0.00 & 0.00 & 0.00 & 0.00 & 0.00 \\
\hline 13-Dec-03 & 0.00 & 0.00 & 0.00 & 0.00 & 0.00 & 0.00 & 0.00 & 0.00 \\
\hline 14-Dec-03 & 0.00 & 0.00 & 0.00 & 0.00 & 0.00 & 0.00 & 0.00 & 0.00 \\
\hline 15-Dec-03 & 0.00 & 0.00 & 0.00 & 0.00 & 0.00 & 0.00 & 0.00 & 0.00 \\
\hline 16-Dec-03 & 0.00 & 0.00 & 0.00 & 0.00 & 0.00 & 0.00 & 0.00 & 0.00 \\
\hline 17-Dec-03 & 0.00 & 0.00 & 0.00 & 0.00 & 0.00 & 0.00 & 0.00 & 0.00 \\
\hline 18-Dec-03 & 0.00 & 0.00 & 0.00 & 0.00 & 0.00 & 0.00 & 0.00 & 0.00 \\
\hline 19-Dec-03 & 0.00 & 0.00 & 0.00 & 0.00 & 0.00 & 0.00 & 0.00 & 0.00 \\
\hline 20-Dec-03 & 213.10 & 0.00 & 0.00 & 0.00 & 0.00 & 0.00 & 0.00 & 0.00 \\
\hline 21-Dec-03 & $3,794.80$ & 0.00 & 0.00 & 0.00 & 0.00 & 0.00 & 0.00 & 0.00 \\
\hline 22-Dec-03 & $5,939.00$ & 0.00 & 0.00 & 0.00 & 0.00 & 0.00 & 0.00 & 0.00 \\
\hline 23-Dec-03 & $6,188.10$ & 0.00 & 0.00 & 0.00 & 0.00 & 0.00 & 0.00 & 0.00 \\
\hline 24-Dec-03 & $6,275.20$ & 0.00 & 0.00 & 0.00 & 0.00 & 0.00 & 0.00 & 0.00 \\
\hline 25-Dec- 03 & $4,964.70$ & 0.00 & 0.00 & 0.00 & 0.00 & 0.00 & 0.00 & 0.00 \\
\hline 26-Dec-03 & $5,966.36$ & 0.00 & 22.14 & 0.00 & 0.00 & 0.00 & 0.00 & 0.00 \\
\hline 27-Dec-03 & $5,954.60$ & 0.00 & 0.00 & 0.00 & 0.00 & 0.00 & 0.00 & 0.00 \\
\hline 28-Dec-03 & $6,021.40$ & 0.00 & 0.00 & 0.00 & 0.00 & 0.00 & 0.00 & 0.00 \\
\hline 29-Dec-03 & $6,538.93$ & 0.00 & 23.07 & 0.00 & 0.00 & 0.00 & 0.00 & 0.00 \\
\hline 30-Dec-03 & $6,487.71$ & 0.00 & 0.00 & 25.09 & 0.00 & 0.00 & 0.00 & 0.00 \\
\hline 31-Dec-03 & $6,581.50$ & 0.00 & 0.00 & 0.00 & 0.00 & 0.00 & 0.00 & 0.00 \\
\hline Adjustment & $1,000.00$ & & & & & & & \\
\hline Total Burned & $96,277.15$ & 0.00 & 237.68 & 198.00 & 27.17 & 0.00 & 0.00 & 0.00 \\
\hline Total Delivered & $124,513.74$ & 0.00 & 237.68 & 198.00 & 27.17 & 0.00 & 0.00 & 0.00 \\
\hline HHV & 8492 & 0 & 15000 & 7187 & 0 & 0 & 0 & 0 \\
\hline$\%$ Ash & $4.86 \%$ & $0.00 \%$ & $7.04 \%$ & $1.10 \%$ & $0.00 \%$ & $0.00 \%$ & $0.00 \%$ & $0.00 \%$ \\
\hline Tons Ash & $4,679.14$ & 0.00 & 70.76 & 23.60 & 0.00 & 0.00 & 0.00 & 0.00 \\
\hline
\end{tabular}




\begin{tabular}{|c|c|c|c|c|c|c|c|c|}
\hline \multirow[b]{2}{*}{ DATE } & \multirow[b]{2}{*}{ Coal } & \multicolumn{5}{|c|}{$\begin{array}{c}\text { BIG STONE PLANT } \\
\text { FUEL BURN RECORD - page } 1 \\
\text { Jan-04 }\end{array}$} & \multirow[b]{2}{*}{$\begin{array}{l}\text { Canvas } \\
\text { Belting }\end{array}$} & \multirow[b]{2}{*}{$\begin{array}{l}\text { Plastic } \\
\text { Chips }\end{array}$} \\
\hline & & P. Coke & TDF & $\begin{array}{l}\text { Waste } \\
\text { Seeds }\end{array}$ & Toner & $\begin{array}{l}\text { Gran. } \\
\text { Insul. }\end{array}$ & & \\
\hline & (Tons) & (Tons) & (Tons) & (Tons) & (Tons) & (Tons) & (Tons) & (Tons) \\
\hline 1-Jan-04 & $6,298.10$ & 0.00 & 0.00 & 0.00 & 0.00 & 0.00 & 0.00 & 0.00 \\
\hline 2-Jan-04 & $6,031.73$ & 0.00 & 22.42 & 93.55 & 0.00 & 0.00 & 0.00 & 0.00 \\
\hline 3-Jan-04 & $6,490.80$ & 0.00 & 0.00 & 0.00 & 0.00 & 0.00 & 0.00 & 0.00 \\
\hline 4-Jan-04 & $6,644.90$ & 0.00 & 0.00 & 0.00 & 0.00 & 0.00 & 0.00 & 0.00 \\
\hline 5-Jan-04 & $6,604.40$ & 0.00 & 0.00 & 35.70 & 0.00 & 0.00 & 0.00 & 0.00 \\
\hline 6-Jan-04 & $6,618.66$ & 0.00 & 26.00 & 25.64 & 0.00 & 0.00 & 0.00 & 0.00 \\
\hline 7-Jan-04 & $6,569.30$ & 0.00 & 0.00 & 0.00 & 0.00 & 0.00 & -0.00 & 0.00 \\
\hline 8-Jan-04 & $6,659.53$ & 0.00 & 22.88 & 23.09 & 0.00 & 0.00 & 0.00 & 0.00 \\
\hline 9-Jan-04 & $6,619.80$ & 0.00 & 45.94 & 142.36 & 0.00 & 0.00 & 0.00 & 0.00 \\
\hline 10-Jan-04 & $6,670.40$ & 0.00 & 0.00 & 0.00 & 0.00 & 0.00 & 0.00 & 0.00 \\
\hline 11-Jan-04 & $5,849.60$ & 0.00 & 0.00 & 0.00 & 0.00 & 0.00 & 0.00 & 0.00 \\
\hline 12-Jan-04 & $6,277.63$ & 0.00 & 22.52 & 66.25 & 0.00 & 0.00 & 0.00 & 0.00 \\
\hline 13-Jan-04 & $6,098.33$ & 0.00 & 23.07 & 0.00 & 0.00 & 0.00 & 0.00 & 0.00 \\
\hline 14-Jan-04 & $6,496.82$ & 0.00 & 0.00 & 22.88 & 0.00 & 0.00 & 0.00 & 0.00 \\
\hline 15-Jan-04 & $6,398.40$ & 0.00 & 0.00 & 0.00 & 0.00 & 0.00 & 0.00 & 0.00 \\
\hline 16-Jan-04 & $6,395.40$ & 0.00 & 46.31 & 73.99 & 0.00 & 0.00 & 0.00 & 0.00 \\
\hline 17-Jan-04 & $6,236.90$ & 0.00 & 0.00 & 0.00 & 0.00 & 0.00 & 0.00 & 0.00 \\
\hline 18-Jan-04 & $6,743.80$ & 0.00 & 0.00 & 0.00 & 0.00 & 0.00 & 0.00 & 0.00 \\
\hline 19-Jan-04 & $6,715.15$ & 0.00 & 0.00 & 73.45 & 0.00 & 0.00 & 0.00 & 0.00 \\
\hline 20-Jan-04 & $6,685.50$ & 0.00 & 22.47 & 25.43 & 0.00 & 0.00 & 0.00 & 0.00 \\
\hline 21-Jan-04 & $6,479.60$ & 0.00 & 0.00 & 0.00 & 0.00 & 0.00 & 0.00 & 0.00 \\
\hline 22-Jan-04 & $6,444.04$ & 0.00 & 22.97 & 122.59 & 0.00 & 0.00 & 0.00 & 0.00 \\
\hline 23-Jan-04 & $6,446.14$ & 0.00 & 0.00 & 49.86 & 0.00 & 0.00 & 0.00 & 0.00 \\
\hline 24-Jan-04 & $6,688.10$ & 0.00 & 0.00 & 0.00 & 0.00 & 0.00 & 0.00 & 0.00 \\
\hline 25-Jan-04 & $6,613.60$ & 0.00 & 0.00 & 0.00 & 0.00 & 0.00 & 0.00 & 0.00 \\
\hline 26-Jan-04 & $6,632.17$ & 0.00 & 0.00 & 23.63 & 0.00 & 0.00 & 0.00 & 0.00 \\
\hline 27-Jan-04 & $6,768.70$ & 0.00 & 22.30 & 0.00 & 0.00 & 0.00 & 0.00 & 0.00 \\
\hline 28-Jan-04 & $6,777.40$ & 0.00 & 0.00 & 0.00 & 0.00 & 0.00 & 0.00 & 0.00 \\
\hline 29-Jan-04 & $6,738.10$ & 0.00 & 0.00 & 0.00 & 0.00 & 0.00 & 0.00 & 0.00 \\
\hline 30-Jan-04 & $6,630.83$ & 0.00 & 0.00 & 110.17 & 0.00 & 0.00 & 0.00 & 0.00 \\
\hline 31-Jan-04 & $6,853.60$ & 0.00 & 0.00 & 0.00 & 0.00 & 0.00 & 0.00 & 0.00 \\
\hline Adjustment & $3,500.00$ & & & & & & & \\
\hline Total Burned & $205,677.43$ & 0.00 & 276.88 & 888.59 & 0.00 & 0.00 & 0.00 & 0.00 \\
\hline Total Delivered & $177,708.33$ & 0.00 & 276.88 & 888.59 & 0.00 & 0.00 & 0.00 & 0.00 \\
\hline HHV & 8540 & 0 & 15000 & 7187 & 1632 & 0 & 0 & 0 \\
\hline$\%$ Ash & $4.71 \%$ & 0.00 & $7.04 \%$ & $4.00 \%$ & $0.00 \%$ & $0.00 \%$ & $0.00 \%$ & $0.00 \%$ \\
\hline Tons Ash & $9,692.63$ & 0.00 & 19.49 & 35.54 & 0.00 & 0.00 & 0.00 & 0.00 \\
\hline
\end{tabular}




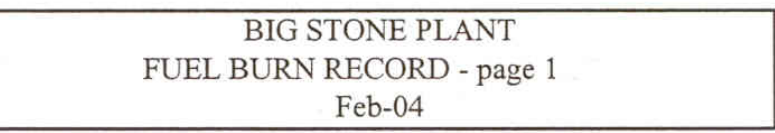

\begin{tabular}{|c|c|c|c|c|c|c|c|c|}
\hline DATE & Coal & P. Coke & TDF & $\begin{array}{l}\text { Waste } \\
\text { Seeds }\end{array}$ & Toner & $\begin{array}{l}\text { Gran. } \\
\text { Insul. }\end{array}$ & $\begin{array}{l}\text { Canvas } \\
\text { Belting } \\
\end{array}$ & $\begin{array}{l}\text { Plastic } \\
\text { Chips } \\
\end{array}$ \\
\hline & (Tons) & (Tons) & (Tons) & (Tons) & (Tons) & (Tons) & (Tons) & (Tons) \\
\hline 1-Feb-04 & $6,271.90$ & 0.00 & 0.00 & 0.00 & 0.00 & 0.00 & 0.00 & 0.00 \\
\hline 2-Feb-04 & $6,495.60$ & 0.00 & 0.00 & 0.00 & 0.00 & 0.00 & 0.00 & 0.00 \\
\hline 3-Feb-04 & $6,676.34$ & 0.00 & 0.00 & 74.26 & 0.00 & 0.00 & 0.00 & 0.00 \\
\hline 4-Feb-04 & $6,867.50$ & 0.00 & 0.00 & 0.00 & 0.00 & 0.00 & 0.00 & 0.00 \\
\hline 5 -Feb-04 & $6,656.28$ & 0.00 & 22.32 & 0.00 & 0.00 & 0.00 & 0.00 & 0.00 \\
\hline 6-Feb-04 & $6,551.50$ & 0.00 & 0.00 & 0.00 & 0.00 & 0.00 & 0.00 & 0.00 \\
\hline 7-Feb-04 & $6,694.10$ & 0.00 & 0.00 & 0.00 & 0.00 & 0.00 & 0.00 & 0.00 \\
\hline 8-Feb-04 & $6,802.10$ & 0.00 & 0.00 & 0.00 & 0.00 & 0.00 & 0.00 & 0.00 \\
\hline 9-Feb-04 & $6,555.50$ & 0.00 & 0.00 & 67.50 & 0.00 & 0.00 & 0.00 & 0.00 \\
\hline 10-Feb-04 & $6,428.92$ & 0.00 & 0.00 & 50.28 & 0.00 & 0.00 & 0.00 & 0.00 \\
\hline 11-Feb-04 & $6,508.50$ & 0.00 & 0.00 & 0.00 & 0.00 & 0.00 & 0.00 & 0.00 \\
\hline 12-Feb-04 & $6,770.16$ & 0.00 & 23.85 & 23.09 & 0.00 & 0.00 & 0.00 & 0.00 \\
\hline 13-Feb-04 & $6,689.70$ & 0.00 & 0.00 & 0.00 & 0.00 & 0.00 & 0.00 & 0.00 \\
\hline 14-Feb-04 & $6,731.40$ & 0.00 & 0.00 & 0.00 & 0.00 & 0.00 & 0.00 & 0.00 \\
\hline $15-F e b-04$ & $6,807.20$ & 0.00 & 0.00 & 0.00 & 0.00 & 0.00 & 0.00 & 0.00 \\
\hline 16-Feb-04 & $6,763.00$ & 0.00 & 22.60 & 0.00 & 0.00 & 0.00 & 0.00 & 0.00 \\
\hline 17-Feb-04 & $6,641.30$ & 0.00 & 0.00 & 0.00 & 0.00 & 0.00 & 0.00 & 0.00 \\
\hline $18-F e b-04$ & $6,703.83$ & 0.00 & 0.00 & 20.67 & 0.00 & 0.00 & 0.00 & 0.00 \\
\hline 19-Feb-04 & $6,538.38$ & 0.00 & 22.02 & 0.00 & 0.00 & 0.00 & 0.00 & 0.00 \\
\hline 20-Feb-04 & $6,568.78$ & 0.00 & 22.82 & 0.00 & 0.00 & 0.00 & 0.00 & 0.00 \\
\hline 21-Feb-04 & $6,781.30$ & 0.00 & 0.00 & 0.00 & 0.00 & 0.00 & 0.00 & 0.00 \\
\hline 22-Feb-04 & $6,488.60$ & 0.00 & 0.00 & 0.00 & 0.00 & 0.00 & 0.00 & 0.00 \\
\hline 23-Feb-04 & $6,756.80$ & 0.00 & 0.00 & 0.00 & 0.00 & 0.00 & 0.00 & 0.00 \\
\hline 24-Feb-04 & $6,797.10$ & 0.00 & 0.00 & 0.00 & 0.00 & 0.00 & 0.00 & 0.00 \\
\hline $25-F e b-04$ & $6,742.48$ & 0.00 & 23.62 & 16.10 & 0.00 & 0.00 & 0.00 & 0.00 \\
\hline 26-Feb-04 & $6,575.00$ & 0.00 & 0.00 & 0.00 & 0.00 & 0.00 & 0.00 & 0.00 \\
\hline $27-F e b-04$ & $6,791.38$ & 0.00 & 22.42 & 0.00 & 0.00 & 0.00 & 0.00 & 0.00 \\
\hline 28 -Feb-04 & $5,821.10$ & 0.00 & 0.00 & 0.00 & 0.00 & 0.00 & 0.00 & 0.00 \\
\hline 29-Feb-04 & $6,755.00$ & 0.00 & 0.00 & 0.00 & 0.00 & 0.00 & 0.00 & 0.00 \\
\hline Adjustment & $1,500.00$ & & & & & & & \\
\hline Total Burned & $193,730.75$ & 0.00 & 159.65 & 251.90 & 0.00 & 0.00 & 0.00 & 0.00 \\
\hline Total Delivered & $186,986.38$ & 0.00 & 159.65 & 251.90 & 0.00 & 0.00 & 0.00 & 0.00 \\
\hline HHV & 8508 & 0 & 15000 & 7187 & 16932 & 0 & 0 & 0 \\
\hline$\%$ Ash & $4.76 \%$ & $0.00 \%$ & $7.05 \%$ & $1.10 \%$ & $0.00 \%$ & $0.00 \%$ & $0.00 \%$ & $0.00 \%$ \\
\hline Tons Ash & $9,220.63$ & 0.00 & 11.26 & 2.77 & 0.00 & 0.00 & 0.00 & 0.00 \\
\hline
\end{tabular}


BIG STONE PLANT

FUEL BURN RECORD - page 1

Mar-04

\begin{tabular}{|c|c|c|c|c|c|c|c|c|}
\hline DATE & Coal & P. Coke & TDF & $\begin{array}{l}\text { Waste } \\
\text { Seeds }\end{array}$ & Toner & $\begin{array}{l}\text { Gran. } \\
\text { Insul. }\end{array}$ & $\begin{array}{l}\text { Canvas } \\
\text { Belting } \\
\end{array}$ & $\begin{array}{l}\text { Plastic } \\
\text { Chips }\end{array}$ \\
\hline & (Tons) & (Tons) & (Tons) & (Tons) & (Tons) & (Tons) & (Tons) & (Tons) \\
\hline 1-Mar-04 & $6,745.64$ & 0.00 & 22.66 & 0.00 & 0.00 & 0.00 & 0.00 & 0.00 \\
\hline 2-Mar-04 & $6,669.80$ & 0.00 & 0.00 & 0.00 & 0.00 & 0.00 & 0.00 & 0.00 \\
\hline 3-Mar-04 & $6,712.50$ & 0.00 & 0.00 & 0.00 & 0.00 & 0.00 & 0.00 & 0.00 \\
\hline 4-Mar-04 & $6,806.30$ & 0.00 & 0.00 & 0.00 & 0.00 & 0.00 & 0.00 & 0.00 \\
\hline 5-Mar-04 & $6,755.47$ & 0.00 & 22.33 & 0.00 & 0.00 & 0.00 & 0.00 & 0.00 \\
\hline 6-Mar-04 & $6,639.10$ & 0.00 & 0.00 & 0.00 & 0.00 & 0.00 & 0.00 & 0.00 \\
\hline 7-Mar-04 & $6,714.90$ & 0.00 & 0.00 & 0.00 & 0.00 & 0.00 & 0.00 & 0.00 \\
\hline 8-Mar-04 & $6,753.55$ & 0.00 & 0.00 & 19.25 & 0.00 & 0.00 & 0.00 & 0.00 \\
\hline 9-Mar-04 & $6,859.30$ & 0.00 & 0.00 & 0.00 & 0.00 & 0.00 & 0.00 & 0.00 \\
\hline 10-Mar-04 & $6,827.09$ & 0.00 & 22.41 & 0.00 & 0.00 & 0.00 & 0.00 & 0.00 \\
\hline 11-Mar-04 & $6,723.99$ & 0.00 & 22.51 & 0.00 & 0.00 & 0.00 & 0.00 & 0.00 \\
\hline 12-Mar-04 & $6,794.60$ & 0.00 & 0.00 & 0.00 & 0.00 & 0.00 & 0.00 & 0.00 \\
\hline 13-Mar-04 & $6,824.50$ & 0.00 & 0.00 & 0.00 & 0.00 & 0.00 & 0.00 & 0.00 \\
\hline 14-Mar-04 & $6,712.40$ & 0.00 & 0.00 & 0.00 & 0.00 & 0.00 & 0.00 & 0.00 \\
\hline 15-Mar-04 & $6,816.55$ & 0.00 & 65.57 & 21.88 & 0.00 & 0.00 & 0.00 & 0.00 \\
\hline 16-Mar-04 & $6,908.70$ & 0.00 & 0.00 & 0.00 & 0.00 & 0.00 & 0.00 & 0.00 \\
\hline 17-Mar-04 & $6,915.80$ & 0.00 & 0.00 & 0.00 & 0.00 & 0.00 & 0.00 & 0.00 \\
\hline 18-Mar-04 & $6,906.30$ & 0.00 & 0.00 & 0.00 & 0.00 & 0.00 & 0.00 & 0.00 \\
\hline 19-Mar-04 & $6,817.39$ & 0.00 & 45.65 & 22.66 & 0.00 & 0.00 & 0.00 & 0.00 \\
\hline 20-Mar-04 & $6,709.60$ & 0.00 & 0.00 & 0.00 & 0.00 & 0.00 & 0.00 & 0.00 \\
\hline 21-Mar-04 & $6,830.10$ & 0.00 & 0.00 & 0.00 & 0.00 & 0.00 & 0.00 & 0.00 \\
\hline 22-Mar-04 & $6,724.85$ & 0.00 & 0.00 & 22.05 & 0.00 & 0.00 & 0.00 & 0.00 \\
\hline 23-Mar-04 & $6,604.00$ & 0.00 & 0.00 & 0.00 & 0.00 & 0.00 & 0.00 & 0.00 \\
\hline 24-Mar-04 & $6,460.41$ & 0.00 & 22.21 & 72.28 & 0.00 & 0.00 & 0.00 & 0.00 \\
\hline 25-Mar-04 & $6,577.85$ & 0.00 & 22.39 & 21.56 & 0.00 & 0.00 & 0.00 & 0.00 \\
\hline 26-Mar-04 & $6,724.83$ & 0.00 & 0.00 & 50.37 & 0.00 & 0.00 & 0.00 & 0.00 \\
\hline 27-Mar-04 & $6,725.10$ & 0.00 & 0.00 & 0.00 & 0.00 & 0.00 & 0.00 & 0.00 \\
\hline 28-Mar-04 & $6,644.50$ & 0.00 & 0.00 & 0.00 & 0.00 & 0.00 & 0.00 & 0.00 \\
\hline 29-Mar-04 & $6,832.19$ & 0.00 & 0.00 & 48.61 & 0.00 & 0.00 & 0.00 & 0.00 \\
\hline 30-Mar-04 & $6,659.98$ & 0.00 & 22.37 & 74.65 & 0.00 & 0.00 & 0.00 & 0.00 \\
\hline 31-Mar-04 & $6,440.37$ & 0.00 & 0.00 & 98.93 & 0.00 & 0.00 & 0.00 & 0.00 \\
\hline Adjustment & $1,200.00$ & & & & & & & \\
\hline Total Burned & $210,037.66$ & 0.00 & 268.10 & 452.24 & 0.00 & 0.00 & 0.00 & 0.00 \\
\hline Total Delivered & $208,077.89$ & 0.00 & 268.10 & 452.24 & 0.00 & 0.00 & 0.00 & 0.00 \\
\hline HHV & 8556 & 0 & 15000 & 7187 & 16932 & 0 & 0 & 0 \\
\hline$\%$ Ash & $4.69 \%$ & $0.00 \%$ & $7.05 \%$ & $1.10 \%$ & $0.00 \%$ & $0.00 \%$ & $0.00 \%$ & $0.00 \%$ \\
\hline Tons Ash & $9,840.55$ & 0.00 & 18.90 & 4.97 & 0.00 & 0.00 & 0.00 & 0.00 \\
\hline
\end{tabular}




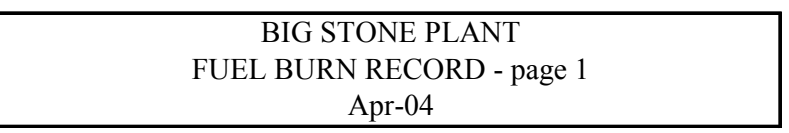

\begin{tabular}{|c|c|c|c|c|c|c|c|c|}
\hline DATE & Coal & P. Coke & TDF & $\begin{array}{l}\text { Waste } \\
\text { Seeds }\end{array}$ & Toner & $\begin{array}{l}\text { Gran. } \\
\text { Insul. }\end{array}$ & $\begin{array}{l}\text { Canvas } \\
\text { Belting }\end{array}$ & $\begin{array}{l}\text { Plastic } \\
\text { Chips }\end{array}$ \\
\hline & (Tons) & (Tons) & (Tons) & (Tons) & (Tons) & (Tons) & (Tons) & (Tons) \\
\hline 1-Apr-04 & $6,572.48$ & 0.00 & 22.84 & 98.88 & 0.00 & 0.00 & 0.00 & 0.00 \\
\hline 2-Apr-04 & $6,711.45$ & 0.00 & 22.17 & 46.78 & 0.00 & 0.00 & 0.00 & 0.00 \\
\hline 3-Apr-04 & $5,523.70$ & 0.00 & 0.00 & 0.00 & 0.00 & 0.00 & 0.00 & 0.00 \\
\hline 4-Apr-04 & $6,039.50$ & 0.00 & 0.00 & 0.00 & 0.00 & 0.00 & 0.00 & 0.00 \\
\hline 5-Apr-04 & $6,139.72$ & 0.00 & 0.00 & 98.68 & 0.00 & 0.00 & 0.00 & 0.00 \\
\hline 6-Apr-04 & $6,472.00$ & 0.00 & 0.00 & 0.00 & 0.00 & 0.00 & 0.00 & 0.00 \\
\hline 7-Apr-04 & $6,481.63$ & 0.00 & 22.40 & 119.97 & 0.00 & 0.00 & 0.00 & 0.00 \\
\hline 8-Apr-04 & $6,613.32$ & 0.00 & 0.00 & 95.68 & 0.00 & 0.00 & 0.00 & 0.00 \\
\hline 9-Apr-04 & $6,665.89$ & 0.00 & 0.00 & 26.51 & 0.00 & 0.00 & 0.00 & 0.00 \\
\hline 10-Apr-04 & $6,709.50$ & 0.00 & 0.00 & 0.00 & 0.00 & 0.00 & 0.00 & 0.00 \\
\hline 11-Apr-04 & $6,726.60$ & 0.00 & 0.00 & 0.00 & 0.00 & 0.00 & 0.00 & 0.00 \\
\hline 12-Apr-04 & $6,358.18$ & 0.00 & 0.00 & 97.32 & 0.00 & 0.00 & 0.00 & 0.00 \\
\hline 13-Apr-04 & $5,728.55$ & 0.00 & 0.00 & 93.85 & 0.00 & 0.00 & 0.00 & 0.00 \\
\hline 14-Apr-04 & $6,138.60$ & 0.00 & 0.00 & 49.20 & 0.00 & 0.00 & 0.00 & 0.00 \\
\hline 15-Apr-04 & $6,302.95$ & 0.00 & 22.39 & 24.06 & 0.00 & 0.00 & 0.00 & 0.00 \\
\hline 16-Apr-04 & $6,532.74$ & 0.00 & 0.00 & 50.06 & 0.00 & 0.00 & 0.00 & 0.00 \\
\hline 17-Apr-04 & $6,463.50$ & 0.00 & 0.00 & 0.00 & 0.00 & 0.00 & 0.00 & 0.00 \\
\hline 18-Apr-04 & $6,499.80$ & 0.00 & 0.00 & 0.00 & 0.00 & 0.00 & 0.00 & 0.00 \\
\hline 19-Apr-04 & $6,689.10$ & 0.00 & 0.00 & 0.00 & 0.00 & 0.00 & 0.00 & 0.00 \\
\hline 20-Apr-04 & $6,659.43$ & 0.00 & 22.27 & 0.00 & 0.00 & 0.00 & 0.00 & 0.00 \\
\hline 21-Apr-04 & $6,591.09$ & 0.00 & 0.00 & 21.81 & 0.00 & 0.00 & 0.00 & 0.00 \\
\hline 22-Apr-04 & $6,803.00$ & 0.00 & 0.00 & 0.00 & 0.00 & 0.00 & 0.00 & 0.00 \\
\hline 23-Apr-04 & $6,680.40$ & 0.00 & 0.00 & 0.00 & 0.00 & 0.00 & 0.00 & 0.00 \\
\hline 24-Apr-04 & 323.90 & 0.00 & 0.00 & 0.00 & 0.00 & 0.00 & 0.00 & 0.00 \\
\hline 25-Apr-04 & $5,039.90$ & 0.00 & 0.00 & 0.00 & 0.00 & 0.00 & 0.00 & 0.00 \\
\hline 26-Apr-04 & $6,479.74$ & 0.00 & 67.77 & 70.49 & 0.00 & 0.00 & 0.00 & 0.00 \\
\hline 27-Apr-04 & $6,604.44$ & 0.00 & 22.79 & 47.97 & 0.00 & 0.00 & 0.00 & 0.00 \\
\hline 28-Apr-04 & $6,163.60$ & 0.00 & 0.00 & 0.00 & 0.00 & 0.00 & 0.00 & 0.00 \\
\hline 29-Apr-04 & $6,644.04$ & 0.00 & 0.00 & 15.36 & 0.00 & 0.00 & 0.00 & 0.00 \\
\hline 30-Apr-04 & $6,537.30$ & 0.00 & 0.00 & 24.30 & 0.00 & 0.00 & 0.00 & 0.00 \\
\hline Adjustment & 0.00 & & & & & & & \\
\hline Total Burned & $185,896.05$ & 0.00 & 202.63 & 980.92 & 0.00 & 0.00 & 0.00 & 0.00 \\
\hline Total Delivered & $196,186.76$ & 0.00 & 202.63 & 980.92 & 0.00 & 0.00 & 0.00 & 0.00 \\
\hline HHV & 8597 & 0 & 15000 & 7187 & 16932 & 0 & 0 & 0 \\
\hline$\%$ Ash & $4.66 \%$ & $0.00 \%$ & $7.05 \%$ & $1.10 \%$ & $0.00 \%$ & $0.00 \%$ & $0.00 \%$ & $0.00 \%$ \\
\hline Tons Ash & $8,658.66$ & 0.00 & 14.29 & 10.79 & 0.00 & 0.00 & 0.00 & 0.00 \\
\hline
\end{tabular}


BIG STONE PLANT

FUEL BURN RECORD - page 1 May-04

\begin{tabular}{|c|c|c|c|c|c|c|c|c|}
\hline DATE & Coal & P. Coke & TDF & $\begin{array}{l}\text { Waste } \\
\text { Seeds }\end{array}$ & Toner & $\begin{array}{l}\text { Gran. } \\
\text { Insul. }\end{array}$ & $\begin{array}{l}\text { Canvas } \\
\text { Belting } \\
\end{array}$ & $\begin{array}{r}\text { Plastic } \\
\text { Chips }\end{array}$ \\
\hline & (Tons) & (Tons) & (Tons) & (Tons) & (Tons) & (Tons) & (Tons) & (Tons) \\
\hline 1-Мay-04 & $6,511.50$ & 0.00 & 0.00 & 0.00 & 0.00 & 0.00 & 0.00 & 0.00 \\
\hline 2-May-04 & $6,541.20$ & 0.00 & 0.00 & 0.00 & 0.00 & 0.00 & 0.00 & 0.00 \\
\hline 3-Мay-04 & $6,625.78$ & 0.00 & 22.32 & 0.00 & 0.00 & 0.00 & 0.00 & 0.00 \\
\hline 4-May-04 & $6,576.44$ & 0.00 & 0.00 & 12.36 & 0.00 & 0.00 & 0.00 & 0.00 \\
\hline 5-May-04 & $6,465.51$ & 0.00 & 47.67 & 25.02 & 0.00 & 0.00 & 0.00 & 0.00 \\
\hline 6-Мay-04 & $6,430.19$ & 0.00 & 91.98 & 42.23 & 0.00 & 0.00 & 0.00 & 0.00 \\
\hline 7-May-04 & $6,415.21$ & 0.00 & 140.49 & 0.00 & 0.00 & 0.00 & 0.00 & 0.00 \\
\hline 8-Мay-04 & $6,550.20$ & 0.00 & 0.00 & 0.00 & 0.00 & 0.00 & 0.00 & 0.00 \\
\hline 9-Мay-04 & $6,401.10$ & 0.00 & 0.00 & 0.00 & 0.00 & 0.00 & 0.00 & 0.00 \\
\hline 10-Маy-04 & $6,421.90$ & 0.00 & 120.00 & 20.00 & 0.00 & 0.00 & 0.00 & 0.00 \\
\hline 11-Мау-04 & $6,416.10$ & 0.00 & 80.00 & 40.00 & 0.00 & 0.00 & 0.00 & 0.00 \\
\hline 12-Маy-04 & $6,307.01$ & 0.00 & 160.00 & 63.99 & 0.00 & 0.00 & 0.00 & 0.00 \\
\hline 13-Мау-04 & $6,222.38$ & 0.00 & 193.12 & 0.00 & 0.00 & 0.00 & 0.00 & 0.00 \\
\hline 14-Мау-04 & $6,285.18$ & 0.00 & 173.71 & 24.51 & 0.00 & 0.00 & 0.00 & 0.00 \\
\hline 15-Мау-04 & $6,443.00$ & 0.00 & 0.00 & 0.00 & 0.00 & 0.00 & 0.00 & 0.00 \\
\hline 16-Мау-04 & $6,479.80$ & 0.00 & 0.00 & 0.00 & 0.00 & 0.00 & 0.00 & 0.00 \\
\hline 17-Мау-04 & $6,494.54$ & 0.00 & 0.00 & 90.46 & 0.00 & 0.00 & 0.00 & 0.00 \\
\hline 18-Маy-04 & $6,658.36$ & 0.00 & 73.93 & 47.71 & 0.00 & 0.00 & 0.00 & 0.00 \\
\hline 19-Мау-04 & $6,398.58$ & 0.00 & 71.60 & 23.52 & 0.00 & 0.00 & 0.00 & 0.00 \\
\hline 20-Маy-04 & $6,723.50$ & 0.00 & 0.00 & 0.00 & 0.00 & 0.00 & 0.00 & 0.00 \\
\hline 21-May-04 & $6,680.82$ & 0.00 & 49.89 & 44.49 & 0.00 & 0.00 & 0.00 & 0.00 \\
\hline 22-Маy-04 & $6,840.70$ & 0.00 & 0.00 & 0.00 & 0.00 & 0.00 & 0.00 & 0.00 \\
\hline 23-Мау-04 & $6,770.40$ & 0.00 & 0.00 & 0.00 & 0.00 & 0.00 & 0.00 & 0.00 \\
\hline 24-May-04 & $6,602.04$ & 0.00 & 122.04 & 63.12 & 0.00 & 0.00 & 0.00 & 0.00 \\
\hline 25-May-04 & $6,529.43$ & 0.00 & 71.65 & 98.32 & 0.00 & 0.00 & 0.00 & 0.00 \\
\hline 26-May-04 & $6,681.67$ & 0.00 & 49.55 & 71.88 & 0.00 & 0.00 & 0.00 & 0.00 \\
\hline 27-Мау-04 & $6,939.00$ & 0.00 & 0.00 & 0.00 & 0.00 & 0.00 & 0.00 & 0.00 \\
\hline 28-May-04 & $6,406.92$ & 0.00 & 47.13 & 69.95 & 0.00 & 0.00 & 0.00 & 0.00 \\
\hline 29-May-04 & $6,233.80$ & 0.00 & 0.00 & 0.00 & 0.00 & 0.00 & 0.00 & 0.00 \\
\hline 30-May-04 & $6,376.20$ & 0.00 & 0.00 & 0.00 & 0.00 & 0.00 & 0.00 & 0.00 \\
\hline 31-Мау-04 & $6,279.80$ & 0.00 & 0.00 & 0.00 & 0.00 & 0.00 & 0.00 & 0.00 \\
\hline Adjustment & $2,000.00$ & & & & & & & \\
\hline Total Burned & $203,708.26$ & 0.00 & $1,515.08$ & 737.56 & 0.00 & 0.00 & 0.00 & 0.00 \\
\hline Total Delivered & $211,380.43$ & 0.00 & $1,515.08$ & 737.56 & 0.00 & 0.00 & 0.00 & 0.00 \\
\hline HHV & 8545 & 0 & 15000 & 7187 & 16932 & 0 & 0 & 0 \\
\hline$\%$ Ash & $4.54 \%$ & $0.00 \%$ & $7.05 \%$ & $1.10 \%$ & $0.00 \%$ & $0.00 \%$ & $0.00 \%$ & $0.00 \%$ \\
\hline Tons Ash & $9,256.53$ & 0.00 & 106.81 & 8.11 & 0.00 & 0.00 & 0.00 & 0.00 \\
\hline
\end{tabular}


BIG STONE PLANT

FUEL BURN RECORD - page 1

Jun-04

\begin{tabular}{|c|c|c|c|c|c|c|c|c|}
\hline DATE & Coal & P. Coke & TDF & $\begin{array}{l}\text { Waste } \\
\text { Seeds }\end{array}$ & Toner & $\begin{array}{l}\text { Gran. } \\
\text { Insul. }\end{array}$ & $\begin{array}{l}\text { Canvas } \\
\text { Belting }\end{array}$ & $\begin{array}{l}\text { Plastic } \\
\text { Chips }\end{array}$ \\
\hline & (Tons) & (Tons) & (Tons) & (Tons) & (Tons) & (Tons) & (Tons) & (Tons) \\
\hline 1-Jun-04 & $6,214.61$ & 0.00 & 52.18 & 70.31 & 0.00 & 0.00 & 0.00 & 0.00 \\
\hline 2-Jun-04 & $6,324.20$ & 0.00 & 47.41 & 94.19 & 0.00 & 0.00 & 0.00 & 0.00 \\
\hline 3-Jun-04 & $6,255.10$ & 0.00 & 0.00 & 0.00 & 0.00 & 0.00 & 0.00 & 0.00 \\
\hline 4-Jun-04 & $4,258.30$ & 0.00 & 0.00 & 0.00 & 0.00 & 0.00 & 0.00 & 0.00 \\
\hline 5-Jun-04 & 0.00 & 0.00 & 0.00 & 0.00 & 0.00 & 0.00 & 0.00 & 0.00 \\
\hline 6-Jun-04 & 0.00 & 0.00 & 0.00 & 0.00 & 0.00 & 0.00 & 0.00 & 0.00 \\
\hline 7-Jun-04 & 0.00 & 0.00 & 0.00 & 0.00 & 0.00 & 0.00 & 0.00 & 0.00 \\
\hline 8-Jun-04 & 0.00 & 0.00 & 0.00 & 0.00 & 0.00 & 0.00 & 0.00 & 0.00 \\
\hline 9-Jun-04 & 0.00 & 0.00 & 0.00 & 0.00 & 0.00 & 0.00 & 0.00 & 0.00 \\
\hline 10-Jun-04 & 0.00 & 0.00 & 0.00 & 0.00 & 0.00 & 0.00 & 0.00 & 0.00 \\
\hline 11-Jun-04 & 0.00 & 0.00 & 0.00 & 0.00 & 0.00 & 0.00 & 0.00 & 0.00 \\
\hline 12-Jun-04 & 212.10 & 0.00 & 0.00 & 0.00 & 0.00 & 0.00 & 0.00 & 0.00 \\
\hline 13-Jun-04 & $5,015.60$ & 0.00 & 0.00 & 0.00 & 0.00 & 0.00 & 0.00 & 0.00 \\
\hline 14-Jun-04 & $6,189.40$ & 0.00 & 0.00 & 0.00 & 0.00 & 0.00 & 0.00 & 0.00 \\
\hline 15-Jun-04 & $6,332.30$ & 0.00 & 0.00 & 0.00 & 0.00 & 0.00 & 0.00 & 0.00 \\
\hline 16-Jun-04 & $6,056.08$ & 0.00 & 173.21 & 66.81 & 0.00 & 0.00 & 0.00 & 0.00 \\
\hline 17-Jun-04 & $5,931.45$ & 0.00 & 129.99 & 117.56 & 0.00 & 0.00 & 0.00 & 0.00 \\
\hline 18-Jun-04 & $5,969.10$ & 0.00 & 100.00 & 0.00 & 0.00 & 0.00 & 0.00 & 0.00 \\
\hline 19-Jun-04 & $5,670.96$ & 0.00 & 100.34 & 0.00 & 0.00 & 0.00 & 0.00 & 0.00 \\
\hline 20-Jun-04 & $5,428.40$ & 0.00 & 0.00 & 0.00 & 0.00 & 0.00 & 0.00 & 0.00 \\
\hline 21-Jun-04 & $5,776.89$ & 0.00 & 93.49 & 22.22 & 0.00 & 0.00 & 0.00 & 0.00 \\
\hline 22-Jun-04 & $5,786.29$ & 0.00 & 73.01 & 23.10 & 0.00 & 0.00 & 0.00 & 0.00 \\
\hline 23-Jun-04 & $6,311.23$ & 0.00 & 155.07 & 0.00 & 0.00 & 0.00 & 0.00 & 0.00 \\
\hline 24-Jun-04 & $6,567.00$ & 0.00 & 0.00 & 0.00 & 0.00 & 0.00 & 0.00 & 0.00 \\
\hline 25-Jun-04 & $6,269.60$ & 0.00 & 122.46 & 39.14 & 0.00 & 0.00 & 0.00 & 0.00 \\
\hline 26-Jun-04 & $5,793.10$ & 0.00 & 100.00 & 0.00 & 0.00 & 0.00 & 0.00 & 0.00 \\
\hline 27-Jun-04 & $5,242.00$ & 0.00 & 100.00 & 0.00 & 0.00 & 0.00 & 0.00 & 0.00 \\
\hline 28-Jun-04 & $5,978.85$ & 0.00 & 96.97 & 44.18 & 0.00 & 0.00 & 0.00 & 0.00 \\
\hline 29-Jun-04 & $6,439.56$ & 0.00 & 95.02 & 49.52 & 0.00 & 0.00 & 0.00 & 0.00 \\
\hline 30-Jun-04 & $6,402.20$ & 0.00 & 0.00 & 0.00 & 0.00 & 0.00 & 0.00 & 0.00 \\
\hline Adjustment & $6,000.00$ & & & & & & & \\
\hline Burned & $136,424.32$ & 0.00 & $1,439.15$ & 527.03 & 0.00 & 0.00 & 0.00 & 0.00 \\
\hline Delivered & $126,893.93$ & 0.00 & $1,439.15$ & 527.03 & 0.00 & 0.00 & 0.00 & 0.00 \\
\hline HHV & 8460 & 0 & 15000 & 7187 & 0 & 0 & 0 & 0 \\
\hline$\%$ Ash & $4.85 \%$ & $0.00 \%$ & $7.04 \%$ & $1.10 \%$ & $0.00 \%$ & $0.00 \%$ & $0.00 \%$ & $0.00 \%$ \\
\hline Tons Ash & $6,611.92$ & 0.00 & 101.32 & 5.80 & 0.00 & 0.00 & 0.00 & 0.00 \\
\hline
\end{tabular}




\begin{tabular}{c}
\hline BIG STONE PLANT \\
FUEL BURN RECORD \\
Jul-04 \\
\hline
\end{tabular}

\begin{tabular}{|c|c|c|c|c|c|c|c|c|}
\hline DATE & Coal & P. Coke & $\mathrm{TDF}$ & $\begin{array}{l}\text { Waste } \\
\text { Seeds }\end{array}$ & Toner & $\begin{array}{l}\text { Gran. } \\
\text { Insul. }\end{array}$ & $\begin{array}{l}\text { Canvas } \\
\text { Belting } \\
\end{array}$ & $\begin{array}{l}\text { Plastic } \\
\text { Chips } \\
\end{array}$ \\
\hline & (Tons) & (Tons) & (Tons) & (Tons) & (Tons) & (Tons) & (Tons) & (Tons) \\
\hline 1-Jul-04 & $6,323.90$ & 0.00 & 100.00 & 50.00 & 0.00 & 0.00 & 0.00 & 0.00 \\
\hline 2-Jul-04 & $6,323.30$ & 0.00 & 0.00 & 0.00 & 0.00 & 0.00 & 0.00 & 0.00 \\
\hline 3-Jul-04 & $6,242.40$ & 0.00 & 0.00 & 0.00 & 0.00 & 0.00 & 0.00 & 0.00 \\
\hline 4-Jul-04 & $5,693.70$ & 0.00 & 0.00 & 0.00 & 0.00 & 0.00 & 0.00 & 0.00 \\
\hline 5-Jul-04 & $5,543.60$ & 0.00 & 0.00 & 0.00 & 0.00 & 0.00 & 0.00 & 0.00 \\
\hline 6-Jul-04 & $5,800.15$ & 0.00 & 204.45 & 0.00 & 0.00 & 0.00 & 0.00 & 0.00 \\
\hline 7-Jul-04 & $5,671.74$ & 0.00 & 337.24 & 46.22 & 0.00 & 0.00 & 0.00 & 0.00 \\
\hline 8-Jul-04 & $6,278.89$ & 0.00 & 96.51 & 0.00 & 0.00 & 0.00 & 0.00 & 0.00 \\
\hline 9-Jul-04 & $6,627.10$ & 0.00 & 120.00 & 0.00 & 0.00 & 0.00 & 0.00 & 0.00 \\
\hline 10-Jul-04 & $6,285.25$ & 0.00 & 238.85 & 0.00 & 0.00 & 0.00 & 0.00 & 0.00 \\
\hline 11-Jul-04 & $6,516.90$ & 0.00 & 0.00 & 0.00 & 0.00 & 0.00 & 0.00 & 0.00 \\
\hline 12-Jul-04 & $6,353.47$ & 0.00 & 178.48 & 23.85 & 0.00 & 0.00 & 0.00 & 0.00 \\
\hline 13-Jul-04 & $6,485.70$ & 0.00 & 0.00 & 0.00 & 0.00 & 0.00 & 0.00 & 0.00 \\
\hline 14-Jul-04 & $1,885.26$ & 0.00 & 241.72 & 200.62 & 0.00 & 0.00 & 0.00 & 0.00 \\
\hline 15-Jul-04 & 226.00 & 0.00 & 0.00 & 0.00 & 0.00 & 0.00 & 0.00 & 0.00 \\
\hline 16-Jul-04 & $5,979.42$ & 0.00 & 24.28 & 108.20 & 0.00 & 0.00 & 0.00 & 0.00 \\
\hline 17-Jul-04 & $6,389.10$ & 0.00 & 0.00 & 0.00 & 0.00 & 0.00 & 0.00 & 0.00 \\
\hline 18-Jul-04 & $6,355.80$ & 0.00 & 0.00 & 0.00 & 0.00 & 0.00 & 0.00 & 0.00 \\
\hline 19-Jul-04 & $6,668.89$ & 0.00 & 0.00 & 1.41 & 0.00 & 0.00 & 0.00 & 0.00 \\
\hline 20-Jul-04 & $1,182.08$ & 0.00 & 283.22 & 0.00 & 0.00 & 0.00 & 0.00 & 0.00 \\
\hline 21-Jul-04 & $4,228.47$ & 0.00 & 46.03 & 0.00 & 0.00 & 0.00 & 0.00 & 0.00 \\
\hline 22-Jul-04 & $4,591.20$ & 0.00 & 0.00 & 0.00 & 0.00 & 0.00 & 0.00 & 0.00 \\
\hline 23-Jul-04 & $3,457.68$ & 0.00 & 67.66 & 28.96 & 0.00 & 0.00 & 0.00 & 0.00 \\
\hline 24-Jul-04 & $5,654.10$ & 0.00 & 0.00 & 0.00 & 0.00 & 0.00 & 0.00 & 0.00 \\
\hline 25-Jul-04 & $6,003.20$ & 0.00 & 0.00 & 0.00 & 0.00 & 0.00 & 0.00 & 0.00 \\
\hline 26-Jul-04 & $6,478.26$ & 0.00 & 114.84 & 0.00 & 0.00 & 0.00 & 0.00 & 0.00 \\
\hline 27-Jul-04 & $5,665.82$ & 0.00 & 167.56 & 22.62 & 0.00 & 0.00 & 0.00 & 0.00 \\
\hline 28-Jul-04 & $5,909.31$ & 0.00 & 192.29 & 0.00 & 0.00 & 0.00 & 0.00 & 0.00 \\
\hline 29-Jul-04 & $5,944.37$ & 0.00 & 167.73 & 0.00 & 0.00 & 0.00 & 0.00 & 0.00 \\
\hline 30-Jul-04 & $5,799.51$ & 0.00 & 167.09 & 0.00 & 0.00 & 0.00 & 0.00 & 0.00 \\
\hline 31-Jul-04 & $5,802.20$ & 0.00 & 200.00 & 0.00 & 0.00 & 0.00 & 0.00 & 0.00 \\
\hline Adjustment & 0.00 & & & & & & & \\
\hline Total Burned & $168,366.77$ & 0.00 & $2,947.95$ & 481.88 & 0.00 & 0.00 & 0.00 & 0.00 \\
\hline Total Delivered & $169,731.25$ & 0.00 & $2,947.95$ & 481.88 & 0.00 & 0.00 & 0.00 & 0.00 \\
\hline HHV & 8485 & 0 & 15000 & 7187 & 16932 & 0 & 0 & 0 \\
\hline$\%$ Ash & $4.69 \%$ & $0.00 \%$ & $7.04 \%$ & $1.10 \%$ & $0.00 \%$ & $0.00 \%$ & $0.00 \%$ & $0.00 \%$ \\
\hline Tons Ash & $7,891.06$ & 0.00 & 207.54 & 5.30 & 0.00 & 0.00 & 0.00 & 0.00 \\
\hline
\end{tabular}




\section{BIG STONE PLANT \\ FUEL BURN RECORD \\ Aug-04}

\begin{tabular}{|c|c|c|c|c|c|c|c|c|}
\hline DATE & Coal & P. Coke & TDF & $\begin{array}{l}\text { Waste } \\
\text { Seeds }\end{array}$ & Toner & $\begin{array}{l}\text { Gran. } \\
\text { Insul. }\end{array}$ & $\begin{array}{l}\text { Canvas } \\
\text { Belting }\end{array}$ & $\begin{array}{l}\text { Plastic } \\
\text { Chips }\end{array}$ \\
\hline & (Tons) & (Tons) & (Tons) & (Tons) & (Tons) & (Tons) & (Tons) & (Tons) \\
\hline 1-Aug-04 & $6,220.00$ & 0.00 & 0.00 & 0.00 & 0.00 & 0.00 & 0.00 & 0.00 \\
\hline 2-Aug-04 & $6,231.90$ & 0.00 & 0.00 & 0.00 & 0.00 & 0.00 & 0.00 & 0.00 \\
\hline 3-Aug-04 & $5,820.97$ & 0.00 & 390.29 & 136.84 & 0.00 & 0.00 & 0.00 & 0.00 \\
\hline 4-Aug-04 & $6,242.70$ & 0.00 & 0.00 & 25.70 & 0.00 & 0.00 & 0.00 & 0.00 \\
\hline 5-Aug-04 & $6,234.70$ & 0.00 & 0.00 & 0.00 & 0.00 & 0.00 & 0.00 & 0.00 \\
\hline 6-Aug-04 & $5,599.51$ & 0.00 & 339.47 & 118.52 & 0.00 & 0.00 & 0.00 & 0.00 \\
\hline 7-Aug-04 & $5,872.30$ & 0.00 & 0.00 & 0.00 & 0.00 & 0.00 & 0.00 & 0.00 \\
\hline 8-Aug-04 & $5,721.00$ & 0.00 & 0.00 & 0.00 & 0.00 & 0.00 & 0.00 & 0.00 \\
\hline 9-Aug-04 & $5,845.91$ & 0.00 & 72.77 & 25.52 & 0.00 & 0.00 & 0.00 & 0.00 \\
\hline 10-Aug-04 & $5,937.55$ & 0.00 & 22.74 & 40.11 & 0.00 & 0.00 & 0.00 & 0.00 \\
\hline 11-Aug-04 & $6,328.43$ & 0.00 & 47.17 & 25.60 & 0.00 & 0.00 & 0.00 & 0.00 \\
\hline 12-Aug-04 & $5,994.00$ & 0.00 & 0.00 & 0.00 & 0.00 & 0.00 & 0.00 & 0.00 \\
\hline 13-Aug-04 & $5,787.90$ & 0.00 & 0.00 & 0.00 & 0.00 & 0.00 & 0.00 & 0.00 \\
\hline 14-Aug-04 & $6,140.30$ & 0.00 & 0.00 & 0.00 & 0.00 & 0.00 & 0.00 & 0.00 \\
\hline 15-Aug-04 & $5,627.30$ & 0.00 & 0.00 & 0.00 & 0.00 & 0.00 & 0.00 & 0.00 \\
\hline 16-Aug-04 & $5,906.56$ & 0.00 & 385.16 & 46.98 & 0.00 & 0.00 & 0.00 & 0.00 \\
\hline 17-Aug-04 & $6,298.44$ & 0.00 & 95.76 & 23.30 & 0.00 & 0.00 & 0.00 & 0.00 \\
\hline 18-Aug-04 & $5,785.59$ & 0.00 & 267.51 & 0.00 & 0.00 & 0.00 & 0.00 & 0.00 \\
\hline 19-Aug-04 & $6,209.00$ & 0.00 & 0.00 & 0.00 & 0.00 & 0.00 & 0.00 & 0.00 \\
\hline 20-Aug-04 & $2,457.97$ & 0.00 & 338.43 & 43.70 & 0.00 & 0.00 & 0.00 & 0.00 \\
\hline 21-Aug-04 & $3,093.40$ & 0.00 & 0.00 & 0.00 & 0.00 & 0.00 & 0.00 & 0.00 \\
\hline 22-Aug-04 & $4,551.70$ & 0.00 & 0.00 & 0.00 & 0.00 & 0.00 & 0.00 & 0.00 \\
\hline 23-Aug-04 & $6,236.43$ & 0.00 & 23.07 & 0.00 & 0.00 & 0.00 & 0.00 & 0.00 \\
\hline 24-Aug-04 & $6,099.90$ & 0.00 & 0.00 & 0.00 & 0.00 & 0.00 & 0.00 & 0.00 \\
\hline 25-Aug-04 & $6,431.44$ & 0.00 & 290.16 & 0.00 & 0.00 & 0.00 & 0.00 & 0.00 \\
\hline 26-Aug-04 & $6,665.00$ & 0.00 & 0.00 & 0.00 & 0.00 & 0.00 & 0.00 & 0.00 \\
\hline 27-Aug-04 & $6,543.40$ & 0.00 & 100.00 & 0.00 & 0.00 & 0.00 & 0.00 & 0.00 \\
\hline 28-Aug-04 & $6,302.70$ & 0.00 & 100.00 & 0.00 & 0.00 & 0.00 & 0.00 & 0.00 \\
\hline 29-Aug-04 & $4,930.14$ & 0.00 & 85.86 & 0.00 & 0.00 & 0.00 & 0.00 & 0.00 \\
\hline 30-Aug-04 & $5,939.43$ & 0.00 & 46.97 & 0.00 & 0.00 & 0.00 & 0.00 & 0.00 \\
\hline 31-Aug-04 & $6,046.79$ & 0.00 & 22.41 & 0.00 & 0.00 & 0.00 & 0.00 & 0.00 \\
\hline Adjustment & 0.00 & & & & & & & \\
\hline Total Burned & $179,102.36$ & 0.00 & $2,627.77$ & 486.27 & 0.00 & 0.00 & 0.00 & 0.00 \\
\hline Total Delivered & $180,630.08$ & 0.00 & $2,627.77$ & 486.27 & 0.00 & 0.00 & 0.00 & 0.00 \\
\hline HHV & 8474 & 0 & 15000 & 7187 & 0 & 0 & 0 & 0 \\
\hline$\%$ Ash & $5.13 \%$ & $0.00 \%$ & $7.04 \%$ & $1.10 \%$ & $0.00 \%$ & $0.00 \%$ & $0.00 \%$ & $0.00 \%$ \\
\hline Tons Ash & $9,195.57$ & 0.00 & 185.00 & 5.35 & 0.00 & 0.00 & 0.00 & 0.00 \\
\hline
\end{tabular}




\begin{tabular}{|c|}
\hline BIG STONE PLANT \\
FUEL BURN RECORD \\
Sep-04
\end{tabular}

\begin{tabular}{|c|c|c|c|c|c|c|c|c|}
\hline DATE & Coal & P. Coke & TDF & $\begin{array}{l}\text { Waste } \\
\text { Seeds }\end{array}$ & Toner & $\begin{array}{l}\text { Gran. } \\
\text { Insul. }\end{array}$ & $\begin{array}{l}\text { Canvas } \\
\text { Belting }\end{array}$ & $\begin{array}{l}\text { Plastic } \\
\text { Chips }\end{array}$ \\
\hline & (Tons) & (Tons) & (Tons) & (Tons) & (Tons) & (Tons) & (Tons) & (Tons) \\
\hline 1-Sep-04 & $6,415.74$ & 0.00 & 49.66 & 0.00 & 0.00 & 0.00 & 0.00 & 0.00 \\
\hline 2-Sep-04 & $6,272.30$ & 0.00 & 0.00 & 0.00 & 0.00 & 0.00 & 0.00 & 0.00 \\
\hline 3-Sep-04 & $6,031.55$ & 0.00 & 271.96 & 47.39 & 0.00 & 0.00 & 0.00 & 0.00 \\
\hline 4-Sep-04 & $6,516.50$ & 0.00 & 0.00 & 0.00 & 0.00 & 0.00 & 0.00 & 0.00 \\
\hline 5-Sep-04 & $6,409.60$ & 0.00 & 0.00 & 0.00 & 0.00 & 0.00 & 0.00 & 0.00 \\
\hline 6-Sep-04 & $5,961.40$ & 0.00 & 0.00 & 0.00 & 0.00 & 0.00 & 0.00 & 0.00 \\
\hline 7-Sep-04 & $5,785.95$ & 0.00 & 240.93 & 45.12 & 0.00 & 0.00 & 0.00 & 0.00 \\
\hline 8-Sep-04 & $5,927.20$ & 0.00 & 0.00 & 0.00 & 0.00 & 0.00 & 0.00 & 0.00 \\
\hline 9-Sep-04 & $6,066.87$ & 0.00 & 192.03 & 0.00 & 0.00 & 0.00 & 0.00 & 0.00 \\
\hline 10 -Sep-04 & $6,162.54$ & 0.00 & 191.46 & 0.00 & 0.00 & 0.00 & 0.00 & 0.00 \\
\hline 11-Sep-04 & $6,462.20$ & 0.00 & 0.00 & 0.00 & 0.00 & 0.00 & 0.00 & 0.00 \\
\hline 12-Sep-04 & $6,045.30$ & 0.00 & 0.00 & 0.00 & 0.00 & 0.00 & 0.00 & 0.00 \\
\hline 13-Sep-04 & $5,949.24$ & 0.00 & 187.26 & 0.00 & 0.00 & 0.00 & 0.00 & 0.00 \\
\hline 14-Sep-04 & $6,353.24$ & 0.00 & 172.26 & 0.00 & 0.00 & 0.00 & 0.00 & 0.00 \\
\hline 15 -Sep-04 & $6,226.68$ & 0.00 & 299.12 & 0.00 & 0.00 & 0.00 & 0.00 & 0.00 \\
\hline 16-Sep-04 & $6,022.77$ & 0.00 & 122.53 & 0.00 & 0.00 & 0.00 & 0.00 & 0.00 \\
\hline 17-Sep-04 & $6,325.42$ & 0.00 & 140.45 & 46.43 & 0.00 & 0.00 & 0.00 & 0.00 \\
\hline 18-Sep-04 & $6,686.60$ & 0.00 & 0.00 & 0.00 & 0.00 & 0.00 & 0.00 & 0.00 \\
\hline 19-Sep-04 & $6,205.90$ & 0.00 & 0.00 & 0.00 & 0.00 & 0.00 & 0.00 & 0.00 \\
\hline 20-Sep-04 & $6,315.21$ & 0.00 & 158.07 & 26.12 & 0.00 & 0.00 & 0.00 & 0.00 \\
\hline 21-Sep-04 & $6,352.20$ & 0.00 & 0.00 & 0.00 & 0.00 & 0.00 & 0.00 & 0.00 \\
\hline 22-Sep-04 & $6,701.10$ & 0.00 & 0.00 & 0.00 & 0.00 & 0.00 & 0.00 & 0.00 \\
\hline 23-Sep-04 & $6,808.50$ & 0.00 & 0.00 & 0.00 & 0.00 & 0.00 & 0.00 & 0.00 \\
\hline 24-Sep-04 & $6,453.00$ & 0.00 & 146.90 & 0.00 & 0.00 & 0.00 & 0.00 & 0.00 \\
\hline 25-Sep-04 & $6,275.80$ & 0.00 & 100.00 & 0.00 & 0.00 & 0.00 & 0.00 & 0.00 \\
\hline 26-Sep-04 & $5,974.60$ & 0.00 & 100.00 & 0.00 & 0.00 & 0.00 & 0.00 & 0.00 \\
\hline 27-Sep-04 & $3,991.58$ & 0.00 & 45.42 & 0.00 & 0.00 & 0.00 & 0.00 & 0.00 \\
\hline 28-Sep-04 & 443.90 & 0.00 & 0.00 & 0.00 & 0.00 & 0.00 & 0.00 & 0.00 \\
\hline 29-Sep-04 & $6,174.22$ & 0.00 & 94.58 & 0.00 & 0.00 & 0.00 & 0.00 & 0.00 \\
\hline $30-$ Sep-04 & $6,337.12$ & 0.00 & 95.08 & 0.00 & 0.00 & 0.00 & 0.00 & 0.00 \\
\hline Adjustment & $-1,500.00$ & & & & & & & \\
\hline Total Burned & $178,154.23$ & 0.00 & $2,607.71$ & 165.06 & 0.00 & 0.00 & 0.00 & 0.00 \\
\hline Total Delivered & $181,803.11$ & 0.00 & $2,607.71$ & 165.06 & 0.00 & 0.00 & 0.00 & 0.00 \\
\hline HHV & 8506 & 0 & 15000 & 7187 & 0 & 0 & 0 & 0 \\
\hline$\%$ Ash & $4.66 \%$ & 0.00 & $7.04 \%$ & $1.10 \%$ & $0.00 \%$ & $0.00 \%$ & $0.00 \%$ & $0.00 \%$ \\
\hline Tons Ash & $8,302.79$ & 0.00 & 51.48 & 12.52 & 0.00 & 0.00 & 0.00 & 0.00 \\
\hline
\end{tabular}




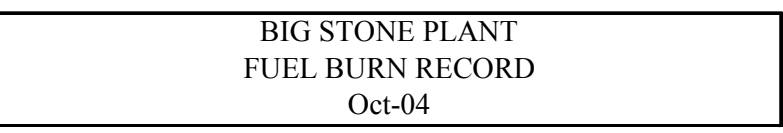

\begin{tabular}{|c|c|c|c|c|c|c|c|c|}
\hline DATE & Coal & P. Coke & TDF & $\begin{array}{l}\text { Waste } \\
\text { Seeds }\end{array}$ & Toner & $\begin{array}{l}\text { Gran. } \\
\text { Insul. }\end{array}$ & $\begin{array}{l}\text { Canvas } \\
\text { Belting }\end{array}$ & $\begin{array}{l}\text { Plastic } \\
\text { Chips }\end{array}$ \\
\hline & (Tons) & (Tons) & (Tons) & (Tons) & (Tons) & (Tons) & (Tons) & (Tons) \\
\hline 1-Oct-04 & $6,130.30$ & 0.00 & 200.00 & 0.00 & 0.00 & 0.00 & 0.00 & 0.00 \\
\hline 2-Oct-04 & $6,031.00$ & 0.00 & 200.00 & 0.00 & 0.00 & 0.00 & 0.00 & 0.00 \\
\hline 3-Oct-04 & $6,217.15$ & 0.00 & 143.65 & 0.00 & 0.00 & 0.00 & 0.00 & 0.00 \\
\hline 4-Oct-04 & $6,171.00$ & 0.00 & 0.00 & 0.00 & 0.00 & 0.00 & 0.00 & 0.00 \\
\hline 5-Oct-04 & $6,385.43$ & 0.00 & 166.07 & 0.00 & 0.00 & 0.00 & 0.00 & 0.00 \\
\hline 6-Oct-04 & $6,571.88$ & 0.00 & 47.42 & 0.00 & 0.00 & 0.00 & 0.00 & 0.00 \\
\hline 7-Oct-04 & $6,634.81$ & 0.00 & 45.69 & 0.00 & 0.00 & 0.00 & 0.00 & 0.00 \\
\hline 8-Oct-04 & $6,408.54$ & 0.00 & 193.26 & 0.00 & 0.00 & 0.00 & 0.00 & 0.00 \\
\hline 9-Oct-04 & $6,794.10$ & 0.00 & 0.00 & 0.00 & 0.00 & 0.00 & 0.00 & 0.00 \\
\hline 10 -Oct-04 & $6,057.80$ & 0.00 & 0.00 & 0.00 & 0.00 & 0.00 & 0.00 & 0.00 \\
\hline 11-Oct-04 & $6,502.70$ & 0.00 & 0.00 & 0.00 & 0.00 & 0.00 & 0.00 & 0.00 \\
\hline 12-Oct-04 & $6,675.90$ & 0.00 & 0.00 & 0.00 & 0.00 & 0.00 & 0.00 & 0.00 \\
\hline 13-Oct-04 & $6,585.30$ & 0.00 & 0.00 & 0.00 & 0.00 & 0.00 & 0.00 & 0.00 \\
\hline $14-$ Oct-04 & $6,638.40$ & 0.00 & 0.00 & 0.00 & 0.00 & 0.00 & 0.00 & 0.00 \\
\hline 15 -Oct-04 & $5,361.65$ & 0.00 & 789.23 & 70.52 & 0.00 & 0.00 & 0.00 & 0.00 \\
\hline $16-O c t-04$ & $6,483.40$ & 0.00 & 0.00 & 0.00 & 0.00 & 0.00 & 0.00 & 0.00 \\
\hline 17-Oct-04 & $6,468.40$ & 0.00 & 0.00 & 0.00 & 0.00 & 0.00 & 0.00 & 0.00 \\
\hline 18-Oct-04 & $6,409.92$ & 0.00 & 23.38 & 0.00 & 0.00 & 0.00 & 0.00 & 0.00 \\
\hline 19-Oct-04 & $6,596.53$ & 0.00 & 44.87 & 0.00 & 0.00 & 0.00 & 0.00 & 0.00 \\
\hline 20-Oct-04 & $6,507.18$ & 0.00 & 68.82 & 0.00 & 0.00 & 0.00 & 0.00 & 0.00 \\
\hline 21-Oct-04 & $6,512.10$ & 0.00 & 0.00 & 0.00 & 0.00 & 0.00 & 0.00 & 0.00 \\
\hline 22-Oct-04 & $5,183.16$ & 0.00 & 46.24 & 0.00 & 0.00 & 0.00 & 0.00 & 0.00 \\
\hline 23-Oct-04 & 0.00 & 0.00 & 0.00 & 0.00 & 0.00 & 0.00 & 0.00 & 0.00 \\
\hline 24-Oct-04 & 0.00 & 0.00 & 0.00 & 0.00 & 0.00 & 0.00 & 0.00 & 0.00 \\
\hline $25-O c t-04$ & 0.00 & 0.00 & 0.00 & 0.00 & 0.00 & 0.00 & 0.00 & 0.00 \\
\hline 26-Oct-04 & 0.00 & 0.00 & 0.00 & 0.00 & 0.00 & 0.00 & 0.00 & 0.00 \\
\hline 27-Oct-04 & 0.00 & 0.00 & 0.00 & 0.00 & 0.00 & 0.00 & 0.00 & 0.00 \\
\hline 28-Oct-04 & 0.00 & 0.00 & 0.00 & 0.00 & 0.00 & 0.00 & 0.00 & 0.00 \\
\hline 29-Oct-04 & 0.00 & 0.00 & 0.00 & 0.00 & 0.00 & 0.00 & 0.00 & 0.00 \\
\hline 30-Oct-04 & $2,415.80$ & 0.00 & 0.00 & 0.00 & 0.00 & 0.00 & 0.00 & 0.00 \\
\hline 31-Oct-04 & $4,298.53$ & 0.00 & 0.00 & 45.37 & 0.00 & 0.00 & 0.00 & 0.00 \\
\hline Adjustment & 0.00 & & & & & & & \\
\hline Total Burned & $146,040.98$ & 0.00 & $1,968.63$ & 115.89 & 0.00 & 0.00 & 0.00 & 0.00 \\
\hline Total Delivered & $139,115.98$ & 0.00 & $1,968.63$ & 115.89 & 0.00 & 0.00 & 0.00 & 0.00 \\
\hline HHV & 8453 & 0 & 15000 & 7187 & 0 & 0 & 0 & 0 \\
\hline$\%$ Ash & $4.77 \%$ & $0.00 \%$ & $7.04 \%$ & $1.10 \%$ & $0.00 \%$ & $0.00 \%$ & $0.00 \%$ & $0.00 \%$ \\
\hline Tons Ash & $6,963.15$ & 0.00 & 51.48 & 12.52 & 0.00 & 0.00 & 0.00 & 0.00 \\
\hline
\end{tabular}




\begin{tabular}{c}
\hline BIG STONE PLANT \\
FUEL BURN RECORD \\
Nov-04 \\
\hline
\end{tabular}

\begin{tabular}{|c|c|c|c|c|c|c|c|c|}
\hline DATE & Coal & P. Coke & TDF & $\begin{array}{l}\text { Waste } \\
\text { Seeds }\end{array}$ & Toner & $\begin{array}{l}\text { Gran. } \\
\text { Insul. }\end{array}$ & $\begin{array}{l}\text { Canvas } \\
\text { Belting } \\
\end{array}$ & $\begin{array}{l}\text { Plastic } \\
\text { Chips } \\
\end{array}$ \\
\hline & (Tons) & (Tons) & (Tons) & (Tons) & (Tons) & (Tons) & (Tons) & (Tons) \\
\hline 1-Nov-04 & $6,456.19$ & 0.00 & 0.00 & 23.11 & 0.00 & 0.00 & 0.00 & 0.00 \\
\hline 2-Nov-04 & $6,847.50$ & 0.00 & 27.60 & 0.00 & 0.00 & 0.00 & 0.00 & 0.00 \\
\hline 3-Nov-04 & $6,708.27$ & 0.00 & 121.74 & 24.79 & 0.00 & 0.00 & 0.00 & 0.00 \\
\hline 4-Nov-04 & $6,370.60$ & 0.00 & 0.00 & 0.00 & 0.00 & 0.00 & 0.00 & 0.00 \\
\hline 5-Nov-04 & $6,521.10$ & 0.00 & 100.00 & 50.00 & 0.00 & 0.00 & 0.00 & 0.00 \\
\hline 6-Nov-04 & $6,009.25$ & 0.00 & 100.00 & 22.95 & 0.00 & 0.00 & 0.00 & 0.00 \\
\hline 7-Nov-04 & $6,376.55$ & 0.00 & 91.75 & 0.00 & 0.00 & 0.00 & 0.00 & 0.00 \\
\hline 8-Nov-04 & $6,417.37$ & 0.00 & 215.61 & 22.82 & 0.00 & 0.00 & 0.00 & 0.00 \\
\hline 9-Nov-04 & $6,218.32$ & 0.00 & 22.59 & 47.99 & 0.00 & 0.00 & 0.00 & 0.00 \\
\hline 10-Nov-04 & $6,489.40$ & 0.00 & 0.00 & 0.00 & 0.00 & 0.00 & 0.00 & 0.00 \\
\hline 11-Nov-04 & $6,474.60$ & 0.00 & 0.00 & 0.00 & 0.00 & 0.00 & 0.00 & 0.00 \\
\hline 12-Nov-04 & $6,045.24$ & 0.00 & 214.64 & 72.92 & 0.00 & 0.00 & 0.00 & 0.00 \\
\hline 13-Nov-04 & $6,169.70$ & 0.00 & 200.00 & 65.00 & 0.00 & 0.00 & 0.00 & 0.00 \\
\hline 14-Nov-04 & $5,955.90$ & 0.00 & 200.00 & 65.00 & 0.00 & 0.00 & 0.00 & 0.00 \\
\hline 15-Nov-04 & $6,288.28$ & 0.00 & 190.31 & 165.61 & 0.00 & 0.00 & 0.00 & 0.00 \\
\hline 16-Nov-04 & $6,417.52$ & 0.00 & 48.24 & 120.64 & 0.00 & 0.00 & 0.00 & 0.00 \\
\hline 17-Nov-04 & $6,650.68$ & 0.00 & 47.43 & 25.39 & 0.00 & 0.00 & 0.00 & 0.00 \\
\hline 18-Nov-04 & $6,640.60$ & 0.00 & 50.00 & 25.00 & 0.00 & 0.00 & 0.00 & 0.00 \\
\hline 19-Nov-04 & $6,235.15$ & 0.00 & 324.85 & 204.40 & 0.00 & 0.00 & 0.00 & 0.00 \\
\hline 20-Nov-04 & $6,092.50$ & 0.00 & 0.00 & 0.00 & 0.00 & 0.00 & 0.00 & 0.00 \\
\hline 21-Nov-04 & $6,340.50$ & 0.00 & 0.00 & 0.00 & 0.00 & 0.00 & 0.00 & 0.00 \\
\hline 22-Nov-04 & $6,398.38$ & 0.00 & 161.30 & 25.02 & 0.00 & 0.00 & 0.00 & 0.00 \\
\hline 23-Nov-04 & $6,683.58$ & 0.00 & 93.60 & 77.32 & 0.00 & 0.00 & 0.00 & 0.00 \\
\hline 24-Nov-04 & $6,736.00$ & 0.00 & 210.00 & 0.00 & 0.00 & 0.00 & 0.00 & 0.00 \\
\hline 25-Nov-04 & $6,029.40$ & 0.00 & 30.00 & 0.00 & 0.00 & 0.00 & 0.00 & 0.00 \\
\hline 26-Nov-04 & $6,286.24$ & 0.00 & 0.00 & 25.16 & 0.00 & 0.00 & 0.00 & 0.00 \\
\hline 27-Nov-04 & $6,447.20$ & 0.00 & 0.00 & 0.00 & 0.00 & 0.00 & 0.00 & 0.00 \\
\hline 28-Nov-04 & $6,711.20$ & 0.00 & 0.00 & 0.00 & 0.00 & 0.00 & 0.00 & 0.00 \\
\hline 29-Nov-04 & $6,674.38$ & 0.00 & 134.27 & 24.95 & 0.00 & 0.00 & 0.00 & 0.00 \\
\hline 30-Nov-04 & $6,533.88$ & 0.00 & 118.67 & 49.55 & 0.00 & 0.00 & 0.00 & 0.00 \\
\hline Adjustment & 0.00 & & & & & & & \\
\hline Total Burned & $192,225.48$ & 0.00 & $2,702.60$ & $1,137.62$ & 0.00 & 0.00 & 0.00 & 0.00 \\
\hline Total Delivered & $179,452.91$ & 0.00 & $2,702.60$ & $1,137.62$ & 0.00 & 0.00 & 0.00 & 0.00 \\
\hline HHV & 8535 & 0 & 15000 & 7187 & 16932 & 6500 & & \\
\hline$\%$ Ash & $4.63 \%$ & $0.00 \%$ & $7.04 \%$ & $1.10 \%$ & $0.00 \%$ & $0.00 \%$ & & \\
\hline Tons Ash & $8,899.99$ & 0.00 & 190.26 & 12.51 & 0.00 & 0.00 & 0.00 & 0.00 \\
\hline
\end{tabular}




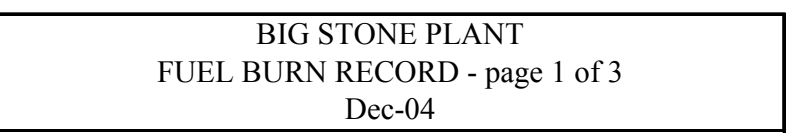

\begin{tabular}{|c|c|c|c|c|c|c|c|c|}
\hline DATE & Coal & P. Coke & TDF & $\begin{array}{l}\text { Waste } \\
\text { Seeds }\end{array}$ & Toner & $\begin{array}{l}\text { Gran. } \\
\text { Insul. }\end{array}$ & $\begin{array}{l}\text { Canvas } \\
\text { Belting } \\
\end{array}$ & $\begin{array}{l}\text { Plastic } \\
\text { Chips } \\
\end{array}$ \\
\hline & (Tons) & (Tons) & (Tons) & (Tons) & (Tons) & (Tons) & (Tons) & (Tons) \\
\hline 1-Dec-04 & $6,677.28$ & 0.00 & 126.45 & 73.87 & 0.00 & 0.00 & 0.00 & 0.00 \\
\hline 2-Dec-04 & $7,045.90$ & 0.00 & 0.00 & 0.00 & 0.00 & 0.00 & 0.00 & 0.00 \\
\hline 3-Dec-04 & $6,664.19$ & 0.00 & 147.63 & 100.08 & 0.00 & 0.00 & 0.00 & 0.00 \\
\hline 4-Dec-04 & $6,638.10$ & 0.00 & 0.00 & 0.00 & 0.00 & 0.00 & 0.00 & 0.00 \\
\hline 5-Dec-04 & $6,724.80$ & 0.00 & 0.00 & 0.00 & 0.00 & 0.00 & 0.00 & 0.00 \\
\hline 6-Dec-04 & $6,484.83$ & 0.00 & 141.25 & 26.02 & 0.00 & 0.00 & 0.00 & 0.00 \\
\hline 7-Dec-04 & $6,873.00$ & 0.00 & 0.00 & 0.00 & 0.00 & 0.00 & 0.00 & 0.00 \\
\hline 8-Dec-04 & $6,631.28$ & 0.00 & 190.00 & 50.22 & 0.00 & 0.00 & 0.00 & 0.00 \\
\hline 9-Dec-04 & $6,765.40$ & 0.00 & 0.00 & 0.00 & 0.00 & 0.00 & 0.00 & 0.00 \\
\hline 10-Dec-04 & $6,351.80$ & 0.00 & 228.32 & 22.88 & 0.00 & 0.00 & 0.00 & 0.00 \\
\hline 11-Dec-04 & $6,512.10$ & 0.00 & 125.00 & 0.00 & 0.00 & 0.00 & 0.00 & 0.00 \\
\hline 12-Dec-04 & $6,737.90$ & 0.00 & 0.00 & 0.00 & 0.00 & 0.00 & 0.00 & 0.00 \\
\hline 13-Dec-04 & $6,769.40$ & 0.00 & 165.91 & 23.09 & 0.00 & 0.00 & 0.00 & 0.00 \\
\hline 14-Dec-04 & $6,785.82$ & 0.00 & 95.48 & 0.00 & 0.00 & 0.00 & 0.00 & 0.00 \\
\hline 15-Dec-04 & $6,783.30$ & 0.00 & 0.00 & 0.00 & 0.00 & 0.00 & 0.00 & 0.00 \\
\hline 16-Dec-04 & $6,761.13$ & 0.00 & 74.93 & 23.74 & 0.00 & 0.00 & 0.00 & 0.00 \\
\hline 17-Dec-04 & $6,611.05$ & 0.00 & 254.18 & 24.37 & 0.00 & 0.00 & 0.00 & 0.00 \\
\hline 18-Dec-04 & $6,890.00$ & 0.00 & 200.00 & 0.00 & 0.00 & 0.00 & 0.00 & 0.00 \\
\hline 19-Dec-04 & $6,831.30$ & 0.00 & 200.00 & 0.00 & 0.00 & 0.00 & 0.00 & 0.00 \\
\hline 20-Dec-04 & $6,657.30$ & 0.00 & 0.00 & 0.00 & 0.00 & 0.00 & 0.00 & 0.00 \\
\hline 21-Dec-04 & $6,718.65$ & 0.00 & 117.58 & 22.07 & 0.00 & 0.00 & 0.00 & 0.00 \\
\hline 22-Dec-04 & $6,911.80$ & 0.00 & 0.00 & 0.00 & 0.00 & 0.00 & 0.00 & 0.00 \\
\hline 23-Dec-04 & $6,918.50$ & 0.00 & 0.00 & 0.00 & 0.00 & 0.00 & 0.00 & 0.00 \\
\hline 24-Dec-04 & $6,886.90$ & 0.00 & 0.00 & 0.00 & 0.00 & 0.00 & 0.00 & 0.00 \\
\hline 25-Dec-04 & $6,979.80$ & 0.00 & 0.00 & 0.00 & 0.00 & 0.00 & 0.00 & 0.00 \\
\hline 26-Dec-04 & $6,927.60$ & 0.00 & 0.00 & 0.00 & 0.00 & 0.00 & 0.00 & 0.00 \\
\hline 27-Dec-04 & $6,692.44$ & 0.00 & 267.76 & 0.00 & 0.00 & 0.00 & 0.00 & 0.00 \\
\hline 28-Dec-04 & $5,440.52$ & 0.00 & 181.78 & 0.00 & 0.00 & 0.00 & 0.00 & 0.00 \\
\hline 29-Dec-04 & $6,224.12$ & 0.00 & 254.10 & 87.68 & 0.00 & 0.00 & 0.00 & 0.00 \\
\hline 30-Dec-04 & $6,573.70$ & 0.00 & 0.00 & 0.00 & 0.00 & 0.00 & 0.00 & 0.00 \\
\hline 31-Dec-04 & $6,559.53$ & 0.00 & 50.27 & 0.00 & 0.00 & 0.00 & 0.00 & 0.00 \\
\hline Adjustment & $-5,500.00$ & & & & & & & \\
\hline Total Burned & $201,529.44$ & 0.00 & $2,820.64$ & 454.02 & 0.00 & 0.00 & 0.00 & 0.00 \\
\hline Total Delivered & $207,087.84$ & 0.00 & $2,820.64$ & 454.02 & 0.00 & 0.00 & 0.00 & 0.00 \\
\hline HHV & 8532 & 0 & 15000 & 7187 & 0 & 0 & 0 & 0 \\
\hline$\%$ Ash & $4.66 \%$ & $0.00 \%$ & $7.04 \%$ & $1.10 \%$ & $0.00 \%$ & $0.00 \%$ & $0.00 \%$ & $0.00 \%$ \\
\hline Tons Ash & $9,388.17$ & 0.00 & 70.76 & 23.60 & 0.00 & 0.00 & 0.00 & 0.00 \\
\hline
\end{tabular}


B15 Fuel Analysis Record

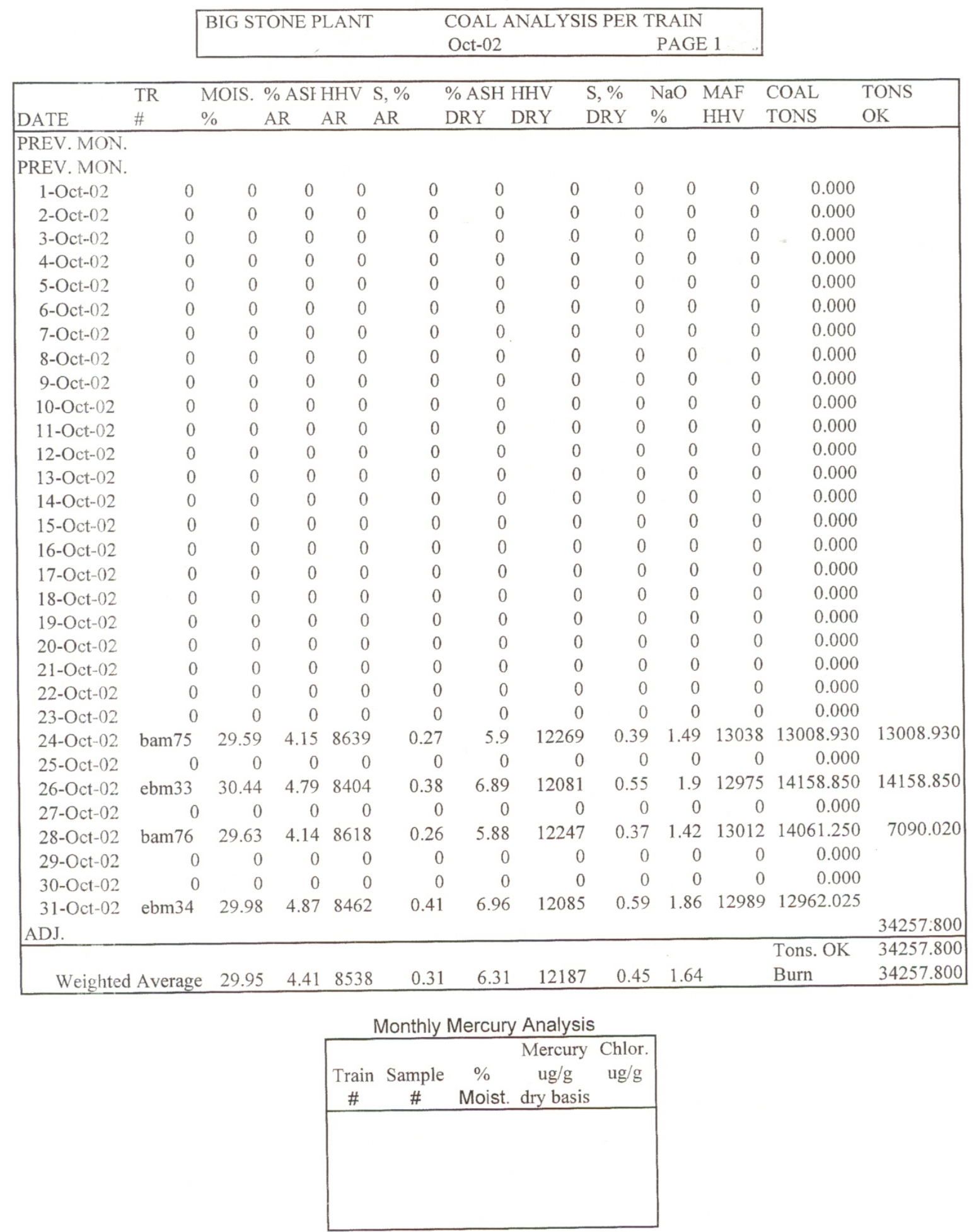




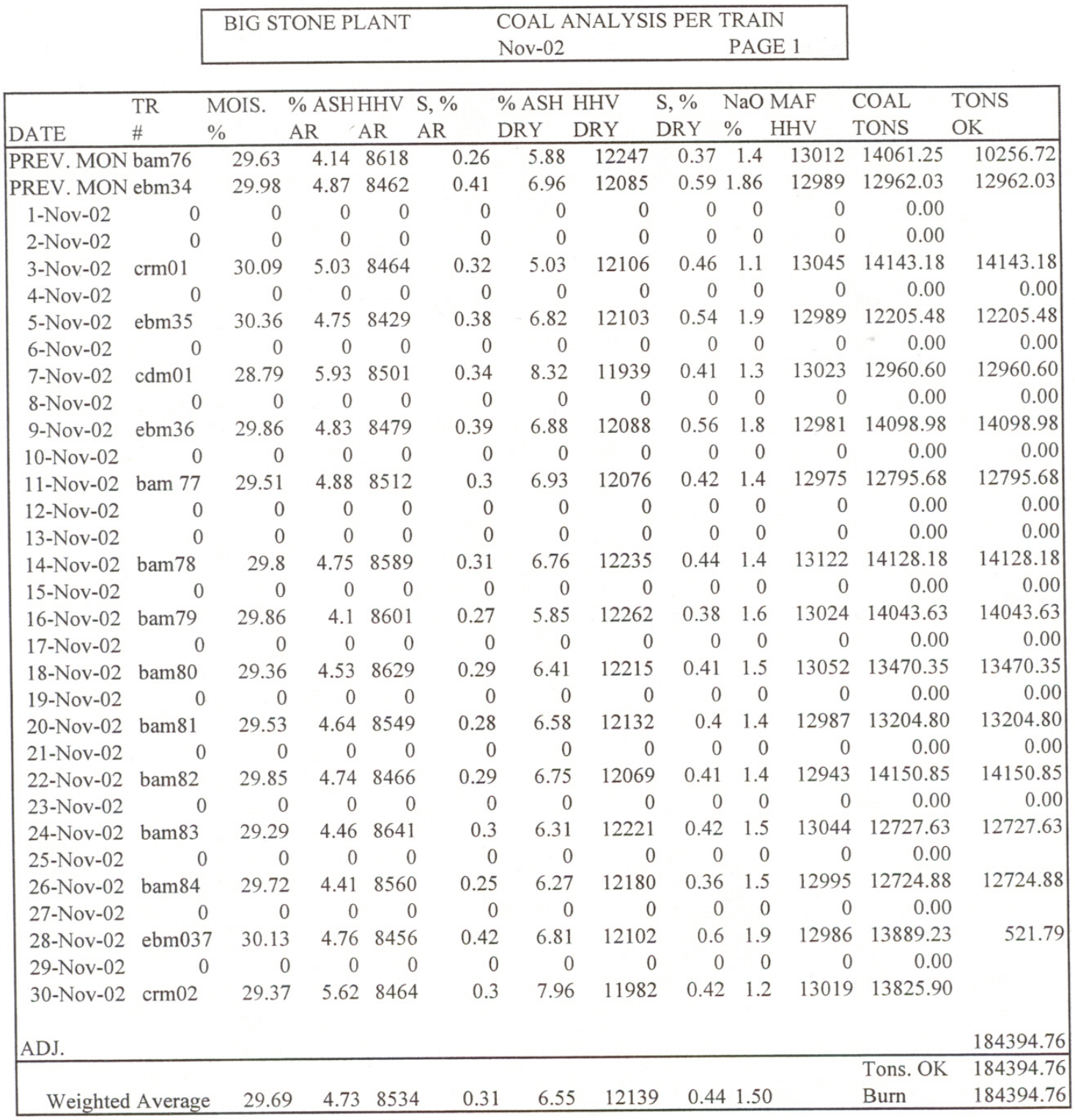

\begin{tabular}{|ccccc|}
\multicolumn{7}{c}{ Monthly Mercury Analysis } \\
\hline Train & Sample & $\%$ & Mercury & Chlor. \\
$\#$ & $\#$ & Moist. & dry basis & ug/g \\
\hline & C2489 & 30.15 & 0.11 & $<0.01$ \\
& & & & \\
& & & \\
& & & \\
\end{tabular}


BIG STONE PLANT COAL ANALYSIS PER TRAIN Dec-02

PAGE 1

\begin{tabular}{|c|c|c|c|c|c|c|c|c|c|c|c|c|}
\hline \multirow[b]{2}{*}{ DATE } & \multirow{2}{*}{$\begin{array}{l}\text { TR } \\
\#\end{array}$} & \multicolumn{3}{|c|}{ MOIS $\%$ ASF HHV } & \multirow{2}{*}{$\begin{array}{l}\text { S, \% } \\
\text { AR }\end{array}$} & \multicolumn{2}{|c|}{$\%$ ASH HHV } & \multirow{2}{*}{$\begin{array}{l}\text { S, } \% \\
\text { DRY }\end{array}$} & \multirow{2}{*}{$\begin{array}{l}\mathrm{NaO} \\
\% \\
\end{array}$} & \multirow{2}{*}{$\begin{array}{l}\text { MAF } \\
\text { HHV }\end{array}$} & \multirow{2}{*}{$\begin{array}{l}\text { COAL } \\
\text { TONS }\end{array}$} & \multirow{2}{*}{$\begin{array}{l}\text { TONS } \\
\text { OK }\end{array}$} \\
\hline & & $\%$ & $\mathrm{AR}$ & AR & & DRY & DRY & & & & & \\
\hline PREV. MON & ebm037 & 30.13 & 4.76 & 8456 & 0.42 & 6.81 & 12102 & 0.60 & 1.92 & 12986 & 13889.23 & 13367.44 \\
\hline PREV.MON & $\mathrm{crm} 02$ & 29.37 & 5.62 & 8464 & 0.30 & 7.96 & 11982 & 0.42 & 1.17 & 13019 & 13825.90 & 13825.90 \\
\hline 1-Dec-02 & 0 & 0 & 0 & 0 & 0 & 0 & 0 & 0 & 0 & 0 & 0.00 & \\
\hline 2-Dec-02 & bam 85 & 30.3 & 4.26 & 8530 & 0.29 & 6.11 & 12234 & 0.42 & 1.49 & 13030 & 10461.98 & 10461.98 \\
\hline 3-Dec-02 & 0 & 0 & 0 & 0 & 0 & 0 & 0 & 0 & 0 & 0 & 0.00 & \\
\hline 4-Dec-02 & 0 & 0 & 0 & 0 & 0 & 0 & 0 & 0 & 0 & $0^{-}$ & 0.00 & \\
\hline 5-Dec-02 & $\mathrm{crm} 03$ & 30.8 & 5.21 & 8348 & 0.28 & 7.53 & 12055 & 0.4 & 1.21 & 13037 & 11797.38 & 11797.38 \\
\hline 6-Dec-02 & bam 86 & 29.3 & 4.37 & 8658 & 0.25 & 6.18 & 12253 & 0.35 & 1.56 & 13060 & 14086.78 & 14086.78 \\
\hline 7-Dec-02 & 0 & 0 & 0 & 0 & 0 & 0 & 0 & 0 & 0 & 0 & 0.00 & \\
\hline 8-Dec-02 & bam 87 & 29.9 & 4.53 & 8554 & 0.33 & 6.47 & 12205 & 0.47 & 1.43 & 13049 & 13267.00 & 13267.00 \\
\hline 9-Dec-02 & 0 & 0 & 0 & 0 & 0 & 0 & 0 & 0 & 0 & 0 & 0.00 & \\
\hline 10-Dec-02 & bam 88 & 29.9 & 4.6 & 8565 & 0.29 & 6.57 & 12220 & 0.42 & 1.45 & 13079 & 14101.13 & 14101.13 \\
\hline 11-Dec-02 & 0 & 0 & 0 & 0 & 0 & 0 & 0 & 0 & 0 & 0 & 0.00 & \\
\hline 12-Dec-02 & bam 89 & 29.4 & 4.32 & 8653 & 0.27 & 6.12 & 12255 & 0.38 & 1.49 & 13054 & 13264.00 & 13264.00 \\
\hline 13-Dec-02 & 0 & 0 & 0 & 0 & 0 & 0 & 0 & 0 & 0 & 0 & 0.00 & \\
\hline 14-Dec-02 & bam 90 & 30.3 & 4.23 & 8537 & 0.26 & 6.07 & 12247 & 0.38 & 1.42 & 13038 & 14113.73 & 14113.73 \\
\hline 15-Dec-02 & 0 & 0 & 0 & 0 & 0 & 0 & 0 & 0 & 0 & 0 & 0.00 & \\
\hline 16-Dec-02 & 0 & 0 & 0 & 0 & 0 & 0 & 0 & 0 & 0 & 0 & 0.00 & \\
\hline 17-Dec-02 & bam91 & 29.1 & 4.56 & 8672 & 0.33 & 6.43 & 12225 & 0.46 & 1.44 & 13065 & 13722.10 & 13722.10 \\
\hline 18-Dec-02 & 0 & 0 & 0 & 0 & 0 & 0 & 0 & 0 & 0 & 0 & 0.00 & \\
\hline 19-Dec-02 & bam92 & 28.7 & 4.28 & 8729 & 0.26 & 6 & 12238 & 0.36 & 1.4 & 13019 & 14141.13 & 14141.13 \\
\hline 20-Dec-02 & 0 & 0 & 0 & 0 & 0 & 0 & 0 & 0 & 0 & 0 & 0.00 & \\
\hline 21-Dec-02 & 0 & 0 & 0 & 0 & 0 & 0 & 0 & 0 & 0 & 0 & 0.00 & \\
\hline 22-Dec-02 & 0 & 0 & 0 & 0 & 0 & 0 & 0 & 0 & 0 & 0 & 0.00 & \\
\hline 23-Dec-02 & ebm38 & 30.2 & 5 & 8396 & 0.37 & 7.17 & 12028 & 0.53 & 1.71 & 12957 & 14159.77 & 14159.77 \\
\hline 24-Dec-02 & 0 & 0 & 0 & 0 & 0 & 0 & 0 & 0 & 0 & 0 & 0.00 & \\
\hline 25-Dec-02 & 0 & 0 & 0 & 0 & 0 & 0 & 0 & 0 & 0 & 0 & 0.00 & \\
\hline 26-Dec-02 & 0 & 0 & 0 & 0 & 0 & 0 & 0 & 0 & 0 & 0 & 0.00 & \\
\hline 27-Dec-02 & ebm39 & 30.4 & 4.85 & 8381 & 0.4 & 6.97 & 12043 & 0.57 & 1.81 & 12945 & 13929.20 & 13929.20 \\
\hline 28-Dec-02 & 0 & 0 & 0 & 0 & 0 & 0 & 0 & 0 & 0 & 0 & 0.00 & \\
\hline 29-Dec-02 & bam93 & 28.6 & 4.45 & 8712 & 0.31 & 6.24 & 12208 & 0.44 & 1.29 & 13020 & 14053.55 & 9182.78 \\
\hline 30-Dec-02 & ebm40 & 30 & 4.76 & 8457 & 0.42 & 6.79 & 12073 & 0.6 & 1.93 & 12952 & 13881.20 & 0.00 \\
\hline 31-Dec-02 & 0 & 0 & 0 & 0 & 0 & 0 & 0 & 0 & 0 & 0 & 14145.23 & \\
\hline ADJ. & & & & & & & & & & & & 183420.32 \\
\hline ghtec & era & 29.78 & 4.71 & 8533 & 0.31 & 6.71 & 12151 & 0.44 & 1.49 & & $\begin{array}{l}\text { Tons. OK } \\
\text { Burn }\end{array}$ & $\begin{array}{l}196553.92 \\
196553.92\end{array}$ \\
\hline
\end{tabular}

Monthly Mercury Analysis

\begin{tabular}{|ccccc|}
\hline & & & Mercury & Chlor. \\
Train & Sample & $\%$ & ug/g & ug/g \\
$\#$ & $\#$ & Moist. dry basis & \\
\hline & & & \\
& & & \\
& & & \\
& & & \\
\hline
\end{tabular}




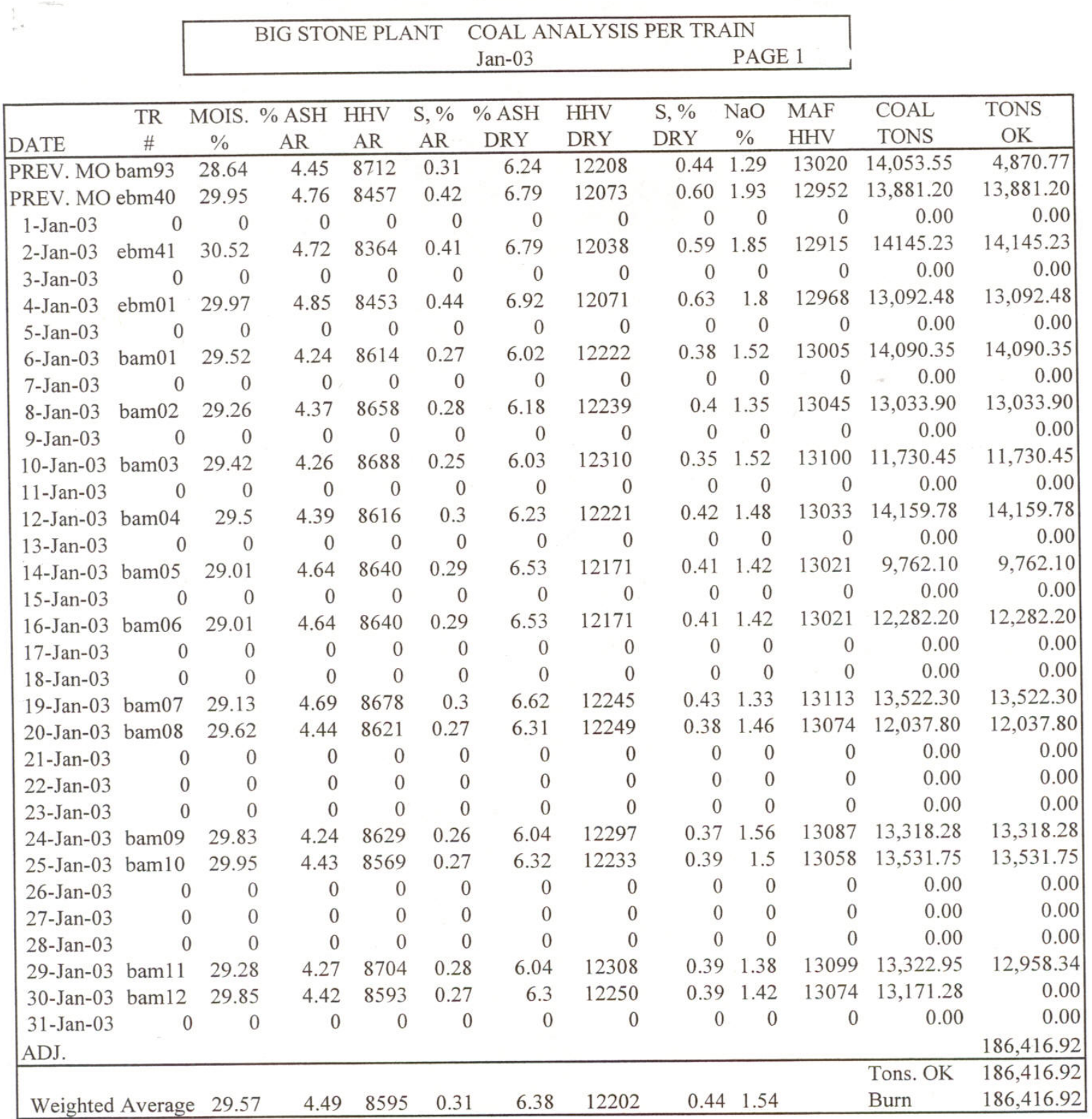

Monthly Mercury Analysis

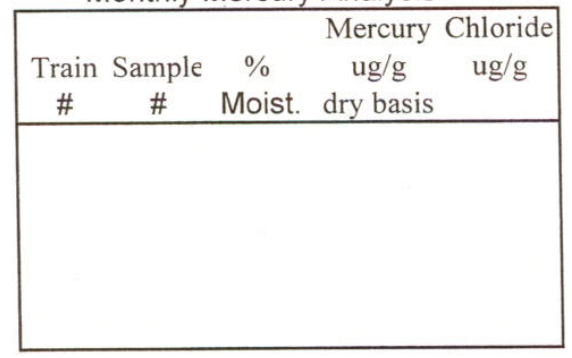




\begin{tabular}{ll|}
\hline BIG STONE PLANT & COAL ANALYSIS PER TRAIN \\
& Feb-03 \\
\hline
\end{tabular}

\begin{tabular}{|c|c|c|c|c|c|c|c|c|c|c|c|c|}
\hline DATE & $\begin{array}{l}\text { TR } \\
\#\end{array}$ & $\begin{array}{l}\text { MOIS } \\
\% \\
\end{array}$ & $\begin{array}{l}\% \text { ASF } \\
\text { AR }\end{array}$ & $\begin{array}{l}\mathrm{HHV} \\
\text { AR }\end{array}$ & $\begin{array}{l}\mathrm{S}, \% \\
\mathrm{AR}\end{array}$ & $\begin{array}{l}\% \text { ASH } \\
\text { DRY }\end{array}$ & $\begin{array}{l}\mathrm{HHV} \\
\text { DRY }\end{array}$ & $\begin{array}{l}\text { S, \% } \\
\text { DRY }\end{array}$ & $\begin{array}{l}\mathrm{NaO} \\
\% \\
\end{array}$ & $\begin{array}{l}\text { MAF } \\
\text { HHV }\end{array}$ & $\begin{array}{l}\text { COAL } \\
\text { TONS }\end{array}$ & $\begin{array}{l}\text { TONS } \\
\text { OK }\end{array}$ \\
\hline PREV. MO & bam11 & 29.3 & 4.27 & 8704 & 0.28 & 6.04 & 12308 & 0.39 & 1.38 & 13099 & $13,322.95$ & 364.61 \\
\hline PREV. MO & bam 12 & 29.9 & 4.42 & 8593 & 0.27 & 6.3 & 12250 & 0.39 & 1.42 & 13074 & $13,171.28$ & 13171.28 \\
\hline 1-Feb-03 & 0 & 0 & 0 & 0 & 0 & 0 & 0 & 0 & 0 & 0 & 0.00 & 0.00 \\
\hline 2-Feb-03 & 0 & 0 & 0 & 0 & 0 & 0 & 0 & 0 & 0 & 0 & 0.00 & 0.00 \\
\hline 3-Feb-03 & bam 13 & 30.2 & 4.24 & 8571 & 0.24 & 6.08 & 12285 & 0.35 & 1.63 & 13080 & 13082.78 & 13082.78 \\
\hline 4-Feb-03 & bam14 & 30.2 & 4.48 & 8530 & 0.25 & 6.42 & 12213 & 0.36 & 1.47 & 13051 & 13160.30 & 13160.30 \\
\hline 5 -Feb-03 & 0 & 0 & 0 & 0 & 0 & 0 & 0 & 0 & 0 & 0 & 0.00 & 0.00 \\
\hline 6-Feb-03 & 0 & 0 & 0 & 0 & 0 & 0 & 0 & 0 & 0 & 0 & 0.00 & 0.00 \\
\hline 7-Feb-03 & bam 15 & 30.1 & 4.29 & 8494 & 0.28 & 6.14 & 12158 & 0.4 & 1.66 & 12953 & 13275.88 & 13275.88 \\
\hline 8 -Feb-03 & 0 & 0 & 0 & 0 & 0 & 0 & 0 & 0 & 0 & 0 & 0.00 & 0.00 \\
\hline 9-Feb-03 & bam 16 & 29.4 & 4.12 & 8681 & 0.28 & 5.84 & 12299 & 0.39 & 1.67 & 13062 & 12953.88 & 12953.88 \\
\hline $10-$ Feb-03 & 0 & 0 & 0 & 0 & 0 & 0 & 0 & 0 & 0 & 0 & 0.00 & 0.00 \\
\hline 11-Feb-03 & 0 & 0 & 0 & 0 & 0 & 0 & 0 & 0 & 0 & 0 & 0.00 & 0.00 \\
\hline 12-Feb-03 & bam17 & 29.2 & 4.5 & 8669 & 0.28 & 6.36 & 12244 & 0.4 & 1.43 & 13076 & 13273.08 & 13273.08 \\
\hline 13-Feb-03 & bam 18 & 29.3 & 4.31 & 8651 & 0.27 & 6.09 & 12229 & 0.38 & 1.46 & 13022 & 12419.18 & 12419.18 \\
\hline 14-Feb-03 & 0 & 0 & 0 & 0 & 0 & 0 & 0 & 0 & 0 & 0 & 0.00 & 0.00 \\
\hline $15-F e b-03$ & 0 & 0 & 0 & 0 & 0 & 0 & 0 & 0 & 0 & 0 & 0.00 & 0.00 \\
\hline 16-Feb-03 & ebm02 & 30.4 & 5.02 & 8413 & 0.45 & 7.21 & 12090 & 0.64 & 1.76 & 13029 & 12751.52 & 12751.52 \\
\hline 17-Feb-03 & 0 & 0 & 0 & 0 & 0 & 0 & 0 & 0 & 0 & 0 & 0.00 & 0.00 \\
\hline 18-Feb-03 & ebm03 & 30.8 & 5.24 & 8316 & 0.39 & 7.57 & 12010 & 0.56 & 1.73 & 12994 & 13309.73 & 13309.73 \\
\hline 19-Feb-03 & 0 & 0 & 0 & 0 & 0 & 0 & 0 & 0 & 0 & 0 & 0.00 & 0.00 \\
\hline $20-F e b-03$ & bam 19 & 29.2 & 4.51 & 8656 & 0.3 & 6.37 & 12218 & 0.43 & 1.51 & 13049 & 13185.42 & 13185.42 \\
\hline 21-Feb-03 & 0 & 0 & 0 & 0 & 0 & 0 & 0 & 0 & 0 & 0 & 0.00 & 0.00 \\
\hline 22-Feb-03 & bam20 & 28.9 & 4.51 & 8639 & 0.28 & 6.35 & 12158 & 0.4 & 1.47 & 12982 & 13672.10 & 12727.61 \\
\hline 23-Feb-03 & 0 & 0 & 0 & 0 & 0 & 0 & 0 & 0 & 0 & 0 & 0.00 & 0.00 \\
\hline 24-Feb-03 & 0 & 0 & 0 & 0 & 0 & 0 & 0 & 0 & 0 & 0 & 0.00 & 0.00 \\
\hline $25-\mathrm{Feb}-03$ & bam21 & 30.4 & 4.3 & 8520 & 0.26 & 6.18 & 12234 & 0.37 & 1.53 & 13040 & 13671.40 & 0.00 \\
\hline 26-Feb-03 & 0 & 0 & 0 & 0 & 0 & 0 & 0 & 0 & 0 & 0 & 0.00 & 0.00 \\
\hline 27-Feb-03 & bam 22 & 29.2 & 4.46 & 8656 & 0.28 & 6.3 & 12230 & 0.39 & 1.47 & 13052 & 10746.15 & 0.00 \\
\hline 28-Feb-03 & 0 & 0 & 0 & 0 & 0 & 0 & 0 & 0 & 0 & 0 & 0.00 & 0.00 \\
\hline ADJ. & & & & & & & & & & & & 143675.26 \\
\hline Weighted & Average & 29.81 & 4.58 & 8551 & 0.30 & 6.53 & 12182 & 0.43 & 1.56 & & $\begin{array}{l}\text { Tons. OK } \\
\text { Burn }\end{array}$ & $\begin{array}{l}154405.86 \\
154405.86 \\
\end{array}$ \\
\hline
\end{tabular}

Monthly Mercury Analysis

\begin{tabular}{|ccccc|}
\hline \begin{tabular}{ccccc|} 
Train \\
$\#$
\end{tabular} & $\begin{array}{c}\text { Sample } \\
\#\end{array}$ & $\begin{array}{c}\text { Mercury } \\
\text { Moist. }\end{array}$ & $\begin{array}{c}\text { Chloride } \\
\text { dry basis }\end{array}$ & ug/g \\
\hline & C303 & 30.26 & 0.103 & $<0.01$ \\
& & & & \\
& & & & \\
& & & & \\
\hline
\end{tabular}




\begin{tabular}{|ll|}
\hline BIG STONE PLANT & COAL ANALYSIS PER TRAIN \\
& Mar-03 \\
\hline
\end{tabular}

\begin{tabular}{|c|c|c|c|c|c|c|c|c|c|c|c|c|}
\hline & TR & MOIS & $\%$ ASH & $\mathrm{HHV}$ & $\mathrm{S}, \%$ & $\% \mathrm{ASH}$ & $\mathrm{HHV}$ & $\mathrm{S}, \%$ & $\mathrm{NaO}$ & MAF & COAL & TONS \\
\hline DATE & $\#$ & $\%$ & $\mathrm{AR}$ & $\mathrm{AR}$ & $\mathrm{AR}$ & DRY & DRY & DRY & $\%$ & $\mathrm{HHV}$ & TONS & $\mathrm{OK}$ \\
\hline PREV. & bam 20 & 28.9 & 4.51 & 8639 & 0.28 & 6.35 & 12158 & 0.4 & 1.5 & 12982 & 13672.10 & 944.49 \\
\hline PREV. & bam 21 & 30.36 & 4.30 & 8520 & 0.26 & 6.18 & 12234 & 0.37 & 1.53 & 13040 & 13671.40 & 13671.40 \\
\hline 1-Mar-03 & 0 & 0 & 0 & 0 & 0 & 0 & 0 & 0 & 0 & 0 & 0.00 & 0.00 \\
\hline 2-Mar-03 & 0 & 29.2 & 4.46 & 8656 & 0.28 & 6.3 & 12230 & 0.39 & 1.5 & 13052 & 0.00 & 0.00 \\
\hline 3-Mar-03 & 0 & 0 & 0 & 0 & 0 & 0 & 0 & 0 & 0 & 0 & 0.00 & 0.00 \\
\hline 4-Mar-03 & 0 & 0 & 0 & 0 & 0 & 0 & 0 & 0 & 0 & 0 & 0.00 & 0.00 \\
\hline 5-Mar-03 & 0 & 0 & 0 & 0 & 0 & 0 & 0 & 0 & 0 & 0 & 0.00 & 0.00 \\
\hline 6-Mar-03 & ebm04 & 30.4 & 4.71 & 8455 & 0.41 & 6.76 & 12143 & 0.59 & 1.8 & 13023 & 13682.43 & 13682.43 \\
\hline 7-Mar-03 & 0 & 0 & 0 & 0 & 0 & 0 & 0 & 0 & 0 & 0 & 0.00 & 0.00 \\
\hline 8-Mar-03 & 0 & 0 & 0 & 0 & 0 & 0 & 0 & 0 & 0 & 0 & 0.00 & 0.00 \\
\hline 9-Mar-03 & bam 23 & 30.8 & 4.27 & 8457 & 0.25 & 6.17 & 12221 & 0.36 & 1.4 & 13025 & 13360.65 & 13360.65 \\
\hline 10-Mar-03 & ebm05 & 30.6 & 4.37 & 8466 & 0.36 & 6.3 & 12195 & 0.52 & 1.9 & 13015 & 13486.15 & 13486.15 \\
\hline 11-Mar-03 & 0 & 0 & 0 & 0 & 0 & 0 & 0 & 0 & 0 & 0 & 0.00 & 0.00 \\
\hline 12-Mar-03 & bam 24 & 29.3 & 4.48 & 8658 & 0.28 & 6.34 & 12239 & 0.39 & 1.5 & 13067 & 13064.15 & 13064.15 \\
\hline 13-Mar-03 & 0 & 0 & 0 & 0 & 0 & 0 & 0 & 0 & 0 & 0 & 0.00 & 0.00 \\
\hline 14-Mar-03 & 0 & 0 & 0 & 0 & 0 & 0 & 0 & 0 & 0 & 0 & 0.00 & 0.00 \\
\hline 15-Mar-03 & bam 25 & 29.1 & 4.69 & 8612 & 0.3 & 6.61 & 12147 & 0.42 & 1.6 & 13007 & 13310.88 & 13310.88 \\
\hline 16-Mar-03 & bam 26 & 29.2 & 4.37 & 8645 & 0.25 & 6.17 & 12212 & 0.36 & 1.6 & 13015 & 13176.13 & 13176.13 \\
\hline 17-Mar-03 & 0 & 0 & 0 & 0 & 0 & 0 & 0 & 0 & 0 & 0 & 0.00 & 0.00 \\
\hline 18-Mar-03 & 0 & 0 & 0 & 0 & 0 & 0 & 0 & 0 & 0 & 0 & 0.00 & 0.00 \\
\hline 19-Mar-03 & 0 & 0 & 0 & 0 & 0 & 0 & 0 & 0 & 0 & 0 & 0.00 & 0.00 \\
\hline 20-Mar-03 & bam 27 & 30 & 4.3 & 8578 & 0.27 & 6.15 & 12256 & 0.38 & 1.5 & 13059 & 14006.18 & 14006.18 \\
\hline 21-Mar-03 & 0 & 0 & 0 & 0 & 0 & 0 & 0 & 0 & 0 & 0 & 0.00 & 0.00 \\
\hline 22-Mar-03 & bam 28 & 29.5 & 4.16 & 8648 & 0.24 & 5.9 & 12270 & 0.34 & 1.6 & 13039 & 13148.65 & 13148.65 \\
\hline 23-Mar-03 & 0 & 0 & 0 & 0 & 0 & 0 & 0 & 0 & 0 & 0 & 0.00 & 0.00 \\
\hline 24-Mar-03 & bam 29 & 29.7 & 4.85 & 8543 & 0.3 & 6.9 & 12143 & 0.42 & 1.3 & 13043 & 14094.48 & 14094.48 \\
\hline 25-Mar-03 & 0 & 0 & 0 & 0 & 0 & 0 & 0 & 0 & 0 & 0 & 0.00 & 0.00 \\
\hline 26-Mar-03 & 0 & 0 & 0 & 0 & 0 & 0 & 0 & 0 & 0 & 0 & 0.00 & 0.00 \\
\hline 27-Mar-03 & bam 30 & 30.1 & 4.58 & 8485 & 0.26 & 6.55 & 12132 & 0.37 & 1.5 & 12982 & 14088.83 & 14088.83 \\
\hline 28-Mar-03 & 0 & 0 & 0 & 0 & 0 & 0 & 0 & 0 & 0 & 0 & 0.00 & 0.00 \\
\hline 29-Mar-03 & bam31 & 29.5 & 4.23 & 8621 & 0.25 & 6 & 12221 & 0.35 & 1.5 & 13001 & 14033.93 & 15501.37 \\
\hline 30-Mar-03 & 0 & 0 & 0 & 0 & 0 & 0 & 0 & 0 & 0 & 0 & 0.00 & 0.00 \\
\hline 31-Mar-03 & bam 32 & 29.6 & 4.78 & 8594 & 0.29 & 6.79 & 12205 & 0.41 & 1.4 & 13094 & 14127.90 & 0.00 \\
\hline ADJ. & & & & & & & & & & & & 165535.78 \\
\hline Weighted & ierage & 02 & 4.45 & 8562 & 0.29 & 6.35 & 12201 & 0.40 & 1.54 & & $\begin{array}{l}\text { Tons. OK } \\
\text { Burn }\end{array}$ & $\begin{array}{l}177636.53 \\
177636.53 \\
\end{array}$ \\
\hline
\end{tabular}

Monthly Mercury Analysis

\begin{tabular}{|c|c|c|c|c|}
\hline $\begin{array}{c}\text { Train } \\
\#\end{array}$ & $\begin{array}{c}\text { Sample } \\
\#\end{array}$ & $\begin{array}{c}\% \\
\text { Moist. }\end{array}$ & $\begin{array}{c}\text { Mercury } \\
\text { ug/g } \\
\text { dry basis }\end{array}$ & $\begin{array}{c}\text { Chloride } \\
\text { ug/g }\end{array}$ \\
\hline & $\overline{C 550}$ & 29.23 & 0.116 & $<0.01$ \\
\hline
\end{tabular}




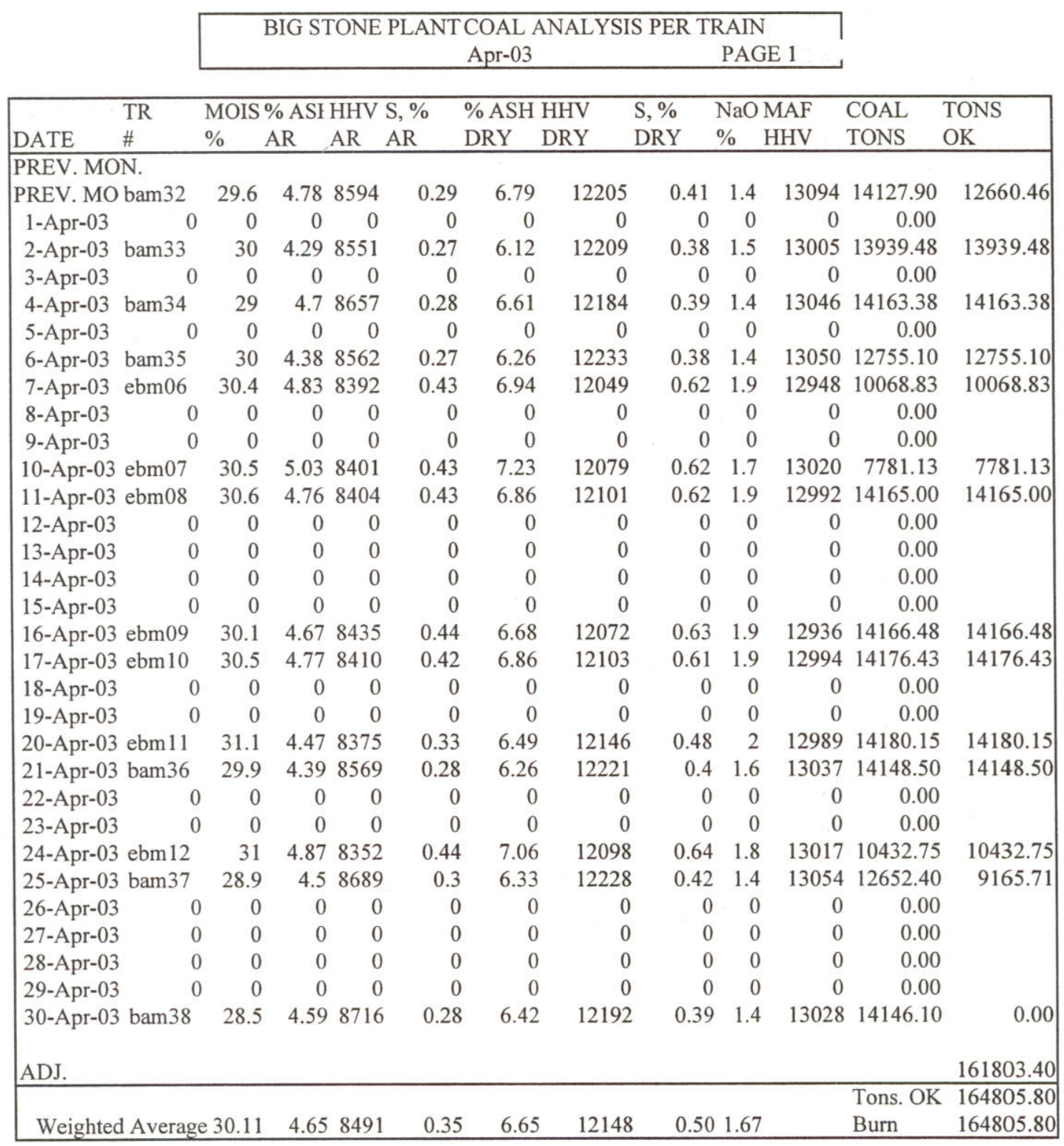

\section{Monthly Mercury Analysis}

\begin{tabular}{|c|c|c|}
\hline $\begin{array}{c}\text { Train Sample } \\
\# \quad \#\end{array}$ & $\begin{array}{cc} & \text { Mercury } \\
\% & \text { ug/g } \\
\text { Moist. } & \text { dry basis }\end{array}$ & $\begin{array}{c}\text { Chloride } \\
\text { ug/g }\end{array}$ \\
\hline & 0.116 & $<0.01$ \\
\hline
\end{tabular}


BIG STONE PLANT COAL ANALYSIS PER TRAIN

May-03

PAGE 1

\begin{tabular}{|c|c|c|c|c|c|c|c|c|c|c|c|c|}
\hline DATE & $\begin{array}{l}\text { TR } \\
\#\end{array}$ & $\begin{array}{l}\text { MOIS } \\
\%\end{array}$ & $\begin{array}{l}\% \text { ASF } \\
\text { AR }\end{array}$ & $\begin{array}{l}\text { HHV } \\
\text { AR }\end{array}$ & $\begin{array}{l}\text { S, \% } \\
\text { AR }\end{array}$ & $\begin{array}{l}\text { \% ASH } \\
\text { DRY }\end{array}$ & $\begin{array}{l}\text { HHV } \\
\text { DRY }\end{array}$ & $\begin{array}{l}\text { S, \% } \\
\text { DRY }\end{array}$ & $\begin{array}{l}\mathrm{NaO} \\
\%\end{array}$ & $\begin{array}{l}\text { MAF } \\
\text { HHV }\end{array}$ & $\begin{array}{l}\text { COAL } \\
\text { TONS }\end{array}$ & $\begin{array}{l}\text { TONS } \\
\text { OK }\end{array}$ \\
\hline PREV. MC & bam37 & 28.9 & 4.5 & 8689 & 0.3 & 6.33 & 12228 & 0.42 & 1.38 & 13054 & 12652.400 & 3486.690 \\
\hline PREV. MC & bam 38 & 28.5 & 4.59 & 8716 & 0.28 & 6.42 & 12192 & 0.39 & 1.36 & 13028 & 14146.100 & 14146.100 \\
\hline 1-May-03 & 0 & 0 & 0 & 0 & 0 & 0 & 0 & 0 & 0 & 0 & 0.000 & \\
\hline 2-Маy-03 & ebm13 & 30.4 & 4.9 & 8415 & 0.42 & 7.03 & 12083 & 0.6 & 1.7 & 12997 & 14172.650 & 14172.650 \\
\hline 3-Мау-03 & 0 & 0 & 0 & 0 & 0 & 0 & 0 & 0 & 0 & 0 & 0.000 & \\
\hline 4-May-03 & bam39 & 29.4 & 4.26 & 8636 & 0.27 & 6.04 & 12237 & 0.38 & 1.48 & 13024 & 14135.200 & 14135.200 \\
\hline 5-May-03 & 0 & 0 & 0 & 0 & 0 & 0 & 0 & 0 & 0 & 0 & 0.000 & \\
\hline 6-Мay-03 & 0 & 0 & 0 & 0 & 0 & 0 & 0 & 0 & 0 & 0 & 0.000 & \\
\hline 7-May-03 & ebm14 & 30.4 & 4.69 & 8416 & 0.42 & 6.73 & 12087 & 0.6 & 1.89 & 12959 & 13846.500 & 13846.500 \\
\hline 8-Мay-03 & 0 & 0 & 0 & 0 & 0 & 0 & 0 & 0 & 0 & 0 & 0.000 & \\
\hline 9-May-03 & bam 40 & 29.1 & 4.66 & 8626 & 0.3 & 6.57 & 12165 & 0.42 & 1.5 & 13020 & 14131.625 & 14131.625 \\
\hline 10-May-03 & 0 & 0 & 0 & 0 & 0 & 0 & 0 & 0 & 0 & 0 & 0.000 & \\
\hline 11-Мay-03 & 0 & 0 & 0 & 0 & 0 & 0 & 0 & 0 & 0 & 0 & 0.000 & \\
\hline 12-May-03 & ebm 15 & 30.7 & 4.76 & 8354 & 0.38 & 6.87 & 12059 & 0.55 & 1.86 & 12949 & 14154.950 & 14154.950 \\
\hline 13-May-03 & bam41 & 29 & 4.53 & 8658 & 0.29 & 6.38 & 12189 & 0.41 & 1.36 & 13020 & 14059.200 & 14059.200 \\
\hline 14-May-03 & 0 & 0 & 0 & 0 & 0 & 0 & 0 & 0 & 0 & 0 & 0.000 & \\
\hline 15-May-03 & 0 & 0 & 0 & 0 & 0 & 0 & 0 & 0 & 0 & 0 & 0.000 & \\
\hline 16-Маy-03 & 0 & 0 & 0 & 0 & 0 & 0 & 0 & 0 & 0 & 0 & 0.000 & \\
\hline 17-Мay-03 & bam 42 & 30.1 & 4.86 & 8488 & 0.27 & 6.96 & 12147 & 0.38 & 1.34 & 13056 & 14163.980 & 14163.980 \\
\hline 18-Мay-03 & bam 43 & 30.1 & 4.9 & 8436 & 0.27 & 7.01 & 12076 & 0.39 & 1.31 & 12986 & 14176.330 & 14176.330 \\
\hline 19-Мay-03 & 0 & 0 & 0 & 0 & 0 & 0 & 0 & 0 & 0 & 0 & 0.000 & \\
\hline 20-May-03 & 0 & 0 & 0 & 0 & 0 & 0 & 0 & 0 & 0 & 0 & 0.000 & \\
\hline 21-May-03 & bam 44 & 29 & 4.57 & 8692 & 0.3 & 6.44 & 12245 & 0.42 & 1.52 & 13088 & 14162.750 & 14162.750 \\
\hline 22-Мay-03 & bam 45 & 29.1 & 4.42 & 8669 & 0.28 & 6.24 & 12232 & 0.4 & 1.52 & 13046 & 11741.200 & 11741.200 \\
\hline 23-Мау-03 & 0 & 0 & 0 & 0 & 0 & 0 & 0 & 0 & 0 & 0 & 0.000 & \\
\hline 24-May-03 & 0 & 0 & 0 & 0 & 0 & 0 & 0 & 0 & 0 & 0 & 0.000 & \\
\hline 25-May-03 & 0 & 0 & 0 & 0 & 0 & 0 & 0 & 0 & 0 & 0 & 0.000 & \\
\hline 26-May-03 & bam 46 & 29.8 & 4.16 & 8576 & 0.25 & 5.92 & 12210 & 0.36 & 1.53 & 12978 & 14149.525 & 14149.525 \\
\hline 27-May-03 & bam 47 & 29.6 & 4.38 & 8582 & 0.25 & 6.22 & 12194 & 0.36 & 1.49 & 13003 & 14181.670 & 14181.670 \\
\hline 28-May-03 & 0 & 0 & 0 & 0 & 0 & 0 & 0 & 0 & 0 & 0 & 0.000 & \\
\hline 29-Мау-03 & 0 & 0 & 0 & 0 & 0 & 0 & 0 & 0 & 0 & 0 & 0.000 & \\
\hline 30-May-03 & 0 & 0 & 0 & 0 & 0 & 0 & 0 & 0 & 0 & 0 & 0.000 & \\
\hline $\begin{array}{l}\text { 31-May-03 } \\
\text { ADJ. }\end{array}$ & ebm 16 & 30.6 & 4.63 & 8390 & 0.43 & 6.67 & 12095 & 0.62 & 1.83 & 12959 & 14184.750 & $\begin{array}{r}134.460 \\
184842.830\end{array}$ \\
\hline Weighted & Average & 29.63 & 4.59 & 8560 & 0.31 & 6.53 & 12163 & 0.44 & 1.52 & & $\begin{array}{l}\text { Tons. OK } \\
\text { Burn }\end{array}$ & $\begin{array}{l}184842.830 \\
184842.830 \\
\end{array}$ \\
\hline
\end{tabular}

Monthly Mercury Analysis

\begin{tabular}{|ccccc|}
\hline & & & Mercury & Chloride \\
Train & Sample & $\%$ & ug/g & ug/g \\
$\#$ & $\#$ & Moist. & dry basis & \\
\hline & & & \\
& & & \\
& & & \\
& & & \\
\hline
\end{tabular}


BIG STONE PLANT COAL ANALYSIS PER TRAIN

Jun-03

PAGE 1

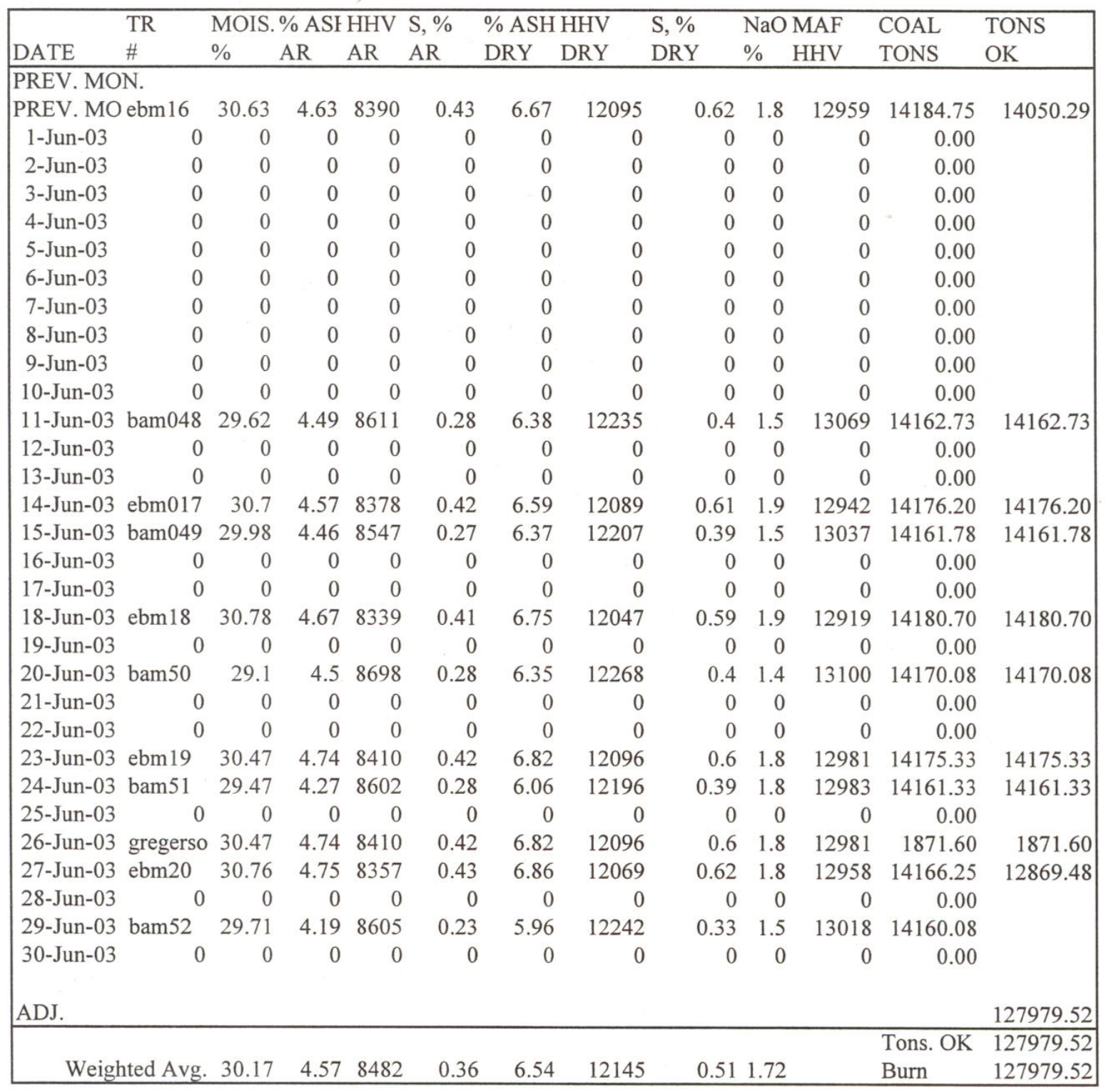

Monthly Mercury Analysis

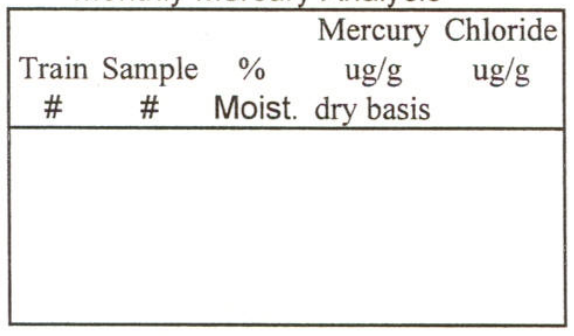




\begin{tabular}{|c|c|c|c|c|c|c|c|c|c|c|c|c|}
\hline DATE & $\begin{array}{l}\text { TR } \\
\#\end{array}$ & $\begin{array}{l}\text { MOIS } \\
\%\end{array}$ & $\begin{array}{l}\% \mathrm{ASl} \\
\mathrm{AR}\end{array}$ & $\begin{array}{l}\text { IHHV } \\
\text { AR }\end{array}$ & $\begin{array}{l}\mathrm{S}, \% \\
\mathrm{AR}\end{array}$ & $\begin{array}{l}\% \text { ASF } \\
\text { DRY }\end{array}$ & $\begin{array}{l}\text { HHV } \\
\text { DRY }\end{array}$ & $\begin{array}{l}\text { S, \% } \\
\text { DRY }\end{array}$ & $\begin{array}{l}\mathrm{NaO} \\
\%\end{array}$ & $\begin{array}{l}\text { MAF } \\
\text { HHV }\end{array}$ & $\begin{array}{l}\text { COAL } \\
\text { TONS }\end{array}$ & $\begin{array}{l}\text { TONS } \\
\text { OK }\end{array}$ \\
\hline \multicolumn{2}{|c|}{ PREV. MC ebm 20} & 30.8 & 4.75 & 8357 & 0.43 & 6.86 & 12069 & 0.62 & 1.83 & 12958 & 14166.25 & 1296.77 \\
\hline \multicolumn{2}{|c|}{ PREV. MC bam52 } & 29.7 & 4.19 & 8605 & 0.23 & 5.96 & 12242 & 0.33 & 1.52 & 13018 & 14160.08 & 14160.08 \\
\hline 1-Jul-03 & 0 & 0 & 0 & 0 & 0 & 0 & 0 & 0 & 0 & 0 & 0.00 & \\
\hline 2-Jul-03 & ebm21 & 31.2 & 4.85 & 8312 & 0.41 & 7.04 & 12075 & 0.6 & 1.76 & 12989 & 14166.88 & 14166.88 \\
\hline 3-Jul-03 & bam 053 & 29.3 & 4.32 & 8606 & 0.25 & 6.12 & 12180 & 0.36 & 1.62 & 12974 & 14173.35 & 14173.35 \\
\hline 4-Jul-03 & 0 & 0 & 0 & 0 & 0 & 0 & 0 & 0 & 0 & 0 & 0.00 & \\
\hline 5-Jul-03 & 0 & 0 & 0 & 0 & 0 & 0 & 0 & 0 & 0 & 0 & 0.00 & \\
\hline 6-Jul-03 & 0 & 0 & 0 & 0 & 0 & 0 & 0 & 0 & 0 & 0 & 0.00 & \\
\hline 7-Jul-03 & bam 054 & 29.3 & 4.47 & 8595 & 0.28 & 6.32 & 12161 & 0.39 & 1.56 & 12981 & 12952.58 & 12952.58 \\
\hline 8-Jul-03 & 0 & 0 & 0 & 0 & 0 & 0 & 0 & 0 & 0 & 0 & 0.00 & \\
\hline 9-Jul-03 & bam 055 & 29.4 & 4.41 & 8585 & 0.26 & 6.24 & 12160 & 0.37 & 1.49 & 12969 & 14160.63 & 14160.63 \\
\hline 10-Jul-03 & 0 & 0 & 0 & 0 & 0 & 0 & 0 & 0 & 0 & 0 & 0.00 & \\
\hline 11-Jul-03 & 0 & 0 & 0 & 0 & 0 & 0 & 0 & 0 & 0 & 0 & 0.00 & \\
\hline 12-Jul-03 & 0 & 0 & 0 & 0 & 0 & 0 & 0 & 0 & 0 & 0 & 0.00 & \\
\hline 13-Jul-03 & bam056 & $5 \quad 28.8$ & 4.73 & 8623 & 0.3 & 6.65 & 12114 & 0.42 & 1.34 & 12977 & 14178.45 & 14178.45 \\
\hline 14-Jul-03 & 0 & 0 & 0 & 0 & 0 & 0 & 0 & 0 & 0 & 0 & 0.00 & \\
\hline 15-Jul-03 & bam057 & $7 \quad 29.5$ & 4.25 & 8610 & 0.26 & 6.03 & 12216 & 0.37 & 1.52 & 13000 & 14178.85 & 14178.85 \\
\hline 16-Jul-03 & 0 & 0 & 0 & 0 & 0 & 0 & 0 & 0 & 0 & 0 & 0.00 & \\
\hline 17-Jul-03 & bam 58 & 29 & 4.38 & 8706 & 0.29 & 6.17 & 12265 & 0.41 & 1.51 & 13072 & 14178.40 & 14178.40 \\
\hline 18-Jul-03 & 0 & 0 & 0 & 0 & 0 & 0 & 0 & 0 & 0 & 0 & 0.00 & \\
\hline 19-Jul-03 & 0 & 0 & 0 & 0 & 0 & 0 & 0 & 0 & 0 & 0 & 0.00 & \\
\hline 20-Jul-03 & 0 & 0 & 0 & 0 & 0 & 0 & 0 & 0 & 0 & 0 & 0.00 & \\
\hline 21-Jul-03 & bam59 & 29.3 & 4.44 & 8634 & 0.31 & 6.28 & 12211 & 0.44 & 1.5 & 13029 & 14140.95 & 14140.95 \\
\hline 22-Jul-03 & ebm22 & 29.9 & 4.91 & 8472 & 0.49 & 7.01 & 12084 & 0.7 & 1.87 & 12995 & 14169.00 & 14169.00 \\
\hline 23-Jul-03 & 0 & 0 & 0 & 0 & 0 & 0 & 0 & 0 & 0 & 0 & 0.00 & \\
\hline 24-Jul-03 & 0 & 0 & 0 & 0 & 0 & 0 & 0 & 0 & 0 & 0 & 0.00 & \\
\hline 25-Jul-03 & 0 & 0 & 0 & 0 & 0 & 0 & 0 & 0 & 0 & 0 & 0.00 & \\
\hline 26-Jul-03 & bam60 & 28.4 & 4.85 & 8630 & 0.26 & 6.78 & 12056 & 0.37 & 1.36 & 12933 & 14154.60 & 14154.60 \\
\hline 27-Jul-03 & bam61 & 28.8 & 4.18 & 8671 & 0.28 & 5.87 & 12179 & 0.4 & 1.55 & 12938 & 14182.30 & 14182.30 \\
\hline 28-Jul-03 & 0 & 0 & 0 & 0 & 0 & 0 & 0 & 0 & 0 & 0 & 0.00 & \\
\hline 29-Jul-03 & 0 & 0 & 0 & 0 & 0 & 0 & 0 & 0 & 0 & 0 & 0.00 & \\
\hline 30-Jul-03 & 0 & 0 & 0 & 0 & 0 & 0 & 0 & 0 & 0 & 0 & 0.00 & \\
\hline 31-Jul-03 & 0 & 0 & 0 & 0 & 0 & 0 & 0 & 0 & 0 & 0 & 0.00 & \\
\hline ADJ. & & & & & & & & & & & & 170092.84 \\
\hline Weighted & Average & 29.49 & 4.61 & 8561 & 0.30 & 6.55 & 12142 & 0.43 & 1.55 & & $\begin{array}{l}\text { Tons. OK } \\
\text { Burn }\end{array}$ & $\begin{array}{l}192005.80 \\
192005.80 \\
\end{array}$ \\
\hline
\end{tabular}

Monthly Mercury Analysis

\begin{tabular}{|c|c|c|c|c|}
\hline $\begin{array}{c}\text { Train } \\
\#\end{array}$ & $\begin{array}{c}\text { Sample } \\
\#\end{array}$ & $\begin{array}{c}\% \\
\text { Moist. }\end{array}$ & $\begin{array}{c}\text { Mercury } \\
\text { ug/g } \\
\text { dry basis }\end{array}$ & $\begin{array}{c}\text { Chloride } \\
\text { ug/g }\end{array}$ \\
\hline & C1364 & 30.39 & 0.105 & $<0.01$ \\
\hline
\end{tabular}


BIG STONE PLANT COAL ANALYSIS PER TRAIN

Aug-03

PAGE 1

\begin{tabular}{|c|c|c|c|c|c|c|c|c|c|c|c|c|}
\hline DATE & $\begin{array}{l}\text { TR } \\
\#\end{array}$ & $\begin{array}{l}\text { MOIS } \% \\
\%\end{array}$ & $\begin{array}{l}\% \text { ASH } \\
\text { AR }\end{array}$ & $\begin{array}{l}\mathrm{HHV} \\
\mathrm{AR}\end{array}$ & $\begin{array}{l}\text { S, \% } \\
\text { AR }\end{array}$ & $\begin{array}{l}\% \text { ASH } \\
\text { DRY }\end{array}$ & $\begin{array}{l}\text { HHV } \\
\text { DRY }\end{array}$ & $\begin{array}{l}\text { S, \% } \\
\text { DRY }\end{array}$ & $\begin{array}{l}\mathrm{NaO} \\
\% \\
\end{array}$ & $\begin{array}{l}\text { MAF } \\
\text { HHV }\end{array}$ & $\begin{array}{l}\text { COAL } \\
\text { TONS }\end{array}$ & $\begin{array}{l}\text { TONS } \\
\text { OK }\end{array}$ \\
\hline \multicolumn{13}{|c|}{$\begin{array}{l}\text { PREV. MON. } \\
\text { PREV. MON. }\end{array}$} \\
\hline 1-Aug-03 & ebm23 & 30.2 & 4.77 & 8449 & 0.43 & 6.84 & 12105 & 0.61 & 1.89 & 12994 & 14170.08 & 14170.08 \\
\hline 2-Aug-03 & bam62 & 28.8 & 4.33 & 8708 & 0.3 & 6.08 & 12227 & 0.42 & 1.58 & 13019 & 14174.10 & 14174.10 \\
\hline 3-Aug-03 & 0 & 0 & 0 & 0 & 0 & 0 & 0 & 0 & 0 & 0 & 0.00 & \\
\hline 4-Aug-03 & 0 & 0 & 0 & 0 & 0 & 0 & 0 & 0 & 0 & 0 & 0.00 & \\
\hline 5-Aug-03 & ebm24 & 30.3 & 5.12 & 8366 & 0.43 & 7.34 & 11997 & 0.62 & 1.78 & 12947 & 14185.32 & 14185.32 \\
\hline 6-Aug-03 & 0 & 0 & 0 & 0 & 0 & 0 & 0 & 0 & 0 & 0 & 0.00 & \\
\hline 7-Aug-03 & bam63 & 29 & 4.36 & 8721 & 0.28 & 6.14 & 12274 & 0.4 & 1.48 & 13077 & 14180.18 & 14180.18 \\
\hline 8-Aug-03 & 0 & 0 & 0 & 0 & 0 & 0 & 0 & 0 & 0 & 0 & 0.00 & \\
\hline 9-Aug-03 & 0 & 0 & 0 & 0 & 0 & 0 & 0 & 0 & 0 & 0 & 0.00 & \\
\hline 10-Aug-03 & bam64 & 28.6 & 4.25 & 8714 & 0.29 & 5.95 & 12211 & 0.4 & 1.49 & 12984 & 14163.80 & 14163.80 \\
\hline 11-Aug-03 & bam 65 & 28.5 & 4.49 & 8712 & 0.31 & 6.28 & 12191 & 0.44 & 1.53 & 13008 & 14179.73 & 14179.73 \\
\hline 12-Aug-03 & 0 & 0 & 0 & 0 & 0 & 0 & 0 & 0 & 0 & 0 & 0.00 & \\
\hline 13-Aug-03 & 0 & 0 & 0 & 0 & 0 & 0 & 0 & 0 & 0 & 0 & 0.00 & \\
\hline 14-Aug-03 & bam66 & 28.8 & 4.43 & 8645 & 0.29 & 6.23 & 12149 & 0.41 & 1.44 & 12956 & 14163.08 & 14163.08 \\
\hline 15-Aug-03 & 0 & 0 & 0 & 0 & 0 & 0 & 0 & 0 & 0 & 0 & 0.00 & \\
\hline 16-Aug-03 & bam67 & 28.7 & 4.71 & 8627 & 0.29 & 6.6 & 12099 & 0.41 & 1.46 & 12954 & 14179.60 & 14179.60 \\
\hline 17-Aug-03 & 0 & 0 & 0 & 0 & 0 & 0 & 0 & 0 & 0 & 0 & 0.00 & \\
\hline 18-Aug-03 & bam68 & 28.6 & 4.52 & 8663 & 0.29 & 6.33 & 12140 & 0.41 & 1.51 & 12960 & 14170.10 & 14170.10 \\
\hline 19-Aug-03 & 0 & 0 & 0 & 0 & 0 & 0 & 0 & 0 & 0 & 0 & 0.00 & \\
\hline 20-Aug-03 & 0 & 0 & 0 & 0 & 0 & 0 & 0 & 0 & 0 & 0 & 0.00 & \\
\hline 21-Aug-03 & 0 & 0 & 0 & 0 & 0 & 0 & 0 & 0 & 0 & 0 & 0.00 & \\
\hline 22-Aug-03 & bam69 & 29.3 & 4.79 & 8541 & 0.29 & 6.78 & 12083 & 0.41 & 1.63 & 12962 & 14042.45 & 14042.45 \\
\hline 23-Aug-03 & bam70 & 29.4 & 4.67 & 8541 & 0.3 & 6.61 & 12099 & 0.43 & 1.54 & 12955 & 14179.40 & 14179.40 \\
\hline 24-Aug-03 & 0 & 0 & 0 & 0 & 0 & 0 & 0 & 0 & 0 & 0 & 0.00 & \\
\hline 25-Aug-03 & 0 & 0 & 0 & 0 & 0 & 0 & 0 & 0 & 0 & 0 & 0.00 & \\
\hline 26-Aug-03 & 0 & 0 & 0 & 0 & 0 & 0 & 0 & 0 & 0 & 0 & 0.00 & \\
\hline 27-Aug-03 & bam71 & 29.4 & 4.6 & 8591 & 0.3 & 6.52 & 12168 & 0.43 & 1.49 & 13017 & 14164.35 & 14164.35 \\
\hline 28-Aug-03 & bam72 & 29.6 & 4.53 & 8590 & 0.27 & 6.43 & 12193 & 0.39 & 1.56 & 13031 & 14167.83 & 4375.44 \\
\hline 29-Aug-03 & 0 & 0 & 0 & 0 & 0 & 0 & 0 & 0 & 0 & 0 & 0.00 & \\
\hline 30-Aug-03 & 0 & 0 & 0 & 0 & 0 & 0 & 0 & 0 & 0 & 0 & 0.00 & \\
\hline 31-Aug-03 & 0 & 0 & 0 & 0 & 0 & 0 & 0 & 0 & 0 & 0 & 0.00 & \\
\hline & & & & & & & & & & & & 174327.63 \\
\hline Weighted & Average & 29.29 & 4.70 & 8575 & 0.31 & 6.66 & 12127 & 0.45 & 1.56 & & $\begin{array}{l}\text { Tons. OK } \\
\text { Burn }\end{array}$ & $\begin{array}{l}200219.47 \\
200219.47\end{array}$ \\
\hline
\end{tabular}

Monthly Mercury Analysis

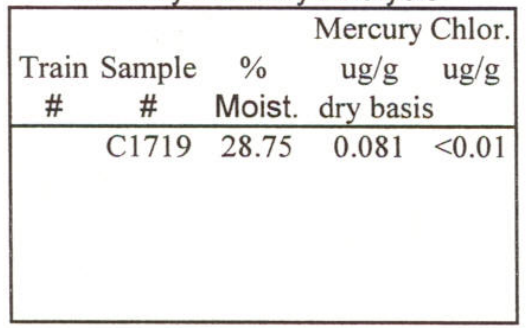




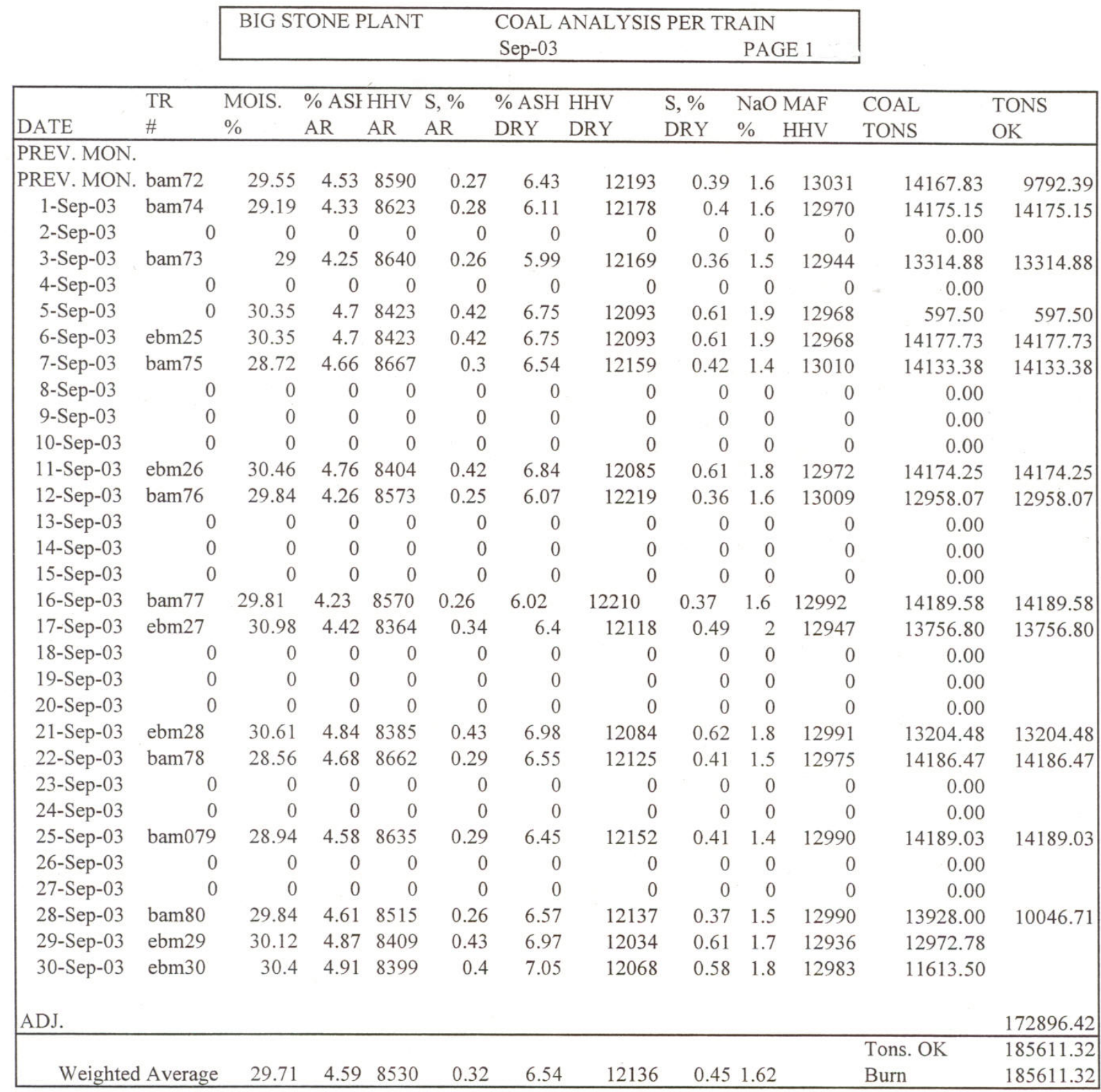

Monthly Mercury Analysis

\begin{tabular}{|ccccc|}
\hline $\begin{array}{c}\text { Train } \\
\#\end{array}$ & $\begin{array}{c}\text { Sample } \\
\#\end{array}$ & $\begin{array}{c}\text { Mercury } \\
\text { Moist. }\end{array}$ & $\begin{array}{c}\text { Chlor. } \\
\text { dry basis }\end{array}$ & ug/g \\
\hline & C2105 & 29.35 & 0.08 & $<0.01 \%$ \\
& & & & \\
& & & & \\
& & & & \\
\hline
\end{tabular}




\begin{tabular}{|lll|}
\hline BIG STONE PLANT & COAL ANALYSIS PER TRAIN \\
& Oct-03 & PAGE 1 \\
\hline
\end{tabular}

\begin{tabular}{|c|c|c|c|c|c|c|c|c|c|c|c|c|}
\hline DATE & $\begin{array}{l}\text { TR } \\
\# \\
\end{array}$ & $\begin{array}{l}\text { MOIS. } \\
\%\end{array}$ & $\begin{array}{l}\% \mathrm{ASF} \\
\mathrm{AR} \\
\end{array}$ & $\begin{array}{l}\mathrm{HHV} \\
\mathrm{AR}\end{array}$ & $\begin{array}{l}\text { S, \% } \\
\text { AR }\end{array}$ & $\begin{array}{l}\% \text { ASH } \\
\text { DRY }\end{array}$ & $\begin{array}{l}\mathrm{HHV} \\
\mathrm{ORY} \\
\end{array}$ & $\begin{array}{l}\text { S, \% } \\
\text { DRY }\end{array}$ & $\begin{array}{l}\mathrm{NaO} \\
\% \\
\end{array}$ & $\begin{array}{l}\text { MAF } \\
\mathrm{HHV}\end{array}$ & $\begin{array}{l}\text { COAL } \\
\text { TONS }\end{array}$ & $\begin{array}{l}\text { TONS } \\
\text { OK }\end{array}$ \\
\hline \multicolumn{13}{|l|}{$\begin{array}{l}\text { PREV. MON. } \\
\text { PREV. MON. }\end{array}$} \\
\hline 1-Oct-03 & 0 & 0 & 0 & 0 & 0 & 0 & 0 & 0 & 0 & 0 & 0.000 & 0.000 \\
\hline 2-Oct-03 & bam81 & 29.59 & 4.37 & 8580 & 0.24 & 6.2 & 12186 & 0.34 & 1.56 & 12991 & 9755.200 & 9755.200 \\
\hline 3-Oct-03 & 0 & 0 & 0 & 0 & 0 & 0 & 0 & 0 & 0 & 0 & 0.000 & 0.000 \\
\hline 4-Oct- 03 & ebm31 & 30.19 & 4.78 & 8446 & 0.42 & 6.84 & 12098 & 0.6 & 1.9 & 12986 & 8781.275 & 8781.275 \\
\hline 5-Oct-03 & bam82 & 29.05 & 4.42 & 8654 & 0.31 & 6.23 & 12197 & 0.43 & 1.49 & 13007 & 9557.500 & 9557.500 \\
\hline 6-Oct-03 & 0 & 0 & 0 & 0 & 0 & 0 & 0 & 0 & 0 & 0 & 0.000 & 0.000 \\
\hline 7-Oct- 03 & bam83 & 28.99 & 4.54 & 8696 & 0.3 & 6.4 & 12246 & 0.42 & 1.71 & 13083 & 8852.525 & 8852.525 \\
\hline 8-Oct-03 & ebm32 & 29.8 & 4.84 & 8515 & 0.41 & 6.9 & 12130 & 0.59 & 1.83 & 13029 & 13087.700 & 13087.700 \\
\hline 9-Oct-03 & 0 & 0 & 0 & 0 & 0 & 0 & 0 & 0 & 0 & 0 & 0.000 & 0.000 \\
\hline $10-$ Oct-03 & 0 & 0 & 0 & 0 & 0 & 0 & 0 & 0 & 0 & 0 & 0.000 & 0.000 \\
\hline $11-$ Oct-03 & 0 & 0 & 0 & 0 & 0 & 0 & 0 & 0 & 0 & 0 & 0.000 & 0.000 \\
\hline $12-O c t-03$ & bam84 & 28.72 & 4.63 & 8673 & 0.31 & 6.49 & 12168 & 0.44 & 1.4 & 13013 & 14172.250 & 14172.250 \\
\hline $13-O c t-03$ & bam85 & 29.19 & 4.26 & 8664 & 0.28 & 6.01 & 12236 & 0.39 & 1.52 & 13018 & 12636.750 & 12636.750 \\
\hline $14-O c t-03$ & 0 & 0 & 0 & 0 & 0 & 0 & 0 & 0 & 0 & 0 & 0.000 & 0.000 \\
\hline $15-$ Oct- 03 & 0 & 0 & 0 & 0 & 0 & 0 & 0 & 0 & 0 & 0 & 0.000 & 0.000 \\
\hline $16-O c t-03$ & ebm33 & 30.09 & 4.77 & 8454 & 0.34 & 6.82 & 12093 & 0.49 & 1.72 & 12978 & 14176.000 & 14176.000 \\
\hline $17-$ Oct- 03 & bam 86 & 29.41 & 4.45 & 8620 & 0.25 & 6.3 & 12212 & 0.36 & 1.54 & 13033 & 14023.050 & 14023.050 \\
\hline $18-O c t-03$ & 0 & 0 & 0 & 0 & 0 & 0 & 0 & 0 & 0 & 0 & 0.000 & 0.000 \\
\hline 19-Oct-03 & 0 & 0 & 0 & 0 & 0 & 0 & 0 & 0 & 0 & 0 & 0.000 & 0.000 \\
\hline $20-$ Oct-03 & btm001 & 26.87 & 5.43 & 8818 & 0.31 & 7.43 & 12058 & 0.42 & 1.19 & 0 & 11990.200 & 11990.200 \\
\hline 21-Oct-03 & btm02 & 26.64 & 5.39 & 8864 & 0.25 & 7.35 & 12083 & 0.34 & 1.17 & 0 & 11620.100 & 11620.100 \\
\hline 22-Oct-03 & 0 & 0 & 0 & 0 & 0 & 0 & 0 & 0 & 0 & 0 & 0.000 & 0.000 \\
\hline $23-$ Oct- 03 & 0 & 0 & 0 & 0 & 0 & 0 & 0 & 0 & 0 & 0 & 0.000 & 0.000 \\
\hline 24-Oct-03 & 0 & 0 & 0 & 0 & 0 & 0 & 0 & 0 & 0 & 0 & 0.000 & 0.000 \\
\hline $25-$ Oct- 03 & btm03 & 27.18 & 5.25 & 8809 & 0.26 & 7.21 & 12097 & 0.36 & 1.25 & 0 & 14197.450 & 14197.450 \\
\hline $26-$ Oct- 03 & 0 & 0 & 0 & 0 & 0 & 0 & 0 & 0 & 0 & 0 & 0.000 & 0.000 \\
\hline 27-Oct-03 & btm04 & 26.96 & 5.36 & 8835 & 0.25 & 7.34 & 12096 & 0.34 & 1.08 & 0 & 13716.600 & 13716.600 \\
\hline 28-Oct-03 & 0 & 0 & 0 & 0 & 0 & 0 & 0 & 0 & 0 & 0 & 0.000 & 0.000 \\
\hline $29-$ Oct-03 & bam 87 & 29.17 & 4.71 & 8647 & 0.31 & 6.65 & 12208 & 0.44 & 1.33 & 13078 & 14149.450 & 6542.450 \\
\hline $30-$ Oct- 03 & 0 & 0 & 0 & 0 & 0 & 0 & 0 & 0 & 0 & 0 & 0.000 & \\
\hline $31-$ Oct-03 & bam 88 & 28.61 & 4.57 & 8693 & 0.31 & 6.4 & 12177 & 0.43 & 1.52 & 13010 & 14104.600 & \\
\hline ADJ. & & & & & & & & & & & 184820.650 & 163109.050 \\
\hline Weighted & Average & 28.87 & 4.83 & 8630 & 0.31 & 6.78 & 12133 & 0.44 & 1.50 & & $\begin{array}{l}\text { Tons. OK } \\
\text { Burn }\end{array}$ & $\begin{array}{l}191576.460 \\
191576.460 \\
\end{array}$ \\
\hline
\end{tabular}

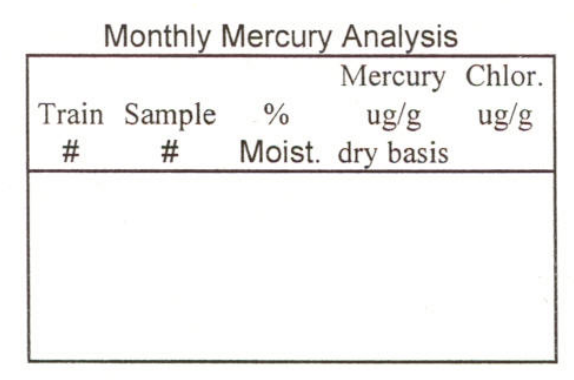




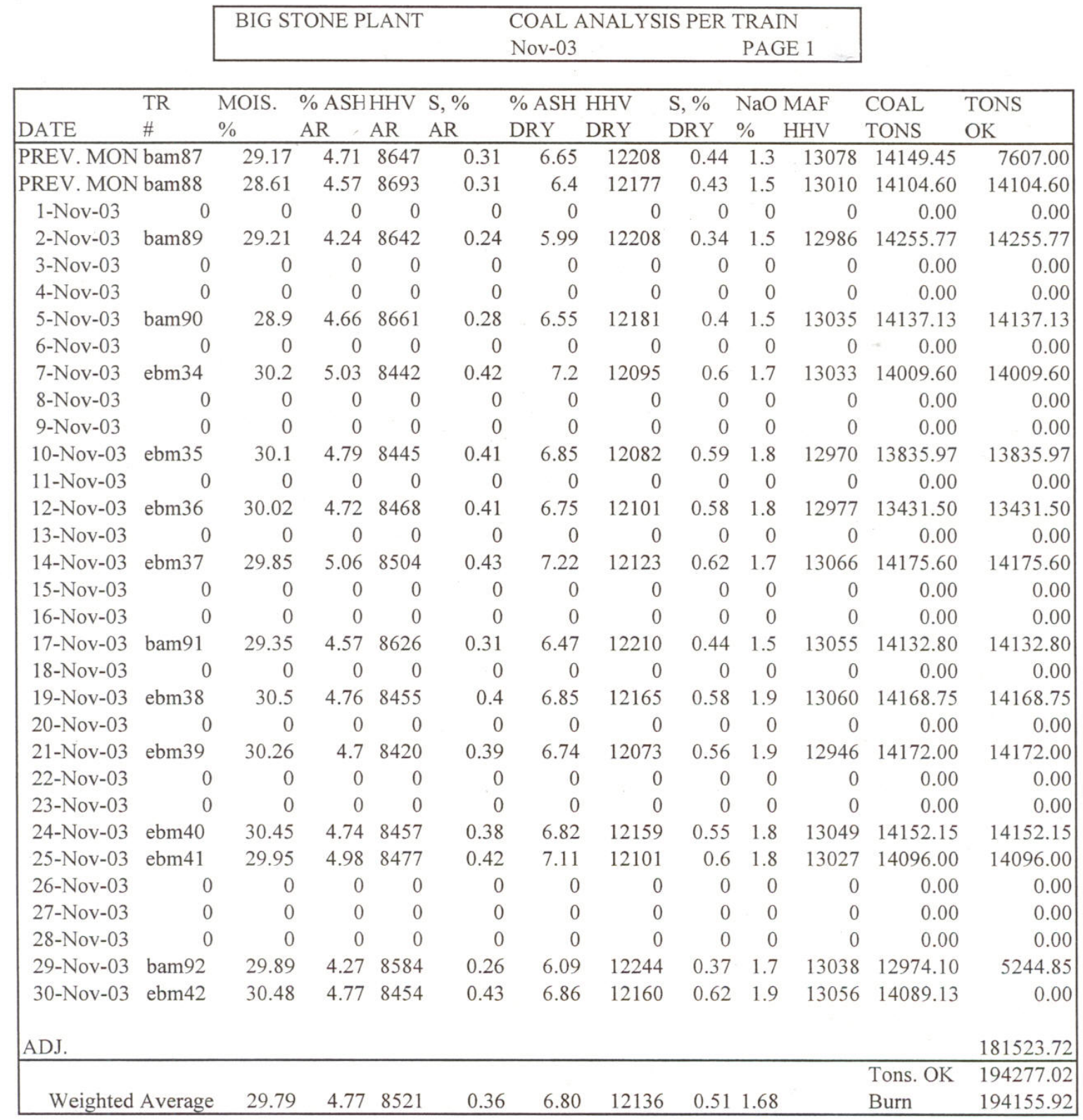

Monthly Mercury Analysis

\begin{tabular}{|c|c|c|c|c|}
\hline $\begin{array}{c}\text { Train } \\
\#\end{array}$ & $\begin{array}{c}\text { Sample } \\
\#\end{array}$ & $\begin{array}{c}\% \\
\text { Moist. }\end{array}$ & $\begin{array}{c}\text { Mercury } \\
\text { ug/g } \\
\text { dry basis }\end{array}$ & $\begin{array}{c}\text { Chlor. } \\
\text { ug/g }\end{array}$ \\
\hline & C2557 & 29.51 & 0.07 & $<0.01$ \\
\hline
\end{tabular}


BIG STONE PLANT COAL ANALYSIS PER TRAIN Dec-03

PAGE 1

\begin{tabular}{|c|c|c|c|c|c|c|c|c|c|c|c|c|}
\hline DATE & $\begin{array}{l}\text { TR } \\
\#\end{array}$ & $\begin{array}{l}\text { MOIS } \\
\%\end{array}$ & $\begin{array}{l}\% \text { ASH } \\
\text { AR }\end{array}$ & $\begin{array}{l}\mathrm{HHV} \\
\mathrm{AR}\end{array}$ & $\begin{array}{l}\text { S, \% } \\
\text { AR }\end{array}$ & $\begin{array}{l}\% \text { ASH } \\
\text { DRY }\end{array}$ & $\begin{array}{l}\text { HHV } \\
\text { DRY }\end{array}$ & $\begin{array}{l}\text { S, } \% \\
\text { DRY }\end{array}$ & $\begin{array}{l}\mathrm{NaO} \\
\%\end{array}$ & $\begin{array}{l}\text { MAF } \\
\text { HHV }\end{array}$ & $\begin{array}{l}\text { COAL } \\
\text { TONS }\end{array}$ & $\begin{array}{l}\text { TONS } \\
\text { OK }\end{array}$ \\
\hline PREV. MON & bam92 & 29.89 & 4.27 & 8584 & 0.26 & 6.09 & 12244 & 0.37 & 1.69 & 13038 & 12974.10 & 7729.25 \\
\hline PREV. MON & ebm 42 & 30.48 & 4.77 & 8454 & 0.43 & 6.86 & 12160 & 0.62 & 1.86 & 13056 & 14089.13 & 14089.13 \\
\hline 1-Dec-03 & 0 & 0 & 0 & 0 & 0 & 0 & 0 & 0 & 0 & 0 & 0.00 & \\
\hline 2-Dec-03 & 0 & 0 & 0 & 0 & 0 & 0 & 0 & 0 & 0 & 0 & 0.00 & \\
\hline 3-Dec-03 & bam93 & 29.3 & 4.31 & 8652 & 0.27 & 6.1 & 12237 & 0.38 & 1.58 & 13032 & 6658.15 & 6658.15 \\
\hline 4-Dec-03 & 0 & 0 & 0 & 0 & 0 & 0 & 0 & 0 & 0 & 0 & 0.00 & \\
\hline 5-Dec-03 & ebm43 & 29.3 & 4.85 & 8575 & 0.42 & 6.86 & 12125 & 0.6 & 1.85 & 13018 & 14134.15 & 14134.15 \\
\hline 6-Dec-03 & 0 & 0 & 0 & 0 & 0 & 0 & 0 & 0 & 0 & 0 & 0.00 & \\
\hline 7-Dec-03 & 0 & 0 & 0 & 0 & 0 & 0 & 0 & 0 & 0 & 0 & 0.00 & \\
\hline 8-Dec-03 & 0 & 0 & 0 & 0 & 0 & 0 & 0 & 0 & 0 & 0 & 0.00 & \\
\hline 9-Dec-03 & ebm44 & 30 & 5.25 & 8419 & 0.43 & 7.5 & 12019 & 0.62 & 1.67 & 12994 & 11198.31 & 11198.31 \\
\hline 10-Dec-03 & 0 & 0 & 0 & 0 & 0 & 0 & 0 & 0 & 0 & 0 & 0.00 & \\
\hline 11-Dec-03 & 0 & 0 & 0 & 0 & 0 & 0 & 0 & 0 & 0 & 0 & 0.00 & \\
\hline 12-Dec-03 & ebm 45 & 29.6 & 5.31 & 8463 & 0.44 & 7.55 & 12030 & 0.63 & 1.58 & 13012 & 0.00 & \\
\hline 13-Dec-03 & 0 & 0 & 0 & 0 & 0 & 0 & 0 & 0 & 0 & 0 & 0.00 & \\
\hline 14-Dec-03 & 0 & 0 & 0 & 0 & 0 & 0 & 0 & 0 & 0 & 0 & 0.00 & \\
\hline 15 -Dec-03 & 0 & 0 & 0 & 0 & 0 & 0 & 0 & 0 & 0 & 0 & 0.00 & \\
\hline 16-Dec-03 & 0 & 0 & 0 & 0 & 0 & 0 & 0 & 0 & 0 & 0 & 0.00 & \\
\hline 17-Dec-03 & 0 & 0 & 0 & 0 & 0 & 0 & 0 & 0 & 0 & 0 & 0.00 & \\
\hline 18-Dec-03 & 0 & 0 & 0 & 0 & 0 & 0 & 0 & 0 & 0 & 0 & 0.00 & \\
\hline 19-Dec-03 & 0 & 0 & 0 & 0 & 0 & 0 & 0 & 0 & 0 & 0 & 0.00 & \\
\hline 20-Dec-03 & 0 & 0 & 0 & 0 & 0 & 0 & 0 & 0 & 0 & 0 & 0.00 & \\
\hline 21-Dec-03 & 0 & 0 & 0 & 0 & 0 & 0 & 0 & 0 & 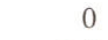 & 0 & 0.00 & \\
\hline 22-Dec-03 & ebm 46 & 30.4 & 4.87 & 8369 & 0.4 & 7 & 12025 & 0.57 & 1.8 & 12930 & 8801.65 & 8801.65 \\
\hline 23-Dec-03 & 0 & 0 & 0 & 0 & 0 & 0 & 0 & 0 & 0 & 0 & 0.00 & \\
\hline 24-Dec-03 & 0 & 0 & 0 & 0 & 0 & 0 & 0 & 0 & 0 & 0 & 0.00 & \\
\hline 25-Dec-03 & 0 & 0 & 0 & 0 & 0 & 0 & 0 & 0 & 0 & 0 & 0.00 & \\
\hline 26-Dec-03 & 0 & 0 & 0 & 0 & 0 & 0 & 0 & 0 & 0 & 0 & 0.00 & \\
\hline 27-Dec-03 & ebm47 & 29.7 & 4.94 & 8523 & 0.44 & 7.02 & 12120 & 0.63 & 1.89 & 13035 & 14139.83 & 14139.83 \\
\hline 28-Dec-03 & ebm 48 & 29.9 & 4.9 & 8469 & 0.45 & 6.99 & 12087 & 0.64 & 1.83 & 12995 & 12957.55 & 12957.55 \\
\hline 29-Dec-03 & 0 & 0 & 0 & 0 & 0 & 0 & 0 & 0 & 0 & 0 & 0.00 & \\
\hline 30-Dec-03 & ebm49 & 29.6 & 5 & 8524 & 0.42 & 7.11 & 12109 & 0.6 & 1.67 & 13036 & 14179.50 & 1341.83 \\
\hline 31-Dec-03 & ebm50 & 29.8 & 5.15 & 8470 & 0.43 & 7.34 & 12073 & 0.61 & 1.54 & 13029 & 12102.48 & \\
\hline ADJ. & & & & & & & & & & & & 91049.85 \\
\hline Weighted & Average & 29.89 & 4.86 & 8492 & 0.40 & 6.93 & 12113 & 0.57 & 1.78 & & $\begin{array}{l}\text { Tons. OK } \\
\text { Burn }\end{array}$ & $\begin{array}{r}96277.15 \\
96277.15 \\
\end{array}$ \\
\hline
\end{tabular}

Monthly Mercury Analysis

\begin{tabular}{|ccccc|}
\hline $\begin{array}{c}\text { Train } \\
\text { \# }\end{array}$ & $\begin{array}{c}\text { Sample } \\
\#\end{array}$ & $\begin{array}{c}\text { Mercury } \\
\text { Moist. }\end{array}$ & $\begin{array}{c}\text { Chlor. } \\
\text { dry basis }\end{array}$ & ug/g \\
\hline & $04-$ C19 & 29.76 & 0.06 & $<0.01$ \\
& & & & \\
& & & & \\
& & & \\
\hline
\end{tabular}




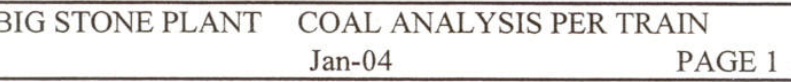

\begin{tabular}{|c|c|c|c|c|c|c|c|c|c|c|c|c|}
\hline DATE & $\begin{array}{c}\text { TR } \\
\#\end{array}$ & $\begin{array}{c}\text { MOIS. } \\
\%\end{array}$ & $\begin{array}{c}\% \mathrm{ASH} \\
\mathrm{AR}\end{array}$ & $\begin{array}{c}\text { HHV } \\
\text { AR }\end{array}$ & $\begin{array}{l}\mathrm{S}, \% \\
\mathrm{AR}\end{array}$ & $\begin{array}{c}\% \text { ASH } \\
\text { DRY }\end{array}$ & $\begin{array}{l}\text { HHV } \\
\text { DRY }\end{array}$ & $\begin{array}{l}\text { S, } \% \\
\text { DRY }\end{array}$ & $\begin{array}{c}\mathrm{NaO} \\
\%\end{array}$ & $\begin{array}{l}\text { MAF } \\
\text { HHV }\end{array}$ & $\begin{array}{l}\text { COAL } \\
\text { TONS }\end{array}$ & $\begin{array}{c}\text { TONS } \\
\text { OK }\end{array}$ \\
\hline PREV.MO & ebm49 & 29.61 & 5.00 & 8524 & 0.42 & 7.11 & 12109 & 0.60 & 1.67 & 13036 & $14,179.50$ & $12,837.67$ \\
\hline PREV. MO & ebm50 & 29.84 & 5.15 & 8470 & 0.43 & 7.34 & 12073 & 0.61 & 1.54 & 13029 & $12,102.48$ & $12,102.48$ \\
\hline 1-Jan-04 & 0 & 0 & 0 & 0 & 0 & 0 & 0 & 0 & 0 & 0 & 0.00 & \\
\hline 2-Jan-04 & 0 & 0 & 0 & 0 & 0 & 0 & 0 & 0 & 0 & 0 & 0.00 & \\
\hline $3-\mathrm{Ja}$ & 0 & 0 & 0 & 0 & 0 & 0 & 0 & 0 & 0 & 0 & 0.00 & \\
\hline 4-Jan-04 & 0 & 0 & 0 & 0 & 0 & 8 & 0 & 0 & 0 & 0 & 0.00 & \\
\hline 5-Jan-04 & ebm01 & 30.62 & 4.84 & 8369 & 0.42 & 6.98 & 12063 & 0.61 & 1.79 & 12968 & $13,520.10$ & $13,520.10$ \\
\hline 6-Jan-04 & 0 & 0 & 0 & 0 & 0 & 0 & 0 & 0 & 0 & 0 & 0.00 & \\
\hline 7-Jan-04 & EBM02 & 30.44 & 4.72 & 8432 & 0.42 & 6.79 & 12122 & 0.6 & 1.81 & 13005 & $13,877.73$ & $13,877.73$ \\
\hline 8-Jan-04 & 0 & 0 & 0 & 0 & 0 & 0 & 0 & 0 & 0 & 0 & 0.00 & \\
\hline 9-Ja & bam01 & 29.21 & 4.7 & 8608 & 0.31 & 6.64 & 12160 & 0.44 & 1.43 & 13025 & $13,617.45$ & $13,617.45$ \\
\hline $10-\mathrm{Ja}$ & 0 & 0 & 0 & 0 & 0 & 0 & 0 & 0 & 0 & 0 & 0.00 & \\
\hline $11-J$ & BAM02 & 29.45 & 4.57 & 8586 & 0.29 & 6.48 & 12145 & 0.41 & 1.4 & 12987 & $14,168.10$ & $14,168.10$ \\
\hline $12-\mathrm{J}$ & 0 & 0 & 0 & 0 & 0 & 0 & 0 & 0 & 0 & 0 & 0.00 & \\
\hline $13-\mathrm{Ja}$ & bam03 & 29.39 & 4.82 & 8544 & 0.28 & 6.83 & 12100 & 0.4 & 1.47 & 12987 & $13,734.48$ & $13,734.48$ \\
\hline 14-J & 0 & 0 & 0 & 0 & 0 & 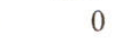 & 0 & 0 & $\sigma$ & 0 & 0.00 & \\
\hline $15-\mathrm{Ja}$ & bam04 & 29.37 & 4.43 & 8641 & 0.31 & 6.27 & 12234 & 0.44 & 1.36 & 13052 & $13,762.80$ & $13,762.80$ \\
\hline 16-Jan-04 & 0 & 0 & 0 & . & 0 & . & 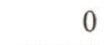 & 0 & 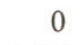 & 0 & 0.00 & \\
\hline $17-\mathrm{J}$ & ebm03 & 30.08 & 4.82 & 8474 & 0.43 & 6.89 & 12120 & 0.62 & 1.77 & 13017 & 97.98 & $13,697.98$ \\
\hline $18-\mathrm{J}$ & bam05 & 29.41 & 4.51 & 8622 & 0.28 & 6.39 & 12214 & 0.39 & 1.73 & 13048 & $13,552.10$ & $13,552.10$ \\
\hline 19-Jan-04 & 0 & 0 & 0 & 0 & 0 & 0 & 0 & 0 & 0 & 0 & 0.00 & \\
\hline 20-Jan-04 & 0 & 0 & 0 & 0 & 0 & 0 & 0 & 0 & 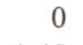 & 0 & 0.00 & \\
\hline 21-Jan-04 & bam06 & 29.27 & 4.44 & 8609 & 0.3 & 6.28 & 12171 & 0.42 & 1.45 & 12987 & 28.30 & 8.30 \\
\hline 22-Jan-04 & bam07 & 29.45 & 4.3 & 8644 & 0.25 & 6.1 & 12252 & 0.36 & 1.65 & 13048 & $11,878.50$ & $11,878.50$ \\
\hline 23-Jan-04 & 0 & 0 & 0 & 0 & 0 & 0 & 0 & 0 & & 0 & 0.00 & \\
\hline $24-\mathrm{Ja}$ & 0 & 0 & 0 & 0 & 0 & 0 & 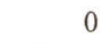 & 0 & 0 & 0 & 0.00 & \\
\hline 25-Jan-04 & ebm04 & 29.94 & 4.95 & 8498 & 0.42 & 7.06 & 12130 & 0.6 & 1.69 & 13051 & $13,757.48$ & $13,757.48$ \\
\hline 26-Jan-04 & bam08 & 29.21 & 4.5 & 8650 & 0.31 & 6.35 & 12219 & 0.44 & 1.55 & 13048 & $13,257.18$ & $13,257.18$ \\
\hline 27-Jan-04 & 0 & 0 & 0 & 0 & 0 & 0 & 0 & 0 & 0 & 0 & 0.00 & \\
\hline 28-Jan-04 & 0 & 0 & 0 & 0 & 0 & 0 & 0 & 0 & 0 & 0 & 0.00 & \\
\hline 29-Jan-04 & 0 & 0 & 0 & 0 & 0 & 0 & 0 & 0 & 0 & 0 & 0.00 & \\
\hline 30-Jan-04 & ebm05 & 29.96 & 4.91 & 8439 & 0.43 & 7.01 & 12049 & 0.62 & 1.71 & 12957 & $13,733.30$ & $13,733.30$ \\
\hline 31-Jan-04 & 0 & 0 & 0 & 0 & 0 & 0 & 0 & 0 & 0 & 0 & 0.00 & \\
\hline ADJ. & & & & & & & & & & & & $199,225.65$ \\
\hline Weighted $A$ & Average & 29.69 & 4.71 & 8540 & 0.35 & 6.70 & 12143 & 0.50 & 1.60 & & Burn & $\begin{array}{l}199,225.65 \\
205,677.43 \\
\end{array}$ \\
\hline
\end{tabular}

Monthly Mercury Analysis

\begin{tabular}{|ccccc|}
\hline \multicolumn{3}{|c}{\begin{tabular}{cccc|} 
Train \\
\#
\end{tabular}} & Mercury & Chloride \\
& Moist. & dry basis & \\
\hline & C53 & 29.33 & 0.093 & $<.01 \%$ \\
\hline
\end{tabular}




\section{BIG STONE PLANT COAL ANALYSIS PER TRAIN}

Feb-04

PAGE 1

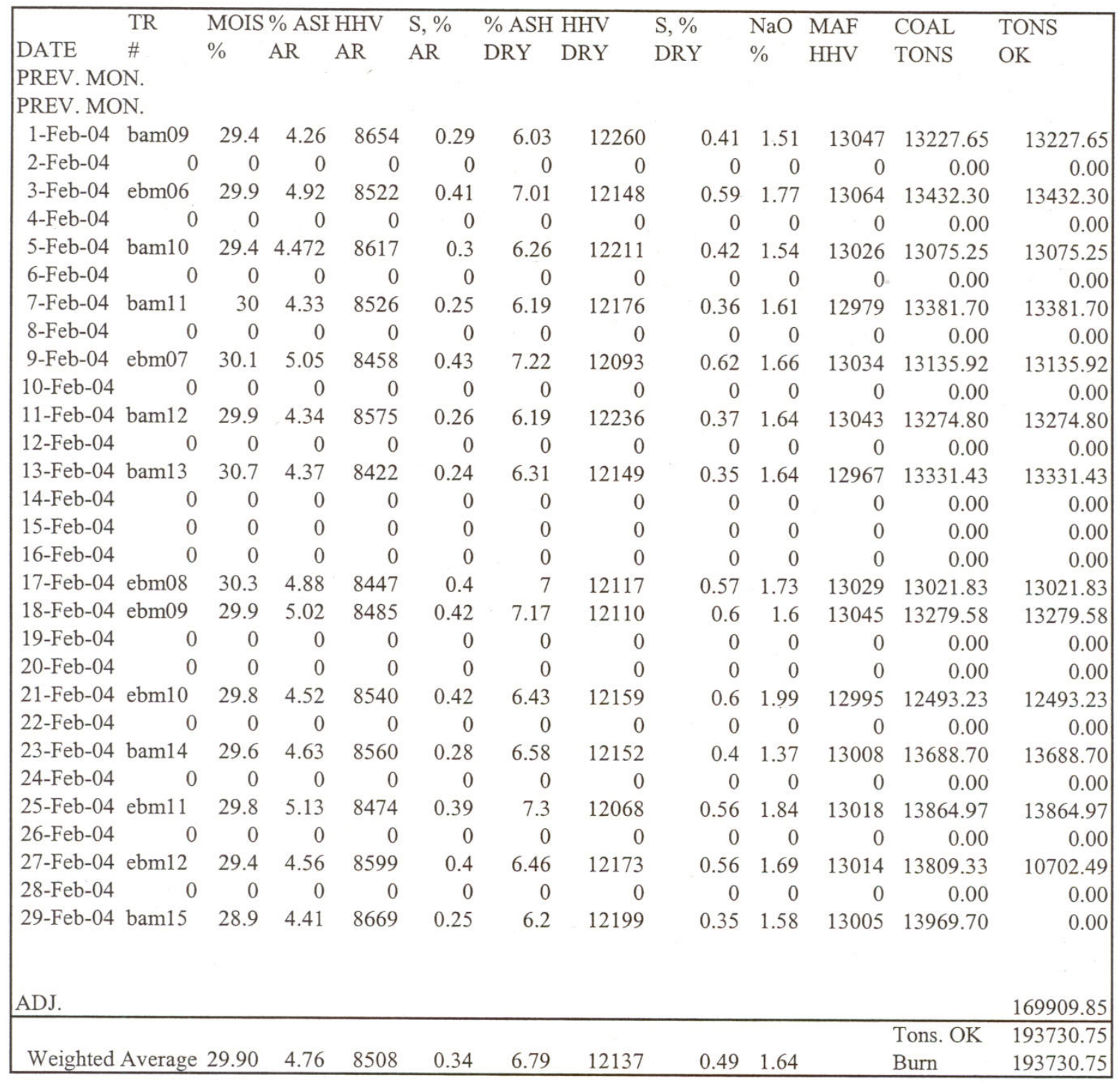

Monthly Mercury Analysis

\begin{tabular}{|c|c|c|c|c|}
\hline $\begin{array}{c}\text { Train } \\
\#\end{array}$ & $\begin{array}{c}\text { Sample } \\
\#\end{array}$ & $\begin{array}{c}\% \\
\text { Moist. }\end{array}$ & $\begin{array}{c}\text { Mercury } \\
\text { ug/g } \\
\text { dry basis }\end{array}$ & $\begin{array}{c}\text { Chloride } \\
\text { ug/g }\end{array}$ \\
\hline & $\mathrm{C} 282$ & 29.27 & 0.035 & $<.01 \%$ \\
\hline
\end{tabular}




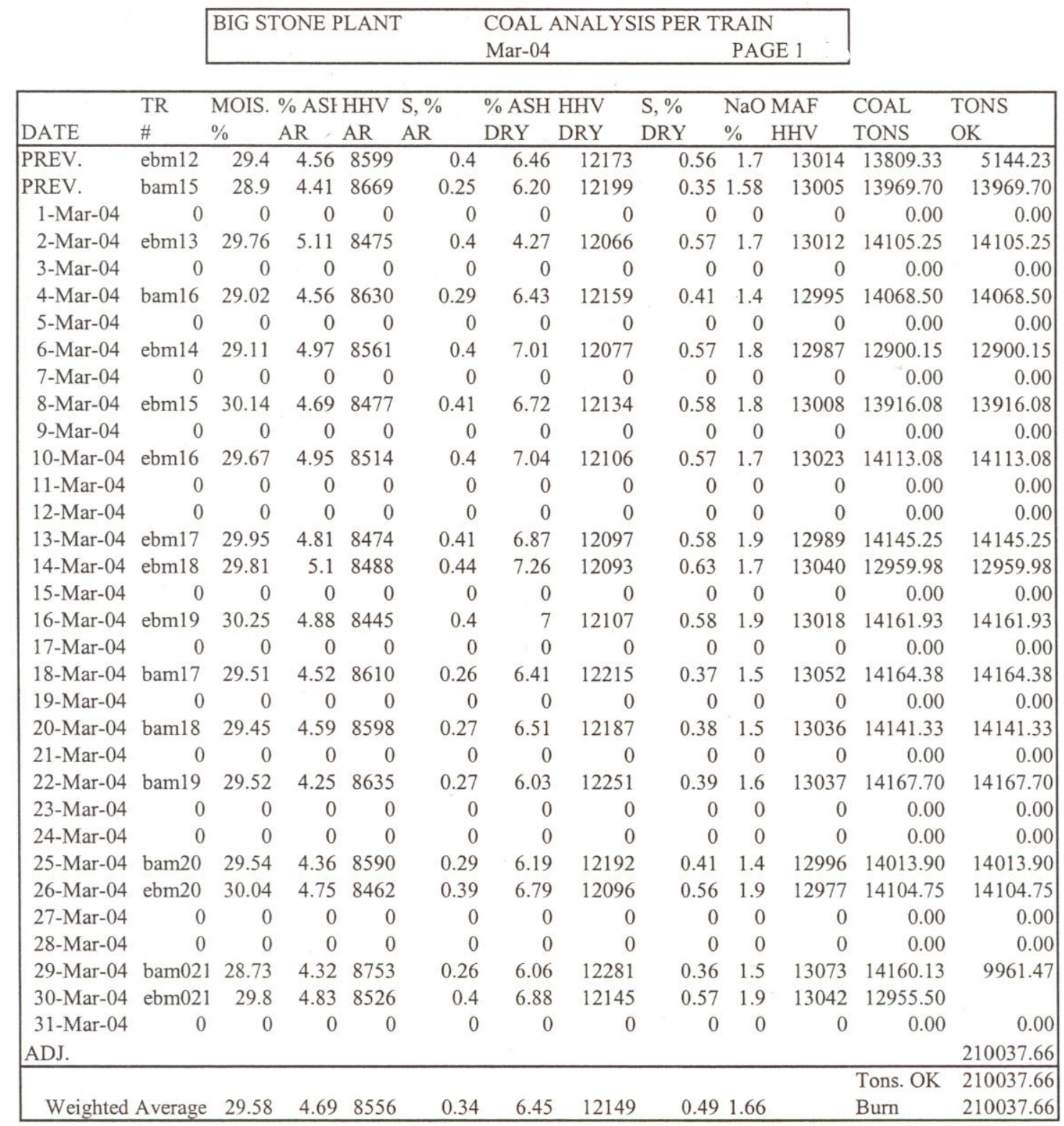

Monthly Mercury Analysis

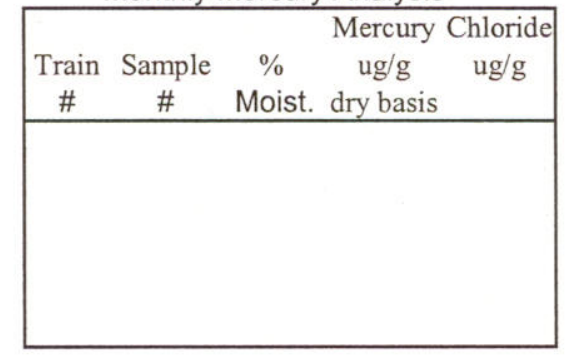




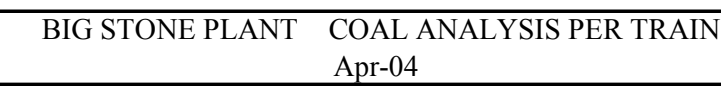

\begin{tabular}{|c|c|c|c|c|c|c|c|c|c|c|c|c|}
\hline & TR & MOIS. & $\% \mathrm{ASF}$ & $\mathrm{HHV}$ & $\mathrm{S}, \%$ & $\% \mathrm{ASH}$ & $\mathrm{HHV}$ & $\mathrm{S}, \%$ & $\mathrm{NaO}$ & MAF & COAL & TONS \\
\hline DATE & $\#$ & $\%$ & $\mathrm{AR}$ & $\mathrm{AR}$ & $\mathrm{AR}$ & DRY & DRY & DRY & $\%$ & HHV & TONS & $\mathrm{OK}$ \\
\hline PREV. MON. & bam021 & 28.73 & 4.32 & 8753 & 0.26 & 6.06 & 12281 & 0.36 & 1.5 & 13073 & 14160.13 & 4198.66 \\
\hline PREV. MON. & ebm021 & 29.8 & 4.83 & 8526 & 0.4 & 6.88 & 12145 & 0.57 & 1.9 & 13042 & 12955.50 & 12955.50 \\
\hline 1-Apr-04 & 0 & 0 & 0.00 & 0 & 0 & 0 & 0 & 0 & 0 & 0 & 0.00 & \\
\hline 2-Apr-04 & 0 & 0 & 0.00 & 0 & 0 & 0 & 0 & 0 & 0 & 0 & 0.00 & \\
\hline 3-Apr-04 & bam22 & 29.18 & 4.29 & 8626 & 0.27 & 6.06 & 12180 & 0.38 & 1.5 & 12966 & 14160.98 & 14160.98 \\
\hline 4-Apr-04 & bam23 & 28.84 & 4.64 & 8625 & 0.3 & 6.52 & 12121 & 0.42 & 1.4 & 12966 & 13350.00 & 13350.00 \\
\hline 5-Apr-04 & 0 & 0 & 0.00 & 0 & 0 & 0 & 0 & 0 & 0 & 0 & 0.00 & \\
\hline 6-Apr-04 & 0 & 0 & 0.00 & 0 & 0 & 0 & 0 & 0 & 0 & 0 & 0.00 & \\
\hline 7-Apr-04 & bam24 & 28.87 & 5.08 & 8607 & 0.29 & 7.14 & 12100 & 0.41 & 1.3 & 13030 & 9835.43 & 9835.43 \\
\hline 8-Apr-04 & bam 25 & 28.87 & 4.87 & 8669 & 0.32 & 6.84 & 12187 & 0.45 & 1.4 & 13082 & 13773.15 & 13773.15 \\
\hline 9-Apr-04 & 0 & 0 & 0.00 & 0 & 0 & 0 & 0 & 0 & 0 & 0 & 0.00 & \\
\hline 10 -Apr-04 & bam026 & 28.83 & 4.85 & 8651 & 0.3 & 6.82 & 12156 & 0.42 & 1.4 & 13046 & 14166.35 & 14166.35 \\
\hline 11-Apr-04 & bam27 & 28.89 & 4.71 & 8622 & 0.28 & 6.63 & 12125 & 0.4 & 1.5 & 12986 & 13800.53 & 13800.53 \\
\hline 12-Apr-04 & 0 & 0 & 0.00 & 0 & 0 & 0 & 0 & 0 & 0 & 0 & 0.00 & \\
\hline 13-Apr-04 & 0 & 0 & 0.00 & 0 & 0 & 0 & 0 & 0 & 0 & 0 & 0.00 & \\
\hline 14-Apr-04 & bam 28 & 29.3 & 4.34 & 8628 & 0.27 & 6.14 & 12204 & 0.38 & 1.6 & 13002 & 14140.08 & 14140.08 \\
\hline 15-Apr-04 & bam29 & 28.83 & 4.36 & 8672 & 0.26 & 6.12 & 12185 & 0.37 & 1.5 & 12979 & 9536.70 & 9536.70 \\
\hline 16-Apr-04 & 0 & 0 & 0.00 & 0 & 0 & 0 & 0 & 0 & 0 & 0 & 0.00 & \\
\hline 17-Apr-04 & 0 & 0 & 0.00 & 0 & 0 & 0 & 0 & 0 & 0 & 0 & 0.00 & \\
\hline 18-Apr-04 & ebm22 & 29.72 & 4.99 & 8478 & 0.39 & 7.1 & 12063 & 0.56 & 1.7 & 12985 & 13080.60 & 13080.60 \\
\hline 19-Apr-04 & 0 & 0 & 0.00 & 0 & 0 & 0 & 0 & 0 & 0 & 0 & 0.00 & \\
\hline 20-Apr-04 & bam30 & 29.69 & 4.20 & 8618 & 0.26 & 5.98 & 12257 & 0.37 & 1.5 & 13037 & 12762.73 & 12762.73 \\
\hline 21-Apr-04 & 0 & 0 & 0.00 & 0 & 0 & 0 & 0 & 0 & 0 & 0 & 0.00 & \\
\hline 22-Apr-04 & 0 & 0 & 0.00 & 0 & 0 & 0 & 0 & 0 & 0 & 0 & 0.00 & \\
\hline 23-Apr-04 & ebm23 & 30.3 & 4.77 & 8474 & 0.39 & 6.84 & 12158 & 0.56 & 1.9 & 13051 & 14181.68 & 14181.68 \\
\hline 24-Apr-04 & 0 & 0 & 0.00 & 0 & 0 & 0 & 0 & 0 & 0 & 0 & 0.00 & \\
\hline 25-Apr-04 & bam31 & 29.12 & 4.66 & 8595 & 0.26 & 6.57 & 12126 & 0.37 & 1.5 & 12979 & 14163.73 & 14163.73 \\
\hline 26-Apr-04 & 0 & 0 & 0.00 & 0 & 0 & 0 & 0 & 0 & 0 & 0 & 0.00 & \\
\hline 27-Apr-04 & 0 & 0 & 0.00 & 0 & 0 & 0 & 0 & 0 & 0 & 0 & 0.00 & \\
\hline 28-Apr-04 & ebm24 & 29.83 & 4.77 & 8525 & 0.44 & 6.8 & 12149 & 0.62 & 2 & 13035 & 12989.30 & 11789.97 \\
\hline 29-Apr-04 & bam32 & 28.56 & 4.24 & 8684 & 0.27 & 5.94 & 12156 & 0.38 & 1.5 & 12924 & 14149.70 & \\
\hline 30-Apr-04 & 0 & 0 & 0.00 & 0 & 0 & 0 & 0 & 0 & 0 & 0 & 0.00 & \\
\hline ADJ. & & & & & & & & & & & & 185896.06 \\
\hline Weighte & d Average & 29.29 & 4.66 & 8597 & 0.32 & 6.59 & 12157 & 0.45 & 1.58 & & $\begin{array}{l}\text { Tons. OK } \\
\text { Burn }\end{array}$ & $\begin{array}{l}185896.06 \\
185896.05 \\
\end{array}$ \\
\hline
\end{tabular}

\begin{tabular}{|ccccc|}
\hline \multicolumn{3}{|c|}{ Monthly Mercury Analysis } \\
\hline Train & Sample & $\%$ & Mercury & Chloride \\
$\#$ & $\#$ & Moist. & dry basis & ug/g \\
\hline & & 30.14 & 0.116 & $<0.01$ \\
\hline
\end{tabular}


BIG STONE PLANT COAL ANALYSIS PER TRAIN

May-04

\begin{tabular}{|c|c|c|c|c|c|c|c|c|c|c|c|}
\hline DATE & $\begin{array}{c}\text { MOIS. } \\
\%\end{array}$ & $\begin{array}{c}\% \text { ASH } \\
\text { AR }\end{array}$ & $\begin{array}{c}\mathrm{HHV} \\
\mathrm{AR} \\
\end{array}$ & $\begin{array}{l}\mathrm{S}, \% \\
\mathrm{AR}\end{array}$ & $\begin{array}{c}\% \text { ASH } \\
\text { DRY }\end{array}$ & $\begin{array}{l}\text { HHV } \\
\text { DRY }\end{array}$ & $\begin{array}{l}\mathrm{S}, \% \\
\mathrm{DRY} \\
\end{array}$ & $\begin{array}{c}\mathrm{NaO} \\
\% \\
\end{array}$ & $\begin{array}{l}\text { MAF } \\
\text { HHV }\end{array}$ & $\begin{array}{l}\text { COAL } \\
\text { TONS } \\
\end{array}$ & $\begin{array}{c}\text { TONS } \\
\text { OK }\end{array}$ \\
\hline PREV. MON ebm24 & 29.83 & 4.77 & 8525 & 0.44 & 6.8 & 12149 & 0.62 & 1.98 & 13035 & 12989.300 & 1199.330 \\
\hline PREV. MON bam32 & 28.56 & 4.24 & 8684 & 0.27 & 5.94 & 12156 & 0.38 & 1.51 & 2924 & 14149.700 & 14149.700 \\
\hline 1-May-04 & 0 & 0 & 0 & 0 & 0 & 0 & 0 & 0 & 0 & 0.000 & \\
\hline 2-May-04 ebm25 & 30.32 & 4.93 & 8396 & 0.4 & 7.07 & 12050 & 0.57 & 1.82 & 12967 & 14183.200 & 14183.200 \\
\hline 3-May-04 bam33 & 29.16 & 4.28 & 8647 & 0.23 & 6.04 & 12207 & 0.33 & 1.48 & 12992 & 14158.475 & 14158.475 \\
\hline 4-May-04 & 0 & 0 & 0 & 0 & 0 & 0 & 0 & 0 & 0 & 0.000 & \\
\hline 5-Мay-04 bam034 & 29.17 & 4.32 & 8693 & 0.28 & 6.1 & 12273 & 0.4 & 1.57 & 13070 & 12965.900 & 12965.90 \\
\hline 6-May-04 & 0 & 0 & 0 & 0 & 0 & 0 & ? & 0 & 0 & 0.000 & \\
\hline 7-May-04 & 0 & 0 & 0 & 0 & 0 & 0 & 0 & 0 & 0 & 0.000 & \\
\hline 8-May-04 bam35 & 29.4 & 4.38 & 8587 & 0.29 & 6.2 & 12163 & 0.41 & 1.55 & 12967 & 12720.880 & 12720.880 \\
\hline 9-May-04 & 0 & 0 & 0 & 0 & 0 & 0 & 0 & 0 & 0 & 0.000 & \\
\hline 10-May-04 bam36 & 29.83 & 4.13 & 8578 & 0.27 & 5.89 & 12225 & 0.39 & 1.4 & 12990 & 14149.800 & 14149.80 \\
\hline 11-May-04 & 0 & 0 & 0 & 0 & 0 & 0 & 0 & 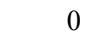 & 0 & 0.000 & \\
\hline 12-May-04 bam37 & 29.88 & 4.53 & 8511 & 0.31 & 6.46 & 12138 & 0.44 & 1.46 & 12976 & 14167.225 & 14167.225 \\
\hline 13-May-04 & 0 & 0 & 0 & 0 & 0 & 0 & 0 & 0 & 0 & 0.000 & \\
\hline 14-May-04 bam38 & 29.56 & 4.61 & 8594 & 0.3 & 6.55 & 12201 & 0.42 & 1.47 & 13056 & 14157.850 & 14157.850 \\
\hline 15-May-04 & 0 & 0 & 0 & 0 & 0 & 0 & 0 & 0 & 0 & 0.000 & \\
\hline 16-May-04 bam39 & 29.55 & 4.35 & 8643 & 0.29 & 6.18 & 12268 & 0.41 & 1.54 & 13076 & 14156.550 & 14156.55 \\
\hline 17-May-04 & 0 & 0 & 0 & 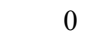 & 0 & 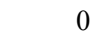 & 0 & 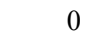 & 0 & 0.000 & \\
\hline 18-May-04 & 0 & 0 & 0 & 0 & 0 & 0 & 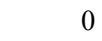 & 0 & 0 & 0.000 & \\
\hline 19-May-04 bam40 & 29.59 & 4.63 & 8563 & 0.3 & 6.57 & 12161 & 0.43 & 1.56 & 13016 & 14149.900 & 14149.900 \\
\hline 20-May-04 ebm26 & 30.26 & 4.94 & 8406 & 0.38 & 7.09 & 12053 & 0.55 & 1.72 & 12973 & 14187.275 & 14187.275 \\
\hline 21-May-04 & 0 & 0 & 0 & 0 & 0 & 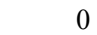 & 0 & 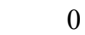 & 0 & 0.000 & \\
\hline 22-May-04 & 0 & 0 & 0 & 0 & 0 & 0 & 0 & 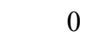 & 0 & 0.000 & \\
\hline 23-May-04 bam041 & 29.12 & 4.69 & 8581 & 0.33 & 6.61 & 12107 & 0.46 & 1.4 & 12964 & 14151.225 & 14151.225 \\
\hline 24-May-04 ebm027 & 30.78 & 4.81 & 8386 & 0.41 & 6.95 & 12115 & 0.59 & 1.8 & 13020 & 13105.525 & 13105.525 \\
\hline 25-May-04 & 0 & 0 & 0 & 0 & 0 & D & 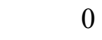 & 0 & 0 & 0.000 & \\
\hline 26-Мay-04 & 0 & 0 & 0 & 0 & 0 & 0 & 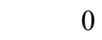 & 0 & 0 & 0.000 & \\
\hline 27-May-04 ebm028 & 30.36 & 4.68 & 8431 & 0.41 & 6.72 & 12106 & 0.59 & 1.76 & 12978 & 14151.046 & 14151.046 \\
\hline 28-May-04 & 0 & 0 & 0 & 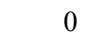 & 0 & 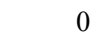 & 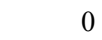 & 0 & 0 & 0.000 & \\
\hline 29-Мay-04 & 0 & 0 & 0 & 0 & 0 & 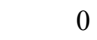 & 0 & 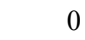 & 0 & 0.000 & \\
\hline 30-May-04 ebm029 & 30.33 & 4.65 & 8445 & .41 & 6.68 & 12121 & 59 & 1.86 & 12989 & 14205.600 & 7954.379 \\
\hline 31-May-04 ebm30 & 29.78 & 4.63 & 8500 & 0.39 & 6.6 & 12105 & 0.56 & 1.7 & 12960 & 14201.880 & \\
\hline ADJ. & & & & & & & & & & & 203708.260 \\
\hline erage & 29.71 & 4.54 & 8545 & .32 & 6.47 & 12157 & 0.46 & 1.59 & & $\begin{array}{l}\text { Tons. OK } \\
\text { Burn }\end{array}$ & $\begin{array}{l}203708.260 \\
203708.260\end{array}$ \\
\hline
\end{tabular}

Monthly Mercury Analysis

\begin{tabular}{|c|c|c|c|c|}
\hline $\begin{array}{c}\text { Train } \\
\#\end{array}$ & $\begin{array}{c}\text { Sample } \\
\#\end{array}$ & $\begin{array}{c}\% \\
\text { Moist. }\end{array}$ & $\begin{array}{c}\text { Mercury } \\
\text { ug/g } \\
\text { dry basis }\end{array}$ & $\begin{array}{c}\text { Chloride } \\
\text { ug/g }\end{array}$ \\
\hline & C817 & 29.19 & 0.086 & $<0.01$ \\
\hline
\end{tabular}


BIG STONE PLANT COAL ANALYSIS PER TRAIN

Jun-04

\begin{tabular}{|c|c|c|c|c|c|c|c|c|c|c|c|c|}
\hline & TR & MOIS & $\% \mathrm{ASH}$ & $\mathrm{HHV}$ & S, \% & $\% \mathrm{ASH}$ & HHV & $\mathrm{S}, \%$ & $\mathrm{NaO}$ & MAF & COAL & TONS \\
\hline DATE & \# & $\%$ & $\mathrm{AR}$ & $\mathrm{AR}$ & $\mathrm{AR}$ & DRY & DRY & DRY & $\%$ & HHV & TONS & OK \\
\hline PREV. MC & ebm029 & 30.33 & 4.65 & 8445 & 0.41 & 6.68 & 12121 & 0.59 & 1.9 & 12989 & 14205.600 & 6251.221 \\
\hline PREV. MC & ebm30 & 29.78 & 4.63 & 8500 & 0.39 & 6.6 & 12105 & 0.56 & 1.7 & 12960 & 14201.880 & \\
\hline 1-Jun-04 & 0 & 0 & 0 & 0 & 0 & 0 & 0 & 0 & 0 & 0 & 0.00 & \\
\hline 2-Jun-04 & 0 & 0 & 0 & 0 & 0 & 0 & 0 & 0 & 0 & 0 & 0.00 & \\
\hline 3-Jun-04 & ebm031 & 30.21 & 4.76 & 8443 & 0.38 & 6.82 & 12098 & 0.55 & 1.7 & 12983 & 14154.15 & 14154.15 \\
\hline 4-Jun-04 & 0 & 0 & 0 & 0 & 0 & 0 & 0 & 0 & 0 & 0 & 0.00 & \\
\hline 5-Jun-04 & 0 & 0 & 0 & 0 & 0 & 0 & 0 & 0 & 0 & 0 & 0.00 & \\
\hline 6-Jun-04 & 0 & 0 & 0 & 0 & 0 & 0 & 0 & 0 & 0 & 0 & 0.00 & \\
\hline 7-Jun-04 & 0 & 0 & 0 & 0 & 0 & 0 & 0 & 0 & 0 & 0 & 0.00 & \\
\hline 8-Jun-04 & 0 & 0 & 0 & 0 & 0 & 0 & 0 & 0 & 0 & 0 & 0.00 & \\
\hline 9-Jun-04 & 0 & 0 & 0 & 0 & 0 & 0 & 0 & 0 & 0 & 0 & 0.00 & \\
\hline 10-Jun-04 & 0 & 0 & 0 & 0 & 0 & 0 & 0 & 0 & 0 & 0 & 0.00 & \\
\hline 11-Jun-04 & 0 & 0 & 0 & 0 & 0 & 0 & 0 & 0 & 0 & 0 & 0.00 & \\
\hline 12-Jun-04 & 0 & 0 & 0 & 0 & 0 & 0 & 0 & 0 & 0 & 0 & 0.00 & \\
\hline 13-Jun-04 & 0 & 0 & 0 & 0 & 0 & 0 & 0 & 0 & 0 & 0 & 0.00 & \\
\hline 14-Jun-04 & 0 & 0 & 0 & 0 & 0 & 0 & 0 & 0 & 0 & 0 & 0.00 & \\
\hline 15-Jun-04 & 0 & 0 & 0 & 0 & 0 & 0 & 0 & 0 & 0 & 0 & 0.00 & \\
\hline 16-Jun-04 & ebm32 & 29.94 & 4.84 & 8474 & 0.39 & 6.91 & 12096 & 0.56 & 1.7 & 12994 & 13927.43 & 13927.43 \\
\hline 17-Jun-04 & ebm33 & 29.35 & 4.87 & 8544 & 0.39 & 6.9 & 12094 & 0.55 & 1.9 & 12990 & 13905.63 & 13905.63 \\
\hline 18-Jun-04 & 0 & 0 & 0 & 0 & 0 & 0 & 0 & 0 & 0 & 0 & 0.00 & \\
\hline 19-Jun-04 & 0 & 0 & 0 & 0 & 0 & 0 & 0 & 0 & 0 & 0 & 0.00 & \\
\hline 20-Jun-04 & 0 & 0 & 0 & 0 & 0 & 0 & 0 & 0 & 0 & 0 & 0.00 & \\
\hline 21-Jun-04 & ebm34 & 30.22 & 4.58 & 8429 & 0.36 & 6.56 & 12079 & 0.52 & 1.8 & 12927 & 14156.00 & 14156.00 \\
\hline 22-Jun-04 & ebm35 & 30.23 & 4.84 & 8440 & 0.43 & 6.93 & 12097 & 0.62 & 1.8 & 12998 & 12427.50 & 12427.00 \\
\hline 23-Jun-04 & 0 & 0 & 0 & 0 & 0 & 0 & 0 & 0 & 0 & 0 & 0.00 & \\
\hline 24-Jun-04 & 0 & 0 & 0 & 0 & 0 & 0 & 0 & 0 & 0 & 0 & 0.00 & \\
\hline 25-Jun-04 & ebm36 & 30.08 & 4.59 & 8479 & 0.41 & 6.57 & 12127 & 0.58 & 1.8 & 12980 & 10909.80 & 10909.80 \\
\hline 26-Jun-04 & ebm37 & 30.21 & 4.63 & 8454 & 0.37 & 6.64 & 12113 & 0.53 & 1.8 & 12975 & 14144.95 & 14144.95 \\
\hline 27-Jun-04 & 0 & 0 & 0 & 0 & 0 & 0 & 0 & 0 & 0 & 0 & 0.00 & \\
\hline 28-Jun-04 & ebm38 & 29.61 & 4.86 & 8526 & 0.43 & 6.9 & 12112 & 0.61 & 1.7 & 13010 & 13080.90 & 13080.90 \\
\hline 29-Jun-04 & 0 & 0 & 0 & 0 & 0 & 0 & 0 & 0 & 0 & 0 & 0.00 & \\
\hline 30-Jun-04 & ebm39 & 29.49 & 4.81 & 8523 & 0.38 & 6.82 & 12088 & 0.54 & 1.8 & 12973 & 9476.88 & 5174.24 \\
\hline ADJ. & & & & & & & & & & & & 118131.32 \\
\hline Weig & hted Avg & . 30.01 & 4.85 & 8460 & 0.38 & 6.93 & 12087 & 0.55 & 1.73 & & $\begin{array}{l}\text { Tons. OK } \\
\text { Burn }\end{array}$ & $\begin{array}{l}136424.42 \\
136424.32\end{array}$ \\
\hline
\end{tabular}

Monthly Mercury Analysis

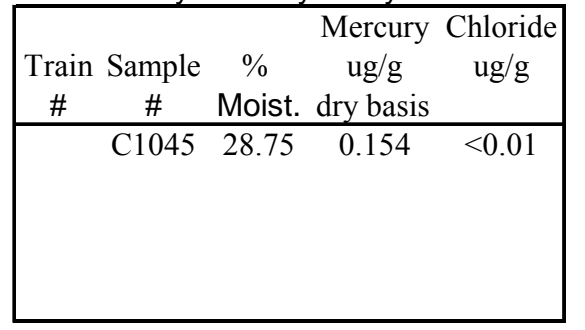




\begin{tabular}{|c|c|c|c|c|c|c|c|c|c|c|c|c|}
\hline \multirow{2}{*}{ DATE } & & \multicolumn{9}{|c|}{ BIG STONE PLANT } & \multirow{2}{*}{$\begin{array}{l}\text { COAL } \\
\text { TONS }\end{array}$} & \multirow{2}{*}{$\begin{array}{l}\text { TONS } \\
\text { OK }\end{array}$} \\
\hline & $\begin{array}{l}\mathrm{TR} \\
\#\end{array}$ & \multicolumn{3}{|c|}{ MOIS \% ASIHHV } & \multirow{2}{*}{$\begin{array}{l}\mathrm{S}, \% \\
\mathrm{AR}\end{array}$} & \multicolumn{2}{|c|}{$\%$ ASE HHV } & \multirow{2}{*}{$\begin{array}{l}\text { S, \% } \\
\text { DRY }\end{array}$} & \multirow{2}{*}{$\begin{array}{l}\mathrm{NaO} \\
\% \\
\end{array}$} & $\begin{array}{l}\text { MAF } \\
\text { HHV }\end{array}$ & & \\
\hline \begin{tabular}{|l} 
PREV MC MC \\
\end{tabular} & $\pi$ & 295 & AN & 8523 & & $\frac{101}{682}$ & $\frac{\text { DN 1 }}{12088}$ & & & & 047688 & $\frac{\mathrm{OK}}{4302}$ \\
\hline PREV. MC & $\mathrm{ON}$. & & 4.01 & (2525 & 0.30 & 0.02 & 12000 & 0.24 & & 12915 & $94 / 0.88$ & 4502 \\
\hline 1-Jul-04 & 0 & 0 & 0 & 0 & 0 & 0 & 0 & 0 & 0 & 0 & 0.00 & \\
\hline 2-Jul-04 & ebm40 & 29.5 & 4.71 & 8490 & 0.39 & 6.67 & 12036 & 0.55 & 1.77 & 12896 & 14152.83 & 14152.83 \\
\hline 3-Jul-04 & 0 & 0 & 0 & 0 & 0 & 0 & 0 & 0 & 0 & 0 & 0.00 & \\
\hline 4-Jul-04 & ebm41 & 29.7 & 4.88 & 8526 & 0.43 & 6.94 & 12124 & 0.61 & 1.71 & 13028 & 13310.50 & 13310.50 \\
\hline 5-Jul-04 & 0 & 0 & 0 & 0 & 0 & 0 & 0 & 0 & 0 & 0 & 0.00 & \\
\hline 6-Jul-04 & 0 & 0 & 0 & 0 & 0 & 0 & 0 & 0 & 0 & 0 & 0.00 & \\
\hline 7-Jul-04 & bam42 & 28.8 & 4.49 & 8692 & 0.3 & 6.3 & 12203 & 0.42 & 1.49 & 13023 & 10669.50 & 10669.50 \\
\hline 8-Jul-04 & ebm42 & 30.3 & 4.61 & 8450 & 0.36 & 6.62 & 12127 & 0.52 & 1.77 & 12987 & 10166.70 & 10166.70 \\
\hline 9-Jul-04 & 0 & 0 & 0 & 0 & 0 & 0 & 0 & 0 & 0 & 0 & 0.00 & \\
\hline 10-Jul-04 & 0 & 0 & 0 & 0 & 0 & 0 & 0 & 0 & 0 & 0 & 0.00 & \\
\hline 11-Jul-04 & cdm01 & 30.6 & 4.68 & 8427 & 0.31 & 6.74 & 12136 & 0.44 & 1.72 & 13013 & 14199.90 & 14199.90 \\
\hline 12-Jul-04 & 0 & 0 & 0 & 0 & 0 & 0 & 0 & 0 & 0 & 0 & 0.00 & \\
\hline 13-Jul-04 & ebm43 & 29.9 & 4.63 & 8500 & 0.4 & 6.6 & 12118 & 0.57 & 1.82 & 12974 & 14179.18 & 14179.18 \\
\hline 14-Jul-04 & 0 & 0 & 0 & 0 & 0 & 0 & 0 & 0 & 0 & 0 & 0.00 & \\
\hline 15-Jul-04 & 0 & 0 & 0 & 0 & 0 & 0 & 0 & 0 & 0 & 0 & 0.00 & \\
\hline 16-Jul-04 & 0 & 0 & 0 & 0 & 0 & 0 & 0 & 0 & 0 & 0 & 0.00 & \\
\hline 17-Jul-04 & $\mathrm{cdm} 02$ & 29.4 & 5 & 8508 & 0.31 & 7.09 & 12052 & 0.45 & 1.18 & 12972 & 14174.55 & 14174.55 \\
\hline 18-Jul-04 & 0 & 0 & 0 & 0 & 0 & 0 & 0 & 0 & 0 & 0 & 0.00 & \\
\hline 19-Jul-04 & ebm44 & 30.4 & 4.66 & 8418 & 0.37 & 6.7 & 12098 & 0.53 & 1.89 & 12967 & 14167.80 & 14167.80 \\
\hline 20-Jul-04 & 0 & 0 & 0 & 0 & 0 & 0 & 0 & 0 & 0 & 0 & 0.00 & \\
\hline 21-Jul-04 & cdm03 & 30.3 & 4.83 & 8411 & 0.3 & 6.93 & 12072 & 0.43 & 1.19 & 12971 & 11770.80 & 11770.80 \\
\hline 22-Jul-04 & 0 & 0 & 0 & 0 & 0 & 0 & 0 & 0 & 0 & 0 & 0.00 & \\
\hline 23-Jul-04 & 0 & 0 & 0 & 0 & 0 & 0 & 0 & 0 & 0 & 0 & 0.00 & \\
\hline 24-Jul-04 & 0 & 0 & 0 & 0 & 0 & 0 & 0 & 0 & 0 & 0 & 0.00 & \\
\hline 25-Jul-04 & 0 & 0 & 0 & 0 & 0 & 0 & 0 & 0 & 0 & 0 & 0.00 & \\
\hline 26-Jul-04 & ebm45 & 30 & 4.44 & 8480 & 0.38 & 6.34 & 12116 & 0.55 & 1.82 & 12936 & 14159.33 & 14159.33 \\
\hline 27-Jul-04 & ebm46 & 29.9 & 4.52 & 8499 & 0.39 & 6.44 & 12115 & 0.56 & 1.94 & 12949 & 14174.38 & 14174.38 \\
\hline 28-Jul-04 & 0 & 0 & 0 & 0 & 0 & 0 & 0 & 0 & 0 & 0 & 0.00 & \\
\hline 29-Ju & 0 & 0 & 0 & 0 & 0 & 0 & 0 & 0 & 0 & 0 & 0.00 & \\
\hline 30-Jul-04 & 0 & 0 & 0 & 0 & 0 & 0 & 0 & 0 & 0 & 0 & 0.00 & \\
\hline $\begin{array}{l}\text { 31-Jul-04 } \\
\text { ADJ. }\end{array}$ & ebm047 & $7 \quad 30.1$ & 4.72 & 8436 & 0.42 & 6.75 & 12075 & 0.6 & 1.64 & 12949 & 14169.90 & $\begin{array}{r}14169.90 \\
163598.01\end{array}$ \\
\hline Weighted & Average & e 29.90 & 4.69 & 8485 & 0.37 & 6.68 & 12103 & 0.52 & 1.67 & & $\begin{array}{l}\text { Tons. OK } \\
\text { Burn }\end{array}$ & $\begin{array}{l}163598.01 \\
168366.77\end{array}$ \\
\hline
\end{tabular}

Monthly Mercury Analysis

\begin{tabular}{|c|c|c|c|c|}
\hline $\begin{array}{c}\text { Train } \\
\#\end{array}$ & $\begin{array}{c}\text { Sample } \\
\#\end{array}$ & $\begin{array}{c}\% \\
\text { Moist. }\end{array}$ & $\begin{array}{c}\text { Mercury } \\
\text { ug/g } \\
\text { dry basis }\end{array}$ & $\begin{array}{c}\text { Chloride } \\
\mathrm{ug} / \mathrm{g}\end{array}$ \\
\hline & C1192 & 29.54 & 0.111 & $<0.01$ \\
\hline
\end{tabular}




\begin{tabular}{|c|}
\hline BIG STONE PLANT COAL ANALYSIS PER TRAIN \\
Aug-04 \\
\hline
\end{tabular}

\begin{tabular}{|c|c|c|c|c|c|c|c|c|c|c|c|c|}
\hline DATE & $\begin{array}{l}\text { TR } \\
\#\end{array}$ & $\begin{array}{l}\text { MOIS } \\
\%\end{array}$ & $\begin{array}{l}\% \mathrm{ASH} \\
\mathrm{AR}\end{array}$ & $\begin{array}{l}\mathrm{HHV} \\
\mathrm{AR}\end{array}$ & $\begin{array}{l}\text { S, \% } \\
\text { AR }\end{array}$ & $\begin{array}{l}\% \mathrm{ASH} \\
\mathrm{DRY}\end{array}$ & $\begin{array}{l}\text { HHV } \\
\text { DRY }\end{array}$ & $\begin{array}{l}\text { S, \% } \\
\text { DRY }\end{array}$ & $\begin{array}{l}\mathrm{NaO} \\
\%\end{array}$ & $\begin{array}{l}\text { MAF } \\
\text { HHV }\end{array}$ & $\begin{array}{l}\text { COAL } \\
\text { TONS }\end{array}$ & $\begin{array}{l}\text { TONS } \\
\text { OK }\end{array}$ \\
\hline \multicolumn{13}{|c|}{ PREV. MON. } \\
\hline 1-Aug-04 & cdm04 & 30.0 & 5.09 & 8460 & 0.36 & 7.28 & 12089 & 0.43 & 1.34 & 13038 & 14198.90 & 14198.90 \\
\hline 2-Aug-04 & 0 & 0.0 & 0 & 0 & 0 & 0 & 0 & 0 & 0 & 0 & 0.00 & \\
\hline 3-Aug-04 & 0 & 0.0 & 0 & 0 & 0 & 0 & 0 & 0 & 0 & 0 & 0.00 & \\
\hline 4-Aug-04 & ebm48 & 30.0 & 4.64 & 8506 & 0.4 & 6.63 & 12155 & 0.57 & 1.77 & 13018 & 14168.05 & 14168.05 \\
\hline 5-Aug-04 & 0 & 0.0 & 0 & 0 & 0 & 0 & 0 & 0 & 0 & 0 & 0.00 & \\
\hline 6-Aug-04 & 0 & 0.0 & 0 & 0 & 0 & 0 & 0 & 0 & 0 & 0 & 0.00 & \\
\hline 7-Aug-04 & cdm05 & 28.6 & 6.13 & 8486 & 0.28 & 8.57 & 11877 & 0.39 & 1.2 & 12990 & 14198.73 & 14198.73 \\
\hline 8-Aug-04 & ebm49 & 30.2 & 4.76 & 8451 & 0.44 & 6.82 & 12102 & 0.63 & 1.75 & 12988 & 14178.08 & 14178.08 \\
\hline 9-Aug-04 & 0 & 0.0 & 0 & 0 & 0 & 0 & 0 & 0 & 0 & 0 & 0.00 & \\
\hline 10-Aug-04 & 0 & 0.0 & 0 & 0 & 0 & 0 & 0 & 0 & 0 & 0 & 0.00 & \\
\hline 11-Aug-04 & 0 & 0.0 & 0 & 0 & 0 & 0 & 0 & 0 & 0 & 0 & 0.00 & \\
\hline \multicolumn{2}{|c|}{ 12-Aug-04 cdm06 } & 29.5 & 5.86 & 8381 & 0.32 & 8.32 & 11893 & 0.46 & 1.3 & 12972 & 11763.95 & 11763.95 \\
\hline 13-Aug-04 & 0 & 0.0 & 0 & 0 & 0 & 0 & 0 & 0 & 0 & 0 & 0.00 & \\
\hline \multicolumn{2}{|c|}{ 14-Aug-04 ebm50 } & 30.1 & 4.74 & 8435 & 0.42 & 6.78 & 12059 & 0.6 & 1.82 & 12936 & 14184.80 & 14184.80 \\
\hline 15-Aug-04 & 0 & 0.0 & 0 & 0 & 0 & 0 & 0 & 0 & 0 & 0 & 0.00 & \\
\hline \multicolumn{2}{|c|}{ 16-Aug-04 cdm07 } & 29.3 & 6.08 & 8425 & 0.29 & 8.59 & 11912 & 0.41 & 1.2 & 13032 & 14163.98 & 14163.98 \\
\hline 17-Aug-04 & 0 & 0.0 & 0 & 0 & 0 & 0 & 0 & 0 & 0 & 0 & 0.00 & \\
\hline \multicolumn{2}{|c|}{ 18-Aug-04 ebm51 } & 30.5 & 4.58 & 8391 & 0.37 & 6.59 & 12068 & 0.53 & 1.85 & 12919 & 14179.95 & 14179.95 \\
\hline 19-Aug-04 & 0 & 0.0 & 0 & 0 & 0 & 0 & 0 & 0 & 0 & 0 & 0.00 & \\
\hline \multirow{2}{*}{\multicolumn{2}{|c|}{$\begin{array}{l}\text { 20-Aug-04 } \\
\text { 21-Aug-04 crm01 }\end{array}$}} & 0.0 & 0 & 0 & 0 & 0 & 0 & 0 & 0 & 0 & 0.00 & \\
\hline & & 28.6 & 5.56 & 8598 & 0.33 & 12.64 & 12038 & 0.46 & 1.17 & 13055 & 12998.88 & 12998.88 \\
\hline 22-Aug-04 & 0 & 0.0 & 0 & 0 & 0 & 0 & 0 & 0 & 0 & 0 & 0.00 & \\
\hline \multicolumn{2}{|c|}{ 23-Aug-04 ebm52 } & 30.6 & 4.71 & 8376 & 0.42 & 6.78 & 12065 & 0.6 & 1.74 & 12943 & 14198.60 & 14198.60 \\
\hline 24-Aug-04 & 0 & 0.0 & 0 & 0 & 0 & 0 & 0 & 0 & 0 & 0 & 0.00 & \\
\hline 25-Aug-04 & 0 & 0.0 & 0 & 0 & 0 & 0 & 0 & 0 & 0 & 0 & 0.00 & \\
\hline \multicolumn{2}{|c|}{ 26-Aug-04 crm02 } & 29.3 & 4.68 & 8601 & 0.27 & 6.61 & 12159 & 0.39 & 1.46 & 13020 & 14216.60 & 14216.60 \\
\hline \multicolumn{2}{|c|}{ 27-Aug-04 bam43 } & 29.3 & 4.53 & 8569 & 0.26 & 6.41 & 12122 & 0.37 & 1.59 & 12952 & 13139.60 & 13139.60 \\
\hline 28-Aug-04 & 0 & 0.0 & 0 & 0 & 0 & 0 & 0 & 0 & 0 & 0 & 0.00 & \\
\hline 29-Aug-04 & 0 & 0.0 & 0 & 0 & 0 & 0 & 0 & 0 & 0 & 0 & 0.00 & \\
\hline 30-Aug-04 & 0 & 0.0 & 0 & 0 & 0 & 0 & 0 & 0 & 0 & 0 & 0.00 & \\
\hline \multirow{2}{*}{\multicolumn{2}{|c|}{ 31-Aug-04 crm03 }} & 29.6 & 5.61 & 8482 & 0.33 & 7.97 & 12056 & 0.47 & 1.33 & 13101 & 10940.73 & 10940.73 \\
\hline & & & & & & & & & & & & 176530.85 \\
\hline \multicolumn{2}{|c|}{ Weighted Average } & 29.66 & 5.13 & 8474 & 0.35 & 7.65 & 12047 & 0.49 & 1.51 & & $\begin{array}{l}\text { Tons. OK } \\
\text { Burn }\end{array}$ & $\begin{array}{l}176530.85 \\
179102.36\end{array}$ \\
\hline
\end{tabular}

Monthly Mercury Analysis

\begin{tabular}{|c|c|}
\hline $\begin{array}{c}\text { Train Sample } \\
\#\end{array}$ & \begin{tabular}{ccc} 
& \multicolumn{3}{c}{ Mercury } & Chlor \\
$\%$ & ug/g & ug/g \\
Moist & drv
\end{tabular} \\
\hline C1446 & $0.144<0.01$ \\
\hline
\end{tabular}


BIG STONE PLANT COAL ANALYSIS PER TRAIN

Sep-04

PAGE 1 of 2

\begin{tabular}{|c|c|c|c|c|c|c|c|c|c|c|c|c|}
\hline DATE & $\begin{array}{l}\text { TR } \\
\#\end{array}$ & $\begin{array}{l}\text { MOIS. } \\
\%\end{array}$ & $\begin{array}{l}\% \text { ASH } \\
\text { AR }\end{array}$ & $\begin{array}{l}\text { HHV } \\
\text { AR }\end{array}$ & $\begin{array}{l}\mathrm{S}, \% \\
\text { AR }\end{array}$ & $\begin{array}{l}\% \text { ASH } \\
\text { DRY }\end{array}$ & $\begin{array}{l}\text { HHV } \\
\text { DRY }\end{array}$ & $\begin{array}{l}\mathrm{S}, \% \\
\text { DRY }\end{array}$ & $\begin{array}{l}\mathrm{NaO} \\
\%\end{array}$ & $\begin{array}{l}\text { MAF } \\
\text { HHV }\end{array}$ & $\begin{array}{l}\text { COAL } \\
\text { TONS }\end{array}$ & $\begin{array}{l}\text { TONS } \\
\text { OK }\end{array}$ \\
\hline \multicolumn{13}{|l|}{ PREV. MON. } \\
\hline $1-S e p-04$ & ebm53 & 30.58 & 4.56 & 8400 & 0.4 & 6.57 & 12100 & 0.58 & 1.69 & 12951 & 14172.68 & 14172.68 \\
\hline 2-Sep-04 & 0 & 0 & 0 & 0 & 0 & 0 & 0 & 0 & 0 & 0 & 0.00 & \\
\hline 3-Sep-04 & 0 & 0 & 0 & 0 & 0 & 0 & 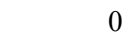 & 0 & 0 & 0 & 0.00 & \\
\hline 4-Sep-04 & crm04 & 29.52 & 5.14 & 8530 & 0.31 & 7.29 & 12101 & 0.43 & 1.39 & 13053 & 12884.68 & 12884.68 \\
\hline 5-Sep-04 & bam44 & 29.61 & 4.52 & 8559 & 0.3 & 6.42 & 12159 & 0.42 & 1.44 & 12993 & 13963.63 & 13963.63 \\
\hline 6-Sep-04 & 0 & 0 & 0 & 0 & 0 & 0 & 0 & 0 & 0 & 0 & 0.00 & \\
\hline 7-Sep-04 & 0 & 0 & 0 & 0 & 0 & 0 & 0 & 0 & 0 & 0 & 0.00 & \\
\hline 8-Sep-04 & crm05 & 29.63 & 4.78 & 8581 & 0.26 & 6.79 & 12194 & 0.38 & 1.4 & 13082 & 14217.38 & 14217.38 \\
\hline 9-Sep-04 & 0 & 0 & 0 & 0 & 0 & 0 & 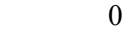 & 0 & 0 & 0 & 0.00 & \\
\hline 10-Sep-04 & ebm54 & 29.95 & 4.85 & 8499 & 0.42 & 6.92 & 12133 & 0.6 & 1.88 & 13035 & 13936.85 & 13936.85 \\
\hline 11-Sep-04 & 0 & 0 & 0 & 0 & 0 & 0 & 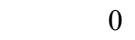 & 0 & 0 & 0 & 0.00 & \\
\hline $12-\mathrm{S}$ & 0 & 0 & 0 & 0 & 0 & 0 & 0 & 0 & 0 & 0 & 0.00 & \\
\hline 13-Sep-04 & 0 & 0 & 0 & 0 & 0 & 0 & 0 & 0 & 0 & 0 & 0.00 & \\
\hline 14-Sep-04 & bam45 & 29.18 & 4.76 & 8555 & 0.29 & 6.72 & 12080 & 0.41 & 1.44 & 12950 & 14152.68 & 14152.68 \\
\hline 15-Sep-04 & 0 & 0 & 0 & 0 & 0 & 0 & . & 0 & 0 & 0 & 0.00 & \\
\hline 16-Sep-04 & ebm55 & 30.64 & 4.81 & 8387 & 0.41 & 6.93 & 12092 & 0.59 & 1.79 & 12992 & 14181.33 & 14181.33 \\
\hline 17-Sep-04 & 0 & 0 & 0 & 0 & 0 & 0 & 0 & 0 & 0 & 0 & 0.00 & \\
\hline 18-Sep-04 & bam46 & 29.06 & 4.66 & 8632 & 0.31 & 6.57 & 12168 & 0.43 & 1.44 & 13024 & 13790.93 & 13790.93 \\
\hline 19-Sep-04 & 0 & 0 & 0 & 0 & 0 & 0 & 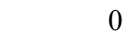 & 0 & 0 & 0 & 0.00 & \\
\hline $20-\mathrm{S}$ & 0 & 0 & 0 & 0 & 0 & 0 & 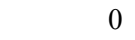 & 0 & 0 & 0 & 0.00 & \\
\hline 21-Sep-04 & ebm056 & 30.69 & 4.49 & 8356 & 0.28 & 6.48 & 12056 & 0.4 & 1.73 & 12891 & 14187.80 & 14187.80 \\
\hline $22-\mathrm{S}$ & 0 & 0 & 0 & 0 & 0 & 0 & 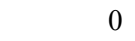 & 0 & 0 & 0 & 0.00 & \\
\hline $23-\mathrm{S}$ & bam47 & 29.44 & 4.35 & 8642 & 0.28 & 6.16 & 12248 & 0.39 & 1.64 & 13052 & 14158.50 & 14158.50 \\
\hline 24-Sep-04 & 0 & 0 & 0 & 0 & 0 & 0 & 0 & 0 & 0 & 0 & 0.00 & \\
\hline 25-Sep-04 & 0 & 0 & 0 & 0 & 0 & 0 & 0 & 0 & 0 & 0 & 0.00 & \\
\hline 26-Sep-04 & bam48 & 30.16 & 4.23 & 8534 & .23 & 6.05 & 12220 & 0.33 & 1.53 & 13007 & 14160.30 & 14160.30 \\
\hline $27-\mathrm{S}$ & ebm57 & 30.3 & 4.6 & 8455 & 0.42 & 6.6 & 12131 & 0.6 & 1.84 & 12988 & 14299.65 & 14299.65 \\
\hline $28-\mathrm{S}$ & 0 & 0 & 0 & 0 & 0 & 0 & 0 & 0 & 0 & 0 & 0.00 & \\
\hline 29-Sep-04 & 0 & 0 & 0 & 0 & 0 & 0 & 0 & 0 & 0 & 0 & 0.00 & \\
\hline 30-Sep-04 & ebm58 & 30.16 & 4.62 & 8484 & 0.41 & 6.61 & 12148 & 0.58 & 1.7 & 13008 & 13696.73 & 6046.72 \\
\hline ADJ. & & & & & & & & & & & & 174153.13 \\
\hline Weighted & Average & 29.92 & 4.66 & 8506 & 0.33 & 6.65 & 12137 & 0.47 & 1.60 & & $\begin{array}{l}\text { Tons. OK } \\
\text { Burn } \\
\end{array}$ & $\begin{array}{l}178154.23 \\
178154.23 \\
\end{array}$ \\
\hline
\end{tabular}

Monthly Mercury Analysis

\begin{tabular}{|ccccc|}
\hline & & & Mercury & Chlor. \\
Train Sample & $\%$ & ug/g & ug/g \\
$\#$ & $\#$ & Moist. & dry basis & \\
\hline & & & & \\
& & & & \\
& & & & \\
& & & & \\
\hline
\end{tabular}




\begin{tabular}{|c|c|}
\hline \multirow{2}{*}{ BIG STONE PLANT } & COAL ANALYSIS PER TRAIN \\
\hline & PAGE 1 of 2 \\
\hline
\end{tabular}

\begin{tabular}{|c|c|c|c|c|c|c|c|c|c|c|c|c|}
\hline DATE & $\begin{array}{l}\text { TR } \\
\#\end{array}$ & $\begin{array}{l}\text { MOIS. } \\
\%\end{array}$ & $\begin{array}{l}\% \text { ASF } \\
\text { AR }\end{array}$ & $\begin{array}{l}\mathrm{HHV} \\
\mathrm{AR}\end{array}$ & $\begin{array}{l}\mathrm{S}, \% \\
\text { AR }\end{array}$ & $\begin{array}{l}\% \text { ASH } \\
\text { DRY }\end{array}$ & $\begin{array}{l}\text { HHV } \\
\text { DRY }\end{array}$ & $\begin{array}{l}\mathrm{S}, \% \\
\text { DRY }\end{array}$ & $\begin{array}{l}\mathrm{NaO} \\
\%\end{array}$ & $\begin{array}{l}\text { MAF } \\
\text { HHV }\end{array}$ & $\begin{array}{l}\text { COAL } \\
\text { TONS }\end{array}$ & $\begin{array}{l}\text { TONS } \\
\text { OK }\end{array}$ \\
\hline \multicolumn{13}{|l|}{ PREV. MON. } \\
\hline PREV. MON. & ebm58 & 30.16 & 4.62 & 8484 & 0.41 & 6.61 & 12148 & 0.58 & 1.70 & 13008 & 13696.725 & 7650.005 \\
\hline $1-O c t-04$ & 0 & 0 & 0 & 0 & 0 & 0 & 0 & 0 & 0 & 0 & 0.000 & \\
\hline 2-Oct-04 & ebm59 & 30.39 & 4.86 & 8412 & 0.43 & 6.98 & 12085 & 0.62 & 1.69 & 12992 & 13567.950 & 13567.950 \\
\hline 3-Oct-04 & 0 & 0 & 0 & 0 & 0 & 0 & 0 & 0 & 0 & 0 & 0.000 & \\
\hline 4-Oct-04 & bam49 & 29.72 & 4.67 & 8496 & 0.25 & 6.65 & 12089 & 0.36 & 1.51 & 12950 & 13918.450 & 13918.450 \\
\hline 5-Oct-04 & 0 & 0 & 0 & 0 & 0 & 0 & 0 & 0 & 0 & 0 & 0.000 & \\
\hline 6-Oct-04 & ebm60 & 30.49 & 4.68 & 8430 & 0.42 & 6.74 & 12128 & 0.61 & 1.77 & 13005 & 14173.825 & 14173.825 \\
\hline 7-Oct-04 & 0 & 0 & 0 & 0 & 0 & 0 & 0 & 0 & 0 & 0 & 0.000 & \\
\hline 8-Oct-04 & 0 & 0 & 0 & 0 & 0 & 0 & 0 & 0 & 0 & 0 & 0.000 & \\
\hline 9-Oct-04 & ebm61 & 30.2 & 4.78 & 8433 & 0.42 & 6.85 & 12082 & 0.6 & 1.75 & 12970 & 14191.575 & 14191.575 \\
\hline $10-O c t-04$ & 0 & 0 & 0 & 0 & 0 & 0 & 0 & 0 & 0 & 0 & 0.000 & \\
\hline 11-Oct-04 & ebm62 & 30.1 & 4.73 & 8438 & 0.43 & 6.77 & 12071 & 0.62 & 1.81 & 12948 & 14184.350 & 14184.350 \\
\hline 12-Oct-04 & 0 & 0 & 0 & 0 & 0 & 0 & 0 & 0 & 0 & 0 & 0.000 & \\
\hline 13-Oct-04 & 0 & 0 & 0 & 0 & 0 & 0 & 0 & 0 & 0 & 0 & 0.000 & \\
\hline 14-Oct-04 & bam50 & 29.61 & 5.09 & 8514 & 0.28 & 7.23 & 12095 & 0.4 & 1.31 & 13038 & 14152.525 & 14152.525 \\
\hline $15-O c t-04$ & ebm63 & 30.32 & 4.78 & 8443 & 0.42 & 6.86 & 12117 & 0.6 & 1.74 & 13009 & 14171.875 & 14171.875 \\
\hline $16-O c t-04$ & 0 & 0 & 0 & 0 & 0 & 0 & 0 & 0 & 0 & 0 & 0.000 & \\
\hline 17-Oct-04 & 0 & 0 & 0 & 0 & 0 & 0 & 0 & 0 & 0 & 0 & 0.000 & \\
\hline 18-Oct-04 & 0 & 0 & 0 & 0 & 0 & 0 & 0 & 0 & 0 & 0 & 0.000 & \\
\hline 19-Oct-04 & bam51 & 29.03 & 4.72 & 8585 & 0.28 & 6.65 & 12096 & 0.39 & 1.36 & 12958 & 12922.100 & 12922.100 \\
\hline 20-Oct-04 & ebm64 & 30.95 & 4.76 & 8349 & 0.41 & 6.9 & 12091 & 0.6 & 1.68 & 12987 & 14183.500 & 14183.500 \\
\hline 21-Oct-04 & 0 & 0 & 0 & 0 & 0 & 0 & 0 & 0 & 0 & 0 & 0.000 & \\
\hline 22-Oct-04 & 0 & 0 & 0 & . & 0 & 0 & 0 & 0 & 0 & 0 & 0.000 & \\
\hline 23-Oct-04 & 0 & 0 & 0 & 0 & 0 & 0 & 0 & 0 & 0 & 0 & 0.000 & \\
\hline 24-Oct-04 & 0 & 0 & 0 & 0 & 0 & 0 & 0 & 0 & 0 & 0 & 0.000 & \\
\hline 25-Oct-04 & 0 & 0 & 0 & U & 0 & 0 & 0 & 0 & 0 & 0 & 0.000 & \\
\hline 26-Oct-04 & 0 & 0 & 0 & 0 & 0 & 0 & 0 & 0 & 0 & 0 & 0.000 & \\
\hline 27-Oct-04 & 0 & 0 & 0 & 0 & 0 & 0 & 0 & 0 & 0 & 0 & 0.000 & \\
\hline 28-Oct-04 & 0 & 0 & 0 & 0 & 0 & 0 & 0 & 0 & 0 & 0 & 0.000 & \\
\hline 29-Oct-04 & ebm65 & 30.4 & 4.68 & 8417 & 0.37 & 6.72 & 12093 & 0.53 & 1.72 & 12964 & 13649.830 & 12924.825 \\
\hline 30-Oct-04 & 0 & 0 & 0 & 0 & 0 & 0 & 0 & 0 & 0 & 0 & 0.000 & \\
\hline 31-Oct-04 & 0 & 0 & 0 & 0 & 0 & 0 & 0 & 0 & 0 & 0 & 0.000 & \\
\hline ADJ. & & & & & & & & & & & 139115.980 & 146040.980 \\
\hline Weighted & Average & 30.13 & 4.77 & 8453 & 0.37 & 6.83 & 12098 & 0.54 & 1.64 & & $\begin{array}{l}\text { Tons. OK } \\
\text { Burn }\end{array}$ & $\begin{array}{l}146040.980 \\
146040.980\end{array}$ \\
\hline
\end{tabular}

Monthly Mercury Analysis

\begin{tabular}{|ccccc|}
\hline & & & Mercury & Chlor. \\
Train & Sample & $\%$ & ug/g & ug/g \\
$\#$ & $\#$ & Moist. & dry basis & \\
\hline & & & \\
& & & \\
& & & \\
& & & \\
\hline
\end{tabular}




\begin{tabular}{|lll|}
\hline BIG STONE PLANT & COAL ANALYSIS PER TRAIN \\
& Nov-04 & PAGE 1 of 2 \\
\hline
\end{tabular}

\begin{tabular}{|c|c|c|c|c|c|c|c|c|c|c|c|c|}
\hline & TR & MOIS. & $\% \mathrm{ASH}$ & IHHV & $\mathrm{S}, \%$ & $\%$ ASH & HHV & S, \% & $\mathrm{NaO}$ & MAF & COAL & TONS \\
\hline DATE & & & AR & AR & & & & & & $\mathrm{HHV}$ & & \\
\hline PREV. MON & & & & & & & & & & & & \\
\hline PREV. MON & J ebm65 & 30.4 & 4.68 & 8417 & 0.37 & 6.72 & 12093 & 0.53 & 1.7 & 12964 & 13649.83 & 725.01 \\
\hline 1-Nov-04 & 0 & 0 & 0 & 0 & 0 & 0 & 0 & 0 & 0 & 0 & 0.00 & \\
\hline 2-Nov-04 & 0 & 0 & 0 & 0 & 0 & 0 & 0 & 0 & 0 & 0 & 0.00 & \\
\hline 3-Nov-04 & ebm66 & 30.32 & 4.88 & 8449 & 0.4 & 7 & 12125 & 0.58 & 1.7 & 13038 & 13933.15 & 13933.15 \\
\hline 4-Nov-04 & 0 & 0 & 0 & 0 & 0 & 0 & 0 & 0 & 0 & 0 & 0.00 & \\
\hline 5-Nov-04 & bam52 & 29.68 & 4.2 & 8621 & 0.26 & 5.97 & 12260 & 0.37 & 1.6 & 13038 & 13423.35 & 13423.35 \\
\hline 6-Nov-04 & 0 & 0 & 0 & 0 & 0 & 0 & 0 & 0 & 0 & 0 & 0.00 & \\
\hline 7-Nov-04 & bam53 & 29.82 & 4.38 & 8584 & 0.27 & 6.24 & 12231 & 0.38 & 1.5 & 13045 & 14140.08 & 14140.08 \\
\hline 8-Nov-04 & 0 & 0 & 0 & 0 & 0 & 0 & 0 & 0 & 0 & 0 & 0.00 & \\
\hline 9-Nov-04 & 0 & 0 & 0 & 0 & 0 & 0 & 0 & 0 & 0 & 0 & 0.00 & \\
\hline 10-Nov-04 & bam54 & 28.96 & 4.38 & 8688 & 0.28 & 6.17 & 12230 & 0.4 & 1.5 & 13034 & 13916.23 & 13916.23 \\
\hline 11-Nov-04 & 0 & 0 & 0 & 0 & 0 & 0 & 0 & 0 & 0 & 0 & 0.00 & \\
\hline 12-Nov-04 & bam55 & 28.86 & 4.67 & 8684 & 0.28 & 6.57 & 12207 & 0.4 & 1.6 & 13065 & 13788.00 & 13788.00 \\
\hline $13-\mathrm{Nov}-04$ & 0 & 0 & 0 & 0 & 0 & 0 & 0 & 0 & 0 & 0 & 0.00 & \\
\hline 14-Nov-04 & bam56 & 29.03 & 4.66 & 8619 & 0.31 & 6.56 & 12145 & 0.44 & 1.4 & 12998 & 12956.32 & 12956.32 \\
\hline 15-Nov-04 & 0 & 0 & 0 & 0 & 0 & 0 & 0 & 0 & 0 & 0 & 0.00 & \\
\hline 16-Nov-04 & ebm67 & 30.21 & 4.59 & 8476 & 0.4 & 6.58 & 12145 & 0.57 & 1.9 & 13000 & 13781.35 & 13781.35 \\
\hline 17-Nov-04 & 0 & 0 & 0 & 0 & 0 & 0 & 0 & 0 & 0 & 0 & 0.00 & \\
\hline 18-Nov-04 & ebm68 & 30.14 & 5.07 & 8401 & 0.41 & 7.26 & 12025 & 0.58 & 1.6 & 12966 & 13174.40 & 13174.40 \\
\hline 19-Nov-04 & 0 & 0 & 0 & 0 & 0 & 0 & 0 & 0 & 0 & 0 & 0.00 & \\
\hline 20-Nov-04 & 0 & 0 & 0 & 0 & 0 & 0 & 0 & 0 & 0 & 0 & 0.00 & \\
\hline 21-Nov-04 & ebm69 & 30.33 & 4.75 & 8395 & 0.42 & 6.82 & 12050 & 0.61 & 1.8 & 12932 & 14172.05 & 14172.05 \\
\hline 22-Nov-04 & 0 & 0 & 0 & 0 & 0 & 0 & 0 & 0 & 0 & 0 & 0.00 & \\
\hline 23-Nov-04 & bam57 & 30.47 & 4.1 & 8508 & 0.24 & 5.9 & 12237 & 0.35 & 1.5 & 13004 & 14144.88 & 14144.88 \\
\hline 24-Nov-04 & 0 & 0 & 0 & 0 & 0 & 0 & 0 & 0 & 0 & 0 & 0.00 & \\
\hline 25-Nov-04 & bam58 & 29.42 & 4.52 & 8592 & 0.29 & 6.41 & 12174 & 0.41 & 1.5 & 13008 & 13937.98 & 13937.98 \\
\hline 26-Nov-04 & 0 & 0 & 0 & 0 & 0 & 0 & 0 & 0 & 0 & 0 & 0.00 & \\
\hline 27-Nov-04 & bam59 & 29.24 & 4.26 & 8614 & 0.25 & 6.02 & 12174 & 0.36 & 1.5 & 12954 & 14023.20 & 14023.20 \\
\hline 28-Nov-04 & 0 & 0 & 0 & 0 & 0 & 0 & 0 & 0 & 0 & 0 & 0.00 & \\
\hline 29-Nov-04 & 0 & 0 & 0 & 0 & 0 & 0 & 0 & 0 & 0 & 0 & 0.00 & \\
\hline 30-Nov-04 & bam60 & 29.66 & 4.71 & 8552 & 0.27 & 6.86 & 12158 & 0.39 & 1.4 & 13030 & 14061.93 & 9015.08 \\
\hline ADJ. & & & & & & & & & & & & 175131.08 \\
\hline Weighted & verage & 9.75 & 4.63 & 8535 & .31 & 6.60 & 2151 & 0.45 & 1.58 & & $\begin{array}{l}\text { Tons. OK } \\
\text { Burn }\end{array}$ & $\begin{array}{l}192225.48 \\
192225.48\end{array}$ \\
\hline
\end{tabular}

Monthly Mercury Analysis

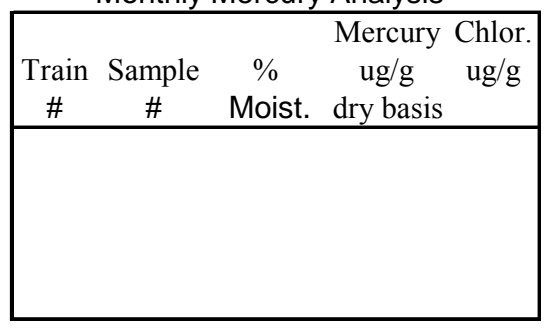




\begin{tabular}{|c|c|}
\hline BIG STONE PLANT & COAL ANALYSIS PER TRAIN \\
\hline & PAGE 1 of 2 \\
\hline
\end{tabular}

\begin{tabular}{|c|c|c|c|c|c|c|c|c|c|c|c|c|}
\hline DATE & $\begin{array}{l}\text { TR } \\
\#\end{array}$ & $\begin{array}{l}\text { MOIS } \\
\%\end{array}$ & $\begin{array}{l}\% \text { ASF } \\
\text { AR }\end{array}$ & $\begin{array}{l}\text { HHV } \\
\text { AR }\end{array}$ & $\begin{array}{l}\mathrm{S}, \% \\
\text { AR }\end{array}$ & $\begin{array}{l}\% \text { ASH } \\
\text { DRY }\end{array}$ & $\begin{array}{l}\mathrm{HHV} \\
\mathrm{ORY}\end{array}$ & $\begin{array}{l}\mathrm{S}, \% \\
\text { DRY }\end{array}$ & $\begin{array}{l}\mathrm{NaO} \\
\%\end{array}$ & $\begin{array}{l}\text { MAF } \\
\text { HHV }\end{array}$ & $\begin{array}{l}\text { COAL } \\
\text { TONS }\end{array}$ & $\begin{array}{l}\text { TONS } \\
\text { OK }\end{array}$ \\
\hline \multicolumn{13}{|c|}{ PREV. MON. } \\
\hline 1-Dec-04 & 0 & 0 & 0 & 0 & 0 & 0 & 0 & 0 & 0 & 0 & 0.00 & \\
\hline 2-Dec-04 & bam61 & 29.1 & 4.85 & 8606 & 0.26 & 6.84 & 12145 & 0.36 & 1.21 & 13037 & 13904.43 & 13904.43 \\
\hline 3-Dec-04 & 0 & 0 & 0 & 0 & 0 & 0 & 0 & 0 & 0 & 0 & 0.00 & \\
\hline 4-Dec-04 & bam62 & 29.3 & 4.56 & 8598 & 0.26 & 6.45 & 12164 & 0.37 & 1.49 & 13003 & 13886.65 & 13886.65 \\
\hline 5-Dec-04 & 0 & 0 & 0 & 0 & 0 & 0 & 0 & 0 & 0 & 0 & 0.00 & \\
\hline 6-Dec-04 & 0 & 0 & 0 & 0 & 0 & 0 & 0 & 0 & 0 & 0 & 0.00 & \\
\hline 7-Dec-04 & bam63 & 29.8 & 4.23 & 8586 & 0.24 & 6.03 & 12227 & 0.34 & 1.58 & 13012 & 12743.53 & 12743.53 \\
\hline 8-Dec-04 & bam64 & 29.5 & 4.17 & 8652 & 0.25 & 5.92 & 12269 & 0.35 & 1.57 & 13041 & 14136.03 & 14136.03 \\
\hline 9-Dec-04 & 0 & 0 & 0 & 0 & 0 & 0 & 0 & 0 & 0 & 0 & 0.00 & \\
\hline 10-Dec-04 & 0 & 0 & 0 & 0 & 0 & 0 & 0 & 0 & 0 & 0 & 0.00 & \\
\hline 11-Dec-04 & ebm70 & 30.2 & 4.93 & 8401 & 0.43 & 7.06 & 12041 & 0.61 & 1.7 & 12956 & 14169.73 & 14169.73 \\
\hline 12-Dec-04 & bam65 & 29.5 & 4.63 & 8580 & 0.27 & 6.56 & 12168 & 0.38 & 1.44 & 13022 & 14133.78 & 14133.78 \\
\hline 13-Dec-04 & 0 & 0 & 0 & 0 & 0 & 0 & 0 & 0 & 0 & 0 & 0.00 & \\
\hline 14-Dec-04 & 0 & 0 & 0 & 0 & 0 & 0 & 0 & 0 & 0 & 0 & 0.00 & \\
\hline 15-Dec-04 & ebm71 & 30.4 & 5.12 & 8410 & 0.4 & 7.36 & 12088 & 0.57 & 1.6 & 13048 & 13872.93 & 13872.93 \\
\hline 16-Dec-04 & 0 & 0 & 0 & 0 & 0 & 0 & 0 & 0 & 0 & 0 & 0.00 & \\
\hline 17-Dec-04 & 0 & 0 & 0 & 0 & 0 & 0 & 0 & 0 & 0 & 0 & 0.00 & \\
\hline 18-Dec-04 & 0 & 0 & 0 & 0 & 0 & 0 & 0 & 0 & 0 & 0 & 0.00 & \\
\hline 19-Dec-04 & bam66 & 29.2 & 4.27 & 8644 & 0.27 & 6.03 & 12207 & 0.38 & 1.57 & 12990 & 14158.68 & 14158.68 \\
\hline 20-Dec-04 & bam67 & 29.1 & 4.65 & 8668 & 0.32 & 6.56 & 12227 & 0.45 & 1.43 & 13085 & 14117.58 & 14117.58 \\
\hline 21-Dec-04 & 0 & 0 & 0 & 0 & 0 & 0 & 0 & 0 & 0 & 0 & 0.00 & \\
\hline 22-Dec-04 & 0 & 0 & 0 & 0 & 0 & 0 & 0 & 0 & 0 & 0 & 0.00 & \\
\hline 23-Dec-04 & ebm72 & 30.6 & 5.01 & 8369 & 0.4 & 7.21 & 12056 & 0.58 & 1.61 & 12993 & 13567.68 & 13567.68 \\
\hline 24-Dec-04 & ebm73 & 30.2 & 4.78 & 8421 & 0.38 & 6.85 & 12061 & 0.55 & 1.69 & 12948 & 13703.60 & 13703.60 \\
\hline 25-Dec-04 & 0 & 0 & 0 & 0 & 0 & 0 & 0 & 0 & 0 & 0 & 0.00 & \\
\hline 26-Dec-04 & 0 & 0 & 0 & 0 & 0 & 0 & 0 & 0 & 0 & 0 & 0.00 & \\
\hline 27-Dec-04 & bam68 & 29.1 & 4.32 & 8703 & 0.26 & 6.09 & 12275 & 0.36 & 1.46 & 13071 & 13384.08 & 13384.08 \\
\hline 28-Dec-04 & ebm74 & 30.2 & 4.62 & 8437 & 0.42 & 6.62 & 12094 & 0.6 & 1.76 & 12951 & 13473.63 & 13473.63 \\
\hline 29-Dec-04 & & 0 & 0 & 0 & 0 & 0 & 0 & 0 & 0 & 0 & 0.00 & \\
\hline 30-Dec-04 & ebm75 & 30.2 & 4.38 & 8485 & 0.4 & 6.28 & 12159 & 0.57 & 1.86 & 12974 & 13891.23 & 11869.01 \\
\hline 31-Dec-04 & bam69 & 29.4 & 4.59 & 8595 & 0.25 & 6.5 & 12172 & 0.35 & 1.5 & 13018 & 12581.33 & 0.00 \\
\hline ADJ. & & & & & & & & & & & & 191121.34 \\
\hline Weighted & Average & e 29.77 & 4.66 & 8532 & 0.32 & 6.63 & 12147 & 0.46 & 1.56 & & $\begin{array}{l}\text { Tons. OK } \\
\text { Burn } \\
\end{array}$ & $\begin{array}{l}201529.44 \\
201529.44 \\
\end{array}$ \\
\hline
\end{tabular}

\section{Monthly Mercury Analysis}

\begin{tabular}{|c|c|c|c|c|}
\hline $\begin{array}{c}\text { Train } \\
\#\end{array}$ & $\begin{array}{c}\text { Sample } \\
\#\end{array}$ & $\begin{array}{c}\% \\
\text { Moist. }\end{array}$ & $\begin{array}{c}\text { Mercury } \\
\text { ug/g } \\
\text { dry basis }\end{array}$ & $\begin{array}{c}\text { Chlor. } \\
\text { ug/g }\end{array}$ \\
\hline & $\mathrm{C} 2384$ & 29.62 & 0.08 & $<0.01$ \\
\hline
\end{tabular}




\section{B16 Ash and Alternative Fuel Analysis Records}

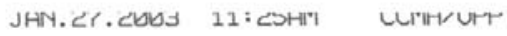

in.

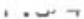

COMMERCIAL TESTING \& ENGINEERING CO.

GENERAL OFFICES: 1919 SOUTH HIGHLAND AVE,, SUTTE 210-B, LOMBARD, ILLINO|S 80148 • TEL: 630-953-9300 FAX. 630-953-9306

SINCE $1008^{\circ}$

들 Member of tho SGS Group (Socicte Générale de Surveillance)

ADDRESS AL+ CORRESPONDENCETO: 2804 HACKATHOPNE LANE GILLETTE, WY B2716 TEL: (307) 682-7917

January 10,2003 in: (307) 682.7951

RAG COAI WEST, INC.

BAGLB BUTTE MINE

P.O. BOX 3040

GILLETTE WY 82717

gample identification by RAG Coal Weot, Inc.

SAMPLE ID: 36-114564

TRATN \#: BSBO41

14145.225
TOTAL TONNAGE: OTTERTAIL POWER

Rind of sample COAL

reported to us

BIG STONE

Sample taken at Eagle Butte

IOAD DATB:

$12 / 31 / 2002$

Sample taken by Eagle Butce

Date ampled December $31,2002$.

Date recelved January 10, 2003

Analysis report no. 44-59398

ANATYSIS OF ASH

\& Weight Ignited Basis

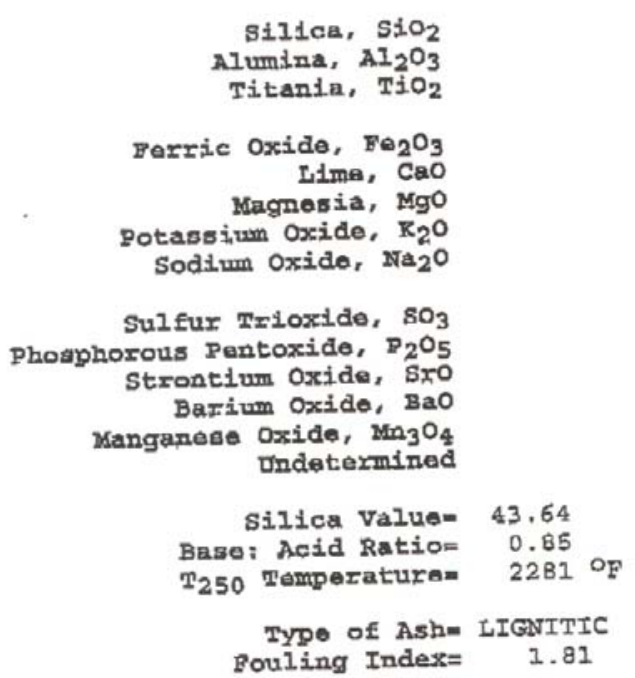

29.92
16.85

1.23

5.33

26.82

6.49

0.23

1.81

11.00

0.59

0.63

0.64

0.03

$x \times 000 \times x$

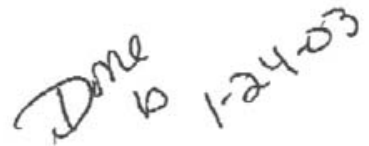

ouling Index= 


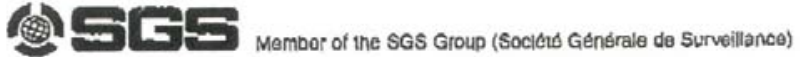

January 10,2003

ADDPESS ALI CORRESPONDENCE TO: 2804 HACKATHOFNE LANE

GIL.LITE, WY 82716

FAX: $(307) 682.7951$

unw.comteco,com

RAG COAL WEST, INC.

BAGLE BUTTE MINE

P.O. BOX 3040

GILLETIE WY 82717

Kind of mample COAI
reported to un
Sample taken at Belle Ayr
Sample taken by RAG Coal West, Inc.
Date campled Jamuary 4, 2003 ,
Date received January 10, 2003

Sample identification by RAG Coal Wegt, Inc.

$\begin{array}{ll} & 36-104330 \\ \text { SAMPLE ID: } & \text { BMBSBO01 } \\ \text { TRAIN \#: } & \text { I4090,350 } \\ \text { TOTAI TONNAGE: } & \text { OTTERTAIL POWER } \\ \text { CUSTOMER: } & \text { BIG STONB } \\ \text { PLANT: } & 01 / 04 / 2003 \\ \text { LOAD DATE: } & \end{array}$

Analysis report no. 44-59397

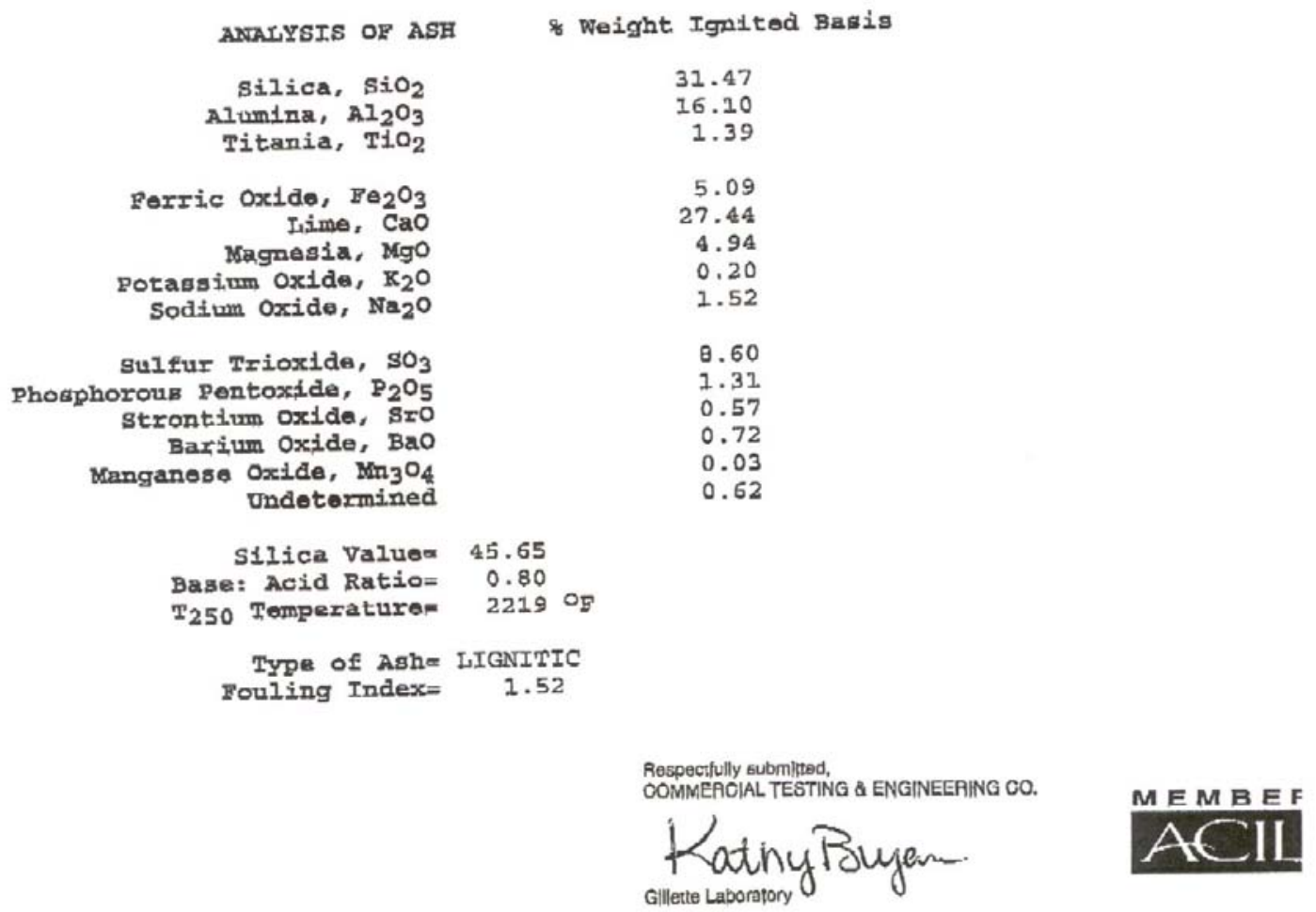


Sample Number: 03-C99

Tom Hrdlicka

Ottertail Power - Big Stone

PO Box 218

Big Stone City SD 57216-0218

Sample Description: Soybeans

Sample Site: OTP Big Stone

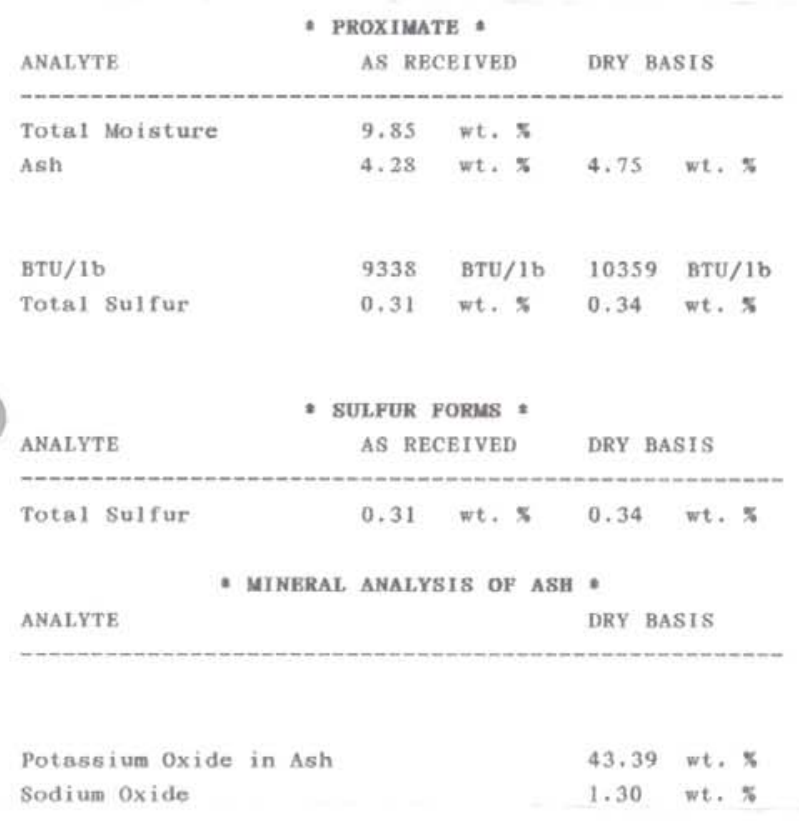

Report Date: 1/21/03

Work Order \#: 89-51

P.O. \#: 7830

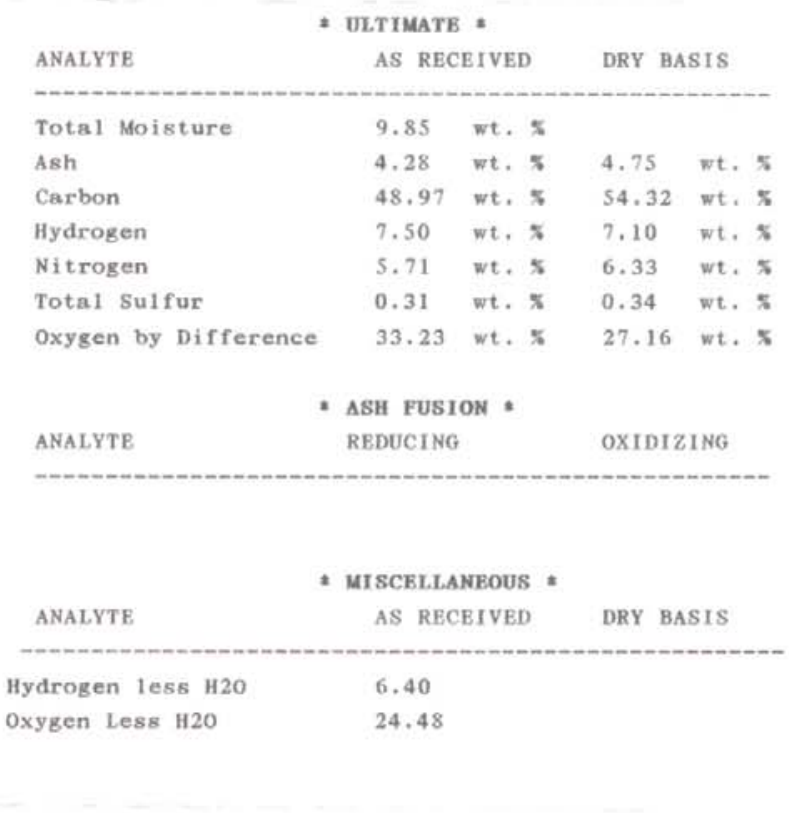

Approved By:

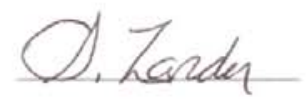

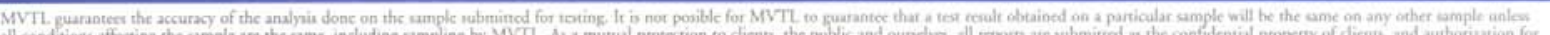

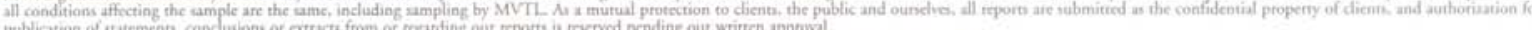
AN EQUAL OPPORTUNITY EMPLOYER 
Sample Number: 03-C98

Tom Hrdlicka

Ottertail Power - Big Stone

PO Box 218

Big Stone City SD 57216-0218

Sample Description: Corn

Sample Site: OTP Big stone

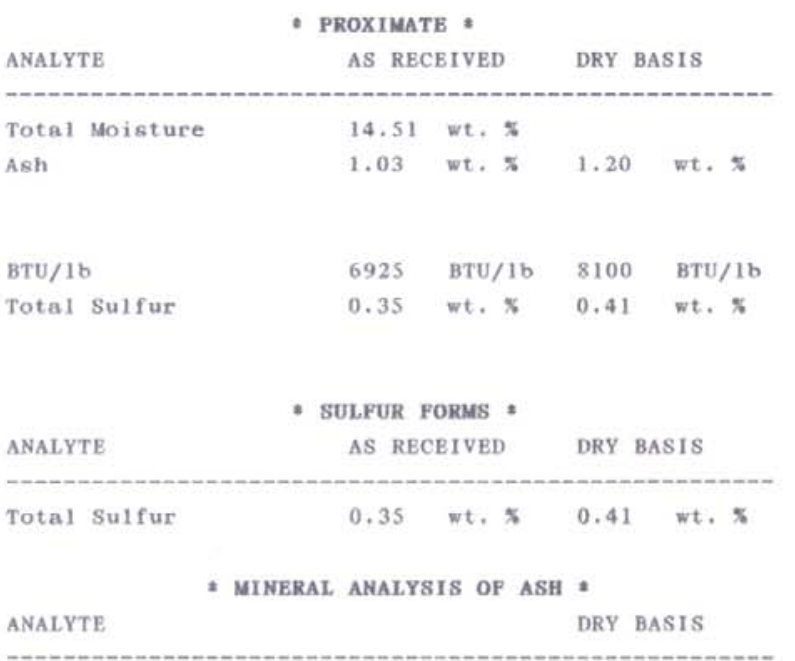

Potassium Oxide in Ash

Sodium Oxide

29.39 wt. $\mathrm{s}$

0.50 wt. 8
Report Date: 1/21/03

Work Order \#: 89-51

P.O. \#: 7830

\begin{tabular}{|c|c|c|c|c|}
\hline \multirow{2}{*}{$\begin{array}{l}\text { ANALYTE } \\
\text { Total Moisture }\end{array}$} & \multicolumn{2}{|c|}{ AS RECEIVED } & \multicolumn{2}{|c|}{ DRY BASIS } \\
\hline & 14.51 & wt. 5 & & \\
\hline Ash & 1.03 & wt. 5 & 1.20 & wt. \% \\
\hline Carbon & 40.12 & wt. 5 & 46.93 & wt. 5 \\
\hline Hydrogen & 6.79 & wt. $\%$ & 6.04 & wt. $\%$ \\
\hline Nitrogen & 1.14 & wt. 5 & 1.33 & wt. $\%$ \\
\hline Total Sulfur & 0.35 & wt. $x$ & 0.41 & wt. $\%$ \\
\hline Oxygen by Difference & 50.57 & wt, 5 & 44.08 & $w t, x$ \\
\hline , & ASH FUS: & DN $=$ & & \\
\hline ANALYTE & REDUCIN & & OXIDI & ING \\
\hline
\end{tabular}

\begin{tabular}{ll} 
ANALYTE & $\begin{array}{c}\text { MISCELLANEOUS * } \\
\text { AS RECEIVED }\end{array}$ \\
\hline $\begin{array}{l}\text { Hydrogen less H2O } \\
\text { Oxygen Legs H2O }\end{array}$ & 5.17 \\
& 37.68
\end{tabular}

Approved By:

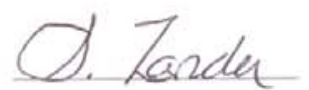

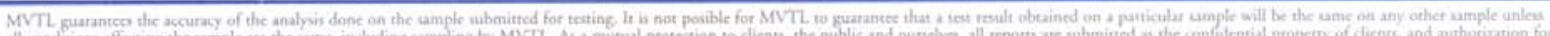

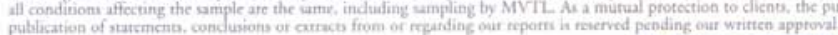
AN EQUAL OPPORTUNITY EMPLOYER 
Sample Site: OTP Big Stone

Sample Description: OTP Fly Ash Sample

Sample Date: 23 Mar 2004

Analyte

SO3 in Ash

\begin{tabular}{cc} 
Results & Units \\
\hline 4.25 & wt. \% \\
30.61 & wt. $\%$ \\
6.88 & wt. $\%$ \\
2.81 & wt. $\%$ \\
0.51 & wt. $\%$ \\
16.80 & wt. $\%$ \\
0.87 & wt. $\%$ \\
6.61 & wt. $\%$ \\
0.06 & wt. $\%$ \\
25.57 & wt. $\%$ \\
0.58 & wt. $\%$ \\
1.38 & wt. $\%$ \\
1.22 & wt. $\%$ \\
43.00 & ug/g \\
32.70 & ug/g
\end{tabular}

Note: Unless otherwise idicated, results are on an As Received Basis. 
B17 Ultimate Coal Analysis

ULTIMATE ANALYSIS

AS RECEIVED

\begin{tabular}{|c|c|c|c|c|c|c|c|c|c|c|}
\hline $\begin{array}{c}\text { Sample } \\
\text { Date }\end{array}$ & $\begin{array}{c}\text { Moisture } \\
\% \\
\end{array}$ & $\begin{array}{c}\text { Ash } \\
\% \\
\end{array}$ & $\begin{array}{c}\text { Carbon } \\
\% \\
\end{array}$ & $\begin{array}{c}\text { Nitrogen } \\
\% \\
\end{array}$ & $\begin{array}{c}\text { Sulfur } \\
\% \\
\end{array}$ & $\begin{array}{c}\text { Hydrogen } \\
\% \\
\end{array}$ & $\begin{array}{c}\text { Oxygen } \\
\% \\
\end{array}$ & $\begin{array}{c}\text { HHV } \\
\text { btu/lb }\end{array}$ & $\begin{array}{c}\mathrm{NaO} \\
\% \\
\end{array}$ & $\begin{array}{l}\text { Merc \% } \\
\text { ug/g Dry }\end{array}$ \\
\hline $06-\operatorname{Jan}-02$ & 29.59 & 5.16 & 49.23 & 0.70 & 0.39 & 3.95 & 10.98 & 8469 & 1.50 & \\
\hline 13-Jan-02 & 29.10 & 5.03 & 49.68 & 0.70 & 0.36 & 3.54 & 11.59 & 8656 & 1.00 & 0.169 \\
\hline 20-Jan-02 & 30.11 & 5.00 & 49.25 & 0.70 & 0.37 & 3.77 & 10.80 & 8492 & 1.40 & \\
\hline 28-Jan-02 & 29.61 & 4.59 & 49.60 & 0.71 & 0.39 & 3.74 & 11.36 & 8568 & 1.80 & \\
\hline 03-Feb-02 & 29.80 & 4.98 & 48.68 & 0.66 & 0.40 & 3.80 & 11.68 & 8570 & 1.80 & \\
\hline $10-\mathrm{Feb}-02$ & 28.86 & 4.81 & 49.03 & 0.64 & 0.39 & 3.76 & 12.51 & 8656 & 1.40 & 0.096 \\
\hline $17-$ Feb-02 & 29.44 & 4.57 & 49.11 & 0.65 & 0.35 & 3.57 & 12.31 & 8690 & 1.70 & \\
\hline 24-Feb-02 & 30.24 & 4.94 & 48.63 & 0.71 & 0.36 & 3.70 & 11.42 & 8172 & 1.60 & \\
\hline 03-Mar-02 & 30.08 & 5.00 & 48.83 & 0.65 & 0.35 & 3.76 & 11.33 & 8399 & 1.50 & \\
\hline 10-Mar-02 & 29.56 & 4.66 & 49.69 & 0.65 & 0.32 & 3.75 & 11.37 & 8559 & 1.50 & 0.058 \\
\hline 17-Mar-02 & 30.39 & 4.68 & 48.93 & 0.65 & 0.40 & 3.96 & 10.99 & 8440 & 1.50 & \\
\hline 24-Mar-02 & 30.22 & 5.00 & 48.86 & 0.65 & 0.44 & 5.09 & 9.74 & 8357 & 1.60 & \\
\hline 31-Mar-02 & 29.69 & 5.49 & 48.97 & 0.66 & 0.37 & 3.64 & 11.18 & 8410 & 1.20 & \\
\hline $07-A p r-02$ & 29.39 & 4.61 & 49.58 & 0.64 & 0.35 & 3.52 & 11.91 & 8660 & 1.70 & \\
\hline 14-Apr-02 & 29.44 & 4.72 & 48.80 & 0.74 & 0.42 & 3.16 & 12.72 & 8528 & 1.50 & 0.113 \\
\hline 21-Apr-02 & 29.80 & 4.20 & 49.70 & 0.64 & 0.35 & 3.47 & 11.84 & 8582 & 1.40 & \\
\hline 28-Apr-02 & 27.53 & 4.58 & 50.37 & 0.69 & 0.32 & 3.77 & 12.74 & 8653 & 1.40 & \\
\hline 05-May-02 & 29.69 & 4.45 & 48.92 & 0.65 & 0.30 & 3.63 & 12.36 & 8550 & 1.40 & \\
\hline 12 -May-02 & Outage & Outage & Outage & Outage & Outage & Outage & Outage & Outage & Outage & \\
\hline $19-$ May-02 & 29.07 & 4.85 & 49.39 & 0.65 & 0.38 & 3.60 & 12.06 & 8627 & 1.60 & 0.087 \\
\hline 26-May-02 & 29.88 & 4.27 & 49.32 & 0.67 & 0.30 & 3.69 & 11.87 & 8483 & 1.90 & \\
\hline 02-Jun-02 & 28.53 & 4.80 & 48.88 & 0.76 & 0.27 & 3.97 & 12.79 & 8557 & 1.60 & \\
\hline 09-Jun-02 & 30.24 & 4.69 & 48.26 & 0.63 & 0.37 & 3.56 & 12.25 & 8381 & 1.30 & 0.07 \\
\hline 16-Jun-02 & NA & $\mathrm{NA}$ & NA & NA & NA & NA & NA & NA & NA & \\
\hline 23-Jun-02 & 26.23 & 5.18 & 51.01 & 0.67 & 0.36 & 3.81 & 12.74 & 8818 & 1.00 & \\
\hline $30-$ Jun-02 & 29.28 & 4.67 & 48.65 & 0.70 & 0.32 & 3.74 & 12.64 & 8500 & 1.50 & \\
\hline $07-J u l-02$ & 29.29 & 4.89 & 49.15 & 0.72 & 0.24 & 3.74 & 11.97 & 8509 & 1.00 & \\
\hline 14-Jul-02 & 29.60 & 4.79 & 48.44 & 0.69 & 0.28 & 3.95 & 12.25 & 8528 & 1.40 & 0.073 \\
\hline 21-Jul-02 & 28.39 & 4.43 & 49.24 & 0.64 & 0.31 & 4.12 & 12.87 & 8636 & 1.20 & \\
\hline 28-Jul-02 & 28.32 & 4.17 & 49.80 & 0.66 & 0.25 & 4.08 & 12.72 & 8629 & 1.50 & \\
\hline 04-Aug-02 & 29.35 & 4.23 & 49.41 & 0.64 & 0.30 & 3.96 & 12.11 & 8644 & 1.40 & \\
\hline 11-Aug-02 & 29.57 & 4.92 & 48.53 & 0.65 & 0.27 & 3.36 & 12.70 & 8487 & 1.00 & 0.078 \\
\hline 18-Aug-02 & 30.00 & 4.67 & 48.33 & 0.67 & 0.37 & 3.66 & 12.30 & 8440 & 1.30 & \\
\hline 25 -Aug- 02 & 30.01 & 5.08 & 47.26 & 0.66 & 0.39 & 3.53 & 13.07 & 8291 & 1.50 & \\
\hline $01-$ Sep-02 & 29.07 & 4.17 & 49.39 & 0.63 & 0.31 & 3.65 & 12.78 & 8692 & 1.90 & \\
\hline 08-Sep-02 & 29.16 & 4.62 & 48.90 & 0.69 & 0.34 & 3.58 & 12.71 & 8579 & 2.00 & 0.099 \\
\hline $15-$ Sep-02 & Outage & Outage & Outage & Outage & Outage & Outage & Outage & Outage & Outage & \\
\hline $22-$ Sep- 02 & Outage & Outage & Outage & Outage & Outage & Outage & Outage & Outage & Outage & \\
\hline 29-Sep-02 & Outage & Outage & Outage & Outage & Outage & Outage & Outage & Outage & Outage & \\
\hline 06-Oct-02 & Outage & Outage & Outage & Outage & Outage & Outage & Outage & Outage & Outage & \\
\hline 13-Oct-02 & Outage & Outage & Outage & Outage & Outage & Outage & Outage & Outage & Outage & \\
\hline $20-$ Oct-02 & Outage & Outage & Outage & Outage & Outage & Outage & Outage & Outage & Outage & \\
\hline 27-Oct-02 & Outage & Outage & Outage & Outage & Outage & Outage & Outage & Outage & Outage & \\
\hline 03-Nov-02 & Outage & Outage & Outage & Outage & Outage & Outage & Outage & Outage & Outage & \\
\hline $10-$ Nov- 02 & Outage & Outage & Outage & Outage & Outage & Outage & Outage & Outage & Outage & \\
\hline $17-\mathrm{Nov}-02$ & 29.90 & 4.16 & 49.30 & 0.65 & 0.30 & 3.41 & 12.28 & 8568 & 1.50 & \\
\hline $24-N o v-02$ & 30.15 & 5.06 & 48.38 & 0.66 & 0.28 & 3.22 & 12.25 & 8375 & 1.20 & 0.074 \\
\hline 08-Dec-02 & 28.99 & 4.40 & 49.89 & 0.62 & 0.24 & 3.67 & 12.19 & 8649 & 1.30 & \\
\hline 15-Dec-02 & 29.35 & 4.32 & 49.52 & 0.66 & 0.27 & 3.57 & 12.31 & 8699 & 1.40 & 0.249 \\
\hline 22-Dec-02 & 29.21 & 4.23 & 49.77 & 0.63 & 0.26 & 3.44 & 12.46 & 8653 & 1.60 & \\
\hline 29-Dec-02 & 29.61 & 5.21 & 48.48 & 0.63 & 0.40 & 3.50 & 12.17 & 8410 & 1.40 & \\
\hline Average & 29.39 & 4.71 & 49.13 & 0.67 & 0.34 & 3.71 & 12.06 & 8539.15 & 1.46 & 0.11 \\
\hline
\end{tabular}


ULTIMATE ANALYSIS

AS RECEIVED

\begin{tabular}{|c|c|c|c|c|c|c|c|c|c|c|}
\hline $\begin{array}{c}\text { Sample } \\
\text { Date }\end{array}$ & $\begin{array}{c}\text { Moisture } \\
\%\end{array}$ & $\begin{array}{c}\text { Ash } \\
\%\end{array}$ & $\begin{array}{c}\text { Carbon } \\
\% \\
\end{array}$ & $\begin{array}{c}\text { Nitrogen } \\
\%\end{array}$ & $\begin{array}{c}\text { Sulfur } \\
\%\end{array}$ & $\begin{array}{c}\text { Hydrogen } \\
\%\end{array}$ & $\begin{array}{c}\text { Oxygen } \\
\% \\
\end{array}$ & $\begin{array}{c}\text { HHV } \\
\text { btu/lb }\end{array}$ & $\begin{array}{c}\mathrm{NaO} \\
\%\end{array}$ & $\begin{array}{l}\text { Merc \% } \\
\text { ug/g Dry }\end{array}$ \\
\hline $05-J a n-03$ & 30.31 & 4.60 & 48.51 & 0.65 & 0.50 & 3.43 & 12.00 & 8415 & 1.90 & \\
\hline 06-Jan-03 & 29.75 & 4.79 & 48.86 & 0.64 & 0.39 & 3.43 & 12.14 & 8465 & 1.30 & \\
\hline 07-Jan-03 & 29.82 & 4.74 & 48.39 & 0.67 & 0.39 & 3.03 & 12.96 & 8431 & 1.70 & \\
\hline 08-Jan-03 & 28.79 & 4.86 & 49.34 & 0.68 & 0.40 & 3.05 & 12.88 & 8593 & 1.60 & \\
\hline 12-Jan-03 & 28.85 & 4.19 & 50.03 & 0.69 & 0.24 & 3.04 & 12.96 & 8692 & 1.30 & 0.093 \\
\hline 19-Jan-03 & 28.91 & 4.75 & 49.71 & 0.66 & 0.29 & 3.59 & 12.09 & 8696 & 1.40 & \\
\hline 26-Jan-03 & 29.09 & 4.23 & 49.73 & 0.85 & 0.24 & 3.55 & 12.31 & 8624 & 1.30 & \\
\hline 02-Feb-03 & 21.42 & 4.44 & 54.26 & 1.05 & 0.28 & 4.19 & 14.36 & 9477 & 2.00 & \\
\hline 09-Feb-03 & 30.26 & 4.23 & 49.20 & 0.69 & 0.25 & 3.48 & 11.89 & 8487 & 1.40 & 0.103 \\
\hline 16 -Feb-03 & 27.91 & 4.37 & 50.12 & 1.08 & 0.28 & 3.79 & 12.45 & 8672 & 1.30 & \\
\hline 23 -Feb-03 & 26.60 & 5.10 & 48.81 & 1.36 & 0.31 & 4.14 & 13.68 & 8618 & 0.31 & \\
\hline 02-Mar-03 & NA & NA & NA & NA & NA & NA & NA & NA & NA & \\
\hline 09-Mar-03 & 29.99 & 4.48 & 49.46 & 0.63 & 0.26 & 4.21 & 10.97 & 8534 & 1.40 & \\
\hline 16-Mar-03 & 29.23 & 4.53 & 49.32 & 0.66 & 0.26 & 3.74 & 12.26 & 8516 & 1.30 & 0.116 \\
\hline 23-Mar-03 & 29.96 & 4.10 & 49.40 & 0.67 & 0.21 & 3.23 & 12.43 & 8581 & 1.10 & \\
\hline 30-Mar-03 & 29.39 & 6.23 & 48.42 & 0.66 & 0.27 & 3.27 & 11.76 & 8402 & 1.80 & \\
\hline 06-Apr-03 & 29.34 & 4.72 & 49.26 & 0.67 & 0.24 & 3.35 & 12.42 & 8514 & 1.20 & \\
\hline $13-\mathrm{Apr}-03$ & 30.14 & 4.96 & 48.57 & 0.69 & 0.39 & 3.62 & 11.63 & 8474 & 1.60 & 0.116 \\
\hline $20-A p r-03$ & 30.16 & 4.87 & 48.65 & 0.68 & 0.49 & 3.70 & 11.45 & 8390 & 1.70 & \\
\hline $27-\mathrm{Apr}-03$ & 30.74 & 4.33 & 48.77 & 0.67 & 0.35 & 3.54 & 11.60 & 8377 & 1.40 & \\
\hline 04-May-03 & 30.57 & 4.81 & 48.95 & 0.66 & 0.30 & 3.59 & 11.12 & 8332 & 1.70 & \\
\hline 11 -May-03 & 29.97 & 4.56 & 50.35 & 0.68 & 0.35 & 3.73 & 10.36 & 8476 & 1.40 & 0.113 \\
\hline 18-May-03 & 29.18 & 4.87 & 50.09 & 0.67 & 0.29 & 3.61 & 11.29 & 8572 & 1.10 & \\
\hline 25 -May- 03 & 29.17 & 4.81 & 50.22 & 0.66 & 0.31 & 3.75 & 11.08 & 8557 & 1.40 & \\
\hline 01-Jun-03 & 29.26 & 4.72 & 49.69 & 0.72 & 0.44 & 3.58 & 11.59 & 8501 & 1.80 & \\
\hline 08-Jun-03 & NA & NA & NA & NA & NA & NA & NA & NA & NA & \\
\hline 15-Jun-03 & 29.96 & 4.43 & 49.24 & 0.70 & 0.45 & 3.63 & 11.59 & 8476 & 1.70 & 0.013 \\
\hline 22-Jun-03 & 29.52 & 4.42 & 49.74 & 0.65 & 0.32 & 3.42 & 11.93 & 8564 & 1.40 & \\
\hline 29-Jun-03 & 30.43 & 4.74 & 48.83 & 0.71 & 0.36 & 3.40 & 11.53 & 8404 & 1.70 & \\
\hline 06-Jul-03 & 29.10 & 4.56 & 50.03 & 0.67 & 0.30 & 3.42 & 11.92 & 8539 & 1.00 & \\
\hline 13-Jul-03 & 30.39 & 4.90 & 48.72 & 0.67 & 0.42 & 3.10 & 11.80 & 8415 & 1.30 & 0.105 \\
\hline 20-Jul-03 & 29.36 & 4.28 & 50.07 & 0.69 & 0.31 & 3.51 & 11.78 & 8663 & 1.20 & \\
\hline 27-Jul-03 & 28.14 & 5.06 & 49.96 & 0.68 & 0.60 & 3.70 & 11.86 & 8633 & 0.90 & \\
\hline 03-Aug-03 & 29.70 & 4.61 & 49.24 & 0.70 & 0.40 & 3.83 & 11.52 & 8474 & 1.40 & \\
\hline 10 -Aug-03 & 28.75 & 4.28 & 50.44 & 0.74 & 0.29 & 4.06 & 11.44 & 8663 & 1.10 & 0.081 \\
\hline 17 -Aug-03 & 29.04 & 5.44 & 49.38 & 0.76 & 0.33 & 3.88 & 11.17 & 8415 & 1.30 & \\
\hline 24-Aug-03 & 28.98 & 4.84 & 49.89 & 0.65 & 0.29 & 3.54 & 11.81 & 8584 & 1.20 & \\
\hline 31-Aug-03 & 28.92 & 4.85 & 49.86 & 0.69 & 0.27 & 3.51 & 11.90 & 8500 & 0.80 & \\
\hline $07-$ Sep-03 & 29.69 & 4.23 & 50.77 & 0.70 & 0.27 & 3.69 & 10.65 & 8656 & 1.40 & \\
\hline 14-Sep-03 & 29.35 & 4.52 & 49.83 & 0.68 & 0.32 & 3.28 & 12.02 & 8489 & 1.40 & 0.084 \\
\hline $21-$ Sep-03 & 30.82 & 4.88 & 48.81 & 0.72 & 0.26 & 3.56 & 11.35 & 8275 & 1.10 & \\
\hline 28 -Sep-03 & 29.26 & 4.74 & 50.11 & 0.75 & 0.35 & 3.65 & 11.14 & 8590 & 1.10 & \\
\hline 05 -Oct- 03 & 29.17 & 4.26 & 50.42 & 0.68 & 0.23 & 3.35 & 11.89 & 8561 & 1.60 & \\
\hline $12-$ Oct-03 & NA & NA & NA & NA & NA & NA & NA & NA & NA & \\
\hline $19-$-Oct-03 & NA & NA & NA & NA & NA & NA & NA & NA & NA & \\
\hline $26-$ Oct-03 & 27.13 & 5.07 & 51.78 & 0.67 & 0.28 & 3.30 & 11.77 & 8847 & 1.10 & 0.069 \\
\hline $02-$ Nov- 03 & 28.99 & 4.46 & 50.15 & 0.71 & 0.35 & 3.58 & 11.76 & 8636 & 1.10 & \\
\hline 09-Nov-03 & 29.51 & 4.26 & 49.18 & 0.69 & 0.28 & 3.51 & 12.57 & 8545 & 1.20 & 0.071 \\
\hline $16-$ Nov- 03 & 29.93 & 4.86 & 47.98 & 0.71 & 0.43 & 3.64 & 12.45 & 8431 & 1.30 & \\
\hline $23-$ Nov- 03 & 30.26 & 4.75 & 47.73 & 0.66 & 0.44 & 3.42 & 12.74 & 8489 & 1.40 & \\
\hline $30-$ Nov- 03 & 30.33 & 4.35 & 48.75 & 0.71 & 0.36 & 3.36 & 12.14 & 8444 & 1.40 & \\
\hline 07-Dec-03 & NA & NA & NA & NA & NA & NA & NA & NA & NA & \\
\hline 14-Dec-03 & NA & NA & NA & NA & NA & NA & NA & NA & NA & \\
\hline 21-Dec-03 & NA & NA & NA & NA & NA & NA & NA & NA & NA & \\
\hline 28-Dec-03 & 29.76 & 5.08 & 49.07 & 0.70 & 0.42 & 3.47 & 11.50 & 8557 & 1.30 & 0.057 \\
\hline
\end{tabular}


ULTIMATE ANALYSIS

AS RECEIVED

\begin{tabular}{|c|c|c|c|c|c|c|c|c|c|c|}
\hline $\begin{array}{c}\text { Sample } \\
\text { Date }\end{array}$ & $\begin{array}{c}\text { Moisture } \\
\%\end{array}$ & $\begin{array}{c}\text { Ash } \\
\%\end{array}$ & $\begin{array}{c}\text { Carbon } \\
\%\end{array}$ & $\begin{array}{c}\text { Nitrogen } \\
\% \\
\end{array}$ & $\begin{array}{c}\text { Sulfur } \\
\%\end{array}$ & $\begin{array}{c}\text { Hydrogen } \\
\% \\
\end{array}$ & $\begin{array}{c}\text { Oxygen } \\
\%\end{array}$ & $\begin{array}{l}\text { HHV } \\
\text { btu/lb }\end{array}$ & $\begin{array}{c}\mathrm{NaO} \\
\%\end{array}$ & $\begin{array}{l}\text { Mercury } \\
\text { ug/g Dry }\end{array}$ \\
\hline 04-Jan-04 & 29.76 & 5.09 & 48.59 & 0.70 & 0.44 & 3.44 & 11.98 & 8471 & 1.60 & \\
\hline 11-Jan-04 & 29.33 & 4.62 & 49.57 & 0.69 & 0.33 & 3.38 & 12.08 & 8624 & 1.10 & 0.093 \\
\hline 18-Jan-04 & 28.30 & 4.40 & 51.62 & 0.75 & 0.33 & 3.57 & 11.03 & 8602 & 1.70 & \\
\hline 25-Jan-04 & 30.05 & 4.26 & 51.23 & 0.73 & 0.28 & 3.38 & 10.07 & 8548 & 1.70 & \\
\hline 01-Feb-04 & 29.85 & 5.27 & 48.97 & 0.69 & 0.46 & 3.44 & 11.32 & 8503 & 1.80 & \\
\hline 08-Feb-04 & 29.27 & 4.31 & 49.78 & 0.70 & 0.27 & 3.48 & 12.19 & 8604 & 1.40 & 0.035 \\
\hline 15-Feb-04 & 30.58 & 4.38 & 49.39 & 0.68 & 0.26 & 3.34 & 11.37 & 8390 & 1.00 & \\
\hline 22-Feb-04 & 29.67 & 4.99 & 49.05 & 0.70 & 0.44 & 3.59 & 11.56 & 8460 & 1.40 & \\
\hline 29-Feb-04 & 28.68 & 4.83 & 50.30 & 0.73 & 0.43 & 3.36 & 11.67 & 8658 & 1.90 & \\
\hline 07-Mar-04 & 29.65 & 4.70 & 50.04 & 0.69 & 0.34 & 3.43 & 11.15 & 8545 & 1.20 & \\
\hline 14-Mar-04 & 28.54 & 4.87 & 50.47 & 0.72 & 0.40 & 3.49 & 11.51 & 8631 & 1.80 & 0.105 \\
\hline 21-Mar-04 & 29.43 & 4.50 & 49.42 & 0.68 & 0.28 & 3.58 & 12.11 & 8543 & 1.70 & \\
\hline 28-Mar-04 & 31.09 & 4.44 & 50.01 & 0.67 & 0.30 & 3.46 & 10.03 & 8428 & 1.50 & \\
\hline 04-Apr-04 & 28.26 & 4.34 & 50.27 & 0.69 & 0.35 & 3.60 & 12.49 & 8712 & 1.80 & \\
\hline 11-Apr-04 & 28.43 & 4.94 & 49.69 & 0.71 & 0.30 & 3.80 & 12.13 & 8622 & 1.50 & 0.089 \\
\hline 18-Apr-04 & 28.75 & 4.22 & 50.96 & 0.67 & 0.26 & 3.36 & 11.78 & 8653 & 1.30 & \\
\hline 25-Apr-04 & 29.68 & 4.72 & 49.54 & 0.68 & 0.38 & 3.36 & 11.64 & 8501 & 1.60 & \\
\hline 02-May-04 & 28.11 & 4.51 & 51.45 & 0.66 & 0.41 & 3.47 & 11.39 & 8698 & 1.40 & \\
\hline 09-May-04 & 29.19 & 4.46 & 50.73 & 0.62 & 0.30 & 3.50 & 11.20 & 8626 & 1.90 & 0.086 \\
\hline 16-May-04 & 29.02 & 4.84 & 50.73 & 0.60 & 0.25 & 3.49 & 11.07 & 8581 & 1.30 & \\
\hline 23-May-04 & 29.30 & 4.54 & 50.00 & 0.70 & 0.43 & 3.49 & 11.54 & 8528 & 1.60 & \\
\hline 30-May-04 & 29.50 & 5.07 & 49.61 & 0.72 & 0.42 & 3.68 & 11.00 & 8449 & 1.40 & \\
\hline 06-Jun-04 & NA & NA & NA & NA & NA & NA & NA & NA & NA & \\
\hline 13-Jun-04 & 29.93 & 5.07 & 49.93 & 0.76 & 0.43 & 3.65 & 10.23 & 8352 & 1.40 & \\
\hline 20-Jun-04 & 28.75 & 5.06 & 51.16 & 0.78 & 0.38 & 3.74 & 10.13 & 8516 & 1.70 & 0.154 \\
\hline 27-Jun-04 & 29.40 & 4.71 & 49.98 & 0.68 & 0.40 & 3.68 & 11.15 & 8449 & 1.70 & \\
\hline 04-Jul-04 & 29.10 & 4.89 & 50.11 & 0.68 & 0.35 & 3.63 & 11.24 & 8519 & 1.60 & \\
\hline 11-Jul-04 & 29.54 & 4.67 & 50.45 & 0.67 & 0.33 & 3.55 & 10.79 & 8503 & 1.30 & 0.111 \\
\hline 18-Jul-04 & 29.47 & 4.87 & 50.59 & 0.70 & 0.38 & 3.55 & 10.44 & 8509 & 1.50 & \\
\hline 25-Jul-04 & 30.43 & 5.26 & 49.63 & 0.73 & 0.33 & 3.65 & 9.97 & 8305 & 1.60 & \\
\hline 01-Aug-04 & 30.66 & 4.60 & 49.96 & 0.67 & 0.37 & 3.68 & 10.06 & 8323 & 1.60 & \\
\hline 08-Aug-04 & 29.01 & 5.68 & 50.50 & 0.69 & 0.33 & 3.69 & 10.10 & 8433 & 1.30 & 0.144 \\
\hline 15-Aug-04 & 21.55 & 5.64 & 55.18 & 0.80 & 0.43 & 3.95 & 12.45 & 9223 & 1.50 & \\
\hline 22-Aug-04 & 29.78 & 4.68 & 50.19 & 0.67 & 0.39 & 3.63 & 10.66 & 8437 & 1.70 & \\
\hline 29-Aug-04 & 28.86 & 5.30 & 50.85 & 0.64 & 0.30 & 3.57 & 10.48 & 8518 & 1.10 & \\
\hline $05-\mathrm{Sep}-04$ & 29.27 & 4.74 & 51.01 & 0.71 & 0.40 & 3.70 & 10.17 & 8606 & 1.60 & \\
\hline 12-Sep-04 & 29.14 & 4.96 & 50.83 & 0.68 & 0.41 & 3.65 & 10.33 & 8500 & 2.10 & 0.08 \\
\hline 19-Sep-04 & 14.38 & 5.96 & 60.86 & 0.86 & 0.43 & 4.32 & 13.19 & 10028 & 1.50 & \\
\hline 26-Sep-04 & 29.37 & 4.35 & 51.85 & 0.67 & 0.25 & 3.69 & 9.82 & 8546 & 1.20 & \\
\hline 03-Oct-04 & 29.32 & 4.63 & 50.39 & 0.81 & 0.37 & 3.61 & 10.87 & 8478 & 1.00 & \\
\hline $10-$ Oct-04 & 29.79 & 4.61 & 50.68 & 0.71 & 0.39 & 3.71 & 10.11 & 8435 & 2.30 & 0.1 \\
\hline $17-$-Oct-04 & 29.50 & 5.11 & 49.88 & 0.69 & 0.41 & 3.53 & 10.88 & 8410 & 1.50 & \\
\hline 24-Oct-04 & NA & NA & NA & NA & NA & NA & NA & NA & NA & \\
\hline 31-Oct-04 & NA & NA & NA & NA & NA & NA & NA & NA & NA & \\
\hline 07-Nov-04 & NA & NA & NA & NA & NA & NA & NA & NA & NA & \\
\hline 14-Nov-04 & 30.14 & 4.72 & 50.46 & 0.67 & 0.34 & 3.54 & 10.13 & 8424 & 1.30 & \\
\hline 21-Nov-04 & 29.84 & 5.14 & 49.95 & 0.66 & 0.41 & 3.48 & 10.52 & 8446 & 1.40 & 0.123 \\
\hline 28-Nov-04 & 25.84 & 5.02 & 53.08 & 0.57 & 0.46 & 3.69 & 11.34 & 8782 & 1.40 & \\
\hline 05-Dec-04 & 29.49 & 5.07 & 50.85 & 0.73 & 0.28 & 3.47 & 10.11 & 8530 & 0.90 & \\
\hline 12-Dec-04 & 29.62 & 4.18 & 51.10 & 0.69 & 0.22 & 3.53 & 10.66 & 8575 & 1.20 & 0.082 \\
\hline 19-Dec-04 & 30.61 & 5.00 & 48.84 & 0.69 & 0.38 & 3.41 & 11.07 & 8284 & 1.20 & \\
\hline 26-Dec-04 & 28.62 & 4.92 & 50.40 & 0.74 & 0.39 & 3.56 & 11.37 & 8611.00 & 1.40 & \\
\hline
\end{tabular}


B18 Photographs from January 19, 2003 inspection

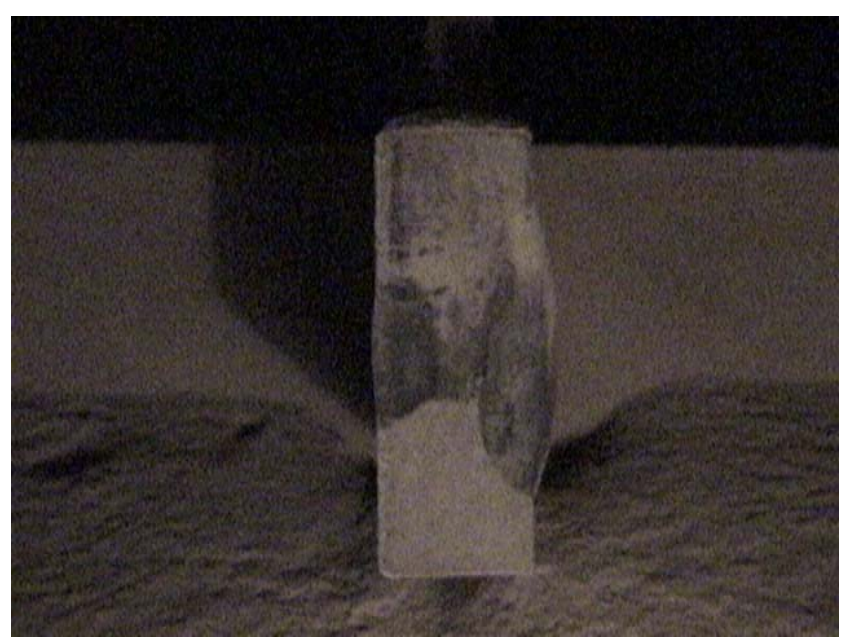

Anvil - Front View

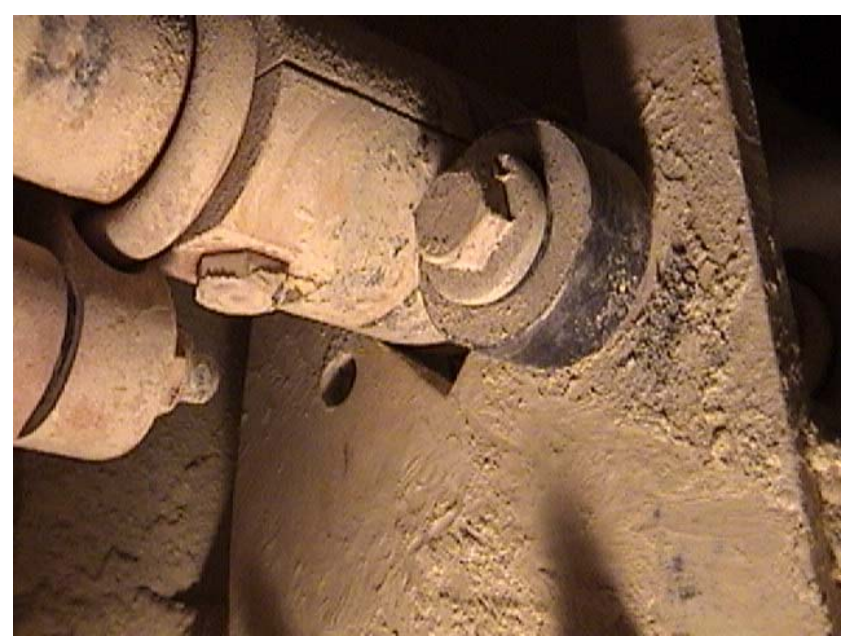

Missing Roller

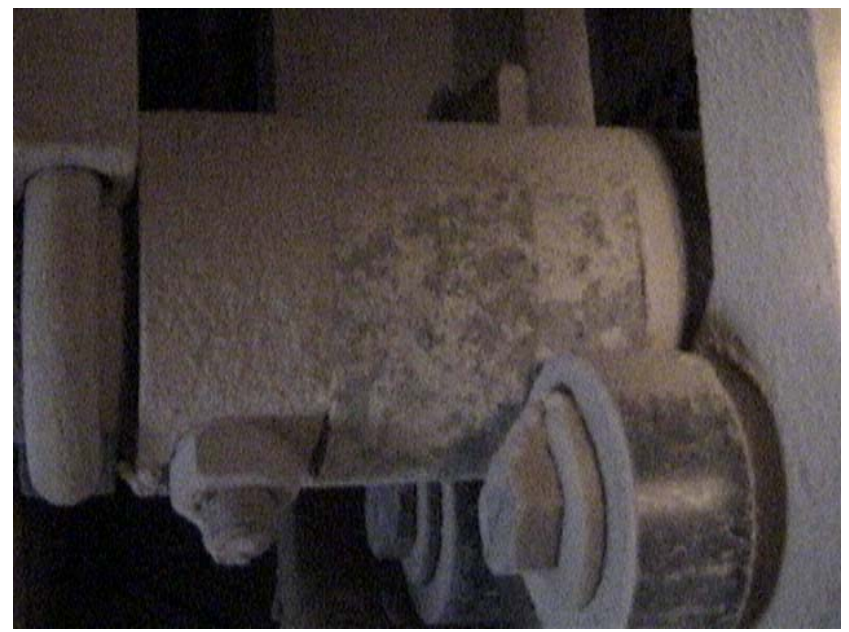

Rapper Shaft Coupler

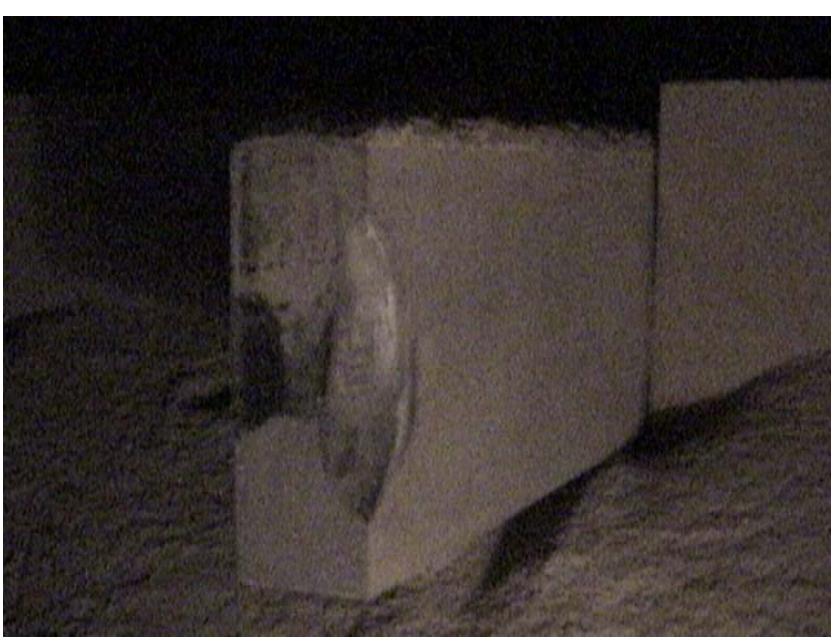

Anvil - Angle View

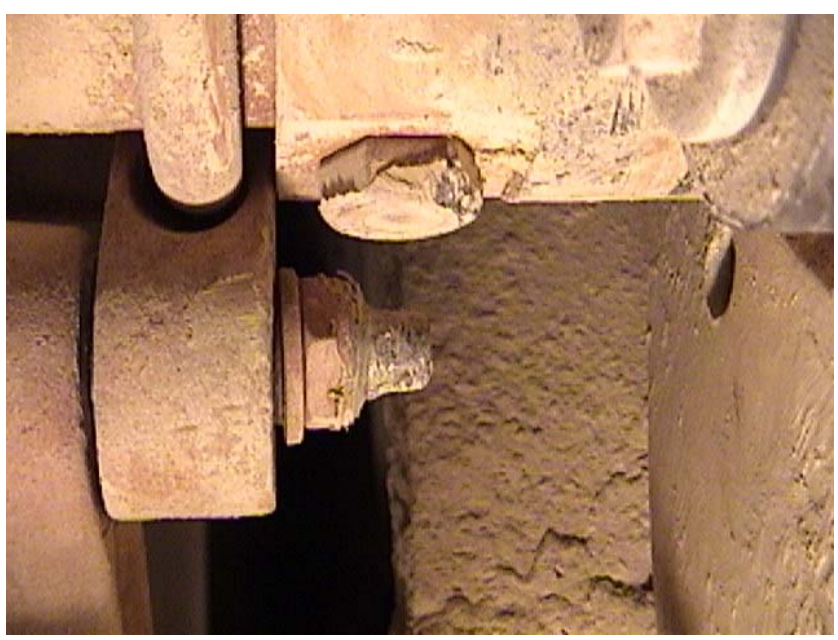

Damaged Bolt \& Nut

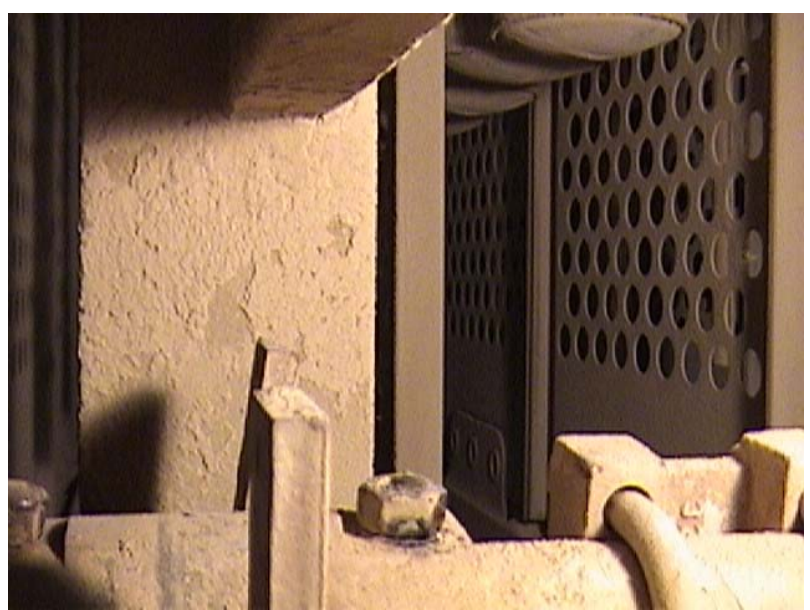

Bent Support 


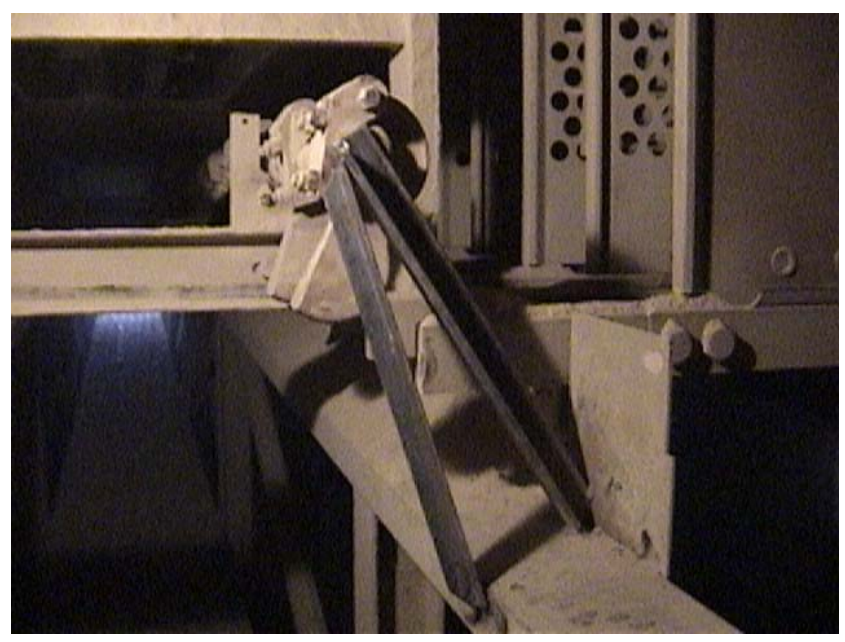

New Thrust Support - End View

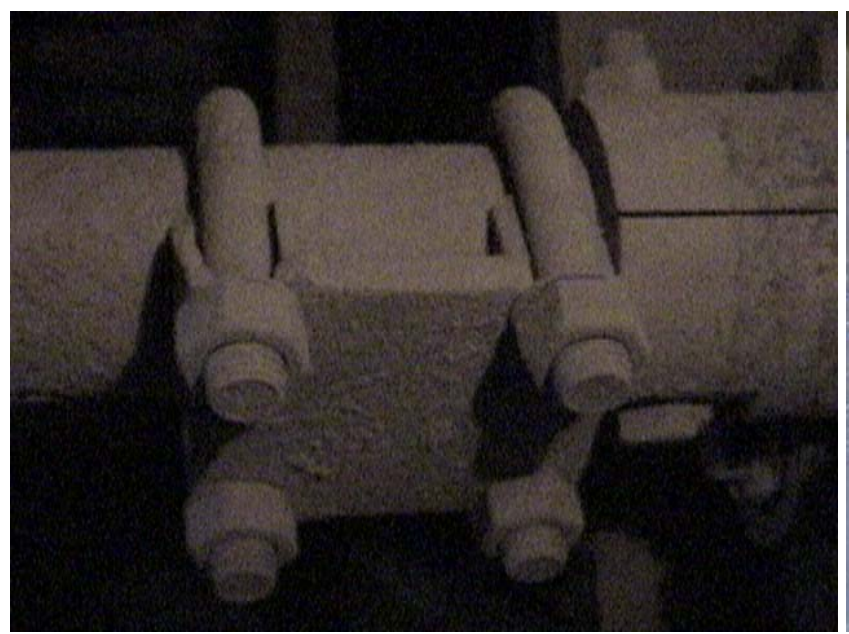

Missing Hammer

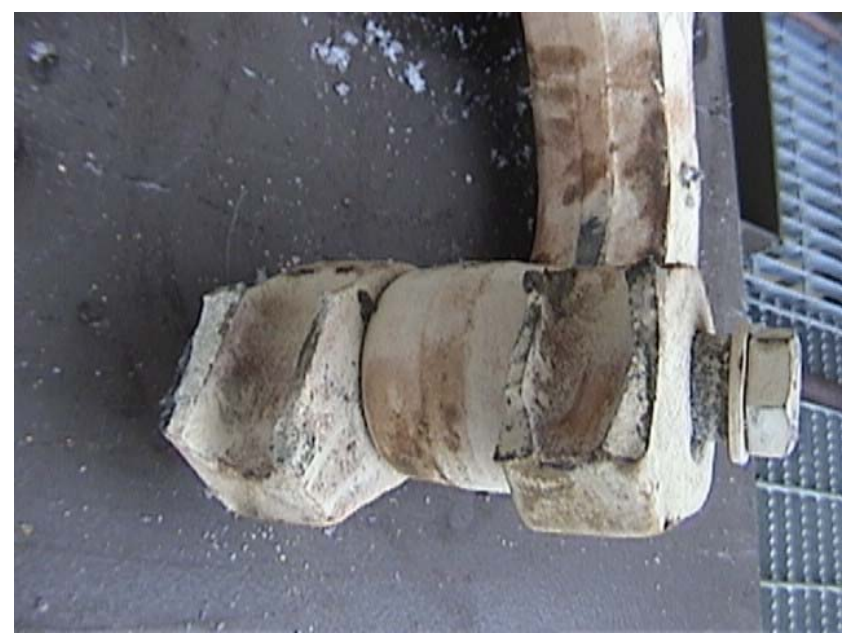

Broken Mount - Close Up View

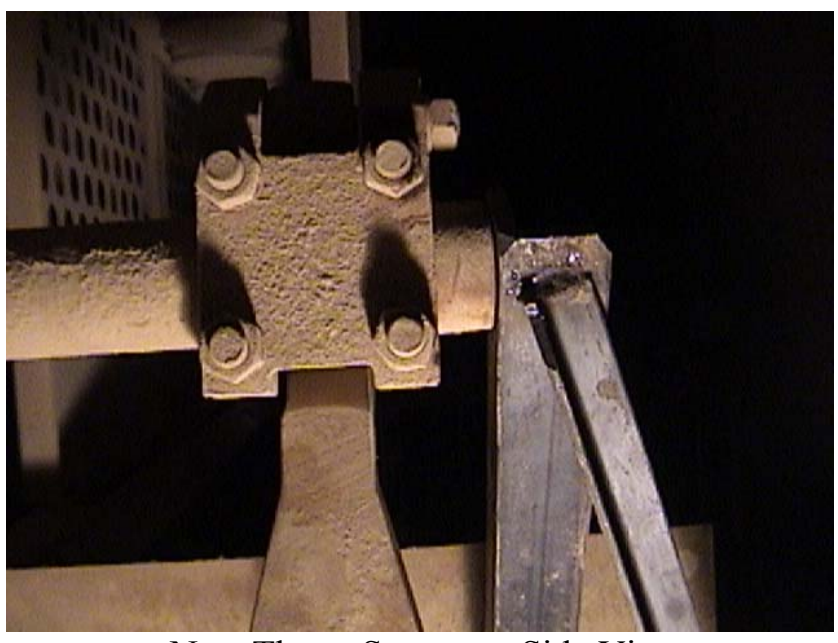

New Thrust Support - Side View

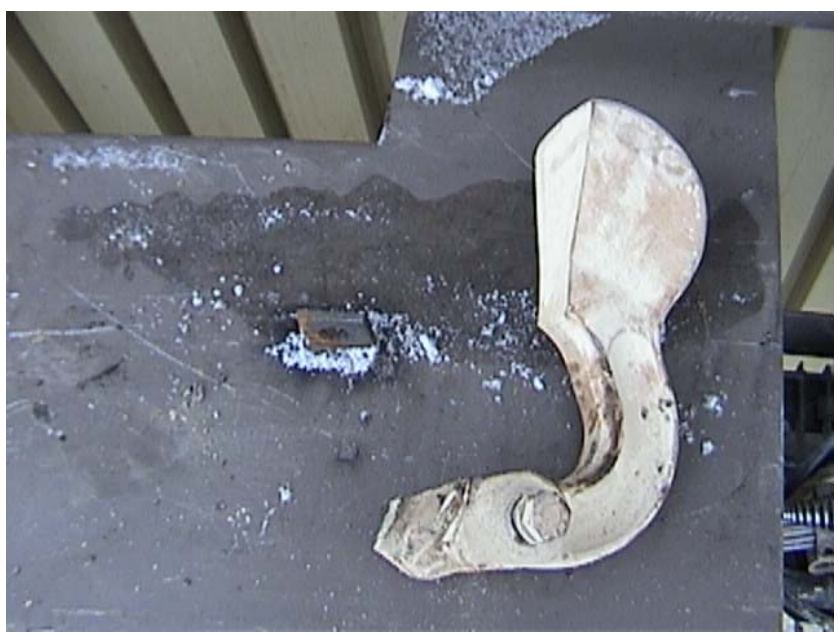

Broken Hammer Mount 
B19 ESP Power by Chamber
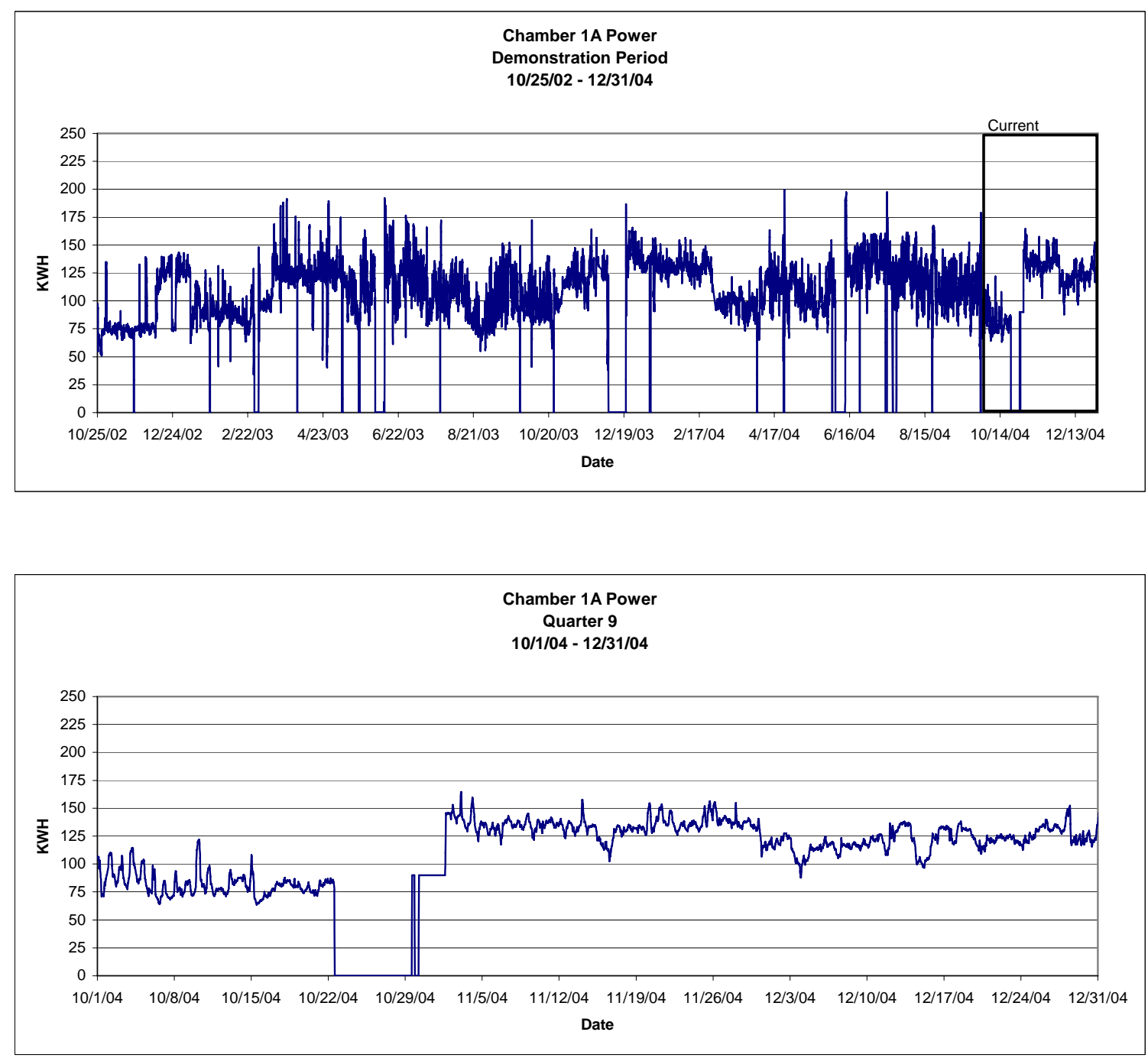

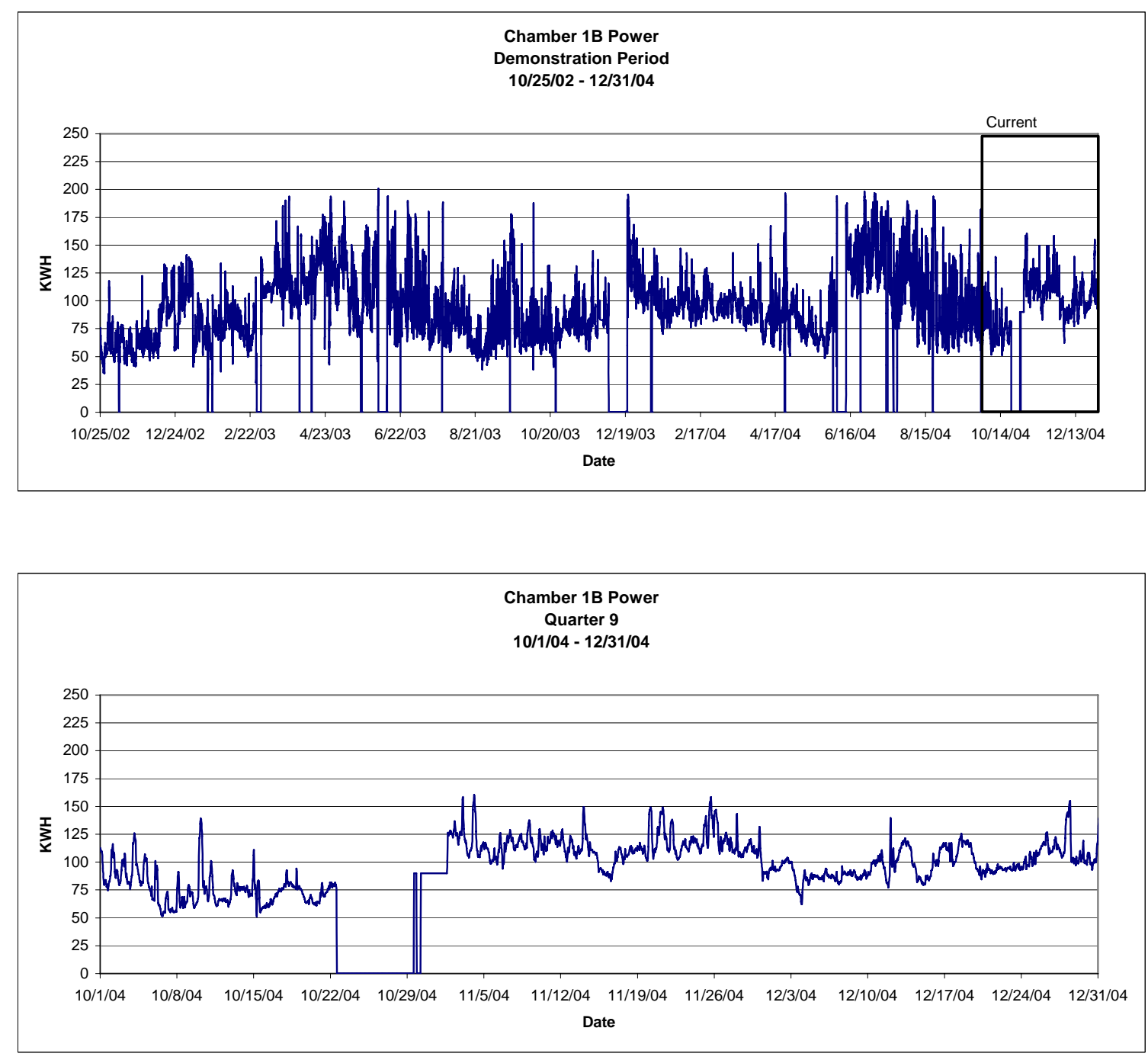

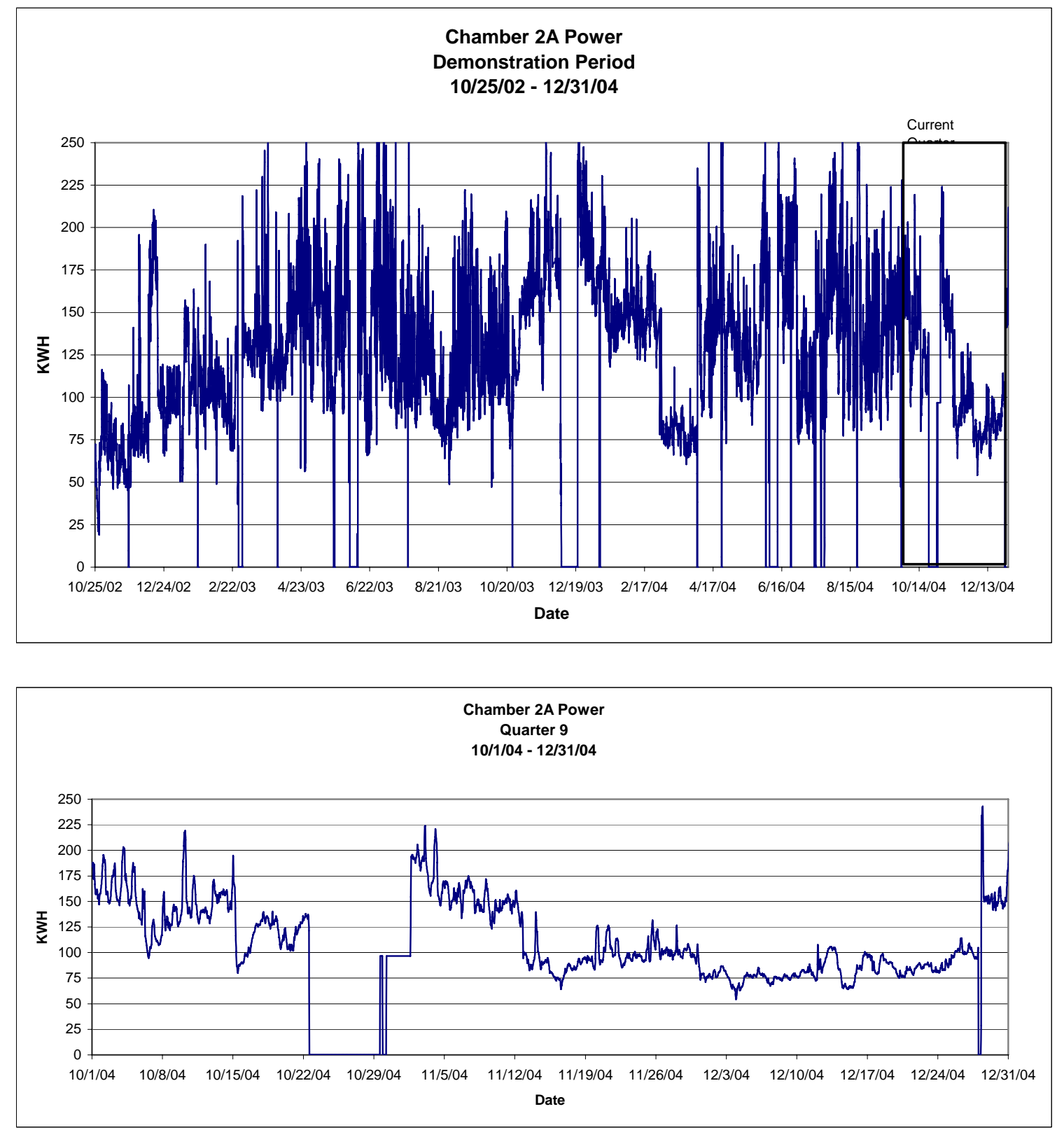

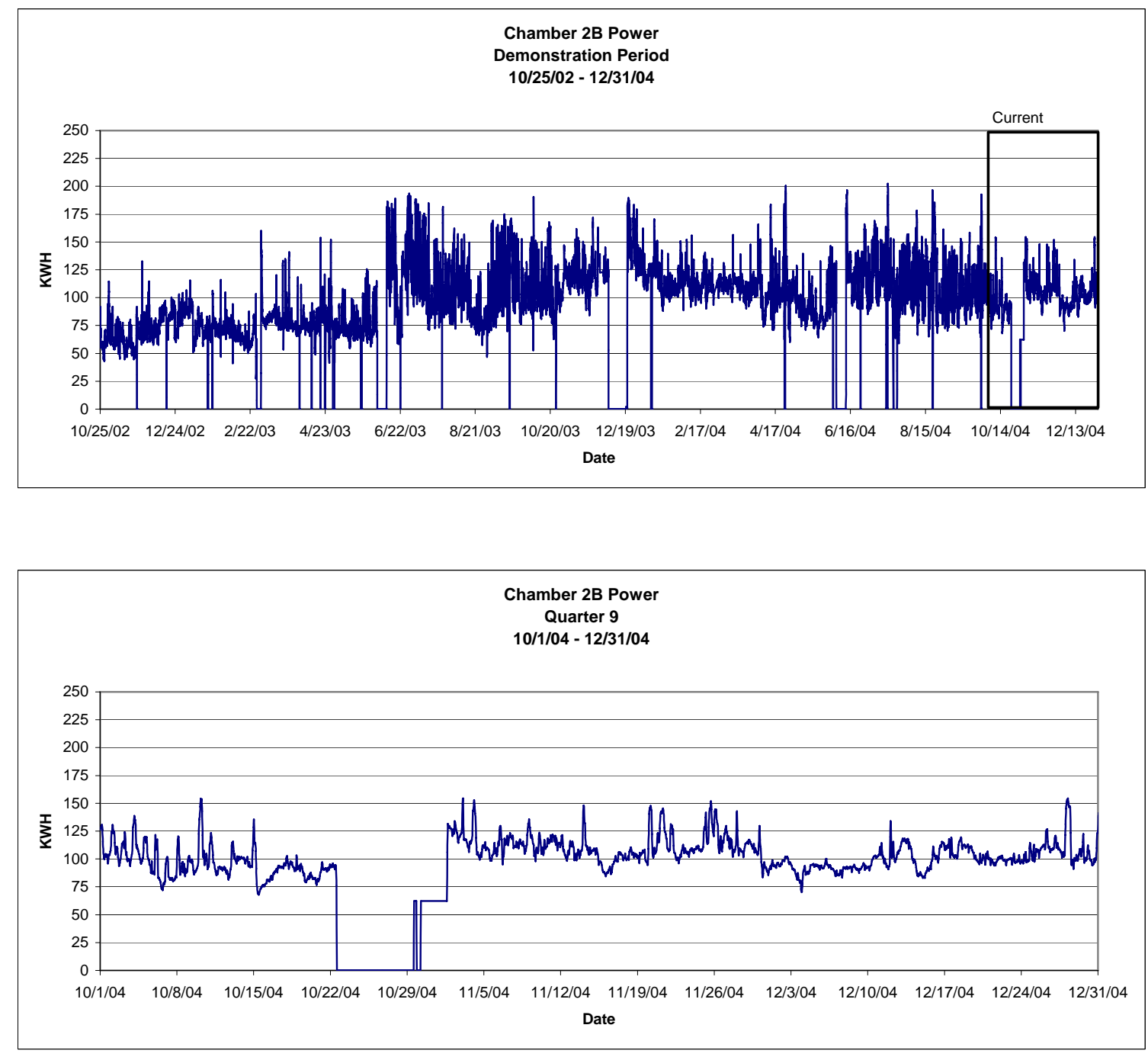
B20 ESP Tabular Data

Transformer/Rectifier Performance Readings

\begin{tabular}{|c|ccc|ccc|ccc|ccc|}
\hline 28-Oct-02 & \multicolumn{10}{|c|}{ Limits: $\mathrm{mA}=700, \mathrm{kV}=45, \mathrm{spm}=12$} \\
\hline Chamber & \multicolumn{3}{|c|}{ Field 1 } & \multicolumn{3}{c|}{ Field 2 } & \multicolumn{3}{c|}{ Field 3 } & \multicolumn{3}{c|}{ Field 4 } \\
& $\mathrm{mA}$ & $\mathrm{kV}$ & $\mathrm{spm}$ & $\mathrm{mA}$ & $\mathrm{kV}$ & $\mathrm{spm}$ & $\mathrm{mA}$ & $\mathrm{kV}$ & $\mathrm{spm}$ & $\mathrm{mA}$ & $\mathrm{kV}$ & $\mathrm{spm}$ \\
\hline 1A & -- & -- & -- & 320 & 45.6 & 11 & 705 & 48.4 & 2 & 705 & 50.3 & 0 \\
1B & -- & -- & -- & 254 & 46.9 & 11 & 711 & 45 & 11 & 711 & 45.6 & 2 \\
2A & -- & -- & -- & 432 & 53.6 & 13 & 320 & 48.4 & 12 & 569 & 47.6 & 12 \\
2B & -- & -- & -- & 361 & 47.2 & 12 & 645 & 42.2 & 11 & 592 & 44.8 & 10 \\
\hline
\end{tabular}

\begin{tabular}{|c|ccc|ccc|ccc|ccc|}
\hline 29-Oct-02 & \multicolumn{10}{c|}{ Limits: $\mathrm{mA}=700, \mathrm{kV}=45, \mathrm{spm}=12$} \\
\hline Chamber & \multicolumn{3}{|c|}{ Field 1 } & \multicolumn{3}{c|}{ Field 2 } & \multicolumn{3}{c|}{ Field 3 } & \multicolumn{3}{c|}{ Field 4 } \\
& mA & kV & spm & mA & kV & spm & mA & kV & spm & mA & kV & spm \\
\hline 1A & -- & -- & -- & 296 & 45.4 & 12 & 705 & 47.2 & 0 & 705 & 50.5 & 0 \\
1B & -- & -- & -- & 284 & 48.7 & 13 & 569 & 45.6 & 12 & 684 & 47 & 13 \\
2A & -- & -- & -- & 409 & 54 & 11 & 284 & 50.2 & 12 & 699 & 50.7 & 11 \\
2B & -- & -- & -- & 391 & 49.2 & 11 & 664 & 43.8 & 12 & 711 & 46.2 & 10 \\
\hline
\end{tabular}

\begin{tabular}{|c|ccc|ccc|ccc|ccc|}
\hline 30-Oct-02 & \multicolumn{10}{c|}{ Limits: $\mathrm{mA}=700, \mathrm{kV}=45, \mathrm{spm}=12$} \\
\hline Chamber & \multicolumn{3}{|c|}{ Field 1 } & \multicolumn{3}{c|}{ Field 2 } & \multicolumn{1}{c|}{ Field 3 } & \multicolumn{3}{c|}{ Field 4 } \\
& $\mathrm{mA}$ & $\mathrm{kV}$ & $\mathrm{spm}$ & $\mathrm{mA}$ & $\mathrm{kV}$ & $\mathrm{spm}$ & $\mathrm{mA}$ & $\mathrm{kV}$ & $\mathrm{spm}$ & $\mathrm{mA}$ & $\mathrm{kV}$ & $\mathrm{spm}$ \\
\hline 1A & -- & -- & -- & 320 & 40.4 & 12 & 711 & 47.9 & 1 & 705 & 50.8 & 0 \\
1B & -- & -- & -- & 260 & 49.2 & 11 & 652 & 47.3 & 11 & 703 & 47.3 & 10 \\
2A & -- & -- & -- & 503 & 53.8 & 12 & 343 & 50.8 & 12 & 705 & 52 & 3 \\
2B & -- & -- & -- & 260 & 48 & 14 & 592 & 45.7 & 11 & 675 & 48.6 & 12 \\
\hline
\end{tabular}

\begin{tabular}{|c|ccc|ccc|ccc|ccc|}
\hline 22-Nov-02 & \multicolumn{10}{c|}{ Limits: $\mathrm{mA}=700, \mathrm{kV}=65, \mathrm{spm}=50$ for F2 and 12 for F3 and F4 } \\
\hline Chamber & \multicolumn{3}{|c|}{ Field 1 } & \multicolumn{3}{c|}{ Field 2 } & \multicolumn{3}{c|}{ Field 3 } & \multicolumn{3}{c|}{ Field 4 } \\
& $\mathrm{mA}$ & $\mathrm{kV}$ & $\mathrm{spm}$ & $\mathrm{mA}$ & $\mathrm{kV}$ & $\mathrm{spm}$ & $\mathrm{mA}$ & $\mathrm{kV}$ & $\mathrm{spm}$ & $\mathrm{mA}$ & $\mathrm{kV}$ & $\mathrm{spm}$ \\
\hline 1A & -- & -- & -- & 332 & 46.7 & 49 & 664 & 48.1 & 11 & 705 & 54.1 & 3 \\
1B & -- & -- & -- & 278 & 51.3 & 50 & 557 & 49.1 & 12 & 213 & 43.2 & 11 \\
2A & -- & -- & -- & 361 & 51.8 & 50 & 284 & 44.7 & 12 & 592 & 50.9 & 12 \\
2B & -- & -- & -- & 367 & 50.9 & 49 & 391 & 49.5 & 12 & 616 & 46.6 & 12 \\
\hline
\end{tabular}




\begin{tabular}{|c|c|c|c|c|c|c|c|c|c|c|c|c|c|c|c|}
\hline & \multicolumn{15}{|c|}{ 1B CHAMBER } \\
\hline \multirow[t]{2}{*}{ Date } & \multirow[t]{2}{*}{ Time } & \multirow{2}{*}{$\begin{array}{c}\text { Inlet } \\
\text { Temp } \\
\text { (F) }\end{array}$} & \multicolumn{3}{|c|}{ 1ST FIELD\| } & \multicolumn{3}{|c|}{ 2ND FIELD } & \multicolumn{3}{|c|}{ 3RD FIELD } & \multicolumn{3}{|c|}{ 4TH FIELD } & \multirow{2}{*}{$\begin{array}{l}\text { ave } m A \text { for } \\
\mathrm{AH} \text { Chamb }\end{array}$} \\
\hline & & & $\mathrm{mA}$ & $\mathrm{kV}$ & spmll & $\mathrm{mA}$ & $\mathrm{kV}$ & spm & $\mathrm{mA}$ & $\mathrm{kV}$ & spm & $\mathrm{mA}$ & $\mathrm{kV}$ & spm & \\
\hline $11 / 22 / 2002$ & 9:00 AM & & off & & & 190 & 51 & 12 & 480 & 49.4 & 12 & 379 & 47.7 & 12 & 349.7 \\
\hline & $11: 10$ AM & & & & & 278 & 51.3 & 50 & 557 & 49.1 & 12 & 213 & 43.2 & 11 & 349.3 \\
\hline $11 / 23 / 2002$ & $18: 00$ pm & & & & & 346 & 53.5 & 50 & 705 & 52.1 & 2 & 705 & 53.3 & 0 & 585.3 \\
\hline $1 / 6 / 2003$ & & & 575 & & & 570 & & & 705 & & & 701 & & & 658.7 \\
\hline began burning & oybeans a & 600 to & 00 ton & s/day & & & & & & & & & & & \\
\hline $1 / 9 / 2003$ & & 309.0 & 94 & 57.3 & & 379 & 50.4 & & 468 & 48.4 & & 420 & 48.5 & & 422.3 \\
\hline $1 / 10 / 2003$ & & 303.0 & 112 & 62.4 & & 400 & 53.4 & & 509 & 52 & & 569 & 53.6 & & 492.7 \\
\hline stopped burni & soybeans & & & & & & & & & & & & & & \\
\hline $1 / 13 / 2003$ & & 297.0 & 302 & 58.4 & & 581 & 50.8 & & 717 & 50.2 & & 711 & 51.4 & & 669.7 \\
\hline $1 / 13 / 2003$ & & & 456 & 67.1 & 99 & 616 & 51.7 & 50 & 723 & 49.6 & 6 & 705 & 51.4 & 1 & 681.3 \\
\hline $1 / 14 / 2003$ & 07:30am & 300.0 & 124 & 58.1 & 99 & 332 & 53.7 & 50 & 509 & 50.9 & 12 & 557 & 52.8 & 11 & 466.0 \\
\hline $1 / 15 / 2003$ & 07:30am & 305.0 & 130 & 60.7 & 100 & 373 & 53.4 & 50 & 498 & 50.6 & 12 & 681 & 53.3 & 11 & 517.3 \\
\hline $\begin{array}{l}\text { inspected and } \\
\text { Burning soybe }\end{array}$ & $\begin{array}{l}\text { epaired com } \\
\text { ns at lower } r\end{array}$ & $\begin{array}{l}\text { ipartmen } \\
\text { rate } 60-2\end{array}$ & $\begin{array}{l}\text { ts } 4 \text { ar } \\
00 \text { ton }\end{array}$ & $\begin{array}{l}\text { nd } 11 \text { o } \\
\text { is/day }\end{array}$ & ollecti & ing pla & te rap & er sh & fts $1 /$ & 9/2003 & & & & & \\
\hline $1 / 20 / 2003$ & 07:30am & 298.0 & 71 & 60.9 & 92 & 379 & 52.5 & 49 & 397 & 48.9 & 12 & 622 & 52.6 & 11 & 466.0 \\
\hline $1 / 22 / 2003$ & plant trippe & d@14 & $40 \mathrm{CT}$ & back & on line & at $\mathrm{mi}$ & dnight & & & & & & & & \\
\hline $1 / 23 / 2003$ & & 296.0 & 94 & 57 & 99 & 343 & 48.7 & 52 & 486 & 47.6 & 12 & 640 & 50.2 & 8 & 489.7 \\
\hline $1 / 26 / 2003$ & & 296.0 & 94 & 55.5 & 100 & 462 & 47.5 & 49 & 492 & 48.7 & 12 & 604 & 48.4 & 11 & 519.3 \\
\hline $1 / 28 / 2003$ & 7:30 AM & 300.0 & 231 & 59.4 & 62.5 & 521 & 49.5 & 49 & 640 & 49.7 & 11 & 723 & 51.9 & 12 & 628.0 \\
\hline & $15: 30$ pm & 304.0 & 189 & 50.8 & 100 & 468 & 50.3 & 53 & 616 & 50.3 & 11 & 723 & 50.2 & 10 & 602.3 \\
\hline $1 / 28 / 2003$ & spark limit s & setpoint & ncrea & sed in 2 & ?nd an & d 3rd & fields t & $99 \mathrm{~s}$ & om & & & & & & \\
\hline $1 / 29 / 2003$ & 7:30 AM & 303.0 & 130 & 58.1 & 99 & 498 & 49.8 & 101 & 735 & 50.1 & 95 & 622 & 48.2 & 4 & 618.3 \\
\hline $1 / 30 / 2003$ & 7:30 AM & 312.0 & 106 & 52 & 101 & 337 & 41.1 & 102 & 575 & 46.9 & 101 & 652 & 49.2 & 9 & 521.3 \\
\hline $2 / 3 / 2003$ & 7:30 AM & 300.0 & 343 & 60.5 & 99 & 521 & 43.6 & 98 & 711 & 49.8 & 1 & 705 & 51.3 & 1 & 645.7 \\
\hline 2/4/2003 & 7:30 AM & 290.0 & 189 & 58.9 & 99 & 403 & 48.4 & 100 & 687 & 49.3 & 100 & 735 & 51.6 & 5 & 08.3 \\
\hline $2 / 5 / 2003$ & 7:30 AM & 302.0 & 177 & 54.7 & 99 & 468 & 46.4 & 101 & 634 & 49.3 & 100 & 711 & 53 & 83 & 604.3 \\
\hline $2 / 6 / 2003$ & 11:30 AM & & & & & & & & & & & & & & \\
\hline $2 / 6 / 2003$ & $15: 20$ pm & 299.0 & 170 & 61 & 100 & 500 & 51 & 100 & 690 & 51 & 99 & 705 & 55 & 38 & 631.7 \\
\hline & $17: 00 \mathrm{pm}$ & 301.0 & 130 & 58 & 100 & 480 & 50 & 100 & 690 & 50 & 99 & 705 & 53 & 66 & 625.0 \\
\hline $2 / 7 / 2003$ & $8: 15$ AM & 299.0 & 142 & 56 & 100 & 569 & 49 & 100 & 634 & 50 & 100 & 705 & 54 & 25 & 636.0 \\
\hline & 12:05 PM & & & & & & & & & & & & & & \\
\hline & $16: 00$ pm & 313.0 & 83 & 56 & 100 & 355 & 43 & 100 & 569 & 45 & 101 & 598 & 48 & 54 & 507.3 \\
\hline 2/8/2003 & $3: 00$ & 288.0 & 177 & 58 & 99 & 480 & 49 & 102 & 687 & 49 & 78 & 705 & 51 & 0 & 624.0 \\
\hline & $4: 42$ & 256.0 & 527 & & 3 & 705 & & 0 & 707 & & 0 & 707 & & 0 & 706.3 \\
\hline & $12: 00$ & 301.0 & 142 & 60 & 100 & 426 & 51 & 101 & 640 & 49 & 100 & 705 & 53 & 0 & 590.3 \\
\hline & 19:00 & 308.0 & 284 & 61 & 98 & 474 & 50 & 100 & 711 & 50 & 13 & 705 & 52 & 0 & 630.0 \\
\hline 2/9/2003 & $10: 00$ & 299.0 & 237 & 63 & 100 & 652 & 52 & 98 & 711 & 52 & 11 & 711 & 50 & 0 & 691.3 \\
\hline npoarily ra & TR curre & t limit se & tpoints & when & comp & artme & ts we & e not & at 100 & spm & $\max w$ & as 10 & $00 \mathrm{~mA}$ & & \\
\hline & $13: 00$ & 313.0 & 130 & 54 & 100 & 430 & 49 & 100 & 570 & 49 & 100 & 806 & 51 & 100 & 602.0 \\
\hline & $14: 45$ & 315.0 & 124 & 56 & 99 & 450 & 49 & 99 & 628 & 49 & 100 & 705 & 51 & 2 & 594.3 \\
\hline & $17: 00$ & 308.0 & 106 & 60 & 99 & 533 & 50 & 99 & 509 & 44 & 100 & 705 & 52 & 0 & 582.3 \\
\hline $2 / 10 / 2003$ & $10: 00$ & 292.0 & 142 & 55 & 101 & 492 & 47 & 99 & 616 & 49 & 97 & 705 & 54 & 53 & 604.3 \\
\hline & $19: 10$ & 300.0 & 201 & 63 & 89 & 438 & 50 & 101 & 699 & 50 & 86 & 711 & 53 & 1 & 616.0 \\
\hline $2 / 11 / 2003$ & $8: 45$ & 308.0 & 184 & 61 & 100 & 379 & 49 & 101 & 604 & 48 & 100 & 705 & 51 & 225 & 562.7 \\
\hline $2 / 12 / 2003$ & $7: 30$ & 293.0 & 118 & 58.2 & 100 & 361 & 44.8 & 101 & 675 & 49.7 & 100 & 705 & 51.5 & 0 & 580.3 \\
\hline $2 / 12 / 2003$ & $10: 40$ & 296.0 & 166 & 57 & 100 & 438 & 52 & 101 & 646 & 51 & 100 & 687 & 53 & 96 & 590.3 \\
\hline Each field was & ndividually $\mathrm{p}$ & ower off & rappe & d start & ing wit & th \#2, & $\neq 3, \# 4$, & and the & en 1st & ield & & & & & \\
\hline IIncreased soy & ean burn rate & e to 500 & ton/da & ay on 1 & 3th & & & & & & & & & & \\
\hline & $17: 00$ & 308.0 & 332 & 64 & 99 & 474 & 46 & 99 & 705 & 49 & 0 & 705 & 49 & 0 & 628.0 \\
\hline 2/13/2003 & $7: 30$ & 302.0 & 142 & 53.7 & 100 & 397 & 48.7 & 100 & 616 & 49.8 & 100 & 634 & 49.5 & 100 & 549.0 \\
\hline $2 / 16 / 2003$ & $7: 30$ & 296.0 & 189 & 60.2 & 99 & 450 & 46.7 & 100 & 521 & 49.1 & 101 & 515 & 44.6 & 50 & 495.3 \\
\hline $2 / 19 / 2003$ & $7: 30$ & & 118 & 55.7 & 99 & 320 & 46.9 & 99 & 616 & 49.7 & 99 & 640 & 49.5 & 99 & 525.3 \\
\hline $2 / 21 / 2003$ & $7: 30$ & & 154 & 60.8 & 99 & 343 & 50.8 & 99 & 563 & 50.7 & 99 & 675 & 53.5 & 100 & 527.0 \\
\hline $2 / 24 / 2003$ & $7: 30$ & & 189 & 63.5 & 100 & 361 & 53.1 & 100 & 592 & 52.7 & 101 & 711 & 54.7 & 8 & 554.7 \\
\hline Plant down for & er was & replacec & first $s$ & section & of coll & lecting & plate & apper & shaft & and $o$ & boar & beari & ing. $\mathrm{R}$ & appec & plates \\
\hline $3 / 3 / 2003$ & $9: 00$ & & 901 & 63 & $101 \|$ & 705 & 49 & 0 & 711 & 43.7 & 0 & 705 & 43 & 0 & 707.0 \\
\hline & $14: 31$ & & 824 & 65 & 6 & 705 & 49 & 0 & 705 & 44 & 0 & 705 & 43 & 0 & 705.0 \\
\hline & 18:35 & & 723 & 62 & 99 & 705 & 50 & 0 & 705 & 46 & 0 & 705 & 45 & 0 & 705.0 \\
\hline & $20: 12$ & & 474 & 63 & 93 & 705 & 52 & 1 & 705 & 47 & 0 & 705 & 47 & 0 & 705.0 \\
\hline & $23: 42$ & & 346 & 61 & 78 & 705 & 52 & 0 & 705 & 48 & 0 & 711 & 48 & 0 & 707.0 \\
\hline $3 / 4 / 2003$ & $7: 20$ & & 296 & 64 & 7 & 681 & 51 & 1 & 705 & 50 & 0 & 705 & 49 & 0 & 697.0 \\
\hline
\end{tabular}


2A CHAMBER

\begin{tabular}{|c|c|c|c|c|c|c|c|c|c|c|c|c|c|c|}
\hline \multirow[t]{2}{*}{ Date } & \multirow[b]{2}{*}{$\mathrm{mA}$} & \multicolumn{2}{|c|}{ 1ST FIEL } & \multirow{2}{*}{$\begin{array}{l}\text { Inlet } \\
\text { |Temp } \\
\text { (F) }\end{array}$} & \multicolumn{3}{|c|}{ 2ND FIELD } & \multicolumn{3}{|c|}{ 3RD FIELD } & \multicolumn{3}{|c|}{ 4TH FIELD } & \multirow{2}{*}{$\begin{array}{l}\text { ave mA AH } \\
\text { chamber }\end{array}$} \\
\hline & & $\mathrm{kV}$ & $\mathrm{spm}$ & & $\mathrm{mA}$ & $\mathrm{kV}$ & spm & $\mathrm{mA}$ & $\mathrm{kV}$ & spm & $\mathrm{mA}$ & $\mathrm{kV}$ & spm & \\
\hline $11 / 22 / 2002$ & off & & & & 296 & 53.8 & 12 & 249 & 57.8 & 12 & 521 & 52 & 12 & 355.3 \\
\hline $11 / 22 / 2002$ & & & & & 361 & 51.8 & 50 & 284 & 44.7 & 12 & 592 & 50.9 & 12 & 412.3 \\
\hline $11 / 23 / 2002$ & & & & & 438 & 56.8 & 50 & 515 & 52.5 & 11 & 705 & 52.7 & 1 & 552.7 \\
\hline $1 / 6 / 2003$ & 23 & & & & 672 & & & 546 & & & 705 & & & 641.0 \\
\hline $1 / 9 / 2003$ & 0 & 0 & & 268 & 349 & 58.4 & & 260 & 51.3 & & 575 & 56.1 & & 394.7 \\
\hline $1 / 10 / 2003$ & 124 & 65 & & 263 & 569 & 56.5 & & 379 & 53 & & 705 & 55.2 & & 551.0 \\
\hline $1 / 13 / 2003$ & 492 & 65 & & 255 & 699 & 54.5 & & 652 & 54.1 & & 705 & 48.9 & & 685.3 \\
\hline $1 / 13 / 2003$ & 527 & 52.6 & 3 & & 711 & 54.5 & 42 & 664 & 54.8 & 12 & 705 & 48.4 & 1 & 693.3 \\
\hline $1 / 14 / 2003$ & 94 & 65.1 & 0 & 255 & 557 & 57.7 & 49 & 343 & 52.3 & 11 & 586 & 52.7 & 11 & 495.3 \\
\hline $1 / 15 / 2003$ & 136 & 65 & 2 & 260 & 557 & 55.2 & 51 & 415 & 52 & 11 & 687 & 52.7 & 2 & 553.0 \\
\hline $1 / 19 / 2003$ & & & & & & & & & & & & & & \\
\hline $1 / 20 / 2003$ & 201 & 65.2 & 0 & 249 & 586 & 52 & 46 & 415 & 51.2 & 12 & 705 & 51.5 & 0 & 568.7 \\
\hline $1 / 23 / 2003$ & 249 & 65 & 1 & 253 & 699 & 57.7 & 34 & 403 & 50.5 & 13 & 705 & 51.3 & 0 & 602.3 \\
\hline $1 / 26 / 2003$ & 195 & 65.1 & 0 & 251 & 640 & 55.7 & 45 & 403 & 50.9 & 11 & 705 & 52 & 8 & 582.7 \\
\hline $1 / 28 / 2003$ & 201 & 65 & 0 & 264 & 723 & 58.1 & 27 & 403 & 51.3 & 12 & 705 & 52.5 & 0 & 610.3 \\
\hline $1 / 28 / 2003$ & 136 & 65.1 & 0 & 259 & 664 & 53.9 & 51 & 415 & 52.8 & 12 & 705 & 53.5 & 0 & 594.7 \\
\hline $1 / 29 / 2003$ & 183 & 65.1 & 4 & 255 & 705 & 59.2 & 11 & 438 & 59.2 & 100 & 705 & 52.3 & 0 & 616.0 \\
\hline $1 / 30 / 2003$ & 189 & 65 & 4 & 267 & 711 & 58.6 & 45 & 373 & 50.8 & 100 & 705 & 52 & 0 & 596.3 \\
\hline $2 / 3 / 2003$ & 367 & 65 & 3 & 255 & 723 & 54.5 & 8 & 563 & 52.7 & 100 & 705 & 49.8 & 0 & 663.7 \\
\hline $2 / 4 / 2003$ & 171 & 65 & 1 & 262 & 705 & 58.8 & 8 & 432 & 52.8 & 100 & 705 & 52.5 & 0 & 614.0 \\
\hline $2 / 5 / 2003$ & 94 & 65.2 & 2 & 265 & 581 & 54.8 & 102 & 343 & 50 & 101 & 675 & 51.7 & 52 & 533.0 \\
\hline $2 / 6 / 2003$ & 130 & 65 & 5 & 265 & 711 & 58 & 94 & 379 & 52 & 98 & 705 & 55 & 1 & 598.3 \\
\hline $2 / 6 / 2003$ & 140 & 65 & 0 & 264 & 699 & 59 & 99 & 380 & 52 & 100 & 711 & 55 & 0 & 596.7 \\
\hline 2/7/2003 & 83 & 65 & 0 & 261 & 634 & 58 & 100 & 355 & 52 & 51 & 705 & 55 & 32 & 564.7 \\
\hline 2/7/2003 & 142 & 65 & 1 & 275 & 610 & 54 & 100 & 332 & 48 & 100 & 711 & 52 & 4 & 551.0 \\
\hline $2 / 8 / 2003$ & 213 & 65 & 3 & 259 & 705 & 58 & 22 & 616 & 56 & 101 & 705 & 51 & 0 & 675.3 \\
\hline 2/8/2003 & 496 & & 0 & 238 & 705 & & 0 & 705 & & 0 & 706 & & 0 & 705.3 \\
\hline 2/8/2003 & 106 & 65 & 3 & 269 & 563 & 56 & 99 & 379 & 51 & 100 & 711 & 53 & 8 & 551.0 \\
\hline $2 / 8 / 2003$ & 177 & 65 & 1 & 264 & 705 & 58 & 11 & 426 & 51 & 100 & 705 & 52 & 0 & 612.0 \\
\hline 2/9/2003 & 166 & 65 & 0 & 260 & 705 & 58 & 12 & 474 & 51 & 99 & 705 & 50 & 0 & 628.0 \\
\hline 2/9/2003 & 189 & 65 & 0 & 278 & 680 & 55 & 87 & 379 & 49 & 100 & 800 & 53 & 1 & 619.7 \\
\hline 2/9/2003 & 166 & 65 & 0 & 278 & 687 & 54 & 82 & 367 & 49 & 100 & 705 & 52 & 0 & 586.3 \\
\hline $2 / 9 / 2003$ & 124 & 65 & 6 & 273 & 640 & 56 & 100 & 349 & 50 & 100 & 711 & 52 & 1 & 566.7 \\
\hline $2 / 10 / 2003$ & 106 & 65 & 0 & 254 & 664 & 56 & 100 & 415 & 51 & 100 & 705 & 53 & 0 & 594.7 \\
\hline $2 / 10 / 2003$ & 130 & 65 & 0 & 257 & 705 & 60 & 40 & 391 & 49 & 101 & 705 & 52 & 0 & 600.3 \\
\hline 2/11/2003 & 177 & 65 & 0 & 265 & 711 & 57 & 67 & 415 & 50 & 100 & 705 & 52 & 0 & 610.3 \\
\hline 2/12/2003 & 166 & 65 & 15 & 252 & 634 & 55.9 & 98 & 373 & 49.4 & 99 & 711 & 52.4 & 69 & 572.7 \\
\hline 2/12/2003 & 94 & 65 & 0 & 262 & 664 & 55 & 92 & 420 & 53 & 100 & 705 & 54 & 0 & 596.3 \\
\hline 2/12/2003 & 177 & 65 & 28 & 267 & 705 & 57 & 1 & 533 & 52 & 100 & 705 & 49 & 0 & 647.7 \\
\hline 2/13/2003 & 85 & 65.1 & 0 & 270 & 634 & 58.4 & 99 & 379 & 47.9 & 100 & 705 & 53.8 & 28 & 572.7 \\
\hline 2/16/2003 & 189 & 65 & 0 & 251 & 652 & 56.5 & 29 & 462 & 53.2 & 100 & 711 & 52.2 & 0 & 608.3 \\
\hline 2/19/2003 & 112 & 65 & 0 & & 509 & 47.3 & 100 & 320 & 50.4 & 101 & 675 & 52.5 & 79 & 501.3 \\
\hline 2/21/2003 & 94 & 65.1 & 3 & & 432 & 50.3 & 97 & 290 & 52.5 & 100 & 669 & 47.7 & 98 & 463.7 \\
\hline $2 / 24 / 2003$ & 130 & 65.1 & 0 & & 699 & 59.7 & 98 & 373 & 62 & 99 & 711 & 55.6 & 0 & 594.3 \\
\hline \multicolumn{15}{|c|}{ line, pulsed bags at low load } \\
\hline $3 / 3 / 2003$ & 1114 & 63 & \#\# & & 705 & 50 & 0 & 705 & 53 & 0 & 711 & 43 & 0 & 707.0 \\
\hline & 966 & 65 & 0 & & 711 & 51 & 0 & 705 & 53 & 0 & 711 & 43 & 0 & 709.0 \\
\hline & 758 & 65 & 1 & & 705 & 51 & 0 & 705 & 54 & 0 & 705 & 44 & 0 & 705.0 \\
\hline & 604 & 65 & 1 & & 705 & 52 & 3 & 705 & 55 & 9 & 711 & 46 & 0 & 707.0 \\
\hline & 509 & 65 & 3 & & 705 & 54 & 0 & 687 & 53 & 89 & 705 & 47 & 0 & 699.0 \\
\hline $3 / 4 / 2003$ & 367 & 65 & 0 & & 705 & 56 & 7 & 509 & 50 & 98 & 705 & 48 & 0 & 639.7 \\
\hline
\end{tabular}




\begin{tabular}{|c|c|c|c|c|c|c|c|c|c|c|c|c|c|c|c|}
\hline & & & & & & & B & Al & & & & & & & \\
\hline Date & Time & $\begin{array}{l}\text { Inlet } \\
\text { Temp }\end{array}$ & & 1ST F & IELD & & $2 N D F$ & IELD || & & $3 R D F$ & IELD || & & $4 \mathrm{TH} \mathrm{FI}$ & ELD & d| ave IIA \\
\hline & & & $\mathrm{mA}$ & $\mathrm{kV}$ & spm & $\mathrm{mA}$ & $\mathrm{kV}$ & spm & $\mathrm{mA}$ & $\mathrm{kV}$ & $\mathrm{spm}$ & $\mathrm{mA}$ & $\mathrm{kV}$ & spm & $\mathrm{AH}$ chamber \\
\hline $11 / 22 / 2002$ & 9:00 AM & & off & & & 320 & 48.9 & 12 & 545 & 48.6 & 12 & 509 & 46.4 & 12 & 458 \\
\hline & $11: 10$ AM & & & & & 367 & 50.9 & 49 & 391 & 49.5 & 12 & 616 & 46.6 & 12 & 458 \\
\hline $11 / 23 / 2002$ & $18: 00$ pm & & & & & 320 & 53.3 & 50 & 705 & 51.2 & 1 & 705 & 51.9 & 5 & 577 \\
\hline $1 / 6 / 2003$ & & & 85 & & & 491 & & & 708 & & & 705 & & & 635 \\
\hline began burning & bybeans at $6 c$ & 000 to 700 & tons/d & & & & & & & & & & & & \\
\hline $1 / 9 / 2003$ & & 303.0 & 35 & 47.1 & & 296 & 52.7 & & 533 & 50.5 & & 521 & 51.6 & & 450 \\
\hline $1 / 10 / 2003$ & & 303.0 & 94 & 49 & & 374 & 56.5 & & 509 & 53.9 & & 503 & 51.6 & & 462 \\
\hline stopped burnin & soybeans & & & & & & & & & & & & & & \\
\hline $1 / 13 / 2003$ & & 292.0 & 94 & 50 & & 409 & 50.2 & & 598 & 51.6 & & 711 & 51.3 & & 573 \\
\hline $1 / 13 / 2003$ & & & 94 & 52.6 & 99 & 486 & 51.3 & 51 & 610 & 52.9 & 12 & 634 & 50.5 & 12 & 577 \\
\hline $1 / 14 / 2003$ & 07:30am & 295.0 & 106 & 48.6 & 101 & 320 & 50.4 & 48 & 462 & 53 & 11 & 486 & 50.4 & 11 & 423 \\
\hline $1 / 15 / 2003$ & 07:30am & 298.0 & 88 & 49.3 & 99 & 420 & 55.3 & 51 & 557 & 53.9 & 12 & 581 & 48.3 & 12 & 519 \\
\hline inspected and & paired comp & partments & and 3 & 11 colle & cting $\mathrm{p}$ & late ra & pper sh & afts $1 / 1$ & $19 / 200$ & & & & & & \\
\hline Burning soybe & s at lower rat & te $60-200$ & tons/d & & & & & & & & & & & & \\
\hline $1 / 20 / 2003$ & 07:30am & 285.0 & 59 & 46.9 & 99 & 355 & 52.7 & 50 & 616 & 49.7 & 12 & 669 & 52.7 & 12 & 547 \\
\hline $1 / 22 / 2003$ & plant trippec & d @ 14:4 & CT b & lack on & line at & midnic & & & & & & & & & \\
\hline $1 / 23 / 2003$ & & 287.0 & 59 & 48.8 & 97 & 379 & 52 & 51 & 669 & 51.3 & 12 & 675 & 51.5 & 8 & 574 \\
\hline $1 / 26 / 2003$ & & 296.0 & 71 & 49.1 & 98 & 385 & 50.1 & 49 & 592 & 48.2 & 12 & 521 & 49.8 & 10 & 499 \\
\hline $1 / 28 / 2003$ & $7: 30 \mathrm{AM}$ & 303.0 & 53 & 49.1 & 98 & 401 & 53.2 & 50 & 581 & 52 & 10 & 634 & 52.8 & 10 & 539 \\
\hline & $15: 30 \mathrm{pm}$ & 291.0 & 83 & 49.9 & 100 & 415 & 54 & 51 & 616 & 50.9 & 12 & 575 & 52.7 & 10 & 535 \\
\hline $1 / 28 / 2003$ & spark limit s & setpoint ir & crease & ed in2nc & $d$ and 3 & rd fielc & s to 99 & spm & & & & & & & \\
\hline $1 / 29 / 2003$ & $7: 30 \mathrm{AM}$ & 288.0 & 94 & 49 & 99 & 450 & 53 & 99 & 640 & 53.4 & 96 & 705 & 53.7 & 36 & 598 \\
\hline $1 / 30 / 2003$ & 7:30 AM & 302.0 & 118 & 51.9 & 99 & 308 & 50.6 & 101 & 705 & 50.8 & 99 & 711 & 52 & 36 & 575 \\
\hline $2 / 3 / 2003$ & 7:30 AM & 293.0 & 112 & 46.7 & 100 & 450 & 48.6 & 100 & 604 & 50.6 & 100 & 729 & 50.6 & 20 & 594 \\
\hline $2 / 4 / 2003$ & $7: 30 \mathrm{AM}$ & 301.0 & 71 & 49.7 & 101 & 438 & 50.9 & 101 & 723 & 51.3 & 95 & 551 & 43.9 & 95 & 571 \\
\hline 2/5/2003 & 7:30 AM & 303.0 & 77 & 46.9 & 100 & 373 & 46.2 & $101 \|$ & 628 & 49.9 & $100 \|$ & 664 & 49.6 & 97 & 555 \\
\hline $2 / 6 / 2003$ & $11: 30 \mathrm{AM}$ & & & & & & & & & & & & & & \\
\hline $2 / 6 / 2003$ & $15: 20$ pm & 300.0 & 70 & 50 & 99 & 280 & 50 & 101 & 695 & 49 & 100 & 604 & 51 & 65 & 526 \\
\hline & $17: 00$ pm & 302.0 & 40 & 54 & 100 & 390 & 52 & 100 & 581 & 51 & 100 & 580 & 53 & 92 & 517 \\
\hline 2/7/2003 & $\begin{array}{l}\text { 8:15 AM } \\
12: 05 \text { PM }\end{array}$ & 299.0 & 106 & 48 & 99 & 391 & 54 & 99 & 640 & 51 & 100 & 735 & 52 & 61 & 589 \\
\hline & $16: 00 \mathrm{pm}$ & 307.0 & 94 & 47 & 99 & 415 & 48 & 101 & 581 & 48 & 99 & 705 & 49 & 36 & 567 \\
\hline $2 / 8 / 2003$ & 3:00 & 293.0 & 77 & 51 & 98 & 486 & 54 & 96 & 699 & 51 & 88 & 711 & 51 & 1 & 632 \\
\hline & $4: 42$ & 265.0 & 92 & & 98 & 663 & & 78 & 707 & & 0 & 706 & & 0 & 692 \\
\hline & $12: 00$ & 307.0 & 94 & 50 & 101 & 379 & 52 & 99 & 652 & 50 & 101 & 711 & 51 & 4 & 581 \\
\hline & 19:00 & 302.0 & 59 & 49 & 98 & 450 & 52 & 99 & 646 & 49 & 97 & 705 & 52 & 15 & 600 \\
\hline $2 / 9 / 2003$ & $10: 00$ & 296.0 & 65 & 49 & 98 & 426 & 77 & $100 \|$ & 515 & 50 & $100 \|$ & 705 & 50 & 21 & 549 \\
\hline tempoarily rais & TR current I & limit setp & ints wl & hen col & npart & ents $\mathrm{n}$ & ere not & at 100 & $\mathrm{spm}$ & $-\max 1$ & was 10 & $000 \mathrm{~mA}$ & & & \\
\hline & $13: 00$ & 315.0 & 94 & 50 & 100 & 272 & 52 & 99 & 580 & $51^{\prime}$ & $100 \|$ & 664 & 50 & 66 & 505 \\
\hline & $14: 45$ & 315.0 & 59 & 49 & 100 & 373 & 53 & 100 & 498 & 48 & 100 & 640 & 48 & 86 & 504 \\
\hline & $17: 00$ & 311.0 & 94 & 47 & 99 & 355 & 46 & 99 & 450 & 46 & 100 & 634 & 46 & 97 & 480 \\
\hline 2/10/2003 & 10:00 & 294.0 & 96 & 51 & 100 & 379 & 54 & 98 & 577 & 51 & 100 & 604 & 43 & 100 & 520 \\
\hline & $19: 10$ & 293.0 & 59 & 53 & 100 & 385 & 54 & 100 & 509 & 49 & 100 & 557 & 48 & 101 & 484 \\
\hline $2 / 11 / 2003$ & $8: 45$ & 301.0 & 59 & 54 & 99 & 355 & 52 & 99 & 557 & 51 & 100 & 551 & 47 & 93 & 488 \\
\hline 2/12/2003 & $7: 30$ & 288.0 & 71 & 47.1 & 99 & 403 & 51.9 & 99 & 498 & 44.5 & 99 & 675 & 50.5 & 99 & 525 \\
\hline $2 / 12 / 2003$ & $10: 40$ & 299.0 & 71 & 50 & 99 & 385 & 52 & $101 \|$ & 486 & 51 & 100 & 569 & 49 & 98 & 480 \\
\hline Each field was & ividually po & ower off ro & pped s & tarting & with \#2 & ,\#3,\#4 & and th & en 1 st & ield & & & & & & \#DIV/O! \\
\hline reased soyb & burn rate & to 500 & /day o & in 13th & & & & & & & & & & & \\
\hline & $17: 00$ & 302.0 & 71 & 48 & 100 & 476 & 52 & 100 & 545 & 51 & 100 & 705 & 50 & 1 & 575 \\
\hline 2/13/2003 & $7: 30$ & 308.0 & 94 & 43.3 & 99 & 391 & 53.8 & $100 \|$ & 563 & 52 & 100 & 652 & 50 & 99 & 535 \\
\hline $2 / 16 / 2003$ & $7: 30$ & 286.0 & 71 & 52.3 & 99 & 397 & 52.2 & 101 & 456 & 51 & 99 & 693 & 51.4 & 98 & 515 \\
\hline 2/19/2003 & $7: 30$ & & 130 & 54.2 & 99 & 367 & 49.8 & 99 & 391 & 50.1 & $101 \|$ & 521 & 50.4 & 99 & 426 \\
\hline $2 / 21 / 2003$ & $7: 30$ & & 53 & 49.1 & 99 & 243 & 48.1 & 101 & 438 & 46.3 & 100 & 616 & 50.5 & 100 & 432 \\
\hline $2 / 24 / 2003$ & $7: 30$ & & 59 & 53.4 & 100 & 355 & 54.1 & 99 & 450 & 53.8 & $101 \|$ & 581 & 50.4 & 39 & 462 \\
\hline Plant down for & oiler wash, re & lacec & st sect & ion of $\mathrm{c}$ & :ollectir & g plat & rapper & r shaft & $s$ and $c$ & outboar & rd bear & ing. $R$ & oped a & plate & ff-line, $p$ \\
\hline $3 / 3 / 2003$ & $9: 00$ & & 326 & 50 & 98 & 711 & 53 & 0 & 705 & 45 & 0 & 705 & 44 & 0 & 707 \\
\hline & $14: 31$ & & 166 & 57 & 99 & 705 & 54 & 5 & 705 & 46 & 0 & 711 & 45 & 0 & 707 \\
\hline & $18: 35$ & & 71 & 53 & 98 & 533 & 49 & 100 & 705 & 48 & 0 & 705 & 48 & 0 & 648 \\
\hline & $20: 12$ & & 71 & 50 & 101 & 480 & 51 & 101 & 711 & 49 & 1 & 705 & 49 & 2 & 632 \\
\hline & $23: 42$ & & 118 & 49 & 98 & 462 & 50 & 99 & 699 & 47 & 93 & 711 & 50 & 1 & 624 \\
\hline $3 / 4 / 2003$ & $7: 20$ & & 47 & 57 & 100 & 468 & 48 & 99 & 717 & 50 & 84 & 711 & 51 & 0 & 632 \\
\hline
\end{tabular}




\section{Transformer/Rectifier Performance Readings}

\begin{tabular}{|c|c|c|c|c|c|c|c|c|c|c|c|c|}
\hline 16-Apr-C & & * Limi & $\lg \mathrm{fac}$ & rs hig & lighte & & & & & & & \\
\hline Chamber & & Field & & & Field & & & Field & & & Field 2 & \\
\hline & $\mathrm{mA}$ & kV & spm & $\mathrm{mA}$ & $\mathrm{kV}$ & spm & $\mathrm{mA}$ & $\mathrm{kV}$ & spm & $\mathrm{mA}$ & kV & spm \\
\hline $1 \mathrm{~A}$ & 192 & 58.8 & 98 & 535 & 44 & 19 & 997 & 50.1 & 3 & 1001 & 52.4 & 0 \\
\hline $1 B$ & 464 & 61.4 & $\overline{97}$ & 661 & 48.9 & 19 & 818 & 48.5 & 19 & 1000 & 51.6 & 1 \\
\hline $2 A$ & 600 & 64.8 & 6 & 774 & 50.3 & 19 & 494 & 46.8 & 19 & 995 & 50.3 & 3 \\
\hline $2 B$ & 84 & 48 & 99 & 433 & 49.3 & 19 & 619 & 46.4 & 19 & 591 & 40.6 & 18 \\
\hline
\end{tabular}

\begin{tabular}{|c|c|c|c|c|c|c|c|c|c|c|c|c|}
\hline \multicolumn{2}{|l|}{ 18-May-03 } & \multicolumn{11}{|c|}{ * Limiting factors highlighted } \\
\hline \multirow[t]{2}{*}{ Chamber } & \multicolumn{3}{|c|}{$\begin{array}{l}\text { Field } 1 \\
\end{array}$} & \multicolumn{3}{|c|}{ Field 2} & \multicolumn{3}{|c|}{ Field 3} & \multicolumn{3}{|c|}{$\begin{array}{l}\text { Field } 4 \\
\end{array}$} \\
\hline & $\mathrm{mA}$ & kV & spm & $\mathrm{mA}$ & $\mathrm{kV}$ & spm & $\mathrm{mA}$ & kV & spm & $\mathrm{mA}$ & $\mathrm{kV}$ & spm \\
\hline $1 \mathrm{~A}$ & 138 & 61.5 & 91 & 425 & 44.3 & 19 & 919 & 49 & 18 & 970 & 54.1 & 15 \\
\hline $1 B$ & 328 & 58.1 & 99 & 480 & 47.6 & 19 & 717 & 47.9 & 19 & 811 & 49.1 & 19 \\
\hline $2 \mathrm{~A}$ & 596 & 62.8 & 86 & 584 & 49.1 & 19 & 587 & 49.7 & 19 & 814 & 48.5 & 19 \\
\hline $2 \mathrm{~B}$ & 96 & 49.7 & $\overline{98}$ & 372 & 49 & 19 & 602 & 46 & 19 & 681 & 48.3 & 19 \\
\hline
\end{tabular}

\begin{tabular}{|c|c|c|c|c|c|c|c|c|c|c|c|c|}
\hline \multicolumn{2}{|c|}{ 17-Jun-03 } & \multicolumn{11}{|c|}{ * Limiting factors highlighted } \\
\hline \multirow[t]{2}{*}{ Chamber } & \multicolumn{3}{|c|}{ Field 1} & \multicolumn{3}{|c|}{ Field 2} & \multicolumn{3}{|c|}{ Field 3} & \multicolumn{3}{|c|}{ Field 4} \\
\hline & $\mathrm{mA}$ & $\mathrm{kV}$ & spm & $\mathrm{mA}$ & kV & spm & $\mathrm{mA}$ & $\mathrm{kV}$ & spm & $\mathrm{mA}$ & $\mathrm{kV}$ & spm \\
\hline $1 \mathrm{~A}$ & 128 & 64.4 & 33 & 664 & 47.3 & 19 & 979 & 49.3 & 11 & 997 & 54.7 & 3 \\
\hline 1B & 283 & 59.7 & 99 & 530 & 48.5 & 19 & 788 & 48.4 & 19 & 788 & 48.4 & 19 \\
\hline $2 A$ & 497 & 63.4 & 46 & 770 & 52 & 19 & 645 & 50.4 & 19 & 953 & 50.1 & 10 \\
\hline $2 B$ & 479 & 60.7 & 98 & 620 & 48.7 & 19 & 949 & 48.7 & 14 & 552 & 36.3 & 18 \\
\hline
\end{tabular}


Transformer/Rectifier Performance Readings

\begin{tabular}{|c|c|c|c|c|c|c|c|c|c|c|c|c|}
\hline \multicolumn{2}{|c|}{ 15-Jul-03 } & \multicolumn{11}{|c|}{ * Limiting factors highlighted } \\
\hline \multirow[t]{2}{*}{ Chamber } & \multicolumn{3}{|c|}{ Field 1} & \multicolumn{3}{|c|}{ Field 2} & \multicolumn{3}{|c|}{ Field 3} & \multicolumn{3}{|c|}{ Field 4} \\
\hline & $\mathrm{mA}$ & kV & spm & $\mathrm{mA}$ & kV & spm & $\mathrm{mA}$ & kV & spm & $\mathrm{mA}$ & kV & spm \\
\hline $1 \mathrm{~A}$ & 68 & 63.7 & 47 & 370 & 45.2 & 19 & 751 & 47.7 & 19 & 770 & 52.6 & 19 \\
\hline 1B & 172 & 55.5 & 99 & 319 & 47 & 19 & 537 & 46.1 & 19 & 601 & 48.2 & 19 \\
\hline $2 \mathrm{~A}$ & 260 & 57.8 & 99 & 492 & 49 & 19 & 498 & 49.1 & 19 & 653 & 48.5 & 19 \\
\hline $2 \mathrm{~B}$ & 262 & 57.3 & 99 & 434 & 48.5 & 19 & 720 & 47.2 & 19 & 620 & 47.5 & 19 \\
\hline
\end{tabular}

\begin{tabular}{|c|c|c|c|c|c|c|c|c|c|c|c|c|}
\hline \multicolumn{2}{|c|}{ 15-Aug-03 } & \multicolumn{11}{|c|}{ * Limiting factors highlighted } \\
\hline \multirow[t]{2}{*}{ Chamber } & \multicolumn{3}{|c|}{ Field 1} & \multicolumn{3}{|c|}{ Field 2} & \multicolumn{3}{|c|}{ Field 3} & \multicolumn{3}{|c|}{ Field 4} \\
\hline & $\mathrm{mA}$ & $\mathrm{kV}$ & spm & $\mathrm{mA}$ & $\mathrm{kV}$ & spm & $\mathrm{mA}$ & kV & spm & $\mathrm{mA}$ & kV & spm \\
\hline $1 \mathrm{~A}$ & 116 & 62.3 & 87 & 413 & 44.9 & 19 & 758 & 47.2 & 19 & 806 & 52.1 & 19 \\
\hline $1 B$ & 194 & 56.3 & 99 & 346 & 47.1 & 19 & 566 & 46.1 & 19 & 597 & 47.9 & 19 \\
\hline $2 \mathrm{~A}$ & 324 & 59.3 & 99 & 541 & 49.6 & 19 & 546 & 49.5 & 19 & 665 & 48.2 & 19 \\
\hline $2 \mathrm{~B}$ & 337 & 59 & 99 & 490 & 49.3 & 19 & 765 & 48 & 19 & 660 & 47.8 & 19 \\
\hline
\end{tabular}

\begin{tabular}{|c|c|c|c|c|c|c|c|c|c|c|c|c|}
\hline 15-Sep-C & & * Limi & fac & rs hig & lighte & & & & & & & \\
\hline Chamber & & Field & & & Field & & & Field? & & & Field 2 & \\
\hline & $m A$ & kV & spm & $\mathrm{mA}$ & kV & spm & $\mathrm{mA}$ & kV & spm & $\mathrm{mA}$ & kV & spm \\
\hline $1 \mathrm{~A}$ & 95 & 64.4 & 33 & 456 & 46 & 19 & 848 & 49.1 & 19 & 882 & 54.1 & 19 \\
\hline $1 \mathrm{~B}$ & 195 & 57.1 & 99 & 359 & 47.6 & 19 & 567 & 46.5 & 19 & 632 & 48.9 & 19 \\
\hline $2 \mathrm{~A}$ & 336 & 60.4 & 98 & 552 & 51.5 & 19 & 541 & 50.6 & 19 & 706 & 49.8 & 19 \\
\hline $2 \mathrm{~B}$ & 317 & 59.4 & 99 & 473 & 49.7 & 19 & 738 & 48.5 & 19 & 681 & 47.9 & 19 \\
\hline
\end{tabular}


Transformer/Rectifier Performance Readings

\begin{tabular}{|c|c|c|c|c|c|c|c|c|c|c|c|c|}
\hline $15-$ Oct-0 & & * Limi & $g$ fac & s hig & lighte & & & & & & & \\
\hline Chamber & & Field & & & Field & & & Field & & & Field 2 & \\
\hline & $\mathrm{mA}$ & kV & spm & $\mathrm{mA}$ & kV & spm & $\mathrm{mA}$ & kV & spm & $\mathrm{mA}$ & kV & spm \\
\hline $1 \mathrm{~A}$ & 80 & 62.8 & 81 & 408 & 46.1 & 19 & 771 & 48.9 & 19 & 832 & 53.8 & 19 \\
\hline $1 B$ & 123 & 55.9 & 99 & 330 & 48.6 & 19 & 534 & 47.5 & 19 & 598 & 48.6 & 19 \\
\hline $2 A$ & 345 & 63.9 & 43 & 607 & 53.5 & 19 & 593 & 52.3 & 19 & 787 & 51 & 19 \\
\hline $2 B$ & 273 & 60.5 & 98 & 457 & 50.2 & 19 & 743 & 49.5 & 19 & 688 & 48.7 & 19 \\
\hline
\end{tabular}

\begin{tabular}{|c|c|c|c|c|c|c|c|c|c|c|c|c|}
\hline $15-N o v-0$ & & * Limi & lg fac & s hig & lighte & & & & & & & \\
\hline Chamber & & Field & & & Field & & & Field 3 & & & $\overline{\text { Field } 4}$ & \\
\hline & $\mathrm{mA}$ & $\mathrm{kV}$ & spm & $\mathrm{mA}$ & kV & spm & $\mathrm{mA}$ & kV & spm & $\mathrm{mA}$ & $\mathrm{kV}$ & spm \\
\hline $1 \mathrm{~A}$ & 113 & 64.6 & 24 & 538 & 46.1 & 19 & 927 & 49 & 16 & 970 & 52.7 & 8 \\
\hline $1 B$ & 223 & 58.5 & 99 & 387 & 48.4 & 19 & 576 & 47.4 & 19 & 702 & 49.2 & 19 \\
\hline $2 A$ & 485 & 64.1 & $\overline{42}$ & 753 & 49.1 & 19 & 750 & 49.7 & 18 & 962 & 48.8 & 9 \\
\hline $2 B$ & 379 & 63.7 & 55 & 566 & 49.7 & 19 & 882 & 49.8 & 18 & 764 & 48.4 & 19 \\
\hline
\end{tabular}

\begin{tabular}{|c|c|c|c|c|c|c|c|c|c|c|c|c|}
\hline \multicolumn{2}{|c|}{ 4-Dec-03 } & \multicolumn{11}{|c|}{ * Limiting factors highlighted } \\
\hline \multirow[t]{2}{*}{ Chamber } & \multicolumn{3}{|c|}{ Field 1} & \multicolumn{3}{|c|}{ Field 2} & \multicolumn{3}{|c|}{ Field 3} & \multicolumn{3}{|c|}{ Field 4} \\
\hline & $\mathrm{mA}$ & kV & spm & $\mathrm{mA}$ & $\mathrm{kV}$ & spm & $\mathrm{mA}$ & $\mathrm{kV}$ & spm & $\mathrm{mA}$ & kV & spm \\
\hline $1 \mathrm{~A}$ & 133 & 64.4 & 33 & 566 & 48 & 19 & 942 & 50.7 & 15 & 971 & 54.8 & 8 \\
\hline $1 B$ & 215 & 60.2 & 99 & 435 & 50.5 & 19 & 627 & 49.2 & 18 & 718 & 50.7 & 19 \\
\hline $2 \mathrm{~A}$ & 427 & 65 & 3 & 791 & 54 & 19 & 786 & 54.5 & 19 & 977 & 52 & 8 \\
\hline $2 B$ & 301 & 64.2 & 29 & 567 & 51 & 18 & 903 & 51.6 & 18 & 688 & 44.7 & 18 \\
\hline
\end{tabular}




\section{Transformer/Rectifier Performance Readings}

\begin{tabular}{|c|c|c|c|c|c|c|c|c|c|c|c|c|}
\hline \multicolumn{2}{|c|}{$26-F e b-04$} & \multicolumn{11}{|c|}{ * Limiting factors highlighted } \\
\hline \multirow[t]{2}{*}{ Chamber } & \multicolumn{3}{|c|}{ Field 1} & \multicolumn{3}{|c|}{ Field 2} & \multicolumn{3}{|c|}{ Field 3} & \multicolumn{3}{|c|}{ Field 4} \\
\hline & $\mathrm{mA}$ & kV & spm & $\mathrm{mA}$ & kV & spm & $\mathrm{mA}$ & kV & spm & $\mathrm{mA}$ & kV & spm \\
\hline $1 \mathrm{~A}$ & 81 & 64.8 & 10 & 609 & 49.9 & 19 & 947 & 51.4 & 9 & 977 & 56.6 & 8 \\
\hline $1 B$ & 219 & 60 & 98 & 443 & 50.2 & 19 & 731 & 50.6 & 19 & 780 & 53.1 & 19 \\
\hline $2 A$ & 250 & 63.4 & 52 & 682 & 56.2 & 19 & 708 & 57.1 & 19 & 939 & 53.6 & 17 \\
\hline $2 \mathrm{~B}$ & 281 & 62.3 & 77 & 505 & 51 & 19 & 839 & 50.9 & 19 & 767 & 49.9 & 19 \\
\hline
\end{tabular}

\begin{tabular}{|c|c|c|c|c|c|c|c|c|c|c|c|c|}
\hline \multicolumn{2}{|c|}{ 15-Mar-03 } & \multicolumn{11}{|c|}{ * Limiting factors highlighted } \\
\hline \multirow[t]{2}{*}{ Chamber } & \multicolumn{3}{|c|}{ Field 1} & \multicolumn{3}{|c|}{ Field 2} & \multicolumn{3}{|c|}{ Field 3} & \multicolumn{3}{|c|}{ Field 4} \\
\hline & $\mathrm{mA}$ & $\mathrm{kV}$ & spm & $\mathrm{mA}$ & $\mathrm{kV}$ & spm & $\mathrm{mA}$ & $\mathrm{kV}$ & spm & $\mathrm{mA}$ & $\mathrm{kV}$ & spm \\
\hline $1 \mathrm{~A}$ & Off & Off & Off & 408 & 49.3 & 19 & 886 & 52.5 & 19 & 990 & 59.6 & 5 \\
\hline 1B & 229 & 61.6 & 97 & 549 & 52 & 19 & 807 & 52 & 19 & 892 & 54.4 & 19 \\
\hline $2 A$ & 811 & 53 & 19 & 393 & 53.3 & 19 & 450 & 53.5 & 19 & 944 & 56.6 & 16 \\
\hline $2 \mathrm{~B}$ & 263 & 64.7 & 12 & 615 & 52.5 & 19 & 918 & 52.7 & 18 & 689 & 41.5 & 18 \\
\hline
\end{tabular}




\section{Transformer/Rectifier Performance Readings}

\begin{tabular}{|c|c|c|c|c|c|c|c|c|c|c|c|c|}
\hline \multicolumn{2}{|c|}{ 15-Apr-04 } & \multicolumn{11}{|c|}{ * Limiting factors highlighted } \\
\hline \multirow[t]{2}{*}{ Chamber } & \multicolumn{3}{|c|}{ Field 1} & \multicolumn{3}{|c|}{ Field 2} & \multicolumn{3}{|c|}{ Field 3} & \multicolumn{3}{|c|}{ Field 4} \\
\hline & $\mathrm{mA}$ & kV & spm & $\mathrm{mA}$ & $\mathrm{kV}$ & spm & $\mathrm{mA}$ & $\mathrm{kV}$ & spm & $\mathrm{mA}$ & kV & spm \\
\hline $1 \mathrm{~A}$ & 94 & 64.9 & 4 & 610 & 49.2 & 19 & 975 & 52.1 & 8 & 981 & 56.3 & 7 \\
\hline 1B & 230 & 59.6 & 99 & 455 & 50.7 & 19 & 723 & 50.3 & 19 & 816 & 52.9 & 19 \\
\hline $2 A$ & 421 & 63.6 & 55 & 704 & 55.5 & 19 & 682 & 55.4 & 19 & 905 & 51.6 & 18 \\
\hline $2 B$ & 313 & 62.8 & 68 & 509 & 51.3 & 19 & 835 & 51.1 & 19 & 778 & 49.9 & 19 \\
\hline
\end{tabular}

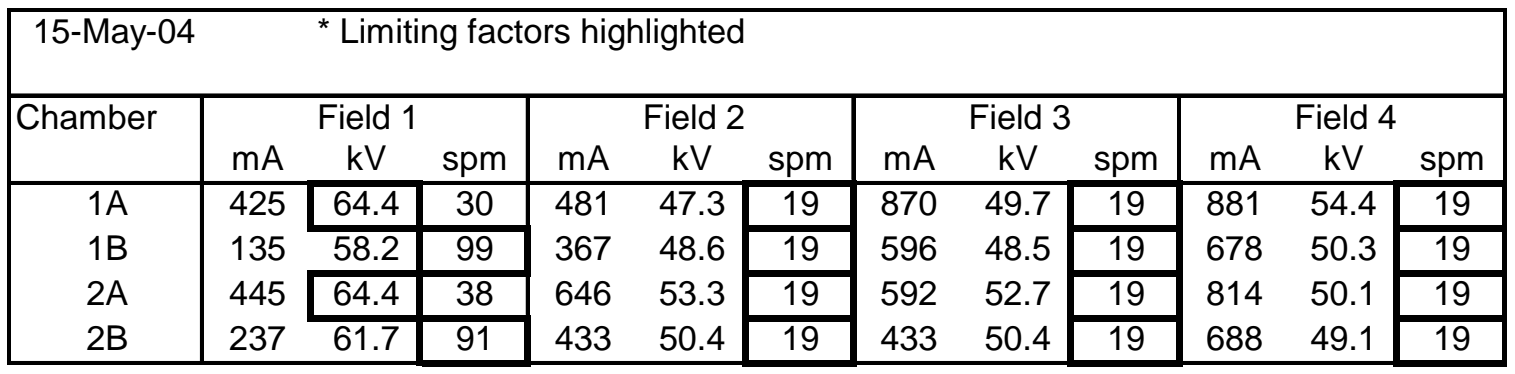

\begin{tabular}{|c|c|c|c|c|c|c|c|c|c|c|c|c|}
\hline \multicolumn{2}{|c|}{ 15-Jun-04 } & \multicolumn{11}{|c|}{ * Limiting factors highlighted } \\
\hline \multirow[t]{2}{*}{ Chamber } & \multicolumn{3}{|c|}{ Field 1} & \multicolumn{3}{|c|}{ Field 2} & \multicolumn{3}{|c|}{ Field 3} & \multicolumn{3}{|c|}{ Field 4} \\
\hline & $\mathrm{mA}$ & $\mathrm{kV}$ & spm & $\mathrm{mA}$ & $\mathrm{kV}$ & spm & $\mathrm{mA}$ & $\mathrm{kV}$ & spm & $\mathrm{mA}$ & $\mathrm{kV}$ & spm \\
\hline $1 \mathrm{~A}$ & 64 & 64.8 & 12 & 533 & 47.9 & 19 & 887 & 49.6 & 18 & 972 & 55.1 & 11 \\
\hline $1 \mathrm{~B}$ & 291 & 60.1 & 99 & 563 & 49.1 & 19 & 823 & 48.9 & 19 & 862 & 51.5 & 19 \\
\hline $2 A$ & 334 & 64.7 & 17 & 706 & 53.8 & $\overline{19}$ & 671 & 53.8 & 19 & 913 & 50.3 & 18 \\
\hline $2 \mathrm{~B}$ & 194 & 63.3 & 62 & 496 & 50.8 & 19 & 705 & 48.7 & 19 & 626 & 44.2 & 19 \\
\hline
\end{tabular}




\section{Transformer/Rectifier Performance Readings}

* Limiting factors in bold box, changes from previous quarter highlighted in red

\begin{tabular}{|c|c|c|c|c|c|c|c|c|c|c|c|c|}
\hline \multicolumn{13}{|c|}{ 17-Jul-04 } \\
\hline \multirow[t]{2}{*}{ Chamber } & \multicolumn{3}{|c|}{ Field 1} & \multicolumn{3}{|c|}{ Field 2} & \multicolumn{3}{|c|}{ Field 3} & \multicolumn{3}{|c|}{ Field 4} \\
\hline & $\mathrm{mA}$ & $\mathrm{kV}$ & spm & $\mathrm{mA}$ & kV & spm & $\mathrm{mA}$ & $\mathrm{kV}$ & spm & $\mathrm{mA}$ & kV & spm \\
\hline $1 \mathrm{~A}$ & 98 & 64.8 & 16 & 572 & 47.8 & 19 & 967 & 50.2 & 13 & 1000 & 56.2 & 1 \\
\hline $1 \mathrm{~B}$ & 299 & 57.6 & 99 & 536 & 48.3 & 19 & 806 & 47.8 & 19 & 801 & 49.1 & 19 \\
\hline $2 \mathrm{~A}$ & 288 & 62.2 & 20 & 742 & 54.1 & 19 & 749 & 54.1 & 19 & 951 & 51.1 & 12 \\
\hline $2 B$ & 308 & 61.4 & 93 & 594 & 50.5 & 19 & 790 & 47.8 & 19 & 666 & 43 & 18 \\
\hline
\end{tabular}

\begin{tabular}{|c|c|c|c|c|c|c|c|c|c|c|c|c|}
\hline \multicolumn{13}{|c|}{ 13-Aug-04 } \\
\hline \multirow[t]{2}{*}{ Chamber } & \multicolumn{3}{|c|}{ Field 1} & \multicolumn{3}{|c|}{ Field 2} & \multicolumn{3}{|c|}{ Field 3} & \multicolumn{3}{|c|}{ Field 4} \\
\hline & $\mathrm{mA}$ & kV & spm & $\mathrm{mA}$ & kV & spm & $\mathrm{mA}$ & $\mathrm{kV}$ & spm & $\mathrm{mA}$ & kV & spm \\
\hline $1 \mathrm{~A}$ & 91 & 61.7 & 82 & 369 & 44.6 & 19 & 738 & 46.3 & 19 & 841 & 49.1 & 19 \\
\hline $1 \mathrm{~B}$ & 226 & 55.6 & 99 & 374 & 44.8 & 19 & 581 & 44.6 & 19 & 525 & 44 & 19 \\
\hline $2 A$ & 235 & 58.6 & 99 & 517 & 45.9 & 19 & 499 & 47.6 & 19 & 621 & 46.1 & 19 \\
\hline $2 B$ & 156 & 58.6 & 99 & 468 & 44.5 & 19 & 701 & 45.3 & 19 & 633 & 44.9 & 19 \\
\hline
\end{tabular}

\begin{tabular}{|c|c|c|c|c|c|c|c|c|c|c|c|c|}
\hline \multicolumn{13}{|c|}{$20-$ Sep-04 } \\
\hline \multirow[t]{2}{*}{ Chamber } & \multicolumn{3}{|c|}{ Field 1} & \multicolumn{3}{|c|}{ Field 2} & \multicolumn{3}{|c|}{ Field 3} & \multicolumn{3}{|c|}{ Field 4} \\
\hline & $\mathrm{mA}$ & kV & spm & $\mathrm{mA}$ & $\mathrm{kV}$ & spm & $\mathrm{mA}$ & kV & spm & $\mathrm{mA}$ & $\mathrm{kV}$ & spm \\
\hline $1 \mathrm{~A}$ & 88 & 59.5 & 99 & 115 & 32.5 & 19 & 795 & 48.7 & 19 & 903 & 54.1 & 19 \\
\hline $1 B$ & 173 & 56.4 & 99 & 357 & 47.8 & 19 & 632 & 45.9 & 19 & 475 & 45.7 & 18 \\
\hline $2 A$ & 308 & 60.9 & 98 & 591 & 52 & 19 & 643 & 52.6 & 19 & 824 & 50 & 19 \\
\hline $2 B$ & 201 & 59.6 & 99 & 467 & 50.2 & 19 & 684 & 48.6 & 19 & 662 & 47.7 & 19 \\
\hline
\end{tabular}




\section{B21 Pulse Counter Readings}
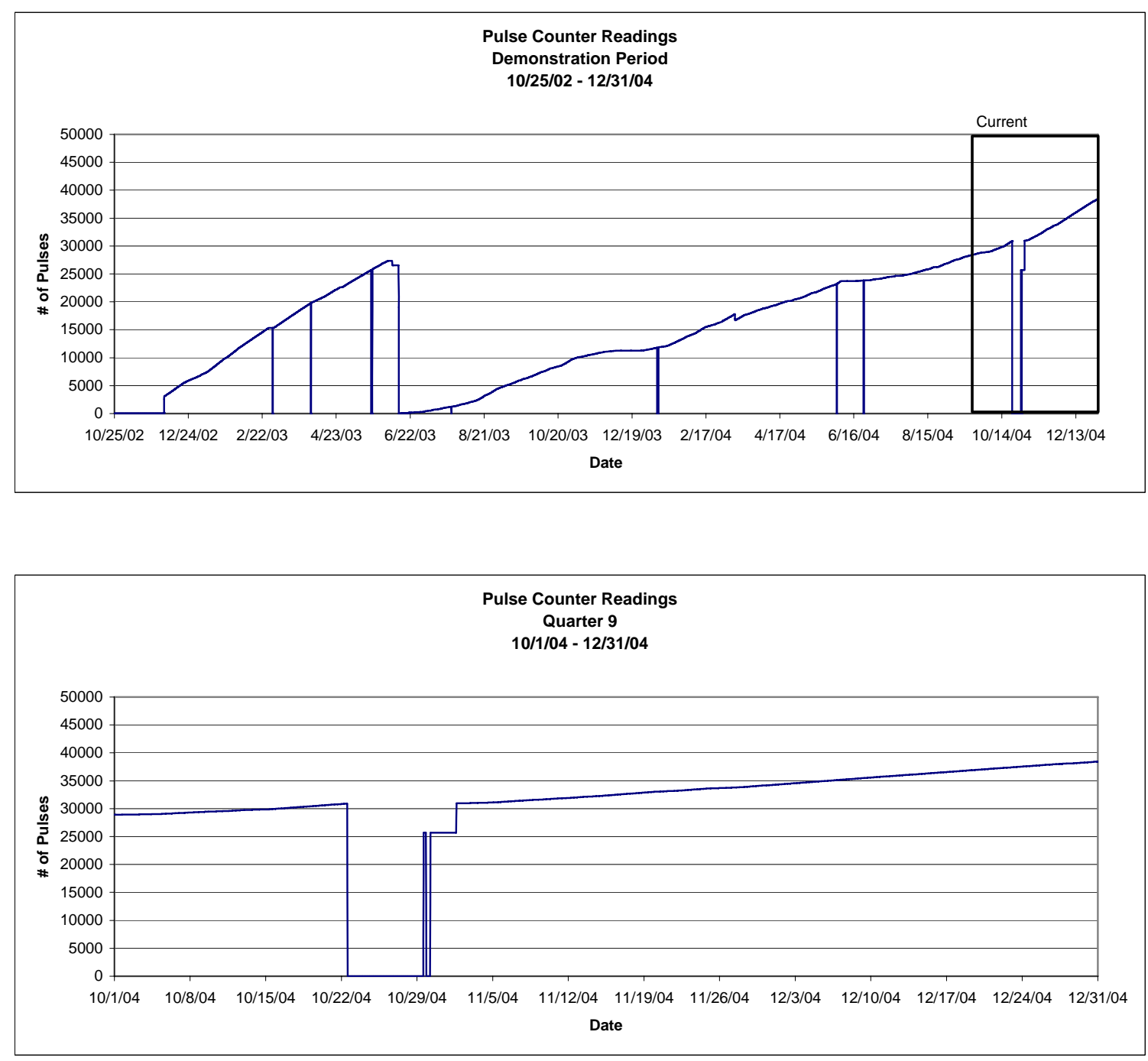
B22 Compressed Air Flow
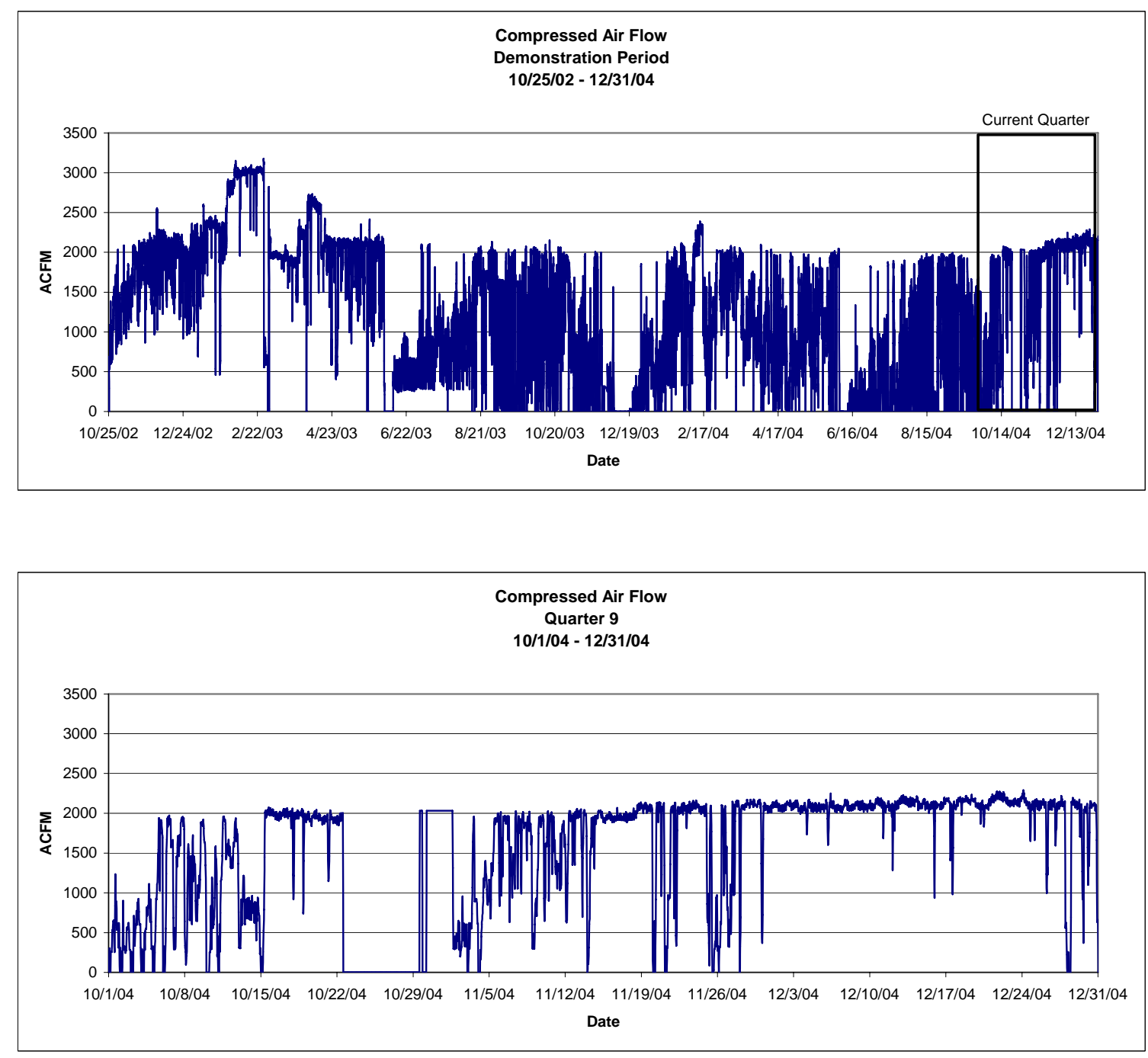


\section{B23 Bag Layout Diagrams}

Bag layout from Start-up until June 2003
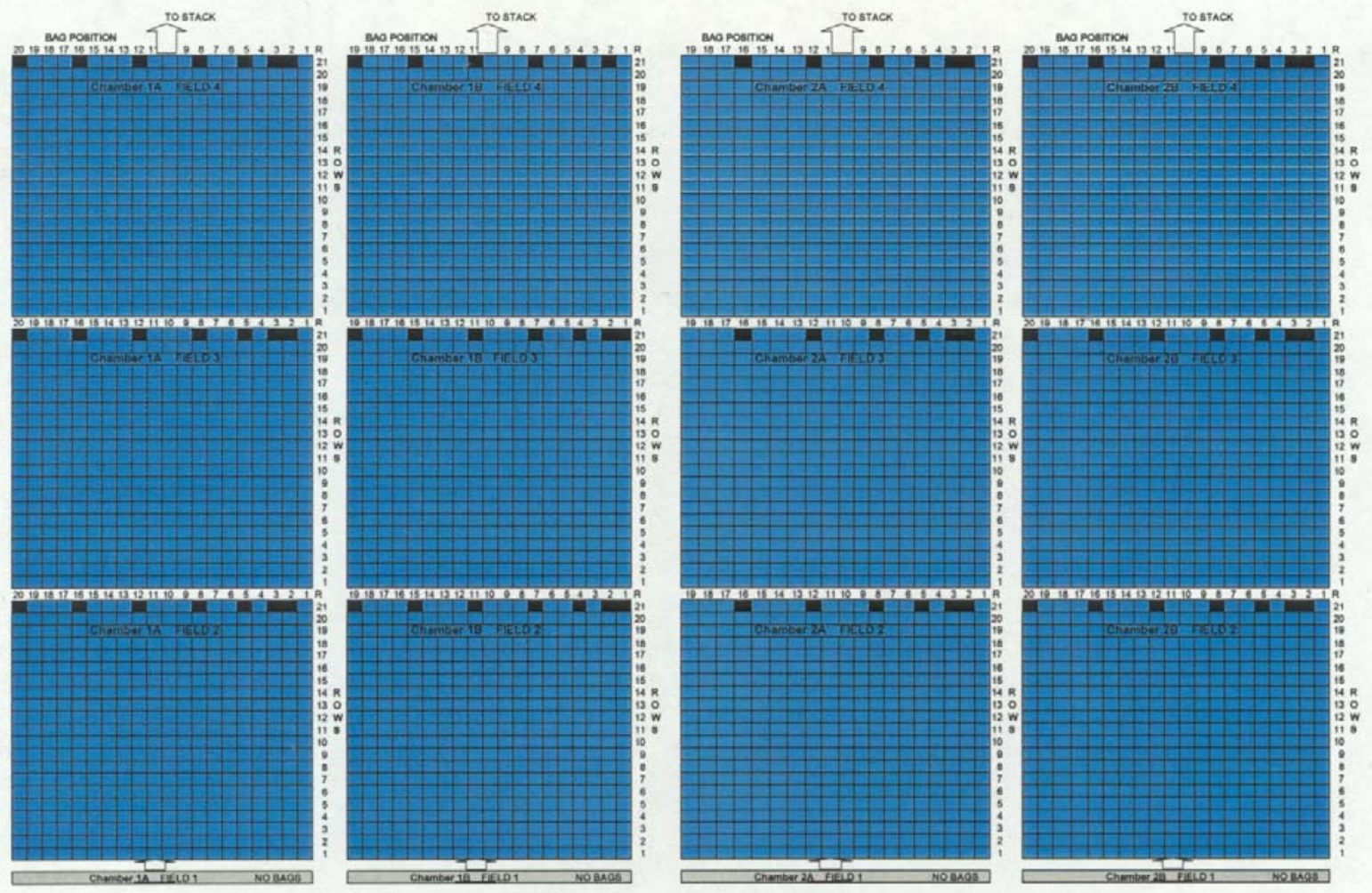

No Filter Bag

Conductive Gore-Tex Membrane/Conductive Gore-Tex Felt (Installed 10/02) 
Bag layout after June 2003 boiler wash outage

\section{Advanced Hybrid Bag Map \\ Big Stone Plant}
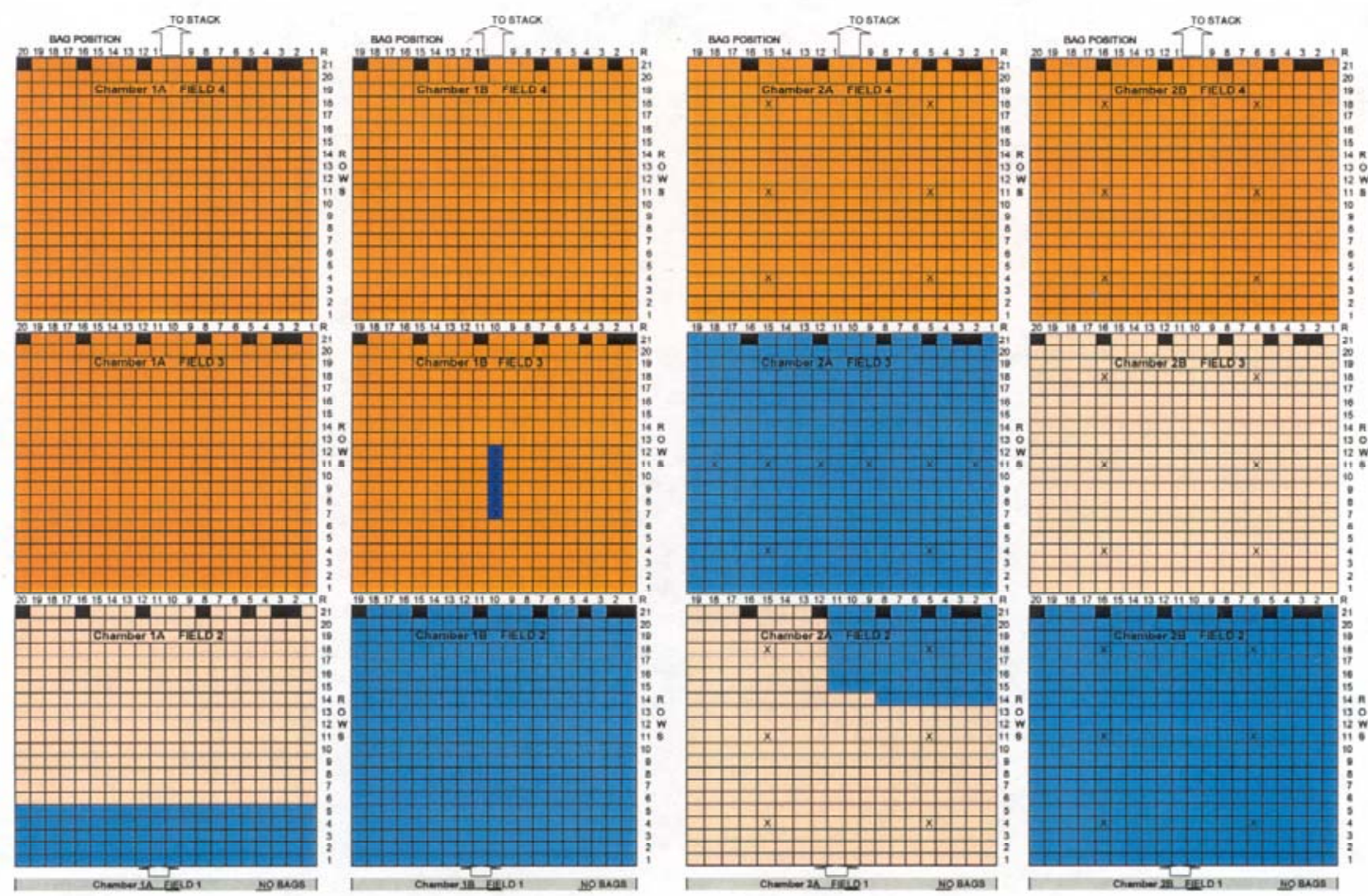

No Filter Bag

Conductive Gore-Tex Membrane/Conductive Gore-Tex Felt (Installed 6/03)

Conductive Gore-Tex Membrane/Conductive PPS Felt (Installed 6/03)

Gore-Tex Membrane/PPS Felt (Installed 6/03)

Test Bags (Installed 6/03)

Pitot Tube Location 
Bag layout after the December 2003 boiler wash outage

\section{Advanced Hybrid Bag Map}

Big Stone Plant
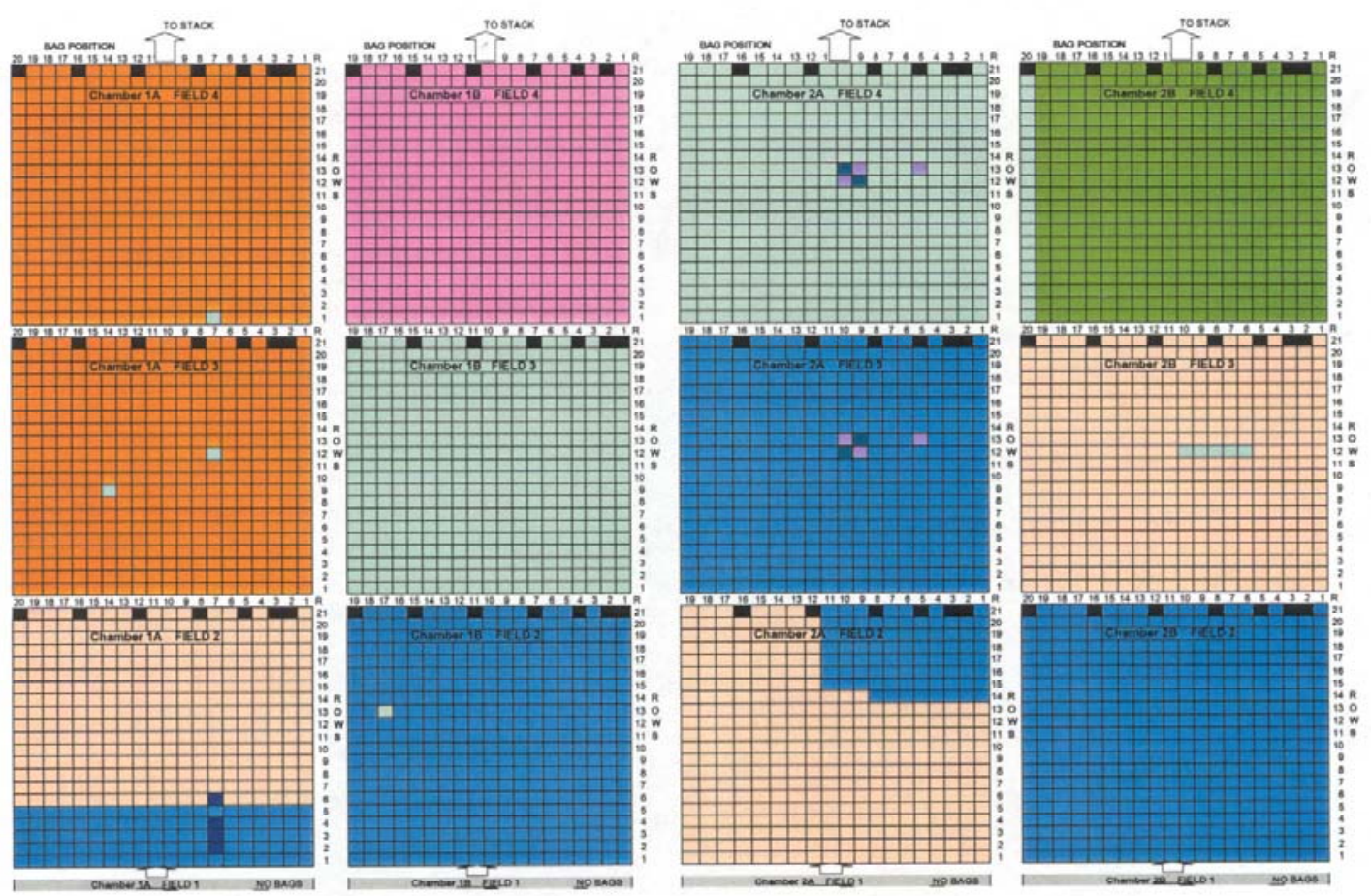

No Fitter Bag

Conductive Gore-Tex Membrane/Conductive Gore-Tex Felt (Installed 6/03)

Conductive Gore-Tex Membrane/Conductive PPS Felt (Installed 6/03)

Gore-Tex Membrane/PPS Felt (Installed 6/03)

Conductive Gore-Tex Membrane/Conductive Gore-Tex Felt (Installed 10/02, removed 6/03, washed, reinstalled 12/03)

BHA-Tex Membrane/Nomex Felt (Installed 12/03)

BHA-Tex Membrane/P84 Felt (Installed 12/03)

BHA Stainless Steel Cage (Installed 12/03) with Conductive Gore-Tex Membrane/Conductive Gore-Tex Felt (Removed 6/03, washed, reinstalled 12/03)

Conductive Gore-Tex Membrane/Conductive Gore-Tex Felt (Installed 12/03)

Gore - Superflex (Installed 12/03)

Gore-Tex Membrane/Fiberglass (Installed 12/03) 
Bag layout after the June 2004 wash outage

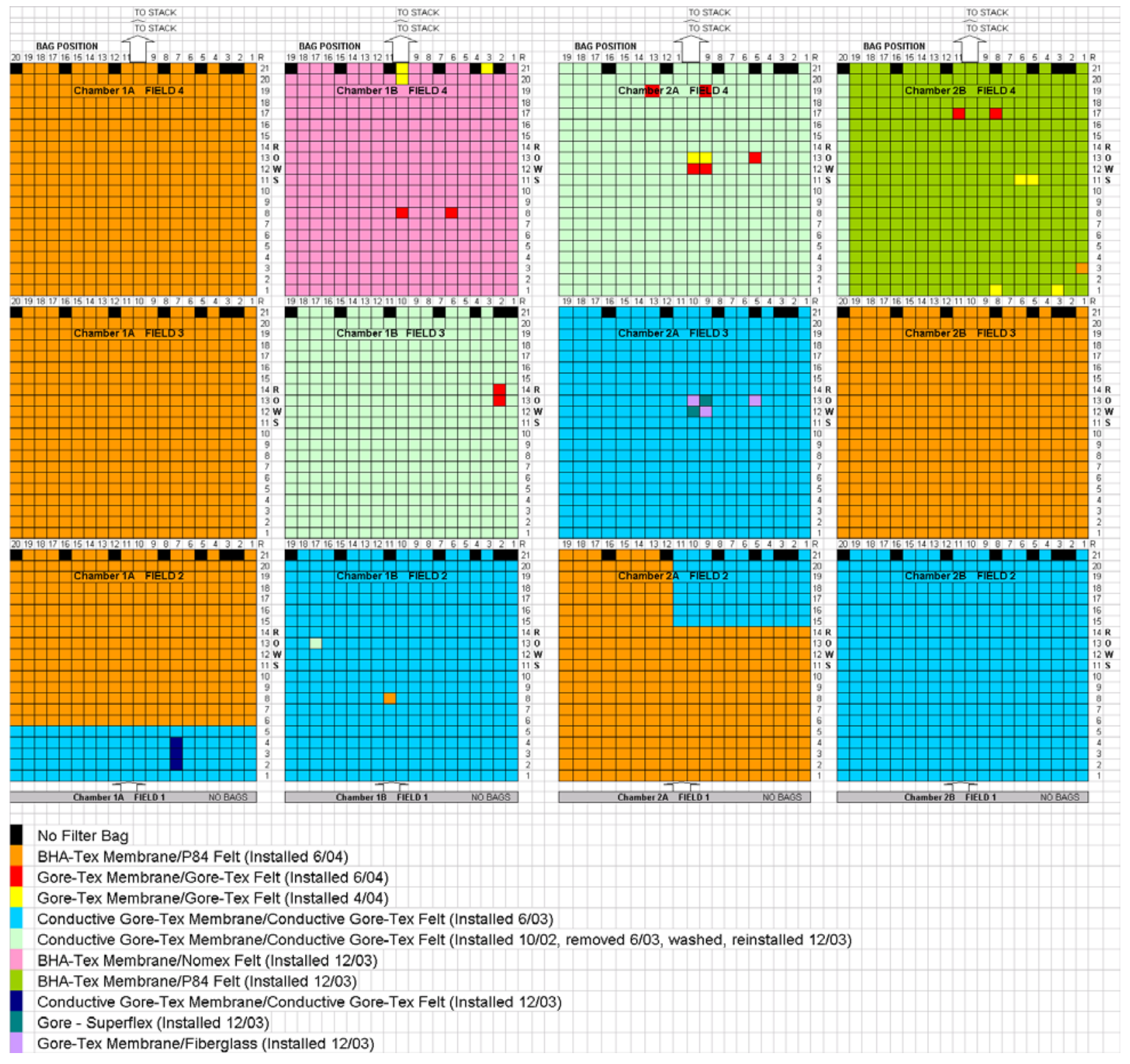


Bag layout after the October 2004 boiler wash outage

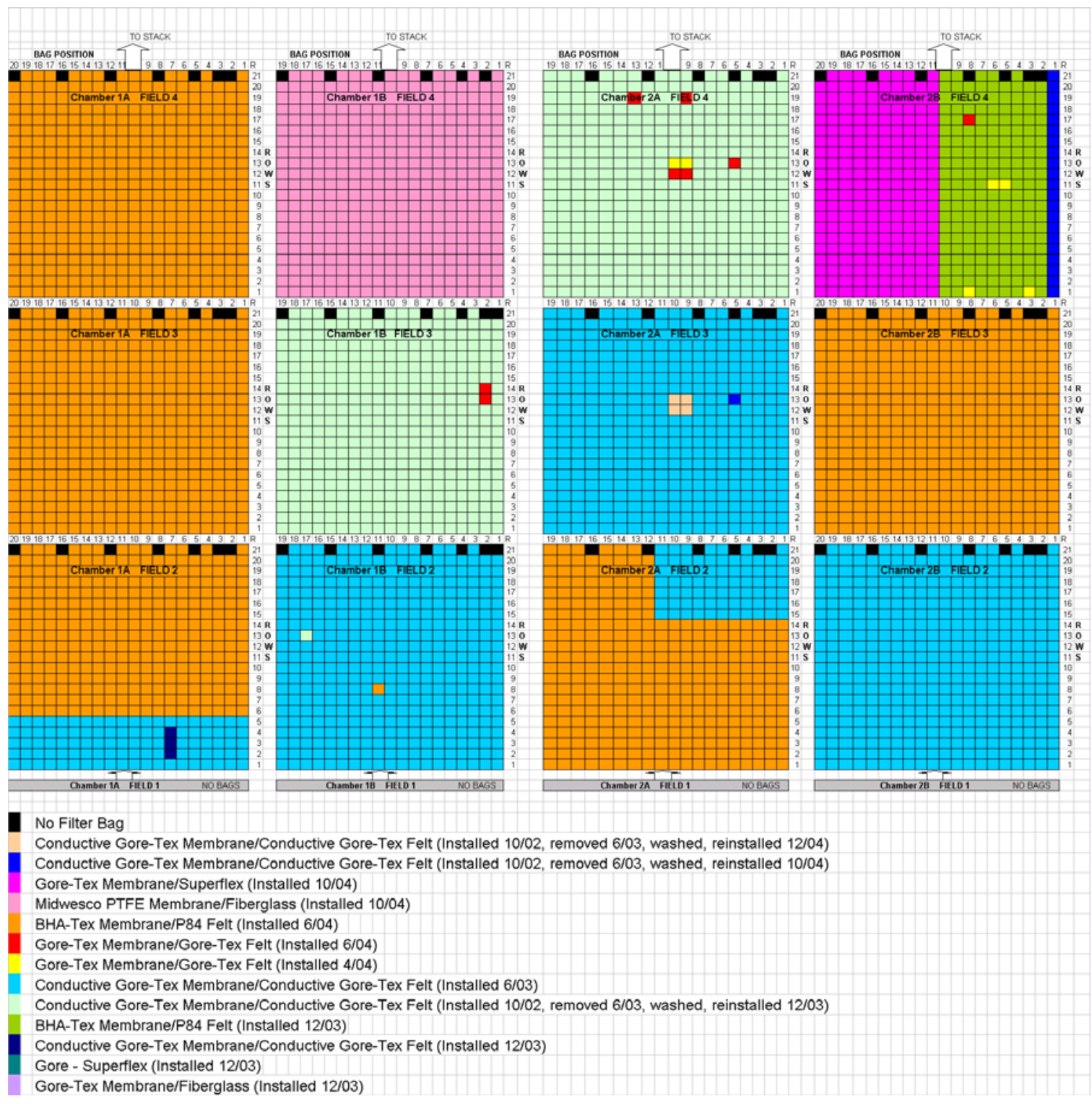


B24 EERC Stack Test - November 19, 2002

Support in Demonstrating a Full-Scale Retrofit of the Advanced Hybrid ${ }^{\text {TM }}$ Technology - TEST SERIES I

\section{Test Series I Report}

(For the period June 1, 2002 - January 22, 2003)

Prepared for:

William Swanson

Otter Tail Power Company

48450 144th Street

PO Box 218

Big Stone City, SD 57216

Prepared by:

Dennis L. Laudal

Energy \& Environmental Research Center

University of North Dakota

PO Box 9018

Grand Forks, ND 58202-9018

January 2003 


\section{EERC DISCLAIMER}

LEGAL NOTICE: This research report was prepared by the Energy \& Environmental Research Center (EERC),

an agency of the University of North Dakota, as an account of work sponsored by DOE. Because of the research nature of the work performed, neither the EERC nor any of its employees makes any warranty, express or implied, or assumes any legal liability or responsibility for the accuracy, completeness, or usefulness of any information, apparatus, product, or process disclosed, or represents that its use would not infringe privately owned rights. Reference herein to any specific commercial product, process, or service by trade name, trademark, manufacturer, or otherwise does not necessarily constitute or imply its endorsement or recommendation by the EERC. 
TABLE OF CONTENTS

LIST OF FIGURES ii

LIST OF TABLES iii

INTRODUCTION 197

\section{APPROACH 197}

RESULTS AND DISCUSSION 199

Coal Analysis 3

Total Dust Loadings and Particulate Collection Efficiency

Particle-Size Distributions

200

Flue Gas Analyses 202

Mass Balances 6

CONCLUSIONS 207 


\section{LIST OF FIGURES}

Schematic of the Big Stone Power Plant showing Advanced Hydrid ${ }^{\mathrm{TM}}$ system and sampling locations 2

Respirable mass measurements at the stack of the Big Stone Power Plant for November 19, $2002 \quad 8$

Respirable mass measurements at the stack of the Big Stone Power Plant for November 20, $2002 \quad 8$

Respirable mass measurements at the stack of the Big Stone Power Plant for November 21, $2002 \quad 9$

Particulate mass distribution at the Advanced Hybrid ${ }^{\mathrm{TM}}$ inlet based on multicyclone measurements 9

Particulate mass distribution at the stack based on an impactor measurement 10 


\section{LIST OF TABLES}

Sampling Test Matrix for Big Stone Power Plant 1

Fuel Burned at the Big Stone Power Plant During Testing 3

Sampling Protocols Used for Test Series I 4

Analyses of Trace Elements in Fuel Fired at Big Stone Power Plant 4

Chemical Analysis of Coal 5

Advanced Hybrid ${ }^{\mathrm{TM}}$ Particulate Collection Efficiency 5

ACGIH Respirable Mass Definition 6

Analyses of Trace Elements in Flue Gas at the Advanced Hybrid ${ }^{\mathrm{TM}}$ Inlet 7

Analyses of Trace Elements in Flue Gas at the Stack 7

Field Blank Results for EPA Method 29 Samples $\quad 10$

Comparison of the Concentration of Trace Elements at the Advanced Hybrid ${ }^{\mathrm{TM}}$ Inlet and Stack 11

Trace Element Analysis of Pilot-Scale Advanced Hybrid ${ }^{\mathrm{TM}}$ Hopper Ash 11

Elemental Analysis of Advanced Hybrid ${ }^{\mathrm{TM}}$ Pilot-Scale Hopper Ash 12 
SAMPLING SUPPORT TO DEMONSTRATE A FULL-SCALE RETROFIT OF THE ADVANCED HYBRIDTM TECHNOLOGY - TEST SERIES I

\section{INTRODUCTION}

A new concept in particulate control, called the Advanced Hybrid ${ }^{\mathrm{TM}}$ Filter, was installed at the Big Stone Power Plant operated by Otter Tail Power Company. The Advanced Hybrid ${ }^{\mathrm{TM}}$ concept combines fabric filtration and electrostatic precipitation in the same housing, providing major synergism between the two methods, both in the particulate collection step and in the transfer of dust to the hopper. The Advanced Hybrid ${ }^{\mathrm{TM}}$ Filter is designed to provide ultrahigh collection efficiency for even fine particulate matter at air-to-cloth ratios significantly higher than those utilized for traditional fabric filters, 10-12 ft/min compared to 3.5-4 ft/min for a pulse-jet baghouse. This report presents the results of the first series of flue gas sampling designed to demonstrate the fine particulate collection efficiency of the Advanced Hybrid ${ }^{\mathrm{TM}}$ Filter. In addition to total particulate measurements, trace elements including mercury, were also measured.

\section{APPROACH}

The original proposal required testing three times during the first 2 years of operation. The results presented in this report were those obtained after about 600 hours of operation. The Advanced Hybrid ${ }^{\mathrm{TM}}$ Filter began operating on October 25, 2002, and sampling occurred during the week of November 18, 2002. Table 1 shows the test matrix for the sampling conducted during this period.

Table 1. Sampling Test Matrix for Big Stone Power Plant - Test Series I

\begin{tabular}{|c|c|c|c|c|c|c|c|c|c|c|}
\hline \multirow[b]{2}{*}{ Activity } & \multirow{2}{*}{$\begin{array}{l}\text { Sampling } \\
\text { Location }\end{array}$} & \multicolumn{2}{|c|}{ Nov. 18} & \multicolumn{2}{|c|}{ Nov. 19} & \multicolumn{2}{|c|}{ Nov. 20} & \multicolumn{2}{|c|}{ Nov. 21} & Nov. 22 \\
\hline & & $\mathrm{AM}$ & PM & AM & PM & AM & PM & $\mathrm{AM}$ & PM & $\mathrm{AM}$ \\
\hline Set-Up and Takedown & & Setup & & & & & & & & Takedown \\
\hline APS/SMPS ${ }^{1}$ & Stack & & & APS & MPS & & & & & \\
\hline EPA Method $29^{2}$ & $\begin{array}{l}\text { Advance } \\
\mathrm{d} \\
\text { Hybrid }^{\mathrm{TM}} \\
\text { Inlet }\end{array}$ & & & $\mathrm{X}$ & & $\mathrm{X}$ & $\mathrm{X}$ & & & \\
\hline EPA Method 29 & Stack & & & $\mathrm{X}$ & & $\mathrm{X}$ & $\mathrm{X}$ & & & \\
\hline EPA Method 17 & Stack & & $\mathrm{X}$ & & & $\mathrm{X}$ & & $X$ & & \\
\hline Multicyclones & $\begin{array}{l}\text { Advance } \\
\mathrm{d} \\
\text { Hybrid }^{\mathrm{TM}} \\
\text { Inlet }\end{array}$ & & & & $\mathrm{X}$ & & & $\mathrm{X}$ & $\mathrm{X}$ & \\
\hline Impactor & Stack & & & & & $\mathrm{X}$ & & & & \\
\hline $\begin{array}{l}\text { Coal Samples and } \\
\text { Hopper Ash }\end{array}$ & & & & $\mathrm{X}$ & & $\mathrm{X}$ & & $\mathrm{X}$ & & $\mathrm{X}$ \\
\hline
\end{tabular}

${ }^{1}$ Aerodynamic particle sizer (APS)/scanning mobility particle sizer (SMPS).

${ }^{2}$ U.S. Environmental Protection Agency. 


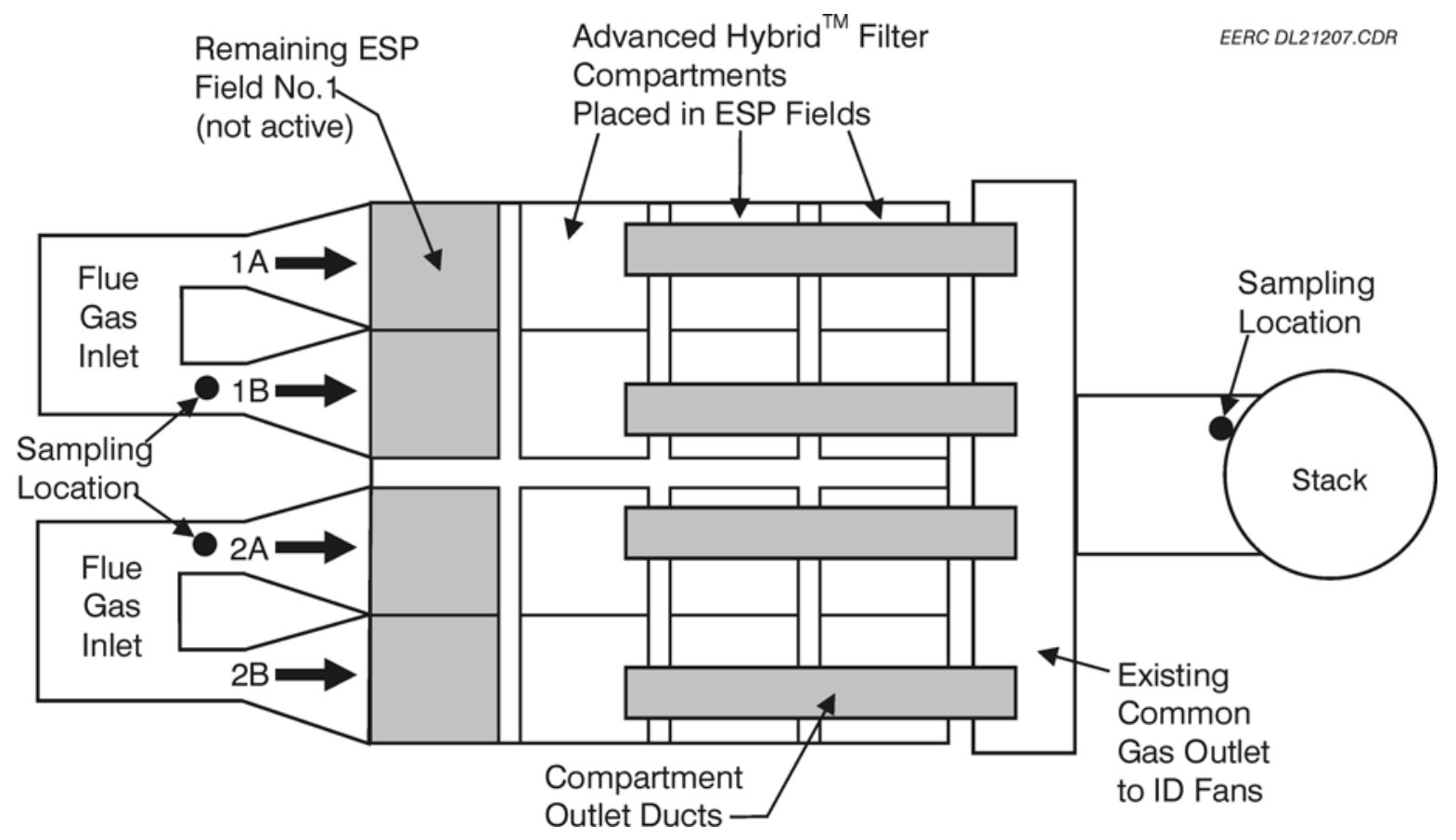

Figure 1. Schematic of the Big Stone Power Plant showing Advanced Hybrid ${ }^{\mathrm{TM}}$ System and sampling locations.

The Advanced Hybrid ${ }^{\mathrm{TM}}$ system has four chambers (1A, 1B, 2A, and 2B) with a separate duct going to each chamber. These ducts recombine at the outlet of the Advanced Hybrid ${ }^{\mathrm{TM}}$ Filter and exit a single stack. Figure 1 is a schematic of the system showing the flue gas sampling points. As can be seen in Figure 1, the Advanced Hybrid ${ }^{\mathrm{TM}}$ inlet sampling was done at two different ducts, $1 \mathrm{~B}$ and $2 \mathrm{~A}$. The reason for this is that the first duct did not have a port large enough to use the multicyclone. Therefore, sampling location was changed from the second duct to the third duct. The sampling in the stack was done at a 288 -ft level. There were four ports located in the stack. One port was used to do EPA Method 29 samples, and a different port was used to collect the EPA Method 17 samples. No traversing was done for these tests.

The fuel burned at the Big Stone Power Plant varies to some degree. The coal is a Powder River Basin (PRB) subbituminous coal from the Belle Ayr mine. However, periodically, the Big Stone Power Plant blends $10 \%$ or less of other combustible materials, including tire-derived fuel (TDF) and a waste seed biomass such as corn. Table 2 shows the fuel that was burned during the four days of testing.

The coal samples provided the Energy \& Environmental Research Center (EERC) by plant personnel for the 4 days of testing were as follows (these samples were not taken directly at the mill, so they are different than those actually burned at the plant on any given day). 
Table 2. Fuel Burned at the Big Stone Power Plant During Testing, by weight

\begin{tabular}{llll}
\hline Day & Coal, $\%$ & TDF, $\%$ & Waste Seed (Corn), \% \\
\hline Nov. 19 & 96.5 & 0.4 & 3.1 \\
Nov. 20 & 100 & 0 & 0 \\
Nov. 21 & 100 & 0 & 0 \\
Nov. 22 & 95.0 & 2.2 & 2.8 \\
\hline
\end{tabular}

$\begin{array}{ll}11 / 18 / 2002 & \text { PRB-waste corn seed } \\ 11 / 18 / 2002 & \text { TDF } \\ 11 / 19 / 2002 & \text { PRB } \\ 11 / 20 / 2002 & \text { PRB } \\ 11 / 21 / 2002 & \text { PRB } \\ 11 / 22 / 2002 & \text { PRB }\end{array}$

The TDF sample was taken prior to mixing with the coal, but the waste corn seed was blended with the coal prior to the sample being taken. The sampling protocols used for the Test Series I sampling effort are presented in Table 3. The trace elements analyzed were as follows:

Antimony

Arsenic

Beryllium

Cadmium

Chromium

Lead

Nickel

Mercury

At the Advanced Hybrid ${ }^{\mathrm{TM}}$ inlet sampling location, the EPA Method 29 and multicyclones were operated for about 2 hours. However, because of the very low emissions at the stack, the EPA Method 17 and impactor trains were operated for 12 hours to ensure enough dust was captured to accurately measure weight. To improve the detection of the trace elements at the stack, EPA Method 17 filters were analyzed, rather than the stack EPA Method 29 filters. To sample the required amount of flue gas isokineticlly, EPA Method 29 can only be operated 2-3 hours compared to 12 hours for EPA Method 17.

\section{RESULTS AND DISCUSSION}

\section{Coal Analysis}

One coal-waste corn blend sample and three PRB coal samples were analyzed for this project for trace elements and chlorides. These results are shown in Table 4. With the exception of nickel, the addition of waste corn seed to the coal reduces all the trace elements. 
Table 3. Sampling Protocols Used for Test Series I

\begin{tabular}{|c|c|c|c|c|}
\hline Sample Method & \multicolumn{4}{|c|}{ Analysis } \\
\hline EPA Method 29 & \multicolumn{4}{|c|}{$\begin{array}{l}\text { Trace elements and total dust loading at the Advanced Hybrid }{ }^{\mathrm{TM}} \text { inlet (fly ash } \\
\text { and flue gas) }\end{array}$} \\
\hline EPA Method 17 & \multicolumn{4}{|c|}{ Trace elements and total dust loading at the stack (fly ash) } \\
\hline Multicyclones & \multicolumn{4}{|c|}{ Particle-size distribution at the Advanced Hybrid ${ }^{\mathrm{TM}}$ inlet } \\
\hline Impactor & \multicolumn{4}{|c|}{ Particle-size distribution at the stack } \\
\hline APS/SMPS & \multicolumn{4}{|c|}{ Particle-size distribution at the stack $(0.03-15 \mu \mathrm{m})$} \\
\hline $\begin{array}{l}\text { Sample } \\
\text { Hopper Ash } \\
\text { Coal }^{3}\end{array}$ & $\begin{array}{l}\text { Trace } \\
\text { Trace }\end{array}$ & $\begin{array}{l}\mathrm{s}, \mathrm{XRF}^{2} \text { ana } \\
\mathrm{s} \text {, ultimate/p }\end{array}$ & $\begin{array}{l}\text { ajor elemen } \\
\text { heating valu }\end{array}$ & $\begin{array}{l}\text { s on ignition }(\mathrm{LOI}) \\
\text { rine }\end{array}$ \\
\hline \multicolumn{5}{|c|}{$\begin{array}{l}{ }^{1} \text { Analyses were done on three hopper ash samples. } \\
{ }^{2} \mathrm{X} \text {-ray fluorescence. }\end{array}$} \\
\hline \multicolumn{5}{|c|}{ Table 4. Analyses of Trace Elements in Fuel Fired at Big Stone Power Plant } \\
\hline Date & $11 / 19 / 02$ & $11 / 21 / 02$ & $11 / 22 / 02$ & $11 / 22 / 02$ \\
\hline $\begin{array}{l}\text { Trace } \\
\text { Element }\end{array}$ & $\begin{array}{l}\text { PRB Coal, } \\
\mu \mathrm{g} / \mathrm{g}\end{array}$ & $\begin{array}{l}\text { PRB Coal, } \\
\mu \mathrm{g} / \mathrm{g}\end{array}$ & $\begin{array}{l}\text { PRB Coal, } \\
\mu \mathrm{g} / \mathrm{g}\end{array}$ & $\begin{array}{l}\text { PRB and waste } \\
\text { corn seed, } \mu \mathrm{g} / \mathrm{g}\end{array}$ \\
\hline Antimony & $<0.1$ & $<0.1$ & $<0.1$ & $<0.1$ \\
\hline Arsenic & 0.56 & 1.1 & 0.60 & 0.49 \\
\hline Beryllium & 0.21 & 0.27 & 0.26 & 0.15 \\
\hline Cadmium & 0.064 & 0.10 & 0.060 & $<0.04$ \\
\hline Chromium & 3.5 & 4.3 & 4.3 & 2.84 \\
\hline Chloride & 8.9 & 22.0 & 9.1 & 200 \\
\hline Lead & 3.5 & 3.3 & 2.9 & 2.0 \\
\hline Mercury & 0.087 & 0.0414 & 0.0586 & 0.0754 \\
\hline Nickel & 5.3 & 5.8 & 4.2 & 14.8 \\
\hline
\end{tabular}

Ultimate and proximate analyses for one PRB coal and the PRB-waste corn seed blend are shown in Table 5.

Total Dust Loadings and Particulate Collection Efficiency

The total particulate collection efficiency is shown in Table 6. As can be seen, the average collection efficiency is $>99.995 \%$. Based on the original proposal, the design specifications for the Advanced Hybrid ${ }^{\mathrm{TM}}$ Filter were $<0.002$ grains/scf and $>99.99 \%$ collection efficiency. The results presented in Table 6 show that the Advanced Hybrid ${ }^{\mathrm{TM}}$ technology easily met these criteria.

Particle-Size Distributions

Near-real-time measurements were made for particles raging from 0.5 to $15 \mu \mathrm{m}$ with the APS. For the APS, rather than looking at emissions of several particle sizes, fine particle emissions are combined by calculating a value for respirable mass. The American Council of Governmental and 
Table 5. Chemical Analysis of Coal, as received

\begin{tabular}{lll}
\hline Date & $11 / 19 / 2002$ & $11 / 22 / 2002$ \\
\hline Description & $100 \%$ PRB & PRB and waste corn seed \\
\hline $\begin{array}{l}\text { Proximate Analysis } \\
\quad\end{array}$ & \\
$\quad$ Moisture, \% & 29.50 & 21.60 \\
$\quad$ Volatile Matter, \% & 33.24 & 37.97 \\
$\quad$ Fixed Carbon, \% & 32.95 & 27.18 \\
$\quad$ Ash, \% & 4.31 & 13.26 \\
Ultimate Analysis & & \\
$\quad$ Hydrogen, \%* & 6.66 & 6.15 \\
Carbon, \% & 48.60 & 53.33 \\
$\quad$ Nitrogen, \% & 0.86 & 0.92 \\
$\quad$ Sulfur, \% & 0.31 & 0.35 \\
Oxygen, \% (by diff.) & 39.26 & 26.00 \\
Heating Value, Btu/lb & 8520 & 9658 \\
Fd, dscf/10 8 Btu & 9488 & 9562 \\
\hline
\end{tabular}

*Includes hydrogen as water.

Table 6. Advanced Hybrid ${ }^{\mathrm{TM}}$ Particulate Collection Efficiency

\begin{tabular}{|c|c|c|c|c|c|c|}
\hline Date & $\begin{array}{l}\text { Sample } \\
\text { Method }\end{array}$ & $\begin{array}{l}\text { Advanced } \\
\text { Hybrid }^{\mathrm{TM}} \\
\text { Inlet } \\
\text { Dust } \\
\text { Loading, } \\
\text { grains/scf }\end{array}$ & $\begin{array}{l}\text { Advanced } \\
\text { Hybrid }^{\mathrm{TM}} \\
\text { Inlet }^{1} \\
\text { Dust } \\
\text { Loading, } \\
\mathrm{lb} / 10^{6} \mathrm{Btu} \\
\end{array}$ & $\begin{array}{l}\text { Stack } \\
\text { Dust } \\
\text { Loading, } \\
\text { grains/scf }\end{array}$ & $\begin{array}{l}\text { Stack }^{1} \\
\text { Dust } \\
\text { Loading, } \\
\text { lb/10 } 10^{6} \mathrm{Btu}\end{array}$ & $\begin{array}{l}\text { Particulate } \\
\text { Collection } \\
\text { Efficiency, } \\
\%\end{array}$ \\
\hline $11 / 18 / 2002$ & EPA Method 17 & & & 0.00002 & 0.00003 & 99.998 \\
\hline $11 / 19 / 2002$ & $\begin{array}{l}\text { EPA Method } 29 \\
\text { Multicyclones }\end{array}$ & $\begin{array}{l}1.02092 \\
0.64099\end{array}$ & $\begin{array}{l}1.38378 \\
0.86882\end{array}$ & & & \\
\hline $11 / 20 / 2002$ & $\begin{array}{l}\text { EPA Method } 17 \\
\text { EPA Method } 29 \\
\text { EPA Method } 29\end{array}$ & $\begin{array}{l}0.85856 \\
0.92151\end{array}$ & $\begin{array}{l}1.16372 \\
1.24904\end{array}$ & 0.00006 & 0.00008 & 99.994 \\
\hline $11 / 21 / 2002$ & $\begin{array}{l}\text { EPA Method } 17 \\
\text { Multicyclones } \\
\text { Multicyclones }\end{array}$ & $\begin{array}{l}0.66113 \\
0.70044\end{array}$ & $\begin{array}{l}0.89611 \\
0.94940\end{array}$ & 0.00003 & 0.00004 & 99.997 \\
\hline
\end{tabular}

${ }^{1}$ Values were calculated based on the Fd factors shown in Table 3 for $100 \%$ PRB.

Industrial Hygienists (ACGIH) definition of respirable mass is presented in Table 7. The ACGIH definition is extrapolated and interpolated to calculate the percentage at the midpoint of each channel for that particle size, as determined by the APS. The respirable mass from all the channels is added to obtain the total respirable mass. This provides a convenient and effective method of showing APS results for fine particle emissions. The results for the APS sampling are presented in Figures 2-4. The

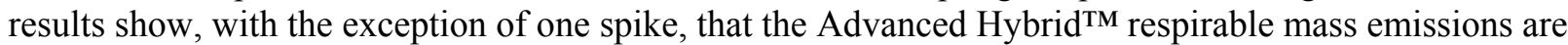
at or below those measured in the ambient air. 
Table 7. ACGIH Respirable Mass Definition

\begin{tabular}{ll} 
Aerodynamic Diameter, $\mu \mathrm{m}$ & Respirable Mass Fraction, \% \\
\hline$<2.0$ & 100 \\
$2-2.5$ & 90 \\
$2.5-3.5$ & 75 \\
$3.5-5.0$ & 50 \\
$5.0-10.0$ & 25 \\
$>10$ & 0 \\
\hline
\end{tabular}

Particle-size distribution was measured at the Advanced Hybrid ${ }^{\mathrm{TM}}$ inlet using a 5-stage multicyclone and at the stack using an impactor. The Advanced Hybrid ${ }^{\mathrm{TM}}$ inlet multicyclone results are presented in Figure 5. As shown in Figure 5, the results for the three multicyclone samples at the inlet are similar and give a mass mean diameter of about $10 \mu \mathrm{m}$. The impactor results at the stack are shown in Figure 6. The results of the impactor are somewhat suspect because the total particulate loading, even after 12 hours of sampling, was so low that is was difficult to measure accurately. However, as shown in Figure 5, the mass loading measured at the stack was substantially finer. The $\mathrm{D}_{50}$ was $<0.2 \mu \mathrm{m}$.

\section{Flue Gas Analyses}

The trace element analyses of the flue gas at the Advanced Hybrid ${ }^{\mathrm{TM}}$ inlet and the stack is shown in Tables 8 and 9. As would be expected based on the vapor pressure for the measured trace elements (with the exception of mercury), the vast majority of each of the trace elements is bound with the particulate matter. It should be noted that the vapor-phase lead values are somewhat suspect, as the field blanks indicated concentrations higher then would be expected. The field blank results are shown in Table 10. The field blank data shown in Table 8 are the total amount of each trace element in the impinger solutions of EPA Method 29. Table 9 represents the blanks for the gas-phase concentrations.

Comparing the Advanced Hybrid ${ }^{\mathrm{TM}}$ inlet and stack trace element analysis (Table 11) shows the Advanced Hybrid ${ }^{\mathrm{TM}}$ was extremely efficient, removing all the measured trace elements with the exception of the vapor-phase mercury. In an attempt to get a measurable quantity of trace elements, the filters from the EPA Method 17 samples were analyzed. The EPA Method 17 sample trains were operated for 12 hours, compared to only two for the EPA Method 29 trains. For all three samples taken at the stack, the trace elements, again with the exception of mercury, was at or below detection limits.

\section{Mass Balances}

In addition to the EPA Method 17 samples, fly ash samples were also taken from the hopper of the pilot-scale Advanced Hybrid ${ }^{\mathrm{TM}}$ that was running at the time. These samples were analyzed for major and trace elements as shown in Tables 12 and 13. The trace element analyses results from the ash samples compared quite well with those obtained from EPA Method 17 samples from the full- 
Table 8. Analyses of Trace Elements in Flue Gas at the Advanced Hybrid ${ }^{\mathrm{TM}}$ Inlet $^{1,2}$

\begin{tabular}{|c|c|c|c|c|c|c|c|c|c|}
\hline $\begin{array}{l}\text { Day } \\
\text { Time } \\
\text { Fuel }\end{array}$ & $\begin{array}{l}11 / 19 / 02 \\
10: 50 \\
\text { PRB, TI }\end{array}$ & and Corn & & \multicolumn{3}{|c|}{$\begin{array}{l}09: 30 \\
100 \% \text { PRB }\end{array}$} & \multicolumn{3}{|c|}{$\begin{array}{l}13: 37 \\
100 \% \text { PRB }\end{array}$} \\
\hline $\begin{array}{l}\text { Trace } \\
\text { Element }\end{array}$ & $\begin{array}{l}\text { Part.- } \\
\text { bound, } \\
\mu \mathrm{g} / \mathrm{Nm}^{3}\end{array}$ & $\begin{array}{l}\text { Vapor- } \\
\text { Phase, } \\
\mu \mathrm{g} / \mathrm{Nm}^{3}\end{array}$ & $\begin{array}{l}\text { Total, } \\
\mu \mathrm{g} / \mathrm{Nm}^{3}\end{array}$ & $\begin{array}{l}\text { Part.- } \\
\text { bound, } \\
\mu \mathrm{g} / \mathrm{Nm}^{3}\end{array}$ & $\begin{array}{l}\text { Vapor- } \\
\text { Phase, } \\
\mu \mathrm{g} / \mathrm{Nm}^{3}\end{array}$ & $\begin{array}{l}\text { Total, } \\
\mu \mathrm{g} / \mathrm{Nm}^{3}\end{array}$ & $\begin{array}{l}\text { Part.- } \\
\text { bound, } \\
\mu \mathrm{g} / \mathrm{Nm}^{3}\end{array}$ & $\begin{array}{l}\text { Vapor- } \\
\text { Phase, } \\
\mu \mathrm{g} / \mathrm{Nm}^{3}\end{array}$ & $\begin{array}{l}\text { Total, } \\
\mu \mathrm{g} / \mathrm{Nm}\end{array}$ \\
\hline Antimony & 26.7 & 0.5 & 26.7 & 17.6 & 0.7 & 17.6 & 15.0 & 0.6 & 15.0 \\
\hline Arsenic & 53.5 & 2.0 & 53.5 & 48.0 & 2.6 & 48.0 & 51.5 & 2.5 & 51.5 \\
\hline Beryllium & 2.9 & 0.5 & 2.9 & 6.4 & 0.7 & 6.4 & 2.7 & 0.6 & 2.7 \\
\hline Cadmium & 7.5 & 0.2 & 7.5 & 5.3 & 0.2 & 5.3 & 4.9 & 0.2 & 4.9 \\
\hline Chromium & 49.4 & 1.4 & 50.8 & 49.4 & 0.6 & 50.0 & 66.0 & 1.6 & 67.6 \\
\hline Lead & 251.5 & 4.2 & 255.7 & 215.9 & 2.1 & 218.0 & 210.9 & 3.0 & 216.9 \\
\hline Mercury & 3.2 & 4.5 & 7.7 & 2.3 & 7.4 & 9.7 & 6.8 & 7.7 & 14.5 \\
\hline Nickel & 228.5 & 3.2 & 231.7 & 191.7 & 4.3 & 196.0 & 170.2 & 3.7 & 173.9 \\
\hline
\end{tabular}

${ }^{1}$ Shaded results are below detection limits. The shown values are the detection limits. Those results that are below detection limits are not added to calculate the total concentrations.

${ }^{2}$ Particulate-bound trace elements were based on the filters of the EPA Method 17 samples.

Table 9. Analyses of Trace Elements in Flue Gas at the Stack $^{1}$

\begin{tabular}{|c|c|c|c|c|c|c|c|c|c|}
\hline $\begin{array}{l}\text { Day } \\
\text { Time } \\
\text { Fuel } \\
\end{array}$ & $\begin{array}{l}11 / 19 / 02 \\
11: 08 \\
\text { PRB, TD }\end{array}$ & and Corn & & \multicolumn{3}{|c|}{$\begin{array}{l}09: 25 \\
100 \% \text { PRB }\end{array}$} & \multicolumn{3}{|c|}{$\begin{array}{l}13: 25 \\
100 \% \text { PRB }\end{array}$} \\
\hline $\begin{array}{l}\text { Trace } \\
\text { Element }\end{array}$ & $\begin{array}{l}\text { Part.- } \\
\text { bound, } \\
\mu \mathrm{g} / \mathrm{Nm}^{3}\end{array}$ & $\begin{array}{l}\text { Vapor- } \\
\text { Phase, } \\
\mu \mathrm{g} / \mathrm{Nm}^{3}\end{array}$ & $\begin{array}{l}\text { Total, } \\
\mu \mathrm{g} / \mathrm{Nm}^{3}\end{array}$ & $\begin{array}{l}\text { Part.- } \\
\text { bound, } \\
\mu \mathrm{g} / \mathrm{Nm}^{3}\end{array}$ & $\begin{array}{l}\text { Vapor- } \\
\text { Phase, } \\
\mu \mathrm{g} / \mathrm{Nm}^{3}\end{array}$ & $\begin{array}{l}\text { Total, } \\
\mu \mathrm{g} / \mathrm{Nm}^{3}\end{array}$ & $\begin{array}{l}\text { Part.- } \\
\text { bound, } \\
\mu \mathrm{g} / \mathrm{Nm}^{3}\end{array}$ & $\begin{array}{l}\text { Vapor- } \\
\text { Phase, } \\
\mu \mathrm{g} / \mathrm{Nm}^{3}\end{array}$ & $\begin{array}{l}\text { Total, } \\
\mu \mathrm{g} / \mathrm{Nm}^{3}\end{array}$ \\
\hline Antimony & $<2.1$ & $<0.5$ & $\mathrm{ND}^{2}$ & $<2.2$ & 0.5 & ND & $<2.2$ & 0.5 & ND \\
\hline Arsenic & $<1.4$ & $<1.8$ & ND & $<1.5$ & 1.9 & ND & $<1.5$ & $<1.9$ & ND \\
\hline Beryllium & $<0.7$ & $<0.5$ & ND & $<0.7$ & 0.5 & ND & $<0.7$ & 0.5 & ND \\
\hline Cadmium & $<0.05$ & $<0.1$ & ND & $<0.05$ & 0.1 & ND & $<0.05$ & 0.1 & ND \\
\hline Chromium & $<0.05$ & 0.4 & 0.4 & $<0.05$ & 0.5 & 0.5 & $<0.05$ & 0.5 & 0.5 \\
\hline Lead & 2.5 & 1.5 & 4.0 & $<1.5$ & 1.4 & 1.5 & $<1.5$ & $<1.0$ & ND \\
\hline Mercury & $<0.05$ & 5.4 & 5.4 & $<0.05$ & 6.1 & 6.1 & $<0.05$ & 6.5 & 6.5 \\
\hline Nickel & $<0.05$ & 3.0 & 3.0 & $<0.05$ & 1.7 & 1.7 & $<0.05$ & 1.0 & 1.0 \\
\hline
\end{tabular}

${ }^{1}$ Shaded results are below detection limits. The shown values are the detection limits. Those results that are below detection limits are not added to calculate the total concentrations.

${ }^{2} \mathrm{ND}$ (not detected) is defined as those results where both forms of the trace element are below detection limits.

scale unit. Some of these trace elements such as beryllium and chromium are very refractory and a large percentage of the total amount measured in the coal is expected to be in the bottom slag which was not analyzed. This was the case as the percentage of beryllium and chromium found in the ash compared as a function of that predicted by the coals was, $13.1 \%$ and $6.3 \%$, respectively. The one element that would be predicted to be almost all (>99\%) vaporized is mercury. Based on the average coal concentration, $F_{d}$ factor, and the heating value of the coal, the mercury in the flue gas is predicted to be $12.3 \mu \mathrm{g} / \mathrm{Nm}^{3}$ on a dry basis, the actual measured concentration is $9.7 \mu \mathrm{g} / \mathrm{Nm}^{3}$ or a balance of $78.8 \%$. It is also interesting to note that the antimony concentration in the coal was below detection limits but was measured in the fly ash both for both the pilot-scale and full-scale units. Using the detection limit of $0.1 \mu \mathrm{g} / \mathrm{g}$ in the coal, the $F_{d}$ factor, and the heating value of the coal the 


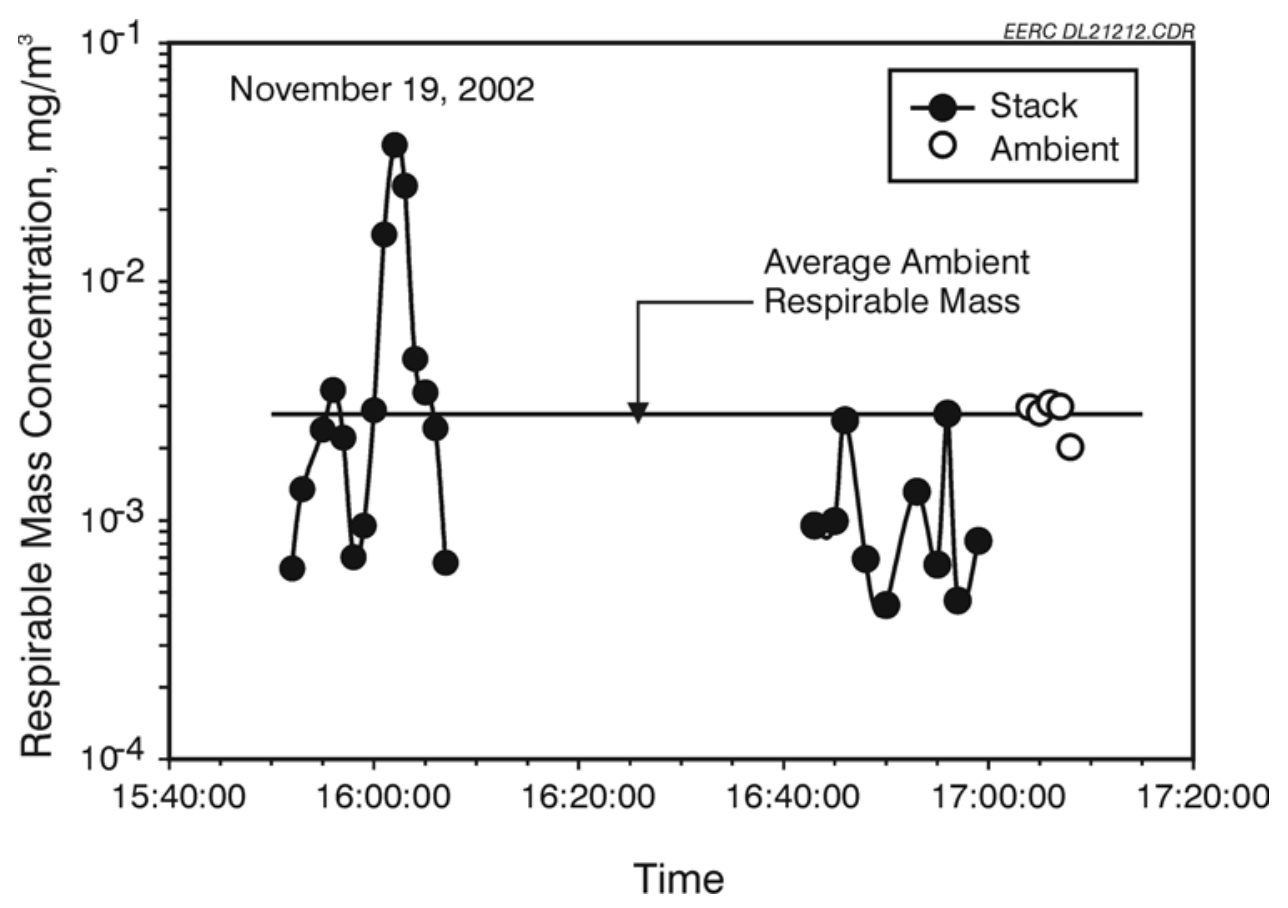

Figure 2. Respirable mass measurements at the stack of the Big Stone Power Plant for November 19, 2002.

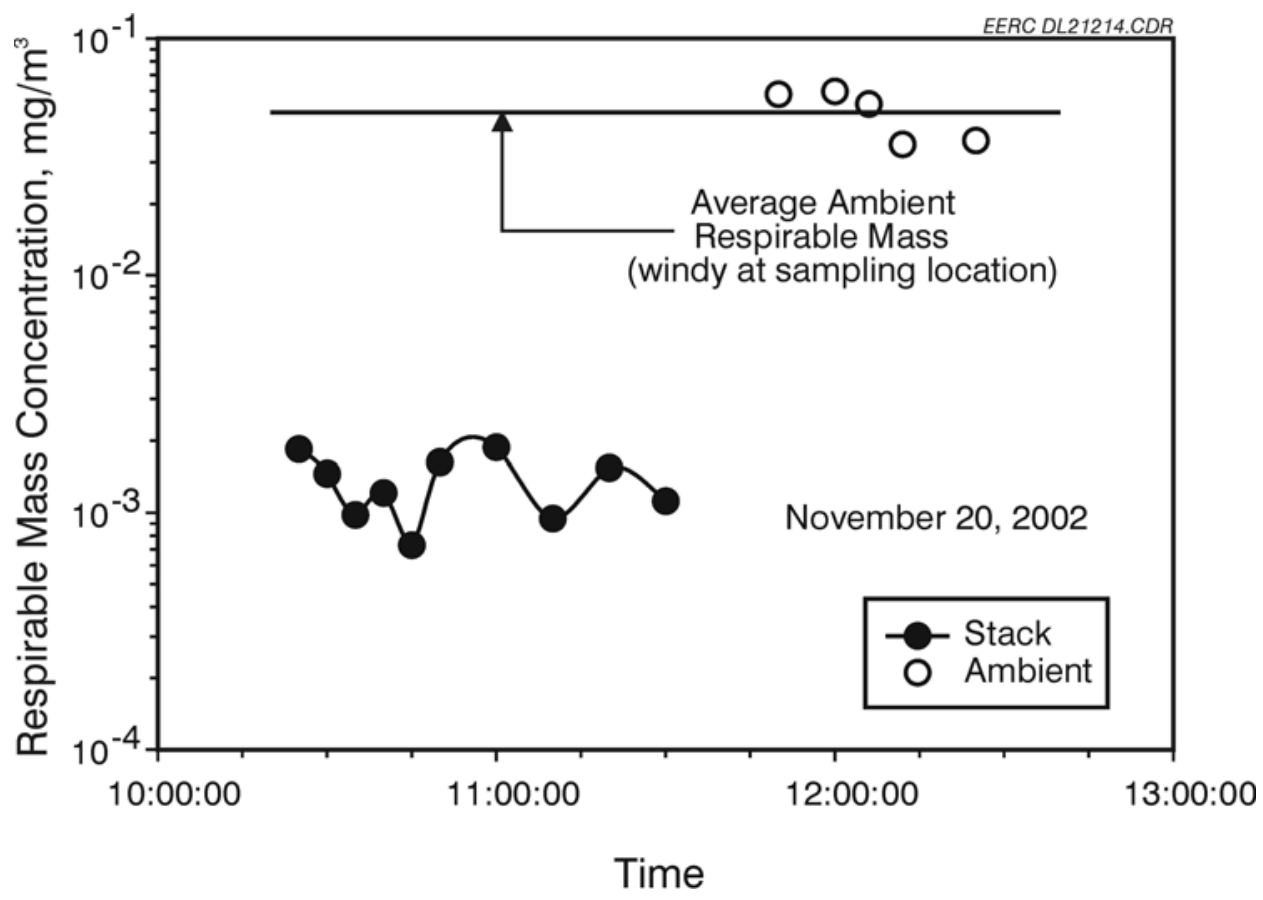

Figure 3. Respirable mass measurements at the stack of the Big Stone Power Plant for November 20, 2002. 


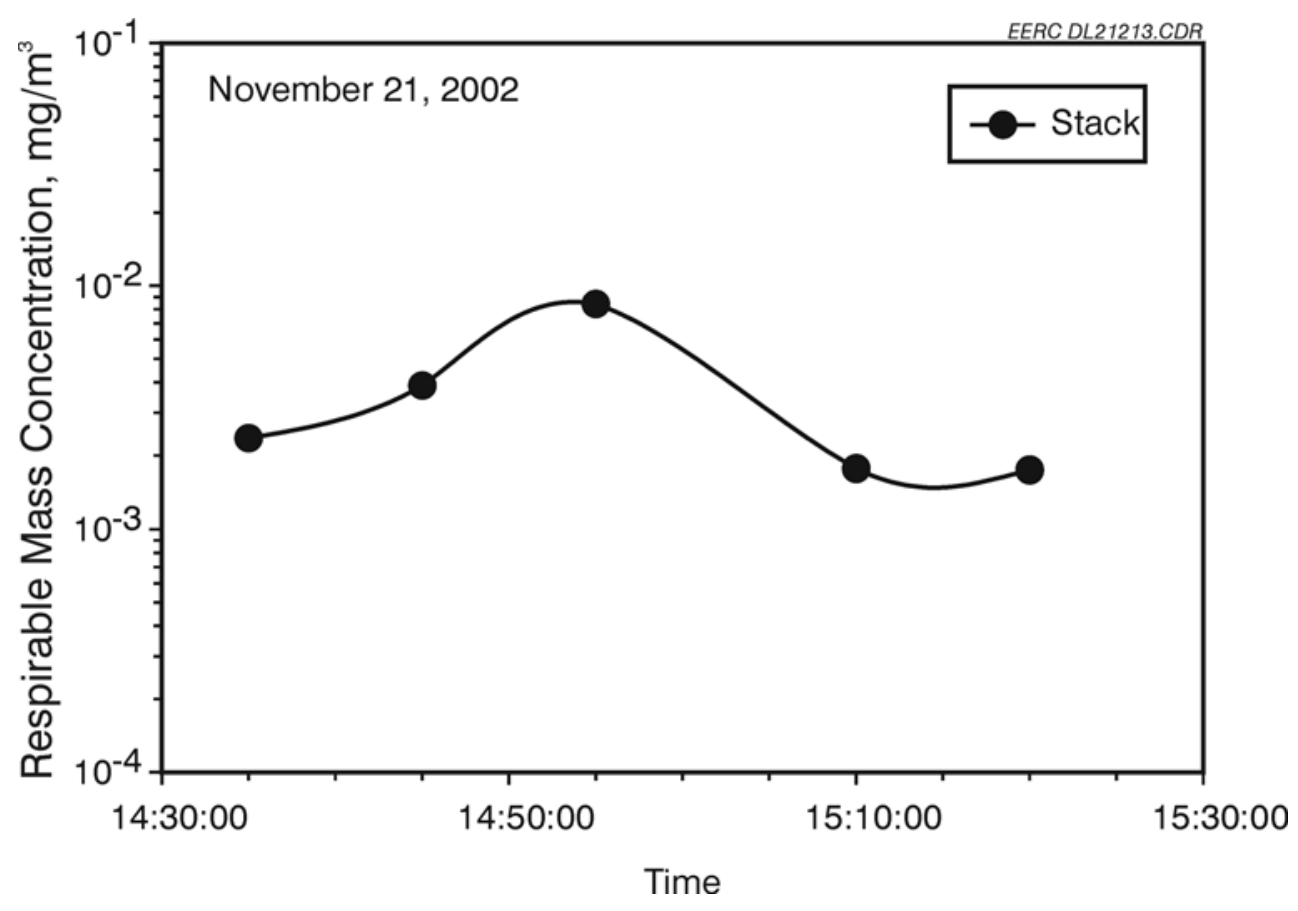

Figure 4. Respirable mass measurements at the stack of the Big Stone Power Plant for November 21, 2002.

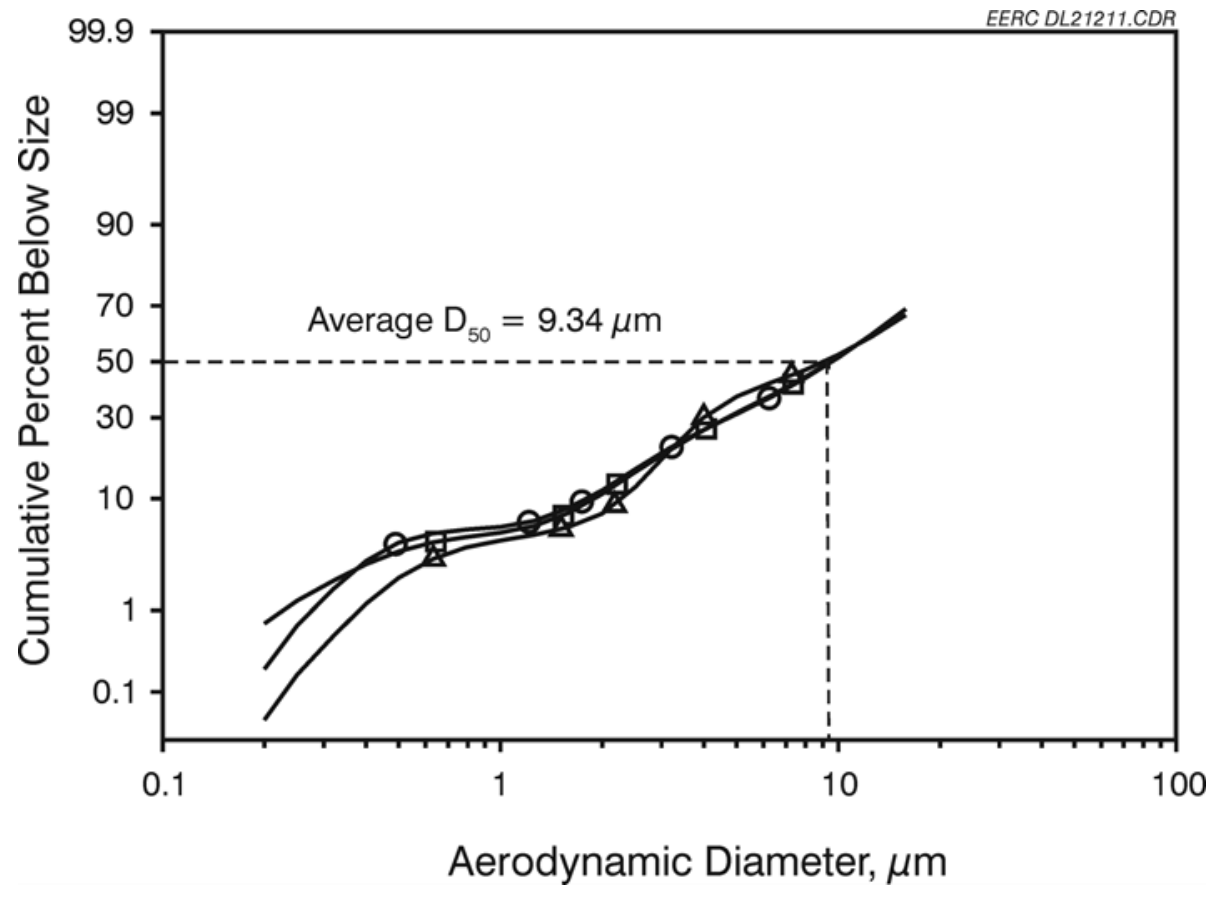

Figure 5. Particulate mass distribution at the Advanced Hybrid ${ }^{\mathrm{TM}}$ inlet based on mutlicyclone measurements. 


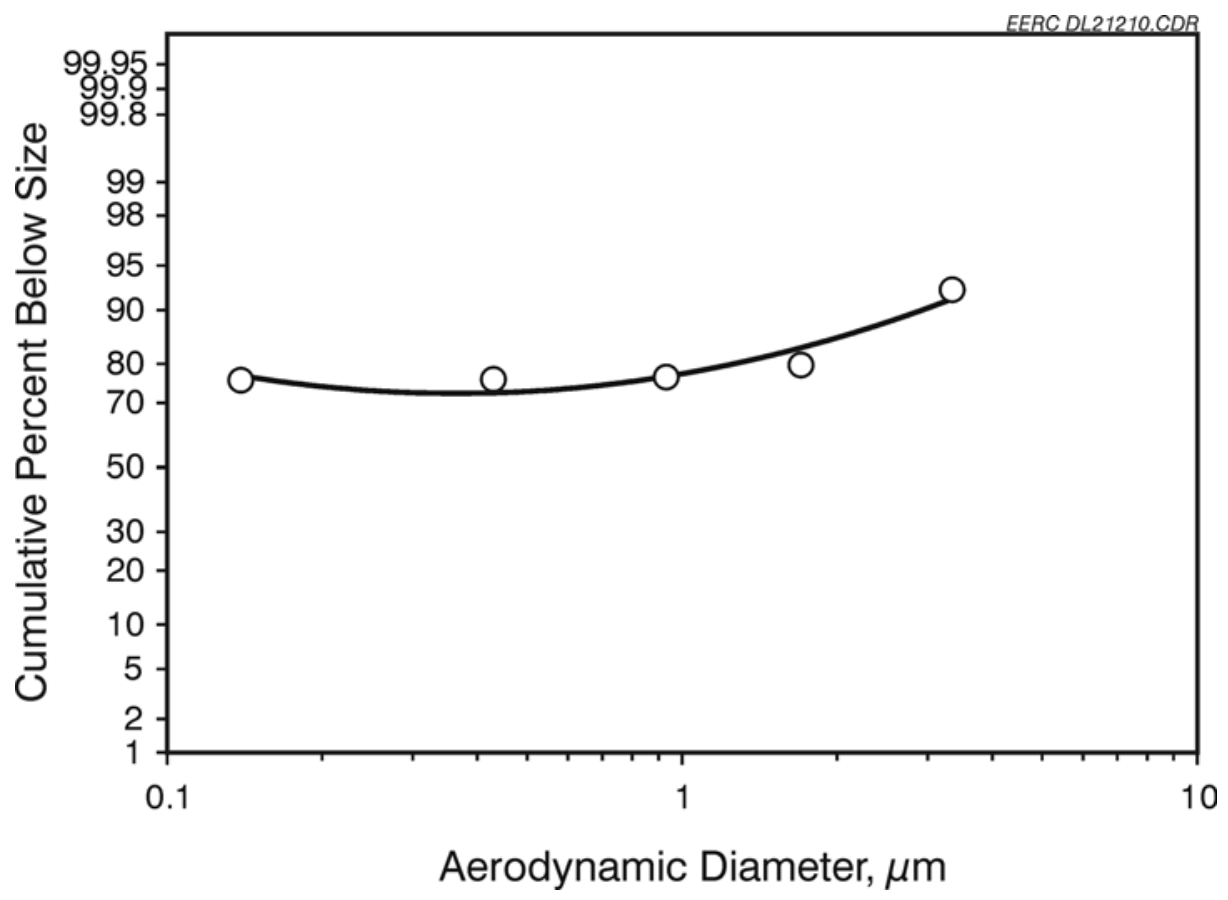

Figure 6. Particulate mass distribution at the stack based on an impactor measurement.

Table 10. Field Blank Results for EPA Method 29 Samples

\begin{tabular}{lllll}
\hline Trace Element & $\begin{array}{l}\text { Day } 1 \\
\mu \mathrm{g}\end{array}$ & $\mu \mathrm{g} / \mathrm{Nm}^{3 *}$ & $\begin{array}{l}\text { Day } 2 \\
\mu \mathrm{g}\end{array}$ & $\mu \mathrm{g} / \mathrm{Nm}^{3 *}$ \\
\hline Antimony & $<0.05$ & $<0.04$ & $<0.05$ & $<0.04$ \\
Arsenic & $<2$ & $<2$ & $<2$ & $<2$ \\
Beryllium & $<0.5$ & $<0.4$ & $<0.5$ & $<0.4$ \\
Cadmium & $<0.15$ & $<0.12$ & $<0.15$ & $<0.12$ \\
Chromium & 0.23 & 0.19 & 0.20 & 0.16 \\
Lead & 3.5 & 3.1 & 3.1 & 2.5 \\
Mercury & 0.16 & 0.13 & 0.10 & 0.08 \\
Nickel & 0.85 & 0.69 & $<0.5$ & $<0.4$ \\
\hline
\end{tabular}

*The gas concentration is calculated on the average volume of gas sampled for all the EPA Method 29 samples $\left(1.227 \mathrm{Nm}^{3}\right)$.

maximum concentration of antimony to the Advanced Hybrid ${ }^{\mathrm{TM}}$ is $19.7 \mu \mathrm{g} / \mathrm{Nm}^{3}$. With the exception of one data point, all the measured concentrations in the ash for both the pilot- and full-scale units are just below the maximum value. Table 13 presents the major element analysis for one of the $100 \%$ PRB ashes. Also shown in Table 13 is the LOI for the three ashes. 
Table 11. Comparison of the Concentration of Trace Elements at the Advanced Hybrid ${ }^{\mathrm{TM}}$ Inlet and Stack $^{1,2}$

\begin{tabular}{|c|c|c|c|c|c|c|}
\hline Day & $11 / 19 / 02$ & & $11 / 20 / 02$ & & $11 / 20 / 02$ & \\
\hline Time & $11: 08$ & & $09: 25$ & & $13: 25$ & \\
\hline Fuel & PRB, TRF, & Corn Seed & $100 \%$ PRB & & $100 \%$ PRB & \\
\hline & Advanced & & Advanced & & Advanced & \\
\hline & Hybrid $^{\mathrm{TM}}$ & & Hybrid $^{\mathrm{TM}}$ & & Hybrid $^{\mathrm{TM}}$ & \\
\hline $\begin{array}{l}\text { Trace } \\
\text { Element }\end{array}$ & $\begin{array}{l}\text { Inlet, } \\
\mathrm{lb} / 10^{12} \mathrm{Btu}\end{array}$ & $\begin{array}{l}\text { Stack, } \\
\mathrm{lb} / 10^{12} \text { Btu }\end{array}$ & $\begin{array}{l}\text { Inlet, } \\
\mathrm{lb} / 10^{12} \mathrm{Btu}\end{array}$ & $\begin{array}{l}\text { Stack, } \\
\mathrm{lb} / 10^{12} \mathrm{Btu}\end{array}$ & $\begin{array}{l}\text { Inlet, } \\
\mathrm{lb} / 10^{12} \mathrm{Btu}\end{array}$ & $\begin{array}{l}\text { Stack, } \\
\mathrm{lb} / 10^{12} \mathrm{Btu}\end{array}$ \\
\hline Antimony & 15.8 & $\mathrm{ND}^{3}$ & 10.4 & ND & 8.9 & ND \\
\hline Arsenic & 31.7 & ND & 28.4 & ND & 30.5 & ND \\
\hline Beryllium & 1.7 & ND & 3.8 & ND & 1.6 & ND \\
\hline Cadmium & 4.4 & ND & 3.1 & ND & 2.9 & ND \\
\hline Chromium & 30.1 & 0.2 & 29.6 & 0.3 & 40.0 & 0.3 \\
\hline Lead & 151.3 & 2.4 & 129.0 & 0.9 & 128.4 & ND \\
\hline Mercury & 4.6 & 3.2 & 5.7 & 3.6 & 8.6 & 3.8 \\
\hline Nickel & 137.1 & 1.8 & 116.0 & 1.0 & 102.9 & 0.6 \\
\hline
\end{tabular}

${ }^{1}$ All values shown are calculated based on Tables 8 and 9 and the Fd factor shown in Table 5 for $100 \%$ PRB.

${ }^{2} \mathrm{ND}$ (not detected) is defined as those results where both the gas-phase and particulate bound forms of the trace elements are below detection limits.

Table 12. Trace Element Analyses of Pilot-Scale Advanced Hybrid ${ }^{\mathrm{TM}}$ Hopper Ash

\begin{tabular}{lllllll}
\hline Date & $11 / 18 / 02$ & \multicolumn{3}{c}{$11 / 19 / 02$} & & $11 / 20 / 02$ \\
Trace Element & $\mu \mathrm{g} / \mathrm{g}$ & $\mu \mathrm{g} / \mathrm{Nm}^{3 *}$ & $\mu \mathrm{g} / \mathrm{g}$ & $\mu \mathrm{g} / \mathrm{Nm}^{3 *}$ & $\mu \mathrm{g} / \mathrm{g}$ & $\mu \mathrm{g} / \mathrm{Nm}^{3 *}$ \\
\hline Antimony & 6.7 & 14 & 6.3 & 14 & 6.9 & 15 \\
Arsenic & 19 & 41 & 20 & 43 & 21 & 45 \\
Beryllium & 1.9 & 4.1 & 2.2 & 4.72 & 1.9 & 4.08 \\
Cadmium & 2.1 & 4.5 & 2.1 & 4.5 & 2.1 & 4.5 \\
Chromium & 20 & 43 & 24 & 51 & 28 & 60 \\
Lead & 78.7 & 169 & 77.5 & 166 & 84.0 & 180 \\
Mercury & 0.655 & 1.41 & 0.564 & 1.21 & 0.551 & 1.18 \\
Nickel & 95 & 204 & 93 & 199 & 84 & 180 \\
\hline
\end{tabular}

* The gas concentration is calculated on an average dust loading of $0.93664 \mathrm{gr} / \mathrm{scf}$ to the Advanced Hybrid ${ }^{\mathrm{TM}}$ hopper (from EPA Method 17 samples on full-scale unit).

\section{CONCLUSIONS}

From the data, the primary conclusion was that the Advanced Hybrid ${ }^{\mathrm{TM}}$ technology is extremely efficient in removing particulate matter. The particulate efficiency is substantially better than the designed basis of $99.990 \%$. The average particulate collection efficiency was $99.997 \%$. The outlet dust loading was almost an order of magnitude lower than the proposed limit of 0.002 grain $/ \mathrm{scf}$. As would be expected from a concept that provides ultra-high collection efficiency for particulate matter, the Advanced Hybrid $^{\mathrm{TM}}$ Filter removed those trace elements associated with the particulate matter at very high efficiencies as well. As measured at the stack, all trace elements, with the exception of mercury, were near or below detection limits. 
Table 13. Elemental Analysis of Advanced Hybrid ${ }^{\text {TM }}$ Pilot-Scale Hopper Ash, $100 \%$ PRB Coal

\begin{tabular}{llll}
$\begin{array}{l}\text { Date Sampled } \\
\text { Oxide }\end{array}$ & $\begin{array}{l}11 / 18 / 02 \\
\%\end{array}$ & $\begin{array}{l}11 / 19 / 02 \\
\%\end{array}$ & $\begin{array}{l}11 / 20 / 02 \\
\%\end{array}$ \\
\hline $\mathrm{SiO}_{2}$ & & 20.9 & \\
$\mathrm{Al}_{2} \mathrm{O}_{3}$ & 16.1 & \\
$\mathrm{Fe}_{2} \mathrm{O}_{3}$ & 7.30 & \\
$\mathrm{CaO}$ & 34.8 & \\
$\mathrm{MgO}$ & & 5.93 & \\
$\mathrm{Na}_{2} \mathrm{O}$ & 3.14 & \\
$\mathrm{~K}_{2} \mathrm{O}$ & 0.80 & \\
$\mathrm{P}_{2} \mathrm{O}_{5}$ & & 2.87 & \\
$\mathrm{TiO}_{2}$ & 1.58 & \\
$\mathrm{BaO}$ & 1.18 & \\
$\mathrm{MnO}$ & & 0.07 & \\
$\mathrm{SrO}$ & 0.53 & \\
$\mathrm{SO}$ & & 4.83 & \\
$\mathrm{LOI}$ & & 0.72 & \\
$\mathrm{Cu}, \mathrm{mg} / \mathrm{kg}$ & 370 & \\
$\mathrm{~V}, \mathrm{mg} / \mathrm{kg}$ & & 300 & \\
$\mathrm{Zn}, \mathrm{mg} / \mathrm{kg}$ & & 2170 & \\
\hline
\end{tabular}




\section{B25 E-mail from Stan Miller on soybean burn}

Effect of Soy Bean Burning on AH performance

Page 1 of 1

\section{Hrdlicka, Thomas}

From: Miller, Stanley J. [smiller@undeerc.org]

Sent: $\quad$ Friday, April 11, 2003 11:07 AM

To: Swanson, William; Hrdlicka, Thomas; Rich Gebert (rgebert@wlgore.com); Dwight R. Davis (ddavis@wlgore.com); Craig Rinschler (P.E.) (crinschl@wlgore.com); Rick Bucher (rbucher@wlgore.com)

Cc: Jones, Michael L.; Olderbak, Michelle

Subject: Effect of Soy Bean Burning on $\mathrm{AH}$ performance

I received two samples from Rich of ash brushed from the bags removed in the full-scale Big Stone $\mathrm{AH}$ in November and March. Our first XRF analysis shows the November potassium level to be $0.4 \%$ compared to $3.2 \%$ for the March bag sample. Keep in mind that these samples would likely be a mixture of the entire dust cake going back to start up so at times the actual potassium level of additional ash on the surface may be much higher. The sulfate level was also much higher for the March sample. We are doing some additional scanning electron microscopy analysis of undisturbed ash from a bag sample which may provide further insight as to the effect of the high potassium levels.

I also looked at the pilot-scale data from February and saw an immediate increase in residual drag and decrease in bag cleaning interval on Feb 4, which is the day when there was a large increase in the amount of waste seeds being burned. The pilot unit was operated until Feb 11, but much of the operation was with single bank and a short pulse interval. However, before shutting down, we operated for about a day in baseline conditions again. By this time the residual drag and bag cleaning interval had deteriorated even more. The waste seed rate feed rate from Feb 5 to 11 was 260 to 315 tons per day. From Feb 12 until Feb 23 the seed feed rate was increased significantly and was over 800 tons per day from Feb 21 to 23.

All of this points to the waste seed burning as having a significant negative effect on the pressure drop.

It should also be noted that in the EERC small-scale pilot tests in January, we saw higher pressure drop when we increased the rate of TDF up to $10 \%$. This is higher than the $5 \%$ that is occasionally burned at Big Stone, but it is another indication that alternative fuel burning can have a very negative effect on the pressure drop.

I suggest that all waste seed and TDF burning be stopped at the plant, at least until the pressure drop issues are solved. This is especially important for the time immediately after washing the bags. It may be shown in the future that a level of alternative fuels can be tolerated, but for the near term if we are looking for all ways to minimize pressure drop, it seems to be the way to go.

I will be out of the office on vacation from April 14 through 22, but can be reached if necessary.

Thanks,

Stan 

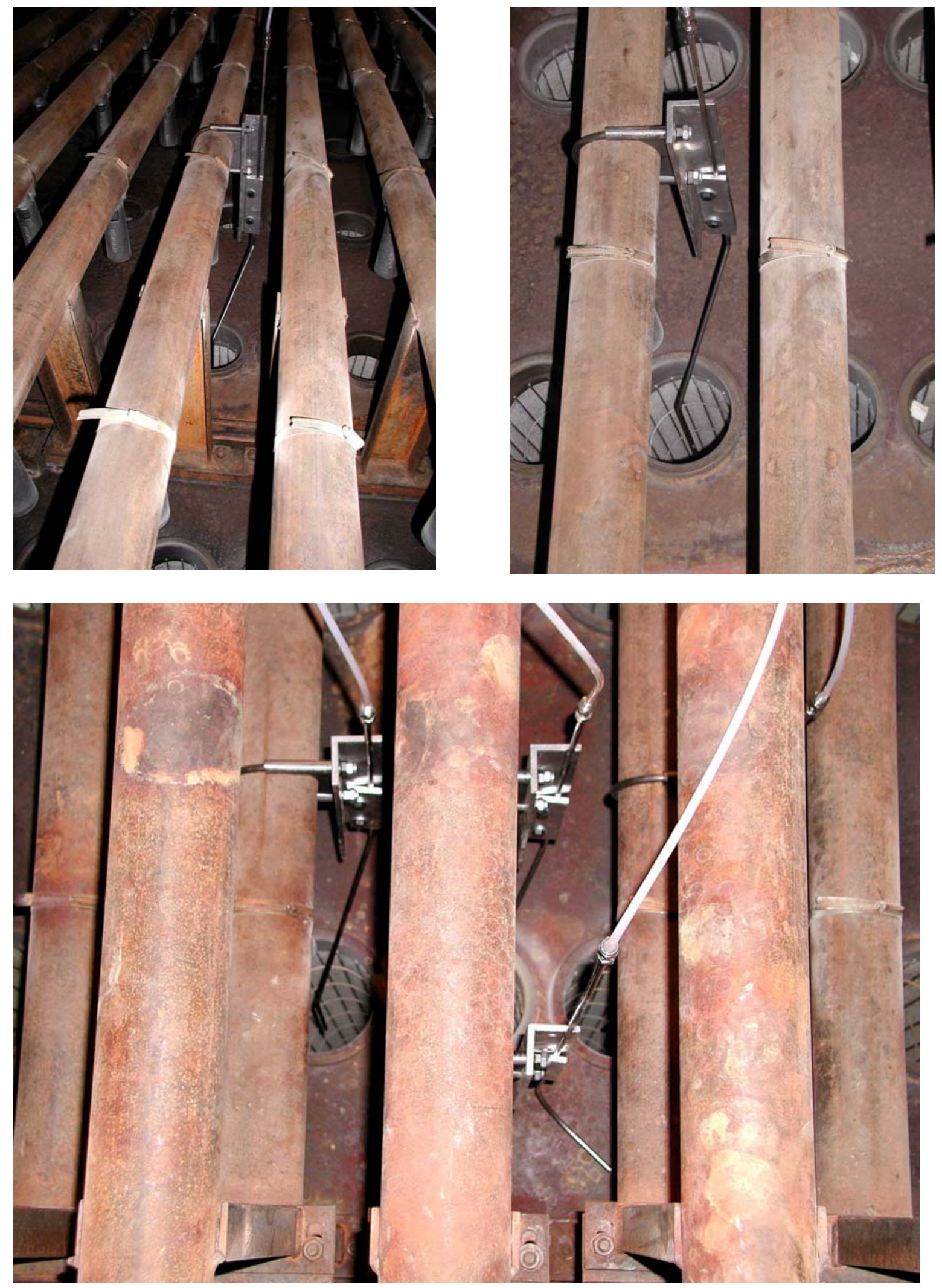


\section{B27 Specific pitot tube information}

Pitot Tube in a Filter Bag, Gas Flow Measurement Device Big Stone Application with 19 inch Spacing between Blowpipe and Tubesheet

Revised on May 28, 2003

\section{Material List}

Material Size Quantity

304 stainless steel tubing

ID 0.12 inch, OD 0.25 inch $\times 0.065$ inch wall

Length of each piece 40 inch

U bolt clamp steel

3.0 inch diameter steel pipe with 3.5" O.D.

Bolt spacing 4.0 inch

McMaster-Carr \# 3042T21

Aluminum or steel angle for Plate Mount 1.5 " x 2.0"x 12"x 0.25 " 10

Aluminum or steel bar for Plate Clamp $1.5 " \times 6 " \times 0.25 " \quad 10$

Steel Bolts

$5 / 16 \times 18 \times 1.25 "$

Steel locking nuts (optional)

$5 / 16 \times 18$ steel locking $\quad 20$

Flat steel washers

$5 / 16 \quad 20$

Flat steel washers $\quad 3 / 8 \quad 20$

Steel locking nuts (for 500F), (optional) $\quad 3 / 8$ steel locking $\quad 20$

\section{Instructions:}

$\underline{304}$ stainless steel tubing

- Cut to 40 inch length

- Create round nose on one end (radius of 0.100-0.125 inch) from center of tubing

- Make 2 bends in same plane ,45 degrees each, as per drawing .

- First bend 45 degrees 10 inches from Nose of tubing

- Second bend 45 degrees 10 inches from previous bend in opposite direction.

- With tubing cutter cut and trim end of tubing for compression fitting

Aluminum or steel angle for Plate Mount 1.5 " x 2.0"x 12 "x 0.25 "

- Drill 2 through holes oversize for $3 / 8$ inch diameter U bolt.

- Drill 2 through holes over size for $5 / 16 \times 18$ bolts

- Machine groove ( 0.125 inch radius) to ( 0.080 inch depth) for $1 / 4$ inch OD tubing

Aluminum or steel bar for Plate Clamp 1.5 " 6 6" x 0.25 "

- Drill 2 through holes over size for $5 / 16 \times 18$ bolts

- Machine groove (0.125 inch radius) to ( 0.080 inch depth) for $1 / 4$ inch OD tubing 


\section{Bag Flow Pitot Tube Measurement Device}

\section{Tubing - Pitot Tube}

\section{4 stainless steel tubing 40 inch length}

- Create round nose on one end (radius of 0.100-0.125 inch) from center of tubing

- Make 2 bends in same plane ,45 degrees each, as per drawing .

- First bend 45 degrees 10 inches from Nose of tubing

- Second bend 45 degrees 10 inches from previous bend in opposite direction.

- Debur opposite end of tubing for compression fitting

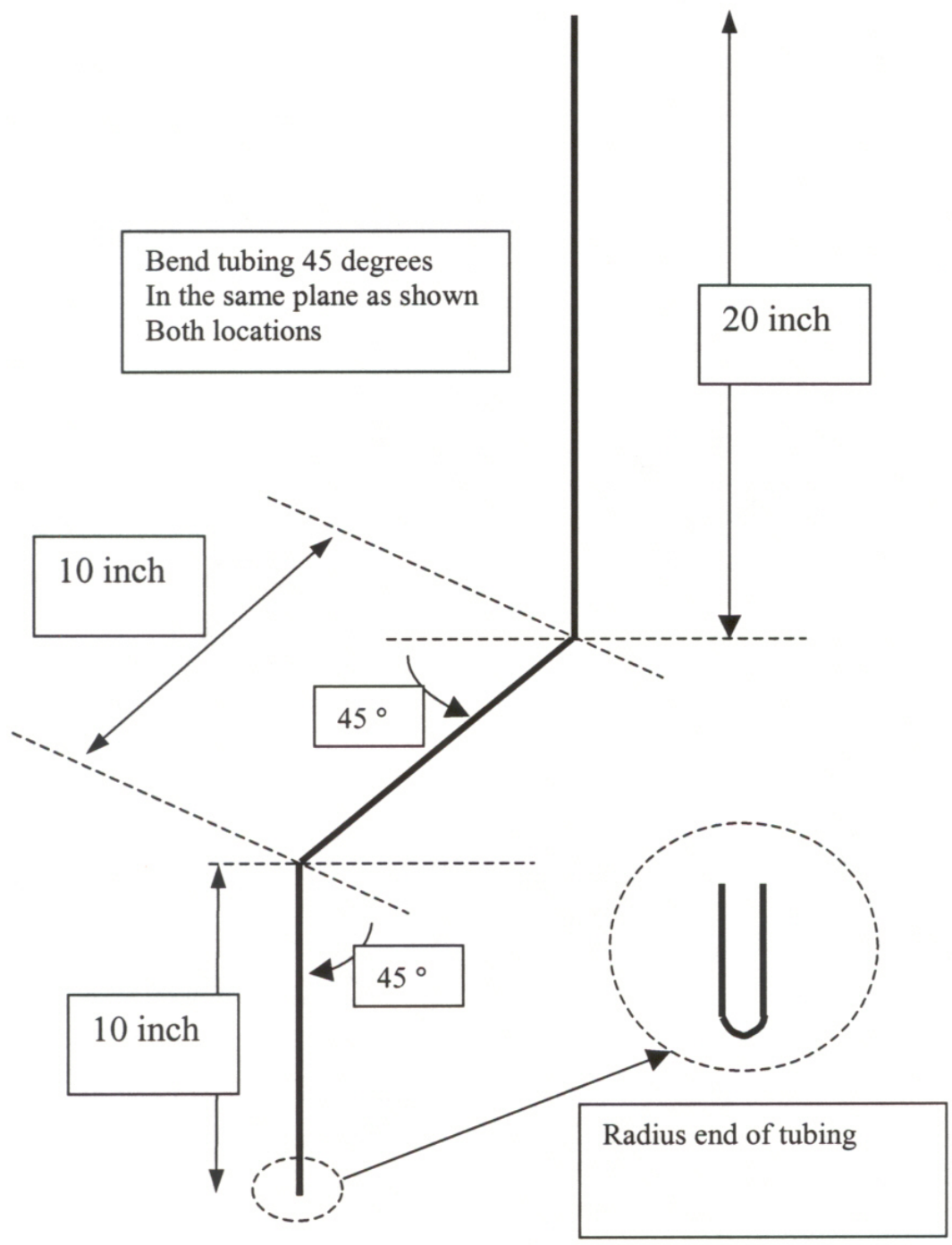




\section{Bag Flow Pitot Tube Measurement Device}

\section{Plate Mount}

Aluminum or steel angle for Plate Mount 1.5 " x 2.0 "x 12 "x 0.25 "

1. Drill 2 through holes and oversize for $3 / 8$ inch diameter $\mathrm{U}$ bolt.

2. Drill 2 through holes and over size for $5 / 16 \times 18$ bolts

3. Machine groove ( 0.125 inch radius) to (0.080 inch depth) for $1 / 4$ inch OD tubing

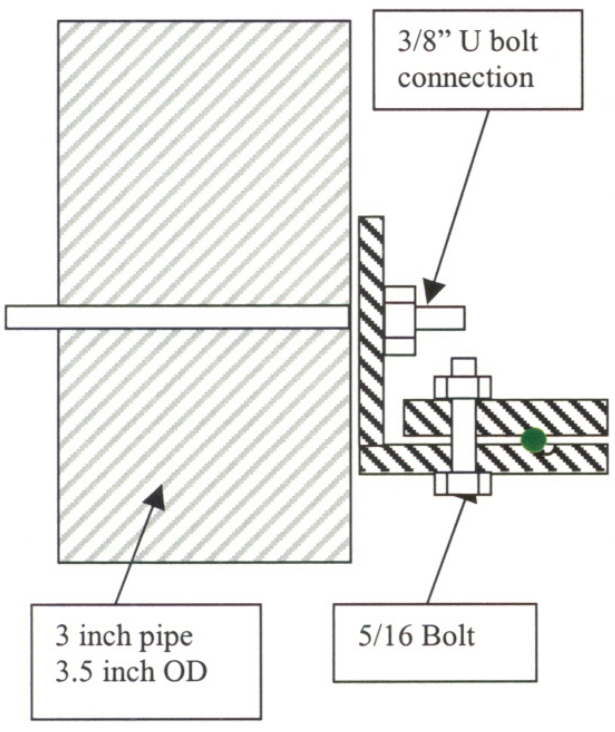

\section{Assembly Drawing}

Richard Gebert

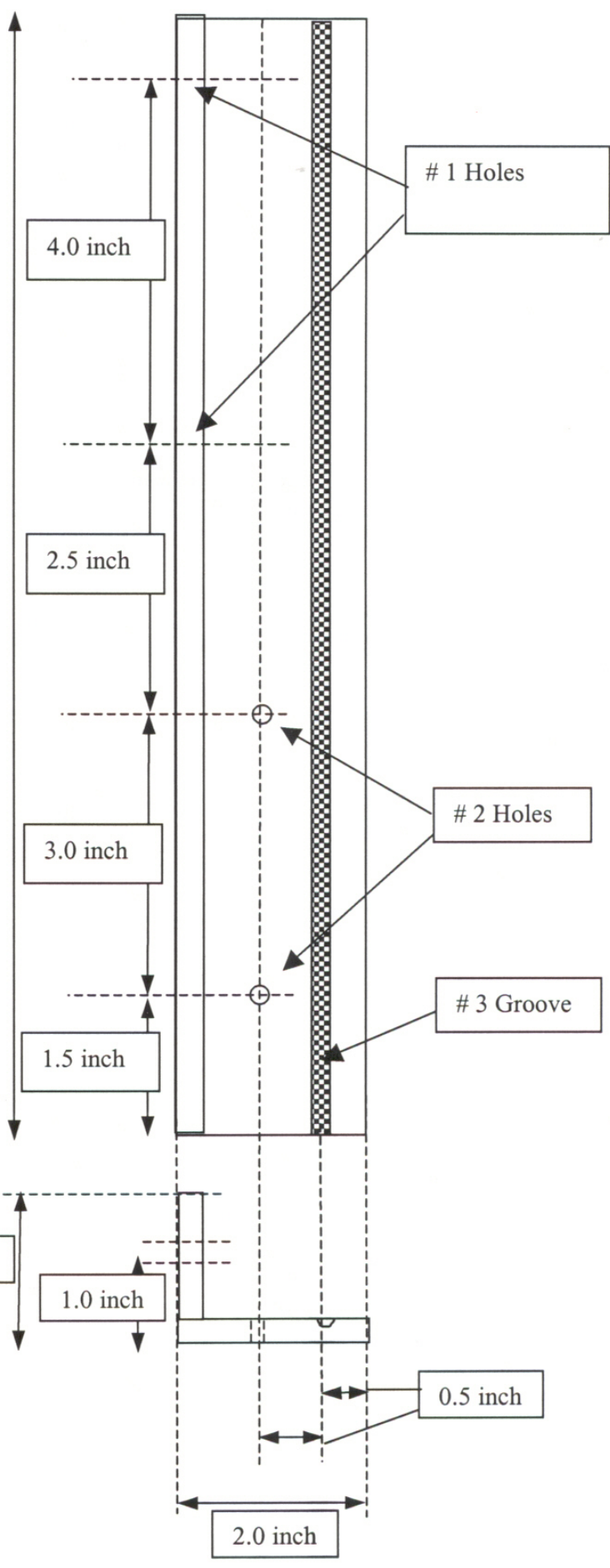

Page 3
$5 / 19 / 2004$ 


\section{Bag Flow Pitot Tube Measurement Device}

\section{Plate Clamp}

Aluminum or steel bar for Plate Clamp $\quad 1.5$ " x 6" x 0.25 "

4. Drill 2 through holes over size for $5 / 16 \times 18$ bolts

5. Machine 0.125 inch radius groove 0.080 inch depth for $1 / 4$ inch tubing

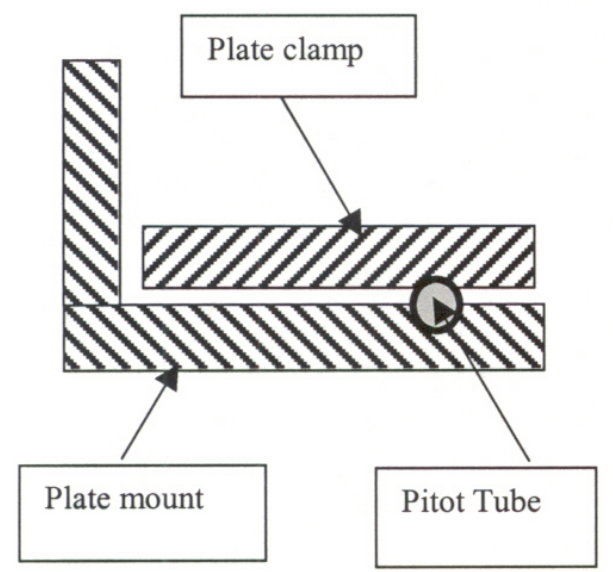

Assembly Drawing

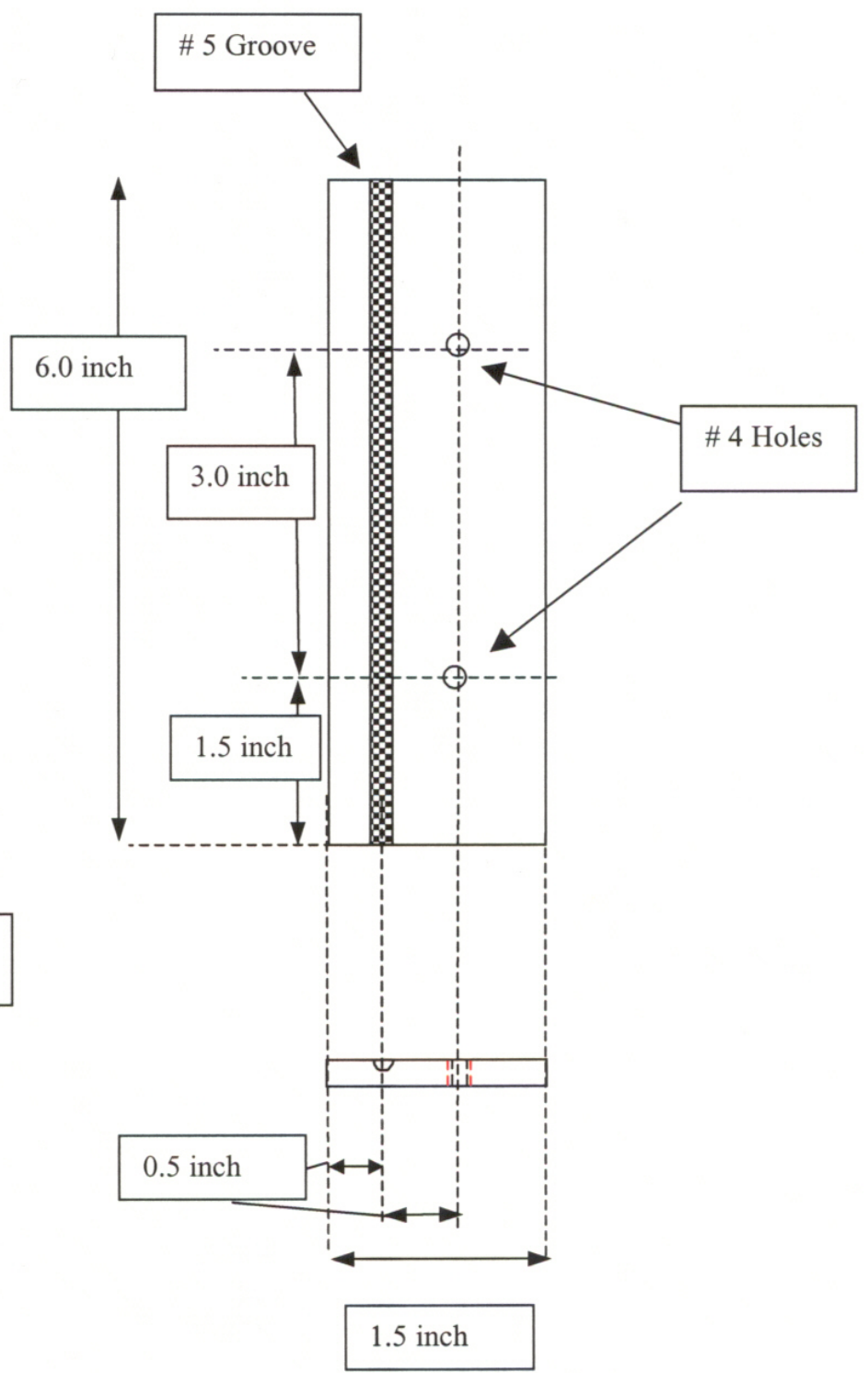


B28 Specific Pitot Tube Placement on Bag Layout Diagram

Advanced Hybrid bag layout Big Stone Plant

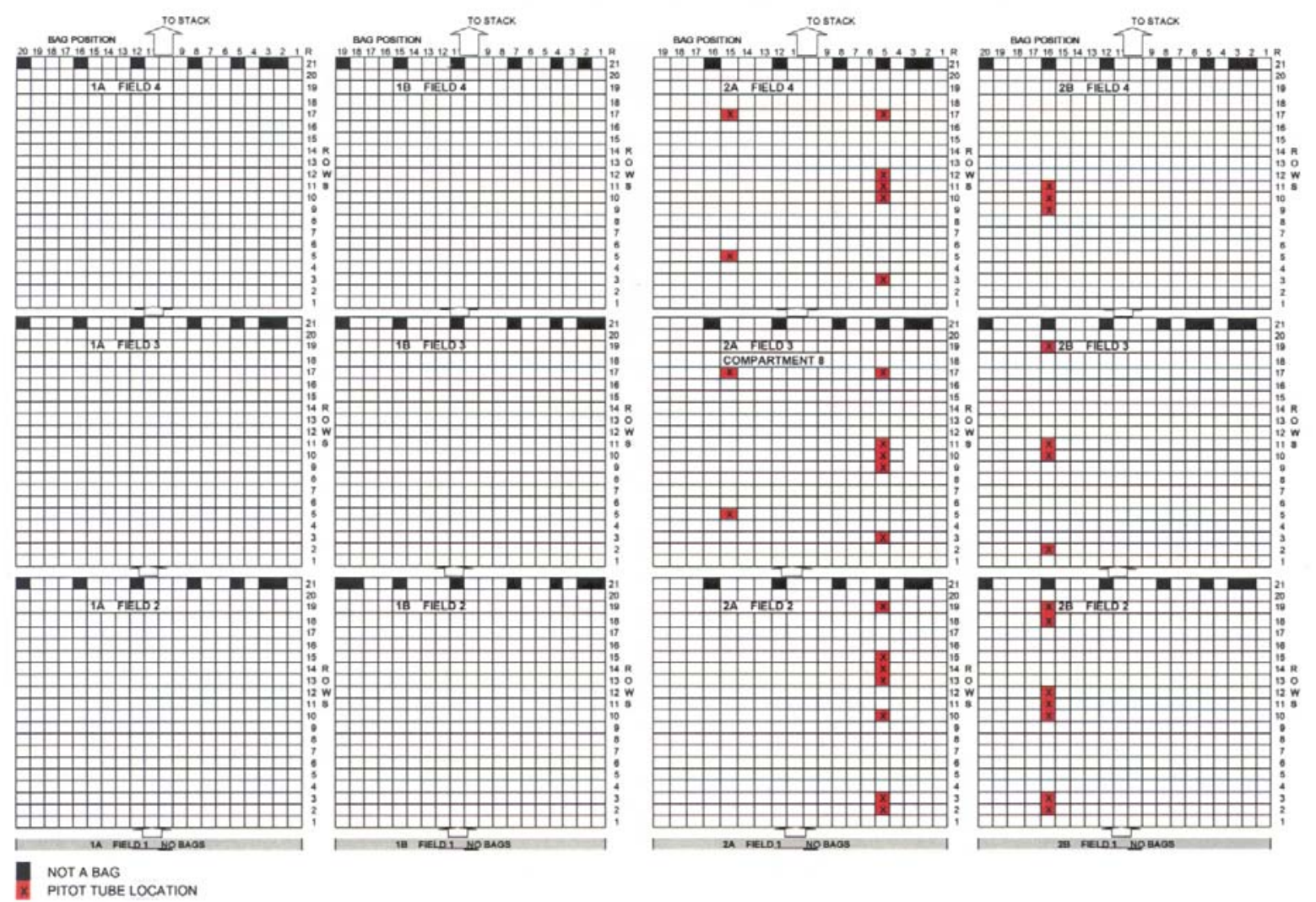


B29 Photographs of pitot tube transmitters

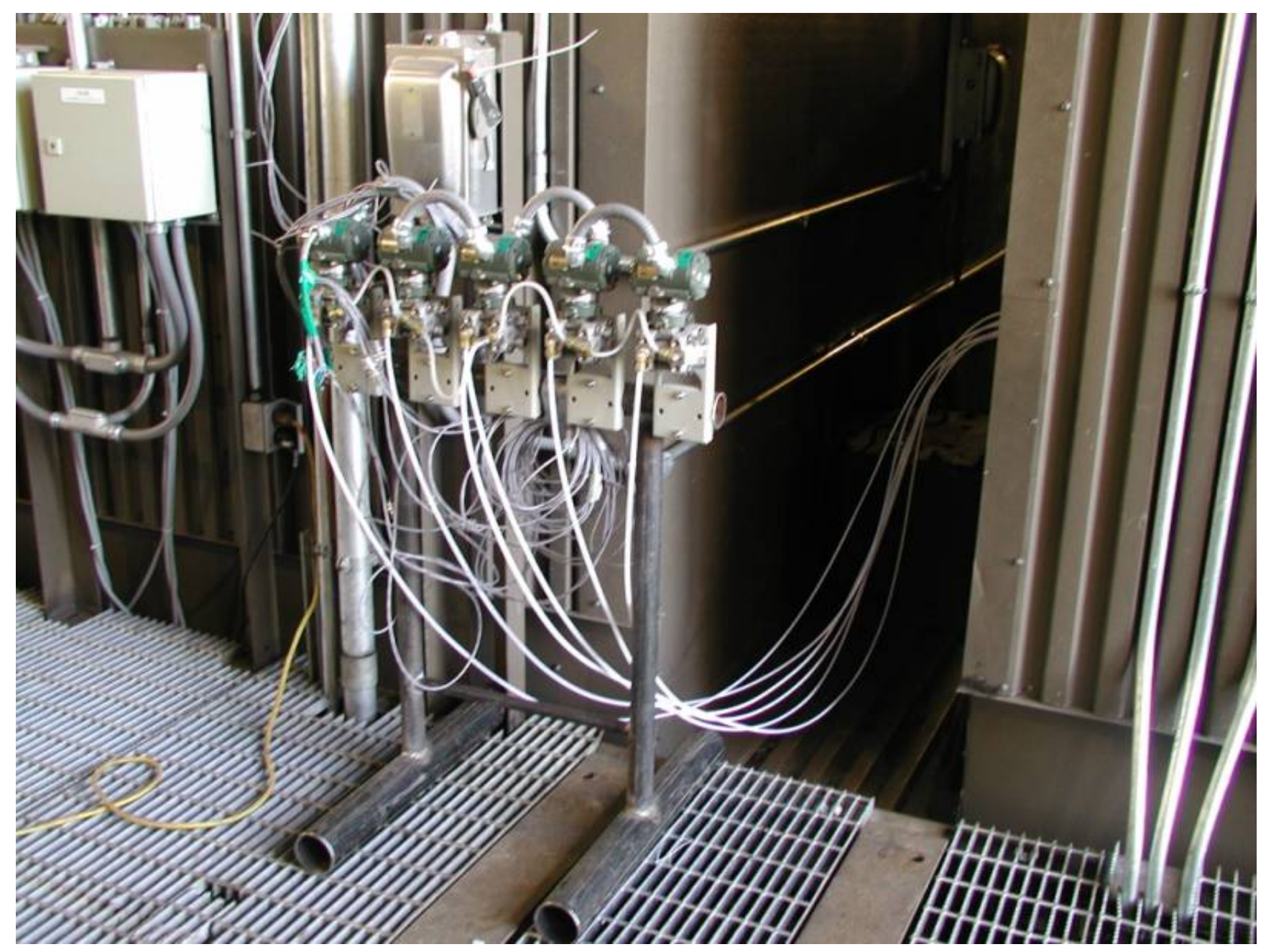




\section{April 29,2003}

Big Stone Plant

AHPC Bag Wash

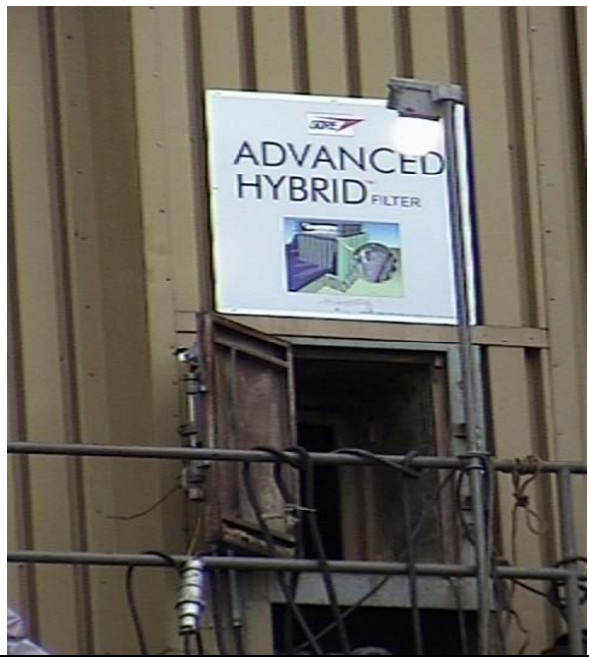

OK, these are Confined Spaces, everyone sign on the Permit

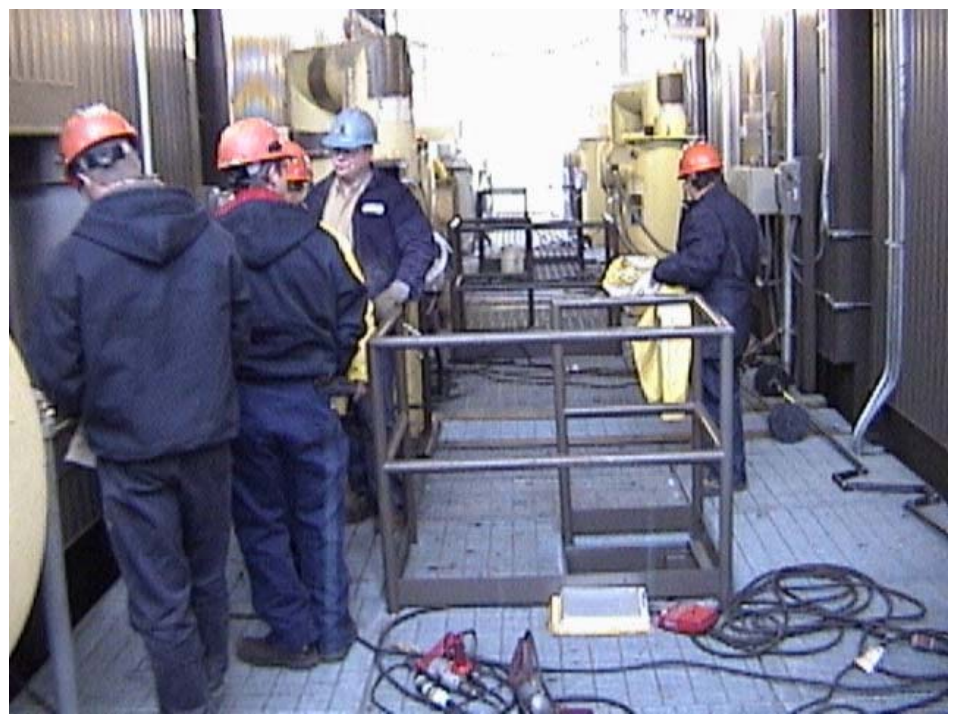




\section{Work begins - Blowpipe removal}

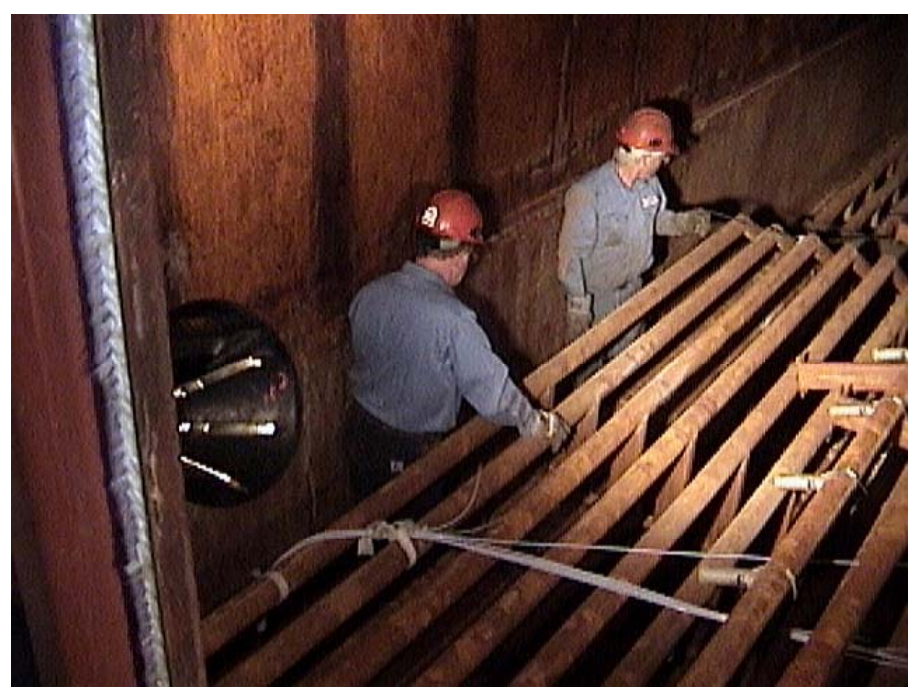

Safety - Make sure the TR Set is Grounded out

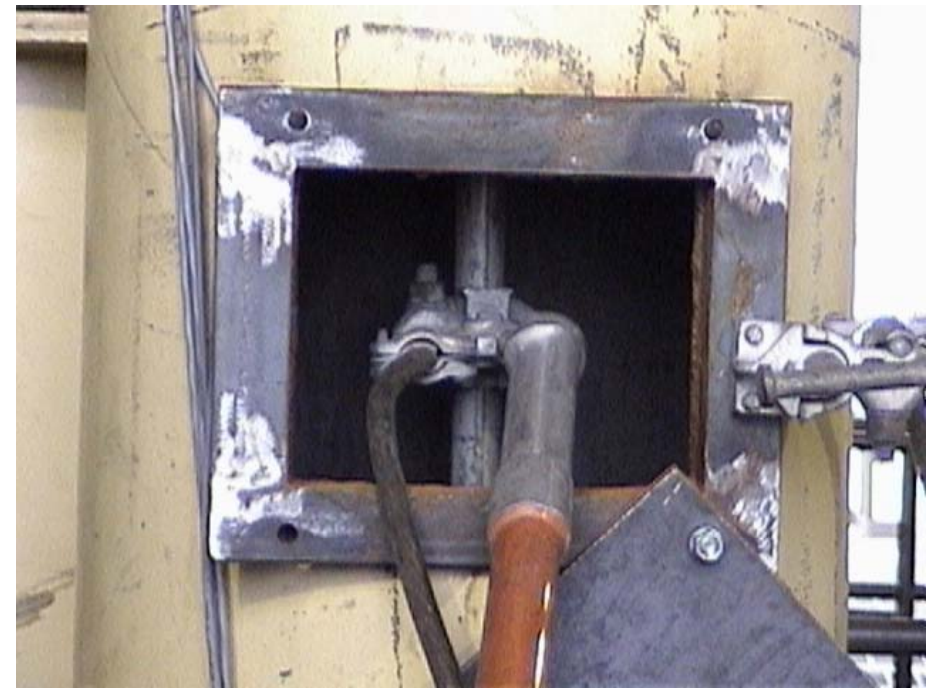




\section{Blowpipe's out}

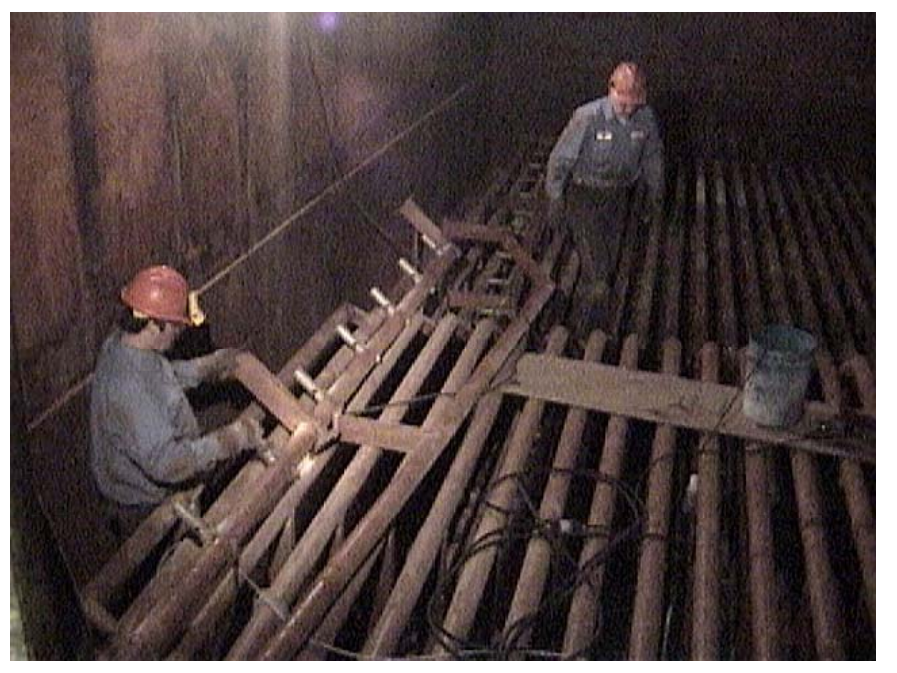

Drilling access holes for the wash

(126 of em')

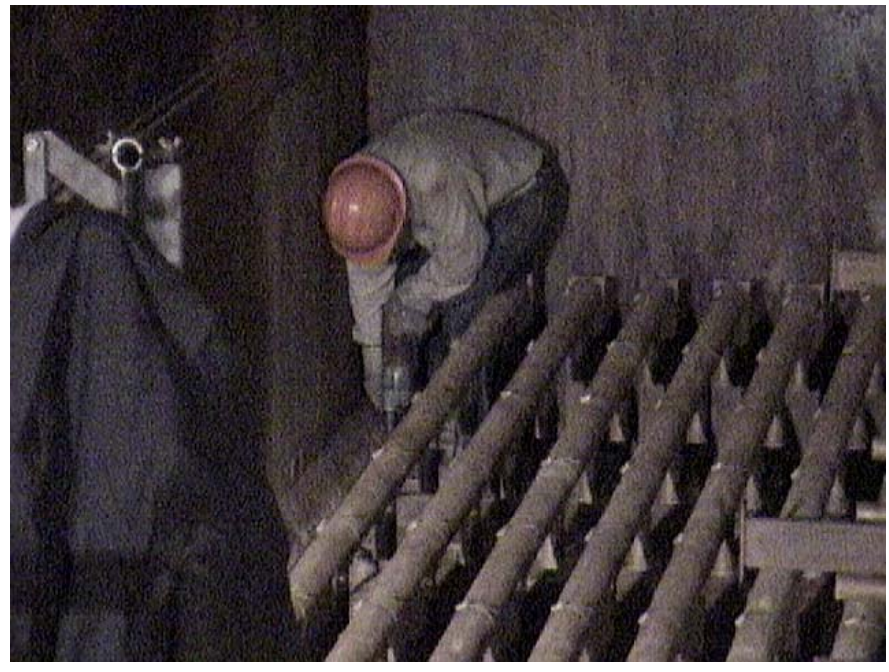




\section{The Wash headers standby - Ready for Service}

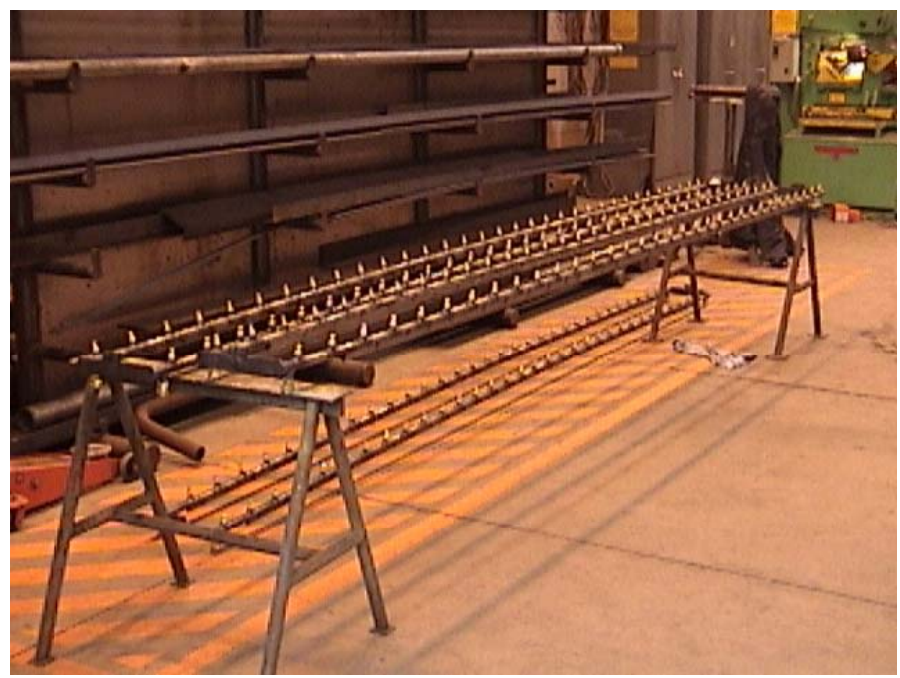

Getting ready to wash Setting up the hoists

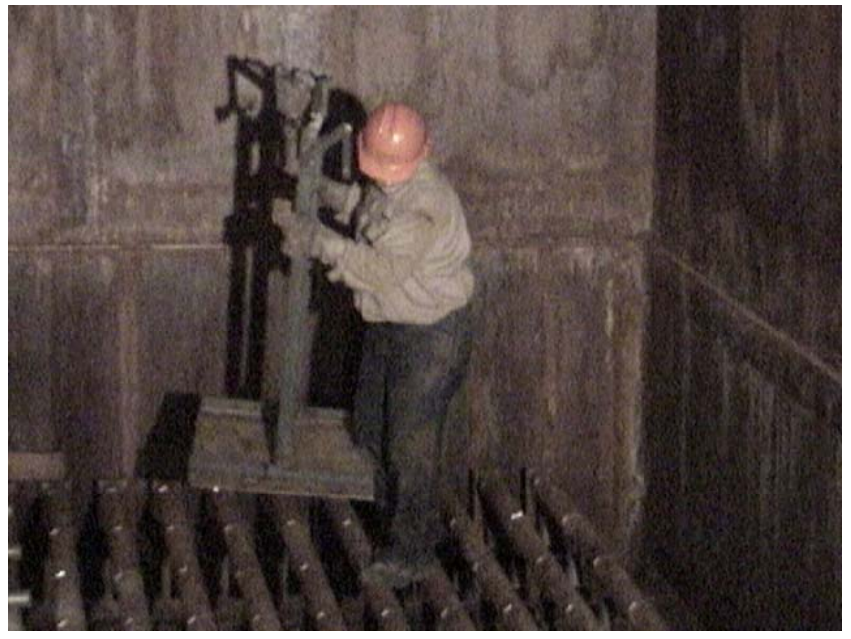




\section{Crews preparing to enter the Gas}

path compartments
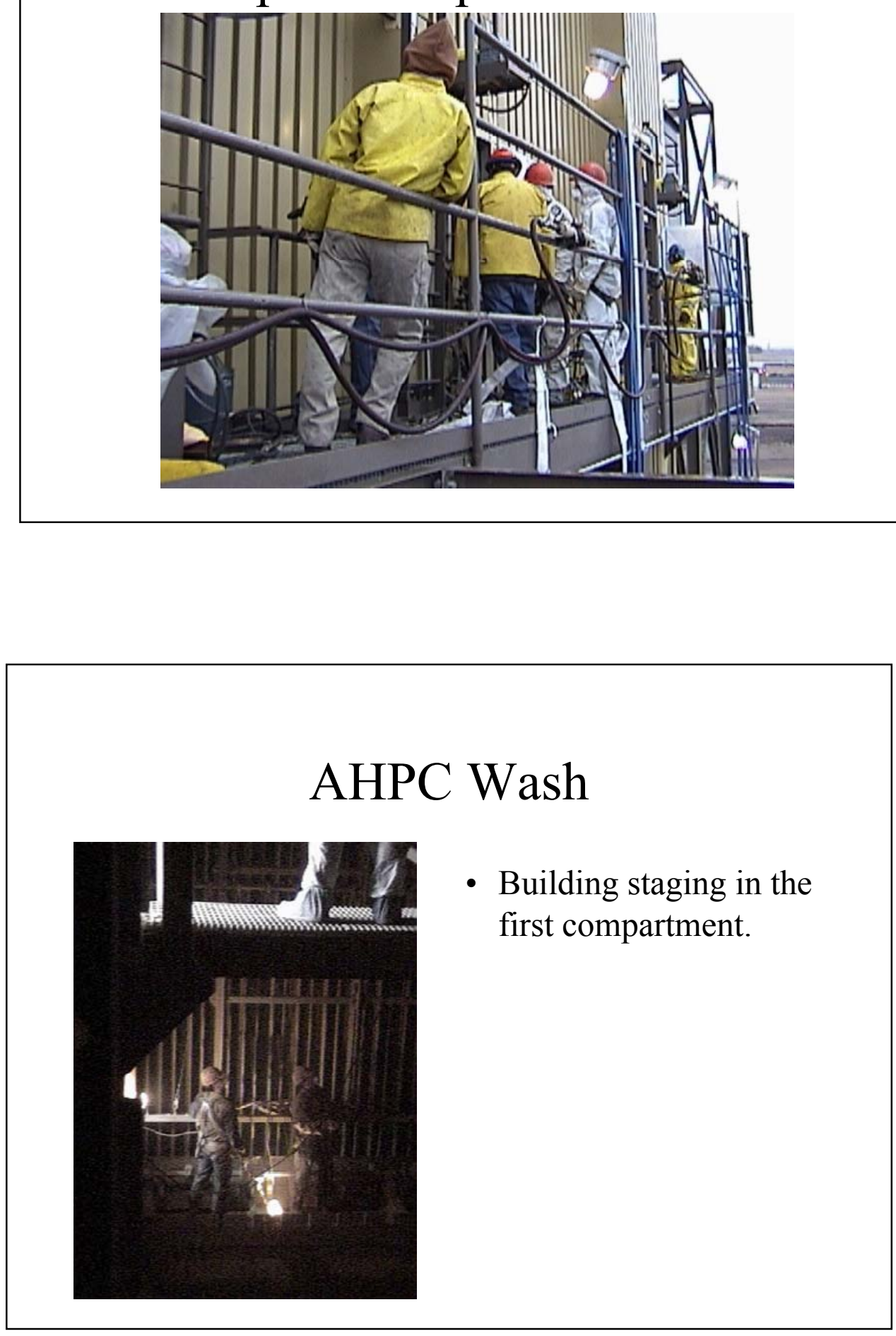


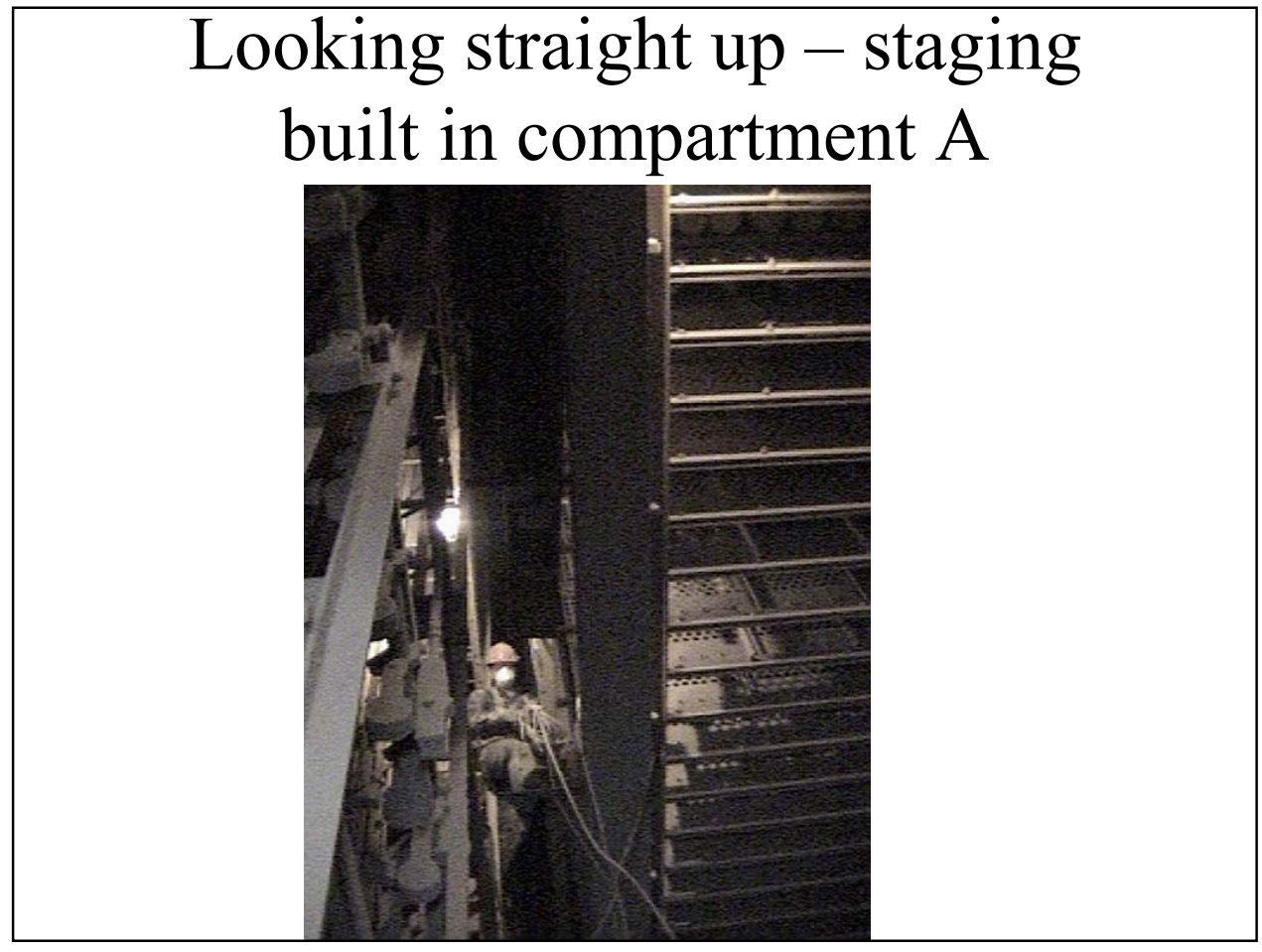

\section{Guide bar removal}

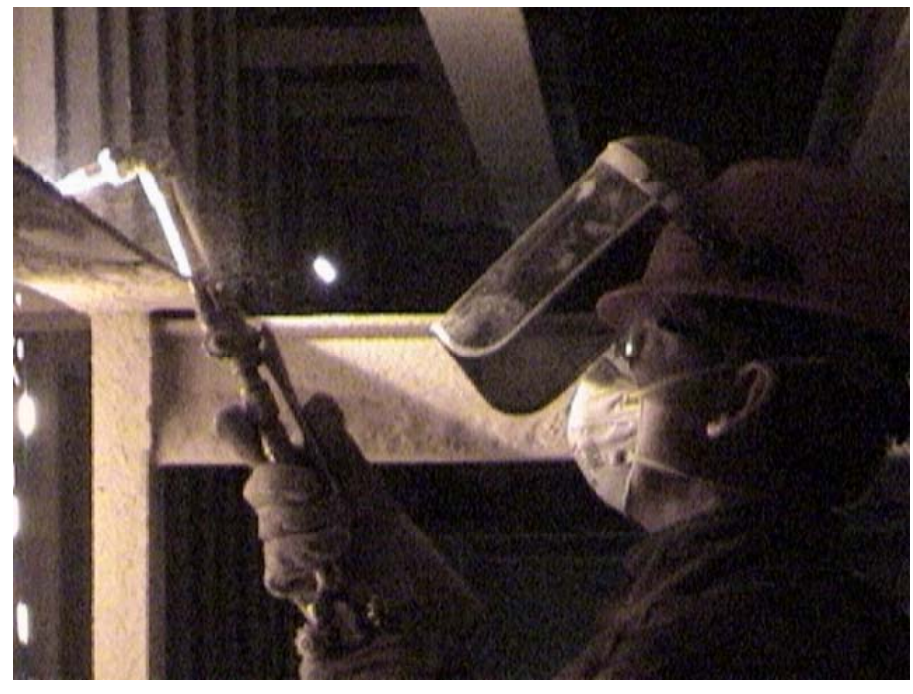




\section{Winching system set for action}

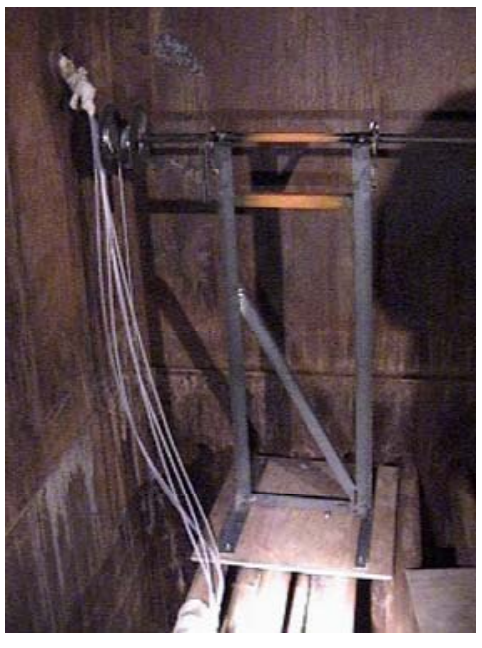

Wash header in place ready for hoisting

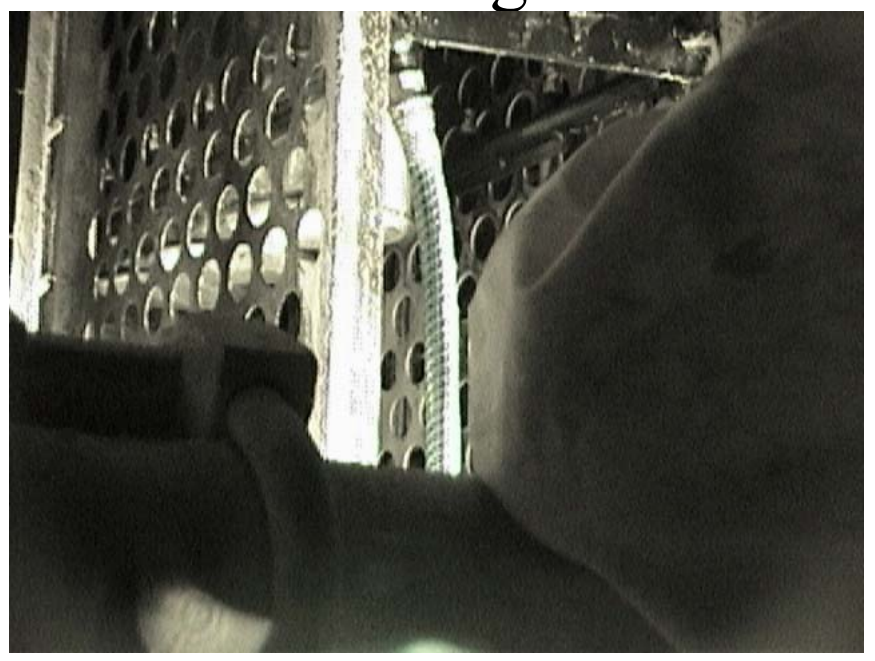


Hoisting the wash rack

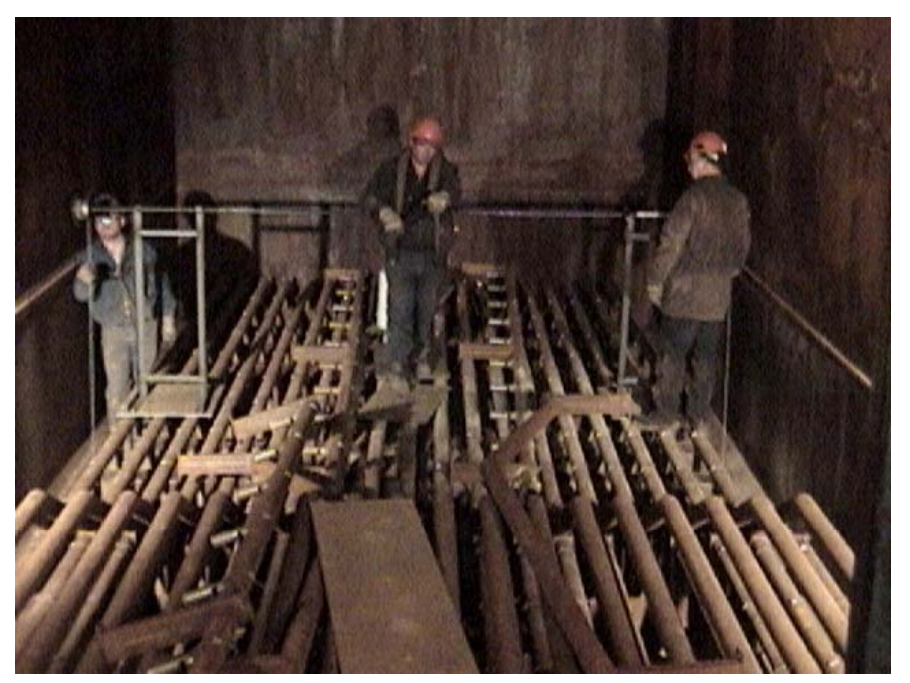




\section{B31 POPR Test Results}

POPR $@ 12 \mathrm{~h} \mathrm{0m} \mathrm{0s}$

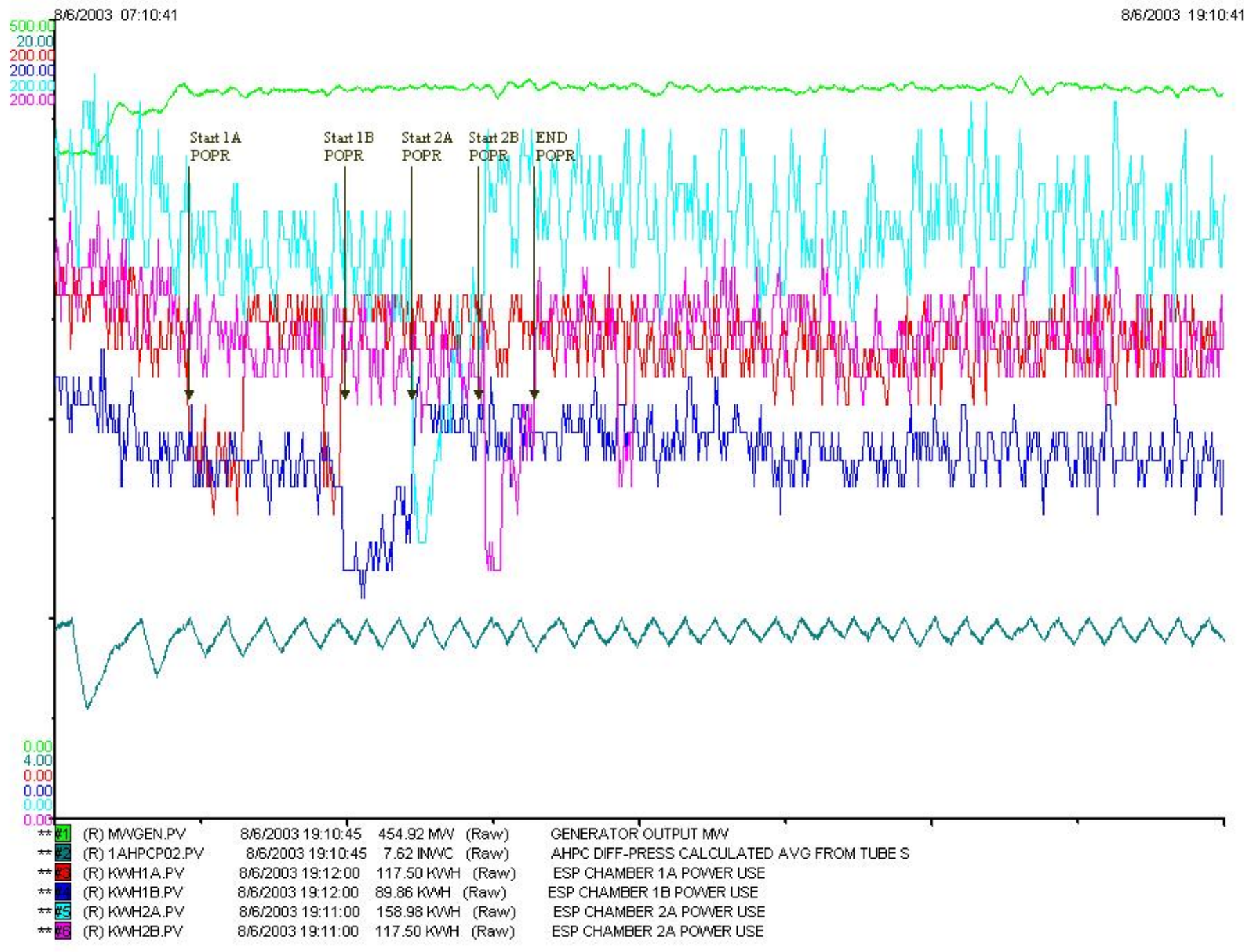




\section{B32 Humidification Test Results}

Humidification Test @12h 0m 0s

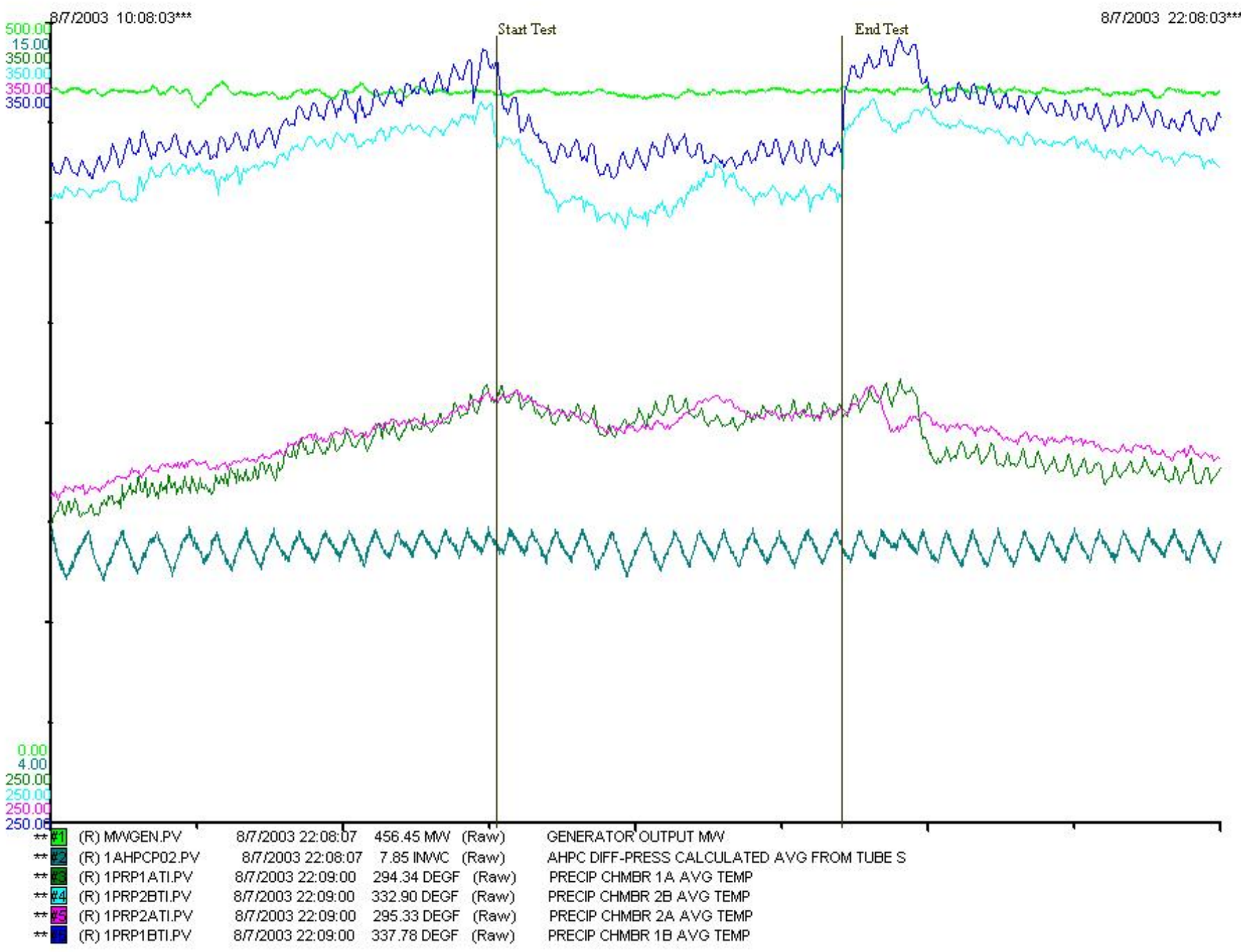




\section{B33 Fluent Study}

\section{Background}

The Advanced Hybrid Particulate Collector (AHPC) is a novel technology that combines the best features of electrostatic precipitators and fabric filters. Demonstration of a fullscale retro-fit of the AHPC technology is taking place at the $450 M W_{e}$ coal-fired Big Stone power plant near Milbank, SD. The full-scale unit is demonstrating consistent high particulate collection efficiencies $(>99.99 \%)$ that far exceed that of a conventional electrostatic precipitator (ESP). However, the demonstration unit does experience problems with higher than expected pressure drops $(\Delta p)$ and substantial variations in particle loading. These problems have lead to: (i) lowered power production due to limitations of the existing fan capacity and (ii) rapid cleaning frequency for the fabric filter bags.

The US Department of Energy (NETL), Otter Tail Power Company (who operates the Big Stone plant), and the parties involved in developing the AHPC technology are discussing several short and long term modifications to overcome the abovementioned problems. Since the uneven loading of fabric filter bags is believed to be largely a flow distribution problem, Fluent Inc. has been commissioned to propose a set of Computational Fluid Dynamics (CFD) studies to assist in the implementation of design modifications that ensure a better distribution of flow in the unit.

This technical memorandum is a project deliverable for this preliminary study. It presents a problem analysis and conclusions in the form of proposed CFD studies of the Big Stone AHPC unit.

\section{Description of Big Stone AHPC Unit}

The AHPC installation at Big stone consist of four parallel chambers retrofitted downstream of an existing ESP. Each chamber holds one existing ESP field and three AHPC filter compartments. Figure 1 gives a schematic representation of this arrangement. The AHPC compartments have 20 rows with 21 fabric filter bags each ${ }^{1}$. Electrostatic charge electrodes are suspended between the rows of bags, with perforated collecting plates separating the fabric filter and ESP zones.

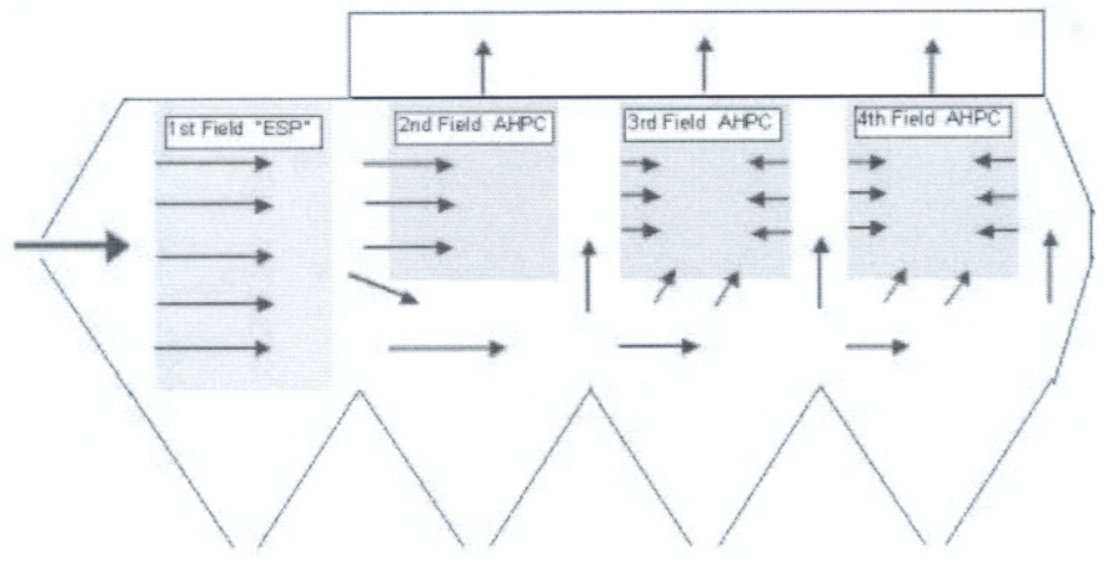

Figure 1: Big Stone AHPC unit. Arrows indicating assumed flow patterns.

\footnotetext{
${ }^{1}$ This translates to $3 \times 20 \times 21=1260$ bags per chamber.
} 
As the old ESP unit is 40ft tall and the new AHPC compartments take up less height (24ft), flow may reach the compartments by way of the space below the retrofitted parts. From there, flow may either enter the ESP zones directly or via the spacing that separates the individual compartments. Thus, flow may enter the individual AHPC compartments from three directions: front, bottom, and back. To maximize the efficiency of the build-in ESP zones, it is desirable to have stratified flow (from one direction) with a reasonable residence time between the collecting plates. Furthermore, localized high velocities and turbulence levels should be avoided in order to prevent re-entrainment of fly ash.

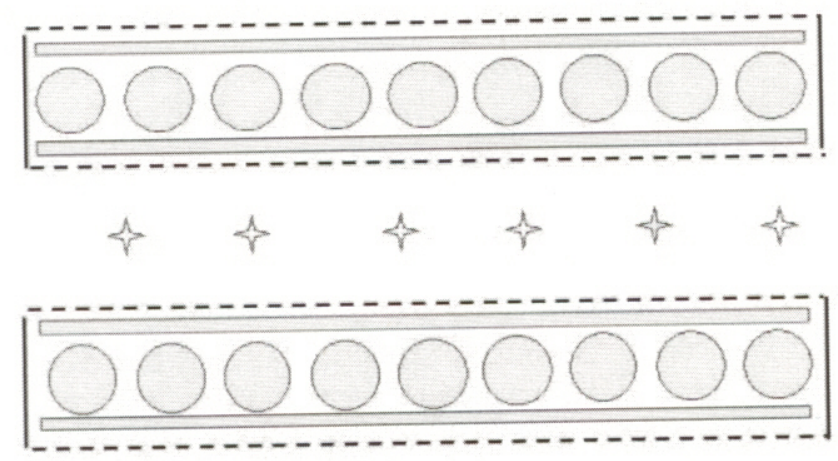

Figure 2: Schematic bottom-view of filter sections. Pictured is an ESP section bounded by two bag rows and their guide rails.

An additional flow-related problem is that of potential gas sneakage, i.e. flue gas bypassing the ESP zone and entering the filter bag sections directly. This is an undesired phenomenon, made possible by the lack of a physical separation at the bottom of the filter bag sections. ${ }^{2}$ Gas sneakage will lead to higher particle loading of the filter bags, and so may be a contributing factor to the quick dustcake build-up being observed.

\section{Proposed CFD studies}

In the following, an overview of the proposed flow modeling of the Big Stone AHPC unit is presented. It is suggested to split this work into three distinct tasks:

1. Modeling of overall flow distribution in the existing unit

2. Modeling of overall flow distribution in the modified unit

3. Detailed modeling of simplified filter compartment

Tasks 1 and 2 will aim at respectively understanding and correcting the overall flow in an entire chamber, while Task 3 will address the abovementioned phenomenon of gas sneakage by means of a detailed CFD model for part of an advanced hybrid compartment. In the following, the technical approach for each of these tasks will be explained in more detail. Finally, Section 4 summarizes work effort, deliverables, and a time schedule for the proposed tasks.

\footnotetext{
2 Metal disks block the bottom of filter bags and there is a set of two guide rails per bag row. A simple analysis shows that this leaves approximately half the surrounding face open to up-coming flow.
} 


\section{TASK 1: Simulation of existing AHPC design}

This task aims at predicting overall flow patterns in the existing Big Stone AHPC unit. The CFD simulation will provide information on the directional partitioning of flow entering the individual AHPC compartments, and will help spot regions with localized high velocities that may have a detrimental effect on ESP performance. The insight into flow patterns gained from this task, may serve in the development and refinement of flow correcting design modifications. The impact of these design modifications will subsequently be evaluated in Task 2 .

While designing the AHPC retrofit for the Big Stone power plant, Elex AG conducted CFD simulations of a full chamber, similar to what is proposed as Task 1 here. At that time, the model size was severely limited by the available computer resources. ${ }^{3}$ However, the Computer Aided Design (CAD) model developed in that context will serve as a good starting point for the current effort. Section 1.1 outlines the CFD modeling approach, and explains the improvements over the Elex model that we intend to implement.

\section{$1.1 \quad$ Modeling approach}

The advanced hybrid filter is a complex system both in terms of geometry and involved physics, for which reason certain simplifications are necessary. As regards physical modeling, simulations will consider isothermal single-phase gas flow. That means, no attempt will be made to model the entrainment of fly ash particles in the flue gas. At the same time this relieves any need to include models for the electro-magnetic field and charge-carrying ability of ash particles. Most coal-derived flue gases are sufficiently dilute to warrant the assumption that the presence of particles does not influence the gas flow.

The pressure drop across the thin fabric filter membranes is modeled using a porous jump condition in the Fluent CFD code. The thin porous medium has a finite thickness over which the pressure change is defined by a combination of Darcy's Law and an additional inertial loss term.

$$
\Delta p=-\left(\frac{\mu}{\alpha} v+C_{2} \frac{1}{2} \rho v^{2}\right) \Delta m
$$

where $\mu$ is the molecular fluid viscosity, $\alpha$ is the medium permeability, $C_{2}$ is the pressurejump coefficient, $v$ is the velocity normal to the porous face, and $\Delta m$ is the medium thickness. Parameters for the porous jump model will be assigned values based on existing measurements of filter bag pressure drops. For the purpose of overall flow modeling (Tasks 1 and 2), the pressure drop across the perforated collecting plates and the fabric filters are lumped. This means that a simple rectangular box represents one row of filter bags and the plates bounding it. ${ }^{4}$

\subsubsection{Geometric modeling and meshing}

The first step will consist in modifying the existing CAD-model so that it corresponds more accurately to the actual retrofit geometry. Here is a commented list of the geometry changes that will be implemented:

\footnotetext{
${ }^{3}$ Simulations were carried out using Fluent 5.5 on a $500 \mathrm{MHz}$ Pentium III processor with $1 \mathrm{~Gb}$ memory.

4 The slender rectangular boxes have porous sides (exception being the outermost bag rows in each compartment that have one solid side), a porous bottom, a solid front and back, and an open top face leading to the clean gas plenums.
} 
- Add collecting plates for old ESP field

The original ESP remains in operation, but its collecting plates were not contained in the exisiting CFD model. However, these solid plates (spaced $1 \mathrm{ft}$ apart), are poised to efficiently stratify the gas flow in its approach to the AHPC compartments. The plates will be modeled as solid walls of infinitesimal thickness.

- Remove girdles from two rear AHPC compartments

In the CFD model created by Elex, there is a $400 \mathrm{~mm}$ high rectangular plate placed perpendicular to the direction of the incoming flow just below the front of each AHPC field. This component (referred to as a girdle) is related to the rapping system that cleans dust of the collecting plates. However, in the actual Big Stone retrofit there is only one such girdle placed in connection with the first AHPC compartment.

- Include catwalk floor in model.

A further assesment is necessary to determine whether the model should be augmented with porous faces representing the floor of catwalks. There is one long grated walkway in the space behind each AHPC compartment. The actual flow blockage from these catwalks is most likely fairly modest, but they are placed in potentially critical spots and their presence may have localized effects in the corners of filter compartments.

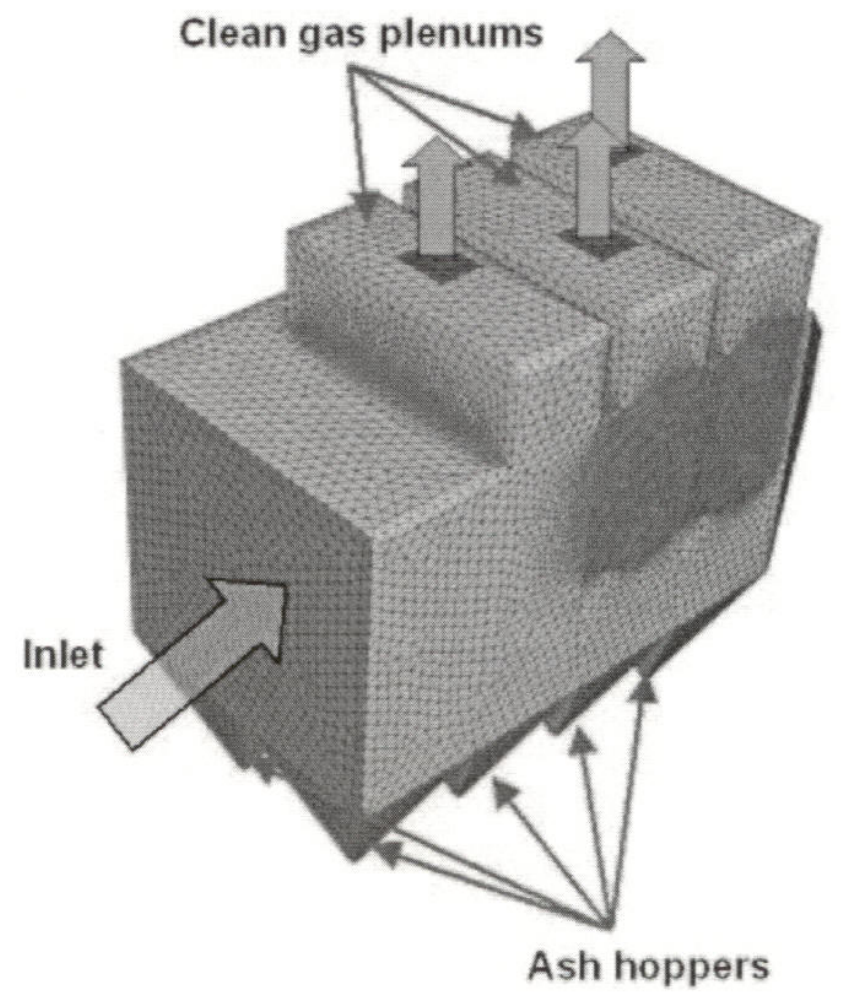

Figure 3: Computational mesh from existing CFD model. 
The Elex CFD model used a mesh discretization with approximately 1.5 million computational cells, see Figure 3. Approximately $2 / 3$ of these cells were used to describe the three AHPC compartments. The computer resources available to Elex made it infeasible to further increase mesh resolution, although it remained relatively coarse inside the compartments. ${ }^{5}$ For the proposed work, use of parallel processing on the extensive computing clusters at NETL in Morgantown will enable an expansion of the model size by a factor of 2-3. Our preliminary investigations indicate that this would be sufficient to resolve the actual geometry of the individual filter bags, but it is our recommendation not to do so but rather to maintain the porous box approach with a finer mesh. The filter bag geometry will be considered in the proposed Task 3 .

In contrast to the Elex mesh that consisted of $100 \%$ tetrahedral cells, we will be employing hexahedral meshing in as far as possible. Because of the spatial interpolation schemes involved in CFD this will achieve a higher solution accuracy. Moreover, a hexahedral mesh typically has significantly lower cell count than a comparable tetrahedral one.

\subsubsection{Boundary conditions}

Current theories on gas flow patterns inside a hybrid filter chamber, see Figure 1, were developed based on Pitôt tube data collected inside a chamber at the Big Stone power plant. These measurements, which may be correlated to the flue gas dust loading, were performed at three locations in each AHPC compartment: front, middle, and back. It is our intent to incorporate this measured data by implementing variations in the $\Delta p$ characteristics (porous jump conditions) that model the pressure drop over filter bags.

All boundary conditions will be re-visited in cooperation with the power plant and technology developers to ensure consistency with the real operating conditions at Big Stone. In comparison with the Elex CFD model, the following changes in the handling of porous jump faces will be implemented.

- Lengthwise splitting of porous jump faces

Each of the large porous faces that separate the ESP zones from the filter bag zones will be sub-divided into three zones. Since a variation in $\Delta p$ over one porous jump face cannot be assigned in Fluent, this sub-division is necessary to allow for variation. The resulting three zones may subsequently be assigned individual jump conditions based on the abovementioned Pitôt data from the front, middle, and back of that compartment. Other subdivisions are possible, but only make sense whenever matched by data.

- Define porous bottom of filter bag zones

Change the bottom of filter sections from a solid to a porous face. Notice the conditions for this face must also contain the (dominant) pressure drop across the fabric filters.

- Catwalk floor porosity

If it is chosen to include the grated walkways in the CFD model, empirical expressions for the induced pressure drop must be taken from literature and implemented.

\footnotetext{
${ }^{5}$ The ESP sections were described using only one cell across the width, while two cells were used inside the porous box that represents a row of bags.
} 


\subsubsection{Simulations}

We propose to initially perform two different simulations: (a) with a uniform pressure drop across all filter bag sections (this corresponds to the Elex model with geometric modifications only), and (b) with a variation in pressure drop that reflects the measured data better. A comparison between these two simulations will reveal how sensitive the overall flow distribution is to perturbations in the prescribed pressure drop conditions. The filter membranes are by far the biggest source of frictional resistance in the entire unit, so logically one would expect these particular boundary conditions to have a significant impact on the distribution of flue gas flow.

After completing these initial CFD simulations, a comparison will be made between predicted and measured flow rates through the individual clean gas plenums. If the split of flow between compartments is predicted with reasonable accuracy, this helps build confidence in the simulations. Another option for model validation is to do additional velocity measurements, preferably by traversing the chamber-width at a position below or in between hybrid compartments. The recorded velocity profile may then be compared with simulation results.

A third simulation (c) will investigate the importance of the inlet velocity profile. In this simulation, an artificially skewed velocity profile will be assigned at the model inlet. This is in contrast to the uniform inlet profile applied in cases (a) and (b). Quite possibly the narrowly spaced collecting plates of the old ESP field may annul this perturbation in inlet velocities. However, should a significant change in flow distribution result there is reason to consider building a separate CFD model that considers the flow manifolding from the air preheater to the four AHPC chambers. ${ }^{6}$

\subsubsection{Post-processing}

Postprocessing of simulation data will produce a collection of plots that describe the chamber flow pattern. Moreover, the directional partitioning of flow into each AHPC compartment (from the front, back, and bottom respectively) will be quantified. This data will help confirm or modify the current hypothesis on flow distribution, which will briefly be outlined under Task 2. Due to the geometric simplifications in representing the filter bag rows, care should be exhibited in interpreting flow patterns within the AHPC compartments. The detailed model, proposed as Task 3 of this effort, will provide a much better basis for such interpretations.

\footnotetext{
${ }^{6}$ Incidentally, such a study might help explain some of the variation that exists between the performance of the four parallel filter chambers. It is currently thought that this variation results from variations in chamber temperatures that impact the ESP performance.
} 


\subsection{Estimated work effort for Task 1}

Table 1 gives an estimate of the work hours involved in Task 1. Sub-tasks correspond more or less to the previous sections.

TASK 1 : Modeling of existing unit

\begin{tabular}{|c|c|c|c|}
\hline Sub-task & Task description & Work effort $[\mathrm{h}]$ & Comments \\
\hline \hline 1.1 & Geometric modeling and meshing & 80 & \\
\hline 1.2 & Boundary condition setup & 40 & \\
\hline 1.3 & Simulations & 90 & Simulations $(a),(b)$, and $(c)$ \\
\hline 1.4 & Post-processing & 30 & \\
\hline \hline TOTAL & & $240 \mathrm{~h}$ & \\
\hline
\end{tabular}

Table 1: Estimated man-hours for carrying out the proposed Task 1

\section{TASK 2: Simulation of design modifications}

This task will determine the effect of two simple design modifications that both aim at improving the flow patterns in the Big Stone AHPC. Based on the already mentioned Pitôt tube measurements, the AHPC technology developers have formed a theory on the gas flow dynamics of this unit, see Figure 1. For the first AHPC compartment, it is believed that gas enters mostly from the front and flows towards the back while gradually effusing via the collecting plate perforations. In the two rear compartments, flow seems to enter the ESP zones from multiple directions (front, back, and bottom). The flow simulations of the existing unit will help confirm or refine this understanding, so that it is advisable to revisit the suggested design modifications after completion of the Task 1.

\subsection{Suggested design modifications}

As mentioned earlier, electrostatic precipitation will generally benefit from a uni-directional gas flow in the electro magnetic field between the collecting plates. For this reason, design modifications should first and foremost attempt to alter flow in the two rear compartments, where cross- and counter-flow is believed to be most prevalent. After consulting with the AHPC developers, it is proposed to investigate the following two design modifications:

A Installation of steel plates on the end of all AHPC compartments

The gas flow in this configuration can enter the ESP zone from the front or bottom of fields. This measure reduces the possible routes that the gas may travel. A simulation will reveal whether this results in a more uniform gas distribution or not.

B Installation of steel plates on both ends of the two rear AHPC compartments

In this configuration the first AHPC field remains unchanged, while gas flow can only enter the rear fields from the bottom. This should ensure similar pat- 
terns in the two affected fields, but may increase problems with gas sneakage and may also cause significant lengthwise variations in the loading of the individual bags.

These two design modifications may have to be implemented in conjunction with a deflector system to limit gas sneakage from the bottom. This will be addressed by the detailed study of a compartment in Task 3. From a CFD perspective, the abovementioned design changes can be easily implemented in the model from Task 1; accomplished by a change in boundary conditions rather than geometry. In both cases it is also possible to investigate the use of perforated rather than solid plates. For both design studies, we will determine the directional re-partitioning of flow and also report any regions of high velocity or turbulence intensity.

\subsection{Estimated work effort for Task 2}

As this Task makes use of the CFD model developed under Task 1, a faster turn-around time can be expected for this second task. Estimates are given in Table 2.

TASK 2 : Modeling of modified unit

\begin{tabular}{|c|c|c|c|}
\hline Sub-task & Task description & Work effort $[\mathrm{h}]$ & Comments \\
\hline \hline 2.1 & Model modification & 25 & Design studies A and B \\
\hline 2.2 & Simulations & 60 & \\
\hline 2.3 & Post-processing & 20 & \\
\hline \hline TOTAL & & $105 \mathrm{~h}$ & \\
\hline
\end{tabular}

Table 2: Estimated man-hours for carrying out the proposed Task 2

\section{TASK 3: Detailed Modeling of Filter Compartment}

With this task it is proposed to build a separate CFD model, which consider a portion of a filter compartment with a more refined geometry representation. This model is intended to predict flow details that cannot reasonably be described by the overall CFD model (Task 1). Most importantly, it will shed light on the sneakage ratio, i.e. the fraction of flow that bypasses the ESP section and instead enters the filter bag sections vertically. The model can also be used to assess deflector arrangements to reduce sneakage.

\section{$3.1 \quad$ Modeling approach}

The model will comprise a layer-wise arrangement of three full bag rows and four ESP zones, see Figure 4. Symmetry boundary conditions will be prescribed at the two model boundaries that cut through the center of an ESP zone. This configuration emulates a sub-domain inside a larger compartment, where the inclusion of several bag rows aims at limiting boundary effects. Flow will exit the model via an artificially defined plenum that receives gas from the bags. 


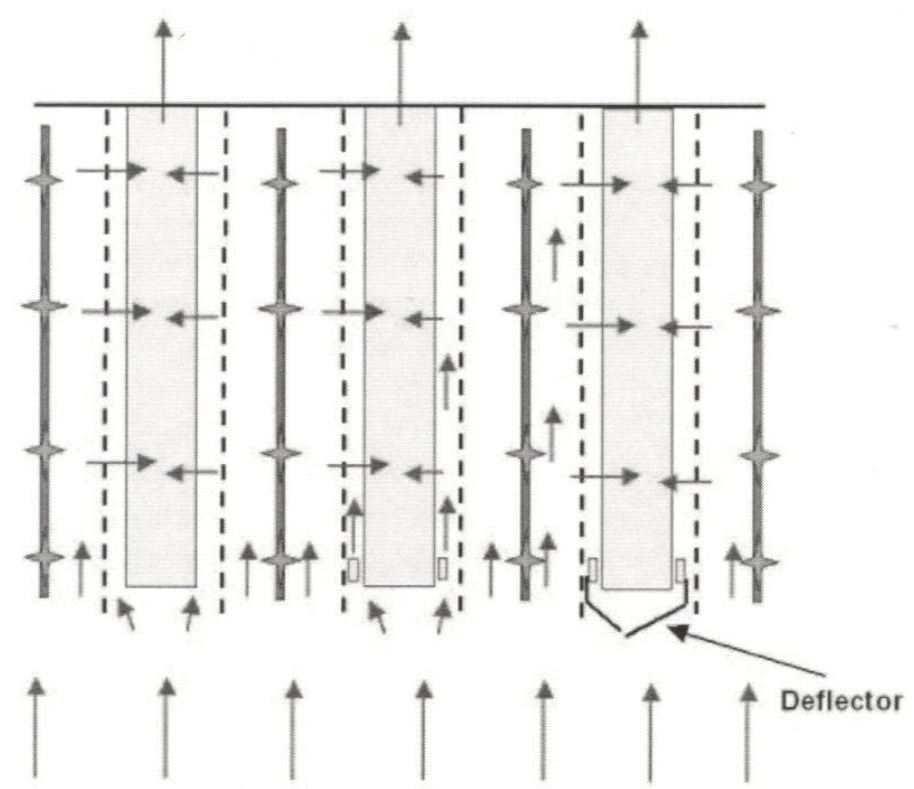

Figure 4: Detailed model of hybrid compartment. Shown discharge electrodes not modeled.

The inlet flow condition will be prescribed in terms of a uniform velocity from the bottom, which may be either vertical or at an angle. The exact velocity magnitude and direction will be estimated based on the flow simulations for the overall chamber (Task 1 and 2). Variations in the approaching flow will exist depending on what part of a compartment you consider. The sensitivity in modeling results can be assessed by computing the sneakage ratio for a series of detailed model simulations with changes in the inlet velocity direction and/or magnitude.

The perforated collecting plates and the individual bags $(3 \times 21$ in the model $)$ will be modeled using different porous jump conditions, see section 1.1. The flow resistance of the perforated plates will be derived from an empirical relation, and should be significantly lower than the flow resistance of the bags.

\subsection{Design studies}

The second part of Task 3 will be a design study, considering the impact of equipping bag rows with a deflector arrangement to limit gas sneakage. An example of such a bag deflector can be seen for the right bag row in Figure 4. The exact deflector design will be provided later by the AHPC technology developers. Simulations will be performed for the same set of inlet conditions that was used in subtask 3.1. While it will be difficult to experimentally verify the predicted sneakage ratios, it is believed that the outlined CFD models (with and without deflectors) will predict trends with confidence. 


\subsection{Estimated work effort for Task 3}

TASK 3 : Detailed Flow Simulation

\begin{tabular}{|c|c|c|c|}
\hline Sub-task & Task description & Work effort $[\mathrm{h}]$ & Comments \\
\hline \hline 3.1 & Geometric modeling and meshing & 60 & From scratch \\
\hline 3.2 & Boundary condition setup & 20 & \\
\hline 3.3 & Simulations & 50 & Varying inlet conditions \\
\hline 3.4 & Post-processing & 20 & \\
\hline 3.5 & Design variation studies & 60 & Bottom deflector plate \\
\hline \hline TOTAL & & $210 \mathrm{~h}$ & \\
\hline
\end{tabular}

Table 3: Estimated man-hours for carrying out the proposed Task 3

\section{Deliverables and Schedule}

A strategy for the deployment of CFD modeling to assist in trouble-shooting of the AHPC unit at Big Stone power plant has been outlined. This section will summarize deliverables, estimated work effort, and present a time schedule for completion of the proposed tasks.

\subsection{Project Deliverables}

Project progress will be reported on a monthly basis in a short written status report. After successful completion of the project, Fluent Inc. will deliver the following items:

- Report summarizing CFD results from modeling of overall chamber flow (Tasks $1+2)$.

- Report summarizing results from detailed modeling of a filter compartment (Task 3).

- Fluent case/data files for all completed simulations.

\subsection{Project time schedule}

The specific breakdown into tasks and an estimate of the engineering hours have been compiled in Table 4.

\begin{tabular}{|c|c|c|}
\hline Task & Task description & Work effort $[\mathrm{h}]$ \\
\hline \hline 1 & Modeling of overall flow distribution in the existing unit & 240 \\
\hline 2 & Modeling of overall flow distribution in the modified unit & 105 \\
\hline 3 & Detailed modeling of simplified filter compartment & 210 \\
\hline \hline TOTAL & & $555 \mathrm{~h}$ \\
\hline
\end{tabular}

Table 4: Summary of estimated man-hours for all tasks

Figure 5 shows the time schedule for completion of the specific subtasks. This chart has been based on work commencing October $1^{\text {st }}$ 2003. As it appears, the total elapsed time 
to complete the project is expected to be six months. While Tasks 1 and 2 are essentially sequential activities, the schedule for completion has been accelerated by working on Tasks 1 and 3 in parallel.

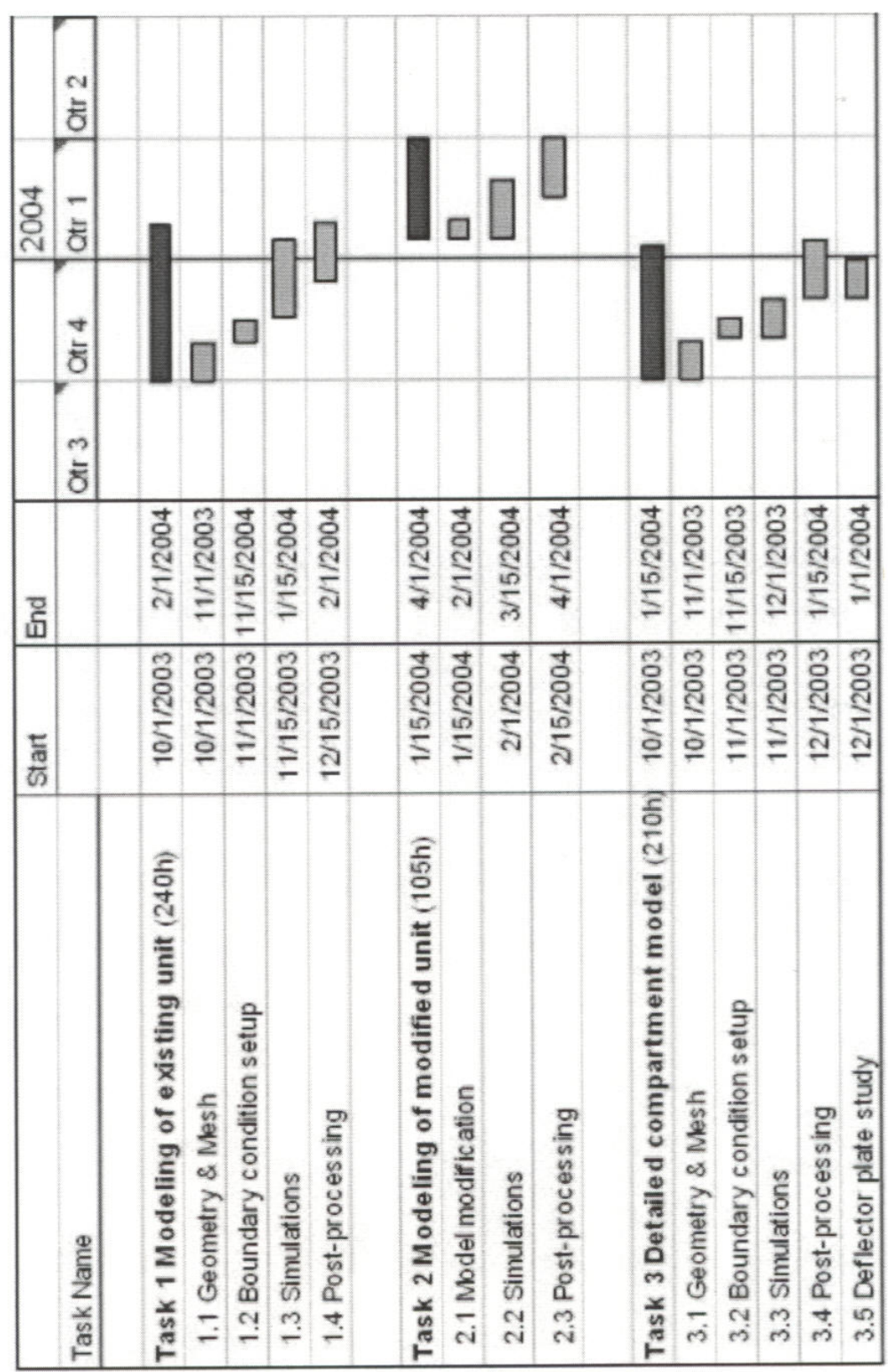

Figure 5: Projected timeline for completion of proposed tasks. 


\section{Advanced Hybrid TM Filter}

Proposed Filter Bag Bottom Flow Restriction

Baffle Design

To:

John Caine SEI

Ulrich Leibacher ELEX

Peter Studer ELEX

From:

Rich Gebert W.L. Gore

September 30, 2003

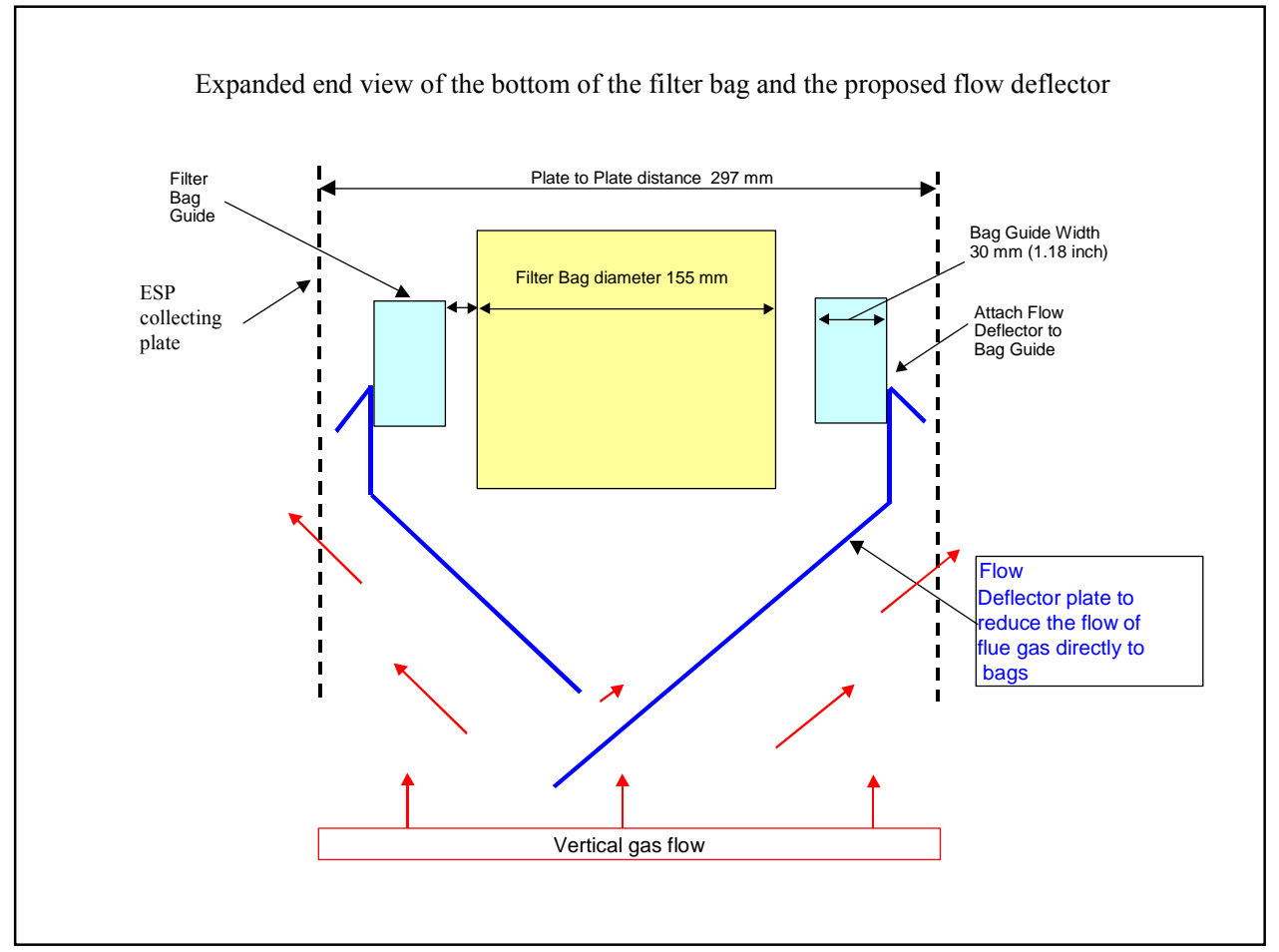




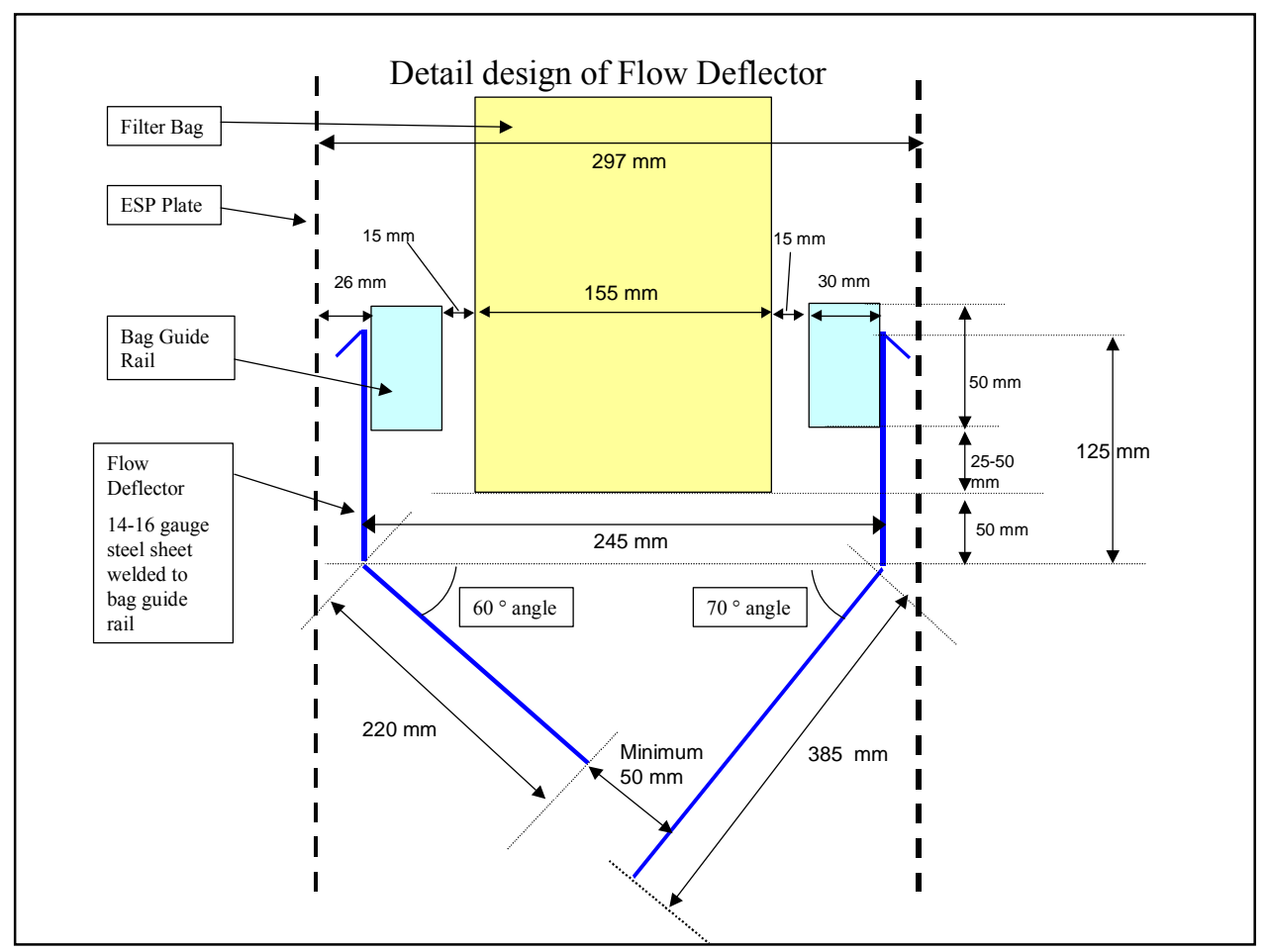

\section{Dimensions}

- The drawings and information contained in this proposal are to be used as a guide for the design of the flow deflector plates.

- The bag guides or rectangular tubing dimensions based on the ELEX drawings are: $30 \mathrm{~mm}$ wide by $50 \mathrm{~mm}$ high by $4570 \mathrm{~mm}$ in length and are placed $15 \mathrm{~mm}$ from the bags and $26 \mathrm{~mm}$ from the collecting plates.

- The bag diameter is $155 \mathrm{~mm}$ and they are spaced $200 \mathrm{~mm}$ on center down the row with 21 bags per row creating a 4.2 meter length of bags.

- The proposed steel sheet deflector plates are designed to reduce the amount of gas flow that passes between the filter bags in the bag row and between the ESP collecting plates.

- The steel sheet $14-16$ gauge can be spot welded, stick or mig welded to the bag guide rail.

- The downward angle is 60-70 degrees to allow the collected dust to fall into the hopper and the minimum clearance between the two plates must be $50 \mathrm{~mm}$.

- Plate \#1 at 60 degrees comprises $125 \mathrm{~mm}$ of vertical section and a $220 \mathrm{~mm}$ length at 60 degrees. The overall area is 1.4 sqmeter $(51 \mathrm{sqft})$.

- Plate \#2 at 70 degrees has $125 \mathrm{~mm}$ vertical section and $385 \mathrm{~mm}$ of sheet at 70 degrees at length of 4.2 meters. The overall area is $2.14 \mathrm{~m} 2$ (75 sqft).

- The area and weight of these plates for 16 gauge steel is $127 \mathrm{lbs}$ and $187 \mathrm{lbs}$ which may be in excess for the structural design limits. 
B35 Photograph of Bag wash of original bags in Big Stone turbine bay

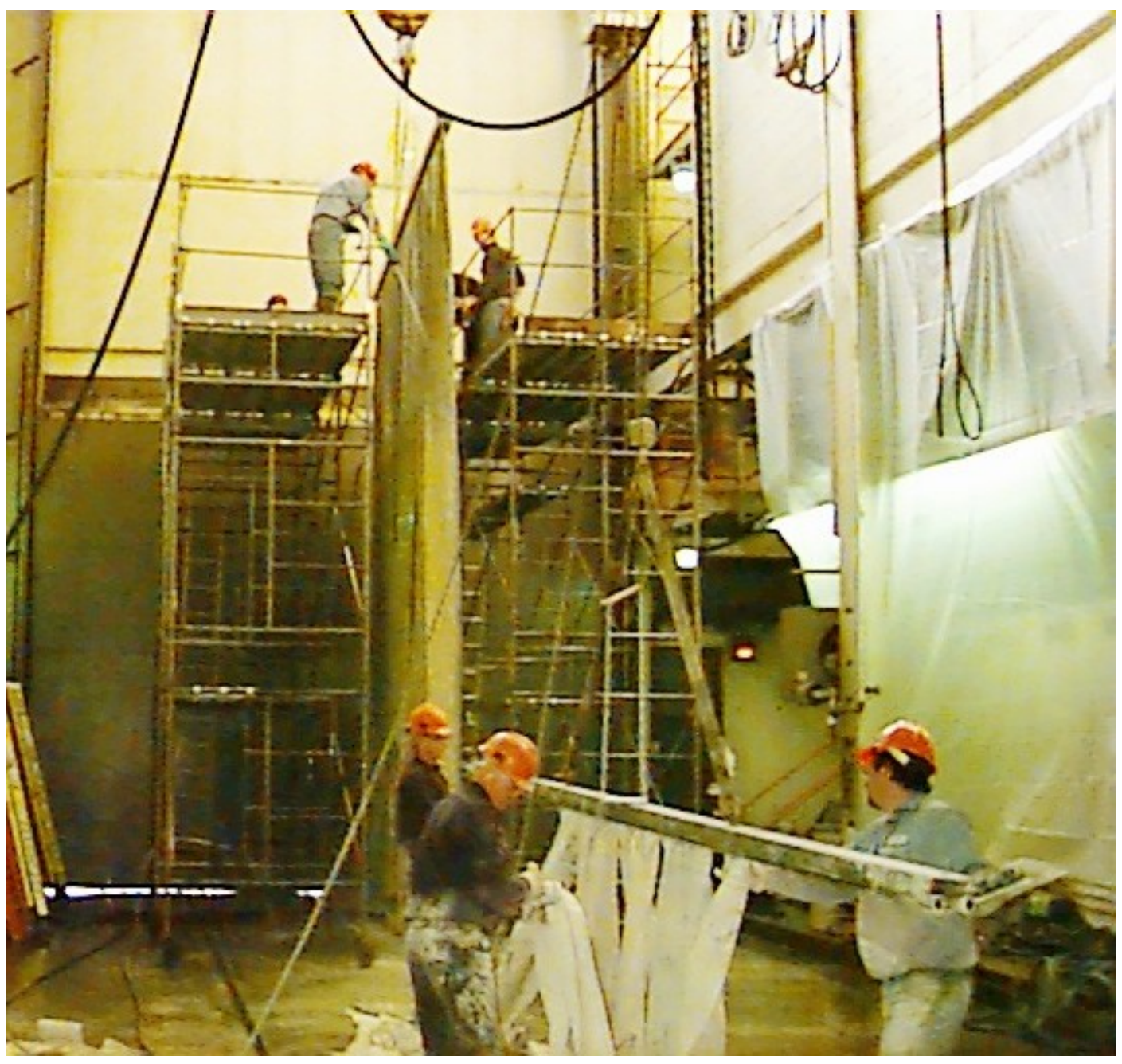


B36 Photograph of bag row baffles prior to installation on Advanced Hybrid walkway

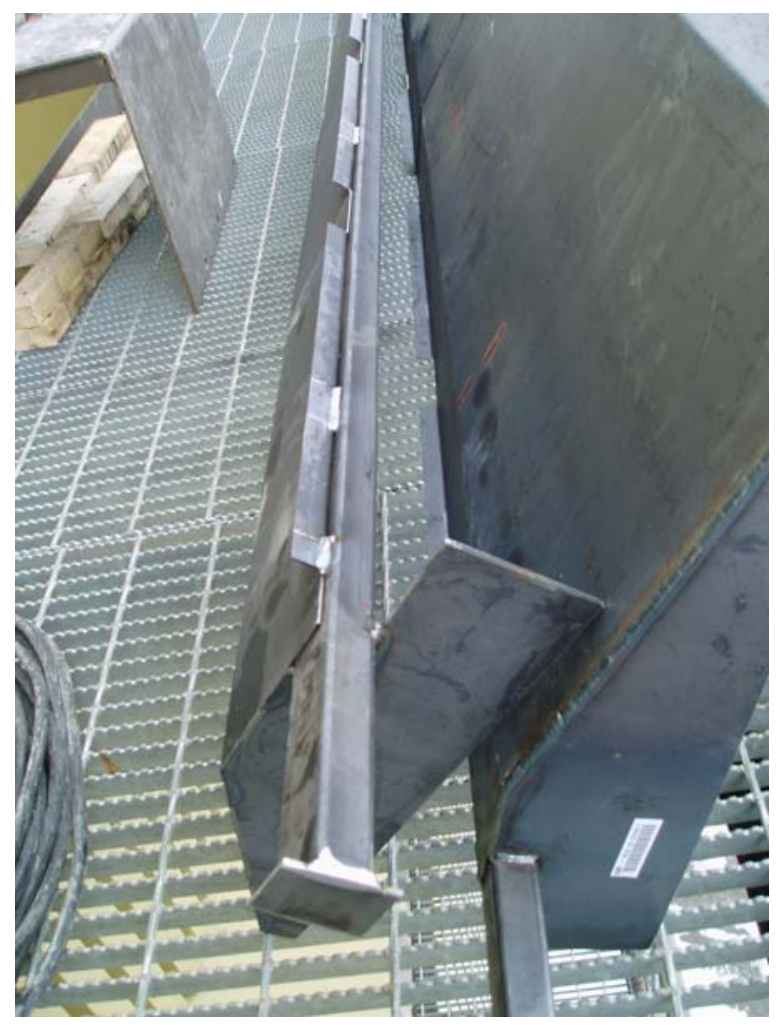




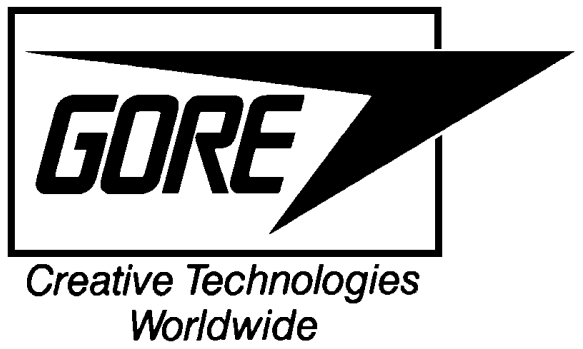

Full scale Advanced Hybrid ${ }^{\mathrm{TM}}$ Filter Big Stone Demonstration Operation Site Filter Bag Analysis

Date: $\quad$ September 4, 2003

Prepared By: $\quad$ Dwight Davis and Rich Gebert

\section{Background:}

Plant Location: $\quad$ Otter Tail Power Company, Big Stone City, South Dakota

Filter Bag Type: GORE-NO STAT ${ }^{\circledR}$ filter bags (GORE-TEX ${ }^{\circledR}$ membrane conductive/GORE-TEX ${ }^{\circledR}$ felt)

Bag Diameter: $\quad 6.0$ inch

Length: $\quad 7$ meter

Air/Cloth: $\quad 10$ to $12 \mathrm{fpm}$

Dust Type: $\quad$ Fly Ash from Coal-Fired Boiler

Coal Type: $\quad$ Eagle Butte, Belle Ayr Mine; Western Sub-bituminous

GORE-NO STAT ${ }^{\circledR}$ filter bags were installed and pre-coated prior to the October 25, 2002 start-up of the full scale Advanced Hybrid ${ }^{\mathrm{TM}}$ Filter at Otter Tail Power Company's Big Stone Plant located in Big Stone City, SD. The unit remained in operation until the Big Stone Plant shutdown for a boiler wash on February 26, 2003. Operation resumed on March 2, 2003, with five conductive GORE-TEX® membrane on conductive polyphenylene sulfide (PPS) felt filter bags installed in Compartment 12. The PPS bags replaced the original filter bags in cross row 21, positions 1,4,6,7 \& 10 (see bag locator chart in the appendix). During the February boiler wash 40 pitot tubes were also installed in compartments $7,8,9,10,11$, and 12 for measuring air flow from individual filter bags. On April $26^{\text {th }}$ and May $8^{\text {th }}$, chambers 2B and 1A respectively, filter bags were washed in place by Big Stone plant personnel while the Big Stone Plant operated at reduced load. The second boiler wash with a bag change out occurred on June 2, 2003.

As part of the Power Plant Improvement Initiative Big Stone Demonstration site DOE funding program, filter bags were removed for lab analysis when compartments or the entire Advanced Hybrid ${ }^{\mathrm{TM}}$ Filter were taken off line. Filter bag/s were removed November 9th after 2 weeks of operation, February $28^{\text {th }}$ after 18 weeks of operation, April $12^{\text {th }}$ after the PPS bags experienced 6 weeks of operation, and June $2^{\text {nd }}$ after the PPS bags experienced 3 months of operation.

Filter Bag Evaluation:

A total of seven filter bags were removed over the eight month time period by W.L. Gore and Associates personnel for evaluation purposes. Various tests including; air permeability, felt strength, residual dust cake particle size and elemental analysis, along with visual observations including membrane microscopic 
examination were undertaken.

\section{Air Permeability Analysis}

The air permeability analysis of the filter bag media was performed in the lab using the Frazierometer. Permeability is the volumetric flow rate of air, measured in cubic feet per minute ( $\mathrm{cfm})$ through a square foot of filter media at a pressure differential of 0.5 inches water gauge (w.g.). The unit of measure is $\mathrm{cfm} / \mathrm{ft} 2 @ 0.5$ "w.g. and is called the Frazier Number (Fn). Samples of the Advanced Hybrid® filter bag media were cut from the top, middle, and bottom bag locations. The sample size was five inches in the vertical bag length direction along the entire circumference of the bag. Typically three measurements per bag sample were taken. An average value is then calculated from the nine measurements per bag. . Each sample is tested for permeability in the condition it was received from the field and again in the identical location after lightly brushing the dust cake. See Table 1:

\begin{tabular}{|c|c|c|c|c|c|c|c|}
\hline \multicolumn{8}{|c|}{ Otter Tail Power Company } \\
\hline \multicolumn{8}{|c|}{ Big Stone Power Plant Improvement Initiative Demonstration Site } \\
\hline \multicolumn{8}{|c|}{ Filter Bag analysis summary chart - All Frazier \#s are reported as cfm/tt2@ $0.5 \mathrm{in.w.g}$. driving force } \\
\hline $\begin{array}{c}\text { Date } \\
\text { installed }\end{array}$ & $\begin{array}{c}\text { Date } \\
\text { removed }\end{array}$ & $\begin{array}{c}\text { installed } \\
\text { time }\end{array}$ & $\begin{array}{l}\text { Laminate } \\
\text { backing }\end{array}$ & $\begin{array}{c}\text { As rec'd } \\
\text { (Fn) }\end{array}$ & \begin{tabular}{|c|} 
After \\
light \\
brushing \\
(Fn)
\end{tabular} & $\begin{array}{l}\text { Flat width } \\
\text { ave.(cm) }\end{array}$ & $\begin{array}{l}\text { Mullen } \\
\text { Burst (psi) }\end{array}$ \\
\hline $10 / 25 / 2002$ & $11 / 9 / 2002$ & 2 wks. & GORE-TEX felt & 2.1 & 4.2 & & \\
\hline $10 / 25 / 2002$ & $3 / 1 / 2003$ & 18 & GORE-TEX felt & 2 & 4.6 & & 701 \\
\hline $10 / 25 / 2002$ & $3 / 1 / 2003$ & 18 & GORE-TEX felt & 1.5 & 4.3 & & 724 \\
\hline $3 / 1 / 2003$ & $4 / 12 / 2003$ & 6 & PPS felt & 1.4 & 6.6 & 24.9 & 323 \\
\hline $3 / 1 / 2003$ & $6 / 2 / 2003$ & 13 & PPS felt & 1.8 & 5.5 & 24.9 & 372 \\
\hline $3 / 1 / 2003$ & $6 / 2 / 2003$ & 13 & PPS felt & 1.7 & 5 & 24.9 & 374 \\
\hline $10 / 25 / 2002$ & $6 / 4 / 2003$ & 32 & GORE-TEX felt & & & 24.6 & 742 \\
\hline
\end{tabular}

Table 1. Test Results Summary Chart

All the filter bags when removed contained a thin layer of dust similar to typical coal fired boiler fabric filter particulate collector applications. This residual filter cake and filter bag media air permeability measurement is shown in the "as received Frazier numbers" column. As the filter bags seasoned, whether the bags consisted of the conductive GORE-TEX felt or conductive PPS felt backing, the differences in the overall permeability of the two types of filter bags narrowed. After light brushing, all the filter bag perms returned to near new levels. It should be noted that when brushing the bags removed March $1^{\text {st }}$, extra effort was required to remove all the dust off the surface of the bag.

\section{Felt Strength}

Mullen burst tests were run on a portion of samples taken for the air permeability measurements. The test consists of applying pressure in the reverse direction of airflow on a three inch diameter filter bag sample, continuously increasing the pressure until the sample is ruptured. The physical strength of new GORETEX ${ }^{\circledR}$ felt backed filter bags averaged 650 psi while the PPS felt filter bags averaged 344 psi. As shown with the Mullen Burst test results, both types of filter bags' physical strength has not been weakened due to chemical or thermal attack of the flue gas environment inside the Advanced Hybrid ${ }^{\mathrm{TM}}$ Filter to date. 
As noted earlier, all the filter bags contained a thin layer of dust cake on the membrane surface, typical of most coal -fired boiler applications. The primary dust cake was easily brushed off the November sampled filter bag and the PPS bags removed in April and June, but required more effort on the bags removed in February. The filter bags were examined for membrane damage from electrostatic discharge or sparking using a microscope - no damage was observed. However, by the February inspection inside the Advanced Hybrid $^{\mathrm{TM}}$ Filter chambers, a portion of the filter bags exhibited wear in two general areas. One located at the center of the bottom disk of the bag, and the second area where the bag occasionally comes into contact with the bottom bag guide rails. The design of the filter bag took into account the expected wear at the bag guide rails incorporating a double layer of material in the bottom cuff.

Samples were taken from two of the filter bags for SEMS and an EDS analysis of the dust layer from the two filter bags removed in February. The results can be found in the APPENDIX. The SEMS indicate the residual flyash dust cake particle size falls in the range of 0.5 to 10 microns. Results from the EDS analyses indicate Potassium's presence in the flyash along with the other expected elements.

A single wrinkle formed on each of the PPS bags indicates some stretching occurred during the operation of the Advanced Hybrid ${ }^{\mathrm{TM}}$ Filter. The flat width measurements of these bags reaffirmed the visual observation showing the bags circumference increased roughly $0.9 \mathrm{~cm}$.

\section{Conclusions:}

- Visual analysis of filter bags revealed excellent membrane integrity.

- Laboratory analysis of the filter bags revealed no membrane damage caused by electrostatic discharge or sparking.

- After 32 weeks of service the GORE-NO STAT® filter bags exhibited no loss in physical strength and the permeability looked good.

- After 13 weeks of service the PPS backed GORE-TEX ${ }^{\circledR}$ membrane filter bags also showed no loss in strength and retained their permeability.

- Future PPS bag manufacturing will incorporate a design change to reduce/eliminate the bag circumference growth.

${ }^{\circledR}$ GORE-TEX and GORE-NO STAT are registered trademarks of W. L. Gore \& Associates, Inc. 

APPENDIX
Bag Locator Chart
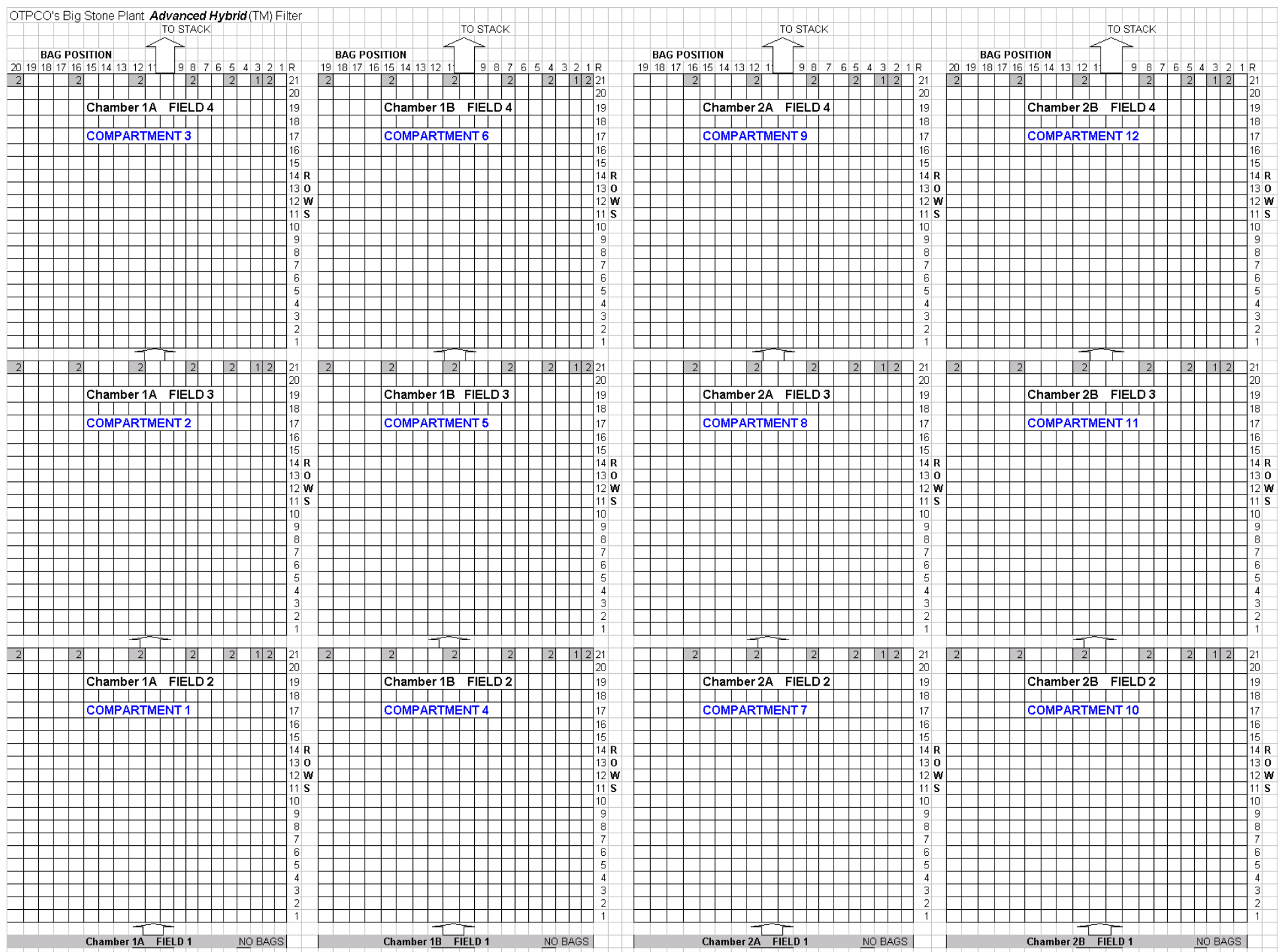

Number Designations

$1 \quad 6 / 1 / 2002$ Bags eliminated due to Rapper Pinwheel Assembly in the way

2 10/12/2002 Bags eliminated due to Rapper Shaft bearing supports in the way 
SEMS Photo

Surface comparison of 777013-Dust Cake and 777023-Dust Cake:
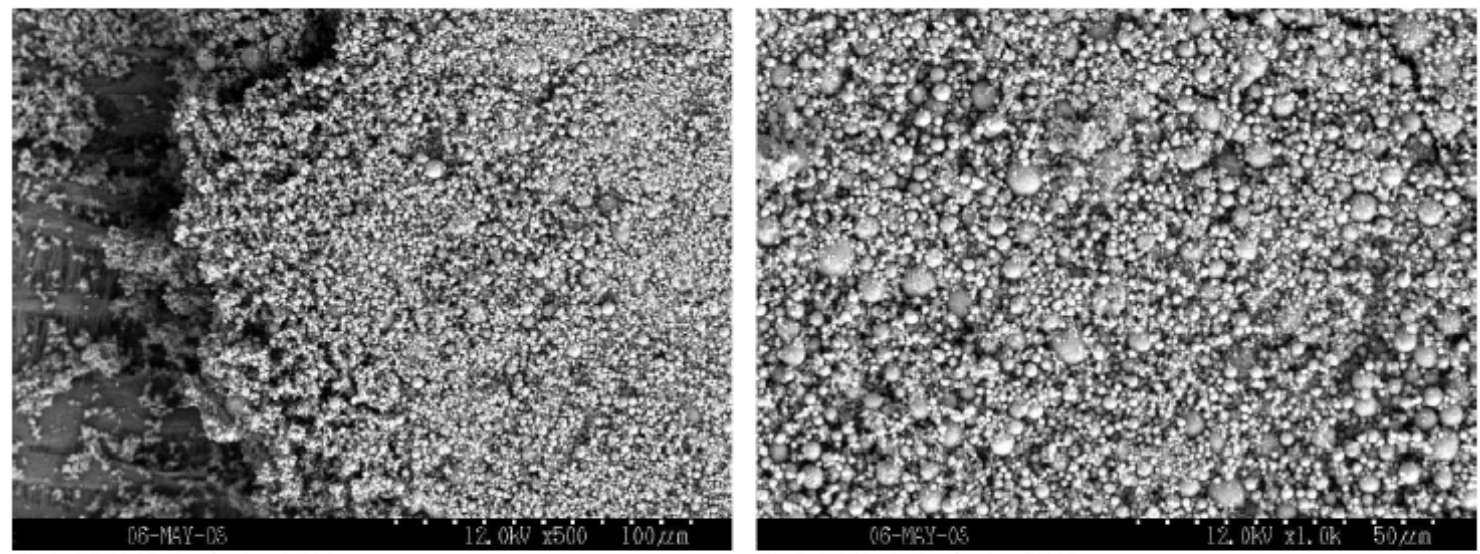

Fig1: 777013-Dustcake-SF01

Fig2: 777013-Dustcake-SF02
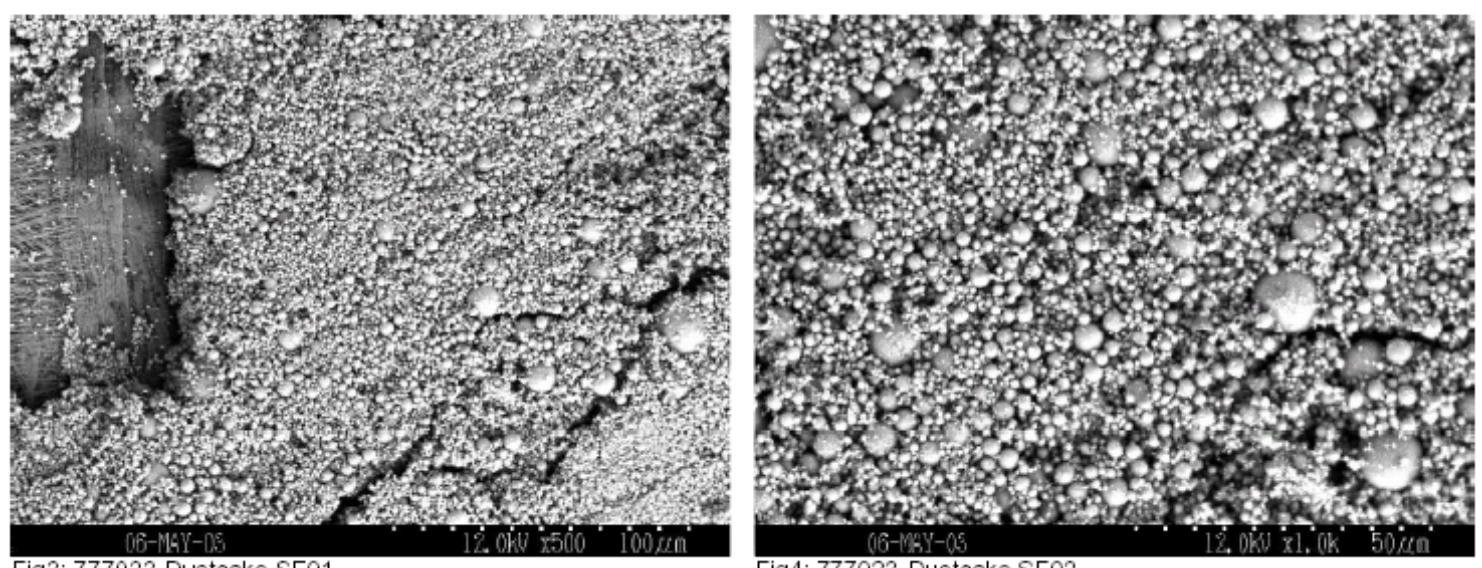

Fig3: 777023-Dustcake-SF01

Fig4: 777023-Dustcake-SF02 


\section{EDS results}

Elemental comparison of 777013-Dust Cake and 777023-Dust Cake:

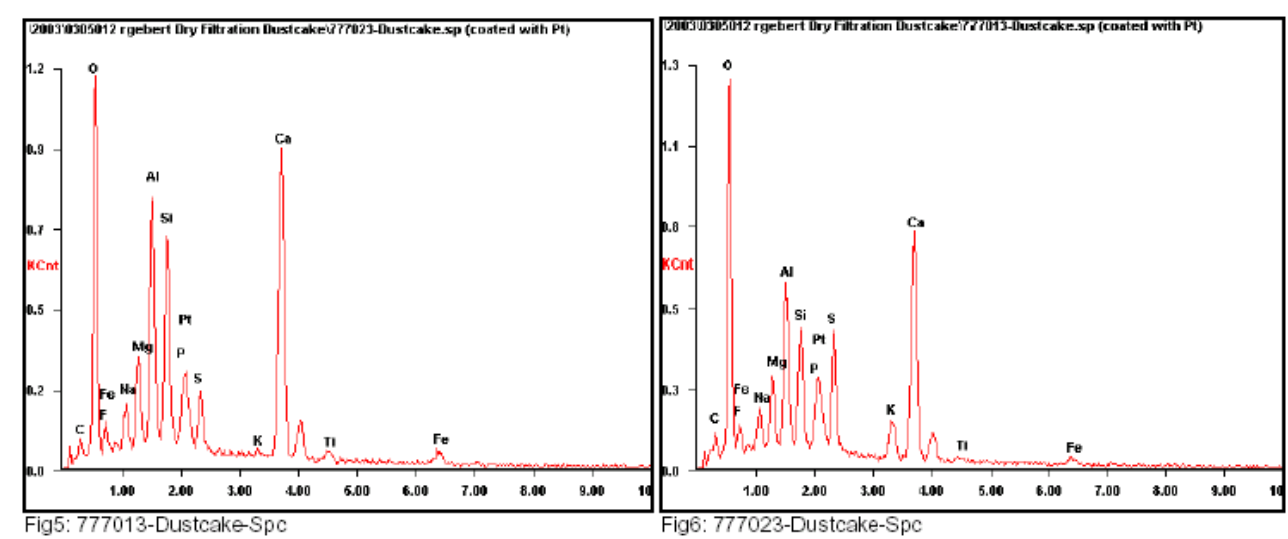

${ }^{\circledR}$ GORE-TEX and GORE-NO STAT are registered trademarks of W. L. Gore \& Associates, Inc. 
B38 Photographs of baffles in place

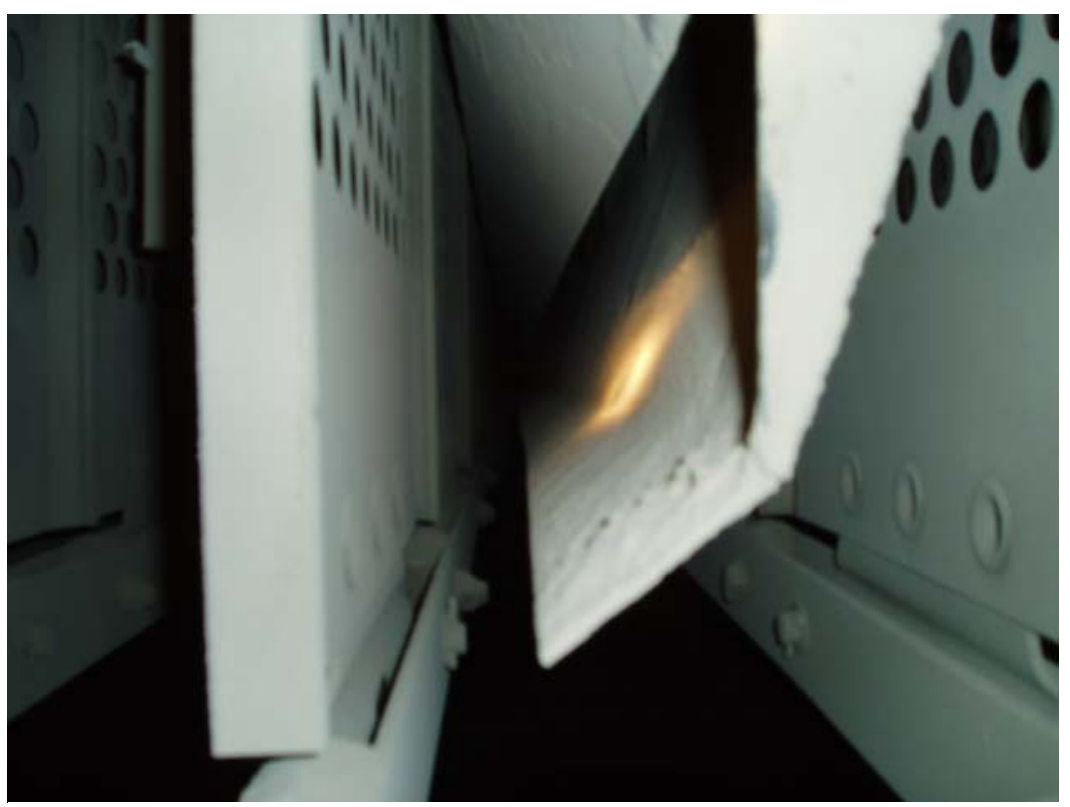

View of exterior of flow baffles

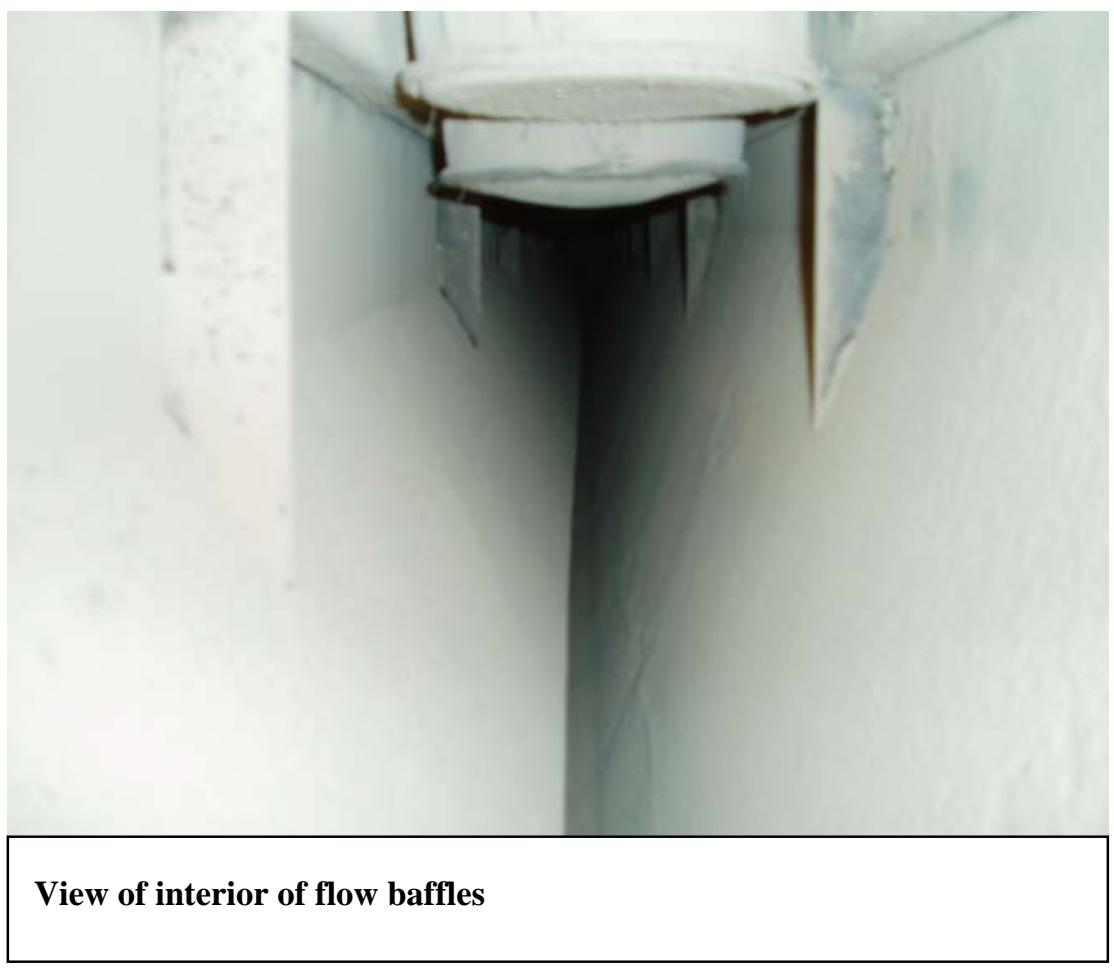


B39 Advanced Hybrid Outage Report June 4 - June 12

\section{Advanced Hybrid Outage Report \\ June 4, 2004 - June 12, 2004}

Prepared By:

Tom Hrdlicka

Plant Engineer

June 14, 2004 


\section{Summary of Work}

1) Bag inspection

2) Bag replacement

3) Installed bag row baffles

4) Modified blowpipes

5) Moved pitot tubes to new locations and checked for proper orientation

6) Repair girder box and bus duct purge air supply line

7) Complete inspection of:

a. Clean gas plenums (leaks, cracks, corrosion, ash on tubesheet, etc.)

b. Discharge electrodes and plates for clearance issues and ash build-up

c. Rapper shafts, pinwheels, hammers and anvils

d. Girder boxes for leaks and insulator crock condition

\section{$\underline{\text { Results and Discussion }}$}

1) Bag Inspection

a. Expectedly found holes in many nonconductive PPS/Gore-Tex bags in 1AF3 and $1 \mathrm{AF} 4$ as well as a few holes in the conductive PPS/Gore-Tex bags in 1AF2, 2AF2 and 2BF3. All the bags in these compartments have been in service for one year and were scheduled to be replaced during this outage.

b. Found two all Gore-Tex bags with holes in the bottom of the bag, one was installed new in June 2003 (1BF2) and the other was an original bag that was washed and reinstalled in Dec 2003 (1BF3).

c. One Nomex bag was found with a hole in 1BF4.

d. The following bags were pulled to be sent in for analysis:

i. 2 BHA-Tex/Nomex (one with a hole in it)

ii. 1 Gore-Tex/Gore-Tex

iii. 1 Gore-Tex/Fiberglass (installed with a 24 vertical wire cage)

iv. 1 Gore-Tex/Fiberglass (installed with a standard 16 vertical wire cage)

v. 1 Gore-Tex/Superflex

vi. 2 BHA-Tex/P84

vii. Two new BHA-Tex/P84 bags will also be sent in for analysis

viii. ECC will perform the bag analysis and issue a report in mid July.

e. Ten missing nozzles were also discovered and new nozzles were installed.

2) Bag Replacement

a. SEI was contracted to replace 1928 filter bags. The replacement bags, provided by BHA Group, Inc., are 14 oz. P84 felt with a BHA-Tex membrane. SEI also replaced 13 additional bags using new Gore-Tex felt with Gore-Tex membrane bags (see updated bag layout below).

b. The blowpipes came apart relatively easy and there were no extra charges incurred during this bag change due to difficult bag or cage removal. 

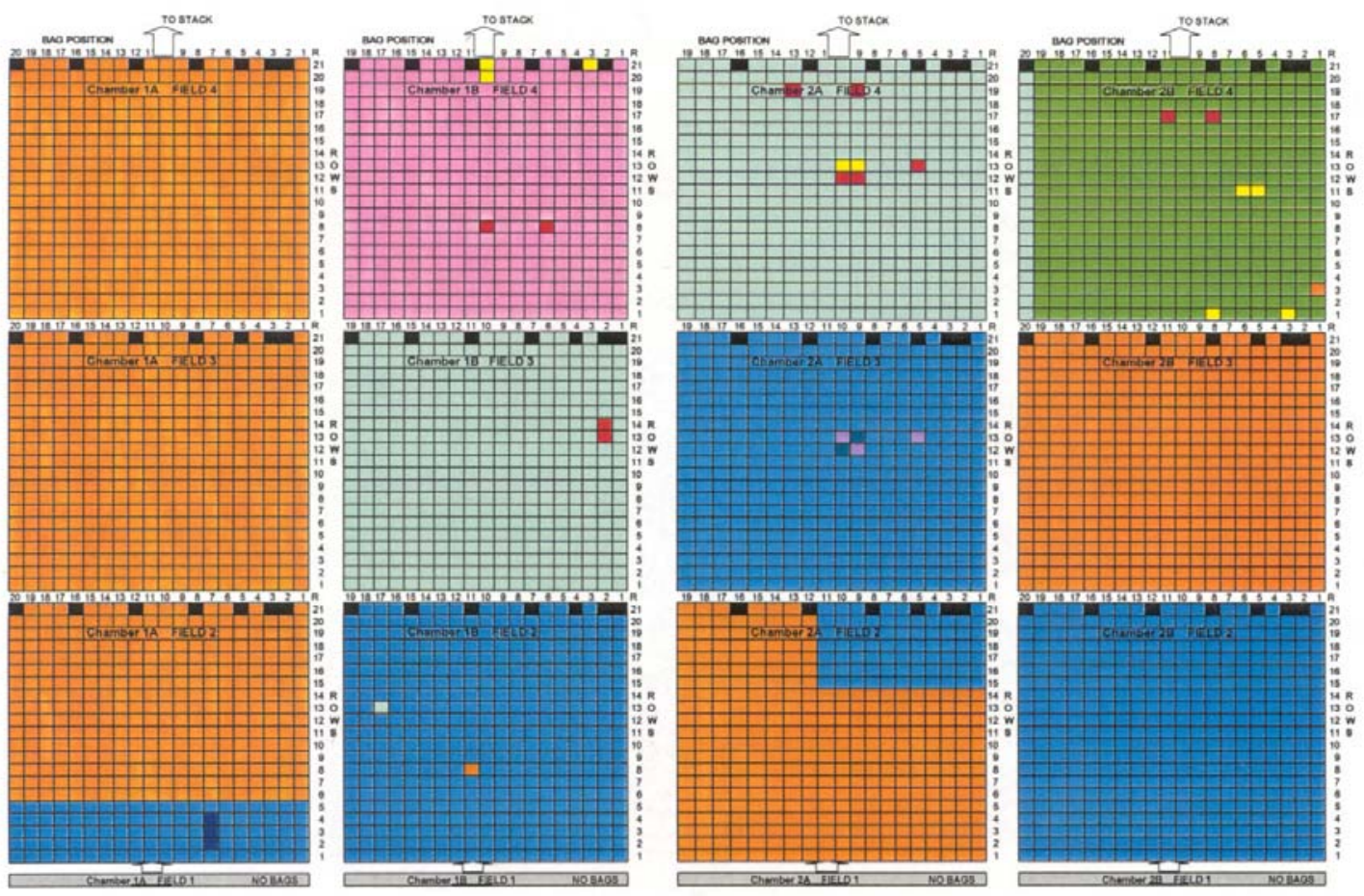

No Filter Bag

BHA-Tex Membrane/P84 Felt (Installed 6/04)

Gore-Tex Membrane/Gore-Tex Felt (Installed 6/04)

Gore-Tex Membrane/Gore-Tex Felt (Installed 4/04)

Conductive Gore-Tex Membrane/Conductive Gore-Tex Felt (Installed 6/03)

Conductive Gore-Tex Membrane/Conductive Gore-Tex Felt (Installed 10/02, removed 6/03, washed, reinstalled 12/03)

BHA.Tex Membrane/Nomex Felt (Installed 12/03)

BHA-Tex Membrane/P84 Felt (Installed 12/03)

Conductive Gore-Tex Membrane/Conductive Gore-Tex Felt (Installed 12/03)

Gore - Superflex (Installed 12/03)

Gore-Tex Membrane/Fiberglass (Installed 12/03)

3) Installed Bag Row Baffles (see Figure1-3 below)

a. SEI was contracted to fabricate and install 57 sets of bag row baffles. The baffles were installed in all compartments of chamber $2 \mathrm{~B}$.

i. Half of the baffles had to be modified because of incorrect fabrication.

ii. Once the modifications were made, all three compartments were installed in only two days.

iii. The decision was made to tack weld the nuts on to support bracket bolts and also to tack weld the ends of the baffles near the bottom to maintain a 2-inch gap.

iv. There is some concern surrounding the clearance between the bag and the cut out portion of the end baffles. 


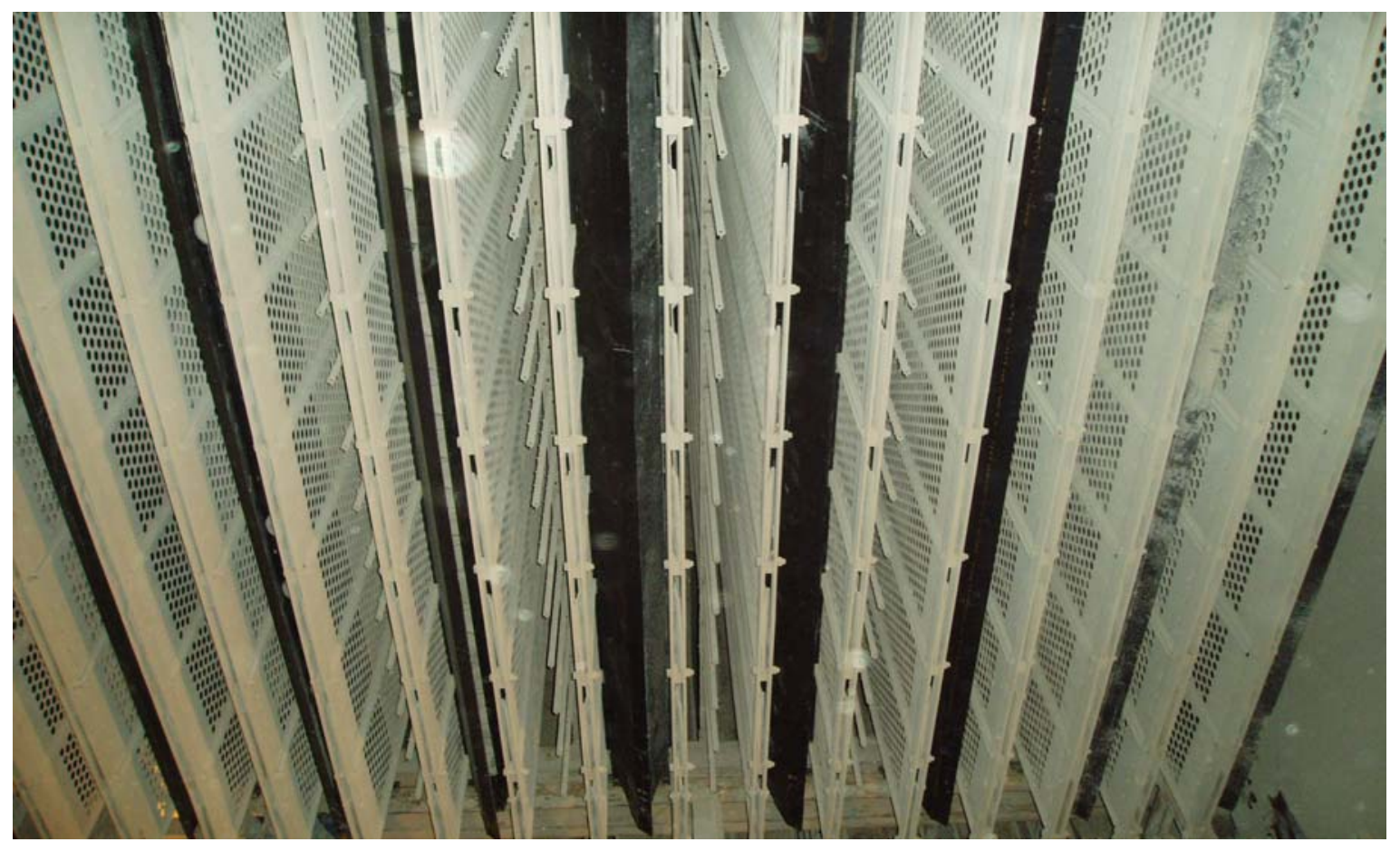

Figure 1: Installed baffles viewed from below.

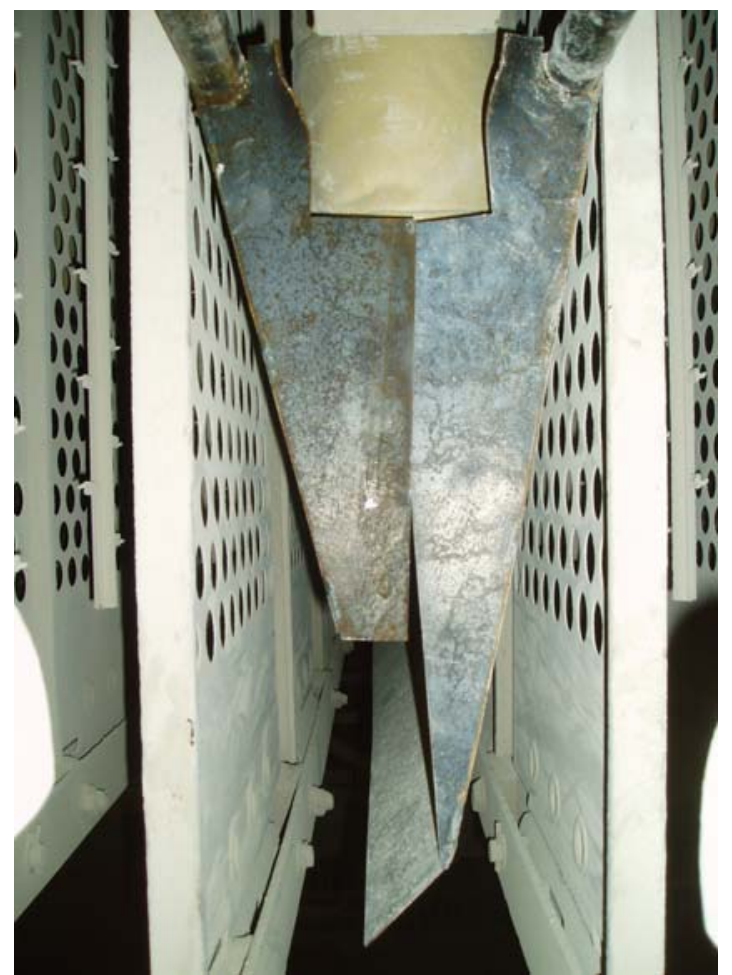

Figure 2: End baffle without tack weld

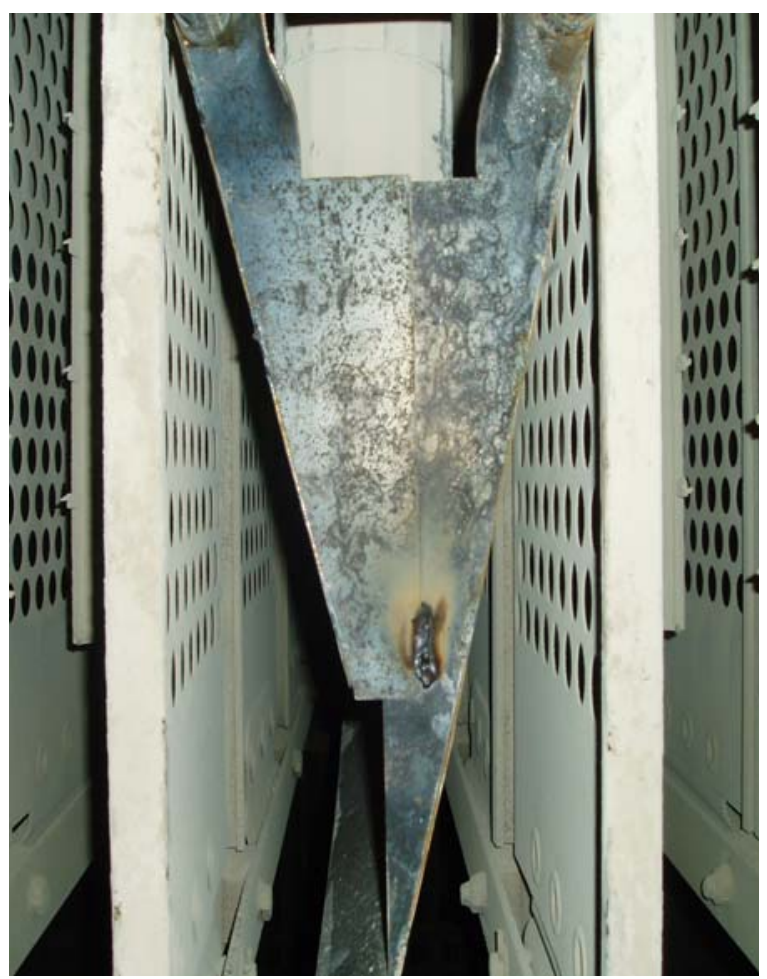

Figure 3: End baffle with tack weld 


\section{4) Modified Blowpipe}

a. One compartment of blowpipes was modified in 1BF3 (see Figure 4)

b. Flat bar was used to seal off the holes for the top header (see Figure 5)

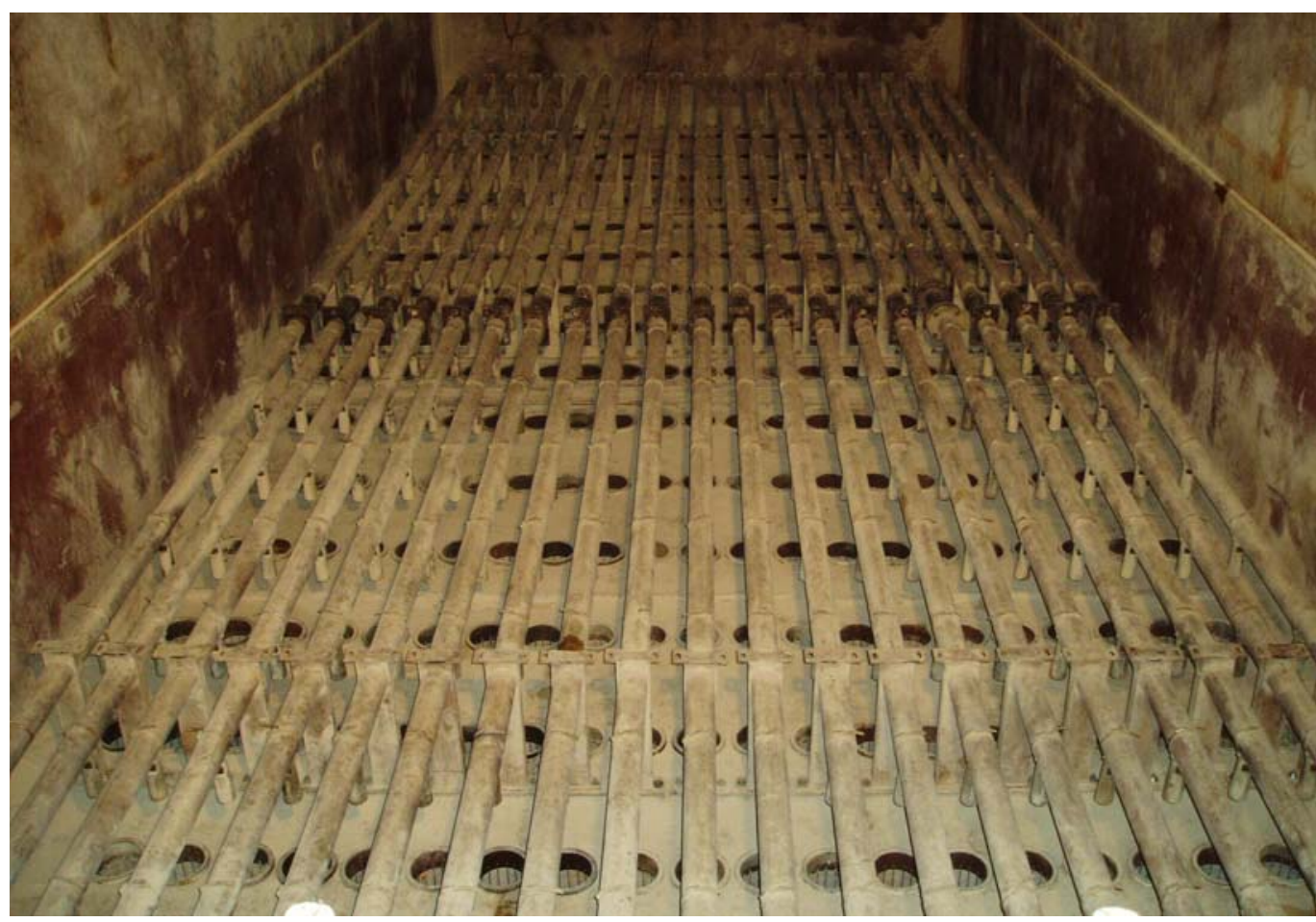

Figure 4: Modified blowpipes in 1BF3

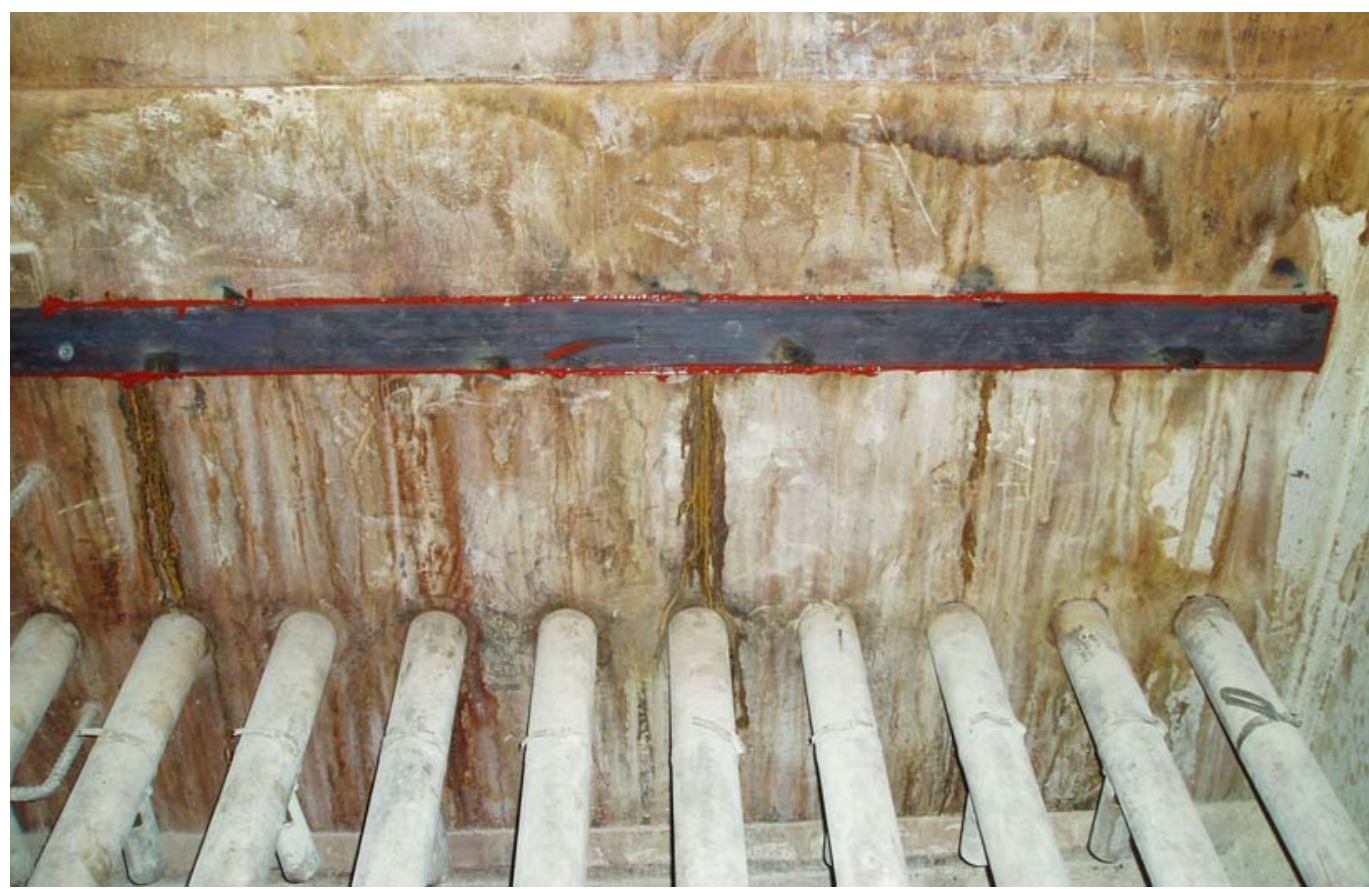

Figure 5: Flat bar used to cover holes in plenum wall 


\section{5) Pitot Tubes}

a. Pitots were repositioned in $1 \mathrm{BF} 3$ to monitor the modified blowpipes and $2 \mathrm{BF} 3$ to help determine the effectiveness of the baffles.

6) Repair Purge Air Supply Lines

a. SEI repaired four girder box and bus duct purge air supply lines. The PVC lines installed in Oct. 2002 were warped due to heat. Metal ducting was installed (see Figures 6-7).

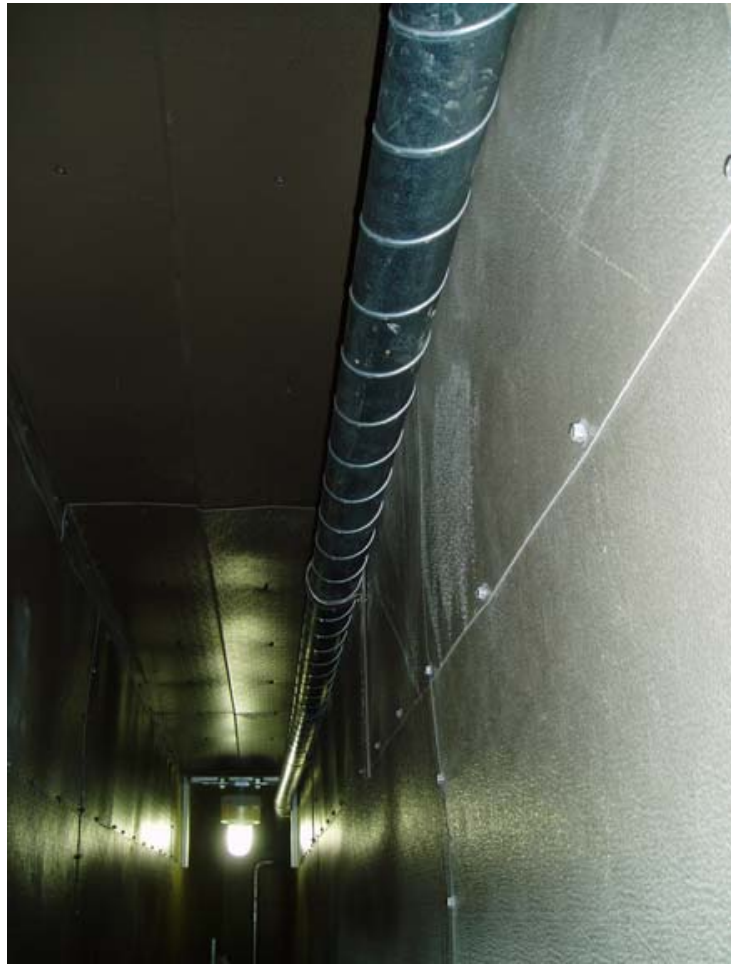

Figure 6. New girder box purge line

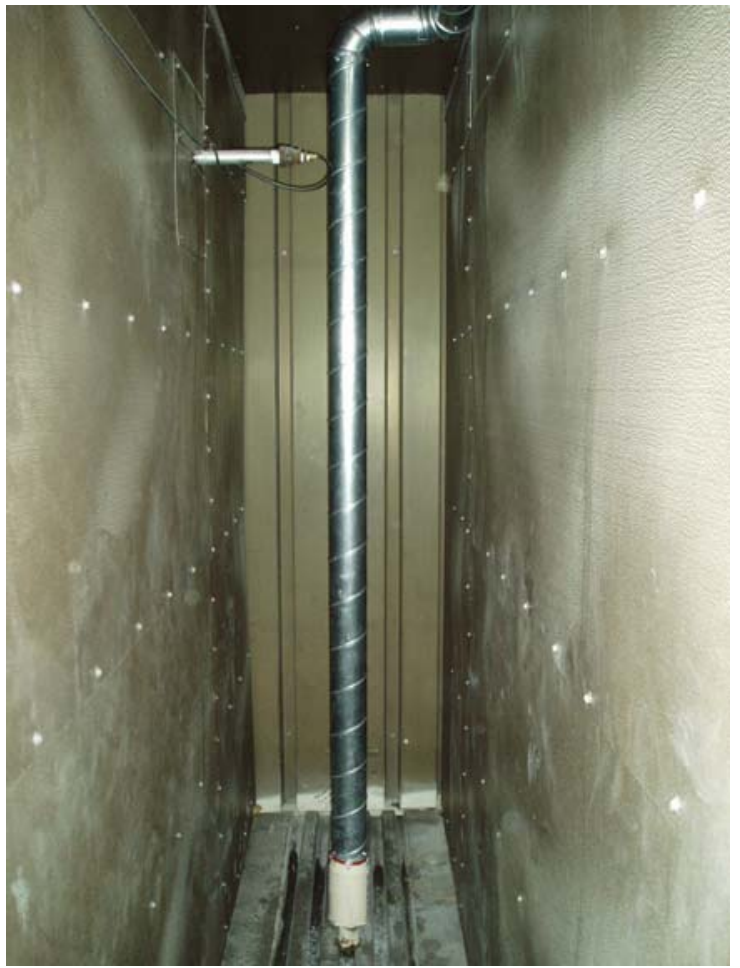

Figure 7: Purge line interface to girder box

7) Complete Inspection

a. Discharge electrodes and plates

i. Discharge electrodes have a thin layer of ash that is uniformly distributed. The ash brushes off with a soft bristle brush.

ii. The plates also had a thin layer of ash that is uniformly distributed. No buildup near the top of the plates was observed and no holes were plugged.

iii. No obvious clearance issues were reported.

b. Rappers

i. The majority $(95 \%)$ of the hammers are striking the anvils on center with the remainder within $1 \mathrm{~cm}$.

ii. No broken hammers or rapper components were reported.

c. Girder Boxes 
i. No ash buildup in the girder boxes.

ii. No cracked insulator crocs reported.

d. Clean Gas Plenums

i. Amount of corrosion on ceilings has increased from last inspection (see Figure 8). Noted water dripping in around one top hatch (see Figure 9).

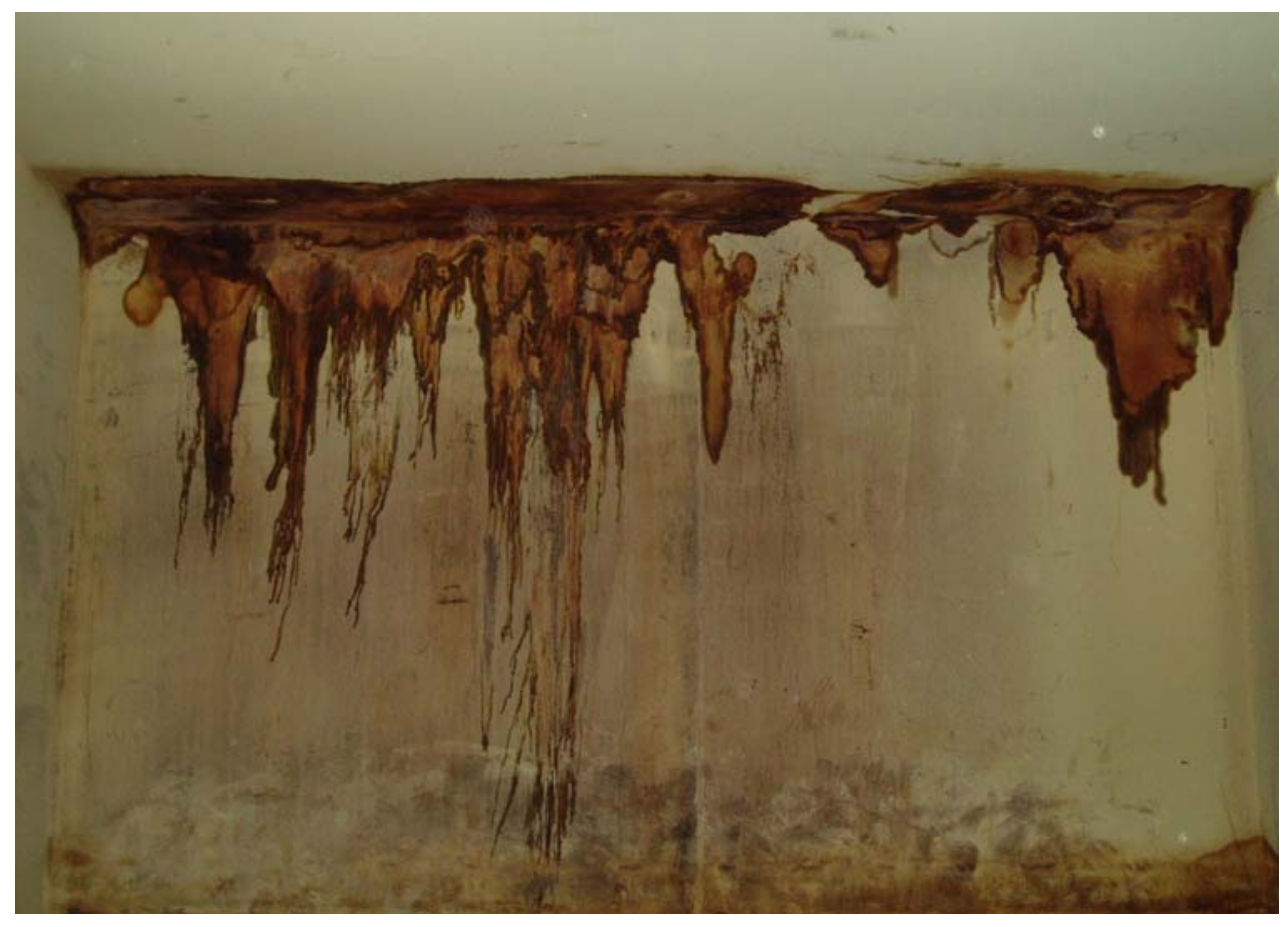

Figure 8. Corrosion on plenum ceiling

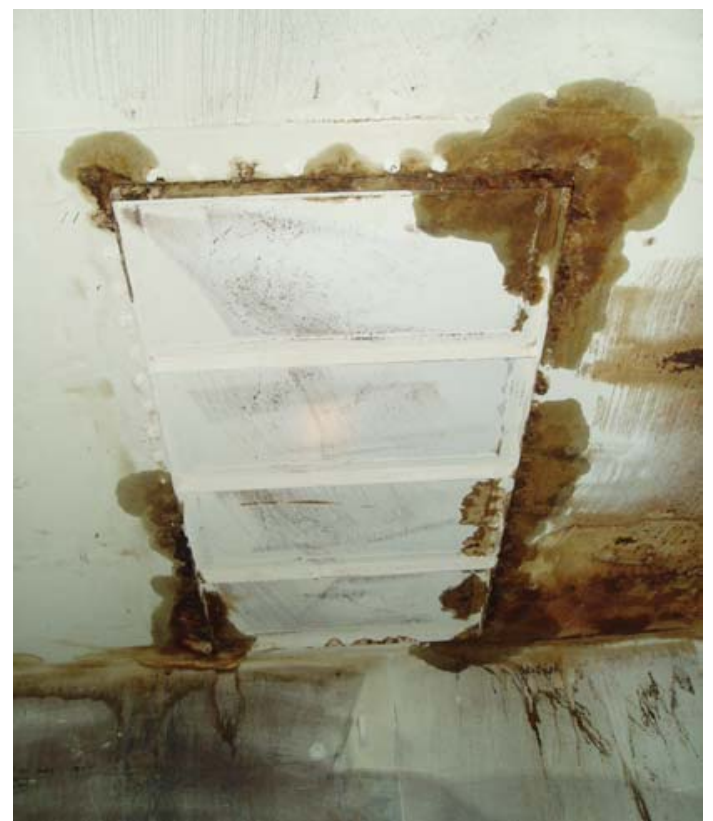

Figure 9. Plenum top hatch corrosion 


\section{$\underline{\text { Recommendations }}$}

- 10 filter bags will be sent in to ECC for analysis including 2 new P84 bags. The new bags will provide some baseline strength data that we do not have to date. Results will be available mid July.

- Standing water that is getting under the roof lagging is causing the corrosion. This problem needs further investigation to develop a solution.

- Pitots have been installed to monitor the modified blowpipes and chamber of baffles. They will have to be rotated on a regular basis to obtain data from different bags.

- The bags near the end baffles will have to be monitored closely. There is potential for abrasive wear and tearing for the bags in these positions. 
B40 W.L. Gore and Associates Bag Report

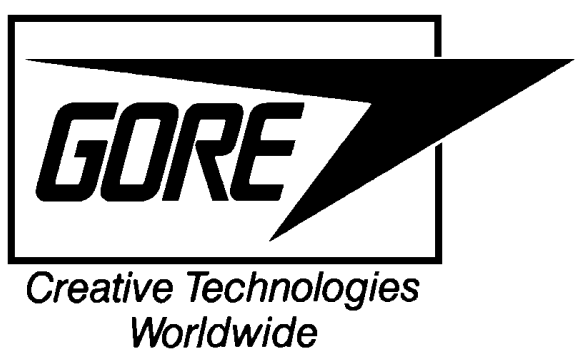

\section{Full scale Advanced Hybrid ${ }^{\mathrm{TM}}$ Filter Big Stone Demonstration Operation Site Filter Bag Analysis \\ Date: \\ June 11, 2004 \\ Prepared By: \\ Dwight Davis}

\section{Background:}

Plant Location: $\quad$ Otter Tail Power Company, Big Stone City, South Dakota

Filter Bag Type: GORE-NO STAT ${ }^{\circledR}$ (GORE-TEX ${ }^{\circledR}$ membrane conductive/GORE-TEX ${ }^{\circledR}$ felt), GORE-

TEX ${ }^{\circledR}$ membrane/PPS (polyphenylene sulfide) felt, GORE-

TEX®membrane/conductive PPS felt, SUPERFLEX®, GORE-

TEX®membrane/woven fiberglass filter bags, NOMEX ${ }^{\circledR}$ and P-84 backed filter bags

Bag Diameter: $\quad 6.0$ inch

Length: $\quad 7$ meter

Air/Cloth: $\quad 10$ to $12 \mathrm{fpm}$

Dust Type: $\quad$ Fly Ash from Coal-Fired Boiler

Coal Type: $\quad$ Eagle Butte, Belle Ayr Mine; Western Sub-bituminous

GORE-NO STAT ${ }^{\circledR}$, GORE-TEX ${ }^{\circledR}$ membrane/PPS felt, GORE-TEX ${ }^{\circledR}$ membrane/conductive PPS felt, SUPERFLEX ${ }^{\circledR}$, GORE-TEX ${ }^{\circledR m e m b r a n e / w o v e n ~ f i b e r g l a s s ~ f i l t e r ~ b a g s ~ w e r e ~ i n s t a l l e d ~ a n d ~ p r e-c o a t e d ~ p r i o r ~}$ to the June 11, 2003 start-up of the full scale Advanced Hybrid ${ }^{\mathrm{TM}}$ Filter at Otter Tail Power Company's Big Stone Plant located in Big Stone City, SD. Refer to the June 11, 2003 bag locator guide found in the appendix. On July 14, 2003 a portion of the filter bags were exposed to a temperature excursion that exceeded their maximum temperature rating. Subsequently Big Stone took a derate to inspect and pull filter bags for analysis in two chambers on September $17^{\text {th }}$, and a third chamber on September $27^{\text {th }}$. On October $24^{\text {th }}$ additional bags were pulled from three chambers for analysis. Big Stone remained in operation until the plant shutdown for a boiler wash on December 5, 2003. Operation resumed on December 20, 2003, with new bags replacing the all PPS filter bags in four of the compartments along with four trial SUPERFLEX ${ }^{\circledR}$ and six trial GORE-TEX ${ }^{\circledR}$ membrane/woven fiberglass filter bags. The filter bags pulled September $17^{\text {th }} \& 27^{\text {th }}$ and October $24^{\text {th }}$ for analysis, indicated the all PPS filter bags had been weakened in four of the compartments. This led to the four compartments' filter bags replacement during the December 2003 boiler wash shutdown. Two of the compartments were outfitted with previously used (Oct '02 to June '03) and washed off-line GORE-NO STAT ${ }^{\circledR}$ bags, the third compartment was outfitted with NOMEX membrane bags and the other with P-84 membrane bags. Refer to the December 2003 bag locator chart in the appendix for the replacement and trial filter bag location. On February $28^{\text {th }}, 2004$ the plant scheduled one last inspection and bag sampling derate prior to their June 
2004 boiler wash outage.

As part of the Power Plant Improvement Initiative Big Stone Demonstration site DOE funding program, filter bags were removed for lab analysis when compartments or the entire Advanced Hybrid ${ }^{\mathrm{TM}}$ Filter were taken off line. Ten filter bags were removed on September $17^{\text {th }}$, one on September $27^{\text {th }}$, five on October $24^{\text {th }}$, and five additional filter bags on February $28^{\text {th }}, 2004$.

\section{Filter Bag Evaluation:}

A total of twenty-one filter bags were removed over the nine month time period by W.L. Gore and Otter Tail Power Company personnel for evaluation purposes by W.L. Gore and Associates. Various tests including air permeability, felt strength using both Mullen Burst and Instron tensile strength tests, along with visual observations including membrane microscopic examination were undertaken.

\section{Air Permeability Analysis}

The air permeability analysis of the filter bag media was performed in the lab using the Frazierometer.

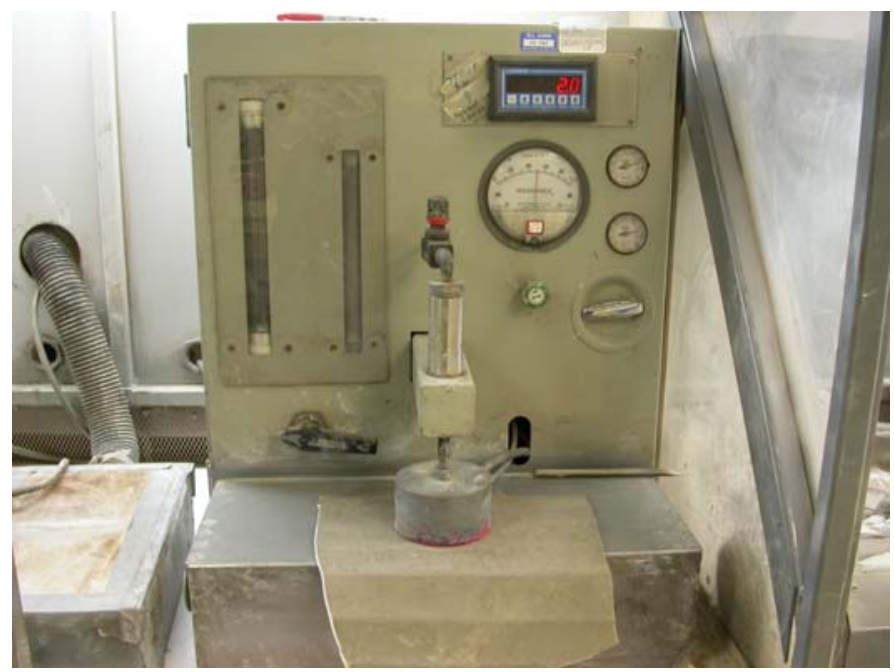

Permeability is the volumetric flow rate of air, measured in cubic feet per minute $(\mathrm{cfm})$ through a square foot of filter media at a pressure differential of 0.5 inches water gauge (w.g.). The unit of measure is $\mathrm{cfm} / \mathrm{ft} 2 @ 0.5$ "w.g. and is called the Frazier Number (Fn). Samples of the Advanced Hybrid ${ }^{\circledR}$ filter bag media were cut from the top, middle, and bottom bag locations. The sample size was five inches in the vertical bag length direction along the entire circumference of the bag. Typically three measurements per bag sample were taken. An average value is then calculated from the nine measurements per bag.

Each sample is tested for permeability in the condition it was received from the field and again in the identical location after lightly brushing the dust cake. See Table 1: 


\begin{tabular}{|c|c|c|c|c|c|c|c|c|c|c|c|}
\hline \multirow{2}{*}{\multicolumn{12}{|c|}{$\begin{array}{l}\text { Big Stone Power Plant Improvement Initiative Demonstration Site } \\
\text { Filter Bag analysis summary chart - All Frazier \#s are reported as cfm/tt2@0.5 in.w.g. driving force }\end{array}$}} \\
\hline & & & & & & & & & & & \\
\hline Location & \begin{tabular}{|l} 
Service \\
Time
\end{tabular} & $\begin{array}{l}\text { Max. } \\
\text { exposed } \\
\text { temp (F) }\end{array}$ & Backing & $\begin{array}{l}\text { As rec'd } \\
\text { (F-n) }\end{array}$ & $\begin{array}{l}\text { Mullen } \\
\text { Burst } \\
\text { (psi) }\end{array}$ & \begin{tabular}{|l} 
Mullen \\
Burst \% \\
Strength \\
Retention
\end{tabular} & \begin{tabular}{|l|} 
Tensile \\
strength \\
cross \\
machine \\
direction \\
(psi)
\end{tabular} & $\begin{array}{l}\% \text { Tensile } \\
\text { strength } \\
\text { retention } \\
\text { cmd }\end{array}$ & \begin{tabular}{|l} 
Tensile \\
strength \\
machine \\
direction \\
(psi)
\end{tabular} & $\begin{array}{l}\% / \\
\text { Tensile } \\
\text { strength } \\
\text { retention } \\
- \text { md }\end{array}$ & Comments \\
\hline 1BF3 R1B1 & $\begin{array}{c}6 / 10 / 03 \text { to } \\
9 / 17 / 03\end{array}$ & 365 & all PPS & 2.9 & 249 & 72 & 113 & 39 & 83 & 61 & membrane OK, tan felt color \\
\hline 1BF3 R1B3 & 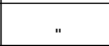 & 365 & all PPS & 3.6 & 226 & 66 & & & & & $\begin{array}{l}\text { membrane cracking along some of the } \\
\text { vertical cage wires }\end{array}$ \\
\hline 1BF3R1B4 & " & 365 & all PPS & 4 & 223 & 65 & & & & & $\begin{array}{l}\text { membrane cracking at vertical/horizontal } \\
\text { cage wire junctures }\end{array}$ \\
\hline 1BF3 R1B6 & $"$ & 365 & all PPS & 3.8 & 182 & 53 & & & 51 & 37 & membrane delaminated during $\mathrm{HEC}$ cleaning \\
\hline 1BF3R1B7 & " & 365 & all PPS & 2.7 & 236 & 69 & 114 & 39 & 61 & 45 & membrane cracking, tan felt color \\
\hline 2BF2 R3B5 & " & 500 & all GT & 1.9 & 717 & 100 & & & & & membrane OK \\
\hline 2BF2 R3B8 & " & 500 & all GT & 1.5 & 735 & 100 & & & & & membrane OK \\
\hline 2BF3 R19B6 & " & 500 & cond PPS & 2.3 & 481 & 96 & 181 & 54 & 243 & 100 & membrane OK, chocalat brown felt color \\
\hline \begin{tabular}{|l|} 
2BF3 R19B7 \\
\end{tabular} & $"$ & 500 & cond PPS & 2.2 & 473 & 94 & 180 & 54 & 200 & 83 & bag turned inside out during removal \\
\hline 2BF4 R20B7 & " & 500 & all PPS & 2.8 & 208 & 60 & 90 & 31 & 73 & 53 & $\begin{array}{l}\text { membrane scraped during removal, dark tan } \\
\text { felt color }\end{array}$ \\
\hline 1AF4 R11B11 & $\begin{array}{c}6 / 10 / 03 \text { to } \\
9 / 27 / 03\end{array}$ & 322 & all PPS & 3.9 & 234 & 68 & 123 & 43 & 90 & 66 & $\begin{array}{l}\text { membrane cracking along vertical and } \\
\text { horizontal cage wires }\end{array}$ \\
\hline 1AF4 R1B20 & $\begin{array}{c}6 / 10 / 03 \text { to } \\
10 / 24 / 03\end{array}$ & 322 & all PPS & 3.6 & 368 & 78 & 104 & 36 & 42 & 31 & $\begin{array}{l}\text { membrane cracking in vertical direction } \\
\text { between vertical cage wires }\end{array}$ \\
\hline 1AF4 R1B12 & $"$ & 322 & all PPS & 4 & 229 & 67 & 73 & 25 & 24 & 17 & $\begin{array}{l}\text { membrane cracking at vertical/horizontal } \\
\text { cage wire junctures, tan felt color }\end{array}$ \\
\hline 1BF3 R21B5 & $"$ & 365 & all PPS & 6.9 & 203 & 59 & 48 & 16 & 10 & 8 & $\begin{array}{l}\text { holes formed through felt backer, choc. } \\
\text { brown felt }\end{array}$ \\
\hline 1BF3 R21B6 & " & 365 & all PPS & 5 & 210 & 61 & 33 & 11 & 2 & 2 & membrane delamination, holes in felt \\
\hline 2AF4 R21B14 & " & 450 & cond PPS & 2 & 463 & 92 & 115 & 34 & 197 & 82 & tan discoloration, hole in felt \\
\hline 1AF2 R15B11 & $\begin{array}{c}6 / 10 / 03 \text { to } \\
2 / 28 / 04\end{array}$ & 322 & cond PPS & 2.6 & 449 & 89 & 224 & 67 & 205 & 85 & membrane $\mathrm{OK}$ \\
\hline 1AF3 R11B15 & " & 322 & all PPS & 3 & 214 & 59 & 125 & 43 & 78 & 57 & $\begin{array}{l}\text { holes formed at vertical/horizontal cage wire } \\
\text { junctures }\end{array}$ \\
\hline 2AF4 R13B10 & $\begin{array}{c}12 / 3 / 03 \text { to } \\
2 / 28 / 04\end{array}$ & 350 & SUPERFLEX & 3.5 & 870 & 100 & 483 & 100 & 405 & 100 & membrane OK \\
\hline 2AF4 R13B9 & $"$ & 350 & Fiberglass & 3.1 & 920 & 100 & 729 & 100 & 461 & 100 & $\begin{array}{l}\text { membrane OK, small areas scraped during } \\
\text { removal }\end{array}$ \\
\hline 2BF4 R11B6 & $"$ & 365 & P-84 & 5.1 & 337 & & 185 & & 97 & & $\begin{array}{l}\text { membrane delamination throughout entire } \\
\text { length of bag }\end{array}$ \\
\hline & new & 80 & NOMEX & 5.4 & 513 & & 408 & & 160 & & brand new \\
\hline & & & new all PPS & & 366 & & 289 & & 137 & & \\
\hline & & & cond PPS & & 503 & & 337 & & 241 & & \\
\hline & & & all GT & & 650 & & & & & & \\
\hline
\end{tabular}

Table 1. Test Results Summary Chart

All the filter bags when removed contained a thin layer of dust similar to typical coal fired boiler fabric filter particulate collector applications. This residual filter cake and filter bag media air permeability measurement is shown in the " as received Frazier numbers" column. After light brushing, all the filter bag perms returned to near new levels. It should be noted that the higher Frazier number readings occurred when the membrane was scraped during removal, had cracked due to a weakened backer, or had become delaminated.

\section{Felt Strength}

Mullen burst tests were run on a portion of samples taken for the air permeability measurements.

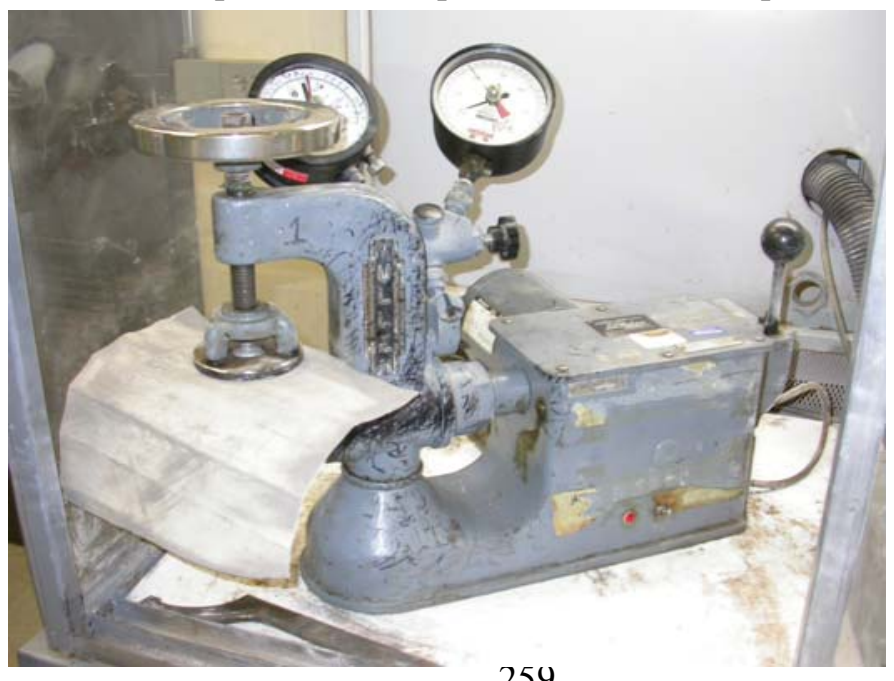


The test consists of applying pressure in the reverse direction of airflow on a three inch diameter filter bag sample, continuously increasing the pressure until the sample is ruptured.

The September 2003 sampled filter bags' physical strength of the GORE-TEX ${ }^{\circledR}$ felt backed and conductive PPS felt backed filter bags maintained their strength while the all PPS felt backed filter bags began to show some minor weakening. Once we noticed the weakening of the all PPS felt backed filter bags, we began running a second type of physical strength test using an Instron test device. The Instron measures the tensile strength in both the machine and cross machine direction of the felt using two 2 inch by 5 inch samples. The sample cut with the long dimension in the vertical direction as the filter bag hangs represents the machine direction, the other sample cut with the long dimension cut in the horizontal (circumference) direction represents the cross machine direction. The Instron tests confirmed the all PPS felt backed filter bags had begun to weaken and the results indicated the higher the temperature exposure, the weaker the felt backer had become. A second set of filter bags was pulled in October 2003 and proved the all PPS felt filter bag continued to become weaker as shown in the appendix. By February 2004 the conductive PPS backed filter bags began to exhibit early signs of strength loss, even at the maximum exposed temperature of $322(\mathrm{~F})$.

\section{Visual and Microscope Analysis}

As noted earlier, all the filter bags contained a thin layer of dust cake on the membrane surface, typical of most coal -fired boiler applications. The primary dust cake was easily brushed off all the filter bags. The filter bags were examined for membrane damage from electrostatic discharge or sparking using a microscope - none was observed. However, membrane cracking began to occur with all PPS backed filter bags with the first set removed in September 2003. The conductive PPS backed and GORE-NO STAT® filter bags membrane integrity remained intact. The filter bags pulled February 2004, after two and a half months service, SUPERFLEX ${ }^{\circledR}$ and fiberglass backed filter bags show no membrane or backer wear. The P-84 backed filter bag had from top to bottom areas where the membrane had become delaminated in 1 to 3 inch diameter sections. The redesign of the filter bag incorporated in the June 2003 bag install utilizing a double layer of material in the bottom cuff apparently solved the wear previous seen with the October 2002 installed bags. .

Conclusions:

- GORE-NO STAT ${ }^{\circledR}$ filter bags continue to maintain excellent membrane integrity and physical strength.

- Laboratory analysis of the filter bags revealed no membrane damage caused by electrostatic discharge or sparking.

- After 10 weeks of service SUPERFLEX ${ }^{\circledR}$ and fiberglass backed filter bags exhibited no loss in physical strength and membrane integrity.

- The all PPS backed and conductive PPS backed GORE-TEX ${ }^{\circledR}$ membrane filter bags have shown they are sensitive to temperature upsets.

- Future physical strength analysis should include Tensile strength testing, preferably using the Instron instrument.

${ }^{\circledR}$ GORE-TEX and GORE-NO STAT are registered trademarks of W. L. Gore \& Associates, Inc. 


\section{APPENDIX}

All PPS backed Filter Bag Retained Strength vs Temperature vs service time

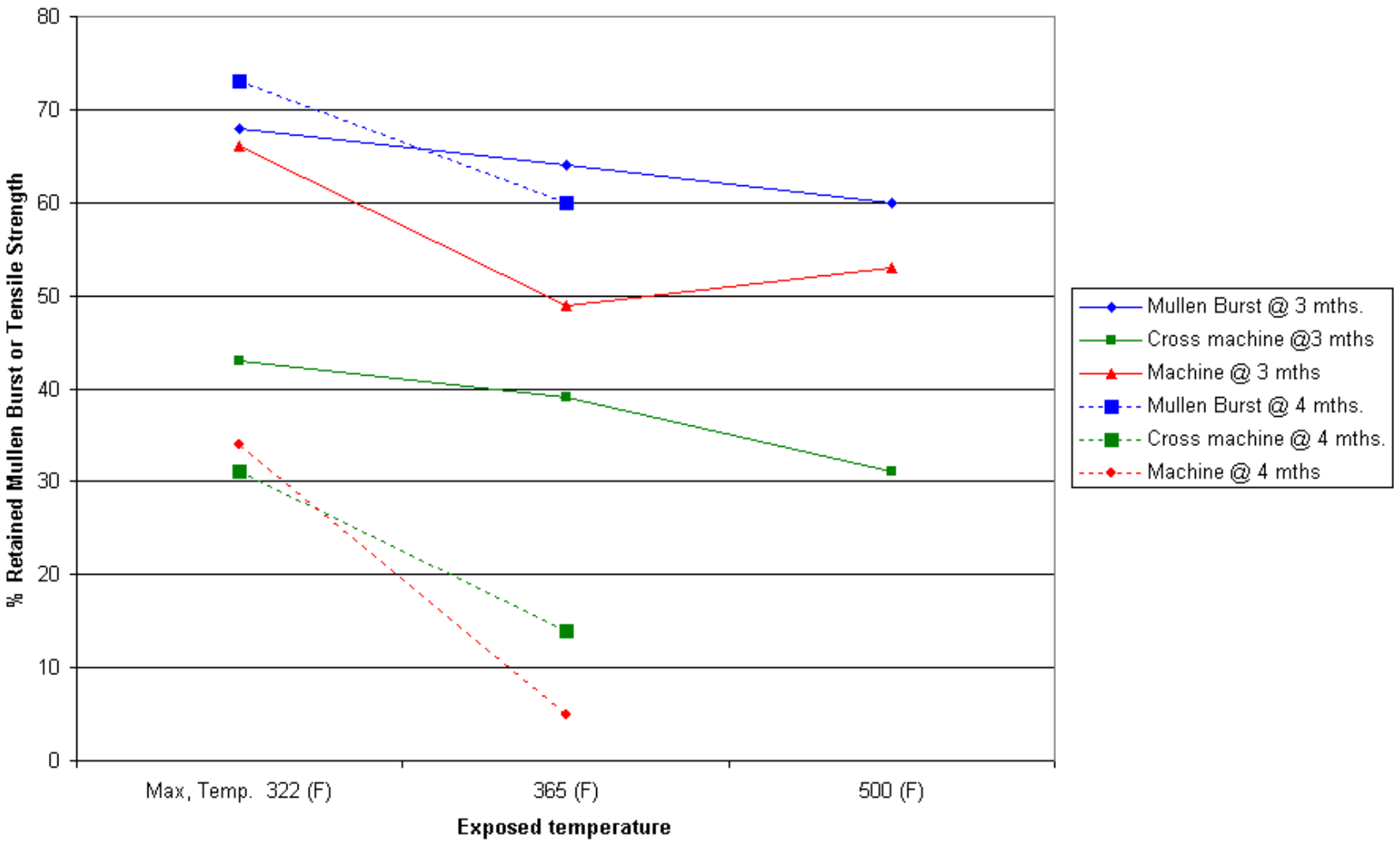


Physical strength retention of Conductive PPS backed filter bags vs temperature and service time

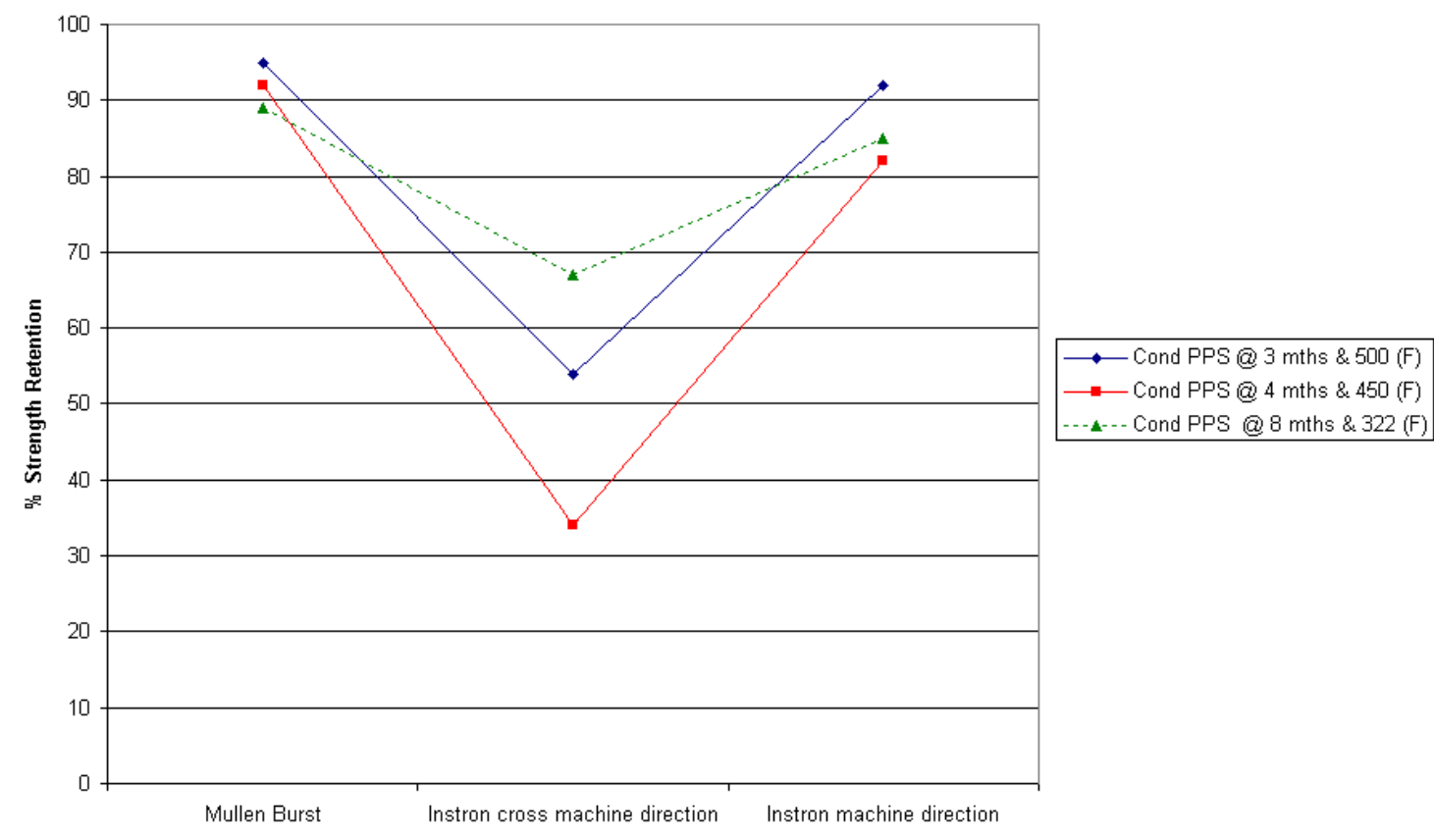


Bag Locator Chart for June 11

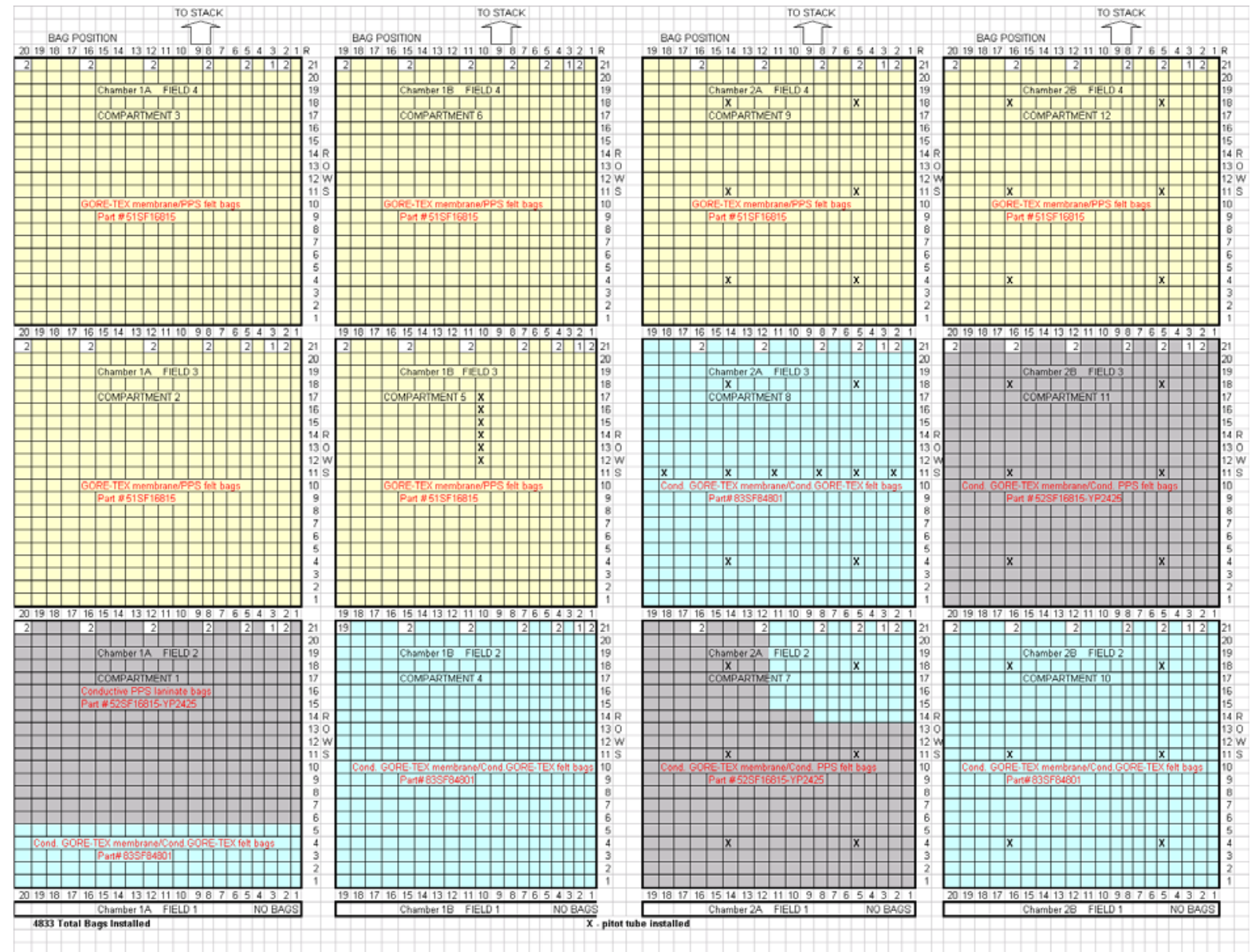


Bag locator guide for December 20, 2003




B41 EEC Bag analysis report from July 22, 2004

Prepared for:

OTTERTAIL POWER COMPANY BIG STONE, SOUTH DAKOTA

JULY 22, 2004

TLN 402 J

July 22,2004

TLN 402 J 


\section{REPORT \\ OTTERTAIL POWER COMPANY}

\section{Reference: Filter Bag Evaluations}

Eleven filter bags ( 2 new and 9 used) were received for testing and evaluation. The bags were sampled from an Advanced Hybrid Filter baghouse colleting fly ash off a coal fired boiler operation.

The baghouse is a pulse jet cleaning unit operating at $320^{\circ} \mathrm{F}$ average to a maximum of $365^{\circ} \mathrm{F}$. Pressure differentials are reported to be 8.0 " w.c. with a maximum differential of 8.5" w.c.

The bags were identified as follows:

\begin{tabular}{|l|l|}
\hline$[1]$ & New Bag - P-84/Membrane BHA Tex \\
\hline$[2]$ & New Bag - P-84/Membrane BHA Tex \\
\hline$[3]$ & R1-B8 - installed $12 / 03-$ out $4 / 04$ \\
\hline$[4]$ & $\begin{array}{l}\text { R5-B13 }- \text { installed } 10 / 02 \text { washed }(*) \\
\text { Washed reinstalled } 12 / 03 \text { out } 6 / 04\end{array}$ \\
\hline$[5]$ & R6-B8 - installed $12 / 03$ out $6 / 04$ \\
\hline$[6]$ & R8-B19 - installed $12 / 03$ out $6 / 04$ \\
\hline$[7]$ & R9-B12 - installed $12 / 03$ out $6 / 04$ \\
\hline$[8]$ & R10-B8 - installed $12 / 03$ out $6 / 04$ \\
\hline$[9]$ & R10-B12 - installed $12 / 03$ out $6 / 04$ \\
\hline$[10]$ & R11-B17 - installed $12 / 03$ out $6 / 04$ \\
\hline$[11]$ & R13-B19- installed washed $(*)$ \\
& Washed reinstalled $12 / 03$ out $6 / 04$ \\
\hline
\end{tabular}

July 22,2004

TLN $402 \mathrm{~J}$

Page 2

The bags are of various generic class (see data sheets) and R5-B12 and R13-B19 were laundered and reinstalled in the unit.

Attached are the results of the testing data.

In general, the as received permeability of the bags yielded generally low throughput characteristics in full profile.

There is no significant differences between the candidates however both laundered candidates (R5-B13 and R13-B19) did generate a lower throughput average.

The following are the average Permeabilities as received of all candidates in order of decreasing 
values:

\begin{tabular}{|l|c|}
\hline \multicolumn{1}{|l|}{ CANDIDATES } & AVERAGE PERMEABILITY \\
\hline R6-B8 & 2.027 \\
\hline R8-B19 & 2.023 \\
\hline R11-B17 & 2.013 \\
\hline R1-B8 & 1.980 \\
\hline R9-B12 & 1.973 \\
\hline R10-B8 & 1.970 \\
\hline R10-B12 & 1.953 \\
\hline \hline R5-B13 & 1.950 \\
\hline R13-B19 & 1.877 \\
\hline
\end{tabular}

The differences are not that significant however, there is about an $8 \%$ gain in flows from the lowest to the highest candidate.

July 23, 2004

TLN $402 \mathrm{~J}$

Page 3

All candidates exhibited a generally porous non-agglomerated cake structure.

Microscopic Photo A and B are views of this as received porous ash cake structure common to all bags. 


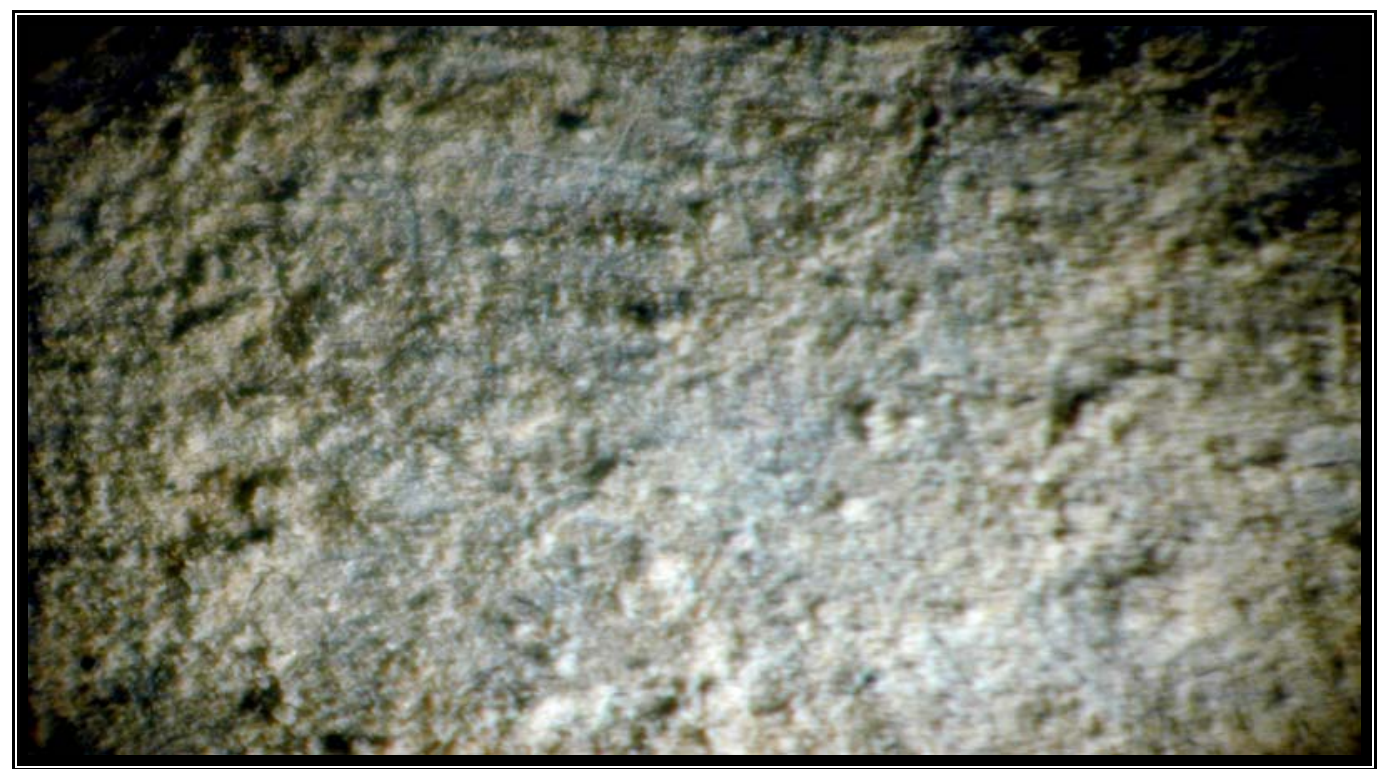

Photo A

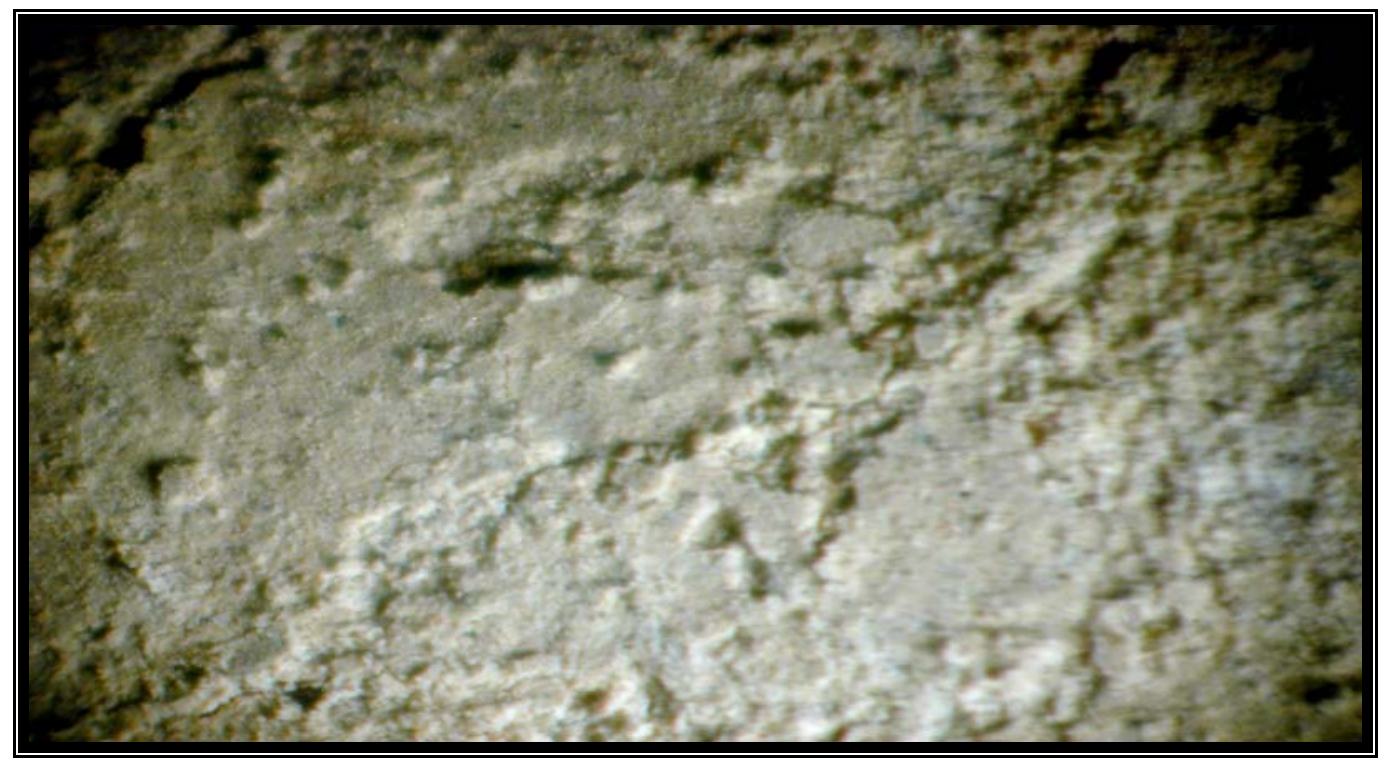

Photo B

July 23, 2004

TLN $402 \mathrm{~J}$

Page 4

Impact generated this outer dust to discharge however directly on the membrane surface were densified ash agglomerations.

Microscopic Photo C and D are views of the impacted membrane surface. 


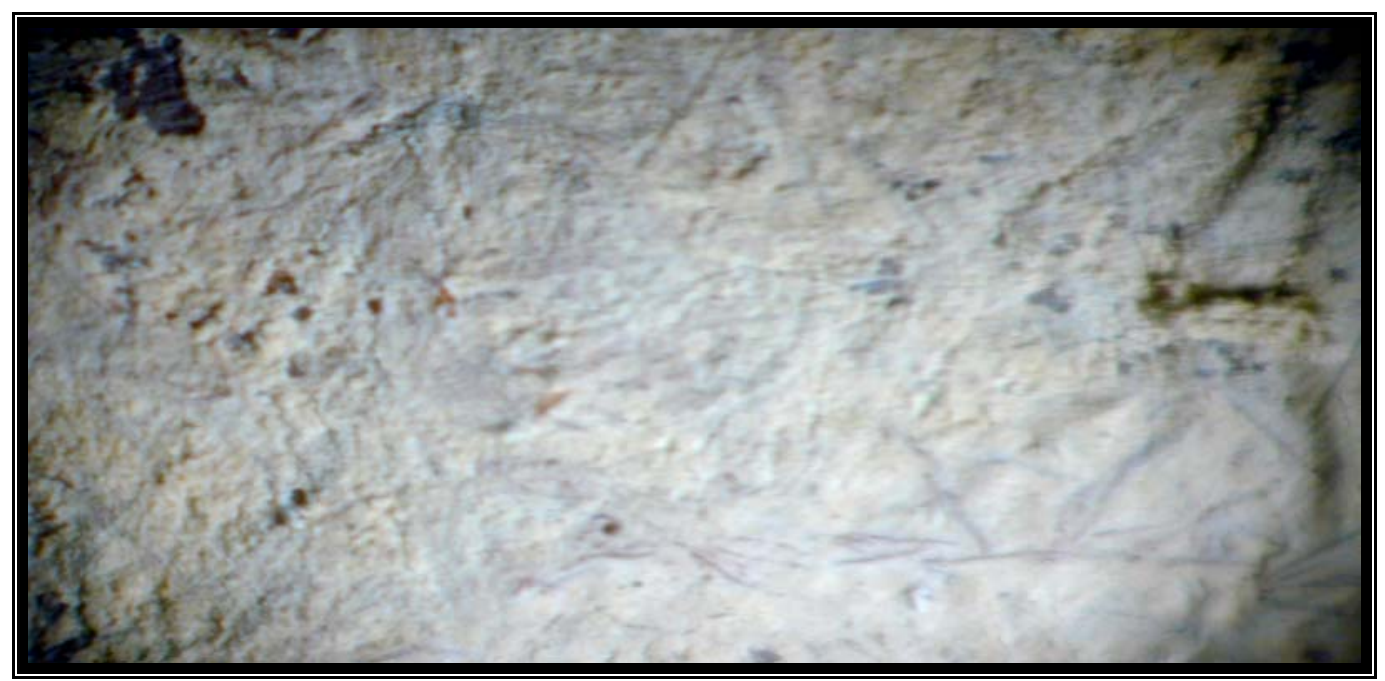

Photo C

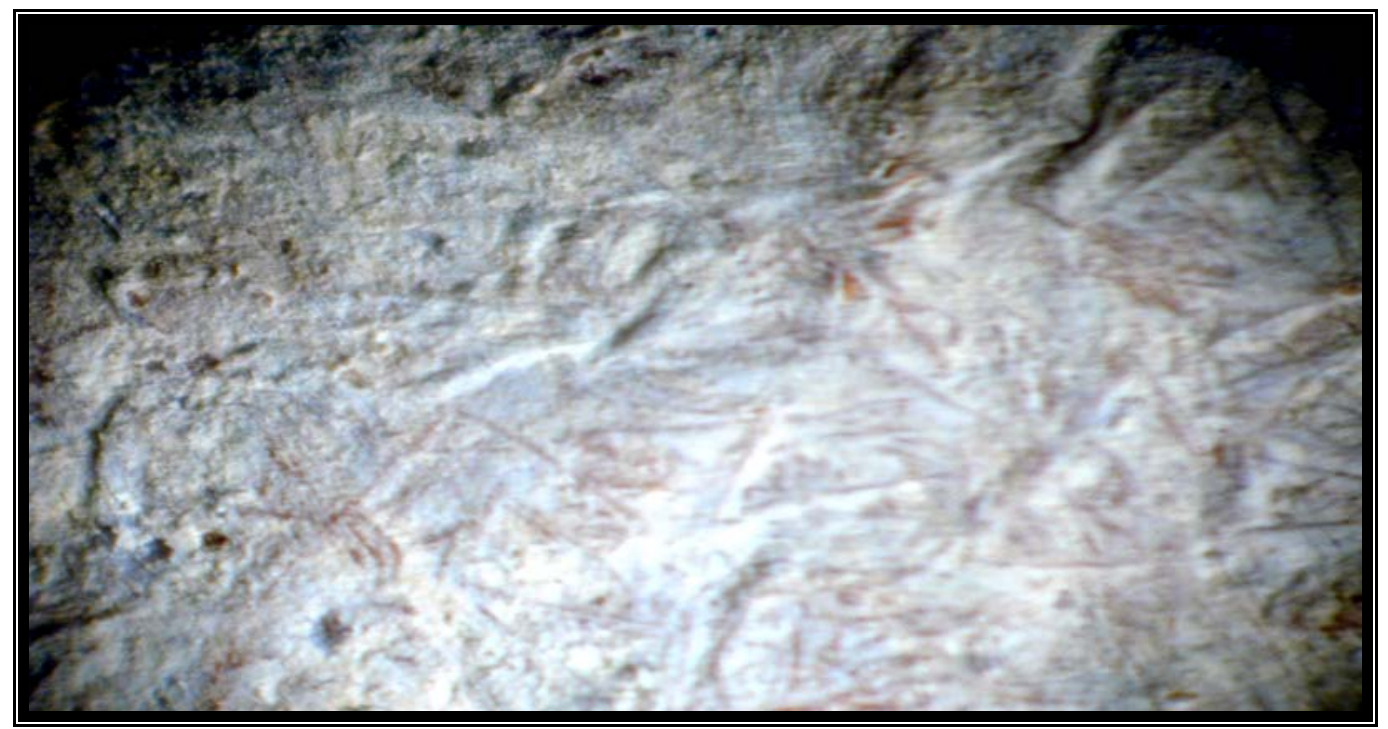

Photo D

July 23, 2004

TLN $402 \mathrm{~J}$

Page 5

This densified thin layer of dust directly on the membrane has caused generally low regain characteristics in Permeabilities.

Again, no significant differences were present between the candidates flow characteristics.

The candidates generally followed the same rankings in regain as the as received conditions.

The following are the required Permeabilities of the candidates: 


\begin{tabular}{|l|c|}
\hline Candidate & Permeability \\
\hline R6-B8 & 2.783 \\
\hline R8-B19 & 2.770 \\
\hline R11-B17 & 2.786 \\
\hline \hline R1-B8 & 2.740 \\
\hline R9-B12 & 2.813 \\
\hline R10-B8 & 2.737 \\
\hline R5-B13 & 2.660 \\
\hline R10-B12 & 2.760 \\
\hline \hline R13-B19 & 2.297 \\
\hline
\end{tabular}

The permeability capacity characteristics of the candidates (except R13-B19) are not at any significant differences with very comparable flows.

R13-B19 yielded abnormal levels of regain.

Physical strengths of breaking tenacity and mullen burst strengths on R10-B8 revealed reductions in values uncommon to all other candidates.

Flex characteristics also revealed an uncommon decline in endurances of Bag R10-B8 exhibited by the other candidates.

July 23, 2004

TLN $402 \mathrm{~J}$

Page 6

Considering the limited reported service use of 6 months the Nomex Aramid bag has undergone added degradation not experienced by the other candidates.

The Nomex candidate was extracted for soluble fraction analysis. Titration (Barium Chloride) resulted in positive sulphate salts within the Aramid Nomex polymer chemistry.

These sulphates result from the gaseous sulfur oxides (primarily sulfur trioxide) degrading the Aramid fiber Polymer.

With catalyst such as valadrum, sulfur trioxide is generated to $2-5 \%$ levels within the sulfur dioxide and will chemically degrade Nomex.

All other candidates did not exhibit any abnormal deterioration under this limited usage.

All losses from the candidates (except Nomex R10-B8) generated normal declines in physical values resulting from service use.

The extractions generated high levels of alkaline sulphates (calcium sulphate) indicative of 
Powder River Basin coal with higher calcium oxide in the ash compared to the level of iron oxide.

This metallic oxide content generates an alkaline chemistry which is not detrimental to any of the candidates.

There is no thermal or chemical deterioration (except R10-B8 Nomex) on the bags with all losses attributed to physical service use fatigue and normal adjustments in values from service use.

All bags exhibited good snap band gasket to tube sheet sealing with no leakage demonstrated.

July 23, 2004

TLN $402 \mathrm{~J}$

Page 7

Examination of the membrane surface revealed no failures/fractures with good bonding to the corresponding sub straight fabric.

Examination of the R5-B12 and R13-B19 (washed candidates) did not exhibit any membrane failures/fractures from the washing procedure.

Bags housed on the 24 wire cages (R18-B12 and R13-B19) did not generate any significant differences in Permeabilities/cleanable compared to the 16 wire candidates.

I would add that fiberglass would undergone reduced cage contact wear/flex with the higher 24 cage wire support and upon time would generally extend bag life on fiberglass.

\section{Conclusions:}

- Nomex has undergone sulfur trioxide degradation and under the 6 month exposure has suffered high deterioration. Nomex Aramid is not recommended for service in this application.

- Fiberglass candidates exhibited good retention in physical strengths and flex endurances. Fiberglass reductions have resulted from normal physical service use fatigue and normal adjustments in value from thermal baghouse exposures (normal for fiberglass).

- The PTFE needled felt candidate exhibited no loss in strength and flex fatigue at this current service use.

- P-84 media experienced normal losses in strength and flex endurances.

- The fiberglass, P-84 and PTFE needled felt are exhibited suitable characteristics for use in this application.

- Life projections of the candidates based on this limited usage/data are as follows: Fiberglass -4 to 4.5 years, P-84 - 5 to 6 years and PTFE felt -8 to 9 years.

- The PTFE expanded membrane of the candidates are all rated at comparable performances.

- All membrane candidates generated good ash collection characteristics with no penetration beyond the membrane.

- Photo E is a cross sectional typical to all bags revealing the internal depths of the media void of any dust penetration. 
July 23, 2004

TLN $402 \mathrm{~J}$

Page 8

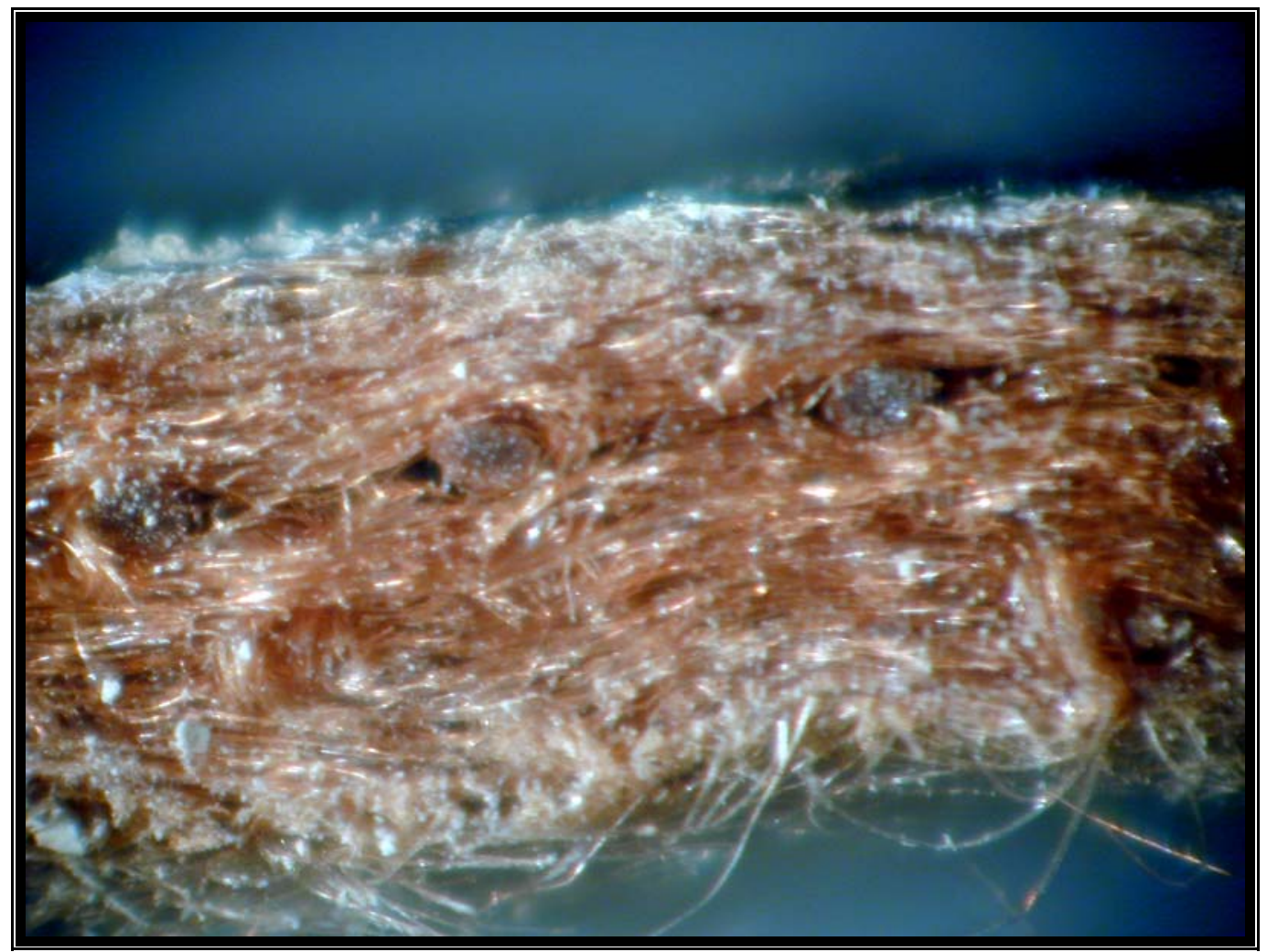

Photo E

July 23, 2004 
TLN $402 \mathrm{~J}$

Page 9

\begin{tabular}{|c|c|c|}
\hline FABRIC & NEW & NEW \\
\hline FIBER & P-84 & P-84 \\
\hline TYPE & NEEDLED & NEEDLED \\
\hline SCRIM SUPPORT & YES & YES \\
\hline SCRIM WEAVE & PW & PW \\
\hline SCRIM YARN & SPUN & SPUN \\
\hline SCRIM COUNT (W X F) & $24 \times 23$ & $24 \times 24$ \\
\hline WEIGHT (OZ/SQ YD) & 18.74 & 17.61 \\
\hline THICKNESS (INCHES) & .084 & .080 \\
\hline $\begin{array}{l}\text { DENSITY (OZ/CUBIC } \\
\text { INCH) }\end{array}$ & 0.1721 & 0.1698 \\
\hline PERMEABILITY (CFM) & 6.9 & 7.3 \\
\hline $\begin{array}{l}\text { MULLEN BURST (LBS/SQ } \\
\text { INCH) }\end{array}$ & 611 & 604 \\
\hline $\begin{array}{l}\text { TENSILE (LBS/INCH) } \\
\text { WARP } \\
\text { FILLING }\end{array}$ & $\begin{array}{l}198 \\
317\end{array}$ & $\begin{array}{l}203 \\
305\end{array}$ \\
\hline FINISH & MEMBRANE & MEMBRANE \\
\hline TYPE & PTFE & PTFE \\
\hline MEMBRANE QUALITY & GOOD & GOOD \\
\hline
\end{tabular}

July 23, 2004

TLN 402 J

Page 10

\begin{tabular}{|l|l|l|}
\hline FABRICATION & NEW & NEW \\
\hline FLAT WIDTH (INCHES) & 9.75 & 9.78 \\
\hline
\end{tabular}




\begin{tabular}{|l||l|l|}
\hline DIAMETER (INCHES) & 6.21 & 6.23 \\
\hline \hline OAL & NO BAND TOP PRESENT & CUT OFF \\
\hline BOTTOM CUFF (INCHES) & 5.9 & 6.0 \\
\hline BOTTOM CUFF STITCH & LOCK & LOCK \\
\hline $\begin{array}{l}\text { BOTTOM CUFF STITCH } \\
\text { ROWS }\end{array}$ & 2 & 2 \\
\hline $\begin{array}{l}\text { BOTTOM CUFF STITCH } \\
\text { YARN }\end{array}$ & PTFE & PTFE \\
\hline \begin{tabular}{l|l|l|} 
BOTTOM CUFF STITCHES \\
PER INCH
\end{tabular} & 5.2 & 5.3 \\
\hline \hline SEAM TYPE & OVERLAP & OVERLAP \\
\hline SEAM STITCH & CHAIN & 3 \\
\hline SEAM STITCH ROWS & 3 & PTFE \\
\hline SEAM STITCH YARN & PTFE & 6.5 \\
\hline $\begin{array}{l}\text { SEAM STITCHES PER } \\
\text { INCH }\end{array}$ & 6.8 & \\
\hline
\end{tabular}


B42 EEC Bag analysis report from December 3, 2004

Prepared For:

OTTER TAIL POWER COMPANY BIG STONE CITY, SOUTH DAKOTA

DECEMBER 3, 2004

TLN 618 J 
December 3, 2004

TLN 618 J

Page 1

\section{REPORT \\ OTTER TAIL POWER COMPANY}

\section{Reference: Big Stone Plant}

\section{TLN 402J of 7/22/04}

Four filter bags were submitted for complete evaluations. The bags were labeled as " $10-\mathrm{H}$ Advanced Hybrid", "8-G Advanced Hybrid", "2AF3 Advanced Hybrid" and "None - Cole Unloading".

\section{Coal Unloading:}

The bag is from a pulse jet unit collecting residual dust from the coal unloading area. The differential pressure levels are 7" w.c. and maintained by an ID damper system. As pressures elevate the flows are reduced to maintain the dp. Temperatures are ambient with current service use @ 3 years.

The submitted bag as received exhibited low permeability throughput acceptances in full profile. Examination of the dust cake revealed a non-agglomerated porous structure with no major obstructions to throughput present.

Cross sectional inspection revealed the cause for the low permeability characteristics.

Microscopic Photo A and B are cross sectional views revealing the presence of fine micron dust penetration into the media depths.

December 3, 2004

TLN $618 \mathrm{~J}$

Page 2 


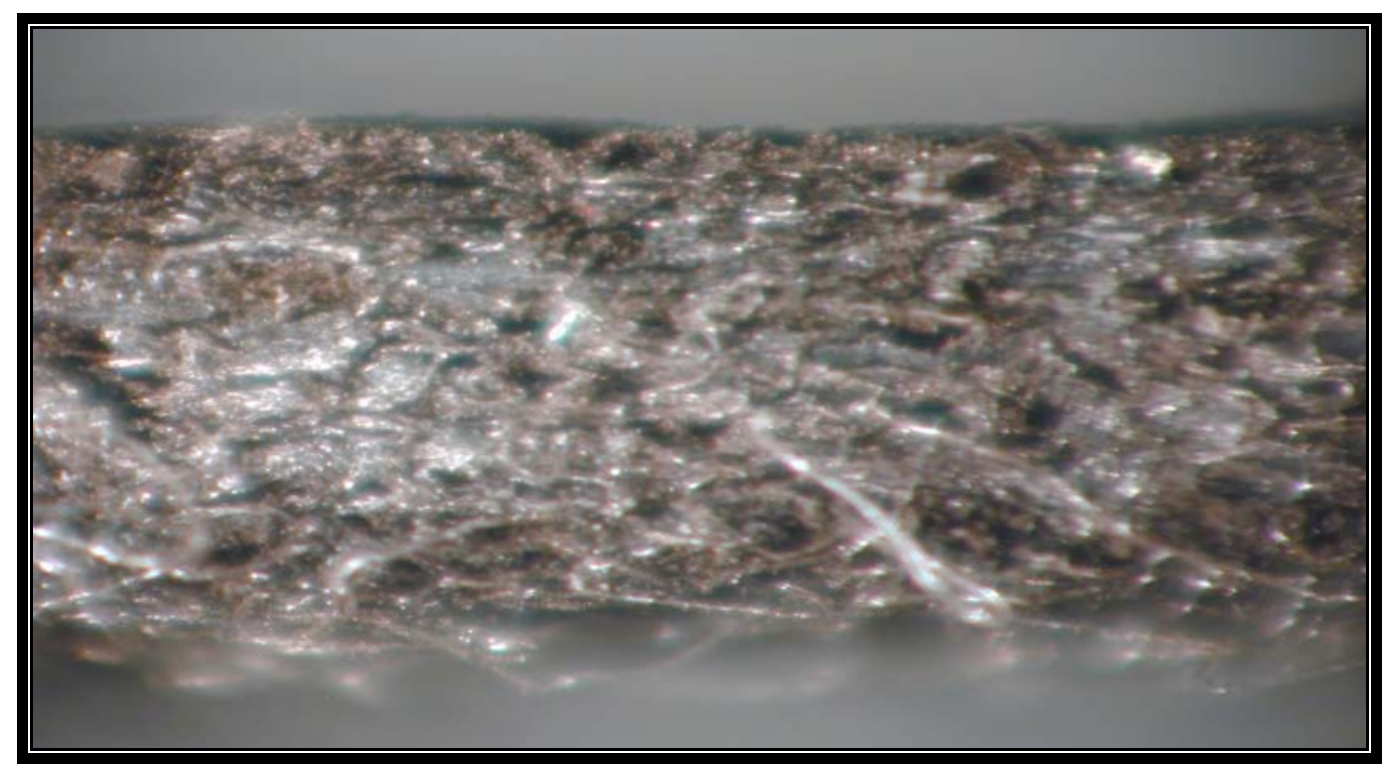

Photo A

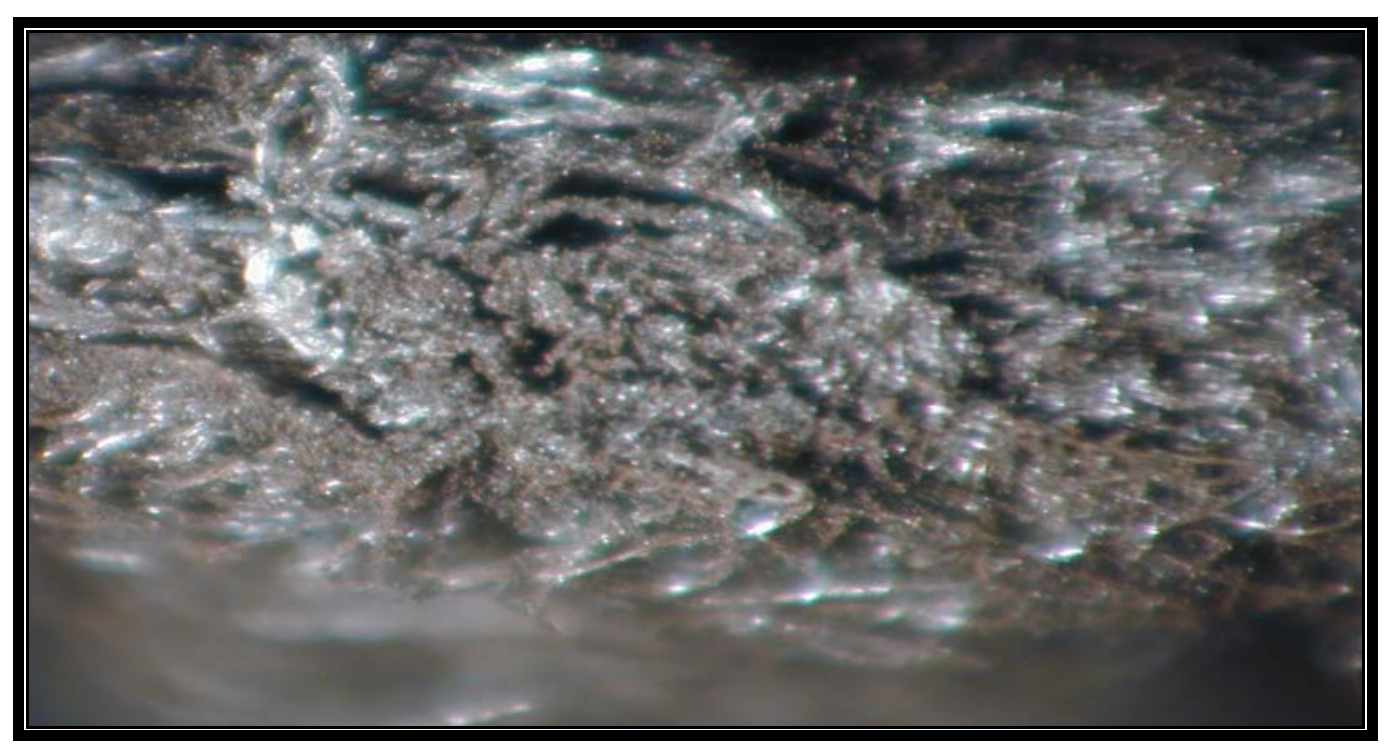

Photo B

The filtration efficiency of this media is at questionable levels.

The use of Duo-density Polyester may be a more suitable replacement when change out is scheduled.

December 3, 2004

TLN $618 \mathrm{~J}$

Page 3

The current chemistry/temperature of the PRB coal unloading is not detrimental to Polyester with no hydrolysis potential present. 
Physical strengths and flex endurances of the bag are at good retention levels in full profile.

All current losses are attributed to physical service use.

This bag is rated at a $35 \%$ maximum termination indicative of good continued service use potential. No abnormal wear was demonstrated on this bag.

\section{Advanced Hybrid Filter - Fly Ash}

All three bags exhibited a porous ash cake common to Powder River Basin Coal ash. This PRB ash contains higher levels of calcium oxide compared to Iron Oxide, hence, the predominant sulphate is the ALKALINE calcium sulphate.

The Permeabilities as received did exhibit a viable level of through. The following are the average permeability flows:

\begin{tabular}{|l|c|}
\hline CANDIDATE & PERMEABILITIES \\
\hline \hline $10-\mathrm{H}$ & 2.090 \\
\hline $8-6$ & 2.083 \\
\hline $2 \mathrm{AF} 3$ & 1.753 \\
\hline
\end{tabular}

The two P-84 membrane candidates (10-H and 8-G) exhibited very abnormal losses in all breaking strengths and mullen burst values in full profile.

Further the bags are at or very near full hole formations with $\mathrm{H}-10$ already demonstrating vertical hole.

December 3, 2004

TLN $618 \mathrm{~J}$

Page 4

Flex endurances on both bags also demonstrated severe losses in full profile with flex fatigue levels at $80 \%$.

The added physical fatigue on the bag fold merely added sufficient stress/strain to generate the vertical failure.

The bag fold is the result of normal bag over sizing in circumference compared to the cage circumference. cleaning.

This over sizing is necessary for cage insertion and the popping action off the bag under pulse for 
This does become the flex position common to all pulse jet bags hence, merely fails along the vertical fold first.

The high losses both on flex positions and off flex zones is indicative of all degradation sources beyond normal physical fatigue.

The fiberglass candidate did not exhibit any significant declines in strength and flex characteristics. chemistry.

Extractions of the media less dust revealed the presence of sulphate (acidic) with the P-84 Imide

Further nitrates were also present in the current chemistry of the P-84 fibers.

The fiberglass was negative of Nitrate involvement in the inorganic fiber chemistry with only Sulphates detected (slight) and they were acidic.

Power River Basin coal will always yield alkaline calcium sulphates in the ash chemistry. However sulfur gases passing through the membrane (ash does not) and condenses out will generate the acid condensate of sulfuric acid which will attack P-84 as well as Nomex.

December 3, 2004

TLN $618 \mathrm{~J}$

Page 5

Also N0x condensate will do the same thing and condensate out as nitric acid which will attack the P-84 however, not the fiberglass.

The low deterioration on the 2AF3 bag and the high degradation on 10- $\mathrm{H}$ and 8-G strongly suggests that moisture condensate in contact with N0x occurred within the clean air side of the system generating the nitric acid and further degrading P- 84 as demonstrated by the P- 84 degradation and the nitrates within the fiber.

Evidence of clean side moisture corrosion was also demonstrated.

Photo $\mathbf{C}$ and $\mathbf{D}$ are views of the clean side of the $2 \mathrm{AF} 3$ revealing the staining that has occurred. 


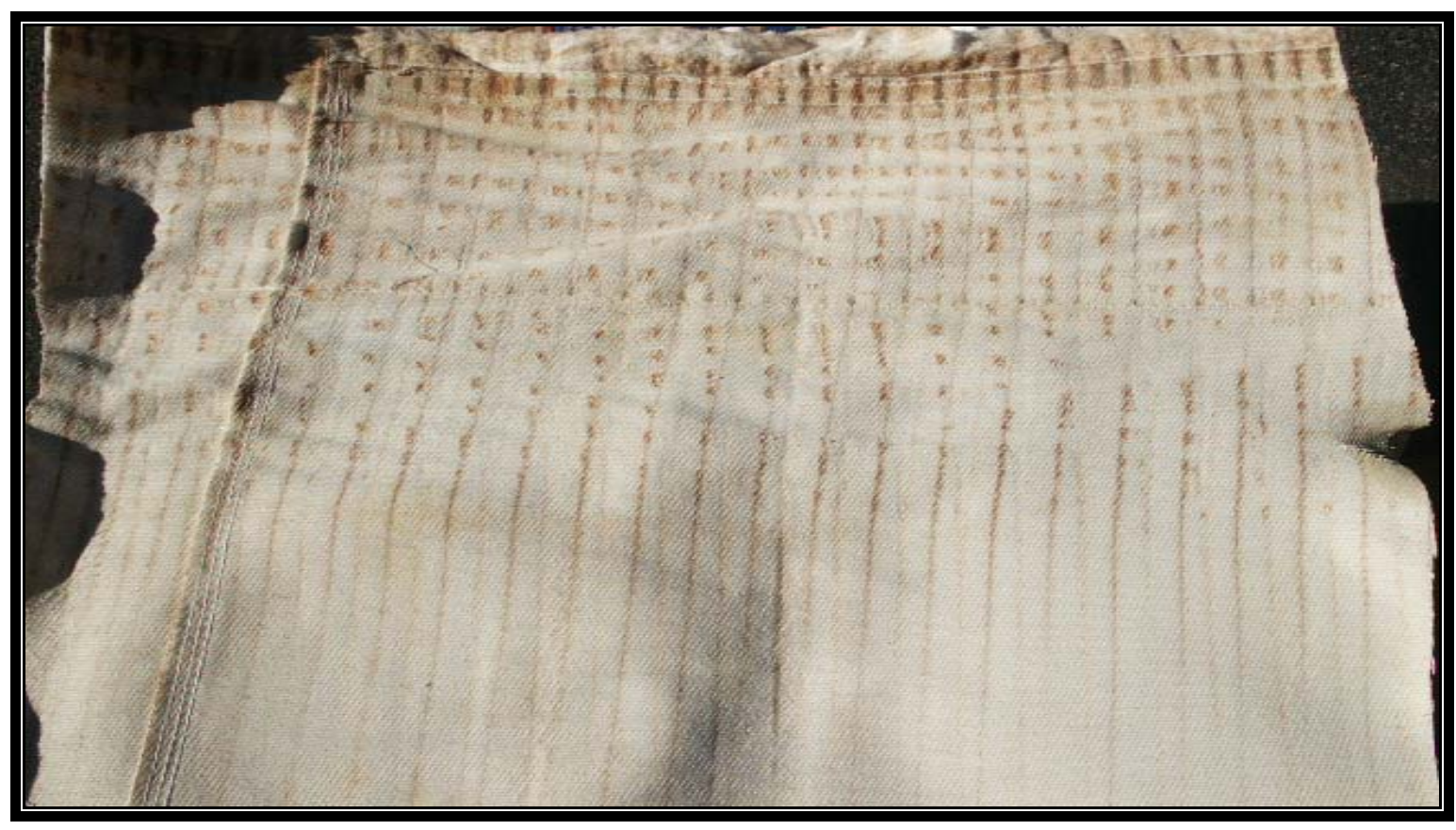

Photo C

December 3, 2004

TLN $618 \mathrm{~J}$

Page 6 


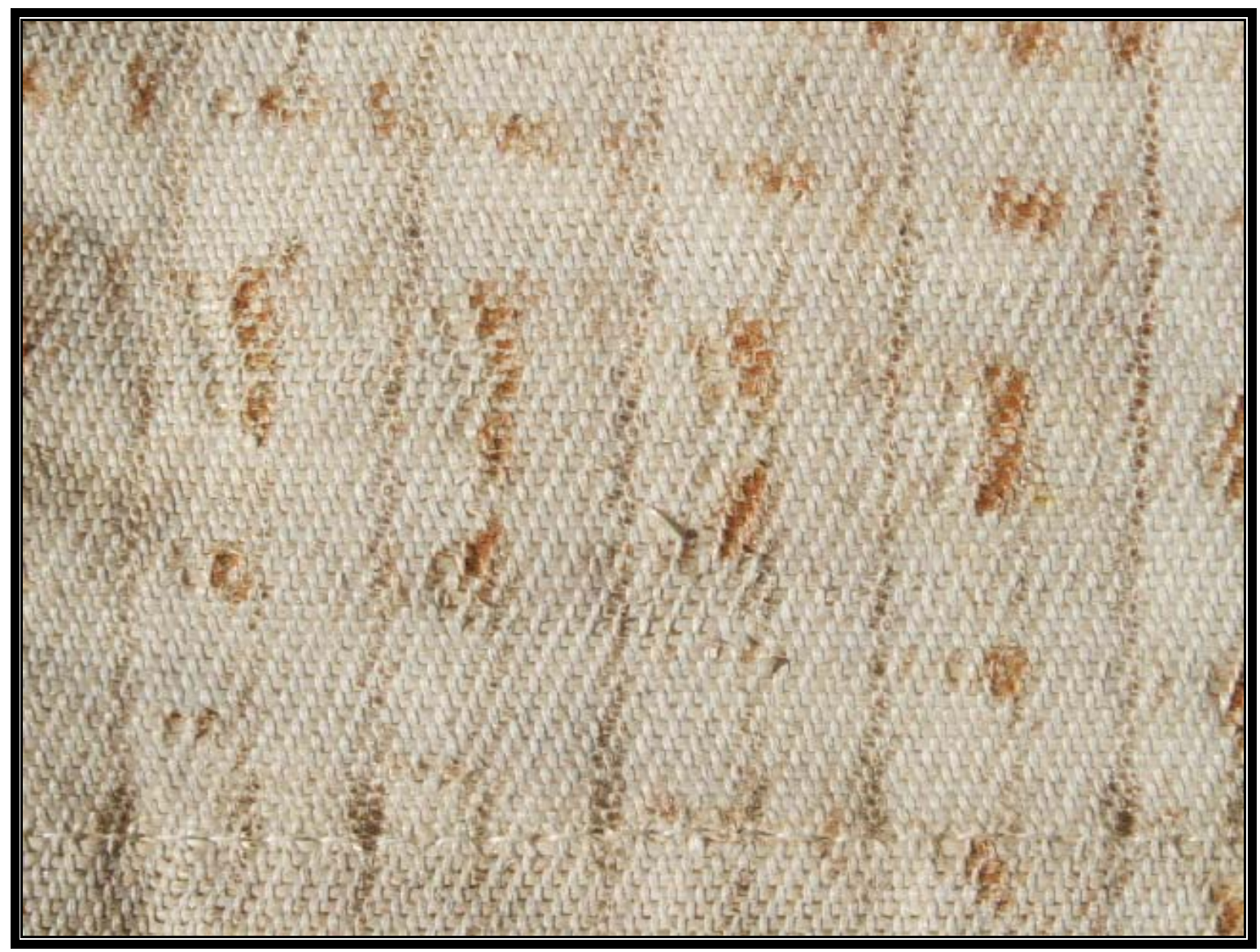

Photo D

The rust material tested positive for both metallic sulphates/nitrates further indicative of the acid generation on the clean air side.

It is evident that moisture has entered the clean air side (plenum) of the baghouse causing the exiting gases of sulfur oxides and nitrogen oxides to condense out as the acid.

This situation has occurred between the sampling of TLN 402J (7/22/04) and the failures being experienced. Clean side condensates are most commonly associated with inleakage of cool air/moisture or moisture condensates in the pulse air line. Further, these acids will also generate rust within the metal fractures such as the cages. 


\title{
B43 Addendum - Startup report after the replacement of the inlet field.
}

\author{
STARTUP REPORT \\ FOR \\ OTTERTAIL POWER COMPANY \\ BIG STONE PLANT \\ MILBANK, SOUTH DAKOTA \\ JUNE 30, 2005 \\ BY: BEN ABBOTT
}

This is a startup report for ESP's 1 and 2 after SEI"s modification to the first fields and bag replacement.

Forry ERC 1001 Rapper Controller and Rappers:

Single impact rappers were installed on the high voltage frame of the first fields. All rappers were installed and adjusted properly. The Forry ERC 1001 rapper controller was set up and programmed. The rapper controller and all rappers are working properly. A copy of the rapper controller set up and program is included with this report. Five plant electricians were trained on the operation of the rapper controller.

\section{Automatic Voltage Controls (AVC) and Transformer Rectifier (TR) Sets:}

During construction some TR sets were relocated to different locations. The AVC's need to be edited to match the name plate ratings of the TR sets. Attached are the settings and operational parameters that are in the AVC's along with suggested settings and parameters. Also attached are the air load readings of the AVC's.

There is a close clearance at the bottom tadpole on the first field of all four chambers. Due to this close clearance the first fields were limited to 21 to $26 \mathrm{kV}$.

With the exception of some sparking, all other fields had good air load readings.

Air load readings are attached.

Support Insulator Heaters:

After drying out the girder boxes, all heaters worked properly.

First field Outlet Dampers:

All four dampers were operated and work properly. The limit switch on chamber 1A did not always indicate the full open position. The plant was to adjust the limit switch the next day.

Tumbling Hammers:

The rotation and operation of all tumbling hammers were checked and worked properly. 
OPERATIONAL VALUES

\begin{tabular}{|c|c|c|c|c|c|c|c|c|c|c|}
\hline AVC & $\mathrm{PA}$ & $\mathrm{PV}$ & SA & $\mathrm{SV}$ & $\begin{array}{c}\text { SPARK } \\
\text { QUENCH } \\
\end{array}$ & $\begin{array}{c}\text { ARC } \\
\text { QUENCH }\end{array}$ & $\begin{array}{l}\text { FAST } \\
\text { RAMP } \\
\end{array}$ & $\begin{array}{c}\text { SET } \\
\text { BACK }\end{array}$ & $\mathrm{S} / \mathrm{M}$ & SCR \\
\hline 1A1 & 327 & 480 & 2000 & 25 & 1 & 3 & 6 & 20 & 99 & 30 \\
\hline$*$ & 327 & 480 & 2000 & 55 & 2 & 4 & 4 & 10 & 60 & 30 \\
\hline $1 \mathrm{~A} 2$ & 327 & 480 & 2000 & 55 & 1 & 3 & 6 & 5 & 20 & 30 \\
\hline$*$ & 327 & 480 & 2000 & 55 & 2 & 4 & 4 & 10 & 30 & 30 \\
\hline $1 \mathrm{~A} 3$ & 327 & 480 & 1000 & 55 & 1 & 3 & 6 & 5 & 20 & 30 \\
\hline$*$ & 245 & 480 & 1500 & 55 & 2 & 4 & 4 & 10 & 30 & 30 \\
\hline 1A4 & 327 & 480 & 1000 & 55 & 1 & 3 & 6 & 5 & 20 & 30 \\
\hline$*$ & 245 & 480 & 1500 & 55 & 2 & 4 & 4 & 10 & 30 & 30 \\
\hline 1B1 & 267 & 480 & 2000 & 25 & 1 & 3 & 6 & 20 & 99 & 30 \\
\hline * & 245 & 480 & 1500 & 55 & 2 & 4 & 4 & 10 & 60 & 30 \\
\hline 1B2 & 327 & 480 & 1000 & 55 & 1 & 3 & 6 & 5 & 20 & 30 \\
\hline$*$ & 327 & 480 & 2000 & 55 & 2 & 4 & 4 & 10 & 30 & 30 \\
\hline 1B3 & 327 & 480 & 1000 & 55 & 1 & 3 & 6 & 5 & 20 & 30 \\
\hline * & 245 & 480 & 1500 & 55 & 2 & 4 & 4 & 10 & 30 & 30 \\
\hline 1B4 & 327 & 480 & 1000 & 55 & 1 & 3 & 6 & 5 & 20 & 30 \\
\hline$*$ & 245 & 480 & 1500 & 55 & 2 & 4 & 4 & 10 & 30 & 30 \\
\hline 2A1 & 327 & 480 & 2000 & 21 & 1 & 3 & 6 & 20 & 99 & 30 \\
\hline$*$ & 327 & 480 & 2000 & 55 & 2 & 4 & 4 & 10 & 60 & 30 \\
\hline $2 \mathrm{~A} 2$ & 327 & 480 & 1000 & 55 & 1 & 3 & 6 & 5 & 20 & 30 \\
\hline$*$ & 327 & 480 & 2000 & 55 & 2 & 4 & 4 & 10 & 30 & 30 \\
\hline $2 \mathrm{~A} 3$ & 327 & 480 & 1000 & 55 & 1 & 3 & 6 & 5 & 20 & 30 \\
\hline$*$ & 245 & 480 & 1500 & 55 & 2 & 4 & 4 & 10 & 30 & 30 \\
\hline $2 \mathrm{~A} 4$ & 327 & 480 & 1000 & 55 & 1 & 3 & 6 & 5 & 20 & 30 \\
\hline$*$ & 327 & 480 & 2000 & 55 & 2 & 4 & 4 & 10 & 30 & 30 \\
\hline 2B1 & 327 & 480 & 2000 & 55 & 1 & 3 & 3 & 10 & 99 & 30 \\
\hline$*$ & 327 & 480 & 2000 & 55 & 2 & 4 & 4 & 10 & 60 & 30 \\
\hline 2B2 & 327 & 480 & 2000 & 50 & 1 & 3 & 6 & 5 & 20 & 30 \\
\hline$*$ & 327 & 480 & 2000 & 55 & 2 & 4 & 4 & 10 & 30 & 30 \\
\hline 2B3 & 327 & 480 & 1000 & 55 & 1 & 3 & 6 & 5 & 20 & 30 \\
\hline$*$ & 245 & 480 & 1500 & 55 & 2 & 4 & 4 & 10 & 30 & 30 \\
\hline 2B4 & 327 & 480 & 1000 & 55 & 1 & 3 & 6 & 5 & 20 & 30 \\
\hline$*$ & 245 & 480 & 1500 & 55 & 2 & 4 & 4 & 10 & 30 & 30 \\
\hline
\end{tabular}

* SUGGESTED VALUES (NOTE: Due to time constraints during air load the suggested values were not implemented. It was discussed that after the boiler was brought back on line, some of the operating parameters would need to be changed. The plant said they could handle this if it is necessary to do so). 


\section{$\underline{\text { AIR LOAD READINGS }}$}

Chamber 1A

\begin{tabular}{|c|c|c|c|c|c|c|c|}
\hline FIELD & PV & PA & SA & SV & SCR & KW & S/M \\
\hline 1 & 148 & 140 & 664 & 25 & 115 & 17 & 0 \\
\hline 2 & 73 & 249 & 296 & 38 & 122 & 9 & 19 \\
\hline 3 & 148 & 260 & 640 & 44 & 108 & 39 & 19 \\
\hline 4 & 158 & 280 & 794 & 54 & 97 & 55 & 17 \\
\hline
\end{tabular}

Field 1 limited at $25 \mathrm{kV}$ due to excessive sparking at higher $\mathrm{kV}$.

\section{Chamber 1B}

\begin{tabular}{|c|c|c|c|c|c|c|c|}
\hline FIELD & PV & PA & SA & SV & SCR & KW & S/M \\
\hline 1 & 161 & 144 & 723 & 25 & 113 & 18 & 0 \\
\hline 2 & 66 & 211 & 343 & 52 & 103 & 26 & 15 \\
\hline 3 & 143 & 295 & 586 & 44 & 100 & 42 & 19 \\
\hline 4 & 113 & 258 & 458 & 50 & 100 & 23 & 19 \\
\hline
\end{tabular}

Field 1 limited at $25 \mathrm{kV}$ due to excessive sparking at higher $\mathrm{kV}$.

\section{Chamber 2A}

\begin{tabular}{|c|c|c|c|c|c|c|c|}
\hline FIELD & PV & PA & SA & SV & SCR & KW & S/M \\
\hline 1 & 113 & 130 & 450 & 21 & 125 & 9 & 0 \\
\hline 2 & 124 & 330 & 430 & 47 & 106 & 15 & 19 \\
\hline 3 & 133 & 289 & 527 & 58 & 100 & 26 & 15 \\
\hline 4 & 121 & 243 & 545 & 53 & 100 & 37 & 14 \\
\hline
\end{tabular}

Field 1 limited at $21 \mathrm{kV}$ due to excessive sparking at higher $\mathrm{kV}$.

\section{Chamber 2B}

\begin{tabular}{|c|c|c|c|c|c|c|c|}
\hline FIELD & PV & PA & SA & SV & SCR & KW & S/M \\
\hline 1 & 180 & 150 & 820 & 26 & 110 & 21 & 0 \\
\hline 2 & 170 & 321 & 420 & 53 & 96 & 25 & 18 \\
\hline 3 & 165 & 227 & 432 & 42 & 117 & 35 & 22 \\
\hline 4 & 106 & 244 & 474 & 46 & 113 & 28 & 19 \\
\hline
\end{tabular}

Field 1 limited at $26 \mathrm{kV}$ due to excessive sparking at higher $\mathrm{kV}$.

Note: If $\mathrm{kV}$ limit is raised on fields 1 the spark rate goes up to approximately $100 \mathrm{~S} / \mathrm{M}$. 
B44 Addendum - Bag Layout map after installation of AH components in the inlet field

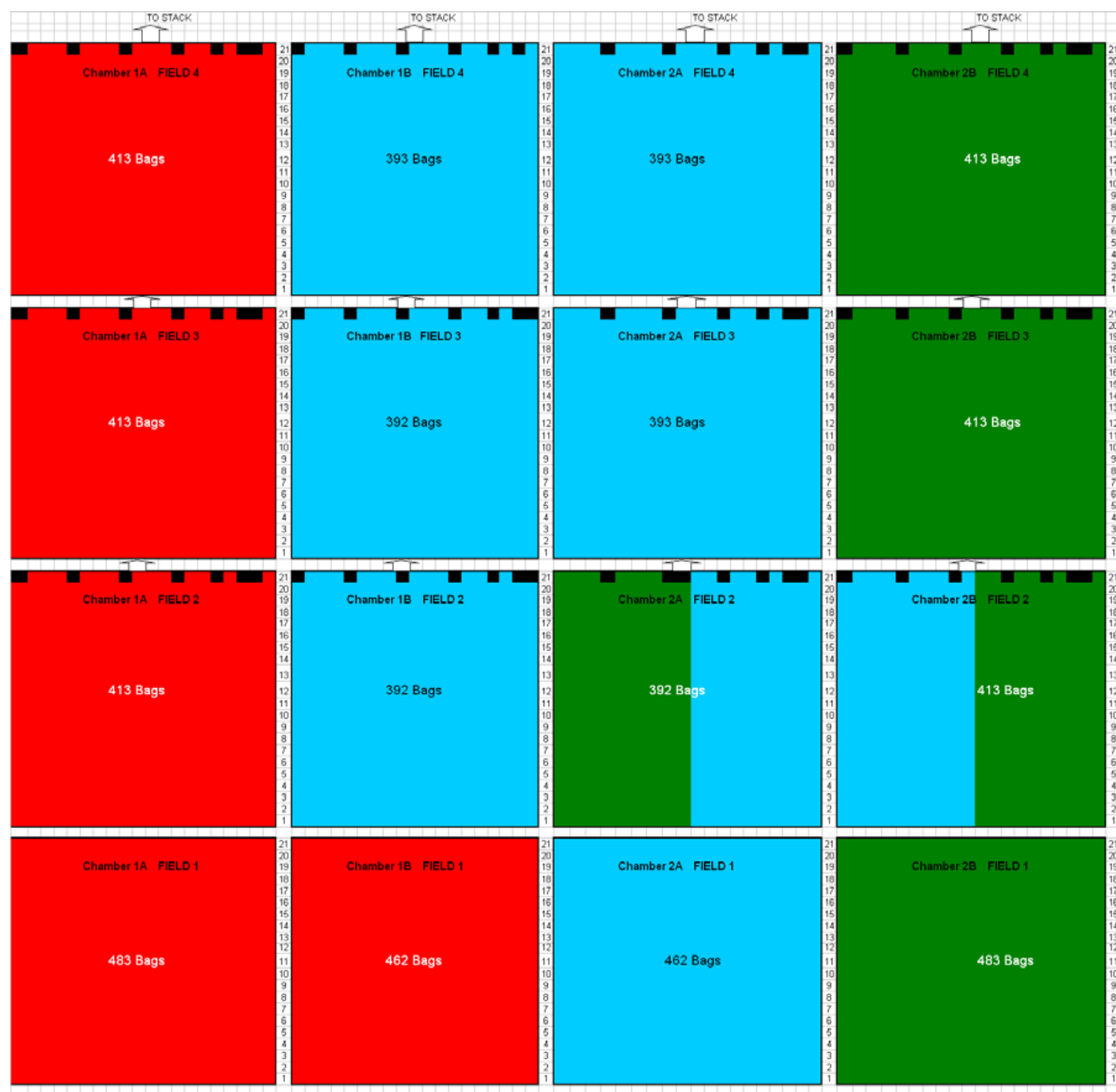

6723 Total Bags

Permanent Plug

Fiberglass/ePTFE membrane (2184 Bags - 33\%)

PTFE/ePTFE membrane (2841 Bags - $42 \%)$

Superflex/ePTFE membrane (1701 Bags - 25\%) 

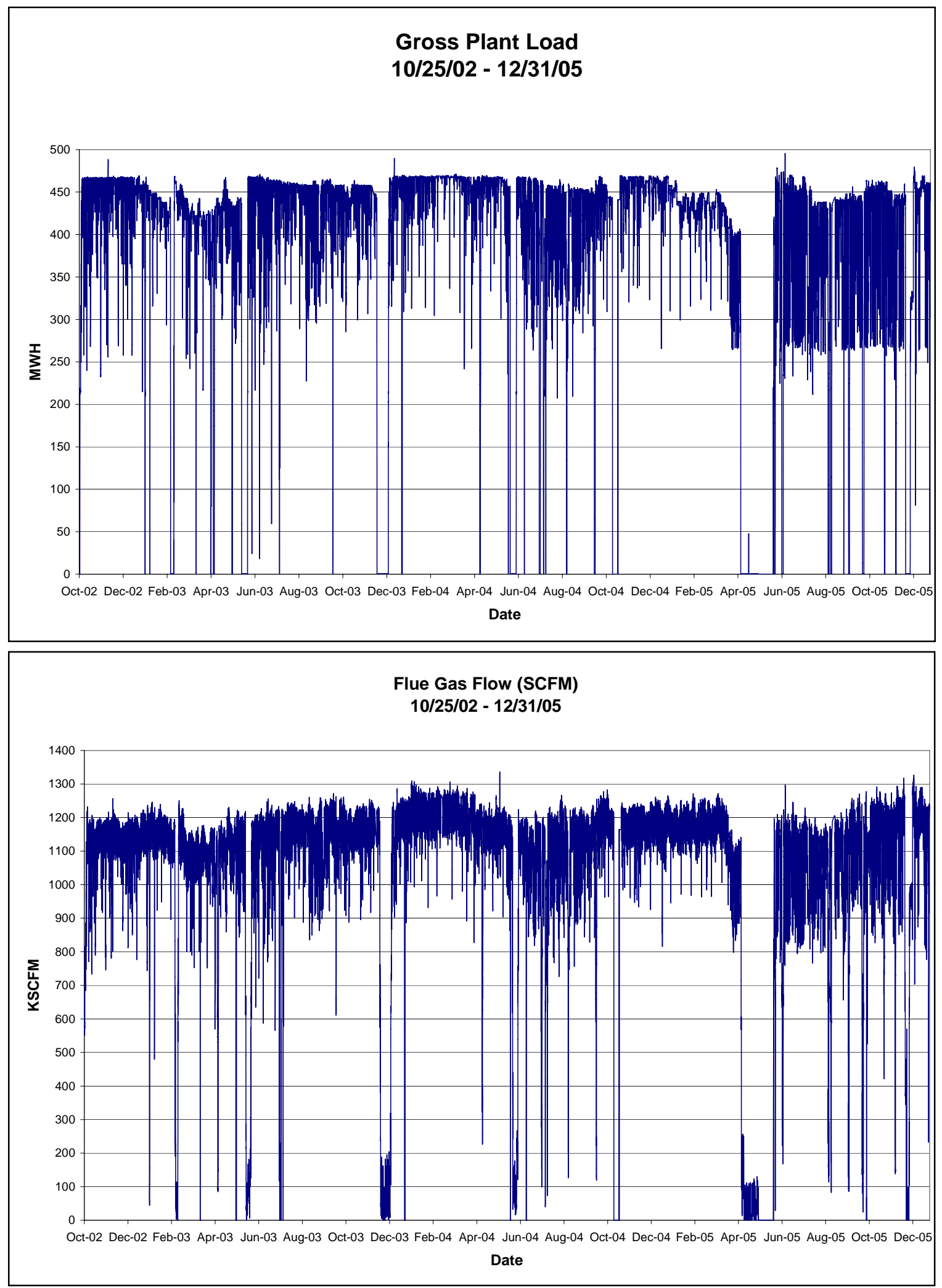



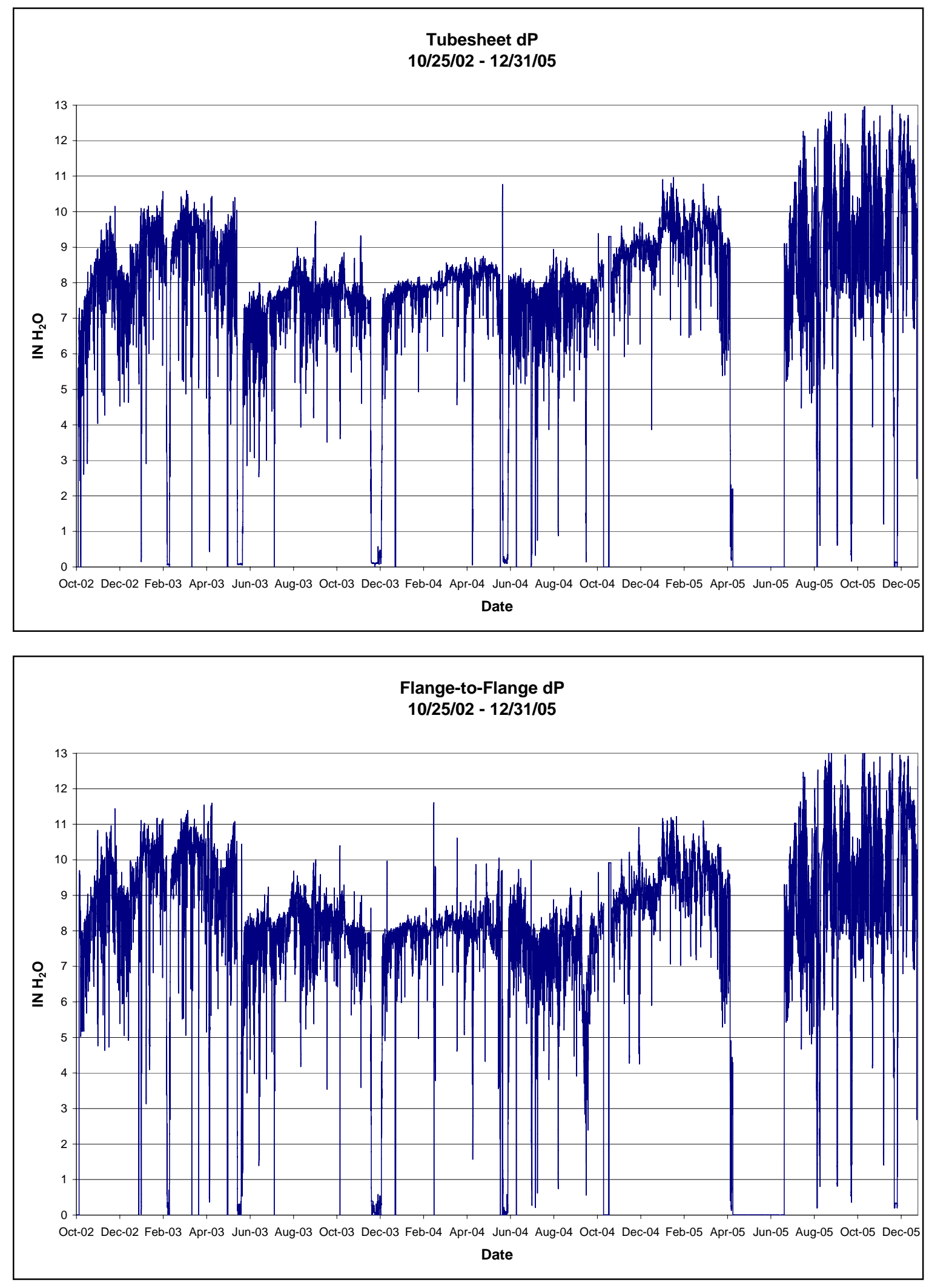

288 

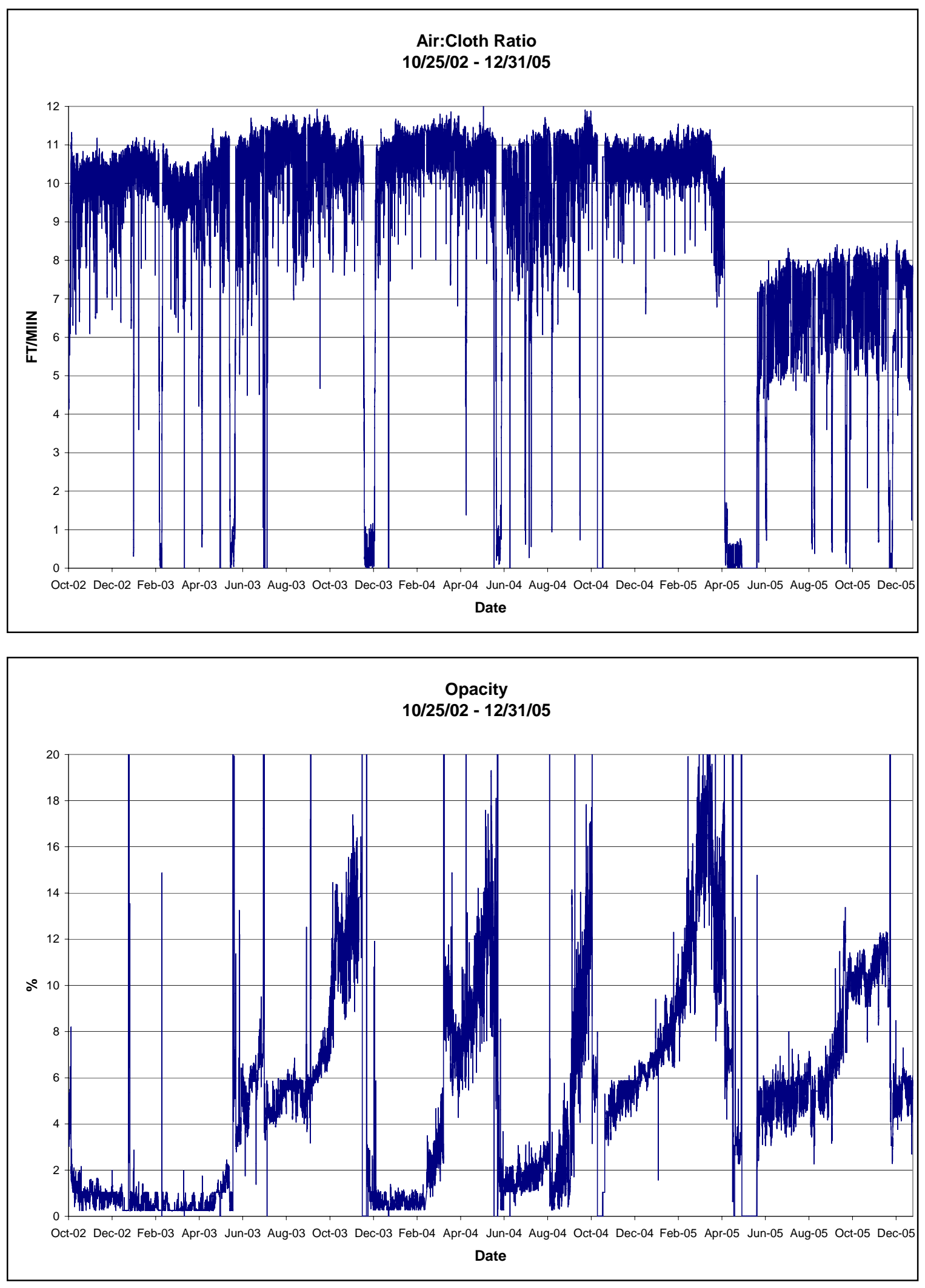

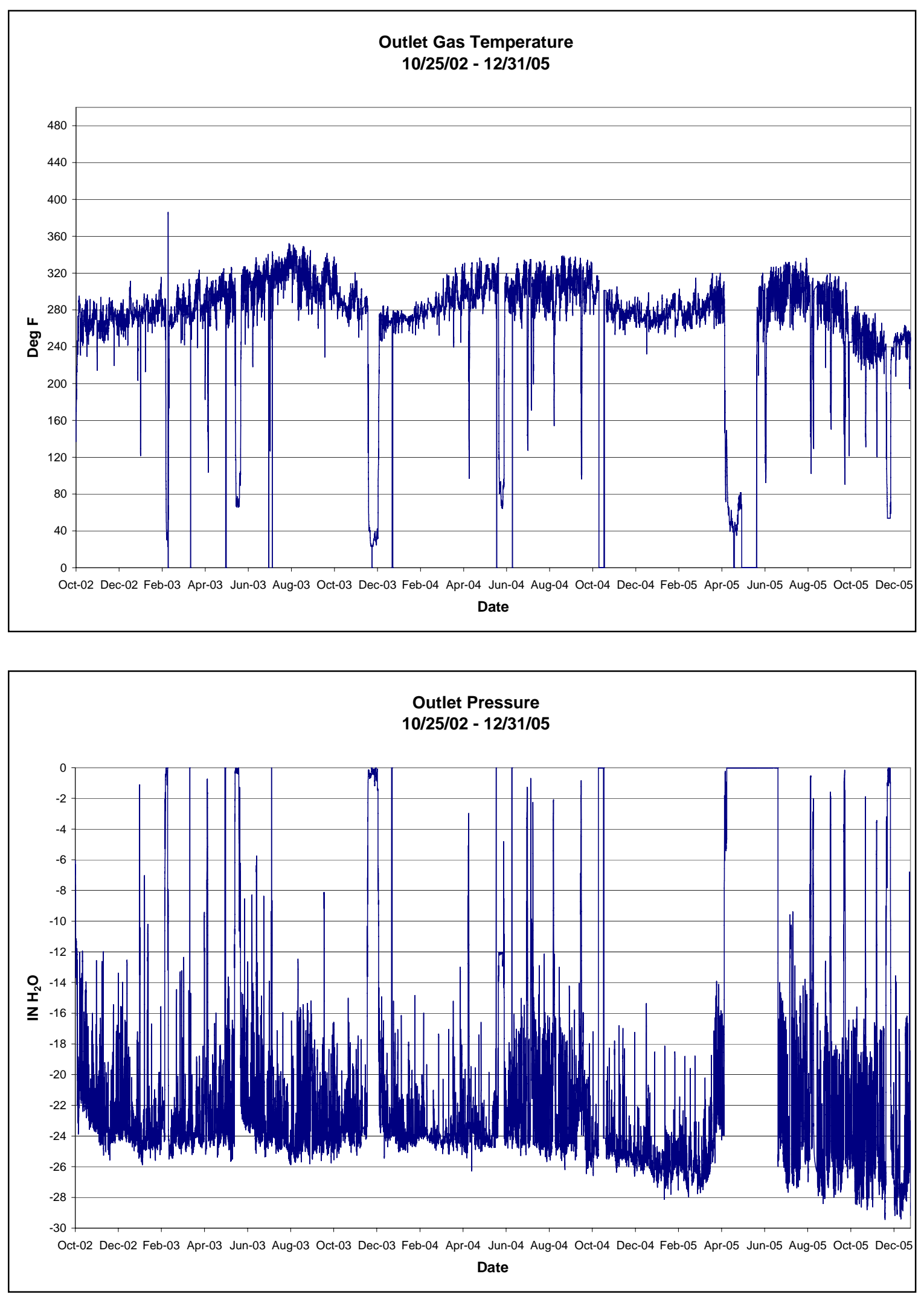

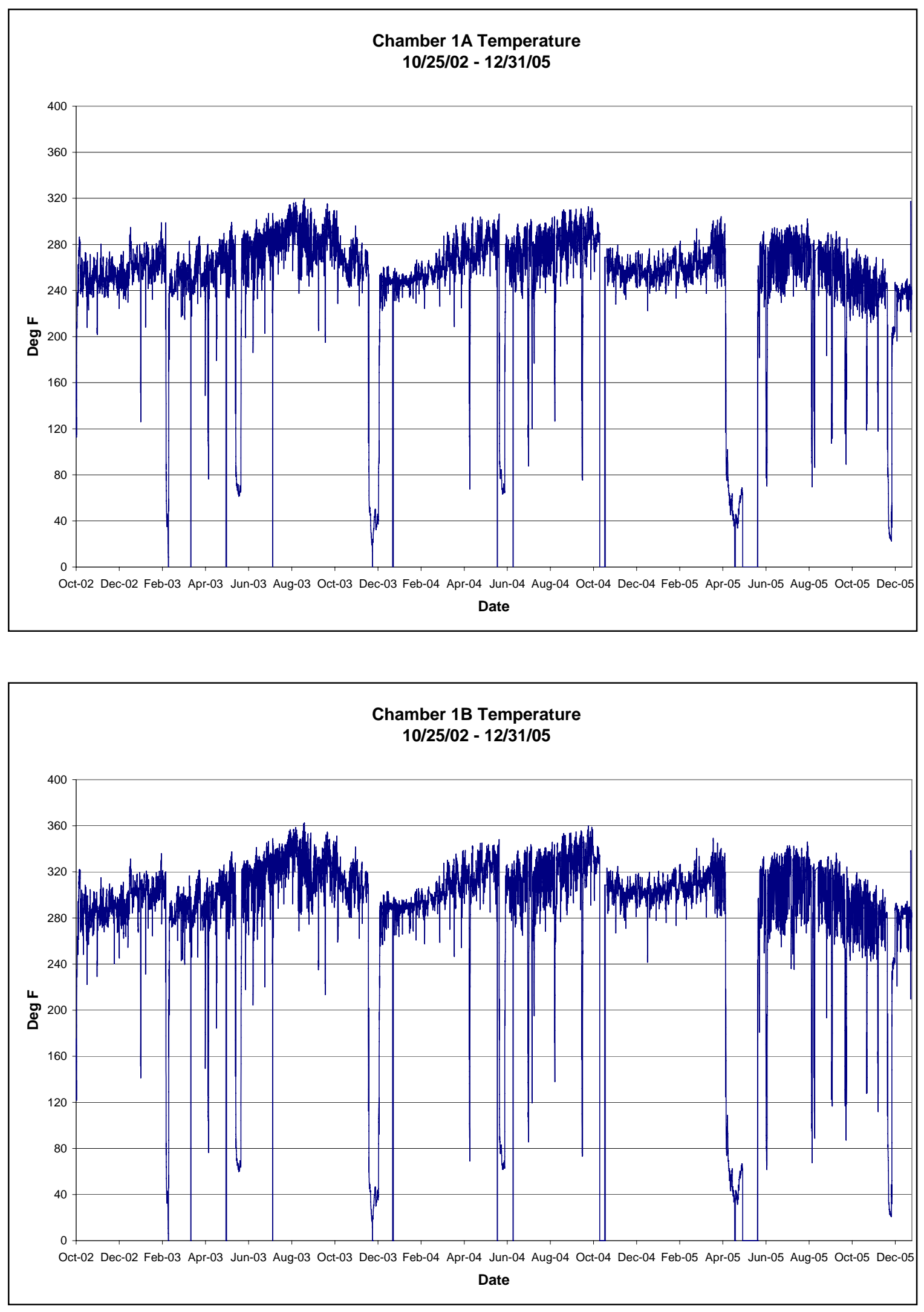

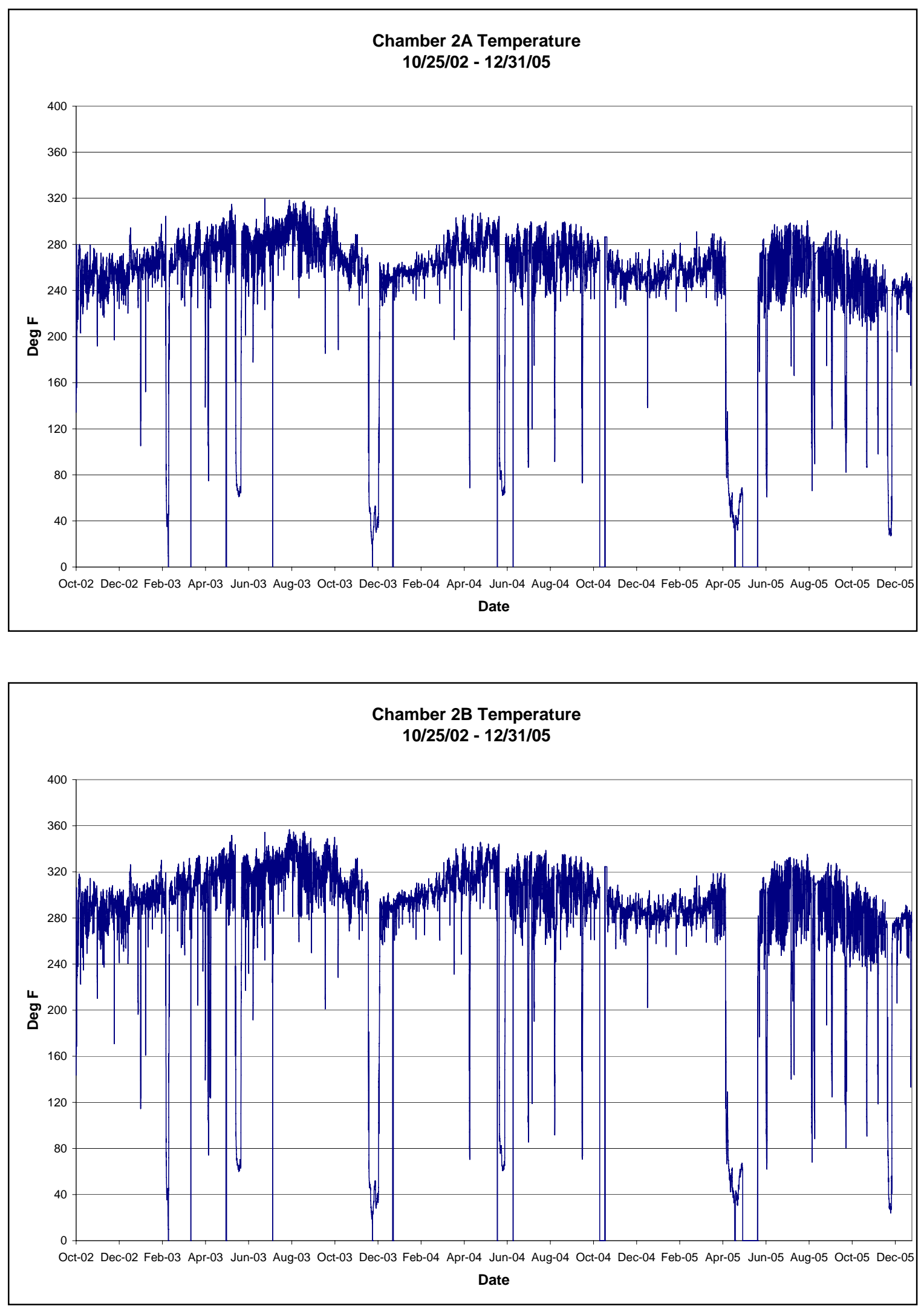

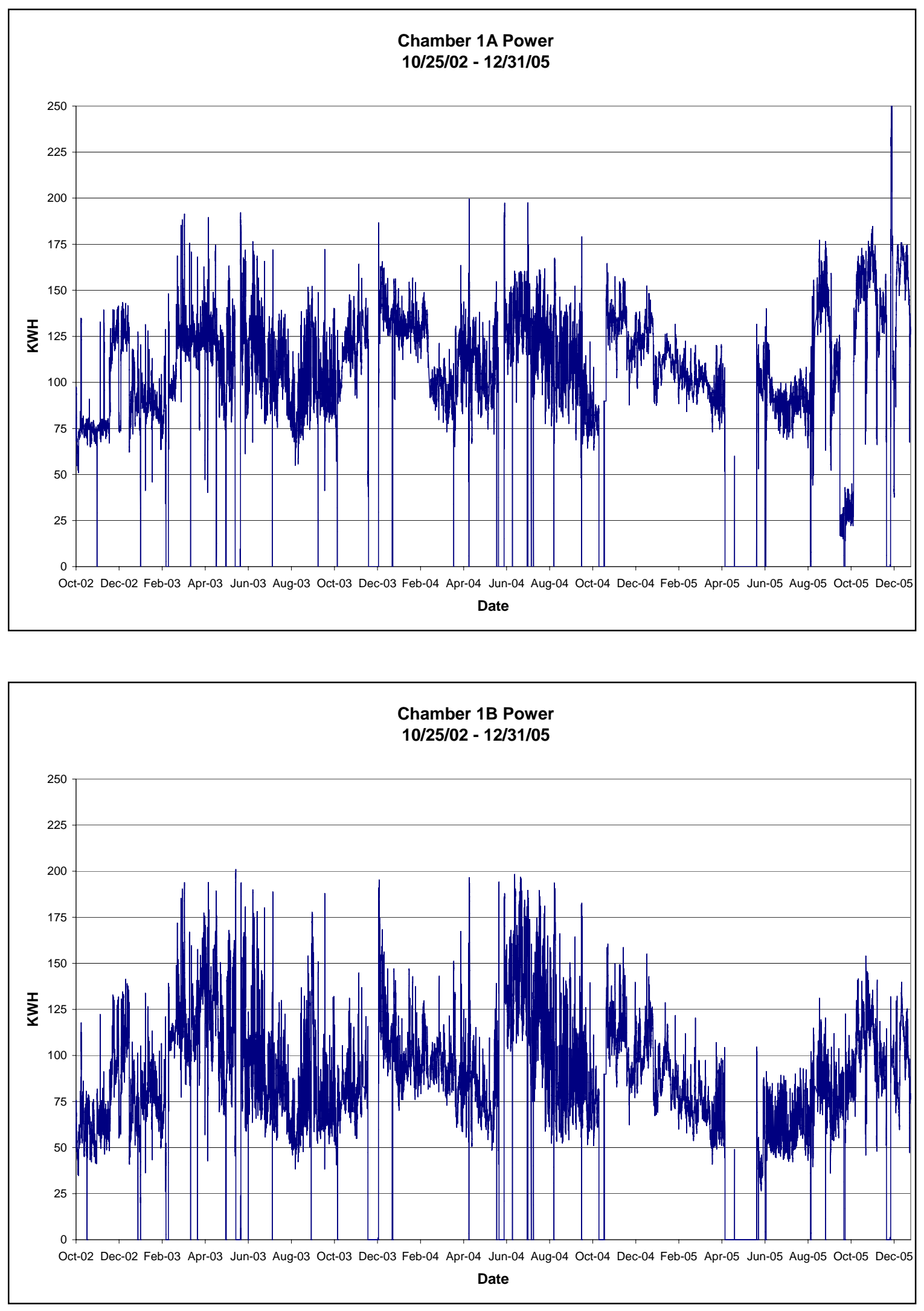

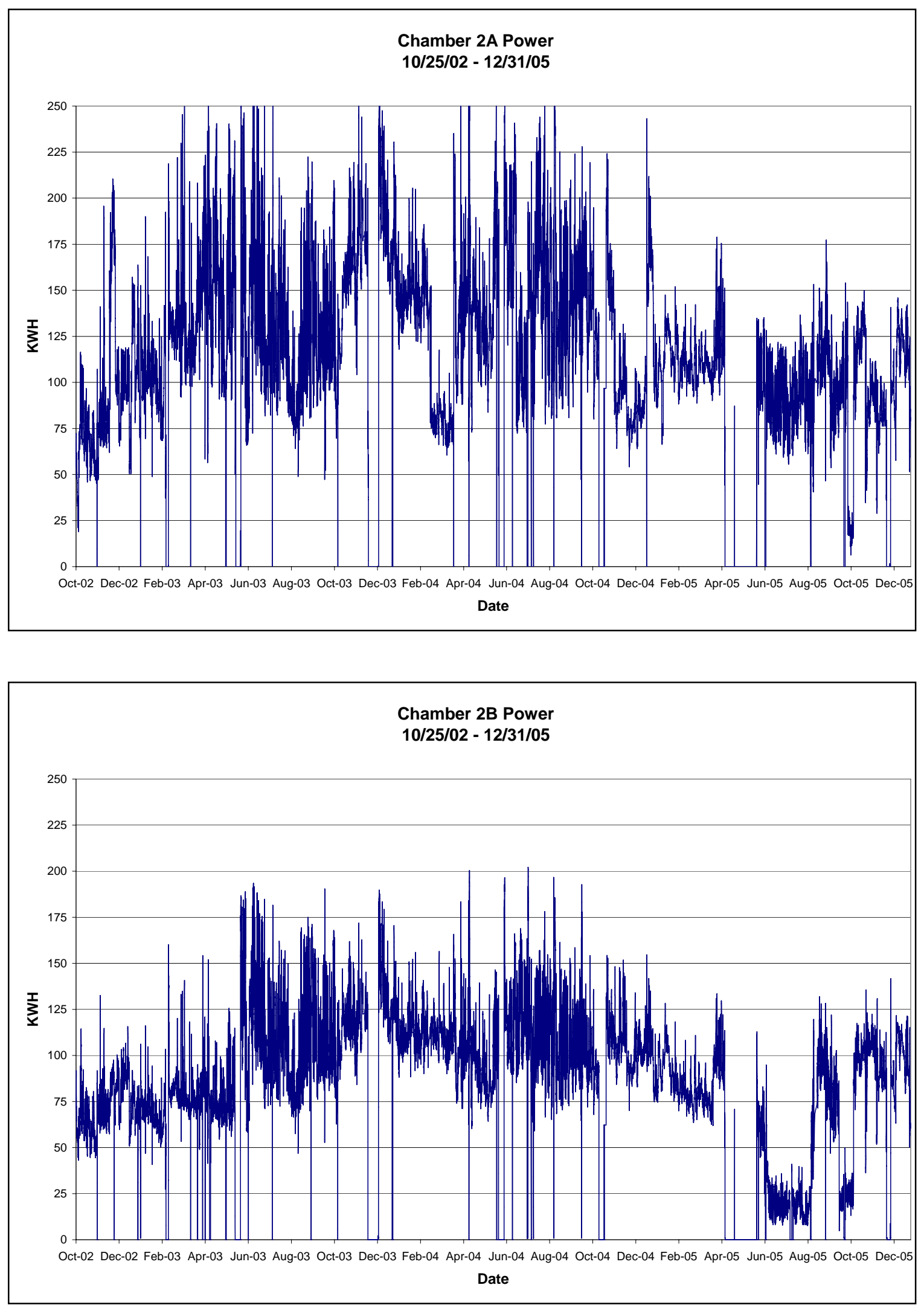

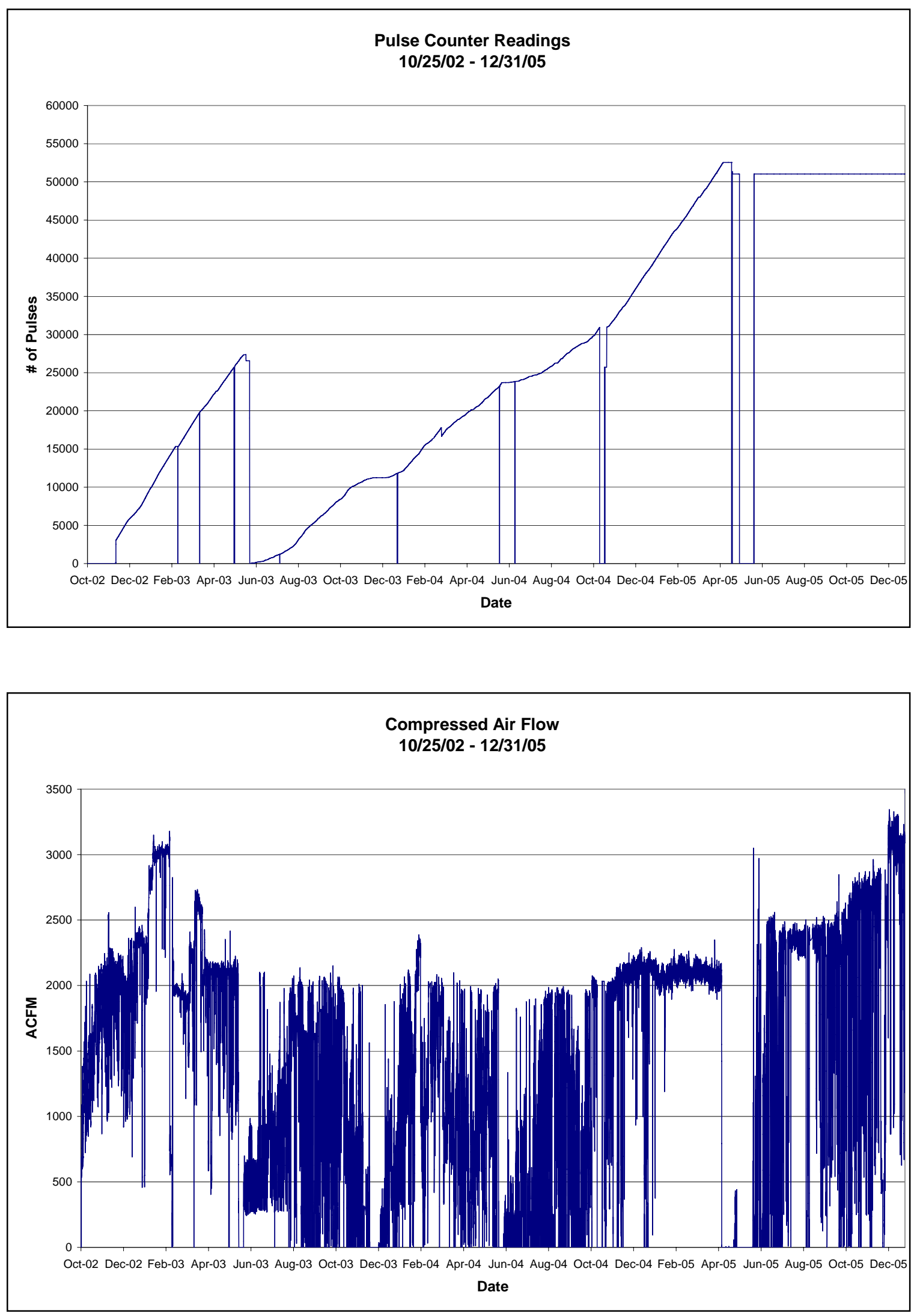

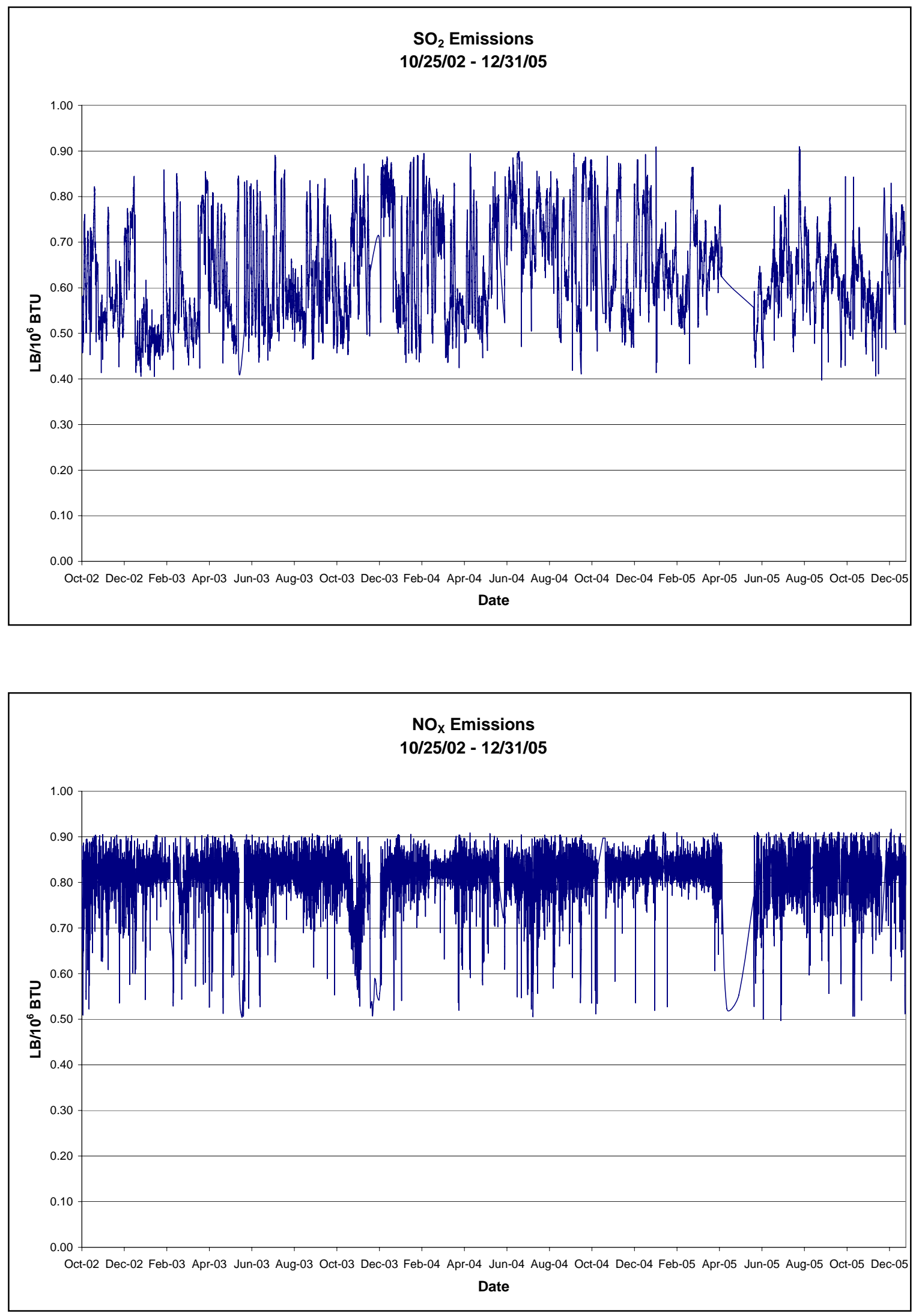